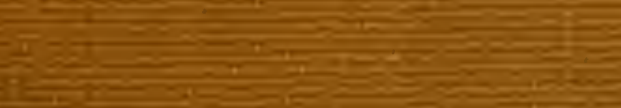

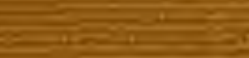




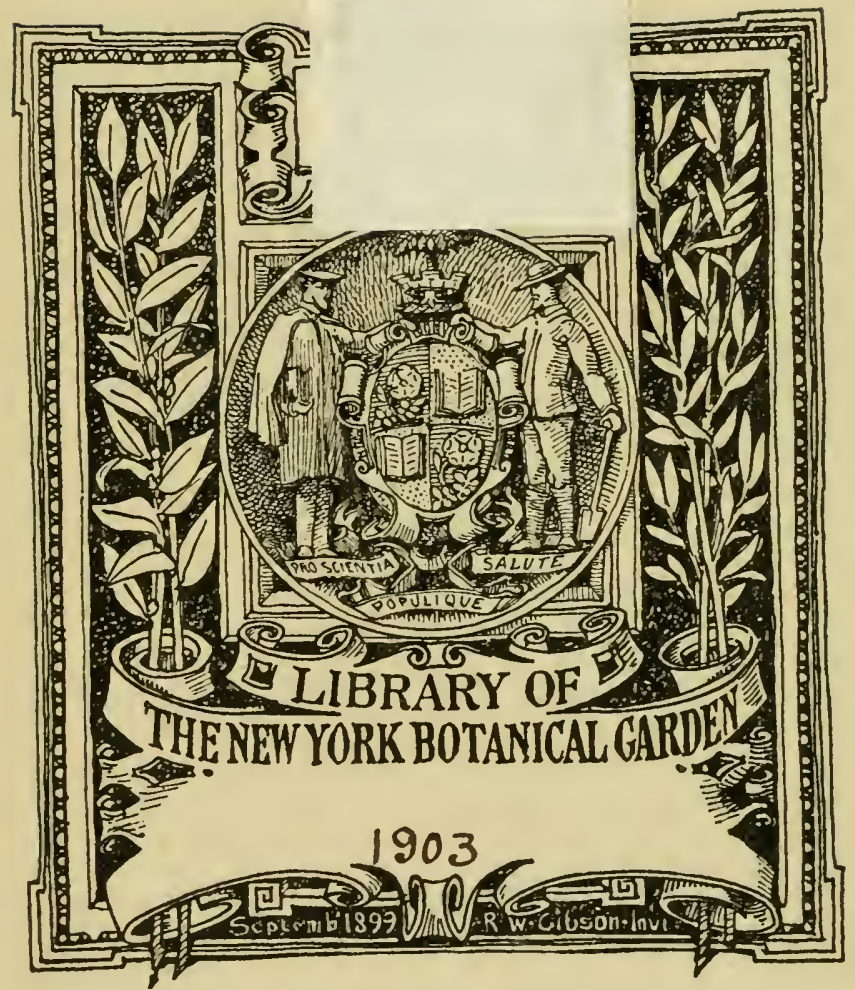








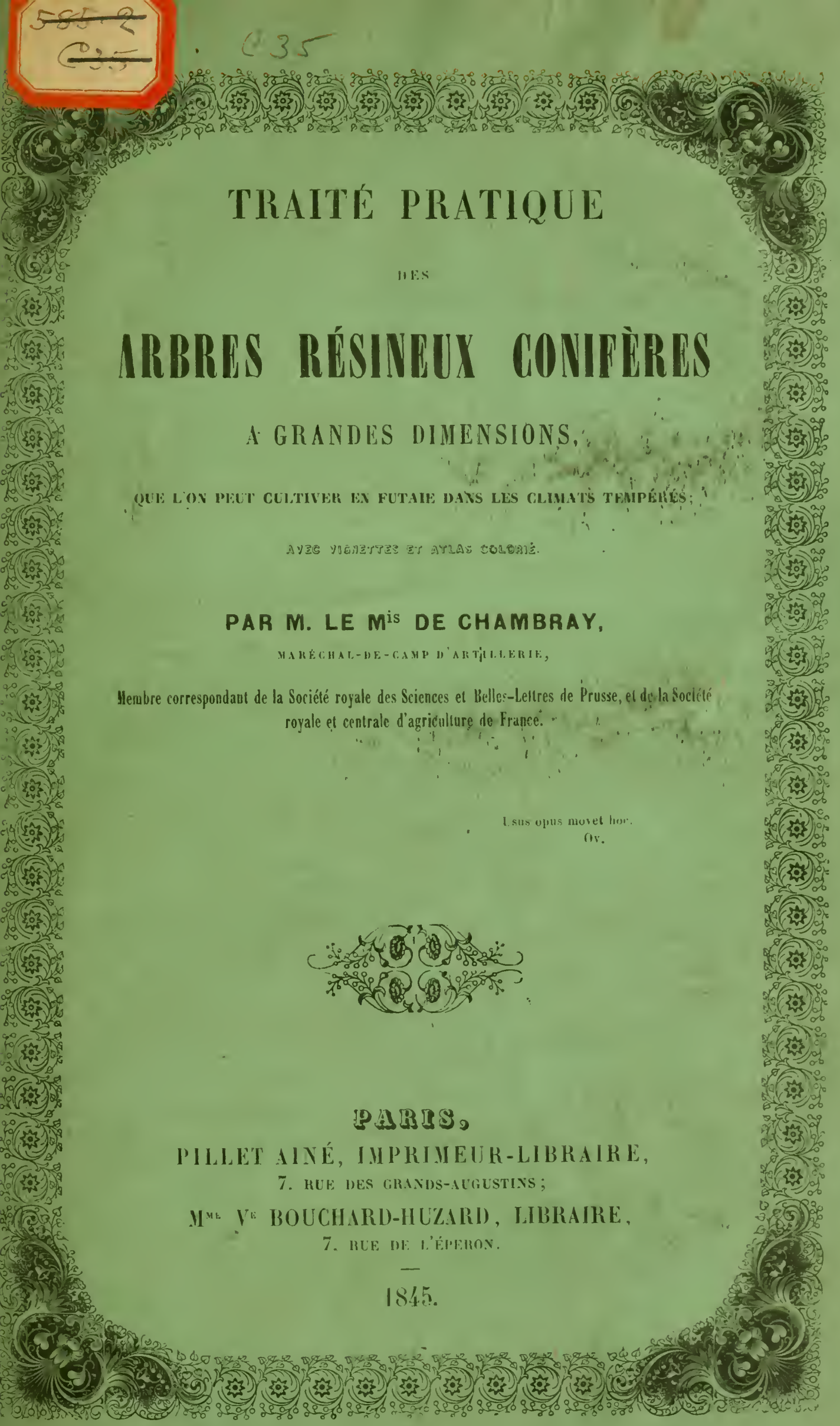





\section{TRAITÉ PRATIQUE}

\section{ARBRES RESINEUX CONIFERES}

I GRAYDES DIMEISIOTS. 


\section{Durrages du mème Auteur:}

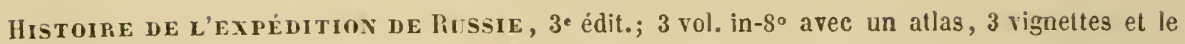

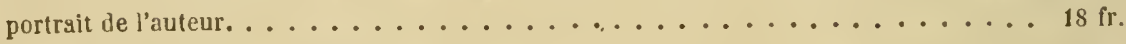

Philosopire de la guerae, 3 édit.; 1 vol. in- $8^{\circ} \ldots \ldots \ldots \ldots \ldots$

MÉLAXGES; 1 rol. in $-8^{\circ} \ldots \ldots \ldots \ldots \ldots \ldots \ldots \ldots \ldots \ldots$

Tratté de la CCLTURE De MELON, sur couche sourde ef en pleine terre. . . . . 3 


\section{TRATTE PRATIQUE}

\section{pess \\ ARBRES RÉSINEUX CONIPÈRES \\ A GRANDES DIMENSIONS,}

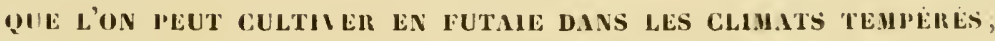

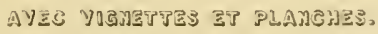

PAR M. LE M ${ }^{I S}$ DE CHAMBRAY,

MARECIIL-DE-CAMP D'ARTILLERIE,

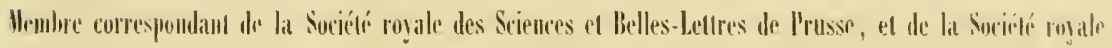
et centrale diagricullume de Prame.

LIBRARY

NEW YORK

BOTANICAL

CARDEN

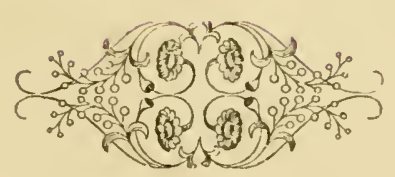

\section{د}

PILLET AINE, IMPRIMEUR-LIBRAIRE,

7 , RUE des graNos-aUgustins;

H"E VE BOUCIILRD-IIUZIRD, LIBRAIRE,

T, RUE DE L'ÉPEROX.

IX隹 
+ QL20
. Alm
C45 


\section{TABLE DES MATIERES.}

Pages"

A VERTISSEMENT.

IX

\section{Chapitre I $^{\text {r }}$. - Considerations generales.}

- Sur la dénomination arbres résineux conifères, cl sur l'expression climat tempéré. . . 1

- Diminution de la superficie du sol boisé en France. . . . . . . . . . . . . . 2

- Avantages que peul offrir en France l'extension de la culture des arbres résineux coni-

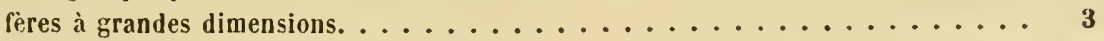

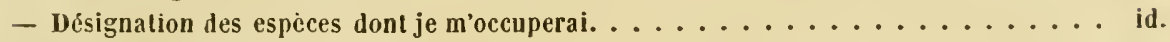

- Confusion dans la nomenclature el la synonymie des pins. . . . . . . . . . . 6

- Geures auxquels appartiennent les espèces dont je m’occuperai; caractères généraux

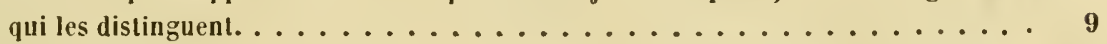

- Influence de la latilude el de l'altilude sur la végélation des arbres résineux conifères. . 10

- Moyens de reproduction de ces arbres. . . . . . . . . . . . . . . 11

- Si l'on doit les exploiter pendant qu'ils sont en sève, ou pendant que la sève est inac-

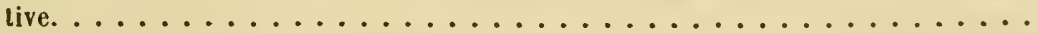

- Doit-on, pour l'abatlage, avoir égard aux phases de la lune et à la direction des

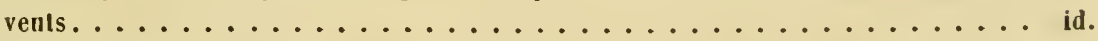

- Réflexions sur l'acception des mols aménagement, exploitation el reproduction. . . . 13

- Le trone des arbres résineux s'augmente-l-il d'une couche ligneuse chaque année.... id.

- Ravages des insecles. . . . . . . . . . . . . . . . . . . . . 14

- Graves erreurs de quelques auteurs de répulation. . . . . . . . . . . . . . 15

Chapitre Il. - Sapin argente, Abies argentea.

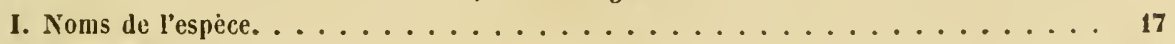

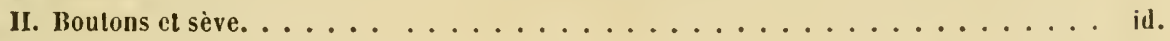

1II. Feuilles, tleurs et cônes. ....................... 18

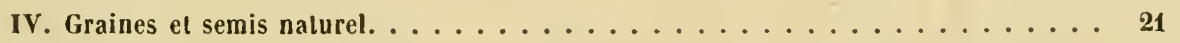

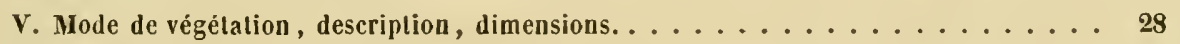

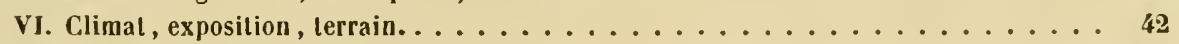

VII. Création d'une futaie de sapins argentés . . . . . . . . . . . . . 48

vili. Aménagement, exploitation et reproduction. ................ 65

Observations préliminaires et travaux communs. ........... as

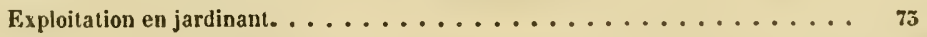

id. par coupes rases. . .................. 83

id. par coupes rases par bandes étroites. . . . . . . . . . 90

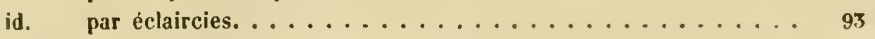

id. par la méthode mixte. ................. 99

Comparaison des cinq modes d'exploitation. . . . . . . . . . . . . 100 
1X. Qualités et usages du bois ; produits divers. ................ 103

X. Accidens, maladies, animaux nuisibles. ................. 106

CHAPITRE III. - SA PIN PICEA, Abies picea.

I. Noms de l'espèce. . . . . . . . . . . . . . . . . . . . . . 118

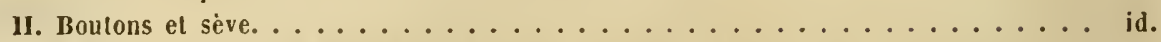

III. Feuilles, fleurs et cônes. .......................... 119

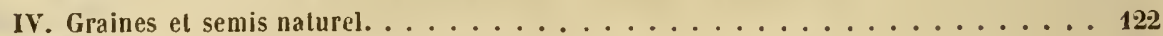

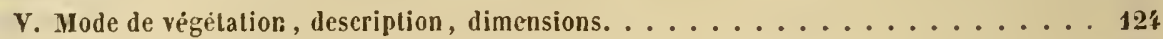

VI. Climat, exposition, terrain. ...................... 133

VII. Crẻation d'une futaie de sapins picéas. . . . . . . . . . . . . . . . 135

VIII. Aménagenent, exploitation et reproduction. . . . . . . . . . . . . 136

1X. Qualitės et usages du bois; produits divers. . . . . . . . . . . . . . . . . . . . . . . . . . . . . . . . . . . . . . . .

X. Accidens, maladies, animaux nuisibles. . . . . . . . . . . . . 140

CHA PITRE IV. - Pin sylvestre, Pinus sylvestris.

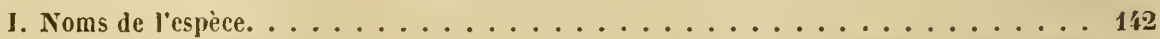

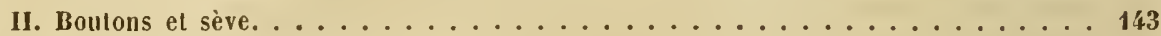

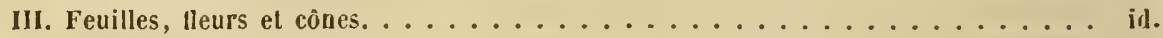

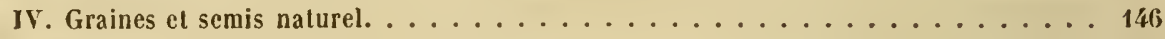

V. Mode de vẻgétation, deseription, dimensions. ................ 154

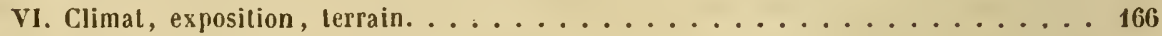

VII. Création d'une futaje et d'un taillis de pins sylvestres. . . . . . . . . . . 170

VIII. Améllagement, exploitation et reproduction. . . . . . . . . . . . . . . . . . . . . . . .

IX. Qualités et usages du bois; produits divers . . . . . . . . . . . . . . 19'

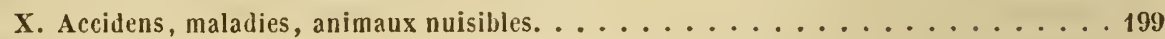

Chapitre V. - Pin maritime, Pinus maritima.

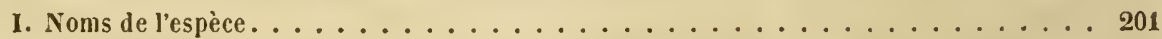

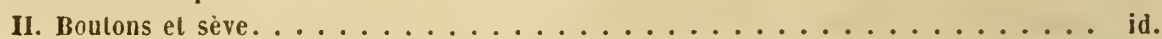

III. Feuilles, fleurs et cônes. . . . . . . . . . . . . . . . . . 202

IV. Graines et semis naturel. . . . . . . . . . . . . . . . . . 204

V. Mode de végẻtation, description, dimensions. ................ 206

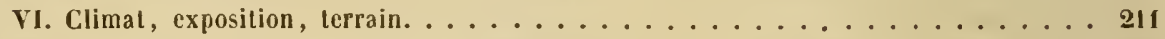

VII. Création d'une futaie de pins maritinses. . . . . . . . . . . . . 213

VIII. Aménagement, exploitation et reproduction. ............... 223

IX. Qualités et usages du bois; produits divers . . . . . . . . . . . . . . . . . . . . . . . . . . . . . . .

X. Accidelıs, maladies, animaux nuisibles. . . . . . . . . . . . . . . . . . . . . . . . . . . . . .

XI. Culture du pin maritime en Solognc. . . . . . . . . . . . . . 210

Cha Pitre vi. - Pin laricio, Pinus laricio.

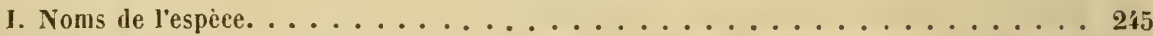

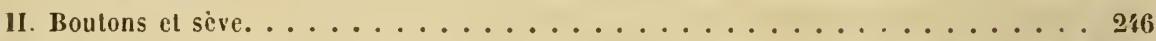

III. Feuilles, fleurs et cônes. ..................... id.

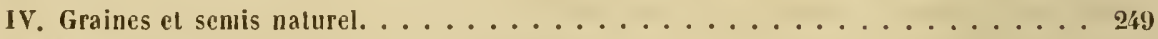

V. Mode de végćtation, description, dimensions. . . . . . . . . . . . . . . . . . . . . . . . . . . . .

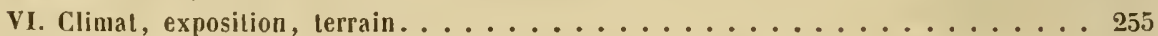

vil. Création d'une futaic de pins laricio. . . . . . . . . . . . . . 257

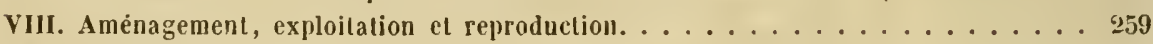

IX. Qualitės et usages du bois : produits divers. . . . . . . . . . . . . . . il.

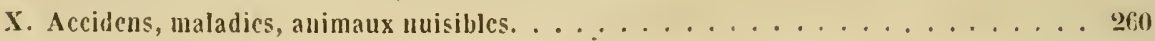


I. Noms de l'espèce. . . . . . . . . . . . . . . . . . . . . . . . 29202

II. Boutons et sève. ...................... id

III. Feuilles, flenrs et cỏnes. . . . . . . . . . . . . . . . 263

IV. Graines el semis naturel. ..................... 265

V. Mode de végétation, deseription, dimensions. . . . . . . . . . . . 266

Vı. Climat, exposition, terrain. . . . . . . . . . . . . . . $2 \pi 1$

VII. Création d'une futaie de pins du lord Weymouth. . . . . . . . . . . 272

VIII. Aménagement, exploitatiou et reproduction. . . . . . . . . . . . 273

IX. Qualités et usages du bois; produits divers. . . . . . . . . . . . iı.

X. Accidens, maladies, animaux nuisibles. . . . . . . . . . . . 276

CHAPITRE VIII. - Mélèze d'Europe, Larix europea.

I. Noms de l'espèce. . . . . . . . . . . . . . . . . . . . . . . . . 277

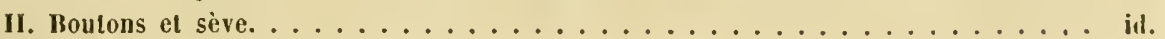

III. Feuilles, fleurs et cônes. . . . . . . . . . . . . . . . . . 278

IV. Graines el semis naturel. . . . . . . . . . . . . . . . . 280

v. Mode de végélation, description, dimensions. . . . . . . . . . . 282

VI. Climat, exposition, terrain. . . . . . . . . . . . . . . . . . . . . . 289

VII. Création d'une fulaie de mélèzes. . . . . . . . . . . . . . . 290

VIII. Aménagement, exploitation et reproduetion. . . . . . . . . . . 301

IX. Qualitės et usages du bois ; produits divers. . . . . . . . . . . . . 302

X. Accidens, maladies, animaux nuisibles. . . . . . . . . . . . 306

Chapitre IX. - Cèdre du Liban, Cedrus Libani.

I. Noms de l'espèce. . . . . . . . . . . . . . . . . . . . 308

II. Sève et feuilles ..................... id.

III. Fleurs et cônes. . . . . . . . . . . . . . . . . 309

IV. Graines et semis naturel. . . . . . . . . . . . . . . 313

V. Mode de végétation, description, dimensions. . . . . . . . . . . 314

VI. Climat, exposition, terrain. . . . . . . . . . . . . . . 320

vir. Culture. . . . . . . . . . . . . . . . . . . . . . . . 322

VIII. Qualités el usages du bois . . . . . . . . . . . . . . . 323

IX. Accidens, maladics, animaux nuisibles. . . . . . . . . . 32'

x. Cèdre du Liban, variété argentée. . . . . . . . . . . . . id.

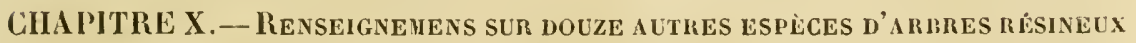
CONIFÈRES.

I. Observations préliminaires. . . . . . . . . . . . . . . 32

II. Pin d'Autriche, Pinus austriaca. . . . . . . . . . . . . . id.

IIr. Pin cembro, Pinus cembra. . . . . . . . . . . . . . 334

IV. Pin d'Espagne, Pinus hispanica. . . . . . . . . . . . . 338

v. Sapin d'Espagne, Abies hispanica. . . . . . . . . . . . . . . . 339

VI. Cèdre de l'Inde, Cedrus indica. . . . . . . . . . . . . . . . 371

VII. Pin du Népaul, Pinus nepalensis. . . . . . . . . . . . . . . . 342

VIII. Pin doux, Pinus mitis. . . . . . . . . . . . . . . 3 3 3

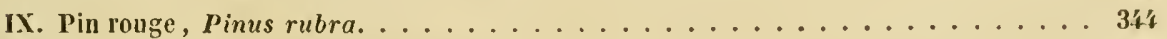

X. Pin de Lambert, Pinus lambertiana. . . . . . . . . . . . . . 316

Xr. Pin tle Sabine, Pinus sabiniana. . . . . . . . . . . . . . 3

XII. Pill de Coulter, Pinus Coulteri. . . . . . . . . . . . . . . . $3: 4$

XIII. Cypris distique, Cupressus disticho. . . . . . . . . . . . . . . . . 349 
CHAPITRE XI. - Pepinieke et plantation a demeure.

I. Observations préliminaires el travaux préparatoires. . . . . . . . . . . 354

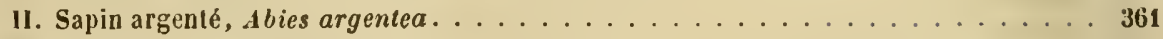

III. Sapin picéa , Abies picea. . . . . . . . . . . . . . . . 375

IV. Pin sylvestre, Pinus sylvestris. . . . . . . . . . . . . 377

V. Pin maritime, Pinus maritima. . . . . . . . . . . . . . . . 379

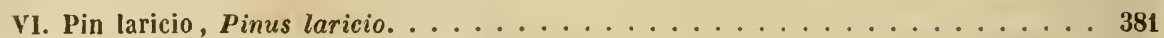

VII. Pin du lord Weymouth, Pinus strobus. . . . . . . . . . . . . . 383

VIII. Mélèze d'Europe, Larix europá. . . . . . . . . . . . . . . . . . . . . . . . . . . . . . . . . . . . . . . . . . . . .

IX. Cèdre du Liban, Cedrus Libani. . . . . . . . . . . . . . . . . . . . . . 387

. Pin d'Autriche, Pinus austriaca . . . . . . . . . . . . . . . 389

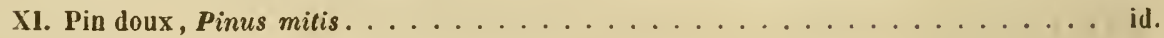

CHAPITRE XII. - ObSERVATIONS, Faits et henseignemens divers.

1. Alternance des bois sur le sol. . . . . . . . . . . . . . . . . . 392

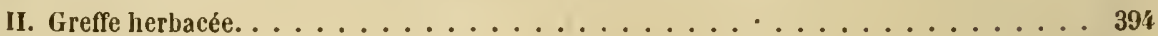

III. Dendromètres. . . . . . . . . . . . . . . . . . . . . . 399

IV. Visile aux bois résineux du Vieil-llarcourt. . . . . . . . . . . . . . . . 401

V. Sur ce que dit M. le docteur Ratzeburg des insectes nuisibles aux arbres résineux. . . 402

VI. Sur la plantation à demeure des arbres feuillus, et surtout des arbres fruitiers. . . . 403

CHAPITRE XIII. - Resumé.

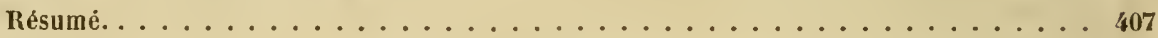

\section{BIBLIOGRAPHIE.}

Titres des ouvrages cilés dans ce Traité, par ordre de date de publication. . . . . 449

\section{PLANCHES.}

Note relative aux dessins qui se trouvent sur les planches I, II, III, IV el V. . . . . . 425

Légende des planches I, II, III, IV et V, ou sout représentés les feuilles, les tleurs, les

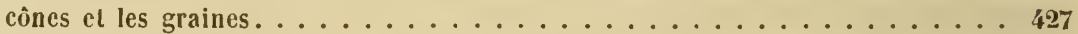

Légende de la planche VI, oủ sont représentés des oulils et des instrumens employés pour l'exploitation des futaies. . . . . . . . . . . . . . . . . . . 428

Légende de la planche VII, oủ sont représeutés des outils employés pour la ctilture des

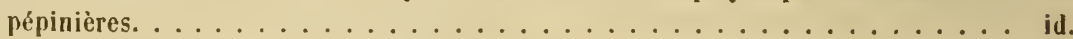




\section{AVERTISSEMEN'T.}

Les arbres résineux conifëres dont je me suis occupé dans ce 'Traité sont appelés vulgairement arbres verts, et ne sont connus de beaucoup de praticiens que sous ce nom. Je crois utile de donner, a vant que d'entrer en matière, quelques renseignemens succincts sur le plan que j’ai suivi et sur la manière dont je l'ai exécuté.

J'ai divisé ce Traité en treize chapitres. Le premier chapitre est une sorte d'introduction. Chacun des huit chapitres qui le suivent est consacré à l'une des espèces d'arbres résineux conifères qui m’ont paru le plus généralement cultivés sous le climat de Paris, et dans chacun de ces chapitres je traite les mêmes matières et dans le même ordre; c'est une nécessité de ce genre de travail. Il en résulte que, pour éviter les répétitions, j’ai dû renvoyer quelquefois aux chapitres précédens, particulièrement au chapitre II et au chapitre III, consacrés, le premier au sapin argenté, le second au pin sylvestre.

Pour bien faire connaître ces espèces, j’ai fait la description de leurs feuilles, de leurs fleurs, de leurs cônes, de leurs graines et de leur mode de végétation, en ce qui peut se distinguer à l'œil nu; et j'ai ajouté au texte des dessins de grandeur naturelle et de demigrandeur exécutés avec beaucoup de soin : toutefois, il ne m’a pas paru nécessaire d'y joindre des dessins des fleurs femelles, qui contiennent le rudiment des cônes par lesquels elles sont bientôt remplacées.

Ce 'Traité n'étant destiné qu’aux praticiens, le principal but que je me suis proposé dans le classement des matières a été de lour faciliter les recherhes; je crois y avoir réussi en adoptant 
l'ordre suivant, pour chacune des espèces auxquelles je consacre un chapitre à part : I. Nons de L'espièce. - II. Boutons et sève. III. Feullees, fleurs et cones. - IV. Graines et senis naturel. V. Mode de végétation, description, dinensions. - VI. Climat, exposition, terran. - VII. Création d'une futaie de ${ }^{\cdots \cdots * *}$. VIII. AnÉNigeneNt, Exploitation et REPROduction.-IX. Qualités ET USAGES DU BOIS; PRODUITS DIVERS.-X. ACCIDENS, MaLidies, aNinAUX suisıbles. Il était d'ailleurs impossible que ces divisions, si utiles pour faciliter les recherches, fussent toujours bien tranchées, et qu'elles n'empiétassent pas quelquefois les unes sur les autres. Ainsi, par exemple, il est évident qu'on ne peut trouver tout ce qui est relatif aux feuilles, fleurs et cônes, qu'en lisant ce qui a été dit, dans l'article Boutons el sève, des boutons et de la marche de la sève, puisque les feuilles et les fleurs sont annoncées par des boutons; on ne peut non plus trouver tout ce qui est relatif aux graines qu'en lisant ce qui a été dit auparavant des cônes qui les contiennent.

J'ai adopté pour chaque espèce le nom français qui m'a par'u le plus propre à la désigner, parmi ceux qui lui sont vulgairement donnés, et je l'ai fait suivre du nom latin qui y correspond. Il serait sans doute à désirer que les noms exprimassent une qualité de l'arbre auquel on les applique, ou indiquassent le pays d'où ils sont indigènes; mais il faut bien adopter les noms déjà usités.

Dans le chapitre $\boldsymbol{X}$, je me suis borné à parler sommairement de douze espèces d'arbres résineux conilères cultivables dans les climats tempérés et en particulier sous le climat de Paris, et j’ai conseillé d'en essayer la culture en grand. Dans le chapitre XI, j'ai traité de la manière d'élever en pépinière et de planter à demeure les arbres résineux conifères de pleine terre, ainsi que je l'ai pratiqué. On trouvera dans le chapitre XII cinq articles sur différens sujets que j'aurais pu intercaler dans plusieurs des chapitres de l'ouvrage, mais qu'il m'a paru préférable de réunir dans un chapitre à part. Enfin, dans un XIII et dernier chapitre, j’ai fait un résumé succinct de ce qui avait été dit dans les chapitres précédens.

Le tronc des arbres est plus ou moins rentlé an niveau du sol, ar 
ce n'est qu'i quelque distance au dessus du sol qu'il commence ì avoir un décroissement à peu près régulier. Lors done que je donnerai le diamètre du trone d'un arbre, ce diamètre aura toujours été pris à un mètre au dessus du sol, et lorsque je donnerai la hauteur, re sera la hauteur totale depuis le sol jusqu’à la cime; s’il en était autrement, $\mathrm{j}$ 'aurais soin de le dire. Les auteurs qui donnent le diamìre du trone sans dire ì quelle hauteur il a été pris, ne fournissent qu'un renseignement fort incomplet, et ceux qui rapportent des hauteurs d'arbres que l'on a évaluées approximativement peuvent reproduire de très-grandes erreurs. Ainsi, par exemple, Loudon, dans son Arboretum et Fruticetum britanxicum, t. IV, p. 2197, dit que le cèdre du Jardin-des-Plantes de Paris, dont il avait sans doute évalué approximativement la hauteur pendant ses voyages dans cette capitale, a 80 pieds anglais (24 mètres) de haut, tandis que cet arbre n'a que $17^{\mathrm{m}}, 50$. Ce même auteur donne, dans l'ouvrage que je viens de citer, un très-grand nombre de dimensions d'arbres, choisis parmi ceux qui se trouvent dans les beaux parcs et jardins si nombreux de la Grande-Bretagne; ces renseiguemens, fournis par les propriétaires, présentent, presque tous, les inconvéniens que je viens de signaler : il ne fait d'ailleurs que bien rarement connaître l'âge de ces arbres; il n'indique jamais dans quelle espèce de sol ils ont crû, ni s’ils étaient isolés ou s’ils se rrouvaient dans des massifs à l'état serré. J'ai cru pourtant devoir reproduire quelques-uns de ces renseignemens, parce qu'ils fournissent le moyen d'établir une comparaison entre les dimensions auxquelles parviennent les différentes espèces, sous le climat de l'Angleterre, et qu'ils font connaitre celles qui y acquièrent de fortes dimensions.

J'ai placé à la fin de ce Traité les titres des ouvrages qui y sont cités par ordre de publication, mais en réunissant pourtant les ouvrages d'un même auteur ; j’ai pu dès lor's me contenter, lorsque je fais une citation, d'indiquer sommairement le titre de l'ouvrage, le tome et la page.

Lorsque, pour éviter les répétitions, je renverrai à un autre pas- 
sage de mon ouvrage, j’indiquerai la page, quand ce passage précédera ; et seulement le chapitre et l'article dans lequel il se trouvera quand ce passage suivra, puisque, dans ce dernier cas, je ne pourrais indiquer la page qui ne sera pas encore imprimée.

Les faits que je rapporte ne peuvent pas toujours être rigoureusement vrais, parce que je dois faire connaitte ce qui arrive ordinairement et ne pas rapporter des cas exceptionnels très-rares. Ainsi, par exemple, je dis que les pins sylvestres tirés d'une pépinière et plantés à demeure, portent quelquefois des cônes dès la dixième année et très-souvent dès la douzième année : que si l'on prétendait qu'ils en portent plus tôt, parce qu'on en voit parfois dans les pépinières sur des arbres de six à sept ans, je répondrais que c'est alors un cas exceptionnel, que ces cônes sont de véritables avortons, et que j'aurais cru surabondant et par conséquent nuisible de rapporter de tels faits dans un traité pratique.

L'expression maturité s'emploie particulièrement en parlant des fruits ; je l'appliquerai aussi, par analogie, aux arbres résineux pour indiquer le moment où leur bois a acquis toutes les qualités dont il est susceptible; et aux fleurs pour indiquer le moment où les fleurs mâles répandent le pollen et où les fleurs femelles, ayant atteint tout leur développement, peuvent ètre fécondées.

Les troncs propres à être convertis en bois d'œuvre ont d'autant plus de valeur, toutes choses égales d'ailleurs, qu'ils se rapprochent plus d'un cylindre, ayant pour base la circonférence de ce tronc à un mètre au dessus du sol; je dirai donc des espèces d'arbres dont le tronc présente le plus d'avantage, sous ce rapport, que ce tronc maintient bien sa grosseur, et de celles dont le tronc en présente le moins, qu'il maintient mal sa grosseur : j’adopte cette locution, qui n'est pas irréprochable, pour la facilité de la rédaction.

J'ai employé les mesures métriques, et lorsque, dans des extraits ou dans des citations de différens ouvrages, il se trouve des quantités exprimées différemment, je les fais suivre immédiatement de la réduction en mesures métriques. Voici la valeur, en mesures mé- 
Iriques, de quelques mesures que des citations introduiront dans mon ouvrage.

Le pied de roi français est divisé en 12 pouces, le pouce en 12 lignes; le pied de roi vaut $0^{m}, 52484$, le pouce $0^{m}, 02707$, la ligne $0^{\prime \prime}, 002236$.

L.e pied anglais est subdivisé comme le pied de roi en 12 pouces, "t le pouce en 12 lignes; le pied anglais vaut 0 ", 04049 , le pouce 0'".025599, la ligne $0^{m}, 002116$. L'acre anglais est de 40 ares 17 centiares; l'acre écossais de 48 ares

Je ferai observer à cette occasion qu’il aurait été à désirer que le gouvernement ê̂t autorisé la division du mètre en J̄ pieds, du pierl en 12 pouces et du pouce en 12 lignes; cette subdivision aurait éri presque toujours beaucoup plus commode, dans la pratique, que la subdivision en décimètres, en centimètres et en millimètres. C'esı par ce motif que, pour les monnaies, il s'est écarté du système décilimal.

Un Traité pratique des arbres résineux conifères à grandes dimensions, que l'on peut cultiver, plus ou moins avantageusement, en futaie dans les climats tempérés, et particulièrement sous celui de Paris, manquait, et je n'aurai pas comblé cette lacune, cela n'aurait pas été possible. Mais j’aurai, je l'espère, posé les bases de l'édifice; j’en aurai commencé la construction, terminé quelques parties ou à peu près, et il sera facile, si mon plan est bon, d'achever cette construction à mesure que l'on pourra se procurer des matériaux. Cet ouvrage pourra alors devenir le vade mecum des personnes qui voudront cultiver les arbres résineux de pleine terre à grandes dimensions, qui peuvent bien réussir dans les climats tempérés.

Nota. Je prie les personnes qui liront cet ouvrage et qui auraient à me communiquer des renseignemens intéressans sur la culture des arbres résineux conifères à grandes dimensions, de me les adresser au château de Chambray, par Damville (Eure). 



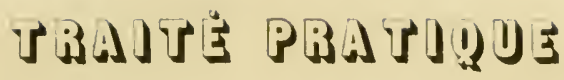

IHIS

\section{ARBRES RÉSINEUX CONIFÈRES}

\author{
I GRIVDES DEINEISOIS.
}

CHAPITRE PREMIER.

\section{COISIDÉRATIONS GÉNÉRALES.}

Les arbes dont je vais m'oceuper daus ce Traté ont reçu en France le nom d'Arbres résineux conifêres, ì cause de deux caractères généraux qui peuvent servir à les distinguer. Les Allemands, qui ont heaucoup écrit sur ces arhres, donnent ì leurs feuilles le nom d'nignilles, parce qu'elles ont quelque ressemblance avee une aiguille, et ils les appellent Nadelberume, littéralement arbres ì aiquilles. Si l'expression allemande avait été mieux motivée que l'expression française, je l'aurais adoptée; mais c'est précisément tou le contraire : j’ai done conservé l'expression française.

ll me paraît nécessaire de domner d'abord quelques éclaircissemens sur l'expression climats tempérés, employéc dans mon tilre, parce qu'elle peut recevoil plus on moins d'extension. J'ai eu principalement en vue le climat de la France, si l'on en retranche et celte partic de son territoire où croit l'olivier, et les parties les plus élevées des hautes montagnes; car la France, dans le reste de son territoire, présente pour les cultures principales des caractères généraux à peu près semblables : cela n'empèche point que, indépendamment du sol, la différence de latitude el d'altitude (hauteur au dessus du nivean de la mer), le voisinage de la mer, l'exposition, n'exercent me notable inlluence et n'upportent, par conséquent, des modifications à ces caractères généraus. C’est, d’ail- 


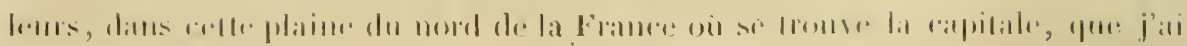

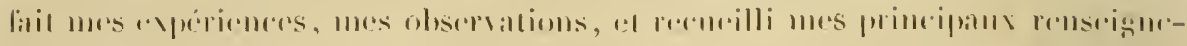

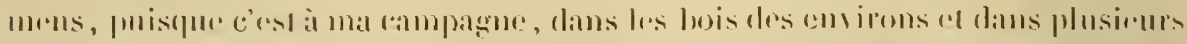

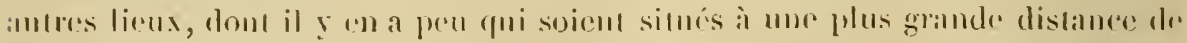
Paris que colle campligne. Ainsi, cest dans mon pare que jai pris les dimm-

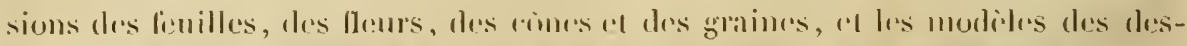

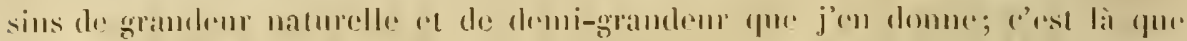

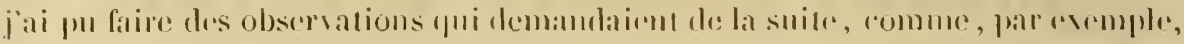

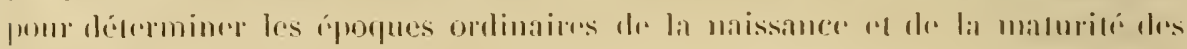
mornes, des comes al dies graines.

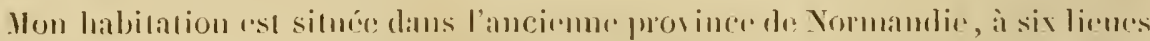

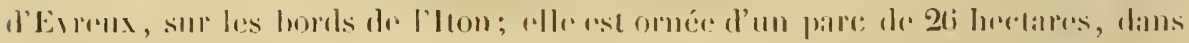

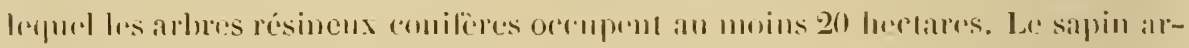

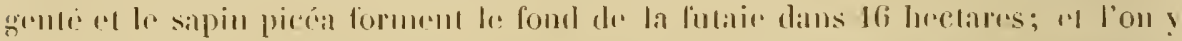

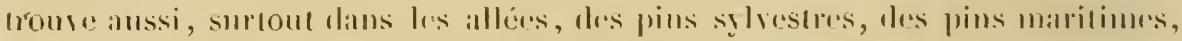

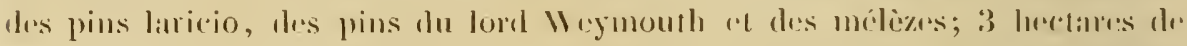

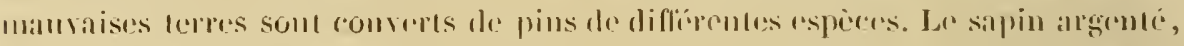

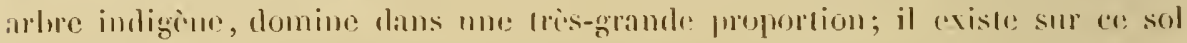

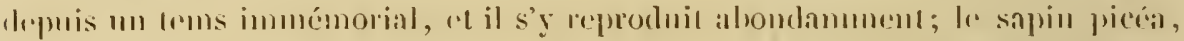

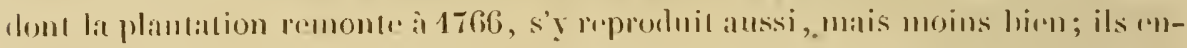

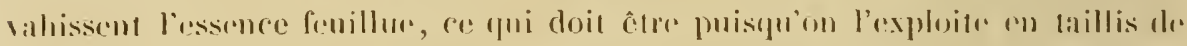

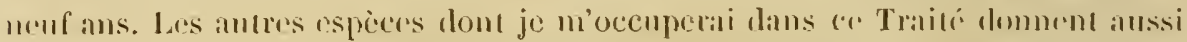
du semis malurel, mais qui me se trouve pas daus les mèmes romditions de réus-

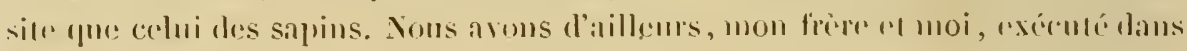

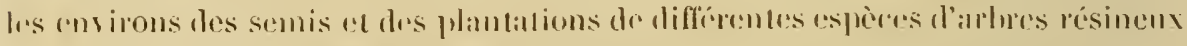
dre pleime larese at grambes dimensioms.

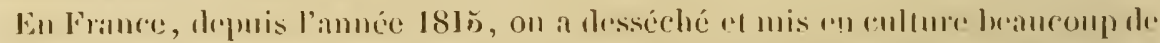

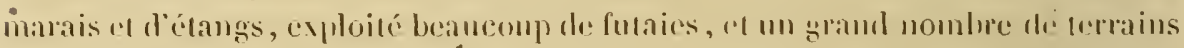

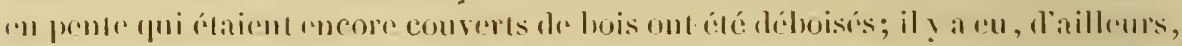

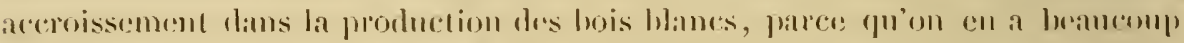

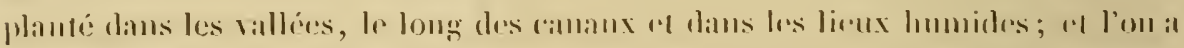

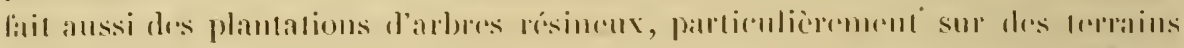

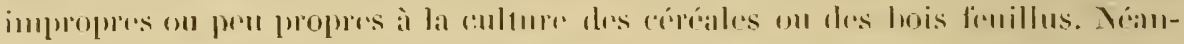

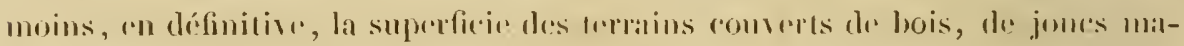

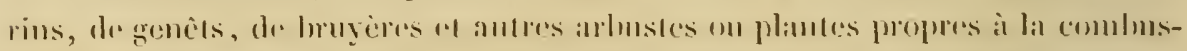

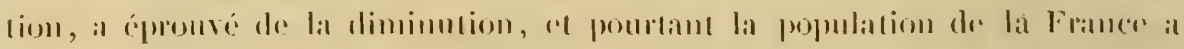

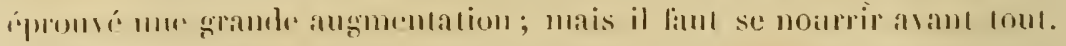

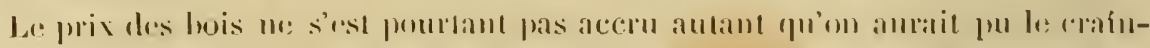

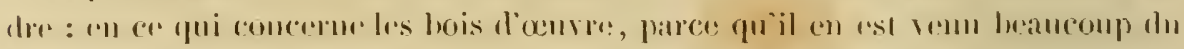

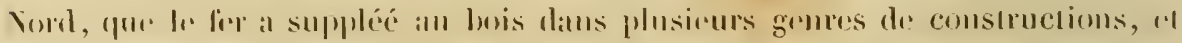

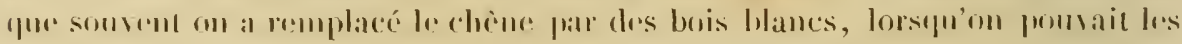

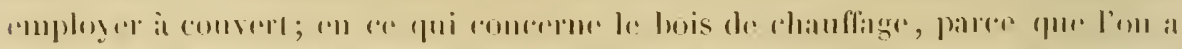
10)18 


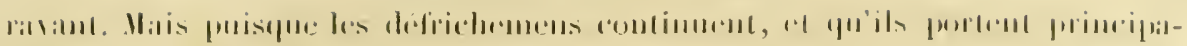

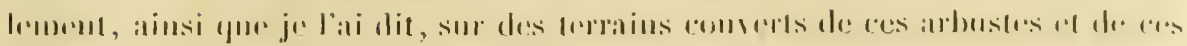

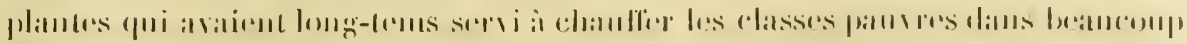

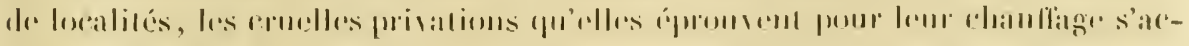

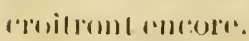

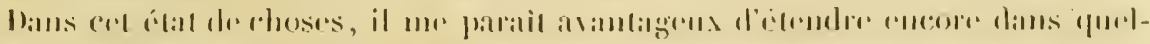

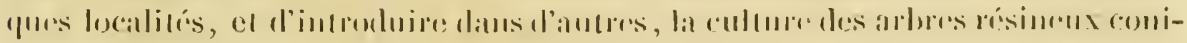

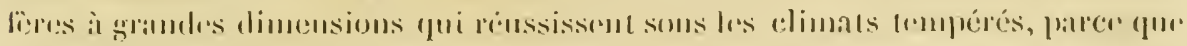

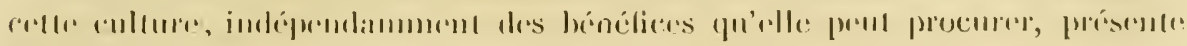

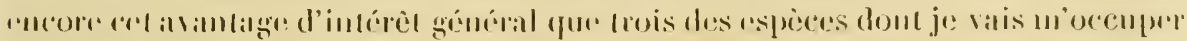

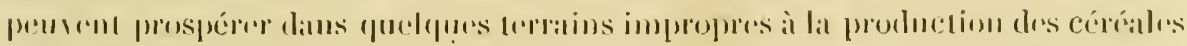

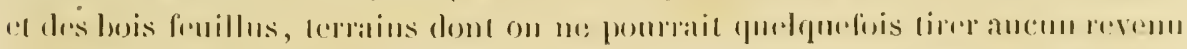

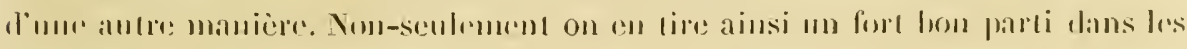

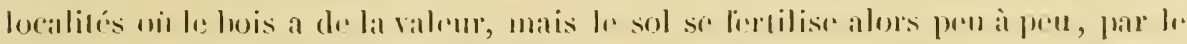

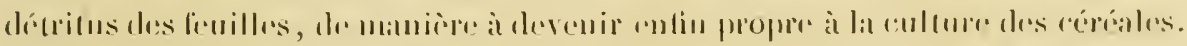

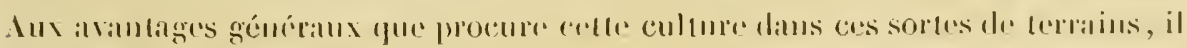

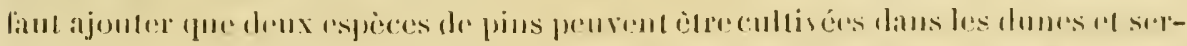

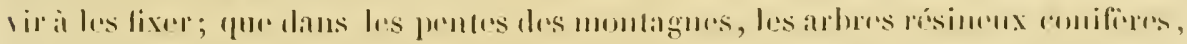

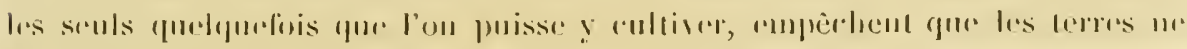

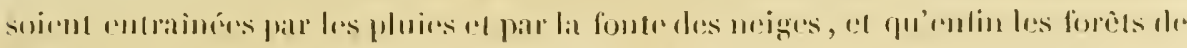

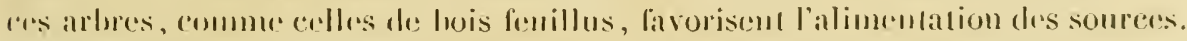

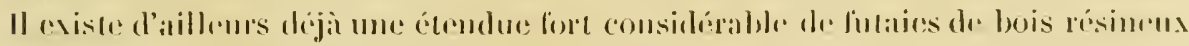

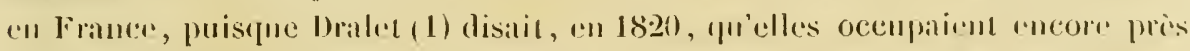

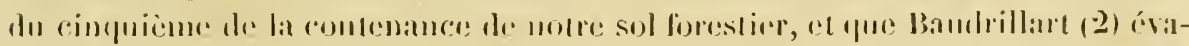

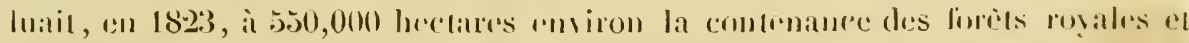

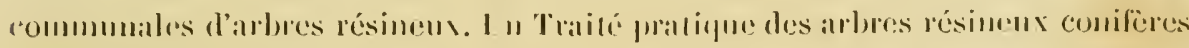

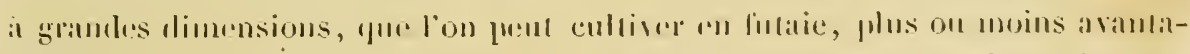

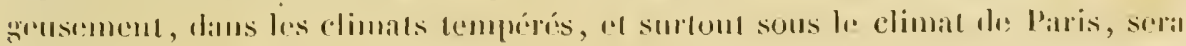
Alume: utili:.

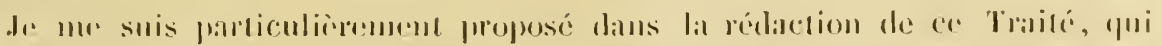

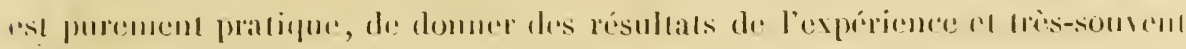

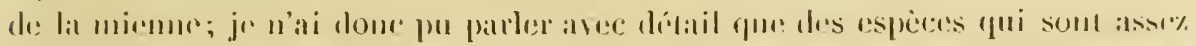

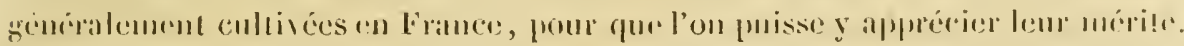

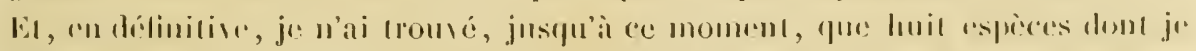

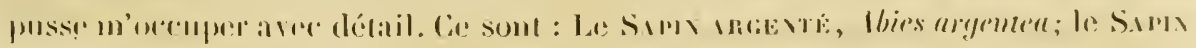

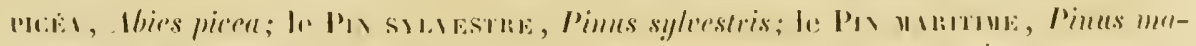

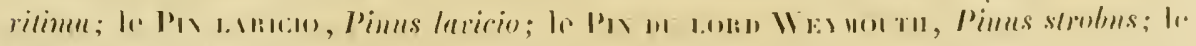

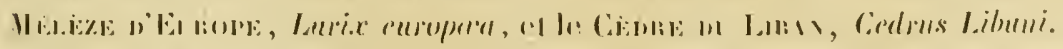

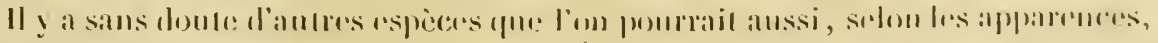

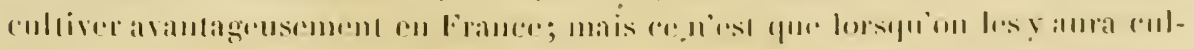

(1) Traili des forits liarbres reineux , p. il.

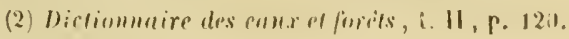




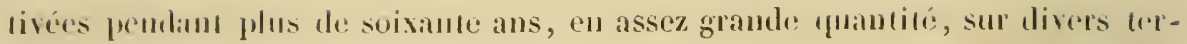
rains, à diverses expositions el en futaies pleines, que l'on pourra lixer son opinion à cet égard. T'el arbre, par exemple, acquiert de grandes dimensions en Amérique, d'où on l'a tiré, qui n'en acquiert plus que de médiocres en France, quoique cultivé sous un climat semblable en ce qui concerne la température. Cependant je consacrerai un chapitre à donner des renseignemens plus ou moins ćtendus sur quinze autres espèces d’arbres résineux à grandes dimensions, cullivibles dans les climats tempérés, el en particulier sous le climat de Paris.

Ces quinze espèces, dont je pense qu'on devrait essayer la culture en grand, en pleine terre, sous le climal de Paris, d'après les renseignemens que j'ai pu mr procurer, sont, en arbres indigènes de l'Europe : le Pux nom d'Autriche, Pinus anstrinca llass; le PIx tachigt e, Pinns taurica Hortus parisiensis; le Pix de Pallas, Pims pullasian Limberl; le PIx d’Espagne, Pinns hispanica S. E. Cook; la: Supro u'Espane, Abies hispanica mili; le Pox cenero, Pinus cembra Decandolla. En arbres indigènes de l'Asie : le Cèdre de L'Ixde, Cedrus indica mihi; le Pro dr Népale, Pinus nepalensis mili; le Pin de Carumane, Pimus caramanicu Iorus parisiensis. En arbres indigènes de l'Amérique: le Pin nozge, Pinus rubra A. Michaux; le Prx doex, Pinus milis A. Nichaux; le Pix en L.ungert, Pims lumbertiana Douglas; le Pix de Sanne, Pinus sabiniuna Douglas; le Pux de Coelten, Piuns Conlevi D. Jon; ('t le: Cr prés mistigue, Cupressus disticha Linné.

Qunnt au Pin rigxox, Pinus pinea Linné, el an Pix d'Alep, Pims alepensis Decandolle, arbres indigènes de l'Europe, si l'on parvient à les conserver pendant quelques années sons le climal de Parris, ils finissent toujours par y périr pendant un hiver rigoureux, ainsi que je l'ai ciprouvé en 1829; ils n'y parvieunent d'ailleurs qu'à de médiocres dimensions. II. A. Michaux (I) conseille d'essayer dans les landes de Bordeaux la culture du Prx acstral, Pinus anstralis A. Michaux, et du Prx a l'excens, Pims toda A. Michaux, arbres indigènes de l'Amérique septentrionale; mais je présume, d’après mon expérience, que ces deux espèces íprouveront, sous le climat de Paris, le même sort que le pin pignon et le pin d'Alep : je n'en parlerai donc point.

Le Sapun blanc, Abies alba A. Michaux; le Stprn nour, Abies nigra A. Michaux;

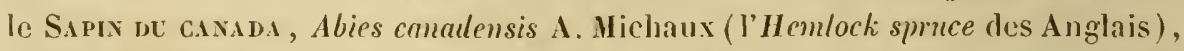
et le Métze n'A MémqLe, Larix americana A. Miehaux, quatre espèces tirées d'Amérique et cultivées en France depuis aussi longtemps que le pin du lord Weymouth, n'y atteignent que de faibles dimensions.

Je n’ai parlé ni de l'If, Taxus baccate Linné, ni du P’s de Cadarre, Pinus brutia Tenore, ni d'autres espèces indigènes d'kurope qui sont de moyemne dimension, parce que j'ai voulu me renfermer strictement dans mon litre. Je n'ai point cru devoir parler non plus de quelques autres espèces indigènes d'A mérique ou d'Asie, malgré ce qu'on a dit de leurs dimensions et de la facilité de les cultiver sous Ins climats tempérés, paree fu'elles sont encore trop peu connues, surtout

1) Itistnire des arbres forestiers de l'Amerique septenirionale, t. I, p. si et 101. 


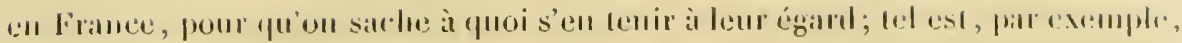

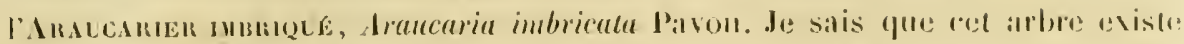
en pleine terre, en Anglelerre, dans le jardin du roi a Kew; che\% laty Granville, i Dropmore; clsez le duc de Devonshire, à Chatworth, ete.; en France, cluez H. Ie matrquis de Vibraye, près de Blois, an midi de celte ville, el, sins doute, dans d'antres lieux encore; mais je n'en commas pas sous le climat de P'aris proprement dit. J'en essaic la culture en pleine terre: réussirai-je?

J'essa ierai de déterminer si les arbres dont je m'ocenperai appartienneint a ume? espèce ou ì une variéré, ou si, sous des noms diflérens, ils napparticndraient pals à la même espèce.

Plusieurs des arbres don je vais moceuper particulierenent dans as Trati. ont recu des bolanistes, el du vulgaire daus divers pays, des noms différens; en outre, quelques bolanistes ont cru voir des variétés, et mème des especés, ou il "ry avait quelquefois qu'une seule el mème espèce, parce qu'ils obsersaient des diflérences qui ne résultaient que des siluations diflérentes dans lesquelles les arbres s'étaient trouvés. Quelques-uns de ces botanistes avaicut trop vécu daun leur cabinct; d'antres n’avaieut fait leurs observalions sur les lieux que pemdant des courses rapides, tandis qu'ils auraient dù observer les arbres pendant plusieurs années, à dilliérens îges, en plaine sous diverses latitudes, dans les monlagnes à diverses hauleurs, el principalement à l'éporque de la lloraison.

Nous n'avons en Europe qu'un mélèze, qu'on ne peul conlondre avec les alutres arbres dont je m'oceupe, puisfu'il perd ses fenilles l'hiver, el qu'elles ont une coulcur et une forme particulières. Nous ne cullivons encore, pour ainsi dire, qu'un seul cèdre, très-lacile à distinguer par son aspect tout particulier. En ce qui concerne les sapins, comme nous n'en avons que deux especes en Lurop: (1), les seules dont je moceuperai; qu'ils diflerenc beancoup par leurs fenilles, leurs fleurs, leurs cones, leurs graines, la couleur de leur écoree el leur aspect; quion lire de l'un d'oux de la lérebenthine el de l'aulre de la poix, il est dillieile de: les confonde.

Il n'en est pas de même des pins, qui sont d'ailleurs phus nombreux; si l'on en excepte de pin cembro, qui a cincf feulles dans une ganne, tous les autres pius d'Europe r'ont que deux feuilles dins une gaine; leurs fleurs mâles el leurs cùnes ont la même forme, et ne diffèrent que par la couleur et les dimensions. Mais on distingue les pius principalement par leurs feuilles, lenrs fleurs ef leurs cònes; secondairement par leurs graines, par leur écorce, par leurs dimensions el par leur aspect; et ces caractères varient plus ou moins selon l'ìge, le sol, la latilude et l'allitude. Ainsi, par exemple, on peut trouver des pins sylrestres chétifs, parce qu'ils sont sous un climat trop chand ou trop froid; l. même arbre pent être médiocre dans les basses vallées das haules montagnes, magnifigue a la hauteur qui lui couvient le mieux, si le sol lui est d’ailleurs li-

(1) Le sapin d'Espagne, nouvellement reconnu, sera la troisième espètec, si ce n'est pas une varéte Jus sipin argente. 


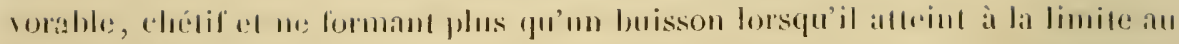

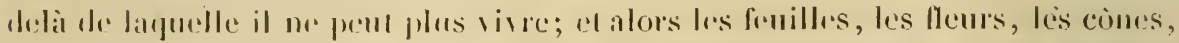

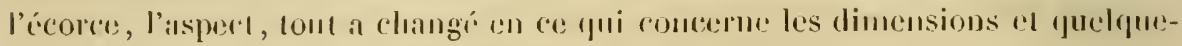

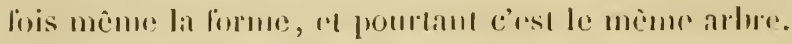

Il asl exart de dire qu'il rexiste une grande ronlusion dans la nomenclature ed

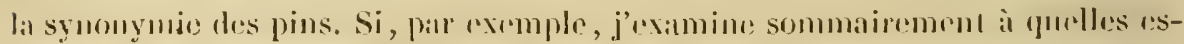

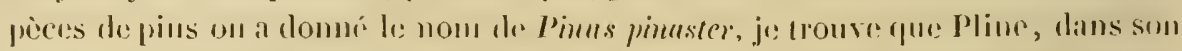

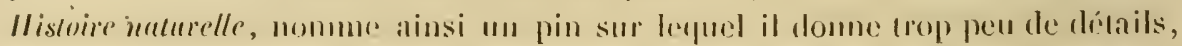

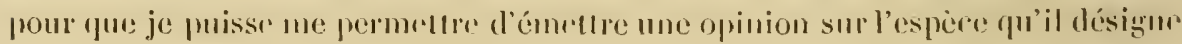
pill ce 110111.

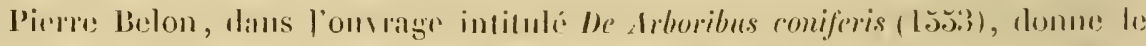

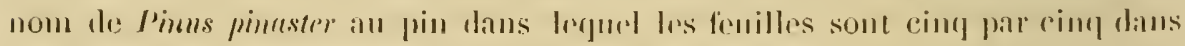
1116e saime, et qu'on appelle actuelloment Pin crmbros.

Rambert bodoens, dans son Stirpium historier (1583), donne le nom de l'iuns sylerster sier Pinuster ì un pin à denr fouilles.

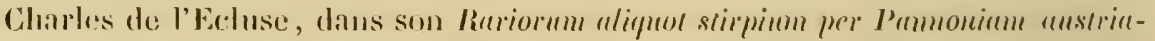

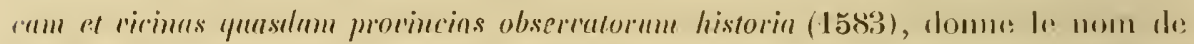

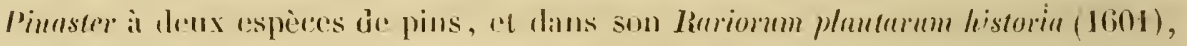

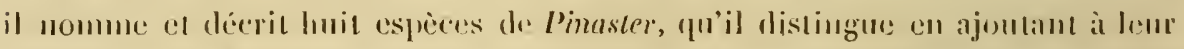

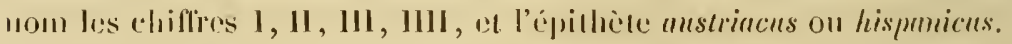

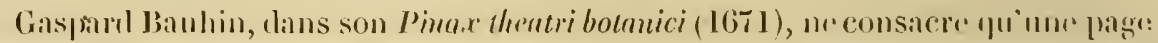

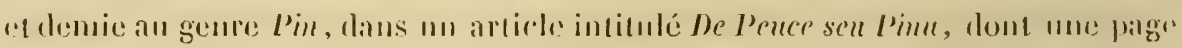
¿ nommer quin\% respeces de pins, parmi lespuelles se trouvent trois espèces de

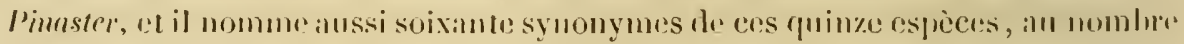

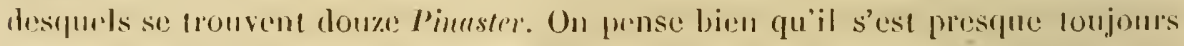

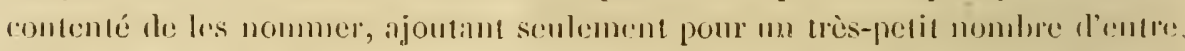
rus une phrase sprécilique; crependant Charles Limné le cite dans sus remois amx synonymes du l'in el des ses variélés, con indicpuant sentement la page.

Charles Limuc, daus son Sprecies pluntureme (1764), donne le nom de Pims pi-

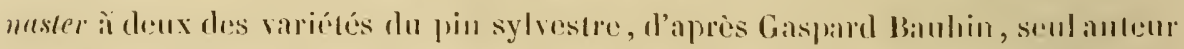
fu’il cile pour ces deux variélés, el il m reproduil la phrase spécilique; mais

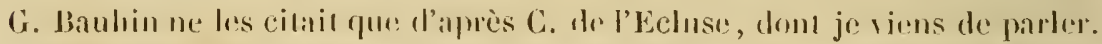

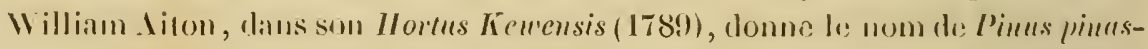

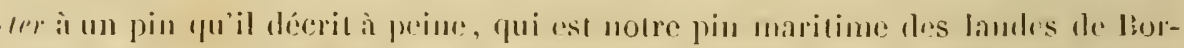

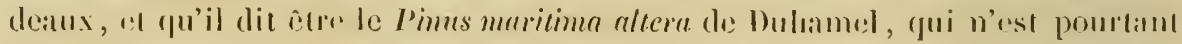
pias le prin marilime des limbles de Bordeanx.

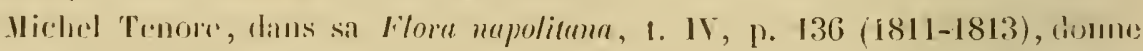
le noun de leimes pinester a l'un des pius des montagnes des Apromins, qu'il

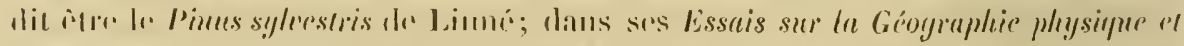

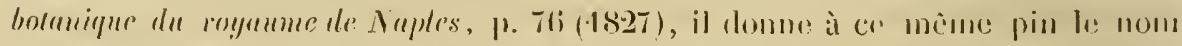

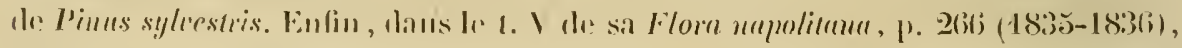

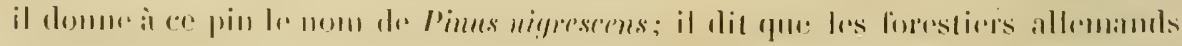

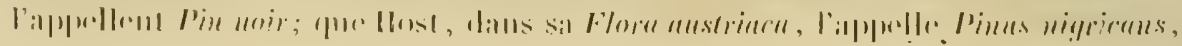




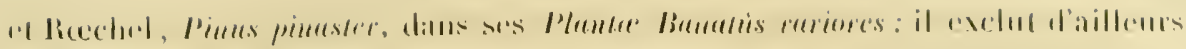

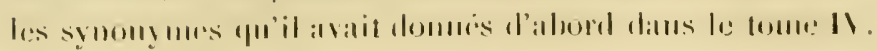

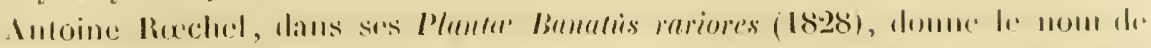

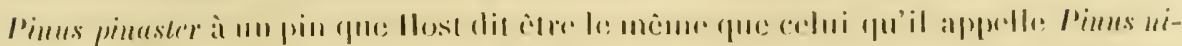

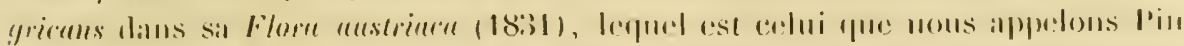

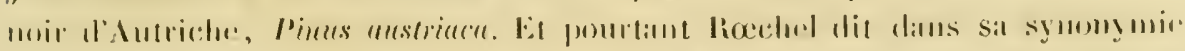

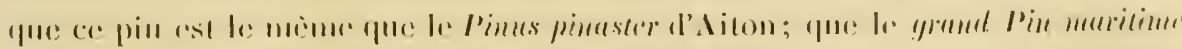

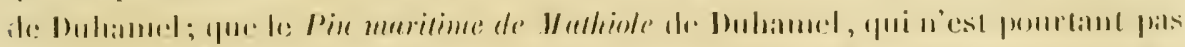

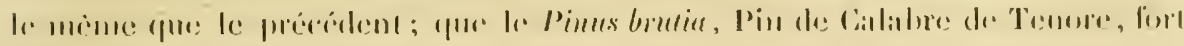

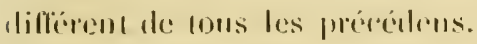

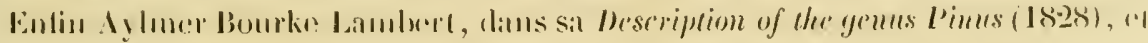

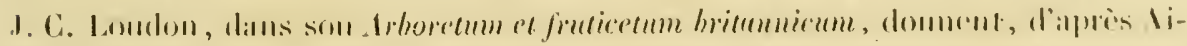
lon, le nom de Pinaster à motre pin maritime des landes de: Boreleans.

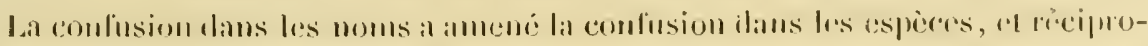

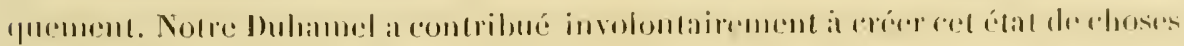

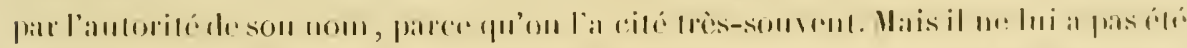

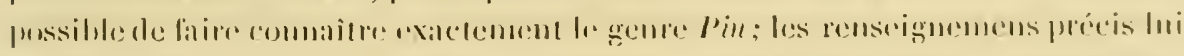

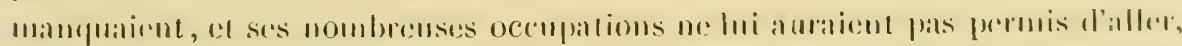

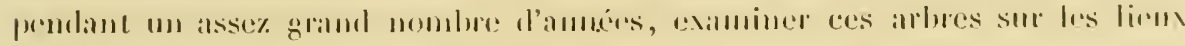

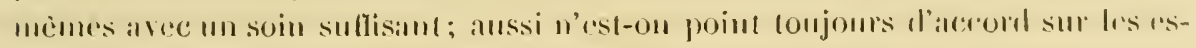

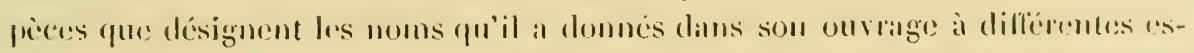

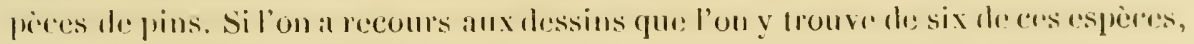

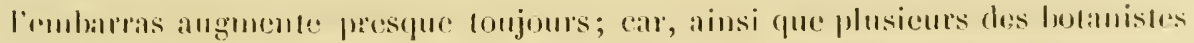

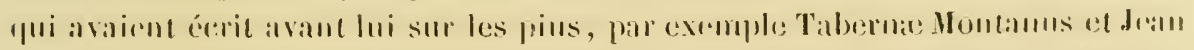

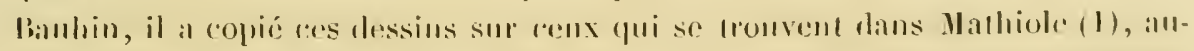

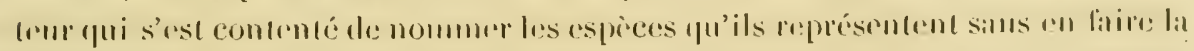

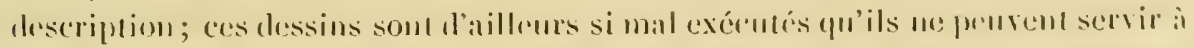

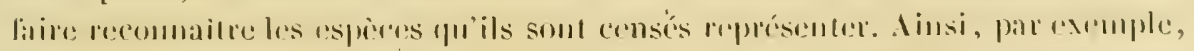

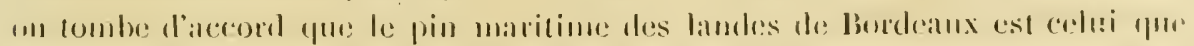

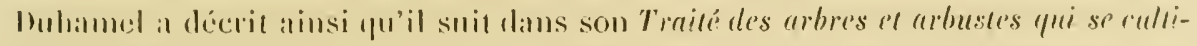

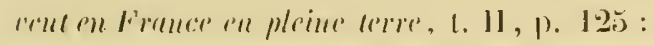

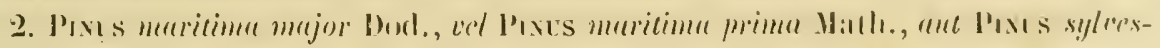

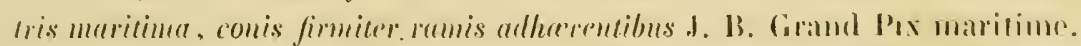

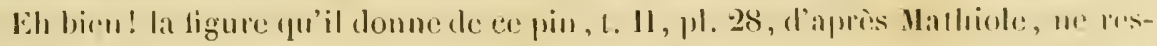

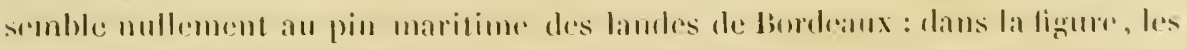
rimes one une puene (ils sont pédonculés); diuns la nallure, ils now ont point (ils

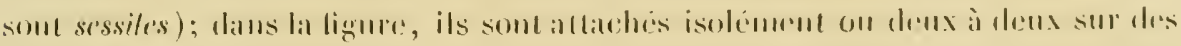

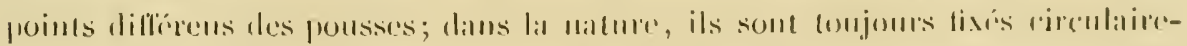

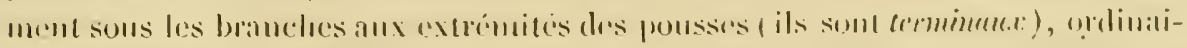

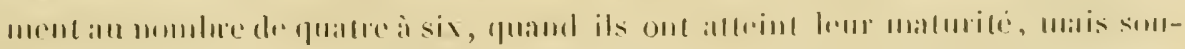

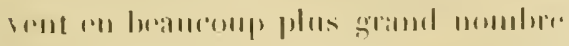

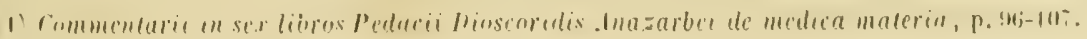


Ja citerai encore un exemple pour justifier ce que je dis de la conlusion qui s'est introduite dans la nomenclature des pins.

Decandolle dit (1) que la variété z du pin sylvestre de Linné (2) est notre pin maritime très-abondant dans les landes de Bordernx. Mais Linné a pris littéralement le nom et la phrase spécifique de cette variété dans Gr. Bauhin (3), lequel les avait lirés d'un onvrage de Clusius (Charles de l'Ecluse), qui avait observé la nature. Eh bien! Clusius appelle le pin que Decandolle prétend être le pin maritime des landes de Bordeaux, Pinctster latifolins, dans l'ouvrage (4) cité par Bauhin, et il en donne une description et une figure qui ne convienuent point au pin maritime; d'ailleurs, dans un onvrage postérieur de dix-huit ans (כ)), Clusius décrit, de nouveau, ce pin sous le nom de Pinaster II anstriacus, et dit qu'on le trouve dans les montagnes de l'Autriche et de la Pannonie, ou l'on ne trouve certainement point le pin maritime des landes de Bordeaux.

Je profite de l'occasion que me fournissent les recherches auxquelles je viens de me livrer, pour parler de la bibliothèque qui m'a servi, en grande partie, à les faire; e’est celle de M. le baron B. Delessert, consacrée spécialement à la botanique, et à laquelle se tronvent joints un berbier et une collection de feuilles ut de graines. Cette bibliothèque, ouverte aux savans et aux personnes qui se livrent ì des recherches, contient, dlans toutes les langues, les ouvrages qui ont paru sur cette partie des sciences naturelles, ce qui ne se trouve nulle part ailleurs aussi complètement : ces billiothèques spéciales me paraissent être d'une grande utilité, parce qu'elles sont orlinairement plus complètes et qu'on's'y procure plus promptement les ouvrages qu'on veut consulter.

L'accompagnement indispensable l'une bibliothèque consacréc à la botanique, est un jardin des plantes, et il y cn a un à Paris, fort remarquable sous plusieurs rapports. Mais il n'existe point en France de jardin forestier des arbres exotiques à grandes dimensions, de pleine terre sous le climat de Paris, et le gouvernement seul pourrait créer et perpétuer un tel établissement : il est inoui qu'un gouvernement qui dépense quatorze millions pour bâtir une maison sur le quai d'Orsay, ne dispose pas de quelques milliers de franes pour créer un tel étal)lissement. Ce jardin forestier serait très-utile aux botanistes pour fixer la nomenclature et la synonymie des arbres, et il ne serait pas moins utile aux praticiens; on devrait y trouver les arbres des différentes espèces, à différens âgres, croissant isolément et croissant en massif à l'état serré, sur différentes natures de sols ét à diverses expositions. On tieudrait, dans eet établissement, des registres contenant, pour chaque espèce, la date des semis et plantations, des notes sur les eirconstances importantes de leur végélation, et des noles sur les qualités êt sur l'usage de Jeur bois.

(1) Flore francaise, t. V1, p. 335.

(2) Species plantarum, 3e édt., 1. 11, p. 1818

(3) Pinax theatri botanici, p. 492.

(4) Rariorum aliquot stirpium per Pannoniam et Austriam, elc.: p. 16.

5 Rariorum plantarum historia, 1. 31 . 
On a consatré, à lat vérité, mo très-petite partic du Jardin-des-Plantes, que l'on appelle le Labyrinthe, i la cullure des arbres el des arhrisseaux toujours verts, de pleine terre sous le climat de Paris; mais exte partie du jardin, en supposant mème que l’on n’y plantât que des arbres résineux conifères à grrandes dimensions, serait bien insuffisante pour que l'on puit en avoir des échantillons de différens ânes; le sol y présente d’aillenrs un caractère tout particulicr, puisque les deux buttes sur lesquelles ont été placées les plantalions, ont été formées avec des plâtrás et des débris de différentes sortes apportés de Paris; enfin, l'atmosphère de cette capitale est contraire à la végétation de plusieurs espèces d'arlores. Ainsi, le èdre, l’if, etc., réussissent hien sur cet emplacement, le pin laricio médiocrement; mais le sapin argenté, le sapin picéa, le pin sylvestre, le pin maritime, le pin Weymouth, etc., après y avoir langui, de manière à devenir méconnaissables, linissent par y périr. Depuis quelques années on remplit de tere franche de grands trous, dans lesquels on plante ensuite de jeunes arlores qui réussissent momentauément; ce n’est qu'un palliatif.

La Société royale et centrale d'agriculture entreprend actuellement de créer un jardin forestier, dans sa propriété de Vicil-Itarcourl (Lure), d’après la proposition qui lui en a été faite par M. A. Michaux, l'un de ses membres, qui surveille, pour elle, l'administration de cette propriété; clle ne pouvait rien entreprendre de plus utile.

Linné a compris les sapins, les pins, les mélèzes el les cèrlres dans un mème: genre, sous la dénomination commune de Pinus, Pın; il m’a semblé qu’il était préférable, dans un ouvrage destiné aux praticiens, d'en faire quatre genres. Je sais qu'il y a des botanistes qui ont adopté aussi cette division, mais je dois déclarer que je ne me suis pas décidé par les mêmes raisons qu'eux; je l’ai adoptée après a roir examiné attent ivement les arlres dont je m’occupe, dans loutes les circonslances, de leur végétation, de leur floraison et de leur fructitication, ainsi que tout praticien peut le faire, sans jamais employer la loupe ni le microscope. Je n'ai mème voulu moccuper de botanique qu'en ce qui concernait les arbres résineux comlères, el qu'autant qu'il le fallait pour me livrer à cet examen; j’aime à me latter (que jobtiendrai l'approbation des praticiens, auxquels est principalement destiné cet ourrage. Toutefois, it cause de la célébrité de I.mué, je donnerai le nom qu'il a adopté et je le ferai suivre du nom qui a été donné à ces mêmes arbres par les botanistes qui en font quatre genres.

Les caractères visibles à l'oeil nu qui servent à distinguer ces quatre genres seront d'ailleurs décrits dans les chapitres ou daus les articles consacrés aus cspèces dont je moccuperai; mais il y en a de très-apparens qui servent à les faile distingner tout d'abord. Ainsi, les sapins diffèrent des pins par leurs feuilles qui sont lixées une à une sur les rameaux et sur les ramilles, et qui sont persistantes tant que l'accroissement du hois on l'ombrage ne les fait pas périr, tandis que le's feuilles des pins sont contenues au nombre de deux à cinf dans une gaine et ne persistent qu'environ trois ans; les cedres different des sipins el des pins par

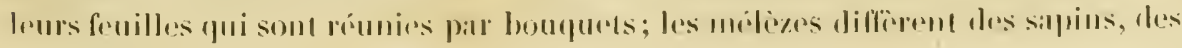




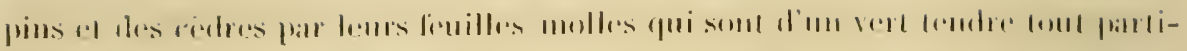

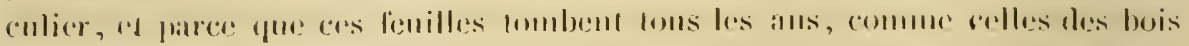
linillus.

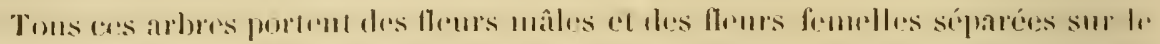

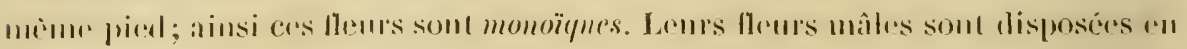

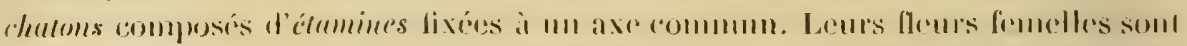

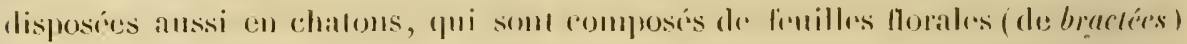

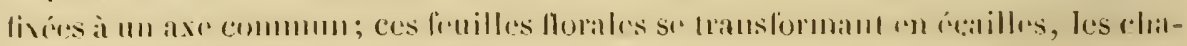
lons lomelles deviemment des comes.

Les flems limelles sont ordinairement an plus gramb nombre que les flems

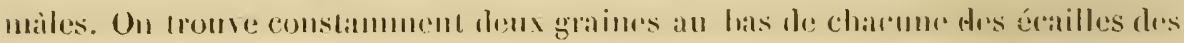

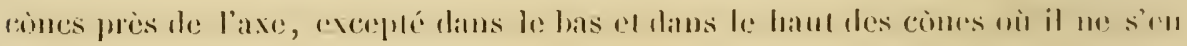

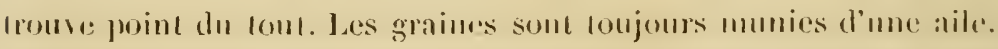

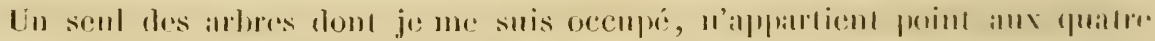

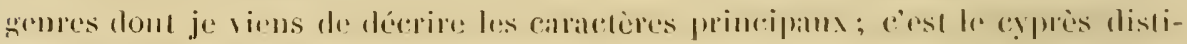

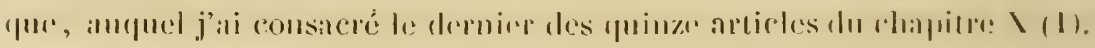

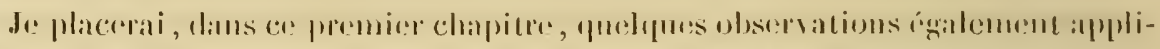

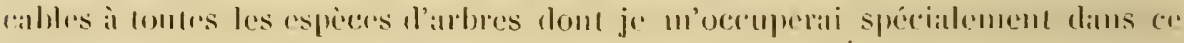

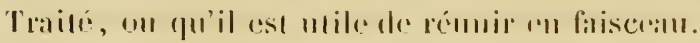

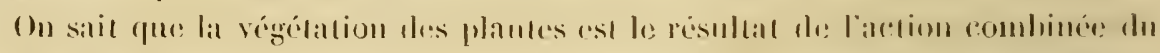

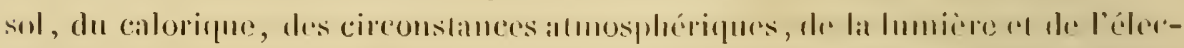

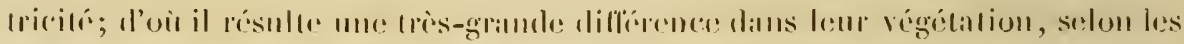

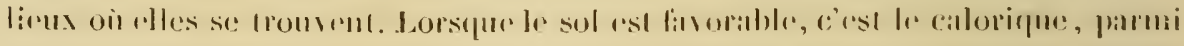

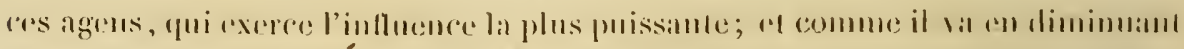

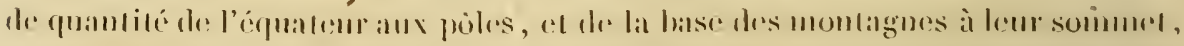

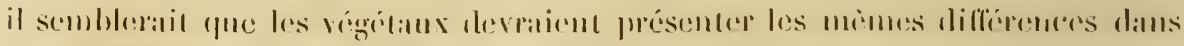

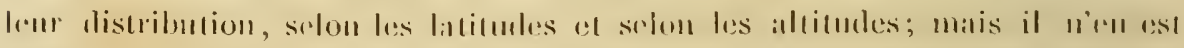

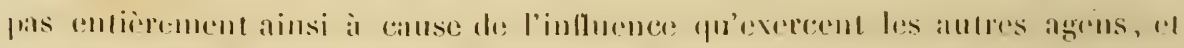

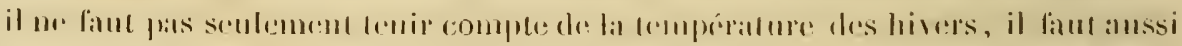

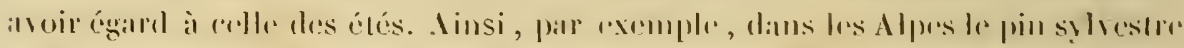

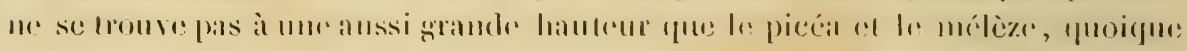

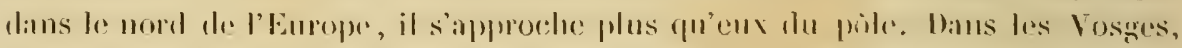

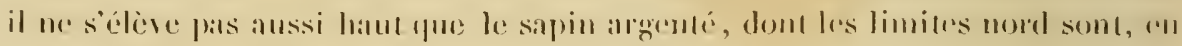

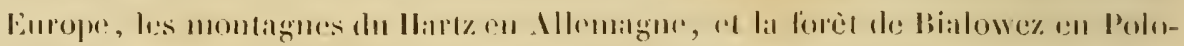

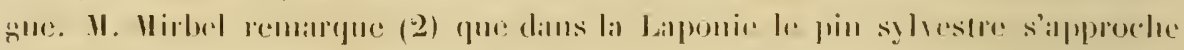

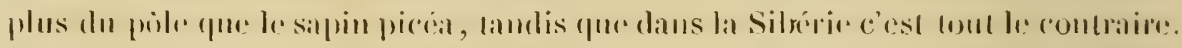

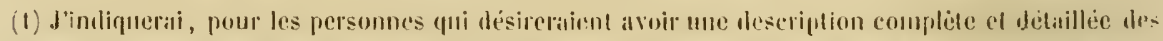

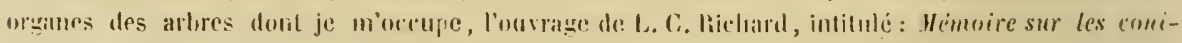

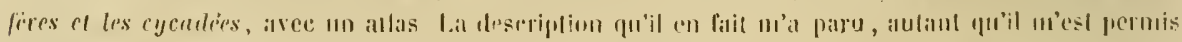

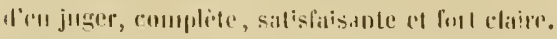

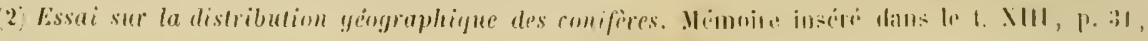

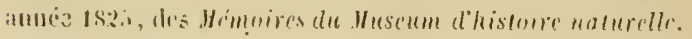




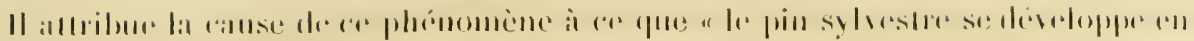

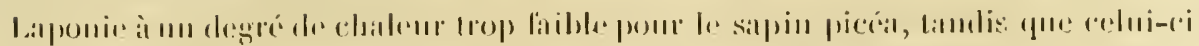

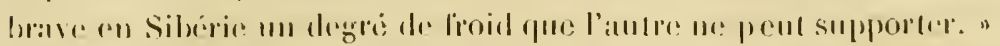

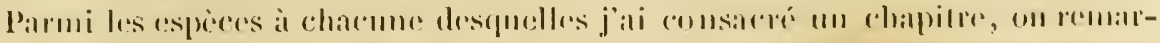

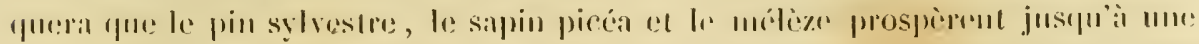

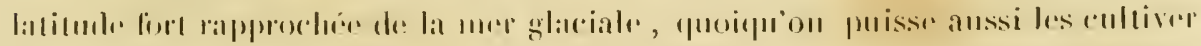

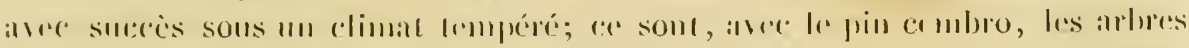

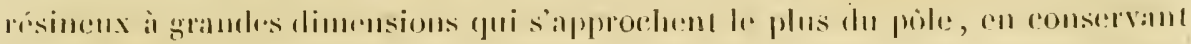

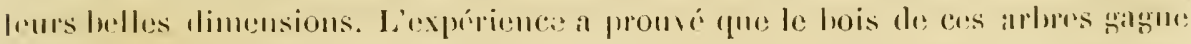

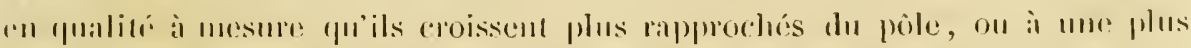

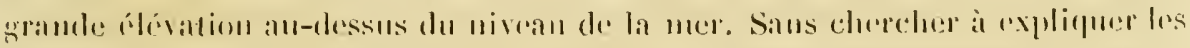

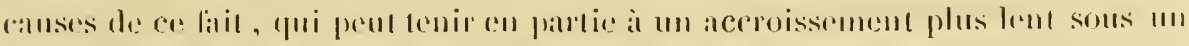

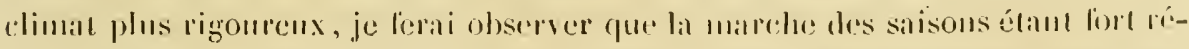

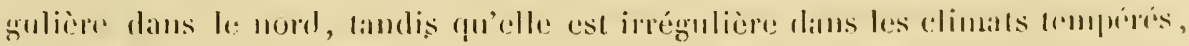

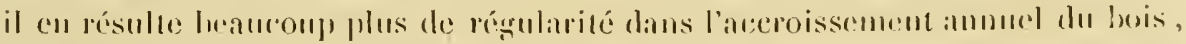

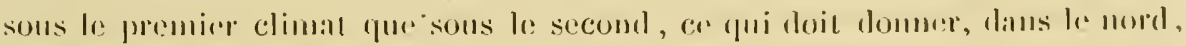

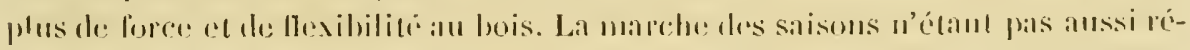

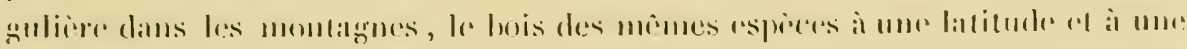

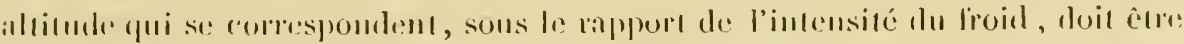

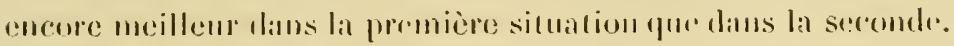

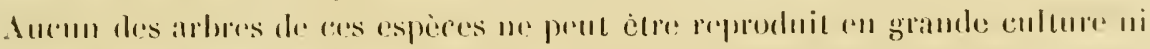

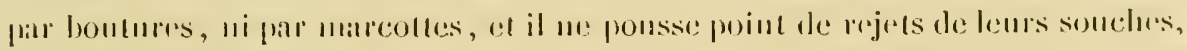

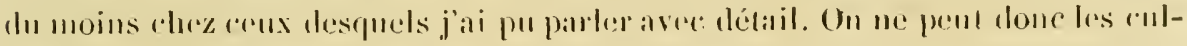

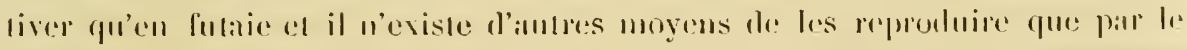

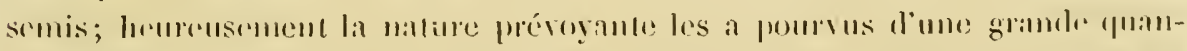

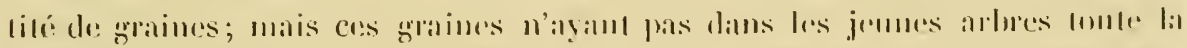

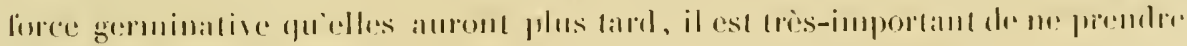

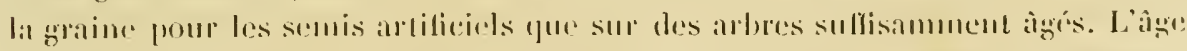

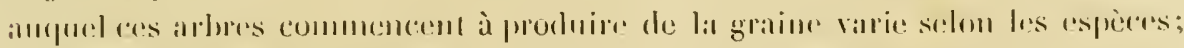

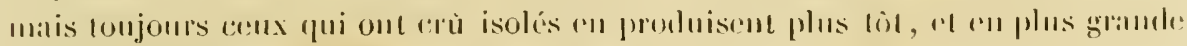
pulutile, que ceux qui onl crì à l'blall serre.

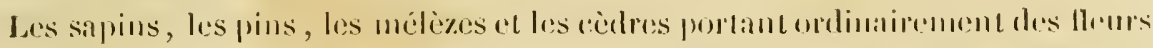

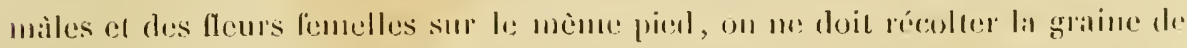

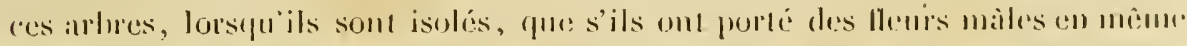

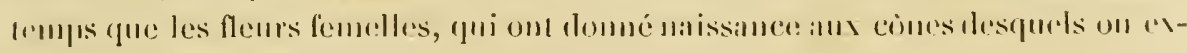
Irail la graine; salls eela cello graine seratil slórile.

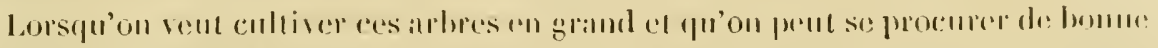

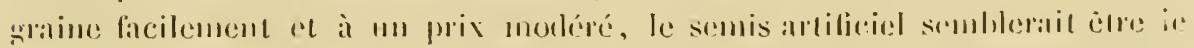

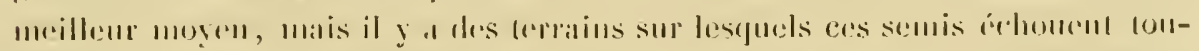

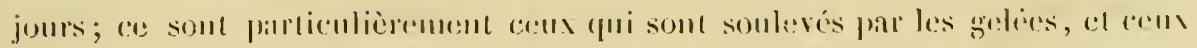

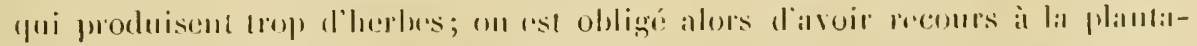

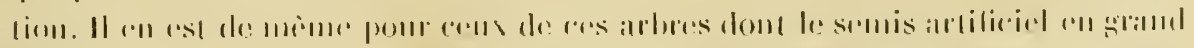

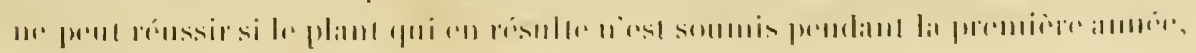




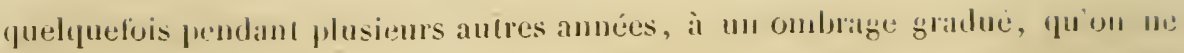
peut pas leur procurer.

Quand on veut créer une futaic de ces arbres, qu'ils soient seuls de leur uspèce, ou qưils soient mêlés a rec leurs congénères, ou enfin avec des bois feuillus, il est très-important de leur faire occuper promptement le terrain sur lequel on les a semés ou plantés; c’est une conséquence de ce qu’ils souffrent du voisinage des arljustes ou des plantes qui, sans cela, garniraient complètement le terrain, quelquefois de l'action du soleil. Le voisinage de leurs congénères ou même de la plupart des bois feuillus à hautes dimensions leur est au contraire généralement utile, pourvu que leur tête ne soit point dominée et qu’ils ne soient point trop serrés; j'entrerai dans les détails nécessaires à ce sujel dans les chapitres consacrés à chacune de ces espèces d'arbres. Lors même que, dans des circonslances particulières, ils auraient une régétation plus active en croissaut isolés, leur trone serait toujours alors branchu, nouenx, quelquefois contourné, ce qui n'arrive pour ainsi dire jamais quand ils onl crù à l'élal serré.

La plupart des auteurs qui ont traité de l'exploitation des bois ont émis une opinion sur la saison la plus favorable à celle exploitation; les autorites les plus imposantes ont été d'avis qu'il est arantageux de couper les loois feuillus pendant le tems oủ la sève est inactive, el l'usage, relalivement à leur exploitalion, est généralement d'accord avec cetce opinion. Les avis ont élć partagés en ce qui concerne Jes bois résineux, el l'usage diffère aussi pour leur exploitation. Je me range à l'opinion des personnes qui veulent qu'on les aballe pendant que la sève est inactive, je pense que le loois coupé alors est d'une meilleure qualité que s’il l'eût été pendant le mourement de la sève, on cause d'ailleurs alors moins de dommagres dans la futaie; il peut pourtant arriver, ainsi qu'on le verra, qu'il soit nécessaire d’abaltre en sève, pour faire écorcer tout de suite, comme préservatif contre certains insectes. Baudrillart examine aree beaucoup de soin celte question, dans son Dictionnaire des eaux el fojêts, 1. II, p. 86; il rapporte l'opinion des atuleurs les plus connus à ce sujet, el tinit par se prononcer contre l'abiltage des bois pendant qu'ils sont en sève. Il serait d’ailleurs possible qu’il fùt préférable d'abattre certaines espèces pendant la sève, d’autres hor's sère, et qu'il fùt préférable d'abattre la même espèce pendant la sève dans un pays, hor's sève dans un autre.

On a pensé longtemps qu'il fallail abattre les arbres pendant le décours de la lme, parce que, disait-on, le bois de ceux qui avient été abattus pendant le cours de la lume, se conservait beaucoup moins bien. Duhamel-Dumoncesu fit ì cesujet (1) des expériences dont le résultat, contrairement à l’opinion généralensent accédilée, fut plus favorable à l'abattage pendant le cours de la lune, qu'à l'abaltage pendant le décours. II. Thomas (2) émet l'opinion qu’il vitut mieux abaltre pendant le cours, parec qu'il pleut moins qu'en décours. Lal plu-

(1) De l'exploilation des bois, t 1, P. 380.

(2) Traile général de stalistique, cullure et exploilation des bois, 1. 1, p. 3:6. 
part des auteors qui ont traté cerle question, depuis Duhamel, out pensé qu'il Etait indifférent d'abatlre en cours ou en décours, et actuellement la croyaner. qu’il est utile de couper les hois pendant le décours de la lune est considérée, par les hommes instruits, comme un préjugé. Néanmoins, elle est encore accrérlitér. dans beaucoup de lieux, et l'on n'y coupe les bois que pendant le décours.

Lá question de savoir s'il faut les couper par un vent plutôt que par un autre. ue ne parait pas mériter d'atcention.

Je consignerai ici quelques réflexions sur l'aceeption des mots aménagement. exploitation et reproduction. L'aménagement d'une fulaie est l'élablissement, dans relle fulaic, d'un ordre ou arrangement régulier ef sucessif, correspondant à un mode d'exploitation déterminé. On ne peut parler de l'aménagement sans parler de l'exploitation el de la reproduction, et réciproquement; aussi, pour plus de clarté, et pour éviter les répétitions, je pense qu'il faut traiter ces matières dans un même article, et e'est ce que je ferai. On se propose ordinairement, par l'aménagement et par l'exploitation, de tirer d'une fulaie le revenu le plus élerŕ qu'elle puisse produire, tout en la maintenant en bou élat; néanmoins, un parliculier, propriélaire d'une petite fulaie, peut préférer un mode d'exploilation qui lui donnerait un revenu anmucl ou périodipue, à un autre mode qui lui donnerait un rerenu plus élevé, mais à des éporjues irréguliòres on trop éloignées les unes des antres; un Elat proul se proposer de se procurer des bois pour sa marine ou pour des constructions de bâlimens, lors même qu’il y aurai de la perte sous le rapport du revenu. J'indiquerai dans les chapitres consacrés chacun à une espèce les divers modes d'aménagement, d'exploitation et de reproduction, applicalbles ì ees diverses espèces.

Tous les arbres s'accroissent au moyen d'un solide ligneux qui s'interpose, chitque année, entre l'écorce et le trone. Lorsque l'on coupe ce tronc perpendiculairement à son axe, on remarque des couches ligneuses distinctes, et il est admis en sylviculture que chacume de ces couches a été produite en une année, même dans les arbres qui ont deux sèves, en sorte qu'on pourrait évaluer l'ìğ: des arbres par le nombre des couches ligneuses, que l'on compte sur leur trone, coupé ainsi que je viens de le dire. Dans beaucoup d’ouvrages el de mémoires relatifs à la sylviculture, l’âge des arbres est évalué ainsi, el presque toujours pour calculer leur accroissement annuel. C'est ainsi que l'âge des pins sylvestres est évalué daus un mémoire intilulé Recherches sur la croissance du pin syluestre dans le nord de l'Europe; mémoire dans lequel MM. A. Bravais et Ch. Martins ont cherché à déconvrir les lois de l'accroissement de cet arbre et i le soumentre au calcul.

Je ne partage pas l'opinion généralement aceréditće relativement à l'exactiunde de ce moyen d'évaluer l'àge des arlores. Én supposant même que chaqur. couche ligneuse fìt le produit de l’accroissement d'une annéc, ce moyen pourrait encore ètre fort incxact, puisqu'il y a des années oú, par différentes causes, l'aceroissement des arbres peut être insensible, s’il n’est nul. Ainsi, parr exmple, prondant les premières anmées les couches ne marquent point, el des 


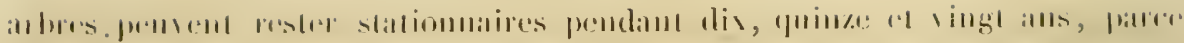

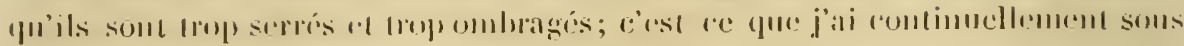

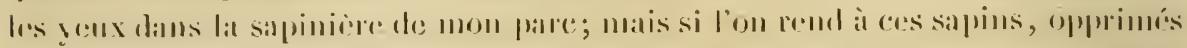

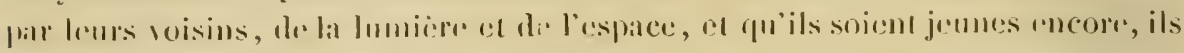

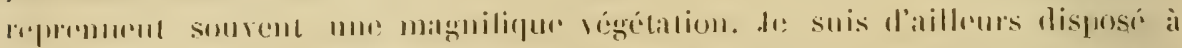

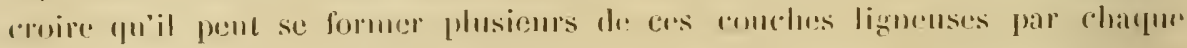

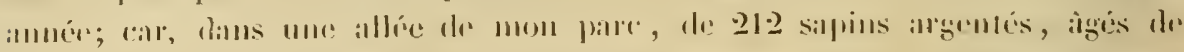

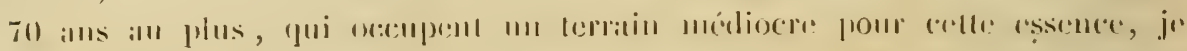

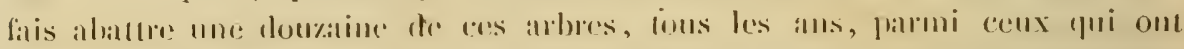

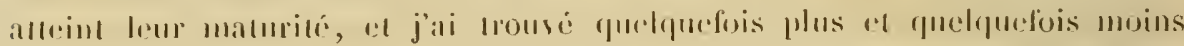

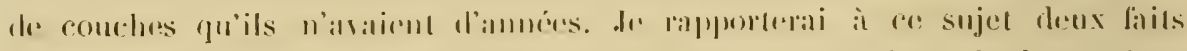

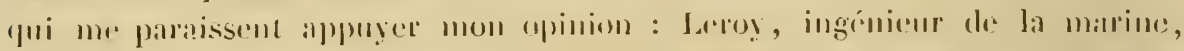

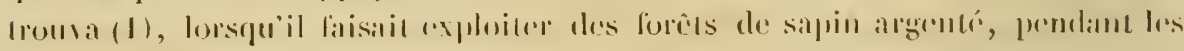

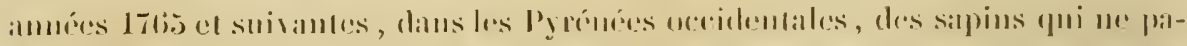

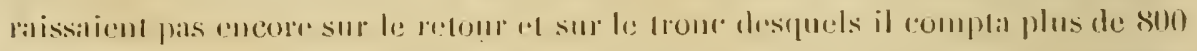

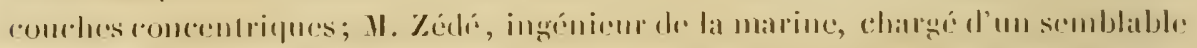

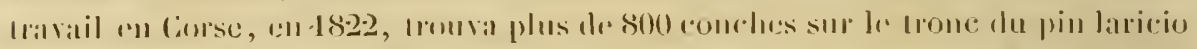

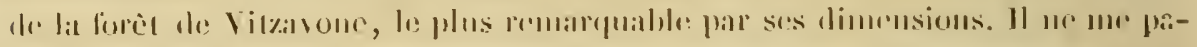

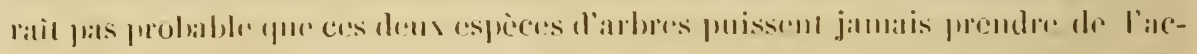

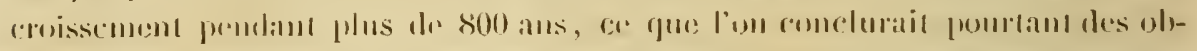

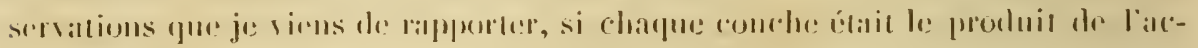
aroissoment d'une anome.

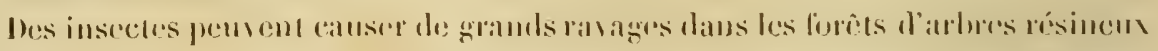

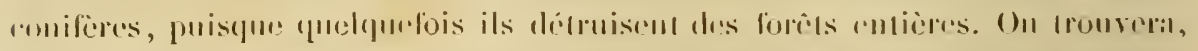

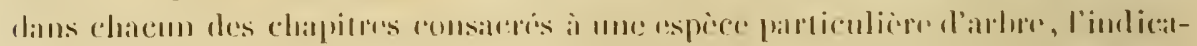

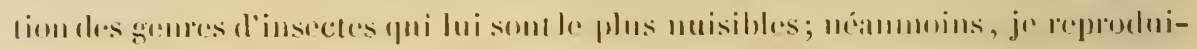

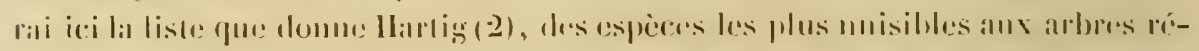

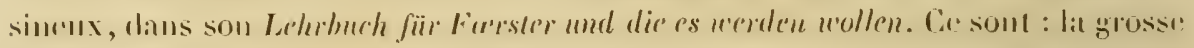

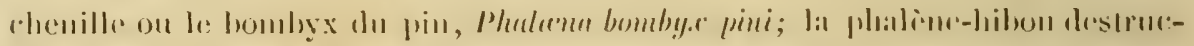

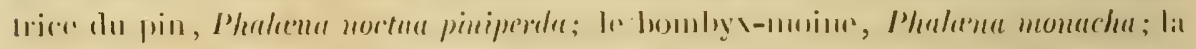

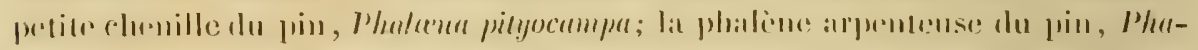

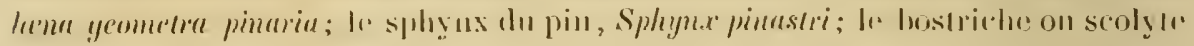

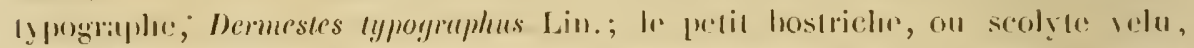

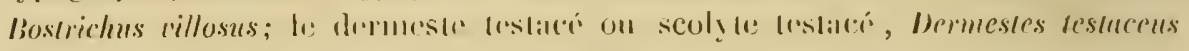

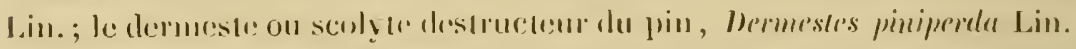

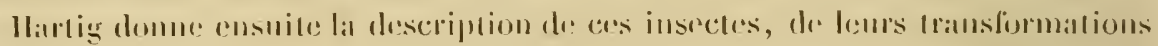

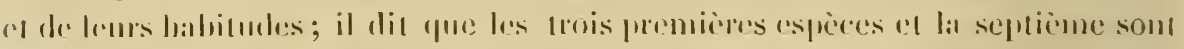

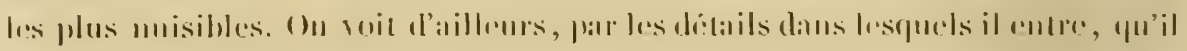

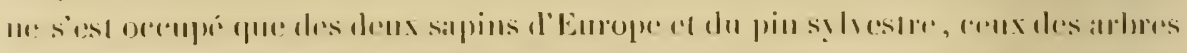

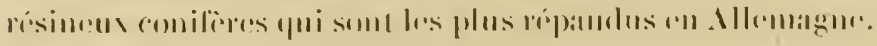

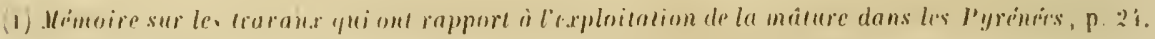

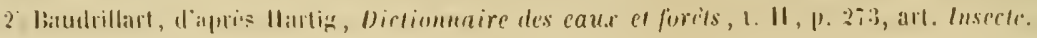




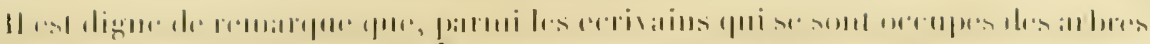

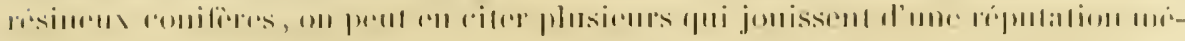

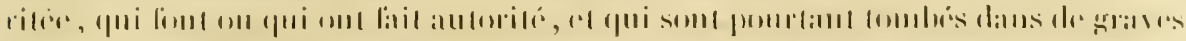

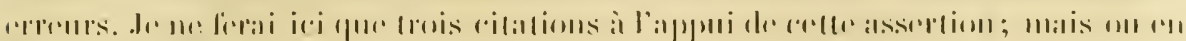

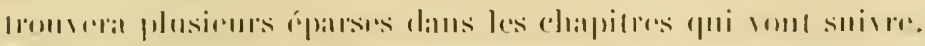

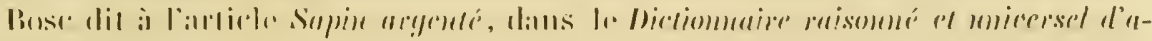

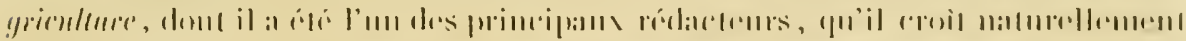

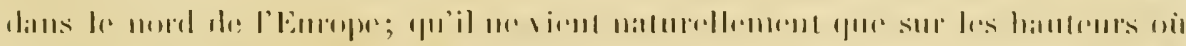

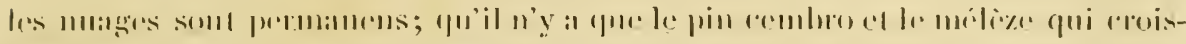

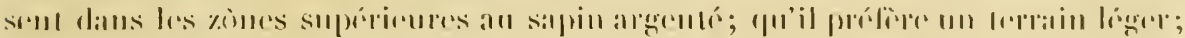

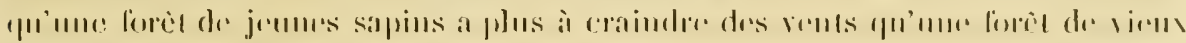

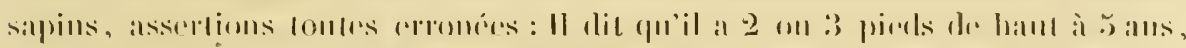

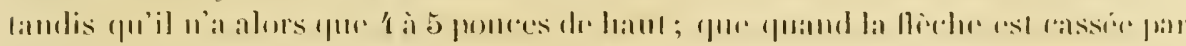

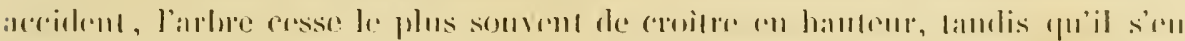

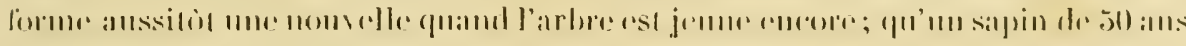

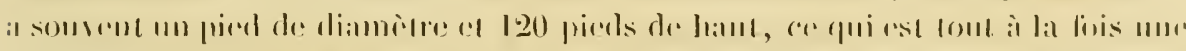

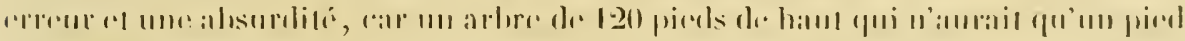

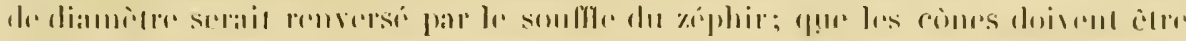

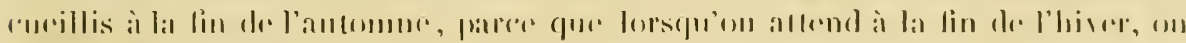

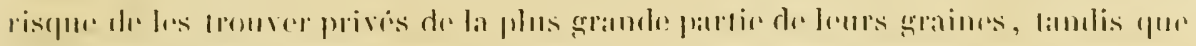

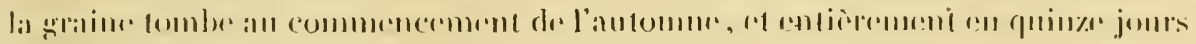
all plus, w1.., , 1\%.

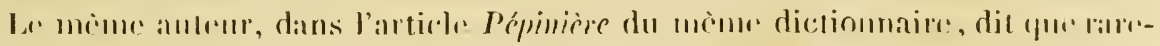

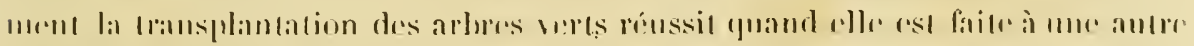
"1

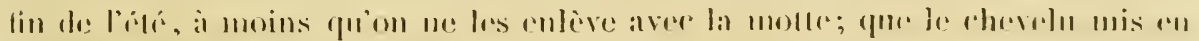

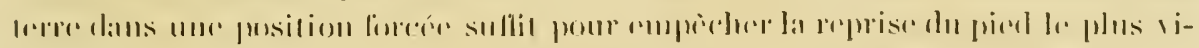

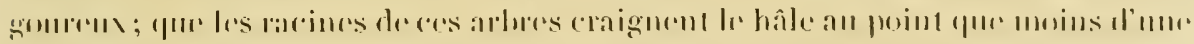

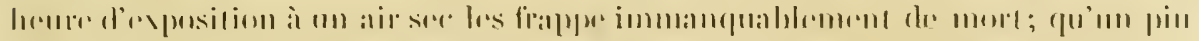

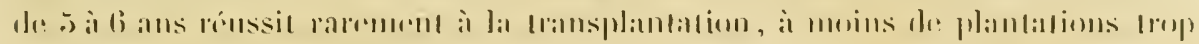

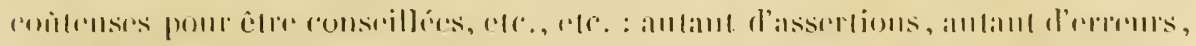

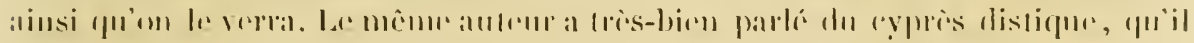

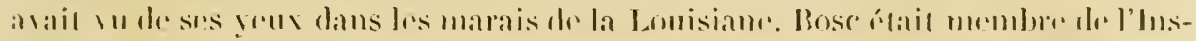

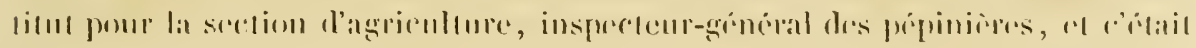

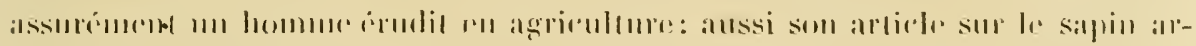

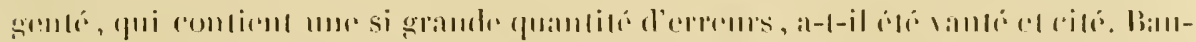

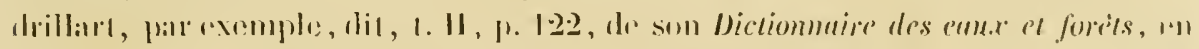

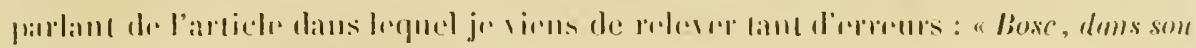

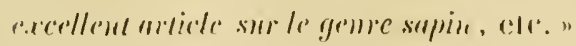

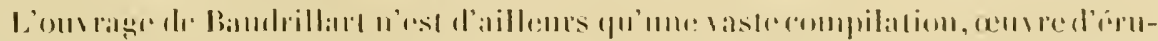

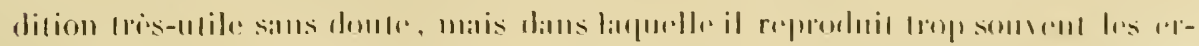

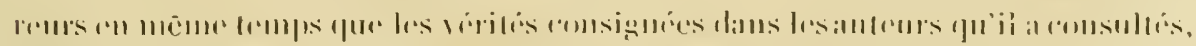

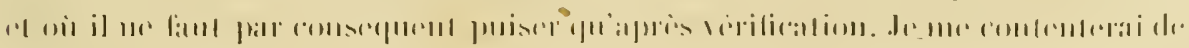


signaler, ì cause de sa singularité, une senle: des erreurs dans lespuelles est tombé cet auteur. "On en fait de très-belles arenues, dit-il dans son article Sapin com" mun, et comme il s'élève très-haut sans branches, on peut entre chaque sapin " intercaler des arbres qui garnissent le pied." Non-seulement le sapin commun ou argenté ne s'élève pas très-haut sans branches, mais il est garni de branclies depuis le sol jusqu'à sa cìne, à moins que, lans les futaies, l'ombrage ne les ait lait périr ou qu'on ne les ait coupées.

L. C. Richard, dans son Mémoire sur les conifères et les cycadées, ouvrage justement estimé d'ailleurs, dit, p. 89, "que la racine des conifêres ne présente jamais " de pirot ou caudex descendant, ainsi qu'on l'observe dans un grand nombre "d'arbres qui croissent dans nos forêts ;... que dans cette famille, oủ plusieurs 's"pèces arrivent à une hauteur si considérable, la force et la longueur des racines "ne sont jamais en rapport avec l'élévation de la tige; que ces racines sont en "général courtes et peu volumineuses, et que, par cette circonstance, les coni"fëres ont quelque ressemblance avec les palmiers, qui offrent la même particu" larité. "Autant d'assertions, autant d'erreurs : les arbres résineux conifères, du moins ceux dont je me suis occupé, ont presque tous des pirots, et ils sont aussi fortement enracinés que les arbres feuillus. Comment pourrait-il en être autrement, puisqu'une partie de ces arbres habitent plus particulièrement les montagnes, et que le mélèze et le pin cembro, par exemple, sont, de tous les arbres ì grandes dimensions, ceux que l'on trouve dans les Alpes, à la plus grande hauteur au-dessus du niveau de la mer? Comment le pin maritime pourrait-il braver les tempêtes de l'océan sur les dunes des landes de. Bordeaux, s'il n'avait un pivot el des racines latérales longues et fortes?

Une erreur commune à presque tous les auteurs qui se sont occupés de la cullure des arbres résineux, e'est d’indiquer l'époque où ils commencent à pousser au printemps comme celle où il est le plus avantageux de les planter, quelquefois comme la seule où l'on doive les planter; tandis que pour presque tous ceux dont je m’oceuperai dans ce Traité, c'est en automne que cette plantation est le plus favorable, du moins sous le climat de Paris. La plantation de ces arbres, au momeut où ils commencent à pousser, présente d'ailleurs cet inconvénient, qu’elle doit alors être exécutée aussitôt après qu'ils ont été arrachés, ce qui n’est pas nécessaire l’automne, quoique cela soit toujours préférable. 


\section{CHAPITRE II.}

\section{SAPIN ARGENTÉ, Aliess argenten.}

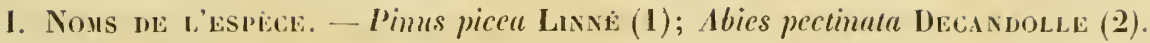

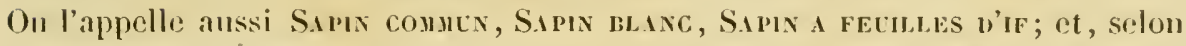
les pays où il se trouve le plus communément en France, Siprs des Yosges, Sipix d'Auvergae, Sipix des Priéxeles, Siptix de Nomuxde; en Bretagne, on l'appelle Bots de crolx.

J'adopte de préférence la dénomination de Sapin argenté, parce qu'elle me parait désigner l’arbre dont je m’oceupe dans ce chapitre par un caractère saillaur. Le nom de Sapin commun me paraîtrait le plus mauvais à adopter; en effet, lesapin argenté est commun dans certains pays, rare dans d'autres, inconnu dans d'autres pays où l'autre sapin d'Europe, le sapin picéa, est très-commun, par exemple, dans tout le nord de l'Europe. Linné n’a fait qu'un genre des sapins, des pins, des mélèzes el des cèdres, sous la dénomination de Pins. Le nom de Pinus picea, e'est-ì-dire Pin ì la poix, qu'il a donné all sapin argenté dlont on n’extrait point la poix, aurait mieux convenu, selon moi, au sapin picúa dont on extrait la poix, et que les Latins appelaient Picę; et le nom de Pinus abies, qu'il a donné au sapin picéa, aurait été convenable pour le sapin argenté que les Latins appelaient Abies fomina.

II. Boutons et sìve. - Le sapin argenté a des boutons à bois et des boutons ì fleurs; ses feuilles naissent en même temps que les pousses llı bois sur lesquelles elles sont fixées.

Crot arbre n'a qu'une seule sève (3) qui commence ordinairement sous le climat

(1) Species plantarum, 3e édi1., t. 11, p. 1420.

(2) Flore française, 1. 111, p. 276.

(3) Duhamel-Dumoncean se trompe done lorsqu'il parle, t. Jer, p. 10, de son Traité des orbres el arbusles, de la sève du printemps et de la sèva d'aont de ret arbre; car il n'en a qu'une, du moins dans les environs de Paris, on il lrabitait comme moi II serait possible qu'il en fùt autrement dans le Midi; car Leroy parle, dans son mémoire, des deur sèves des sapins dans les Pyrẻnées. 


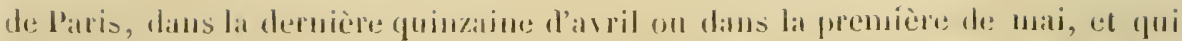
s’arète, en ce qui concerne la longueur des prousses, au lout de cinq à neul semaines, selon la tempéralure: qui a régné. lin 1812, année chaude. la sève ne dura qu'un peu plus de cinq semaines; en 1813, amnée humide et froide, elle dura neuf semaines. Lorsque la sève est arrêtée, en ce qui concerne la longueur de la flèche et des pousses, les boutons qui donneront naissance à la flèche et aux pousses de l'annéc suivante sont parfaitement formés; mais les pousses prennent encore de l'accroissement en grosseur, et elles deviennent ligneuses d'herbacées qu'elles étaient.

La sève fait d'abord pousser les boutons des branches qui sont placées le plus bas, puis successivement les autres bontons jusqu'au sommet de l'arlore; c'est le bouton duquel doit partir la nouvelle fiche qui pousse le dernier, circonstance heureuse, parec qu'il se trouve moins cxposé aux ravages gu'exercent quelquefois les gelées tardives sur les jeunes pousses.

Lorșque l'action de la sève est arrêtéc on est devenue insensible, on remarque sur quelques parties des pousses de l'année, et toujours à lenr extrémité, au hout de la fleche et sur quelques parties de cetle flèche, les boutons à bois de l'année suivante. Ceux qui sont an bout de la flèche sont an nombre de quatre à sept, le plus communément au nombre de six dans les arbres bien venans, qui ont dépassé 1 š ans; le bouton du centre, toujours situé dauns le prolongement de la llèche, est destiné à produire la lièche de l'année suivante; les autres boutons, placés autour de ce bouton central, donneront naissance aux branches nouvelles. Les boutons qui se trourent sur la lièche, sur les parties latérales et sur le dessus des branches, ne donnent ordinairement naissance qu'à des ramilles.

Les boutons à fleurs paraissent en mêne temps que les boutons à bois; ceux qui donneront naissance id des fleurs feunclles sont d'abord semblables aux boutons ì bois, mais à l'atutomme ils en different sensiblement parce qu'ils sont devenus plus gros; ils se trouvent vers la cime de l'arbre, sur le dessus de quelques pousses de l'année. Les boutons qui contiennent le pudiment des fleurs mâles, beaucoup plus petits que les boutons ì bois, sont agglomérés sous les poussess de l'année, et ue se trourent jamais sur les mênes pousses que les boutons à fleurs femelles. Ces deus espeeces de joulons se distinguent parfaitement dès le $1^{\text {er }}$ octobre.

Il parait des boulons atrentils sur le tronc du sapin dans les circonstances accidentelles suivantes : lorsque le tronc d'un sapin argenté, jeute encore, se trouve brisé, ou guand, après avoir perdu la plupart de ses loranches, parce qu'il a été privé de lumière, d'espace et de pluie par les arbres de son voisinage, il est ensuite délarrassé de ces voisins qui l'opprimaient. J'entrerai dans quelques détails à ce sujet quand je m’occuperai du mode de végétation du sapin argenté.

111. Fechles, rleulis et còxes. - Les feuilles du sapin argenté (pl. I, fig. 1 et 2) commencent à paraitte, ainsi que je l'ai dit, dans la dernière quinzaine d'avril ou daus la premiere de mai, on même temps que les ponsses sur lespuelles elles sont fivires; clles sont raides, linéaires, aplaties, arrondies ou bchancrórs par la 


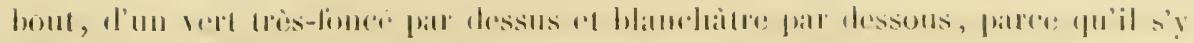

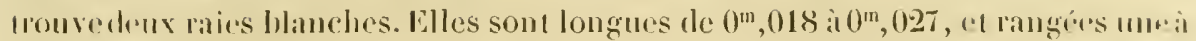
une sul un seul rang, de chaque còte des ramilles, comme les deuts d’un peigno,

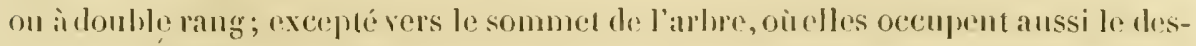
sus de ces ramilles, et sur la fleche, quelles couvernt entièument. Elles persis-

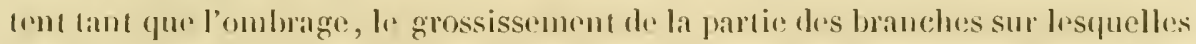
alles se tronvent, ou des maladies, ne les font point périr. Linsi Kastlonlir (1) י1 Lorrnt\% (2) se trompent en disant qu'elles prosistent pendant trois ans. I.es linilles qui comvent la flèche persistent pendant six ou lunit ans, tant que l'arlore: croil; e’est seulement au bout de ce temps que le irone cul est débarrassé, jrobablement par suite du grossissement de ce trone at de l’ombrago qualles éprouvout, à mosure que l’abre s'élòve. Les feuilles qui garnissent les ramilles lixérs sur le tronc et sur la partie des branches qui avoisineut le trone, périsseut aussi successivement par la même cause, let les ramilles qui portaient ces feuilles, privés de lumière, périssent aussi; mais de nouwlles pousses convertes dle. feuilles nowvelles paraissent annuellument dans los parlies qui jonissent dres licufaits de la lumière.

Les fleurs du sapin argenté ( Voy. p. 10) commencent à paraitre en mêne: temps, plusicurs jours avant l'apparition des pousses, c'est-iblite pendant la première ou pendant la scconte quinzaine du mois d'avril.

Les chutons mâles (pl. I, fig. 1) sont agglomérés à l’extréunité des rameanx u des ramilles, sous le bois de l’année précédente et le plus communément vers la partie supéricure de l'arbre; mais quelquefois il s'm trouve sur toutes les branches, sans exception, comme il peut arriver aussi qu'il n’y en ait point dlu 10ut. Ces chatous sont souvent très-nombreux, et avant que d'avoir atteint lemp maturité, ils sont rougeatres et ressemblent à uno très-petite fraise des bois dr. lorme régulière; lorsqu’ils l’ont atteinte, environ dix jours après leur apparition, ils sont d'un jaune-citron lavé de violet, ofeupent plus de volume, sont plus allongés et se joignent.; ils laissent alors échapper me poussière jaune (le pollen), "( dams le même lemps les pousses commencent à paỉaitre. Les sapins argintés ne portent pas tots les ans des fleurs mâlis, mais ils un portent plus somvent que des fleurs femelles.

Les chatons femelles du sapin argenté, annoncés dès l’automme précéclent par des boutons plus gros que les boutons à bois, se trouvent vers la cime de l'arlore sur le dessus de quelques branches, mais seulement sur du bois de l'ammée prócédente; ils sont oblongs, d’un vert pâle, ont la pointe tournéc vers le ciel (sont érigés), et leurs feuilles florales (leurs bractées) se transformant en écailles, ils deviennent des cònes : celte transformation est déja très-apparente daus la première quinzane de mai, environ un mois après qu'elles ont paru.

Les romes (pl.I, fig.2) ncenpent une position sensiblement verticale, sur l.

(1) Le Guide dans les fore's, 1. 1, 1. :s.

2) Cours élrmenenire de cullure des bois, $\mathrm{p}$. !o 
dessus de's branchrs, li pointe tourne vers le riel; ils sunt lixés au bois par une queue très-courte (ils sont pédonculés), mais on en remarque pourtant quelques-uns qui sont lixés immédiatement sur le bois (qui sont sessiles). Colta se: trompe done lorsqu’il dit, dans son Traicé de multure forestière, [1. 250, qu'ils sont placés à l'extrémité des branches. les cônes sont d'abord d'un vert pâlle et censervent cette couleur jusque peu de temps avant heur maturité, qui arrive à la fin de septembre ou au commencement d'octobre de l'annéc même où ils sont nés. On reconnait celte maturité aux signes suivaus : ils se couvrent sur quelques points dune efflorescence de résine très-blanche, deviennent brun-clanir et peu de jours après, dans ce même mois de septembre on an rommencement d'oetobre, ils laissent échapper les graines qu’ils contiennent. Chacune des écailles des cònes se détaclie do l'axe et tombe au pied des arbres, avec on sans les deux graines qui alors y sont ì peine fixérs; lorsque les graines se síparent des ceailles, ces graines, ćtant munies d'une aile, sont guelquefois transporlies au loin par les vents; il ne reske sur l'arbre que les axes des connes avee quelques écailles de leur partie inférieure (pl. V, fig. I), qui persistent orlinarement peindant plusirurs amés : la dispersion des graines est terminée an bout de peu de jours. Les cónes du sipin argenté, lorspu’ils ont atleint leur maturité, sont ohlongs, longs de $0^{\mathrm{m}}, 11$ i $0^{\mathrm{m}}, 16$, a se composent d'écailles surées les mes contre les autres, adhérentes ì un axe conmmu, el plus épaisses à la partir lixée à l'axe: ì li base interne do ces écailles se trourent deux graines munies d'une aile.

Cette dispersion de la graine du sapin argenté, dès l’année de la naissance des cônes, est un fait tròs-apparent, et la trace subsiste longtemps encorc après, puisque les axes dépouillés des écailles restent pendant plusienrs années sur l'arlore; cependint Dulamel (1), Miller (2), Desfontaines (3), Dralet (1), Remond (5), Bose, ainsi (fu’on l'a vu p. 1与̆ et autres, tombent à ce sujet dans des crreurs qui prouvent qu'ils n'avaient pas vu de leurs yeux: Duhamel dit en outre (6) que les fleurs femelles des sapins sont d'un assez. beau rouge, et il n'y a que celles du sitpin picéa qui onf celle couleur, cellus du sapin argenté sont vertes.

Les sapins proveuaut de semis naturel ne commencent à porter des cònes qur lorsqu'ils ont atteint 25 ans environ, et la plupart n'in portent pas si tot; mais la graine que ces cònes rontiennont n'pst ordinairment fertile, dit Burgstorfl( 7 ),

(1) Traité des arbres el arbustes, t. lir, p. 4.

(2) Dictionnaire des jardiniers et des cultirateurs, att. Sapin.

(3) IIstoire des arbres et arbrisseaux qui peurent Atre cultivés en pleine terre sur le sol de la France, 1. 11, P. 582.

(i) Traité des forêts d'arbres résineux, p. 12.

(5) Remond, ancien inspecieur des forêts dans le départrment du Jura, dil dans ses Obserrations sur l'aménagrment et l'exploitation des forêts de sapin, r. 7 , que le silpin argenté a denx sères, liurd's qưil r'en a qu'une, et que la graine reste deux ans à se former, lan lis qu'elle nail, nınit ef tombe dans la mème année.

(6) Trailé des arbres et arbustes, 1. I'r, P. 2.

(7) Sourfau Mamul forestier, 1. Iex, p. il3. 


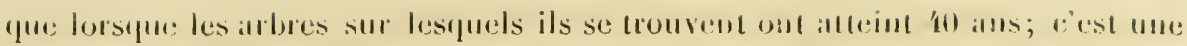

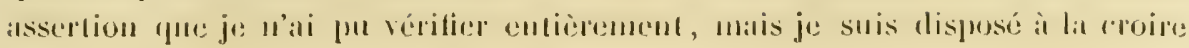

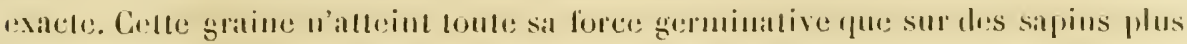

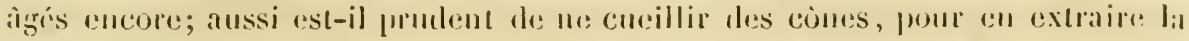

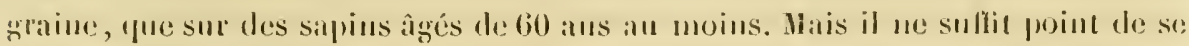

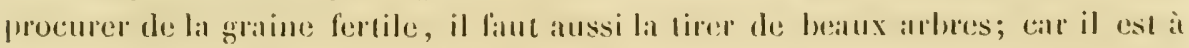

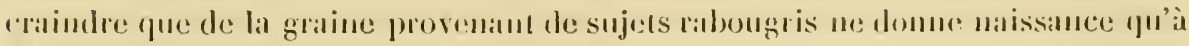
des arlores qui se lessentent de lenr origine.

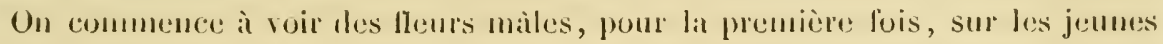
sippins an mème âge à pen pres que l’on commence à y voir des concs, quelpues

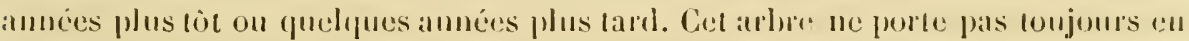
même lemps des fleurs mâles el des fleurs femelles, surtout dius sa jeumesse, car lorsqu'il approche de sa maturité ou qu'il l'a alleinte, cela se remarfue presque loujours; il porte des lleurs mâles plus somvent el en leaucoup plus grande: fuantité que des flems fomelles. Lors done que l’on veut récollar de la graine: sur un sapio isolé, il faul s'assurer qu'il a eu des fleurs mâles an miome lemps

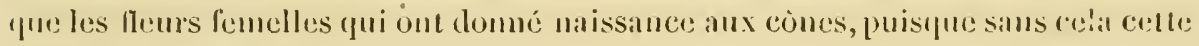
šrane serait stérile.

Le saphin argenténe portr point des eònes tous les ans, et l'on remarque, dims les sippinieres, des années d’abondance cel des années de diselle. Las années d'abondinee sont ordinairement celles ou la graine est la meillente et où elle est le moins allaquée p por les vers; il n’y a guère qu'une annéc d’abondance par chaque: période de cing anuécs.

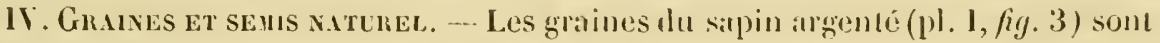
Mesque triangulares, conleur chatain, somt munies d'une aile el ont $0^{\mathrm{m}}, 009 \mathrm{de}$ longuenr moyenne; a vec celte aile, elles ont $0^{\prime \prime}, 025$ de longurur mogenne. Nous avons vu que le sapju argenté porte des cones à environ 25 ans; ces cones ne clomment de granes lertiles que lorsque l'arbre a ateint environ 40 ans, el ces granines n’acpuichent oralinarement assez de loree germinative pour donnce du semis nalurel que lorsque l’arbre a dépassé 50 ans; ma is je ne l’ai troaré ellicace $1 \cdot 1$ abondant que par des arbres qui avaient 60 ans.

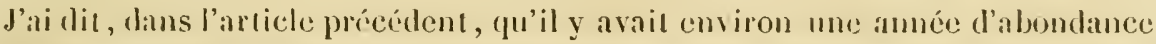
le concs sur cinf, que la graine des cones élail alors meilleure que dans les atuées on les arbres n'en ont qu'une pelite quantite, el qu'on ne roit cueillit des cones, pour en extraire la graine, que sur des arbres îgris ale bio ans au moins.

Si l'on veul se procurer de la graine, un peul en faire ramissor par letre, sous les sippins, el l'on obtiendra de la graine de choix; mais pour cela il fint qu'ily en aic benucoup, qu'ellen’ait pas été porlée an loin par les vents, que le terrain soit uni, comme, far excmple, celui d’ume alléc on d’un fulate sombre, et que l'on saisisse le moment wüblle tombe, ear il y a des oiseaux qui la mangent: ce procédé est d'aillcurs toujours long el ne fuul an procurer qu'une pelile:

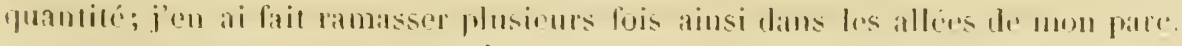


SIPIT IIEETIE.

Lorsqu' on reut se procmer une plus grande quantite de graines de silpin angenté, on doit farre cueillir les cònes aussitôt qu'un voil paraître les signe's indicaleurs dle leur maturité, tels que je les ai decrits dans l'artiele précédent, puisque quelques jours plus tard les écailles se dispersent et qu'il ne reste plus sur l'arbre que les axes des cônes. Ce travail demande à être brusqué, car, deux ou trois jours sculement avint la dispersion des graines, les écailes tiennent si peu a l'axe, qu'en jelant alors les cònes à terre, du sommet de l'arbre, où ils se trouvent tous, le choc disperse les écailles et les graines. Si l'on doit abaltre des sapins, qu'il y en ait parmi eux qui soient chargés de cônes, il faut saisir le moment de la maturité de leurs cones pour les abattres, et la récolte s'en fait alors très-jromptement.

Pour extraire la graint: des cones, si l'un reut l'avoir le plus promptement ‘u'il est possible, on les ćtale au soleil ou clans une chambre chande, sur un rang seulement, mais il ue faut pas que la chaleur de la chambre soil plus élevée que celle du soleil. Les écailles et les graines se détachent bientòt d'ellesmêmes des cônes et s'en séparteut aussitôt qu’on les remue; il ne restu que quelques écailles fixées à la base des axes. Cette séparation des écailles, tes graines et des axes a lieu également bien, fors même que les cùnes seraient dans un endroit entièrement abrité, mais un peu plus tard. La graine que l’on olıtient ainsi est munie de ses ailes, et elle se conserve mieux que celle qui est désailée; néinnoins, comme elle accupe plus de volume el qu'elle est plus difficile à bien semer et à enterrer, il est utile de la débarrasser de ses ailes.

Si l'on ne vent désailer qu'une petite quantite de graines, on la frotte entre sies mains; on peut aussi la frotter et la secouer dans un sac que l'on ne remplit pats entièrement. Enfin, lorsqu'on veut en désailer une plus grande quantité et plus promptement, on la met en tas sur urr grenier, at on la mouille très-légèrement, de manière à ce qu'elle devienne humide; le las s'échauffe légèrement, saus que cela soit nuisible à la qualité des graines, et en le renuant à plusicurs reprises, les ailes des graines se détachent peu à peu. On vanne cnsuite la graine soit avec un van, soit avec le moulin à vauner le blé, auquel on ajuste un gril ayant des mailles d'une dimension conrenable; si l'on lient à avoir la graine très-nette, on la passe au crible.

L'extraction en grand de la graine du sapin argenté s'exécute ainsi qu’il suit: On réunit les cones en tas, on les remue tous les trois jours, sans quoi ils pourraient s'échauffer assez pour clétruire la faculté germinative des graines, on les bat arec un batton recourbé s'il est nécessairc, et non-seulement les écailles et les graines se détachent des axes des cônes, mais l'on obtient ainsi la graine désailér et parfaitement bonne d’ailleurs. Ce désailement résulto probablement d'une légère fermentation qu'éprouve le tas et du frottement que subissent les graines lorsfu'on remue le tas. On sćpare la graine des écailles et on la nettoie, ainsi que je l'ai dit plus haut. Il y a toujours une partie de la graine qui est gâtre, paree que des rers, semblables a ecux que l'on observe dians les fruils, mais plus gros, se trouvent diats une partie dis rones, mangent les graines, ph fout coller 


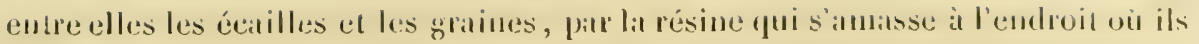
ont percé les cònes, ce qui muil à l'extraction des graines.

Selon Colla (1), il faul cinq à six boisseaux de: connes pour en obtenir un de: graines, avec les ailes je crois; dins la sapinière de Raveton, près de Laigle, un obtenait un boisseau de garaines sans ailes de treize boisseanx de cônes.

Il est impossible de se procurer la graine de sapin angenté entièrement nelle, parce que les écailles tombant en même tempis que les graines, il s'y tronve ton-

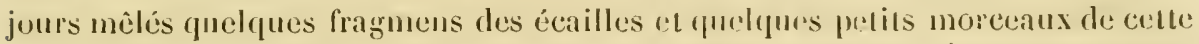
résine qu'on trouve souvent sur les eones; les graines sont d'ailleurs de différentes grosseurs, et les plus pelites sont presque loujours manvaises. On vend ordinairment la graine de sapjon 15 fr. le demi-hectulitre à Laigle, et quelduelois jusqu'à $25 \mathrm{fr}$., lorsqu'elle est rare; on n'en troure d'ailleurs point chez les unarchands grainetiers; pour s'en procurer, il faulendemander à un propriétaire: en 1843 elle coùtait 3 fr. 20 e. le kilogramme, en détail, dans la maison AndrieuxVilmorin. Ordinairement il n'y a que la moitié environ des gaanes qui lèvent, malgré le soin que l'on a pris de se les procurer de bonne qualité, ol il n'y en il qu'un petit nombre qui conservent leur faculté germinative au delà d’un an a près leur récolte. Hartig dit (2) " que la graine de sappin se conserve an plus deux ans " comme semence, el qu'elle a besoin d’être bien élendue et remuée sourent. "

Je semai, en 1812, de la graine de sapin récoltée en 1840, qui avait très-biẹn levé en 1841, el que j’avais conservée avec beaucoup de soin dans un lieu see : il n’en leva pas une seule; de la graine de pin laricio récoltée la même annéc el contscrvée dans le mème lieu que celle dont je viens de parler, leva assiz bien : on me; doil done employer que de la graine de sapin argenté récoltée l’automne qui précède le printemps où on la sème. Les délails que je viens de donner expliquent fourquoi la grainede sapin argenté que l'on achète se trouve si souvent nnatraise.

Selon Ilartig (3), 20 décalitres de graine de sapin arğenté sans ailes pèsent 48 kilogrammes, c'est-ì-dlire qu'un litre pèse 2 '10 g rrammes; Cotta (4) dit qu'un litr: pèse 52.2 grammes. Cus deux auterrs, comme on le voit, ne sont pas d'aceorl, el quoiqu'il puisse y avoir de notables différences dans le poids de la graine du sippin argenté comparé all volume, selon qu'elle est plus ou moins grossis plus on moins nette ch plus ou moins attaquée des vers, il y a évidemment erreur daus une de ees deux évaluations, peut-ètre dans loutes les deux. Voice le résultat des

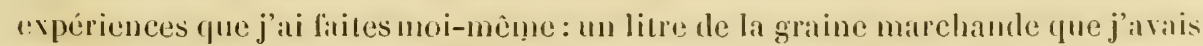
arhelée à Laigle, en 1812, pesait 0 kil. 368 gr. el contenait 6,310 graines; ainsi l. hilugramme de celle graine ocenpail un volmme de 2 lit. 71 el contenait 17,228

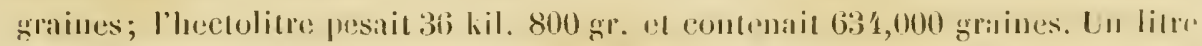

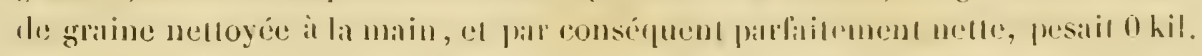

(1) Traité de cullure foresticie, p. 250.

(2) Tristruclion sur la cullure du bois, p. 1.s?.

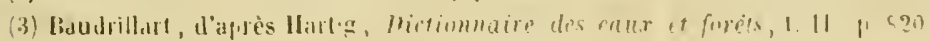

(i) Traite de rullute fresestiorer, p. 3 í. 
419 gr. et contenait 7,800 graines; ainsi le kilogramme de cette graine occupait u12 volume de 2 lit. 44 et contenait 19,070 graines; l'hectolitre pesait 40 hil. $900 \mathrm{gr}$. et contenait 780,000 graines.

Le sapiu argenté me parait ĉtre le seul des arbres résineux conifères, dont je m'occupe, qui soit indigène sous le climat de Paris proprement dit; il y en a, depuis un temps immémorial, des futaies dans les environs de Laigle et dans quelques autres parlies de la Normandie. Il donne très-abondamment du semis naturel, quand il est suffisamment âgé el que la graine se trouve placée dans des circonstances favorables. Je vais citer quelques faits á l'appui de cette assertion et de ce que j'ai dit de l'âge auquel ees arbres donnent du semis naturel eflicace.

Le bisaĩeul de $\mathbf{1 1}$. le comte d'Erard, dont Ja propriété est situće à 8 kilomètres le la mienne, fit venir en 1762 , de sa belle sapinière du Fontenil, situćc à une demi-lieue de Laigle, de très-petit plant de sapin argenté, qui pouvait avoir de 3 ì 6 ans. Un garde l'apporta dans une hotte et on le planta irégulièrement dans un bois taillis d'environ 5 hectares, qu'il créait alors, et que l'on appelle encore le Bois-Neuf; ce bois a été aménagé en taillis avec une réserve de balireaux de chênes et des sapins dont je viens de parler. Trente de ces sapins seulement existent encore, et il y cn a eu environ dix d'abaltus par les propriétaires ou par les vents; aujourd'hui le Bois-Neuf contient cent fois plus de plant, provenant de semis naturel, qu'il n'est nécessaire pour le transformer en une sappinière. Les trente sapins ont de $19^{\mathrm{m}}, 50$ à $21^{\mathrm{m}}$, 45 de haut; le plus gros a $2^{\mathrm{m}}, 46$ de circonférence, le moins gros $1^{\text {m }}, 50$; leur écorce est grise et ruguense. Une partic: de ces sapins ont encore une fliche; les autres n'en ont plus et cessent de s'élever.

J'ai visité cette sapin ière naissante plusicurs fois et en 1840 , c'est-il-dire 78 ans après la plantation des trente sapins, j’évaluai approximativement, ainsi qu'il suit, l'âge des arlores qui la compositient : un sapin de 40 ans, quelques-uns de 20 à 30 ans, un grand nombre de 10 à 20 ans, el me quantité beaucoup plus grande encore de 10 ans et au dessous. Ainsi, ce n'est qu'après a voir dépassé 60 ans que les sapins, plautés en 1762, ont donné abondamment du semis naturel efficace. Le taillis dans lequel est née celte sapinière est fort épais; on le coupe tous les dix ans, et je l'ai vu couper, les deux dernières fois, en 1829-1830 et en 1839-1810. Chaque fois nous avons examiné attentivement, le propriétaire et moi, les jeunes sapins, thous ne nous sommes pas apercus que le passage d'un ombrage presque: complet, pour les plus jeunes, à une exposition cntièrement découverte, en ait lait périr, on même en ait rendu quelques-uns malades, dı moins d'une nanière apparente. Mais leur régétation restait languissante pendant l’annéc ou les deux années qui suivaient l'exploitation; elle reprenait ensuite de l'activité, el elle chait de nouveau retardéc par l'ombrage, dans les ammées suivantes, pour les sipius que le tailiis dominait entièrement.

On planta, il y a environ un siècle, une allée d'une centaine de sapins argentés dans un bois taillis, silué près de Trun, départonent de l’orne, dans une pro-

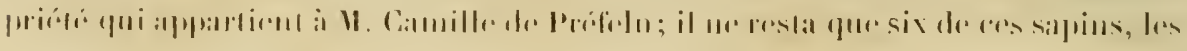


autres moururent peu apres leur flantation, probablenent pated quils atsaient été tirés d’une sapinière "t non d’une pépinière. Cés six sipins ont donné naissance, an moyen du semis naturel, ì une sapintère que je n’ai point visitée; mais je tiens de M. de Préfeln, qui m’a donné ces renseignemens en 1810, qu'elle contient une innombrable quantité de sapuns qui nedépassaient point encore 2 mètres de hant; quelques-mus seulenent avaient depuis 2 mètres jusqu’à 7 mères. (uoique ces sapins aicut beaucoup) sonflert des alternatives d'un ombrage trop épais et d'une exposition trop découverte, quand on coupait de taillis oil ils se trouvent, je présume que les plus âgés ne devaient pas alors avoir plus de $\mathbf{4 0}$ ans; ainsi ce ne serait qu'après avoir dépassé 60 ans que les six sapins auraient domué abondamment du semis naturel efficace.

Il serait d'ailleurs possihle qu'en évaluant l'îge des sippins provenus de semis uaturel, dans les deux cas que je viens de citer, je n'eusse pas tenu assez de comple du retard fue les allernatives d'ombrage trop épais at d'exposition trop découverte aurout dù apporter dans la croissance des jeunes sapins.

Jait trois sippins, distans entre eux de quelques pieds seulement, et qui se tronvent seuls daus un bois taillis que l'on compe tous les neuf ans. Lorsque j'ai remarqué, pour la première fois, de leur semis naturel dans ce bois, ces sapins avaient plus de 60 ans, et ce semis était sous leur gouttière; depuis, le semis s'est étenclu. J'ai fait la même remarque pour le semis naturel domé par les sapins de deux allées de mon pare, plantées de 1786 a 1788 , dans les endroits ou elles bordent on traversent un taillis.

Ce sont les arbres qui ipprochent le plus de leur maturité ou qui l'ont atteinte qui, pour la même quantité de graines, donnent le plus te semis naturel, et éest par conséquent la graine de ces arbres que l'on doit préférer pour farire des semis. Las graines que portent les sapins trop jeunes encore pour tomer du semis thaturel penvent d’ailleurs, si clles ont été fécondées, être semées avec succès sur une lerre préparée exprès; mais le plant que l’on olstient ainsi sera généralement moins beau : cette remarque s'applipue ì tous les arbres dont je m'oceupe dans ce Tritité. Les graines du sapin argenté, quoiqu'elles tombent l'antomme, ne lèrent qu’au printemps suivant et du 15 mars au 15 avril, sclon les circonslances atmosphériques; ('11 1811 elles commencèrent ì lever be 18 mars. On concoil, au reste, qu’il n'y al que celles qui se trouvent dans des conditions toutes farticulières, par rapport ì la mature du sol el à la manière dont clles y sout pla(eées, qui puissent lever, et que la plus grande partie périt ou est mingéée par des amimaux ou des oiseaux. An nombre des circonstances les plus farorables, je flace la formation à la surface du sol d'un terrean lort léger, résultant du détritus des fenilles du sapin, terrean qui se coure souvent de mousse; un deni-onlnage me paraît d’ailleurs indisprusable sous le climat de l'atris.

La graine du silpin argenté lève d'ailleurs très-bien daus des conditions moins farorables; ansi, quelpues sapius plantés diuns un taillis d'essenee leuillue donHeront, à la longue, naissamo à une sappinière, si le terran leur convient, et jo

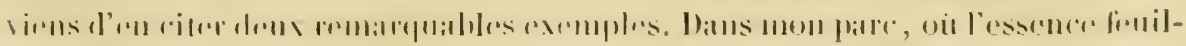


lue est amenagee en taillis que l'on coupe fous les nenf ans, lat siphinere gatghe du terrain sur l'essence lenillue au moyen du semis naturel, quand le terrain convient au sapin argenté; mais dle s'est arrêtée devant un terrain de trèsmauvaise qualité, couvert de bruyère et d'un laillis de chênes rabougris; elle s'y est arrêtée comme devant un mur d'airain. J'at converti ce manvais taillis en une pinière dans laquelle duminent le pin latriciu et le pin d'Écosse, et oü se trouvent quelques sapins picéas provenant de senuis naturel, car ils sont moins délicats, sur le terrain, que les sippins argentés.

On trouve aussi du semis naturel dans toutes les allées dle ma sapinière, que le: sol y soit convert de mousse, de terreau, de gencis, de gazon on mène de sablı; mais je suis persuadé que, dans les deux derniers cas, les graines qui lèvent ainsi proviennent d'arbres assez âgés pour que leurs graines aient acquis leur maximum de force germinative. Ces plants sont détruits par les gelées tardires, par les insectes, par l'ombrage dans les endroits trop onbragés, par les promeneurs, par mes vaches qu'on mène pailre dans les allées oin il y a de l'herte, par les charrettes; je fais enlever ce qui a ichappé à ces dangers, frour le launsplanter dans mes pépinières on daus mes bois.

Je rapporterai, à ce sujet, un fait qui n’est pas sans intérèt : j’avais fail cucullir des cònes en 1810 , sur les sapins des denx altées dont j’ai parlé plus haut, prour en extraire la graine, el on les avait mis dans une allée bien sablée, oin ils n'étaient exposés an soleil que pendant une partie de la journcé on les remua plusieurs lois, et lorsque quelques-unes des écailles s'étaient déjà séparées elés axes des cònes, on les transporta daus un pudpuit où le suleil donnait toute la journée. Au printemps de 1811, depuis le 18 mars jusqu'il la fin de ce mois, je fus furt étonné de voir lever, dans l'enlroit où avaient été les cônes, une si grande quantité de plants de sappins qu’ils étaient aussi épais que l'herbe des pratiries.

Je tis barrer en partie l'allée pour les protégor contre les promeneurs; il en mourut environ un liers jusqu'au commencement de l'hiver, ce qui ne pouvait d'ailleurs manquer d'arriver, ne füt-ce pue patr suite de leur cntassenent. L'hiver de 1811-1842 ne leur causa pas un grand dommage; l'été de 1812, qui fut trèssec, en fit périr envirun la moitić, el sur onze mètres carrés qu’ils occupaient, il en restait encore, à l'atutomne de 1812 , cuviron 900 ; ils élaient moins forts que ceux du même âge de ma pépinière, et je n’en remarquai qu'm senl qui eût une petile branche sur sa lige. A l'anlumne de 1813 , il n'en restail plus qur 700 environ, dont 200 de rebut et 200 que je repiquai dans ma pépinière; ils avaienst déjà des pirots, el les plus beaux n’axaient encore que 0 , ${ }^{\text {m}} 0$ de draul, landis que parmi ceux que l'on avail obtenus avec la graine provenaut des momes comes, far la culture en pépinière, on en trouvail de $0^{\mathrm{m}}, 16 \mathrm{~d}$. haut.

La graine du sapin argenté lève très-facilement, pour peu qu'elle soil placée daus une situation favorable au développement du germe, et elle a la ficulté de lever sous un épais omblage; quoigie celle graine ait une aile, clle est assom

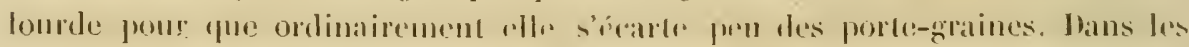

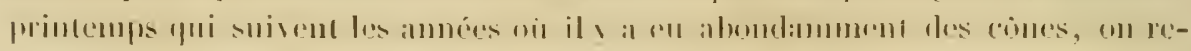


marque partout, dans les sippinières, une très-grande quantité de jeunes plants, et pourtant il ne leve qu'me bien fable partie des graines qui tombent. Une très-petite partic de ce jeune plant survit à l'année de sa naissance; mais iorsque le jeune sapin a alteint trois ans, il a beaucoup de chances te devenir un arbre, s’il n'est point détruit par un accident, par la concurrence des plants qui l'avoisinent, ou élouffé sous l'ombrage. Il résiste d'ailleurs très-longtemps, même quant il est lort serré, et si on lui procure entin la lumière el l'esparce, qui lui sont d’autant plus nécessaires qu'il devient plus âgé, il se ranime, prent ane: belle végélation, lutte contre les jeunes plants de toute espèce qui l'a voisinent, étouffe à la longue toute végétation sous sa gouttière, et parvient aux plus belles dimensions, malgré les max qui avaient accablé son enlance.

Diuns un bois taillis qui touche à une sapinière, c'est à l'ombre les gramls arbres, tels que les chênes, les hètres et les châtaigniers, qui ont étouffé le taillis suus leur ombrage, que naît ordinairement le sapin; il supporte leur ombrage que n’a pu supporter le bois laillis, et il s'élève au travers des branches de ces grands arbres. Dans le bois taillis proprement dit, si ce laillis a une régétation vigoureuse, le plant est souvent tué par l'ombrage el étouffé sutus les feuilles mortes la première amée de sa naissance.

de terminerai ce que j’ai à dire du semis naturel du saphin argenté par une citalion tirée du Trailé des forêts d'arbres résineux de Draled, ouvrage dans lequel ect auteur s'occupe particulièrement du sapin argenté; mais ee qu'il y dit des arbres résineux en général n’est applicable qu'au sapin argenté et au pin sylvestre, seuls arbres résineux que l’on trouve, selon lui, dans les Pyrénées, el il ne leur est applicable que dans ces montagnes ou que dans des montagnes soumises à un semblable climat, ou plus méridionales encore. II m’a paru utile de m’appuyer te l'autorité d'un autenr qui a eu la surveillance des forêts des Pyrénées, que je u’ai point parcourues, du moins depuis que je m’oceupe de ce Traité.

"Les arbres résineux, dit-il, page 99, sont indigènes des contrées les plus " froides de l'Europe. Dans les montagnes mêmes où l’hiver exerce son empire, "pendant sept ou huit mois de l'année, on ne trouve guère de forêts d'arlores ré"simenx qu’̀̀ l'exposition du nord. Les semences de ces allbres, que fres vents "Iransportent sur les montignes voisines, mais exposées an midi, y germent "Parement, et lorsqu'elles viennent à éclore, le jeune plant ne limble pas à se lessćcher et à périr.

"Dans les terrains qui aroisinent les forêts, les semences naturelles ne font ") remarquer leurs produits qu’ì travers les broussallles. On voit rarement sortir " un jeune sapin d'une lerre découverte, plus rarement encore y prospère-t-il. "La rive d'une forèt qui n’est point fréquentée par les bestians s'ćteud al domue " Haissince ì de jeunes sapins, à mesure qu'elle s'est girnie, d'abord d'herbes "Ćparses, ensuite d'arbustes. Mais la rive d'une forêt ne dépasse pas son an-

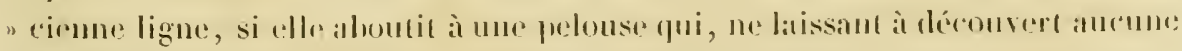

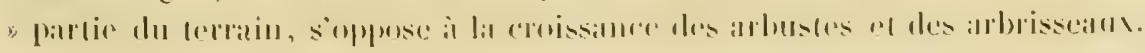


"Les clatrières qui se: trouvent dans l'intérieur des bois, lorsqu'elles ne sont "point fréquentées par les bestiaux, se regarnissent insensiblement de la mal" nière suivante : si la clairière n’offre ancune végétation, les herbages, les ar" bustes, et parmi eux les jeunes sapins commencent à s'étalolir sur ses lords à " l'ombre du massif, et d'annće en année ils gagnent du terrain vers le centre, ") jui linit par être repeuplé à son tour. Lorsque cefte opération de la nature est " terminée, il est curieux d'observer, an milieu du lerrain repeuplé, des silpins " natissant à l'ombre de leurs aînés, et ceux-ci s'élevant graduellement jusfu'au "bord de l'ancien bois : en sorte que la nonvelle peuplade présente la figure " l'un còne renversé.

"Il n'en est pas de mêne dans les clairières dont quelques parties se trouvent " ombragées par d'anciens vígétaux. Un arlsrisseau isolé, tel qu'un genevrier, " devient le centre et l'appui d’une pépinière de sajpins : il forme la pointe d'un " cône dont la base s'élargit à mesurr que les jeunes plants qui st: sont d'alord " pressés autour de sa lige ont protégé la naissance des herbes el des arbustes " servamt de bereau à de nouveaux salpius."

Je rematrque dins ce passage quelques erreurs que j'indiquerai succinctement. Tous les arbres résineux ne sont pas indigènes des contrées les plus froides de l'Europe, ainsi que le dit Dralet : il s'en trouve un aussi grand nombre dans les parties méridionales; tels sont le pin maritime, le pin d'Alep, le pin pignon, le pin laricio, le pin ut le sapin d'Lispagne. Il est possible que dans les l'yrénées, montagnes méridioniles, on ne tronve point de lutaies de sapins argrentés et de pins d'Ecosse à l'exposition du midi; mais, plus au nord, il s'en trouve en grande quantité à relte cxposition; je comna dis dus mon voisinage une còte très-rapide exposée an midi et couverte de silpins argentés qui se reproduisent parfititenent par le semis; il en est te même du pin sylvestru. Néannoins, sons le climat de P'aris, l'exposition du midi me paraît être celle qui convient lemoins au sapin argenté; plus an norl, il jeut en être antrenent. On verra dans ce Traté la différence qui existe mutre ce que Dralet a olsservé dans les forèts de sapins argentés et de pins sylvestres des Pyrénées, el ce qui se remarque plus au nord, partisulièrement sous te climat de Paris.

V. MODE de vegtation, meschiption et duensions. - Le mode de végétalion du sapin argenté a été décrit an commencement de ce chapitre, en ce qui concerne la marche de la sève, ses boutons, ses leuilles, ses fleurs el ses cônes; ct l'on lrouvera, chap. XI, art. II, des détails sur sa végétation et son accroissement, dripuis le semis jusqu'au moment de le planter à demeure. Je n’essaierai point de domer de semblatbles détails relativement au plant provenant de semis naturel, parce qu’il présente beancoup de variété dans son accroissement, selon les circonstances différentes dans lesquelles il se trouve placé; je me contenterai de dire que te plant de semis naturel leve beaucoup plus tôt que celui de somis artificiul ne lève dans les pripinières, et qu'il a ordinairement un

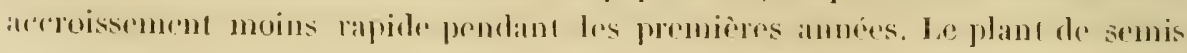




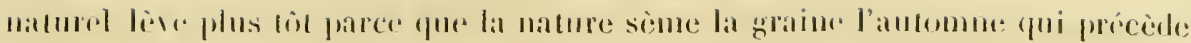
le printemps oi elle bève, landis que dins la culture en pépinière on simme an printemps, par les raisons que j’en donne dius le chapitre XI. La graine de semis naturel live quelquefois avant mème l'époque ou l'on exécule le semis artilicicl; ainsi l'annéc 1840 ayaṇ élé une année d'ahondance de cônes dans mon pare, le semis naturel commença à lever abondimment le 18 mars 1841.

I. Nuirot dit, dans son Traité de la culture des forets, p. 298, que diuns les sapinières du Jura un sapin de 12 ans n'a guère que 3 pieds de haul, , j’ai remarant: qu’à 8 ou 9 ans, âge où l'on plante le sapin de pépinière, le sapiu de sem is nature? u’a guère que $0^{\mathrm{m}}, 6 \mathrm{~b}$ de haul; mais il commence alors à pousser avec vivacité, ot fuand il a deplassé 20 ans, on remarqur quelquefois des flèches d’un mètro de long. On ue peut d'ailleurs considérer un aceroissenent annuel d'un mètro qur comme une exception; la longueur ordinaire de la flèche, dans des circonslances liavorables, lorsque l'arbre a tlépassé 20 ans, me paraît être de $0^{\mathrm{m}}, 32$ ì

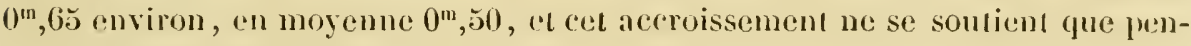
danc un certain nombre d'années, 1 pur plus ou un peu moins longlenps, selon lat nature des terrains, des siluations el des sujets; enfin l'arlore cusse de croitro en hauteur, mis souvent il continue d'augmenter en grosseur. C'est orlimairement de 15 ì 45 ans que le sapin prend annuellement le plus d'aceroissement en lamutrur; la tête de cet arbre pendant ce temps, et même tant qu'il conserve une flèche of une régétation actire et régulière, est semblable à un jrune sapin. Voilà ce que j’ai observé dans la sapinière du pare de Chambray, dont te terrain léger, silico-argileux, souvent pierreux, n'est pas celui qui convient le mienx an sapin argenté; il me paraît done que l’on doil trouver des flèches de plus d'un mètre dans les localités les plus liavorables à cet arbre; c'est ce que je n’ai pas eu le temps de rérifier.

Le sappin argenté a ordinairement une racine pirot et des racines latérales qui s'élendent an loin el s'enfoncunt pen; il y en a même qui sont à lleur de terro.

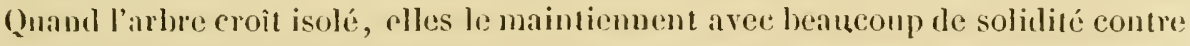
les vents les plus violens, ainsi qu'on le voil dans plusieurs parties de la Normandie, où l'on plante beancoup de ces arhres dans les haies et à l'rutrée des habitations; il n'en est pas de mème dans les sapinières, parce que les sapins y croissent quelquefois tellement serrés que leurs racines ne peuvent pas bien se. développer, d'où il résulte que si alors, par suite des exploitations , ils se tronrent exposés à l'action des vents ils peuvent être renversés. Cependant, dans mon pare, j’ai remarqué que presque tons les sapins qui étaient renrersés par les rents avaicnt une partie de leurs racines plus ou moins allaquéce par la pourriture.

Le trone du sapin argenté est tonjours troit, soit qu’il croisste isolé, soit qu’il croisse à l'étal serré; son écorce, qui est l’aborl blanchâtrer et unir, l'où lui viont probablement le nom de sapin blanc, devient grise et rugueuse à mesure que l'arbre approche de sa maturitć. Dans les futaies pleines, e'est-it-dire qui sont composés d'arbres à peu pròs dr meme hauteur et dont les rimes, in- 


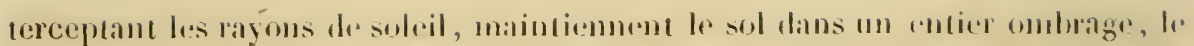
tronc des sapins finit par se clépouiller de branches jusqu’aux deux tiers environ de sa hauteur. Mais si l'on abat quelques-mus des arlores qui entourent un sapin "t qu'on rende ainsi à son trone de la lumière, il paraît bientôt sur ce trone, dans la partie où l'écorce est lisse encore, des boutons adventifs qui donnent naissance à des ramilles, à moins que l'arbie n'approche de sa maturité; car, dans sa jeunesse, cela se remarque toujours, et d'autant plus qu'il est plus jeune.

Lorsque cet arbre croît isolé, ou qu'il n'est pas trop serré par d'autres arlures, son trone est entièrement couvert de branches depuis le sol jusqu'à la cîme. Tant que l'arbre est jeune, sain et vigoureux, son tronc est toujours terminé par une flèche; lorsqu'il approche de l'àge de sa maturité, ou que sa croissance a été arrêtée par une cause quelconque, il n'a plus de flèche, sa tête s'étale et forme une espèce de buisson d'ume très-petite étendue, même dans les sapins des plus belles dimensions : si la cause qui a arrêté la croissance de l'arbre en hautour cesse, il repart quelquefois une flèche. Le trone est en queue de rat quand lo sapin argenté croìt isolé; il maintient au contraire beaucoup mieux sa grosseur, jusqu’à environ les deux tiers de sa hauteur, quand il croit en futaie.

Si l'on brise le trone du sapin argenté, dans sa jeunesse, il paraît un ou plusieurs boutons adventifs sur le tronc, à l'endroit où il a été brisé, et l’un des jets qui partent de ces boutons s'empare de la sive, devient jet terminal et proIonge le trone; s'il se trouve une branche près de cette brisure, il arrir souvent :unssi qu'il parait des boutons adventifs sur lo dessus du corps de cette branche, près du trone; quelquefois enlin une branche se transforme en trone, mais il est tonjours préférable (qu'il se forme sur le trone un bourgeon adrentif, d'où il parte une flèche, et e'est ce qui arrive presque toujours quand l'arbre n'a pas plus de 25 ans. J’ai compté dans mon parre jusqu'ì six fleches sur des sapins argentés de 25 à 35 ans, qui avaient élé brisés par la chute d'autres arlores, tant sur le trone que sur ume branche voisine de la brisure; il y a une ou deux de ces flèches qui s'emparent de la sève, les autres s'arrêtent; lorsque l'arbre ne se lífurque point, les traces de cet accident disparaissent ordinairement par la suite. Si le salpin argenté approchatit de sa maturité lorsfue cet accident arrive, le ironc resterait mutilé, ot si la cassure élait trop rapprochée du sol, l'arbre périrait.

Je citcrai à ce sujet un fait, rapporté par Leroy (1), qui me paraît fort extraordinaire:

“La forèt d'Issaux, dlont j’ai parlé jusqu'ici, est celle qui a fourni de la grande " mâture jusqu’à la fun de 1793; il y en a une autre siluée dans la vallée d’Ossau, " à quatre lieues du port d'Atas, ờ l'on a exploité de la petite mâture comme "matéraux, épars doubles et simples, manches de gaffes, etc. Cétte forêt s'ap"pelle le Benou; elle est une espèce de phénomènr, parce que tout le bois qui

(1) Memoires sur les travaur qui out rapport ì lecplositation de la mature dans les Pyrénées, p. 26. 


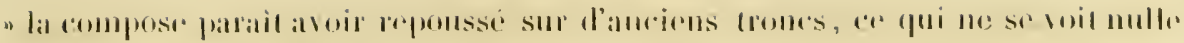

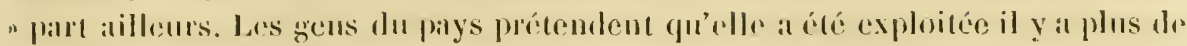
" eent ans, el les arbres furent coupés à plus de 1 pieds dr hautrur, seton l'usage "du lieu. C'est sur ces trones que se sont élevées des branches verticales, domt " quelquetiois on voit jusqu'a douze sur le même tronc; ce sont ces branches que "l'ou a exploitces pour la pedite milture. Il est vaisemblable que celle maniòre "l'expluiter ne donmenit pas ailleurs ume reproduction semblable; mais be sol " rest très-gras dans la forêt de Benou."

Je présunce que Leroy s'est 1 romper on disant qu'il y avait jusqu'à douze branches verlicales sur le même trone, ou qu'il y a une faute d'impression dans son ouvrage, car je n’ai jamais vu rester plus de deux branches verticales, au bout d'un petit nombre d'amnées, sur le trone d'un jeme sapin qui avait ‘lé brisé. Le fait que ripporte cel ingénicur ne me parait d'ailleurs pas invraisemblable dans un terrain qui est d'une grande fertilité et très-loon pour le sapin : 'n eflid, puisque l'on ne conpait les arbres qu“ì / pieds $\left(1^{m}, 30\right)^{\prime}$ de terr, les plus gros et les plus vieux seulement auront pourri; il aura poussé sur les plus jeunes salpins des lourgeons adventil's qui auront domné naissance à des llè(hes, el par suite à un ou deux trones, et peut-être même à trois; la forct se serat converte: d'arbres bifurqués et trifurqués, dont les jets vigoureux auront élouffé presque tous les arbres d’un seul trone qui étaient plus jeunes.

Il arrive quelquefois que la flèche du sapin argenté rencontre un obstacle, comme par exemple une grosse branche de chêne on de tout autre arbre; nonseulement elle ne peut le franchir, mais, par suite de l'action des vents, elle est brisće on meurtrie contre celte branche. Alors, l'une des branches du sapin de l'étage où la flèches prend naissance se transforme en flèche et franchit l'olsstacle; puis la partic supérieure du trone se redresse peu à peu chaque année, de manière à venir se placer daus le prolongement de la partie du lronc qui se tromb an desscus de l'obstacle : an houl de quelques annces, on croirait que: e'rst la flèche qui a tourné autour de l'obstacle.

Lorsque, daus sa jeumesse, le sapin argenté est longtemps privé d'espace u die lumière par des arbres de son voisinage, il we conserve de branclies ef dw fenillıs qur vers le sommet, sa végélation devient insensible, cel, après avoi lulli longlemps, il linit par périr. Mais si on lui procure de l'espace, et surtout de la lumière, el que sa ronstitution n’ait pas été entièrement altérće par l'état d'oppurssion où il a vécu, il se coure de houtons adventifs qui donnent maissance à une flèche, à des branches et ì des ramilles; au bout de quelques anmées, il présente l'aspect de la plus lelle végétation, et ne conserve plus aucune trace les anmées de souffrance qui l'avaient réduit à un si triste élat. Toutefois, quelle que soit l'apparence, el tuules choses égales d'aillentr, des arbres qui out souffert ainsi pendaut leur jemnesse no peuvent atteimlre aux mêmes dimensions qur ceux dont la croissance n'a pas subi d'intermption : les années que ces arlores ont passées dans un ćtat de léthargie n’on sont pas moins all nombre do relles qui lemr sonl assignios par lit malmrr. 


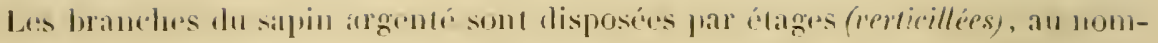
bre de trois à six par chacpur étage, el elles diminuent de longueur à mesurr qu'clles sont plus rapprochées du sommet de l'arhre; cette disposition régulière saltire à mesure que las lmanches vicillissent, parce que quelques-unes d'ontre elles s'élèrent pendant que d'autres s'abaissent. Dans les jeunes sapins, ef rers to sommrt des sapins qui ont encore unc végétation vigoureuse, les branches sont sensiblement horizontales dans la partic la plus rapprochéc du trone, puis alles se redressent vers leur axtrémiti; mais les branches plus rapprochées du sol cui sont plus âçécs, surtout quand le sapin approche de sa maturité, fléchissent sous le poids des rameaux, des ramilles et des feuilles, et ne conservent plus les formes que je viens de décrire. J’ai mesuré en 1810, dans une allée de mon parre, sur des sapins âgés alors d'environ 66 ans, des branches qui prenaient naissance à environ 4 mètres du sol, el qui étaient longues de plus de $6{ }^{\mathrm{m}}, 50$, quoique leur croissance eùt élé retardée par le roisinago d'un taillis.

Le sapin argenté, considéré dans son ensemble, conserve toujours la forme conique quand il croît isolí ou fu’il n'est pas trop serré par d’autres arbres; mais l'axe de ce cône s'allonge dans une proportion plus grande que la base ne s'agrandit. Cet arbre est le plus sombre des arbres verts; c'est le noir sapin mélancolique des poètes.

L'accroissement anmuel en diamètre du sapin argenté ne doit être examiné que. sur des arbres dont l'accroissement n'a jamais ćti interrompu, sans quoi l'on obtiendrait des résultats très-diffírens selon les circonsınces, puisque cet arbre peut rester stationnaire lorsqu'il est privé de lumière et d'espace, ct par d'autres causes encore. Il m’a paru inutile à l'oljet que je me propose de faire des expririencers suivies à ce sujel : je me contenterai do rapporter quelques faits. L'accroissement du sapin argenté, qui est lent jusqu’ì environ 10 ans, devient ensuite plụs rapide; un sapin de 70 ans qui a crù dans un terrain el dans des circonslances farorables, peut avoir jusqu’ì 26 mètres de hauteur, et un diamètre

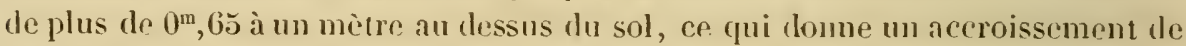
$0^{\mathrm{m}}, 009$ par an au moins, terme moyen.

J'ai dans mon pare, devant mon habitation, une allée qui a $16^{m}, 40$ de large, et qui est séparée en deux parties par un rond-point : dans l'une des parties, ce sonı des sapins picéas, de différens âğs, an nombre de 22:2 dans l'autre, des sapins argentés, au nombre de 112, qui sont à 4 mètres les uns des autres; ainsi, quoiqu'ils traversent une sapinière et un taillis, ils n'ont pas été gênés dans leur accroissement. Ees sapins ont élé plantés en 1786-1787 arec du plant que l’on prit dans la sapinière, et qui ćtait âgé d'environ 12 ans; ils avaient donc environ 70 ans en 1811. Le plus haut cle ces arbres avait alors 21 mètres, et le plus gros $n^{\mathrm{m}}, 65$ de diamètre à un mètre au dessus du sol; ceux de movenne dimension avaient $0^{\mathrm{m}}, \breve{s} 1$ de diamètre et $18^{\mathrm{m}}, 00$ de haut. Ainsi ces derniers avaient eu un accroissement moyen annuel de $0^{\mathrm{m}}, 0073$. Mais il y a des termains beaucoup plus favorables à la production du sapin argenté que celui où ils se trouveut; ils ont dù d’ailleurs éprourer de grands retards dans leur végétation, n’ayant pas 
¿́cé pris dans une pépinière, quoiqu'on les rù artachés et plantés avec lr plus grand soin, et qu'on les eùt arrosés tontes les luis qu’ıl était nécessaire.

Le plus gros des trente saprus âgés de 85 ans, dont j’il parté à la pagere 24, provenant aussi de plantation, avait, en 1810, $0^{\mathrm{m}}, 78$ de diamètre, ce qui domne un accroissement de $0^{m}, 009$ par an, terme moyen; et comme cet accroissement a été beaucoup moindre dans la jeunesse de l'arbre et aux approches de sa malurité, il a fallu qu’il fìt beaucoup plus fort pendiunt les ammées intermédiaires.

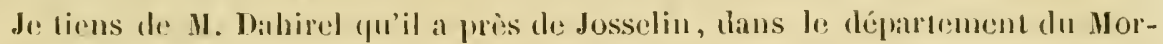
bilıu, des sapius argentés qui ont été semés il y a soixante ans; le diamèIre moyen de ces sapius est de $0^{m}, 50$, el leur hauteur moyenue de 19 mères; mais les plus gros ont $0^{\mathrm{m}}, 60$ de diamètre. Un sappin isolé àgé de $80 \mathrm{ans}$, qu'il fit mesurer arec soin, avait $19^{\mathrm{m}}, 80$ de hatu et $1^{\mathrm{m}}, 9 \mathrm{~s}$ de tour. Ces dimensions sont d'accord ave ee que l'on remarque dans les bonnes terres ì sapin de la Normandie ef donncnt à peu près le même aceroissement annuel que celui que j’ai déjà indiqué. Il me dit aussi que dans les environs de Ploërmel, dians lo mêne département, il avait vu vendre, en 1839, un lot de sapins, êgés alors de 80 ans, qui avaicut de 23 à 2 ' $^{\text {m, }}, 50$ de haul; ees siphins furent vendus à raison de 8 fr. seulement chaque sapin, pour ètre employés à Nantes comme bois de charpente, et pourtant le canal de Nantes à Brest, qui passe ì deux licues de celle futaice, domnait la facilité de les transporter : e'est que les bois du Nord (sapins picé:us et pins sylvestres) arrivent dins fous nos ports de mer et ne paient que de très-faibles droits, el que les droits de péage sur le canal de Nantes à Brest sont très-élevés.

M. Dahirel a vendu aussi, en 1839, quarante-cinq beaux sapins argentés, âgés de 85 ans, qui étaient situés près de Malestroit of à un quart de licue du canal

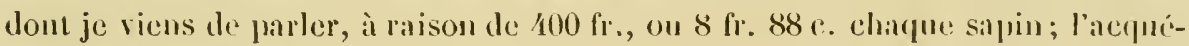
reur qui les convertit en planches n'y gagrona point. Elevez done des futates de: sappius daus les localités où il n’y a pas de débouchés sur les lieux mêmes, "l ui les bois du Nord entrent en concurrence! Vous nen tirerez pas de puoi payer l'impôt, qui est le même pour les futaies que pour les taillis.

Dans la localité (fue j'habite, les bois résineux du Nord entrent aussi en coucurrence are te hois des sapins qu'on y exploite, mats ils ue peuvent arriver pall wan

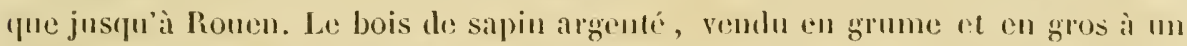
marchand, y vaut environ 31 fr. le mètre eube. A insi, en suppusant que les sapins

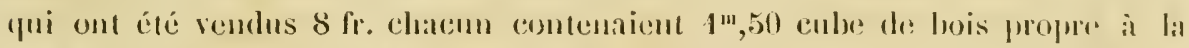
vente, ils y auraient été vendus 46 lir. 50.

On pent conclure des firts que je viens de: rapporter que, sous le climat de l'aris, le sapin argunté, dans une siluation favorable, croit au moins de (), "mog en diamètre, par an, terme moyen.

Je rapporterai ce que disent MM. Noirot el Dichie, de l'aceroissement annuel du sapin argenté, quoigu’ils airnt calculé l’age des arbores clont ils parlent,

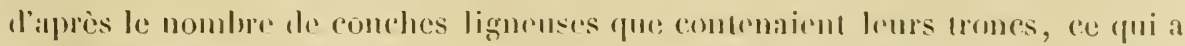

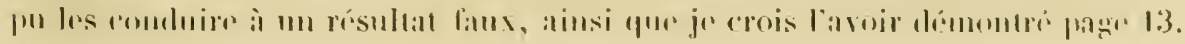


Mais la comnaissance de l'épaisseur moyenne des conches lignenses est un renseignement qui peut devenir utile par la suite. Jo forai remarquer aussi que ces deux auteurs avaient pris le diamètre des arbres an gros bout après l'abattage, tandis que je l'ai pris à un mètre au dessus du sol, c'est-à-dire un peu plus haut.

M. Noirot dit (1) que " dans les montagies du Jura, le grossissement annuel " du sapin argenté, calculé sur un arbre dépouillé de son écorce, varie de.2 li"gnes $1 / 3\left(0^{\mathrm{m}}, 005\right)$ jusqu’à 4 lignes $1 / 2\left(0^{\mathrm{m}}, 01\right)$, sur le diamètre de l'arbre."

M. G. Dickie, dans un article (2) Sur les forêts et les wibres du comté d'Aberdeen, silué dauns le nord de l'Écosse, donne un tableau de l’accroissoment ammel dr. quelpues sapins argentés, de différens âges, que je vais reprodarie.

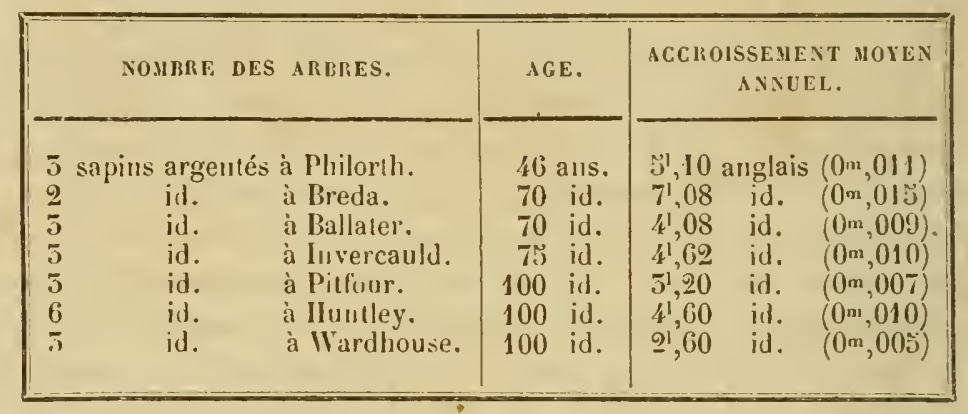

Un peut, jusqu’à l'âge de 40 ans environ, ćaluer asse\% rxactement l'âge du sapin par lo nombre des élages de branches, lorsque l'arbre a crù avec régularité en lauteur el qu'étant isolé ou peu pressé il a conservé tontes ses tranches: on ajoulerait 10 ans pour les premières amées. Dans un âge plus avancé ce: moyen deviendrait inexact on impraticable, paree qu'on ne peut pas toujours bien distinguer les étages des branches, par les rasons que j’ai données page 32. Si la croissance d’un sapin avait été arrètée pendant plusieurs années, on commettrait de graves erreurs en évaluant ainsi son âge, puisque pendant ce temps il ne se forme point d'étages de loranches. Il en serait de mêmo si l'arhre arait été brisé dans sa jeunesse.

Un arbre atteint sa maturité au moment où son bois a acquis toutes Jes qualités dont il est susceptible; le bois se conserve pendant plusieurs années dans cot état et dépérit ensuite. L’âge auqquel les sapins argentés atteignent leur maturité varie dans certaines limites en raison du sol, du climat et de l'exposition, et ne peut être déterminé d'une manière précise. 11 y a dans la vie de cet arbre deux époques importantes qui se présentent à des îğes différens, selon les sujets "1 les circonstances, a qui pourraient induire en erreur sur l'éporque de sa ma-

1) Traité de la culture des forêts, p. 131.

2 Cet article se treure dans te Quarterly Journal of agriculture, no 60 , mars 1813, p. 394. 
turité; ce sont celle ou il eesse de croitre en hanteur, et il est alors termine par un luisson au lieu de l'être par me lleche, el celle où il cesse de croiltre en grossecul.

La maturité du sapin argenté n’arrive ondinairement qu'après qu’il a cessé de croitre en hatuteur, ef je ne saturais domner des moyens cortains de la reconnaìte. Il arrive d'aill'urs souvent qu'un arbre contiune à prentre de l'aceroissement en grosseur, quoiqu'il ail dépassé l'âge de sa maturite; il arrive quelquefois aussi que la croissance en hauteur s'arrête, par suite d'une succession d'années sèches, et qu'ensuite il repart une llèche. Ce fut ce que je remarpuai dans celle allée de mon parle, dont j’ai rejà parlé, et dont les sapins étaicnt âgés, en 1811, d'environ 70 ans; les années 1833, 1831, 1835) et 1836, ayant élé fort siches, ces sapins s'arrèterent presque tous; mais depus il reparlit une llecho à la plupirt d'entre eux.

Un de mes voisins, 11 . Grazan, avait un sapin argenté auquel on avait coupé Ia tête (pour en faire un mai) et qui n'avait alors que $0^{\mathrm{m}}, 6 \mathrm{~g}$ te tireonférences. Ge sapin occupait un terrain silicenx el callonteux fort maigre qui me lui convenait point; il élait resté longtemps stationnaire et paraissait aroir une vieillesse prématuréc, lorsçue, étant tố d'environ 60 ans, il se troura compris dans un emplacement qu'on fit défoncer at mêlar de terres argileuses ponr y farire des plantalions; il recommença dès lors à prendre de l'aceroissement en grosseur, et au bout de 30 ans, e'est-ì-dire à l'âge de 90 ans, lorsqu'on l'abattit, il avait 1" $1^{\mathrm{m}}, 62$ de circonférence, quoiqu'il n'eùt pas crù en haufeur; on en lira de lort bonnes planches.

Burgstlorl (1), IIarlig (2) et Cotta (3), qui ne se sont occupés que des forèts de l'Allemagne, disent que les sapins argentés atteignent leur maturité à 120 ans, sans doute dans des circonstances favorables sous fous les rapports; car IIartig s'exprime ainsi qu'il suil, dans une note de l'ouvrage intitulé Instruction sur la culture du bois ì l'usage des forestiers, page 81 de la traduction, relativement à l'âge auguel on peut exploiter les forêts d'arbres résineux : "L'exploitation des " forêts d'arbres résineux a lieu, dit-il, plus tôt ou plus tart, selon que les cir" constances l'exigent. Quand on veut avoir du bois de charpente ou du bois de " chauffage, on doit les exploiter à 100 ans, si d’ailleurs elles sont situées sur un " lerrain de bonne qualité el qui conviemne à celte essence. Quand, au con" traire, le sol est mauvais, il fixut les exploiter à 60 ut 70 ans, parce que passé "celte époque l'accroissement se ralentit ol cesse quelquefois tont-i-fait. Si l'on

1) Nouveau Manuel forestier, tableau à la fiı du lome ler.

(2) Baudrillart, d'après Hartig, Dictionnaire des eaux el forêts, t. II, p. 126.

(3) a L'exploitabilité du hètre, dit Cutta, p. 31 de son Traité de culture forestière, est compıise entre n 80 et 160 ans; sa rérolution la plus ordinaire est de 120 ans; cet arbre a atteint à cette époque sun " plus grand accroissement, et il est alors propre à tous les usages auxquels on l'emploie.. Cet auteur, en parlant du sapin argenté, p. 5í, se contente, pour faire connaitre l'àge de sa maturité, do dirc: - Il y a parite entre le hètre et le sapin pour la révolution. " 
"veut se procurer du fort bois de construction, pour la marine, on pour faire "des poutres, on doit attendre 120 à 180 ans, ef choisir pour cela les meilleurs " terrains; parce qu'un mauvais sol ne produira jamais des arbres propres ì ced " usage, les laissât-on sur pied jusqu’i ce qu’ils aient atteint leur plus haut degré

"d'aceroissement."

Dralet dit (1) que dans la forêt de Comefrède, situéc dans les Pyrénées, département de l'Aude, le sapin argonté alteint sa maturité ì 80 ans; il me parait en etre de même dans mon pare. Je présune que sous le climat de Paris, proprement dit, dans des circonstances favorables sous tous les rapports, le sapin argenté alteint sat maturité à environ 90 ans et (quel(quefois, dans des cas exeep)tionncls, à 100 ans et plus; il cesse ordinairement de croilte cn hauteur de 70 ¿ 90 ans, et c'est alors que son écorce devient grise el rugueuse.

Le-sapin argenté aequiort de magnitiques dimensions lorsqu’il se trouve diuns des circonstances de tout point farorables à sa végétation. Je rapporteriti ce que disent à ce sujet différens auteurs qui se sont oecupés de ect arlure.

Rémond, ancien inspecteur des eaux et forêts, dans le département du Jura, dit daus une brochure de seize pages intituléc Observations sur l'exploitation et l'aménagement des forcíts de sappins : "1l existe, dans les sapinières de l'est, des "sapins de 6 à 8 mètres de tour; j'en ai fitit abattre trois de 9 mètres de tour, " ayant employé, pour sortir chaque pièce de la forèt, un attrigu composé de " seizo paires di boufs et de six vigoureux chevaux."

Inalet, dans l’ourage précédemment cité, dit page 11 : "Le sapin argenté, " ì l'âge de 80 ans, aequiert une hauteur de 20 à 25 mòtres; j'en ai vu plusienrs " qui, à l'âge de 120 ans, s'élevaient à 40 mùtres. "

Bandrillart (2) reproduit l'opinion de Burgstorl' qui sera rapportée plus loin. Selon Lorentz (3) "il parrient souvent à une hauteur de 40 à 45 mètres et l'on " a coupé des sapins qui présentaient jusqu'i 6 et 9 mètres de tour à la base. "

Noirot, dans l'ouvrage précédemment cité, consicre un chapitre à parler des sapinières du Jura, el il dit (1) que " dans la grande forêt de la Joux, située entre "Salins et Pontarlier, les sappins argentés de 10 ì 12 pieds $\left(3^{\text {n }}, 25\right.$ ì $\left.3^{\text {m }}, 90\right)$ de "tour sont assez nombreux. "I eite, page 298, les dimensions de l'un des plus beaux sapins de la forè de Fresse; " il avait 109 pieds $\left(35^{\text {th }}\right.$, 40) de longueur " totale et sa circonférence, prise à 4 pieds $\left(1^{\mathrm{m}}, 30\right)$ du sol, était de 13 pieds " $\left(4^{\mathrm{m}}, 22\right)$ et à 81 pieds $\left(26^{\mathrm{m}}, 31\right)$ de 40 pouces $\left(1^{\mathrm{m}}, 08\right)$. "Leroy clonne, dans le mímoire précédemment cité, les dimensions d'un seul sapin : "On coupa, dit-il, v un sapin argenté, en $\mathbf{4 7 6 7}$, dans le quartier de Barlagne, de la forèt d'Issaux, " qui aviait plus de ă pieds $\left(1^{\mathrm{m}}, 62\right)$ de diamètre à sa culée, et 98 pieds $\left(31^{\mathrm{m}}, 83\right)$ " de service. On trousa an milieu de sa sonche celle l'un sapin, d'environ six

\footnotetext{
(1) Traité des forêts d'arbres résineux, p. 159.

(2) Dictionnaire des eaux et foréts, t. II, p. 776 .

3) Cours élémenlaire de culture des bois, p. 90.

¿ Traité de la cullure des forfts, p. $29 \%$.
} 
"ponces de diamètre, qu'il avait enveloppé en croissant : la pwlitr: sunche était "encore verte ed l'on y distinguait les coups de hache qui l'avaicut antrefois " coupée, à 8 on 900 ans de là, à en jugrer par l’âge du grand arbre. Il lallut " haire un train exprès pour celui-ci, qui a depuis été employé à Toulon pour

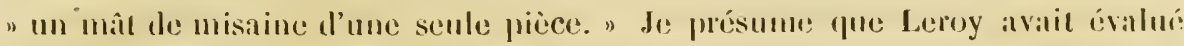
l'âge de ce sapin par le nombre des couches lignenses gu'on computit sur son Irone.

"Le sapin argenté, dit burgstorf (1), est, parmi les artores lorestiers de, " l'Allemagne, colui qui alleinl la plus grande hanteur avec uns grosseur pro"portionnée. On le trouve sur les montagnes de moyenne élévation, quel que " soit le terrain, mats sirtout quand ce terrain est bon et que l'exposition est "fraiche. Dans cette position son accroissement est tel qu'il peut, en 300 ans, " lorsques son bois est sain ef n’éprouve ancun arcident, pousser une lige de 160 "pieds $\left(51^{\mathrm{m}}, 97\right)$ de hant, et parfaitement droite, et acquérir par le bis 111 " diamètre de 6 pieds ( $1^{\mathrm{m}} 95$ ) et plus. 11 n'est pas rare d'abatle des sapins qui, " à une hatuteur de 80 pieds $\left(25^{m}, 98\right)$, ont encore 4 pieds $\left(1^{m}, 30\right)$ de diamètre."

Kasthofer (2), haut forestier à Uterseen en Suisse, dit "qu'il y a des liges de " sapins argentés qui mesurent 6 pieds Berne $\left(1^{m}, 7 \breve{b}\right)$ de diamètre et 1.50 pieds " $\left(43^{\mathrm{m}}, 95\right)$ de longueur. "

"Il atteint, sclon Pfeil (3), une grandeur colossale, de manière ì dépasser " lous les autres conjè̀res indigènes."

M. G. Dichie, dans l'article cité quelques pages plus haut Sur les foréts et les arbres du comté d'dberdeen, dit que le sapin argenté n’est pas commun dans le comté d'Aberdeen, et il donne pourtant un tablean de la circonférence de quelpues-uns de ces arbres à différens âges; je vais reproduire ce tableau dans lequel l'àge est calculé par le nombre des couches ligneuses du trone (Voy. p. 13).

\begin{tabular}{|c|c|c|c|}
\hline LOC.ILITÉS. & AGE. & $\begin{array}{l}\text { CIRCONFÉR LXCE } \\
\left.\text { á f pieds } 1^{\mathrm{m}}, 20\right) \text { llu sol. }\end{array}$ & NATURE DU SOL. \\
\hline $\begin{array}{l}\text { Plilorll. } \\
\text { P.Ifotr. } \\
\text { Striticn. } \\
\text { Wardhouse. } \\
\text { Bredla. } \\
\text { Hunily-Loulge. } \\
\text { Ballaler. } \\
\text { Invereauld. }\end{array}$ & $\begin{array}{l}16 \text { ans. } \\
100 \text { id. } \\
100 \text { id. } \\
100 \text { id. } \\
70 \text { id. } \\
100 \text { id. } \\
70 \text { id. } \\
75 \text { id. }\end{array}$ & $\begin{array}{ll}4 \mathrm{p} . S p^{\mathrm{es}} \text { angl } & (1 \mathrm{~m}, 12) \\
5-9 & (1 \mathrm{~m}, 75) \\
10-11 & (3 \mathrm{~m}, 32) \\
6- & (1 \mathrm{~m}, 83) \\
9- & \left(2^{\mathrm{m}}, 7 \mathrm{i}\right) \\
9-6 & \left(2^{\mathrm{m}}, 89\right) \\
5- & \left(1^{\mathrm{m}}, 52\right) \\
6-6 & (1 \mathrm{~m}, 98)\end{array}$ & $\begin{array}{l}\text { Sol de liruyère, sablunncux. } \\
\text { Fond d'argile. } \\
\text { Loam (4) à la sniface, sous-sol de gravier. } \\
\text { Terreau léger et gravier. } \\
\text { Sol paure. } \\
\text { Loan argileux riche. } \\
\text { Loan sablonneus léger, sous-sul de gravier. } \\
\text { Gravier riche. }\end{array}$ \\
\hline
\end{tabular}

(1) Noureau Hanuel forcstier, t. [er, p. 400.

(2) Le Guide dans les foréts, t. Ier, p. 79.

(3) Cours complet d'ayriculture pratique, p. 354.

(i) Le mot anglais loam me parait aroir l'acception ytue nous donnons il l'expression terre franche ainsi un loan est une terre de bonne qualité pour la rulture des céréales, mais dont la composition n’est pas déterminée d’une manière précise. 
II. Dickic dil ensuite yue les sapins argentés de lal forè d'lusereauld, dont le plus gros se trouve classé dans le tablean, araient de 70 à 80 pieds 121 à 21 mètres) lle haut el poussaient encore de $i$ à 9 pouces $\left(0^{\mathrm{m}}, 17\right.$ à $\left.0^{\text {m }}, 22\right)$ par an; il rapporte enlin fue près de Plymoull, pendant la guerre, à l'épogue des prix les plus élevés, les constructeurs de vaisseaux avaient olfert, à un propriétaire du voisinage de celte ville, la somme de cent guinées pour un arbre de celle espèce.

Loudon dit au commeneement de l'article Picea pectinata de son Arboretum et fruticetum britamicum, tome $\mathbf{1 V}$, page 2331 , que " le sapin argenté s'élève à la "hauteur de 160 à 180 pieds (48 à ó1 mètres) avec une tige droite régulièrement "gatrnie d'étages de brauches en candúlabre, el que le tronc, dans les arlores qui " ont pris tout leur développement, peut alleindre 6 ì 8 pieds $\left(1^{\mathrm{mt}}, 8\right.$ à $\left.2^{\mathrm{m}}, 4\right)$ de " diamètre. "Il donne à la fin de cet article les dimensions de plusieurs sapins argentés, situés dans les pares de la Grande-Bretagne; je vais reproduire ce qu’il dit de cenx de ces arbres qui avaient les plus belles dimensions; on ne peut d'ailleurs comparer leur accroissement annuel, parce qu'il n'indiruc pas à quelle hanteur, au tlessus du sol, a été pris le dianc̀tre du trone, ni s’ils ont crû isolés ou à l'élat serré, el qu'il ne donne presque jamais leur âge. 11 arrive d'ailleurs ordinairement que l'évaluation approximative que l'on fait de la hautem d'un arbre qui est debout est exagérée; ainsi, par exemple, Louton ćvalue approximativement la hauteur du cèdre du Jardin-des-Plantes de P'aris à 21 mètres, et cel arlore n'a que $17^{\mathrm{m}}, 30$ du sol à la cîme.

En Angleterre. -- Dans les environs de Londres, à Whitton, un sapin argenté a 97 pieds anglais $\left(29^{\mathrm{m}}, 10\right)$ de haut et son tronc un diamctre de 3 pieds 9 pouces

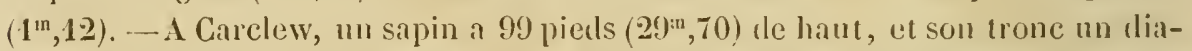
mètre de 3 pieds 9 pouces $\left(1^{\mathrm{m}}, 12\right)$. - $\mathrm{A}$ Bicton, 104 pieds $\left(31^{\mathrm{m}}, 20\right)$ de liaut, son tronc un diamètre de 3 pieds $\left(0^{\mathrm{m}}, 90\right)$. - A Areslord, planté il y a 81 ans, 83 pieds $\left(24^{\mathrm{m}}, 90\right)$ de haut, son trone un diamète de 3 pieds $\left(0^{\mathrm{m}}, 90\right)$. - A Strathliceldsaye, 120 pieds (36 mètres) de lant, son trone un diamètre de 4 pieds 10 ponces $\left(1^{\mathrm{m}}, 42\right)$.- A Knowle, 106 pieds $\left(31^{\mathrm{m}}, 20\right)$ de hant, son trone un diamètre de 4 pieds 10 ponces $\left(4^{\mathrm{m}}, 12\right)$.- - A King's Wirston, 104 pieds $\left(31^{\mathrm{m}}, 20\right)$ de latut, son tronc un diamètre de 4 pieds 3 poures ( $\left.1^{\mathrm{m}}, 95 \mathrm{~b}\right)$. - A Cowdraty, 120 pieds (36 mètres) de haut, son tronc un diamètre de 4 pieds 6 ponces $\left(1^{\mathrm{tm}}, 35\right)$, dépouillé de branches jusqu'à 5o piecls $\left(16^{\mathrm{m}}, 50\right)$. - A Longleat, planté dlepuis 180 ans, 138 pieds $\left(41^{\mathrm{m}}, \mathbf{4 0}\right)$ de haut, son tronc un diamètre de š pieds 8 pouces $\left(1^{\mathrm{m}}, 70\right)$. - A Kecldlustone, il y a plusicurs sapins de 130 ì 150 pieds (39 à 45 mitres) de haut, ef dont le trone a une circonférence de 10 ì 16 pieds (3 à jo mètres). -- A IIartburn, planté clepuis $83 \mathrm{ans}, 138$ piecls $\left(11^{\mathrm{m}}, 40\right)$ de haut, son tronc un diamètre de 4 pieds $\left(1^{\mathrm{m}}, 20\right)$. - A Castle lloward, 130 pieds (39 mitres) de haut, son tronc un diamcitre de 3 piels 6 pouces $\left(\mathrm{i}^{\mathrm{m}}, 05\right)$.

En Écossc.-- A Ilopetoun Ilouse, un sapin argenté, âgé rle 100 ans, a 90 pieds (27 mères) de haut, et son trone un diametre de 3 pieds 7 ponces $\left(1^{\mathrm{m}}, 0 \bar{t}\right)$. - A Kilkerran, 90 pieds (27 mitres) de hant, son trone un diamedre de by pieds (1"n, 50$)$. 
A Mintu, plimle depuis 75 atus, 90 pieds (27 mères) de hatul, son trome 14 diat-

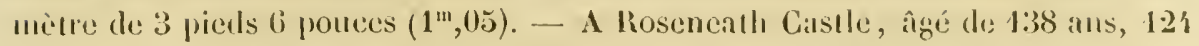
pieds $\left(37^{\mathrm{m}}, 20\right)$ de haut, son trone, it 3 pieds $\left(0^{\mathrm{m}}, 90\right)$ du sol, un diamètre de 6 picels 4 pouces (i "',90); 111 autre du même âge a environ 120 pieds (36 mètres) de haul, a son trone un diamètre de 7 pieds $\left(2^{m}, 10\right)$ ì un pied $\left(0^{m}, 30\right)$ du sol. - A Blarir Drummonıl, âgé de 120 ans, 90 pieds (2 mètres) de haut, son tronc un diamètre de 3 pieds $\left(0^{\mathrm{m}},(0) 0\right)$.

En Irlande. - A Wootstork, $11 n$ silpin aigrenté, planté depuis 80 ans, a 91

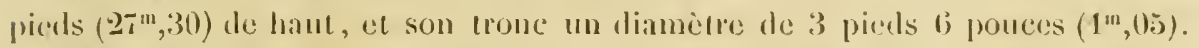
- A Hoira, 90 pieds (27 mètres) de haut, son trone un diamètre de 3 pieds 6 pon( $\cos \left(1^{\mathrm{m}}, 0 \mathrm{j}\right)$.

A ees citations, tirées de dillérens auteurs, relativement aux magniliques dimensions que pent atteindre le sapin argenté, j'ajonterai les renseignemens que j’ai recueillis de différentes personnes et eeux que je me suis procurés moiutème.

Je tiens les reuseignemens yui suivent, sur les dimensions des sapius argenles dans les montagnes des Vosges, de II. G. Gand, alors sous-inspectent des furèts à Sénomnes, déprartement des Vosges. Les sapins qui ont crû daus un bon fonds, ont généralement à l’âge de 100 à 120 ans, époque ordinare de leur exploitation, à $1^{\prime \prime}, 33$ du sol, 2 mètres à $2^{\text {m }}, 50$ de circonférence et une laatuteur de 30 ¿1 33 mètres; il y en a sonvent qui dépassent cette hauteur et qui atteignent 35 à 3 to mètres; enlin quelquess-tuns, par exception, alleignent à me hauteur de 10) mètres avec une circonférence de 3 mètres à $3^{\mathrm{m}}, 30$. Le tableau suirant fait connitile les dimensions de quelques sapins argentés de la lorêt de Framont, siluéce dinus les Vosges, canton de Schimeck, lépartement des Vosges : l'àge a été évalué pir le nombre des couches ligneuses du trone (Voy. 1). 13).

\begin{tabular}{|c|c|c|c|c|c|c|}
\hline 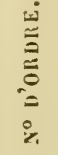 & $\begin{array}{c}\text { Élévaliou } \\
\text { approsimalive } \\
\text { au dessus du } \\
\text { niveau de la } \\
\text { mer. }\end{array}$ & Exposilion. & AGE. & $\begin{array}{c}\text { Circonférence } \\
\text { a Insż du sol, } \\
\text { ecorce com- } \\
\text { prise. }\end{array}$ & Ilauteur. & Volume. \\
\hline $\begin{array}{l}1 \\
2 \\
5 \\
4 \\
5 \\
6 \\
7 \\
8 \\
9 \\
10 \\
11 \\
12 \\
15 \\
11 \\
15 \\
11\end{array}$ & mèlres. & Plateau. & $\begin{array}{r}\text { Ans. } \\
93 \\
100 \\
93 \\
123 \\
100 \\
113 \\
125 \\
153 \\
153 \\
113 \\
120 \\
100 \\
115 \\
125 \\
90 \\
130\end{array}$ & $\begin{array}{l}\text { m. } \\
1,500 \\
1,680 \\
1.800 \\
0,141 \\
1,500 \\
1,520 \\
1,200 \\
0,158 \\
1,550 \\
9,010 \\
0.099 \\
0,1,1 \\
0,109 \\
1,620 \\
1,290 \\
1,1,0\end{array}$ & $\begin{array}{l}m . \\
27,90 \\
26,72 \\
21,00 \\
23,80 \\
21,00 \\
18,85 \\
25,50 \\
21,10 \\
23,55 \\
50,00 \\
23,00 \\
26,50 \\
28,93 \\
27,93 \\
21,53 \\
22,00\end{array}$ & $\begin{array}{l}\text { m.c. } \\
2.500 \\
2,111 \\
0,687 \\
1,941 \\
1,815 \\
1,201 \\
1,201 \\
1.750 \\
1,710 \\
4,900 \\
0,835 \\
2,194 \\
1,805 \\
2,930 \\
1,510 \\
1,041\end{array}$ \\
\hline
\end{tabular}




\begin{tabular}{|c|c|c|c|c|c|c|}
\hline 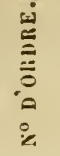 & $\begin{array}{c}\text { Élevation } \\
\text { approximative } \\
\text { ant dessus 114 } \\
\text { niveau de la } \\
\text { mer. }\end{array}$ & Exposition. & AGE. & $\begin{array}{c}\text { Circonference } \\
\text { a } 1 \text { maz du sol, } \\
\text { écorce com- } \\
\text { prise. }\end{array}$ & II auleur. & Volume. \\
\hline $\begin{array}{l}17 \\
18 \\
19 \\
20 \\
21 \\
22 \\
25 \\
23 \\
25 \\
26 \\
97 \\
28 \\
29 \\
30 \\
51 \\
32 \\
53 \\
51 \\
35 \\
56 \\
57 \\
58 \\
59 \\
40 \\
41 \\
42 \\
43 \\
44 \\
43 \\
46 \\
47 \\
48 \\
49 \\
50 \\
51 \\
59 \\
53 \\
51 \\
53 \\
56 \\
57\end{array}$ & metres. & Plat all. & $\begin{array}{r}\text { Ans. } \\
115 \\
85 \\
100 \\
95 \\
110 \\
105 \\
120 \\
100 \\
95 \\
150 \\
90 \\
95 \\
95 \\
75 \\
65 \\
60 \\
105 \\
53 \\
110 \\
93 \\
115 \\
90 \\
103 \\
110 \\
105 \\
110 \\
115 \\
115 \\
85 \\
95 \\
90 \\
95 \\
95 \\
95 \\
125 \\
125 \\
120 \\
150 \\
95 \\
90 \\
75\end{array}$ & $\begin{array}{l}1,710 \\
1,960 \\
0,910 \\
1,950 \\
1,140 \\
0,950 \\
1,140 \\
1,530 \\
1,620 \\
1,410 \\
1,110 \\
0,780 \\
2040 \\
1,520 \\
1,120 \\
1,140 \\
1,550 \\
1,140 \\
1,710 \\
2,160 \\
2,880 \\
1,170 \\
0,990 \\
1,030 \\
1,630 \\
1690 \\
1,440 \\
1,170 \\
1,110 \\
0,990 \\
1,680 \\
1,250 \\
0,900 \\
2,460 \\
1,860 \\
1,350 \\
2,250 \\
1,620 \\
2,150 \\
1,470 \\
1,100\end{array}$ & 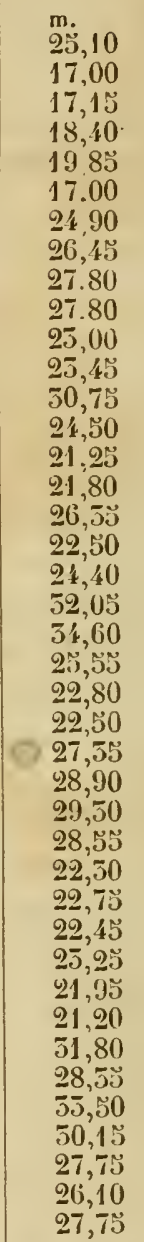 & 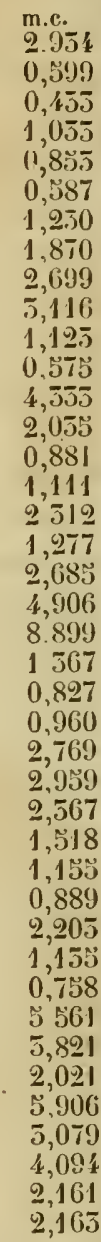 \\
\hline
\end{tabular}

I. Le général marquis de La Bourdonnaye ne transmit, le 1er févier 1842, les renscignemens suivans que son beat-frère avait recueillis lui-même clrez son père, le comte de Lantivy, qui habite sa terre de Laporte, à trois lieues au sud de Josselin, département du Morbihan. On trouve sur celte propriété des sapins argentés de la plus grande beauté, qui sont mêlés avec des bois feuillus. Sous l'Empire, un agent de la marine offrait d'en payer cent, quil choisirait, à raison de $1,000 \mathrm{fr}$. chacun, ì condition (qu'on les ferait conduire au port de Lorient, qui se trouve à quinz lienes de li; mais cela semblait, pour ainsi 
dire, impossible, at cause du matuvais étal des chemins. Tous ces salpins existent encore en ce moment, et l'on peut juger par ee que j’ai dit précédrmment ì quel prix peu élevé on pourrait s'en défaire. Au $\mathrm{I}^{\mathrm{er}}$ janvier $\mathbf{1 8 1 2}$, le plus gros le ces sapins avait, à un mètre au dessus du sol, $4^{m}, 5 /$ de circonférence, et l'on en remarquait plusienrs qui avaient 3 mètres de circonférence et au delà; le plus ćlevé de ces sapins atteignait 40 mètres. Ils avaient cté plantés par lo bisaïenl łu conte de Lanlivy, propriétaire actuel; on évaluait leur âge à environ 150 ans.

M. Auguste de Saint-Priest, qui habite, dans le département de l'Ardéche, l'arrondissement de Tournon, ou se trouve le mont Mezin, la plus haute monlagne des Cévennes, m’adressait, le 29 juin 1811, le renseignement suivant: "Voici, me disatit-il, un fait que je vons transmets tont chatul. Un sapin argenté " de $36^{\mathrm{m}}, 38$ de hauteur, d'une circonférence de $4^{\mathrm{m}}$, ăs à ceinture d'homme, vient "d’être coupé, mis en planches, conduit à Ammonay et payé zo0 fr., dont il "faut cléduire environ 200 lir. de frais. On assure qu'on serait embarrassé "injourd'hui de trouver une centaine de tels arbres, qui étaicnt nombreux " autrefois."

Je terminerai par domner les dimensions de quelques sapins argentés sous le climat de Paris proprement dit. Le phus gros de ces arbres que j’aie mesuré se trouve dans ume futaie de hètres, altenant au châtean de Couterne, qui appartient à 11 . te comte de Frollé, et est situé à 3 kilomètres lles eaux de Bagnoles (Orne); on avait probablement aljattu quelques liêtres pour favoriser son développenent, car il est garni de branches depuis le sol jusqu'i la eime. Cet arbre provient de plantation, puisqu'il n'en existe point d'autres dans la futaie où il se trouve. Je l’ai mesuré en juillet 1837 : il avait 4 mètres de circonfërence et $35^{m}, 73$ de haut; il s'élevinit l'environ 16"',2't an dessus dis lat lutaie de hêtres dans laquelle il se trouve; un coup de vent le brisa à $9^{\mathrm{m}}, 7 \mathrm{z}$, à partir du sommet, peu avant l'époque où je le vis, sans qu'il en fùt ébranlé; sa tête était encore alors sur le terrain. Je présume que ce sapin argenté est actuellement le plus gros et le plus élevé qui existe en Normandie; néammoins il s'en trouve dans quelques haies des vallées d'Auge el du pays de Caux qui sont fort remarquables par leurs dimensions.

On tronve dans un bois de la terre de Menil-Jean, près de Putanges (Orme), qui appartient ì M. lo comte d'Orglandes, un assez graud nombre de sapins argentés; la dernière fois que l'on abattit des sapins dans ce bois, il y a 5 ă ans, les deux plus gros de ceux que l'on conserva avaient environ 40 ans, ainsi ils ont aujourd'hui environ 95 ans : l'un de ces arbres a $3^{\mathrm{m}}$, 25 de circonférence à 1'" 1 1't atu dessus du sol, et l'autre $2^{\text {n }}, 76$; on donne au premier $27^{m}$, (i) de haut, el l'on évalue la hauteur du second à 31 mètres.

J'ai mesuré, en aoü 1840 , le plus gros sapin de la sapinière de Raveton, situéc à une liene et demie de Laighle; e'est un arlore que l'on a conservé comme portegrane, mais plutôt encore par amour-propre de propriétaire; car il est désavantagenx, ainsi qu'on le verta, d'en ronserver de redte dimension dans les sapi- 
nières des environs de Laigle; il a $3^{\mathrm{m}}, 22$ de circonférence et $2^{1 \mathrm{~m}}, 66$ de haut. M. le baron de Montuel, propriétaire de cette belle sapinière, qui est, je crois, la mieux aménagée de toutes celles des environs de Laigle, a bien voulı m'aider à y recueillir tous les renseignemens que je pouvais lésirer, et M. Baudry, son homme d'affaires, qui s'oceupe depuis quarante-sept ans de l'exploitation des sapinières dans les environs de Laigle, a mis à ma clisposition le secours de son expérience. Il me dit qu'avant la révolution française, le bois des sapinières des convirons de Laigle a vait peu de valeur, et qu'on y trouvait alors des arbres monstrueux; il y a fait exploiter un sapin qui avait $43^{\mathrm{m}}, 85$ de long et environ $3^{\mathrm{m}}, 90 \mathrm{de}$ rirconférence.

Pendant la dernière guerre maritime entre la France et l'Angleterre; la Suède et la Russicne pouvant plus envoyer de sapins picéas ni de pins sylvestres en France, le sapin de Normandie prit beaucoup de valeur, et l'on abattit presque tous les sapins qui avaient plus de $0^{\mathrm{m}}$, ă 1 (20 ponces) de circonférence à I I', 30 ('l pieds) au dessus du sol. Le prix du bois des sipinières rle Laigle s'est soutenu, malgré la concurrence des bois du Nord, à un tauxassez élevé, par suite de l'accroissement de la population, des développemens du commerce et de l'industrie, et des défrichemens des bois feuillus.

On trouvait en 1811, dans la commune de Saint-Aubin-d'Ecrosville, lépartement de l'Eure, de magnifiques sapins argentés, appartenant à M. Pavyot, parmi lesquels il y en avait plusieurs qui étaient îgés de 100 ans at moins, et qui avaient au delà de 3 mètres de circonférence : on les a abattus en 1812.

A 3 kilomètres de chez moi, il y a, dans le pare de M. Mossehman, à Condé-surIton, un sapin argenté qui a $3^{\mathrm{m}}, 20$ de circonférence et 2:3 mètres de haut.

On m’a envoyé, en 1810, la mesure d'un sapin argenté qui se trouve dans la commune de Coubert, département de Seinc-et-0ise, à 36 kilomètres de Paris, chez. M. Rigaud; il avait $3^{\mathrm{m}}, 8 \bar{t}$ de circonférence ot 30 mètres de: haut : on le: croil âgé de 100 ans.

hans mon pare, les sapins argentés ne paraissent pas pouvoir atteindre à des dimensions aussi remarquables : les plus gros ont 2 mètres de circonférence et ils ne dépassent pas 22 mìtres de hant; mais rette propriété ayant été vendue pendant la révolution française, la compagnic qui l'avait achetée avait lait abattre les plus beaux sapins. Ion père racheta l'habitation et le parce en 1803 , peu après son retour de l'émigration; depuis celle époque, la sapinière a été ménagée.

Vi. Chmit, expositiox, terhax. - Le sapin argenté croît spontanément dans la partie méridionale et dans la partie centrale de l'Europe : dans la première partie, il ne se trouve que dans les chaînes de montagnes el à une certaine élévation au dessus du niveau de la mer; mais dans la seconde, il se trouve aussi dans les plaines, quoique rarement, parce qu’il en aura été chassé par la culture. Ainsi on le trouve en plaine, en France, dans quelques parties

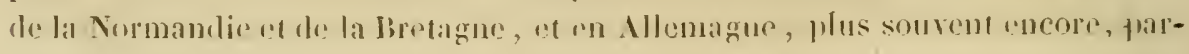




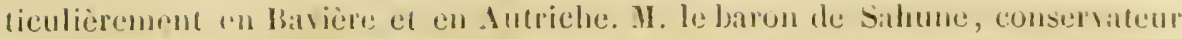
des forèts di: la couronne, se trompe donc lorsqu'il dit (1) : "que le sapin "argenté est essentiellement arbre de montagne, et qu’il ne prout prospérer en " masse pue lì. "

Au midi de l'Europe, on remarque particulièrement le sapin argenté sur les montagnes de la Grèce el du Péloponèse, et dans tonte la chaine des Apennins. Tr.nore dit (2) que "le sipju (.tbies pectinalı) croit anssi dans les forêts rle " cette région (les monts $\lambda$ pemnins) et qu'il abonde principalement sur les " llancs orientaux des Siles; mais que c'est sur le Pollino (montagne de la Cala" lre-Citćricure), el précisément dans la forêt de liubia, que cet arlire étale " toute sa beauté. Là, ajoute-t-il, il n'est pas difficile de trouver des sapins de " 130 ì 1 žo pierls dont les cîmes noirâtres semblent vouloir disputer aux mes "l'empire des régions aériennes. " Le point le plus mériclional de l’Europe wi l'on voit de grandes forêts de eet arlore est le mont Taggète. "Ils lorment, " disent Chaubard et Bory de Saint-Vincent (3), une région ou ceinture an" tour des grands sommets du Taygète, à la limite des meiges qui perséverent "le plus dans l’été.

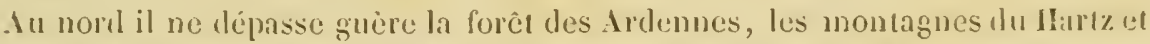
li's montagnes du nord de la Bohème; il est abondant dans les harpathus, et plus au norl, Eichwald (') dit qu'il ne l'a pas trouvé au delà de la forèt de Bialowesc, daus laquelle il n'y en a plus que quarante. Selon bouton, il n'est jas indigèm:

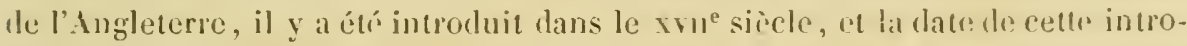
duction est incommete.

On n’a encore trouvé le sapin argenté ni en Amérique, ni en Afrique; en Asie, il croit dans les montagnes du Caucase, dans colles de l'Asir-llincure, ct - saus doute dans d'autres licux encore.

Cet arbre croîl seul ou mélangé arec différentes espèces, particulièrement avee le lêtre ou le sapin picéa, selon le climat; ainsi, par exemple, au micli de l'Europe, où l'on ne trunve point le sapin picéa, c’ust arec le hêtre qu’il est le plus ordinairment mélangé; en s'avançant vors ie nord, il est aussi mêlé arec le picéa.

Dans les hautes montagnes, telles que les Alpes, ou le climat der ient de plus en plus rigoureux à mesure que l'on s'élève, c'est au bas des montagnes ef dans les vallées basses que se trouvent placés tes sapins argentés. Kasthofer dil (J) que daus les Alpes "le froid le fail périr daus l’isolement; " c'est-ì-clire qu’il supporte un froid plus intense lorsqu'il est réuni en futaie que lorsqu'il est isolé. Dans les P'yrénées, qui sont situées sous un climat plus chaud que les Alpes, te sapiu argenté se trouve à une plus grande hauteur au dessus lu niveau de la mor

1 Annales forestières, ferritr 1 sí3.

(2) Essai sar la géographie physique el holonique du roynume de Taples, p. i6.

(3) Yonrelle Flure du Péloponèse el des Cyclades, p. 65.

(4) Valurhistorische skizze von Lilhauen, Wolhymien und Podolien, p. 1:9.

5. Le Guide dans les forêts, 1. Ir, p. 79, art. du Sinpin blanr. 
et occupe ordinairement, selon Draled (1), les pentes silućes au nord. "Ciel D arbre, dit le mème auteur page 32 , dont la région moyenne est l'apanage, "ne laisse pas que d'empiéter quelquefois sur celles qu'occupent plus bas les "forêts de hêtres. Son domaine est immense dans toutes les montagnes de "France, oì il occupe les neuf dixièmes des forêts composées d'arbres verts." Cette évaluation, lors même qu'elle ne serait pas entièrement exacte, fait sentir quelle est, pour la France, l'importance des forêts de sapins argentés.

M. Loiseleur-Deslongchamps, auteur du tome V du Nouveau Duhamel, a inséré dans ce tome, page 315, un mémoire de M. Mougreot, médecin à Bruyères (Vosges), relatif aux arbres résineux des montagnes des Vosges; on y trouve que 200,000 hectares sont recouverts de forêts dans ce département, que les forêts d'arbres résineux en composent la plus grande partie, et qu'elles contiennent trois espèces d'arbres: le sapin argenté, le sapin picéa et le pin sylvestre. "On évalue, dit M. Hougeot, à peu près à neuf dixièmes la quantité des sapins, " à un vingtième celle de la pesse (sapin picéa), et à autant celle du pin sauvage "( pin sylvestre)."

M. G. Gand m’a donné, sur les forêts d'arbres résineux de la chaîne des montagnes des Vosges, les renseignemens suivans, qui font connaitre leur importance et en particulier celle du sapin argenté qui y est l'essence dominante. Les forêts d'arbres résineux de la chàne des montagnes des Vosges occupent approximativement une étendue de 1500,000 hectares, dont 75,000 dans le département des Vosges, 20,000 dans celui de la Meurthe, autant dans celui du BasRhin, et 35,000 dans celui du Haut-Rhin. Le sapin argenté forme environ les neuf dixièmes du peuplement de ces forêts, mêlé en général d'un dixième le lıêtre.

En France un trouve principalement lesapin argenté dans les montagnes des * Vosges, dı Jura, des IJpes, de l’Auvergne, des Cévennes, des P’yrénées ct dans quelques parties de la Normandie et de la Bretagne. "Le pin sauvage, dit Dralet, "page 33 de l'ouvrage cité plus haut, est le seul des arbres résincux qui se soit " naturalisé avec le sapin clans les Pyrénées, et e’est par erreur que plusieurs " écrivains ont avancé qune le mélize déploie dans les Pyrénées la beanté de sa v'érgé" tation, et que d'autres ont dit que le picéa y forme des forêts."

Le même auteur dit, pages 48 et suivantes : "Plusieurs contrées le la "France possédaient autrefois des forêts d'arbres résineux dont clles sont main" nant lépourvues. Il n’existe plus de sapins dans la montagne Noire ni dans " celle de Lacaune (Tarn), qui en produisait autrefois de la plus forte dimenn sion. Le pin a disparu dans plusieurs montagnes, notamment en Bourgogne; " et celles qui ont conservé des forêts, ont été le théâtre de toute espèce de ra" vages. La charrue a sillonné le fonds des vastes forêts de pins et de mélèzes " qui couvraient autrefois une partic du département de Vauchuse. Les défriche" mens et les coupes immolérées ont, depuis cincuante ans, appauvi les mon- 


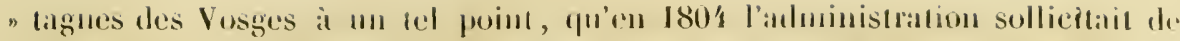
"promptes mesures pour prévenir, disait-elle, la ruine totale des forêts. Une "grande partie des Alpes, antrefois courertes d'immenses silpinieres, se troure "tellement déboisée, que les tabitans de certanins cantons, tel que celui de "Grave, sont réduits, comme nous l'avons déjà dit, à se chatuffer avec liı

" house séchée au soleil.

"Mais de toutes nos montagnes, les Pyrénées sont celles où l'ignorance et le " lélire de la cupielité ont causé les plus aflligeans désastres. Les sappinières "qu'elles renferment sont les seules qui, en France, puissent être exploitées " avec avantage punr la mâture de nos vaisseaux. Silnces près des fleuves de la "Garome, de l'Adonr, des Gaves le l'au el d’Oléron, elles foumissent depuis " longtemps aux ports de l'Océan des sapins de grambes dimensions, bien pro"portionnés, peu noneux et pen sujets à la piqùre des vers, l’un grain lin et " d'une grande légèreté. Lorsqu'ils ont été récenment coupús, ils sont anssi "Elastiques que les pins du Nord, auxquels ils ne le cèdent que sous le rapport " le la durée. Ceux-ci font un usage trois fois plus long que celui de nos sapins; " mais, rendus dans nos ports, ils coutent quatre lois plus; on sorte que l'appro" visionnement fat dans les Pyrénces nous est avantageux sous le rapport de " la dépense; et il est tonjours assuré, tandis que la gnerre peut nous priver, " d'un moment à l'autre, des ressources que présente la Russie.

"Tontes ces considérations furent apprécićes par nos ancêtres: Lonis XIV tit " extraire des Pyrénées la plupart des mâts qui furent nécessaires pour le rétablis" sement et l'entretien de la marine frangaise. Depuis 1675, ees montagnes ont " fourni plus de trois millions de pieds cubes de bois de matture. On u'est point " étomné de cetle immense exploitation, lorsque l'on a pris connaissance des tra" vaux dispendieux qui furent faits, notamment juspu'en 1775, pour l'extraction " de cetle natture; malheureusement ces dépenses ne nous ont laissé que des "regrets. Les foumisseurs de la marine ont détruit tontes les forêts ou ils ont "pénétré. Les routes, les chaussées, les ponts, les glissoirs ne conduisent plus " qu’ì des cléserts. Ils étaient cependant de puissans motil's pour conserver et "pour aménager sagement les forêts, it l'occasion desquelles ils avinent été " coustruits.

"Les forêts de la Basse-Navarre qui, sous Louis XIV, ćtaient on état de " fonrnir seules à l'entretien de tontes les flottes th Roi, ne présentent plus de res" sources à la marine que dans les parties inaccessibles. On troure i peine: quel-

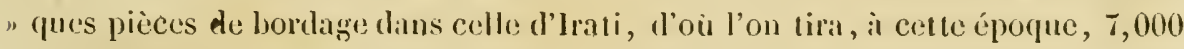
" mâts de navires.

"Les forèts du Pact et de Benou (Basses-Pyrénées), qui, depuis 1758 jus" qu'en 1773, furent exploitées avec un grand sucè̀s pour la mâture de Bayonne, "ne renferment plus que des arbres rabougris et des broussailles.

"La vallée d’Aure (Ilautes-Pyrénćes), qui, en 17̄̌l, possédait 3,000 máls "des plus fortes dimensions, ne présente plus de ressource à la marine que " pour la fourniture des resparts a autres menus hois. La forêt de Margourilh. 
" dans la territoire de Bagnères-de-Bigorre, n'est plus qu'un vaste pâturage qui

"va s'étendre sur celle de 'Transoubat, si l'administration ne prend de promptes " mesures pour en prévenir la ruine totale.

"La forêl de Galbas ( Basses-Pyrénées), où la marine a, depuis 30 ans, un bel "établissement que je viens de visiter, a élé si maltraitée, qu’elle parait aroir "été incendiée dans presque toutes les parties qui ont été exploitées. Sans " une prompte réforme, c'en est lait, avant quinze ans, de la senle forêt qui, "dans les Pyrónces et la France entière, fournisse encore des bois pour la " แlıิture.

"Tw est l'état des parties occidentales et centrales des Pyrénérs; celles qui " se rapprochent de la Méditrerance ne présentent pas un tablean plus satisfai" sant. "L'auteur continue cusuice l'énumération de ces dévastations dans les départemens de l'Ariége, de la Haute-Garonne et de l'Aude. Voili comment s'exprimait, en 1820, l’inspecteur principal tes forêts du Mirli! A-t-il étć apporté un remède à cet état dle choses? je l'ignore, et il n'est pas de mon sujet de m’en occuper.

Le sapin argenté préfère un terrain substanticl, profond, argilo-siliceux, qui conserve suffisamment l'humidité; les terres siliceuses arides, dans lesquelles peuvent prospérer les pins maritimes, les pins sylrestres et les puns laricio, ne lui conviennent point, non plus que les terres marécageuses ou trop humilles el les terres trop calcaires; il y périrait ou n’y aurait qu’une végétation languissante. "Il vient de préférence, dit Ilartig (1), dans un fonł mêlé de bonne terre, d'un " peu d'argile et de petites pierres; mais on peut aussi le cultiver avec sucès " sur un sol de médiocre qualité. Il ne se plait pas dans les terres limoneuses, " fangeuses el aquatiques. "

Burgselorf dit (2) que a les sapins ne viennent bien que dans un terrain de "honne qualité, profond el substantiel; " et dans fe tablean qui se tromve ì la lin du tome ${ }^{\text {er }}$, il indique la terre végétale prre, mêlée de plus de glaise que de sable, comme celle qui lui convicnt.

Il serail d'ailleurs possible que la nature des terres dans lesquelles on peut cultiver avec succès le sapin argenté, présentât quelque variété sclon le climat, rt selon tu'il occupe les montagues on les plaines. Cet arbre vient tries-bien au milieu des rochers lorsque la terre qui s'y trouve lui convient d'ailleurs; ce sont ceux qui sont dans cette situation dans les Pyrénées que Leroy préférait pour la mâture.

Sur les montagnes rles Vosges, la végétation des sapins argentés est plus active dans les terrains à base granitique et euritique que dans ccux qui ont une base de grès; mais, dans ces derniers, le bois est d'une qualité supérieure. C'est, toutes choses égales d'ailleurs, dans des terrains profonds, riches en terre végétale, qui ne sont ni sees ni marécageux, que le sapin y a la plus belle

(1) Instruction sur la culture du bois, p. 205.

(2) Nouceau Manuel forestier, 1. 11, p. 268. 
végétation. Dans les partices basses des montagnes, il croit sul les pentes exprosées au nord el à l'est; vers 4 à 500 mètres d'élévation, on le trouve à toules les expositions, quoiqu'il prélìre encore le nord et l'est; dans les régions flus élevies, l’influence de l'exposition est moindre; vers 900 et 1,000 mètres, sil végétalion se ratlentit beancoup el vers 1,100 i 1,200 mètres il cède successivement la place au hêtre (1).

La terain des sapinières des environs de Laighle est argilanx, et je me suis assuré qu'il ne contenait pas de carhonate de chatux; la terre de ces sapinières est grasse, colle après la chatrue, dans las tomps humides, de manière à empercher quelquefois de lahourer et reticut l'ean; de conticut du minerai de fer.

L'air des grandes villes est contraire all sipin argentí, du moins cemx que j’y ai vus clans les jardins mon paru chélifs. L'on en a plante à plusienrs reprises au Jardin-rles-Planles, dans celte partie consacrée anx arbres foresticrs qu'on appelle le Labyrinthe, ils sont presque tous morts et ceux qui ont survícu ont le plus tristo asprect; il est possible d'atilleurs que le terrain ne leur ronvienne point du tout.

Le sapill argentio est, de tous les arbres qui peuvent se cultiver an futaie sous Ie elimat de Paris, enlui qui prorluit, ainsi fu'on le verra, le revemu le plus élevé, lorsqu'il so trouve placé dans des circonstances entièrement favorables. Mais on ne tirerait, pour ainsi dire, aucun revenu d'un terrain sur lequel ou s'ulstimerait à le cultiver, si ce termin no lui convenait point, ear il y resterat "lúfil et rabougri. Les fulaies de ret arbre ne peuvent être d'un bon rapport qur lorsqu'une partic des sapins, convenablement espacés d'ailleurs, peuvent attrindre une dimension qui permetle d'en faire de la planche, et que si leur végétalion rst assez active pour que, dans des circonstances favorables, ils puissent atteindre celte dimension à 60 ans : e'est ce qui arrive dans les sapinières de Laigle et même dans la mienne, qui pourtant n'ocenpe pas un terrain anssi favorable à celle espèce d'arbres.

Les autcurs qui ont émis une opinion sur l'exposition qui convient an sapin argenté indiquent celle du norl; j’ajouterai que eette intieation est juste lorsqu’il s'agit de monlagnes méridionales à pentes rapides. Ainsi J)ralct (2), inspec1eur des forôts des Pyrénées, dit que dans les montagnes des Pyrénćns, lorsque des futaies de sapin argenté et des futaies de chêne se trouvent dans la même forèt, les premières oceupent phus particulièrement les pentes qui sont situres au nord, el les secondes celles qui sont siluées au midi. L'on a vu que dans les parties basses des monlagnes des Vosgẹ, il préfère les pentres exposées au norl et à l'est. Dins les sapinières de Laigle, qui sont situées en plaine on sur des côteaux peu élevés el orlịnairement peu rapides, on ne remarque point qu'une exposition soit préférable à une autre; cest le sol qui exerce la prineipale infuence.

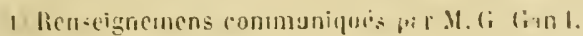

(2) Trailé des forrits d'ar ures résinerer, p. sii. 


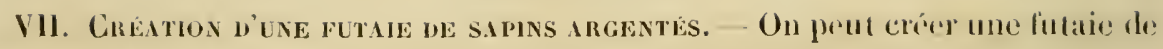
sapins argentés de deux manières, par la plantation ou alu moyen du semis, et l'on peut exécuter cette création sur un terrain couvert d'arbres, d'arbrissranx, d'arbustes, de plantes, ou sur un terrain entièrement libre. J'indiquerai, au commencement du chapitre XI, les terrains el les situations dans lesquelles les semis sur place des arbres résineux conifèrus ne réussissent jamais. Le premier soin doit être de tracer les chemins de la funaie future el d'assainir les parties qui en auraient besoin; on se conformera, à cet égart, à ce que je dirai atu commencement de l'article suivant. Je m'occuperai d'abord de la création d'une futaie de sapins argentés au moyen de la plantation, el je supposerai qure l'on a fait choix d'un ferrain favorable à lis culture du sapin, condition sans latuelle on échouerait ou l'on réussirait mal.

La plantation est le moyen le plus sùr et le plus prompt, à cause de la difficulté de linire réussir les semis artificiols de sapin argenté, exécutés en grand sous le climat de Paris, parce qu'il leur faut un demi-ombrage; les arbres obtenus par la plantation sont d'ailleurs susceptibles d'atteindre d'anssi helles dimensions que cenx qui proviemment de semis maturel ou de semis artificiel. On doit, antant qu'on le peut, n'employer que du plant de pépinière, mais il faut que l'on en ait une chez soi; car si l'on trouve du plant de sapin argenté chè les pépiniéristes, e'est ordintirement en petite quantité, parce qu’ils ont plus d'avautage à élever d'atutres espèces, dont l'atecroissement est plus prompt daus les premières amées. Le plant provenant de semis naturel que l'on prendrait dans une sapinière ayant été ćlevé à l'ombre, ayant peu de chevelu, ayant eu le pivot brisé en l'arrachaut et souvent quelques racines latérales endommagées, reprend difficilement, à moins qu'il ne soit très-jeme; et s'il reprend, il bourle souvent pendant plusieurs années et atteint plus rarement ì de fortes dincensions. Le: plant de pépinière, an contraire, élevé et planté à demeure, ainsi que je le lirai (hap. XI, art. II, ne manque, pour ainsi dire, jamais; il pousse bien des l'annce de sa plantation, el encore mieux les amnées suivantes. On peut pourtant cmployer du plant pris dans une sapinière; mais il est à clésirer qu'il u’ait pas plus de $0^{\mathrm{m}}, 21$ de haut, qu'il soit levé en motte, avee le plus grand soin, el qu’il soit planté dans un bois où il se trouve suffisammont à l'oubre, comme dans la sapinière d'oủ on l'a tiré; on preut même avece ce jente plant, qui a déjà 4 ou 5 ans, former une pépinière en terrain découvert, ainsi qu’on le verra dans le chapitre que je viens de ciler.

Le plant de pépinière le plus jeune que l'on doive employer, pour la plantation à demeure, est celni de 3 ans, qui a de $0^{\mathrm{m}}, 09$ à $0^{\mathrm{m}}, 16$ de hamt, et lo plus âgé, celui de 8 à 9 ans, qui a de un mètre à $\mathrm{I}^{\mathrm{m}}, 50$ de haut. Si l'on emploie du plant de pépinière plus âgé et par conséquent plus haut que celui-là, il faudra l'arra(her et le planter avec le plus grand soin, le liner non pas une senle fois, ainsi que je le prescris chap. XI, art. II; mais deux on trois fois, dans l'année (uii suit la plantation, et même l'arroser si on le juge indispensalule. Pour plan-

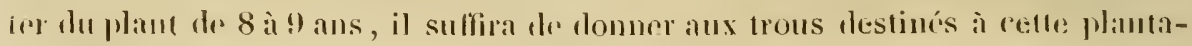


tion un mètre de colté el $0^{\mathrm{m}}$, כ0 de profondeur, mais je les fais laire de $1^{\mathrm{m}}, 14$, ce qui est encore mieux. Pour planter du plant de 5 ans on donnera aux trous $0^{\mathrm{m}}, 50$ de côté et $0^{\mathrm{m}}, 25$ de profondeur. Eufin, pour planter dlu plant de 3 ans, on donnera aux trous de $0^{\mathrm{m}}, 27$ à $0^{\mathrm{m}}, 32$ de còté et $0^{\mathrm{m}}, 22$ de prófondeur. Un ouvrier peut, chez moi, faire cinq trous de $0^{\text {m }}, 50$ de côte et dix de $0^{\mathrm{m}}, 32$, pendant qu'il en ferait un de $1^{\mathrm{m}}, 14$. On trouvera, chap. Xl, art. II, tous les renseignemens qu'on peut désirer sur la plantation à temeure.

On peut, sous le climat de Paris, planter des sapins argentés dans des terres arables qui soient assez substauticlles, dans de belles futaies d'essence feuillue, dans des bois taillis de bonnt? qualité de cotto même essence, daus certaines terres ì jones marins, etc. Les sables maigres ne sont point propres à la culture du sapin ; les terres qui produisent spontanément la bruyère et le genêt ne lui conviennent ordinairement pas non plus. On peut le cultiver, avec plus ou moins de succès, dans des terres où croît spontanćment le jonc marin, selon la nature de ces turres; mais les jeunes sapins que l'on planterail au milieu de ces plantes pourraient diflicilement y prospérer, à en juger par ce que j’ai éprouvé. Je plantai des sapius parmi des joncs marins, situés sur une côte exposée au midi; ils restèrent plusieurs années saus pousser et allaient probablement périr, car ils étaient devenus jaunes, lorsque j’y semai en potets de la graine de pin maritime et de pin laricio. Le semis prospéra et au bout de quelques annces il étouffa presque entièrement les joncs marins; les sapins reprirent alors une belle couleur, puis une belle végétation, et ils luttent actuellement avec les pins. Il serait possible d'ailleurs que l'ombrage eût contribué aussi à leur rétablissement.

Delamarre dit, p. $356,3^{\circ}$ édit. de son Trailé pratique de la culture des pins: "Dans ma contrée, il n'existe de sapius du pays (sapins argentés) qu’autour "des haluitations, et les essais que j'en ai faits, dans mes landes et clairicres "d'anciens hois, m’ont donné à peine quelques sujês qui restent chétifs." " Les terrains sur lesquels M. Delamare avait fait ees essais pouvaient bien ue pas convenir au sapin argenté; mais, s'ils étaient bien garnis de joncs marins, l'oceupation seule du terrain par celte plante pouvait les empecher de prospérer. Les plantatious de sapins réussissent presque tonjours dans les belles futaies de bois feuillus et dans les taillis de bois feuillus dr bonne qualité, aninsi que jo l'ai dit plus latu; plus on moins bien selon la nature de ces terres, on prenant les précautions que je vais indiquer.

Si l'on veut crécr une futaie de sapins argentes sur un terrain où il existe un taillis; ou, pour parler plus exactement, si l'on veut substituer une futaic de sapins à ce taillis, de manière à le conserver jusqu'ì ce que les sapins „puissent domer des prodhits, on procédera ainsi qu'il suit : On plantera de jeumes satpins dans les clairières, s’il y en a ; entre les crepes, dans les endroits les plus clairs; sous les arbres qui ont étouffé te taillis, le plus loin possible du trone, quoique sous la gouttière de l'arbre, ainsi que la ualure nous en doune l'exemple. Mais comme lo hois fentllu pousse hien dans les tertains qui conviennent au sapin, les taillis yne l'on roudra transformer ansi anront ordinairement une 
belle végétation, "t l'on ne deval y planter que du plant de 3 ans on de żans an filus, parce qu’il réussit mieux à l'ombre que du plant plus îgé; dans les clairières on pourra planter du plant de 8 à 9 ans. Chez moi, on rst dans l'usage de couper les taillis tous les neuf ans, el des sipins plantés ainsi y réussissent bien; rhez un de mes voisins, qui les fail comper tous les dix ans, ils réussissent aussi; je ne saurais d'ailleurs dire combien d'années il faudrait conserver le taillis pour qu’il élouffìt le jeune plant que l’on aurait planté ånsi. On abattra les arbres sous lesquels on aura planté, aussitòt rue les sapins auront atteint la hauteur qu'a le taillis dans l'année oủ on le coupe.

Les sapins ne causent au taillis qu'un dommage insigniliant, pendant les premières années, mais leur végétation est alors fort lente et cela ne saurait êtro antrement. En effet, elle est languissante tant que le taillis les convre entièrement el ils finiraient par périr si, en conpant le taillis, on ne leur rendait de lat lumière 'f de l'espace; mais l'année qui suit l'exploitation, ils soufrent du passagge de l'ombre à une exposition entièrement découverte, puis leur végétation reprend de l'activité, et elle redevient de nouveau langnissante, si le taillis parvient de nouveau à les dominer. Ce n'est que lorsque les sapins dépassent le, maximum de hanteur auquel atteint be taillis, qu'ils commencent à pousser avec rapielité et régularité. Ils ont d’ailleurs eu aussi à soutenir sous torre une lutle contre les racines de ce taillis.

Les effets produits par cette plantation sur le taillis seront très-différens selon le nombre des sapins que l'on plantera : si l'on plante à 16 mètres à peu près èn tous sens, c'est-à-dire 40 sapins environ par hectare, et ce nombre sera plus que suffisant pour transformer par la suite le taillis en une sapinière, cette transformation sera très-lente. Les sapins commenceront ordinairement à domner du semis naturel de trente-cinq à quarante ans après leur plantation, mais ce semis ne sera nombreux el efficace que quinze ans plus tarl; et si le terrain convient anx sapins, au bout de cent à cent vingt ans après la plantation, ils s'en seront emparés. Jusqu'à environ soixante ans après la plantation, le revenu que l'on tirera du taillis n'éprouvera pas une grande diminution, pourvu que l'on ne laisse point, ou presque point, d'autres arbres de haute tige que ces $\mathbf{1 0}$ sapins par hectare. Ainsi le propriétaire qui aura fait cette plantation n’aura, pour ansi dire, rien perdu de son revenu, quelque longue qu'ait été sa carrière el il aura créé, pour ses petits-enfans, un capital très-élevé comparalivement à la valeur du terrain qu'occupera la sapinière.

Si l'on plante à 5 mètres, à peu près, en tout sens, on mettra cnviron 400 sapins par hectare et trente ans après la plantation, si l'on a conservé les 400 sapins par hectare, ces arbres commenceront à causer un grand dommage an taillis; vingt ans plus tard, ils l'auront réduit à l'état rabouĝ̣i, et quelques annéns plus tard, ils l'auront à peu près détruit. Mais si l'on veut crécr une futaie deslinée à être exploitée en jardinant ou par la méthode mixte, la sapinière devra être maintenue daus um lof chat, par les éclaireissiges, que les sapuns de tous les îges puissent y prospérer, walors le taillis souffer mais ne perit point. 
Si l'on rult, en transformant un taillis en sippinière, accólérer l'accroisso-

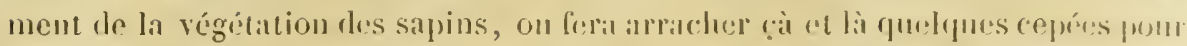
obtenir de petites clatrières, et l'on plantera, dans chacune de ces clairieres, quatre sapins, dont un dans l'emplacement mème de la cepée; celte précaution devient indispensable si le taillis se coupe dans un âge assez avancé pour qu'il doive faire périr, par son ombrage, le plant qu'on planterait ainsi.que je l’ai dit plus liant.

Pour créer une futaie de sapins argentés sur un terrain où il existe me futaie de bois feuillus, on y plantera du plant de sapin, en plus ou moins grande quantité, comme pour la plantation dans un bois taillis, et après avoir abattu le nombre d'arbres nécessaire pour lui procurer assez do lumière, si la futaie est très-sombre. S'il y a des clairières, ce sera là principalement qu'on plíntera, et il ne sera peut-être pas nécessaire d'abattre des arbres pour le moment; mais cula sera indispensable par la suite, si l'on veut que la sapinière preme tout l'aceroissement dont elle est susceptible. L'occupation du terrain par les sapins arrivera avant l'époque que j’ai indiquée précédemment, si l'on a soin de les protéger eldt: leur domner l'espace et la lumière qui leur sont nécessaires, à mesure fu’ils grandissent, en abaltant successivement les arbres de la futaie; car ils se trouveront alors dans la situation la plus favorable pour prospérer. Cette transformation d'une futaic de bois feuillus en une futaic de sapins argentés, est une des plus belles et des plus avantagenses opérations que l'on puisse entreprendre en sylviculture.

Pour créer une futaie de sapins argentés sur un terrain entièrement libre, le moyen qui concluit au meilleur résultat est rle faire, sur ce terrain, une pépi-

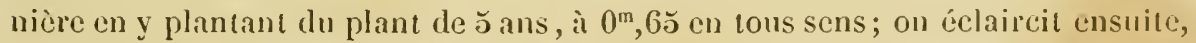
quand il est nécessaire, en ventant du plant, ou en le plantant atilleurs, on enlin en le coupant rez. terre. Mais cette manière de créer une futaie, en commencant par faire une pépinière, serait un moyen fort dispendieux, si l'on était réduit à faire de la bourrée avec les éclaircissages, et elte serait d'ailleurs difficilement praticable en grand, ì cause de la quantité de plant qu'il faudrait se procurer. J'ai vu près de cette belle sápinière de Raveton, clont j’ai déjà parlé page 41, une jeune sapinière, d'une étendue de 2 hectares 50 ares, qui n'était encore qu’à l'état de pépinière; on y avait planté à $0^{\mathrm{m}}, 65$, en tout sens, du plant de 5 ans qui avait été repiqué à deux ans et qui avait été ćlevé dlans une clairière de la sapinière; le plant provenant des éclaircissages était venclu ou planté à demeure.

Lorsqu'on ne commencera pas par faire une pépinière pour la transformer en sapinière (ce qui est un moyen exceptionnel), on plantera du plant de pépinière de 3 , de 5 ou de 8 à 9 ans au plus; on le plantera à plus ou moins de distance ce en employant du plant plus ou moins âgé dans les limites que j’ai indiquées, selon la dépense que l'on veut faire et selon que l'on veut que la sapinière marque: plus tót ou plus tard; mais on ne plantera point à plus de 4 mètres en tout sens.

Pour utiliser of peur oceuper plus promptement fe terrain, ef pour procurer

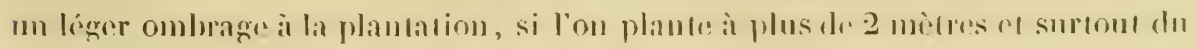


plant ayant moins de: 8 à 9 ans, on pourra, deux ans avant cetle plantation, planter très-clair du plant d'une espèce de bois convenant au sol et poussant promptement. On pourrait aussi, l'année qui précédera cette plantation, semer du pin maritime qui lère partout el qui a une végétation rapicle dans ses premières années : on couperait successivement le plant qui en résulterait rez terre i mesure que le sapin occuperait le terrain. Le pin laricio et le pin sylrestre pourraient rendre le même service, mais leur semis est un peu plus délicit ę ils ont un accroissement plus lent dans les premières années : ce sont d'ailleurs de leaux ét bons arbres qu'il faudrait non pas sacrifier au sapin, mais élever en concurrence ávec lui. La précautiou de se procurer de l'ombrage est particulièrement nécessaire si l'on n'il que du plant tiré d'une sapinière; car si c'est du plant de pépinière, il réussira très-bien sans cela, surtout si on Je fail hiner par un temps de lıâle, dans le courant des mois d'avril ou de mai qui sıivront la plantation.

J'ai indiqué, au commencement de cet article, quelle devait être la dimension les trous, sclon la force du plaut dont on fait usage; mais on peut aussi planter du plant do petite dimension, de 3 ans par exemple, dans des rigoles auxquelles on peut domner $0^{\text {nn }}, 32$ de large et que l'on peut fitire de main d'homme, ou avec la charrue, quand le terain et la situation le permettent. Je me contenterai de dire, à ce sujet, que des trous dont les cùtés auraient la largeur de la rigule me semblent ordinairement préférables, parce qu'on peut alors mieux disposer la terre sur les racines; et que cette plantation coùte moins qu'une plantation dans des rigoles faites de main d'homme, et peut-être aussi moins qu'une plantation dans des rigoles faites à la charrue, parce qu'il faut remplir ces rigoles. Ce dernier geure de plantation ne me parait d'ailleurs convenir que dans les terres meubles, comme celles des pépinières, et non dans les terres gazonnées ou couvertes de plantes. Les plantations sur les berges des fossés sont au contraire presque toujours avantageuses, quand ces berges sont assez fortes, et cest là qu'on doit planter lorsque les fossés ont été faits pour assainir des parties humides sur lesquelles le sapin n’aurait pu réussir sans cette précaution.

Toutes les plantations, dont je viens de parler, seront trop espacées, pendant un nombre plus on moins grand d'années, dépendànt de l'âge du plant que l'on aurat employé et de la distance à laıuelle on aura mis les plants les uns des autres; puis elles se trouveront trop serrées par la suite, même celles où les plants auraient été placés à 4 mètres en tout sens, si le terrain, ainsi que je le suppose, est favorable à la culture du sapin argenté; il faudra donc éclaircir, un peu plus tôt ou un peu plus tard. On verra, quand je parlerai de l'aménagement, de l'exploitation et de la reproduction, de quelle manière doivent être dirigís ces éclaircissages, selon le mode d'aménagement et d'exploitation que l'on se propose d'employer.

Je clois d'ailleurs conseiller aux personnes qui, sans s'inquiéter de la dépense, veulent créer le plus tôt possible une belle futaie de sapins argentés sur un terrain qui est libre, le planter serré; car la végétation du sapin ne devient magnifique qur lorsqu'il a couvert le terrain soul on conjointement avec d'autres 
arlores. Mais il lint ensuile élareir successivement, en compant rez lerre ces arbres, ou mème des sapins, aussitô qu’il sera nécessaire, el c’est à quoi les propriétaires ne se décident souvent qu’avec beaucoup dépépugnance : rien n’est pourtant plus utile, car, sans cela, il faut que les sapins les plus vigoureux étouffent les plus chétifs, et ils éprouvent alors du retarl dans leur végétation.

J'ai créć ainsi une pelite futaie de sapins argentés; j’avais planté des arlores de pépinière ì 2 mètres les uns les autres, en quinconce, et dims les intervalles j'avais mis du plant de $0^{\mathrm{m}}, 08$ i $0^{\mathrm{m}}, 10$ de haut, levé en motte, dans Jes allées de mon pare; ma plantation occupa ainsi le terrain plus promptement, et je me procurai en même temps du plant. Il ne mourut dans l’année qui suivit la plantation qu'un seul plant de pépinière, mais il mourut environ un sixième de celui qui avait été pris dans le parc.

Je dois déclarer d'ailleurs que ce qui se trouve consigné dans ce chapitre est priucipalement ce que j’ai remarqué en Normandie, e’est-à-dire sous le climaı le l’aris proprement dit; il est possible que cela ne soit pas entièrement applicable à ce qui se remarque dans d'autres climats. Je citerai, à ce sujet, ce que Dralet rapporte des lutaies de sapins argentés situées dans les Pyrénées.

Après avoir dit (1) que le chêne se rencontre très-rarement sur les montirgnes avec le sapin; que le premier occupe ordinairement l'exposition du midi, rt le second celle du nord, cet auteur ajoute: "Cependant il n'est pas vrai, comme l'ou! "répété divers écrivains, que le sapin est un arbre intolérant, qu'il fail périr l'antre "bois; el que dans les forêts de sapins, le sol ne produit ancune antre espèce de vérgé" taux. Le sapin est moins intolérant que le chêne de nos contrées méridionales : " tandis que celui-ci peuple exclusivement les forêts, le sapin ne dédaigne pas " le voisinage du bouleau, et il admet dans ses rangs l'orme, le tilleul et plu" sieurs autres espèces de bois blancs. Mais le hêtre est de tous les arbres, celui " qui s'approche le plus communément de la région des sapins. Quelquefois ils

"forment ensemble des massifs de futaie, comme dans les forêts d'Aygnes"bomnes, des Graras et des Fanges (Aude); dans une partie de celles du Jura el " dans la forêt d'Athas (Basses-P'yrénées). Le plus souvent ils se disputent le ter"rain et le plus fort fait périr l'autre. Quant aux arbrisscaux, il en est de plu" sieurs espèces qui cróissent au pied des sapins; les uns, tels que le genevrier " et le genêt, semblent y avoir été placés par la nature, ainsi que nous l'expli" querons dans la suite, pour favoriser la première croissance des jeunes sapius; " les autres, tels que le myrtil, le buis et le sureau, sont le fléau des sapi"nières........ Ce n'est point le sapin qui est intolérant sur les hautes monta"gues situées vers le nord; ce sont les frimas qui n'en permettent pas l'accès aux " arlores à feuilles. "Dans un autre ouvrage (2), Dralet dit: "Lorsque le sapin et "le hètre viennent à se disputer le terrain, toutes les chances sont défavorables

(1) Truité des forèts d'arbres résineis, p. 36.

2) Traité du hêtre el de son aménagement comparé ì celui du chéne el des arbres résincux, p. $13 i$ ol 131. 
"au sapjin.......... La propagation du sapin au détriment lu hẽtre ne ré" jouit que rarement les amis des forêts, tandis qu'ils sont, à chaque pas, attris"tés de la vue des lunestes conquêtes llu hètre."

Voilà ce que Dralet a remarqué dans les Pyrénécs; mais on conçoit que lorsque le sapin argenté se trouve dans d'autres circonstances, il peut en être autrement. Hartigo dit, page $10 a$ de son Instruction sur lá culture du bois à l'usage des forestiers: "On a remarqué, et l'expérience le prouve, que le bois rési"neux fait périr l'autre, et qu'il finit par demeurer seul dans les endroits où "ils croissent ensemble. "Cet auteur a en vue le sapin argenté, le sapin picéa et le pin sylvestre, puisque c'est dans les forêts du centre el du nord de l'Allemagne qu'il a fait ses observations. M. Mougeot dit, t. V, p. 316 du Nouveau Duhamel, en parlant des arbres résineux des Vosges : "Les sapins argentés "tendent à se répandre dans les forêts voisines, ou ils ne se remarquaient pas "auparavant, et l'on observe, par opposition, que d'autres espèces de bois, " comme les hêtres, les bouleaux, se jettent aussi dans certaines sapinières trop "éclaircies. "

En Normandie, le sapin argenté paraît intolérant dans les terrains qui lui conviennent; mais on le favorise en aménageant l'essence feuillue en taillis, et je n'ai d'ailleurs point assez de données pour émettre une opinion tranchée à ce sujet; on favorise aussi, dans cette province, le mélange du sapin argenté avec telle ou telle espèce de bois. Le hêtre y réussit sur les terrains où prospère le sapin; mais il réussit très-bien aussi sur des terrains siliceux qui ne conviennent point au sapin. Le taillis qui se trouve dans les sapinières de la Normandie est ordinairement du taillis mêlé dans lequel le chêne domine, et lorsqu'il s'y trouve du haut bois de l'essence l'euillue, ee sont ordinairement des chênes qui, sous ee climat, viennent à toutes les expositions; ces arbres ayant presque partout plus de valeur que les hêtres, on en favorise la reproduction. Dans ma sapinière, sauf des exceptions pour expériences ou pour ornement, je ne conserve que quelques baliveaux de chênes, de châtaigniers et de trembles. Dans la sapinière de Raveton, il y a un bois taillis d'essences mêlées où le chêne domine, et point d'autres lıuts bois avec le sapin, que des cliênes et des trembles. Je connais d'ailleurs des localités où le hêtre a plus de valeur que le chêne, parce qu'on l'emploie à la boissellerie, alors on favorise le hêtre; la main de l'homme empêche de distinguer la marche de la nature. Quant aux arbustes que l'on remarque dans les sapinières de la Normandie, ce sont: la ronce, l'épine noire, l'épine blanche, le houx, le framboisier, le néflier, le myrtil on airelle et même la bruyère, selon la nature des terrains; on n'y voil jamais, pour ainsi dire, le buis, le sureau et le genevrier qui dominent dans les șapinières des Pyrénées.

Dralet se trompe, lorsqu'il dit que les frimas ne permettent point l'accès du nord aux arbres à feuilles; le bouleau aequiert de plus belles dimensions dans le Norl que sous le climal de Paris, ainsi que je l'ai vu de mes yeux, pendant l'expédition de Russie; éest l’arbre qui s'approche le plus du pôlr; tr: hêtre et le rhêne supportent un rlimal plus rigoureux que le sapin argenté. 
Lat depense pour exículer les travaux que je viens de decrire, varie selon lo mole que l'on adopte: celui qui peut se proeurer, dans une sapinière, du plant de quelques pouces de haut, levé en motte, et qui n’en fail planter qu'une petite quanticé dans un bois taillis, ainsi que je l'ai indiqué; ou mieux encore qui y finit planter du plaut de pépinière de 3 à 5 ans, lera une faible dépense.

J'engage mes lecteurs à relire, à ce sujet, ce que j’ai dit, jag'e 21, de la créattion d'une lutaic de sapjus argenlés dans un bois laillis, par suile de la plantation qui y fut faite en 1762 , de quelques jeunes sapins, âtés de 3 à 6 ans, tirés d'une: sappinière. d'al lait la description de l'état dans lequel se trouvait celte jenne sapinière, lorsque jo: la visitai en 1840; elle n'avait jusqu'alors calusé que peu de dommage au revenu que le propriébilire tirait du taillis dans lequel elle se trouvait; les sapins qui y avaicnt domné naissance avaient élé plus nuisibles, mais ils u'étaient plus alor's qu'au nombre de trente et ils élaient tous de grosseur ì faire de la planche. Le plus gros avait $2^{\mathrm{m}}, 16$ de circonférence et $21^{\mathrm{m}}$, 4 ó de haut, le moins gros $1^{\mathrm{m}}, 50$ de circonférence el $19^{\text {m }}, 50$ de haut. J'évalue le prix de ces trente sapins ainsi qu'il suit: Je supposerai approximativement que ces sapins avaient terme moyen $1^{\mathrm{m}}, 62$ de circonférence el $1 /$ mètres de longueur propre à lat vente. Ils avaient dès lors à 7 mètres de hauteur une circonlérence moindre d'un quart environ (fu'à mn mètre, aiusi que ju l’ai remarqué dans ma sapinjère, c'est-ii-dire $1^{\mathrm{m}}, 22$ de circonférence. L'équarrissage des arbres de eette dimension est de $0^{\text {m }}, 30$ (1); chaque arlure contiendra donc $1^{\text {mit }}, 26$ cube. J'évalue le mètre cube de bois en grume de cette dimension, dans la localité que j'labite, à 31 fr. vendu en gros; ainsi chaque arbre vandra 39 fr. 6 c. el les trente arbres 1,171 fr. 80 . e. Celte somme est unc compensation du dommage que ces arbre's ont causé; et la sapinière à laquelle ils ont donné naissance produira, ainsi qu'on le verra, beaucoup plus que le taillis qu'elle va remplacer. J'ai planté aussi du plant de sapuin de 3 à 6 ans tiré de ma sapinière, dans des bois taillis; il en est mort sans doute, mais il en est resté une assez grande quantité qui prospère. Si, avant de flanter, on fait arracher quelques eepées pour former des clairières, la dépense sera plus élevéc; mais ee sera rarement un obstacle, lorsque l'on plinte principalement pour l'ornement.

La dépense est assez élevéc lorsque l'on plante du plant de pépinière d'au moins un mètre de haut, de manière à en garnir complètenent un terrain découvert. Voici approximativement quelle serait cette dépense dans le lieu que j’habite en plantant à 4 mètres en tout sens; on calculcra facilement consuite ce qu'il en conterait pour planter plus rapproclıé, ec qui serait bien prélérable.

Pour planter un hectare de terrain en sapins argentés à 4 mètres de distance les uns des autres, en tout sens, il faudra faire 62j trous carrés, de un mètre de

(1) L'usage de la localité que j'babite est de prendre le quart de lit circonférenee pour aroir l'iquarrissage, parce que l'on n'équarrit posint à vive arête. 
côté au moins et acheter 625 plants; il en coùtera environ 15 c. par trou (1), ou $93 \mathrm{fr}$. 75 c. pour les 625 trous, et l'on paierait au moins $40 \mathrm{c}$. chaque plant de sapin ou $250 \mathrm{fr}$. pour 625 plants; ainsi la plantation d'un hectare coûterait $343 \mathrm{fr}$. 75 c. Mais on ne trouve pas facilement du plant de sapin argenté chez les pépiniéristes, el il sera toujours avantageux d'avoir une pépinière chez soi, puisque l'on pourra alors arracher les arbres a vec soin et les planter immédiatement après les avoir arrachés; cela sera d’ailleurs fort économique.

En plaçant les sapins à 5 mètres les uns des autres, il n'en faudrait que $\mathbf{4 0 0}$ par hectare; il n'en coûterait que 220 fr. pour acheter le plant ct le planter. Enfin, si l'on ne plantait que tous̉ les 10 mètres, il ne faudrait que 100 plants par hectare, il en coûterait ร̌ $\mathrm{fr}$. et ces sapins se trouveraient ì une distance convenable pour bien couvrir le terrain de semis naturel, quand ils seront en âge d'en domner : il faut ajouter à ces dépenses celles qui résulteront des remplacemens pendant les années qui suivront la plantation, et celles qu'il faut faire pour garnir la partic du terrain qui reste libre avec une autre essence, quand on le peut, car cela est toujours utile.

La dépense pour créer une sapinière, en commençant par faire une pépinière, serait beaucoup plus forte: je ferai le calcul pour un hectare. Si l'on plante du plant de trois ans repiqué à $0^{\mathrm{m}}, 65$, en lous sens, il en faudra 22,500 ; il coùterait $15 \mathrm{fr}$. le mille, m'a-t-on dit, à Laigle, mais il coûte $40 \mathrm{fr}$. à Orléans, ce qui frrait 337 fr. 50 c. ou $900 \mathrm{fr}$; ; il faut ajouter $40 \mathrm{fr}$. pour deux labours et leux hersages; et enfin, les frais de plantation. On voit qu'on ne pourrait exécuter ee genre de plantation, avec économie, qu'en élevant du plant chez soi, et celi serait indispensable si l'on plantait plus d'un hectare, car, même pour cette étendue de terrain, on ne trouverait peut-être pas la quantité de plant nécessaire chez les pépiniéristes. Cette nanière de créer une sapinière est d'ailleurs celle qui procurera les plus beaux résultats, puisque l'on choisira les sapins que l'on conservera parmi un très-grand nombre.

En ne plantant qu'à un mètre de distance en tout sens, ce qui me paraît sufdisant, si l'on a principalement pour but la création d'une futaie, il ne faudrait que 10,000 plants par hectare; mais l'on devrait alors employer du plam de 5 ans. On ne doit d'ailleurs point perdre de vue que le sapin argenté, ainsi que tous les arlores à grandes dimensions, n’aequiert toute la foree de végétation dont il est susceptible que quand il a pris possession du terrain, ou lorsque ce terrain est occupé par lu bois et non par des plantes et des arbustes. Ainsi l'on voit qu'on ne peut mieux faire que de commencer par créer une pépinière et d'éclaircir ensuite snccessivement; mais que cela serait fort dispendieux, si l'on ne trouvait point ì se défaire du plant superflu, soit en le vendant, soit en l'employant a remplir les vides d'une sapinière. Aux évaluations de dépense que je viens de

(1) Chez moi, wù la terre est légère, il m'en coùte $15 \mathrm{e}$ par trou de 1 m, 1 í de côté el de 0 m, 50 de profondeur 
linire if faut ajouter la iépense qui résultera des remplacemens, pendant les années qui suivront la plantation.

Pour eréer une futaic de. sapins argentés au moyen du semis à demeure, il est indispensable de procurer à ce semis un ombrage ou un demi-ombrage sans lequel il ne pourrait rẹussir; cette opinion est généralement accréditée et a été reproduite par tous les auteurs qui ont traité de la culture du sapin argente. Je rapporterai à ee sujet ce qui fut dit au congrès agricole et forestier qui se réunit ì Stutgart en septenubre 1812 (1). Un garale général, dont le cantonnement était situć dans la Forêt-Noire, dit qu’il a vait fait exécuter, depuis 1836, des semis arlificiels cle sapin argenté dans des clairières de bois confiés à sa surveillance, sur une étendue de 83 hectares; quo Je terrain avait été préparé par bandes altermes; qu’il avait été employé quelquefois jusqu’à ă6 kilogrammes le graines ailées par' hectare; qu'il avait semé l'automne et le printemps, et qu’il avait bien réussi, mais encore micux l'autome que le printcmps. Il ajouta que les semis de sapin argenté prospèrent particulièrement dans un sol frais à l'exposition du norl, que sur un sol entièrement mauvais ils ne réussissent point, et qu'ils exigent du couvert ou tout au moins de l'ombrage. Jes forestiers du Wurtemberg soulinrent, au contraire, que les semis de sapin pouvaient se passer d'ombrage.

Je pense que le cas général est la nécessité de l’ombrage ou d'un demi-ombrage; mais je pense aussi que dans les parties élevées des montagnes, particulièrement à l'exposition du nord, si la terre est facilement pénétrable aux racines du jeune plant, le semis de sapin argenté peut réussir sans ombrage; il me semble entin que, sous le climat de Paris, on trouverait bien difficilement cette rúunion de circonstances exceptionnelles. Je citerai deux faits à l'appui de mon opinion.

En 1837, je pris un liectare de terre dans un défrichement de joncs marins (d'ajoncs) mèlés de bruyère, mis en bon état de culture depuis quatre ans: Ia terre y était silico-argileuse; un tiers tle ce terrain était de très-mauvaise qualité et contenait une assez grande quantité de pierres siliceuses de différentes grosscurs, pour cacher presfue entiòremcnt la terre végétale; le reste était d'assez home qualité, et les arbres dont j’allais faire un semis avaient très-bien réussi dins des terrains semblables. La terre ayaut été mise en bon étit par un labour et des hersages, fut partagée en plusieurs parties dans chacune desquelles un sema, le $1^{\text {er }}$ mai 1837 , des graines des espèces d'arbres résineux dont je m’oceupe spécialement dans ce Traité; seules ou mélangées, ainsi que je vais le dire, puis on domm un léger conp de herse pour enterrer les graines.

On sema de la grane de pin maritime et de la graine de pin laricio mêlées dans la partic du terrain qui était la plus couverte de pierres, avec l'iutention

(1) Les membres de la section d'économie furestière étaient au nombre de 83 , tous allemands, excepté M. Parade, directeur de l'Eçle royale fortstière de Nancy, qui prit part aux travaux de celte section et en a rendu compte dans les Annales forestic̀res de juin 18 \$3; c'est dans son article que j'ai puise ce que je rapporte relativement au sapin argenté. 
S.IPIN ARGENTE.

de sacritier le pin maritime au pin laricio; il leva assez de plant pour occuper le terrain dès la seconde année. On sema de la graine de pin laricio seule dans la partie où le terrain était le meilleur; il ne leva pas, à beaucoup près, assez de plant pour occuper le sol; car il est encore gazonné actuellement (1844). On sema de la graine de pin sylvestre, mêlée avee de la graine de mélèze, espérant que le semis du premier protégerait quelques plants du semis du second; il leva une quantité de pin sylvestre assez grande pour occuper le terrain dès la seconde année, peu de mélèzes, et il n'en est resté que deux, quoiqu'on les ait protégés. Les sapins argentés el les sapins picéas furent semés à part dans la meilleure terre, il en leva un assez bon nombre, mais aujourd'hui (1844), il n'en reste pas un seul; cependant des plantations de ces arbres réussissent bien dans ce terrain. Il leva des pins du lord Weymouth, qui avaient été semés à jart, à côté des sapins, mais en petit nombre, et pourtant il en reste actuellement assez pour occuper le terrain dans quelques années; je présume que la graine n’était pas aussi bonne que celle des autres pins; ils ont d'ailleurs été retardés, parce que le sol s'est gazomné. Il en fut absolument de même du pin noir d'Autriche.

Je tiens de M. de Boisdliyver, inspecteur des forêts de la couronne, qui a fait exécuter des repeuplemens très-considérables en essences résineuses, dans la forêt de Fontainebleau, que des semis de graines mêlées de sapins argentés, de pin maritime et de pin sylvestre sur labour, et par conséquent sans abri, ont réussi pour les deux espèces de pins, et ont échoné pour le sapin argenté, dont tous les plants ont fini par périr. Le semis de la graine de picéa exécuté dans les mêmes conditions a réussi, mais le plant qui avait déjà 5 ou 6 ans en 1843, a eu une croissance fort lente; il faut d'ailleurs remarquer que le terrain sur lequel ont été exécutés ces semis est sablonneux, peu substantiel, ne convient par couséquent point du tout at sapin argenté, et ne convient probablement guère non plus au sapin picéa.

Les travaux préparatoires pour transformer un taillis en une sapinière par la voie du semis, sont les mêmes que ceux que je viens de décrire pour cette transformation en employant la plantation, avec la diffêrence qu'au lieu de trous on fera des potets dans lesquels on semera. On donne le nom de potets à de petites surfaces carrées ou circulaires que l'on a lait cultiver avec soin. La terre de ces potets doit être rendue meuble, et l'on doit conserver à la surface celie qui s’y trouve, parce qu'elle est li plus fertile. Ces potets doivent être de uiveau avec le terrain environnant, bombés ou creusés au milieu, selon la situation où ils se trouvent, la mature des terres et l'espèce de plantes qui convrent le terrain. Des polets carrés ou circulaires de $0^{\mathrm{m}}, 65$ de côté on de diamètre sont suffisans, lorsque le terrain est courert de gazon, de mousse ou de plantes semblables; mais lorsqu'il est garni de plantes qui peuvent en peu de temps convir les potets et occuper le terrain par leurs racines, comme par exemple, des jones marins, il faut les faire plus grands. Ordinairement il suffit alors de leur donnır un mètr. de côté ou de diamètre, selon qu'vu les fait carrés ou rireulinires. 
Après s'ère proeuré de bome graine, ce qui n’est pats toujours sans diflliculté, ainsi qu'on l'a vu, on sèmera, dans chacun de ees potets, du 15 mars au $i^{\text {er }}$ mai, une vingtaine de graines, paree qu'il y en a toujours beaucoup de mauvaises et qu’une partie de ce qui.lève périt par diverses causes; on enterrera très-légèrement la graine au moyen d'un rûteau, ou ce qui serait chcore mieux, on la couvrira d'un peu de terre très-meuble, par exemple de terreau de feuilles pris sous le bois, et celui que l'on trouve sous les sapins est le meilleur. Il est surtout prélérable de convrir ainsi la graine lorsque le terrain des potets est plus bas que lo terrain environnant, ear alors les feuilles du taillis qui couvrent ces potets pendant l'hiver peuvent étoufler le semis de sapin; dans les semis que j’ai fait exécuter ainsi, on tenait le milieu des potets plus élevé que le sol. Si l'ombrage est nécessaire au semis de sapin argenté exécuté ainsi à demeure, un ombrage trop épais lui serait nuisible ou le ferait périr; on prendra done à ce sujet les mêmes précautions que j’ai prescrites en parlant de la formation d'une sapinière par la plantation.

On pourrait sans doute, initant la nature, semer en automne, aussitôt après avoir récolté les graines; mais alors le plant lèverait plutòt au printemups, et serait par conséquent beaucoup plus exposé à ctre détruit par les gelées lardires; il pourrait arriver aussi que des animaux on des insectes mangeassent les graines pendant l'hiver.

Dralet (1) a fitit pratiquer, dans les forêts des Pyrénées, un mode de semis qui a de l'analogie avec celui que je viens de décrire et qui a parfaitement réussi : "On enlève, dit-il, à de eertaines distances des mottes de gazon de 8 à 10 pouces " en carré; on travaille avec un petit outil la terre ainsi découverte, on y répand " quatre à einq faines ou une pareille quantité de graines d'arbres résineux, on " les recouvre légèrement avec les doigts, ct on replace la motte de gazon ì côtć " de ce semis pour lui servir d'abri. C'est ainsi que, depuis trois ans, je fais em"ployer dans les Pyrénées les graines de pin laricio, de mélèze et d'épicéa qui " m’ont été procurées par l'administration. Je viens de visiter ces semis, qui "s'étendent sur plus de 100 hectares dans diverses forêts des départemens de " l'Aude et de l'Ariége, et j’ai trouvé qu'ils ont parfaitement réussi. "

L'administration des forèts a fiat exécuter en grand dans les Vosges, depuis 1820 jusqu'en 1841 , des semis de sapin argenté, de sapin picéa, de pin sylvestre el de mélèze, et presque tous dans les parties élevées de ces montagnes (2). Les semis de sapin argenté et de sapin picéa ont été exécutés sur les points les plus élevés, ou ils réussissaient mieux que les semis des deux dernières espèces, contrairement à ce qui se remarque dans les $\Lambda$ lpes pour le mélèze.

On semait par sillons el par bandes alternes horizontales, sur les llancs des montagnes à pentes rapides; sur les pentes peu rapides, et sur les plateatux, on employait te procédé suivant :

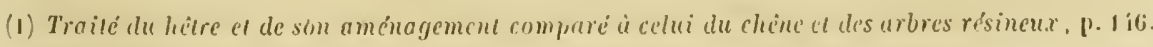

(2) Annales forestives, siptembere 1si3, 11. Si6. 
On préparait le terrain par potets carrés, ayant $0^{\mathrm{m}}, 65$ de còté et disposés en échiquier; on coupait perpendiculairement et assez profondément le gazon sur les quatre faces, et on le retournait sur les cases vides, de sorte que les cases cultivées, alternant avec les cases vides, se trouvaient plus basses que ces dernières de la double épaisseur du gazon. Il en résultait que le semis s'exécutait dans des potets assez profonds, dont les parois abritaient les plantes à une certaine distance, de quelque côté que vinssent les rayons du soleil; on y trouvait aussi cet avantage que le terrain s'y conservait plus frais : ces semis ont parfaitement réussi.

On remarquera que ce genre de semis est fort dispendieux, puisqu'il faut faire plus de 6,000 trous par hectare et employer par conséquent beancoup de graine; que la meilleure terre est retirée des potets et reste inoccupée, et que cette disposition des potets ne conviendrait point dans des terrains qui seraient humiles ou dont le sous-sol serait argileux.

Un moyen très-simple et très-économique de se procurer de l'ombrage pour le semis de sapin argenté en potets, est de semer de la graine de pin maritime dans les potets mêmes où l’on a semé le sapin argenté, parce que le pin maritime a une végélation beaucoup plus rapide que le sapin. On ne conserve que quatre on cinq pins maritimes par potet au printemps de la secondeannée et autant desapins; on ne conserve que deux ou trois pins maritimes au printemps de la troisième année, et qu'un seul au printemps de la quatrième; il ne doit rester alors que deux ou trois sapins par potet. On supprime enfun le pin maritime quand on juge que les sapins n'ont plus besoin d'ombrage. J'ai vu réussir très-bien ce moyen pour le sapin, le picéa, et même le mélèze, dans des terres qui laissaient très-facilement passer l'eau : on doit, lorsqu'on s'en sert, employer des potets d'un mètre de diamètre.

Si l'on veut semer un terrain libre, situé en plaine ou à peu près, on y plantera d'abord, arec les soins convenables et en lignes du levant au couchant, des rangées de plant d'essence feuillue, ayant la croissance la plus prompte dins le sol ou l'on doit faire le semis de sapin argenté; ce semis ne s'exécutera que lorsque les hois feuillus commenceront à procurer de l'ombrage. Un semis de pins maritimes pourrait aussi remplir ce but; et, dans quelques localités, on obtiendrait un abri suffisant avec du genêt et même avec des topinambours, dont on conserverait les tiges. Dans les terrains en pentes très-rapides, les bois destinés à servir d'alıri seront plantés par lignes horizontales.

Les rangées de bois destinées à servir d'abri seront plantées ì 3 mètres au plus les unes des autres en terrain de plaine, et les potets seront placés en quinconce, ì 3 mètres les uns des autres, en tout sens, de milieu en milieu; ils seront placés près et à l'ombre de ces rangées. En terrain de montagne, les lignes seront plus ou moins éloignées les unes des autres selon la pente. A cette distance, les sapins étoufferont, par la suite, le bois destiné d'aborl à les ombragers, et cela arrivera plus tôt si les potets sont plus rapprochés, ce qui serait plus avantigeux. Pour qu'ils y parviennent plus ficcilement at pour favorisor leur végétation, on recéperä 
ces bois ou l'on éclaircira, si c'est du pin maritime, fuand on s'apercevra qu'ils muisent au sapin par un trop épais ombrage. Sans cetle précaution, il y aurait des essences telles que le hêtre, le chêne el le châtitignier qui lui disputeraient le terrain. On pourra laisser quelques baliveaux de ces essences, s'il y en a de bien venans, et si leur bois a de la valeur, mais en petite quantité.

Au lieu de linire des potets, on ponra labourer des bandes de terre entre les alris, que je supposerai alors à 4 mètres ele distance; on hersera, puis on sèmera ì la volée, et l'on hersera, après le semis, avec une bourrée d'épine, ou l'on se contentera de faire pisser un rouleau pour appuyer la graine contre la terre. I.es graines qui sont trop enterrées ne lèvent point, celles qui le sont pen on qui ne le sont pas du tout lèvent bien dans une terre qui a été mise en culture. Il faudra semer un peu de graine dans les bandes mêmes destinées à servir d'abri; car il en lèvera quelques-unes, et ce seront peut-être celles qui réussiront le mieux. Je n'ai point pratiqué ce genre de semis, ainsi je ne pnis dire au juste combien il faudrait de graine par hectare; mais je présume qu'il en faudrait bien 15 hilogrammes, dont 3 kilogrammes dans les aloris.

Lorsque l'on crécri par la voie du semis une sapinière destince à être exploitée $r n$ jardinant, on plantera en même temps quelques silpins âgés de 15 ans, s'il est possible, et avec le plus grand soin; ce seront par la suite des portegritines qui donneront du semis naturel quinze ans plutôt que les sapins provenant de semis.

Les soins à prendre de ces semis sont peu dispendieux; mais on devra faire semer de nouveau el tous les ans de la graine dans les potets oì il ne se trouverait pas de plant, jusqu'ì ce qu'ils en contiennent tous. Loin qu'il y ait de l'inconvénient à ce qu'il se trouve plusieurs plants dans chaque potet, cela sera avantageux, s'ils ne sont pas trop nombreux, parce que l'on pourra faire un ehoix; d'ailleurs, il en périt beaucoup; souvent des insectes détruisent tout. Quatre ans après le semis, on ne laissera que trois ou quatre plants par potet; on coupera les autres avec la serpette; deux ans plus tard, on n'en laissera que deux ou trois; et, enlin, quand ils auront 8 ans, on n'en laissera qu'un; néanmoins, si dleux plants étaient également heaux, on pourrait les laisser par exception, car (leux sapins qui se touchent peuvent atteindre à de belles dimensions; on pourrait dailleurs couper le moins beau lorsqu'ils seraient assez gros pour en laire du chevron. Pendant les deux ou trois années qui suivront le semis dans une futaic ou dans un taillis, on fera passer un ouvrier, portcur d'un râteau de fer, après la chute complète des feuilles, pour retirer celles qui couvriraient des potets de manière à étouffer le plant. Si le plant se trouvait trop ombragé, on abattrail des arbres dans la futaie; on couperait ou l'on déracinerait des cepées, ou l'on couperait des branches au croissant, de manière à lui procurer assez de lumière et d'espace. On prendra des soins analogues à ceux que je viens de décrire pour le semis par handes.

La dépense pour le semis en potets sera de 2 à 3 fr., selon la nature du terrain, pour faire 100 potets carrós de $0^{\mathrm{m}}$, fó de côté, en les faisant faire par dos femmes. 
J'alopterai $2 \mathrm{fr}$. 50 c. pour prix moyen, et con supposant les potets à 1 mètres les uns des autres, de milieu en milieu, il faudra 625 potets par hectare, qui coûtcront $15 \mathrm{fr} .60 \mathrm{c}$; ; et, à raison de 20 graines par potet, il en faudra 12,500 pour les semer tous, c'est-à-dire moins d'un kilogramme, puisque chaque kilogramme de graine nettoyée en contient 17,400 environ; mais j'engage à y cmployer un kilogramme de graine, qui coûte orlinairement 3 fr. à Paris. J'estime à un jour le temps qu'il faudra à deux hommes pour semer lesं 625 potets, en enterrant la graine au râteau, s'il n'y a point d'embarras pour passer d'un potet au suivant et j'évaluerai ces deux journées à $3 \mathrm{fr}$.; ainsi il en contera en totalité environ $23 \mathrm{fr}$. Si l'on fait faire des potets circulaires d'un mètre de diamètre, ils coûteront un tiers plus cher. Dans un terrain qui était primitivement libre, les potets étant à 3 mètres les uns des autres, en tout sens, il y en aura 1,089, et la dépense s'élèvera en totalité à environ 41 lir. : il faut ajouter ì cette dépense la dépense préparatoire de la plantation des bandes de bois, de genêts ou de topinambours, destinés à donner l'ombrage nécessaire. Elle sera différente sclon les localités et la nature des abris, et l'on n'éprouvera point de difficultés pour l'évaluer. La dépense pour l'exécution du semis par bandes, tel que je l'ai décril, sera de 45 fr. pour 15 kilogrammes de graine, de 16 fr. pour le labour et les hersages, et de $3 \mathrm{fr}$. pour semer; en totalité, $61 \mathrm{fr}$., non compris la dépense préparatoire de la plantation des bandes pour procurer au scmis l'ombrage nécessaire.

Dans les pays où domine le sappin argenté, on a un moyen économique de repeupler de cette essence les terrains déboisés voisins des sapinières; e’est d'y créer des pinières, car aussitôt qu'elles commencent à ombrager le sol, il y lève du semis naturel de sapin : cela est arrivé sur les montagnes des Vosges, dans les endroits où l'on avait créé des pinières dans le voisinage des sapinières, et l'on a remarqué que la graine du sapin avait été quelquefois trinsportée à de grandes distances. En faisant porter les éclaircissages sur les pins, on obtiendra une sapinière ou une futaie mêlée, s'il n'y a pas assez de sapins. 11 in est de même des taillis de bois feuillus voisins des sapinières, que l'on coupe assez souvent pour que le semis naturel de sapin n’y soit pas étouffé; ces taillis linissent par se transformer en sapinières. Tout ce que je viens de dire ne s'applique d'ailleurs évidemment qu’à un terrain qui convienne au sapin argenté.

On peut semer de la graine de sapin à la volée dans un taillis ou dans une futaie, en initant la nature, et il lèvera quelques graines; mais pour garnir ainsi le terrain d'une quantité sulfisante de plant, il faudrait semer beaucoup de graine. L'époque la plus favorable pour somer ainsi, dans un taillis, est celle où ou le coupe; on doit y semer la graine l'automme, aussitot qu'on se l'est procurée; les ouvriers l'enterent ou la loulent contre terre en piétinant le terrain, pendant l'exploitation, et il en lève alors beaucoup plus. La vidange de la coupe doit être terminće dix jours avant l'époque où peuvent lever les premières graines, c'est-à-dire dans la première quinzaine de mars, sous le climat de Paris. Si l'on rent favoriser la prospérité de ces semis, on doit faire des éclairr.issages, ainsi qure jo l'ai dit, s'il est néressaire. Il y a d’ailleurs des terrains où 
res sortes de semis ne pourritent reussir, paree que: l'herle y pousse si abondamment, après qu'on y a c'oupé le bois, qu'elle étouffe tout le jeune plant; quelques-uns de ces plants peuvent pourtamt échapper sous les ronces, d'autres sous les cepées où il y a moins d'herle; mais ils sont alors exposés à être étouflés sous les feuilles mortes ou par l'ombrage rle la cepée.

J’ai vu des semis exéculés ainsi que je viens de le dire, qui avaient asse\% bien réussi : peut-ètre serait-il prélérable de ne semer que la scconde année qui suivra l'exploitation paree que le plant aurait un peu plus d'ombrage; e'est ce que j’ai r'ssayé ol ce serà avee suerès, ju crois. J'ai fatil semer à la voléc, le 16 février 1813, dans un bois taillis qui avait été coupé pendaut l'hiver de 18111812, de la graine de sapin argenté sans autre précaution que de faire donner quelques coups de rîteau dans les endroits les plus déconverts, par deux onvriers qui suivaient le semeur. On a commencé à voir quelques plants, provenant de cette graine, le 22 avril, et il en a levé une quantité suffisante, aussi bien daus les endroits où l'on n'avait point donné de coups de râteau que dans ceux où l'on en avait donné; le plant a lonne apparence, j'espère qu'il prospèrera. J'ai fail somer aussi de la même graine, lo $1^{\text {er }}$ et le 14 mars 18,13, dans l'autres bois plus âgés, également à la volée, et il a levé du plant; mais je crains qu'il ne soil étonffé par le taillis ou par les feuilles mortes, du moins en partic.

Baudrillart dome, d'après Iartig (1), un tableau de la quantité de graines de différentes espèces d'arbres que l'on doit employer pour semer en plein un heclare; an nombre de ces espèces se tronve le sapin argenté. Il dit que, en terrain fivorable, il faut, pour semer un hectare de cette espice d'arlore, 72 kilog. de graine avec ses ailes, on 48 kilog. de graine sans ailes, et que dans un terrain qui n'est point favorable il faut 96 kilog. de graine avee ses ailes, ou 66 kilog. de graine sans ailes. Ces renseignemens élant tirés d'un ouvrage qui n’a point élé traduit, je ne puis savoir comment IIartig prescrit d'exécuter ce semis en plein qui ne peut réussir sans abri.

Colla preserit d'exécuter le semis de sapin argenté ainsi qu’il suil (2) : Les "semis de sapin argenté laits sans aucun abri ne réussissent presque janais, " dit-il, et ils viemnent à l'état libre encore plus difficilement que les hètres. D Ainsi, lorsqu'on veut faire un semis de cette essence dlans un lieu oì il n'existe "point d'atbres, il faut le couvrir avec soin de beancoup de branches d'athres ") résineux, et renouveler celles-ci l'annéc suivante : on laisse ces branches "pourrir sur place. "Cet auteur dit qu'il faut employer, par hectare, pour l'exécution du semis (3) en plein, 73 kil. $400 \mathrm{gr}$. de graine avec les ailes, ou $57 \mathrm{kil} .400 \mathrm{gr}$. saus les ailes. Cette évaluation se trouvaut dans un tableau à la tin de l'ouvrage, j'ignore s'il appelle semis en plein colui qu'il décril dans le pas-

(1) Diclionnaire des eaux el forèts, i. $11, p .820$.

(2) Traili de culture forestière, p. 273.

(3) Traité de cullure forestière, p. 3ii. 
sage que je viens de reprouluire, mais je le présume, celte désignation ne se trouvant point dans son ouvrage ailleurs qu'en tête du tableau. On doit croire à la bonté d'un procédé dlonné par un forestier d'une aussi grande réputation que Cotta, mais je ne l'ai pratiqué qu'en petit et en 1813 seulement. Je puis donc dire seulenent que le plant a bien levé, qu'il avait boune apparence à la fin de l’année 1813 et qu'il en restait encore assez à l'automne de $\mathbf{1 8 1 4 .}$

Baudrillạt rapporte, d'après Hartig (1), que ce forestier " voulant mettre en " essence de sapin argenté de mauvais cantons de bois à feuilles, á éclairci légè" rement ces cantons, y a fait semer des graines de sâpins, puis a fait remuer la "surface du sol qui était encore converte de feuilles. Les semis ainsi abrités et " recouverts par les feuilles mortes et un peu de terre ont levé parfaitement; " et au moyen d'une ćclaircie faite trois ou quatre ans après, parmi les bois à " feuilles et plus tard en les enlevant complétement, ils ont formé un très-heau "bois d'essence pure de sapin. "

"Les semis de sapin argenté, soit en plaine, soit sur les montagnes, dit "Burgselorf (2), réussissent très-bien dans les terrains de bonne qualité, fermes, n frais, pierreux, couverts de terre régétale, exposés au nord at dans une si"Ltuation fraiche et ombragée... On se contente de gratter la surface du terrain " et de répandre la semence sans l'enterrer; il en faut 31 kilogrammes par hec" tare. "Les conditions exigées par Burgsdorf, pour la bonne réussile d'un semis de sapin, ne sont pas faciles à réunir.

Il y a des terrains oủ le semis de sapin ne peut prospérer, quoique ces terrains soient d’ailleurs favorables à la végétalion du sapin; tels sont, par exemple, ceux que soulèvent les gelées, parce que le jeune plant y esı déchaussé et périt; on est alors contraint d'employer la plantation. Le semis est d'ailleurs un moyen long et incertain de créer une sapinière du moins sous le climat de Paris, tantlis que par la plantation on réussit toujours, que le terrain soit farorable ou non à la réussite du semis.

Je dois, avant de terminer cet article, faire une olseirvation pour le cas ou l'on destinerait la sapinière nouvellement créée à être exploitéc en jardinant. Si elle résulte du semis naturel de quelques sapins argentés qui avaient été planlés dans un taillis, ainsi que j’en ai cité un exemple, page 24, elle contiendra des sapins de différens âges, pourvu que les sapins-mères aient élé conservés assez longtemps. Mais si elle a élé créée par le semis artiticiel ou la plantation, tous les arlsres qu'elle contient seront à peu près du même âge, jusqu'à soixante ans qu'ils commeneeront à tonner abondamment du semis naturel efficace; c'està-dire qu'ils ne différeront d'âge que de cinq ans, par exemple, si l'on a ressomé ou replanté pour remplacement pendant cinq ans. Il faulra donc, si l'on reut que la sapinière soit meubléc de sapins de différens âges, lorsque commencera, à proprement parler, l'exploitation en jardinant, semer ou plauter ì cing ou six

(1) Diclionnaire des caux et foréts, 1. 11, p. :39.

2) Nouceau Manuel forestier, 1. 11, P. 238. 
reprises en commençant lorsque la sapinière aura quinze ans, et continuant jusqu'ì ce qu'elle ait quarante ans. On plantera dans les endroits clairs, s'il y en a, ou que l'on éclaircira s'il n'y en a pas; le mieux serait alors de planter du plant de quatre à cinq ans élevé en pépinière.

VIII. Aminaguent, explotration et meprodection (Voy.p. 13.) - ll y a cinq modes d'exploitation des futaies de sapins argentés, modes qui doivent être accompagnés de soins relatif's à l'aménagement et à la reproduction : $1^{\circ}$ en jarrdinant; $2^{\circ}$ par coupes rases; $3^{\circ}$ par roupes rases par bandes étroites; $4^{\circ}$ par éclaircies; $5^{\prime \prime}$ par une méthode qui tient des deux premières, et que par cette raison j’appellerai méthode mixte. Je décrirai ces cinc modes d'exploitation dans l'ordre où je viens de les nommer; mats d'abord je vais m'occuper de ce qui leur est également applicable à tous.

Toutes les futaies doirent être percées de chemins d'exploitation, en ligne droite autant que cela est possible. Si la futaie est petite, il suffira d'avoir des chemins de 5 mètres de large en leur donnant en quelques endroits la largeur nécessaire pour le passage de deux voitures chargées; on conservera, en outre, quelques places circulaires à l’intersection des chemnins. Si l'étendue de la futaie le rend nécessaire, on tracera aussi un ou plusieurs chemins de 8 mètres de large, sur lesquels deux voitures clıargées puissent se croiser facilement; ils ne seront pas bordés de fossés à moins qu’il n’y ait nécessité. Tous ces chemins, dont on ne peut d'ailleurs se passer, seront très-utiles à la futaie, parce qu'ils y introduiront de la lumière et du soleil, el qu'ils serviront au renouvellement de l'air qui alimente les arbres par leurs feuilles. Lorsqu'on crée une fulaie, e'est par le tracé de ces chemins que l'on commence.

Les allées tracées dans les pares, devant les habitations, doivent aroir une largeur qui dépend de leur longueur el de l'étendue de la façade devant laquelle elles se tronvent. Lorsqu'on reut créer une allée de sapins argentés, on les plante d'abord à 2 mètres de distance les uns des autres, et lorsqu'ils ont atteint une grosseur qui permette de faire de chacun de ces arbres de lá solive et des cherrons, on en abat un sur deux, et ils se trouvent à 4 mètres. A cette distance, et peu d'années après ce dédoublement, les branches se joignent bientòt el l'allée se trouve bordée de deux murailles de verdure de la plus grande beauté.

Toutes les futaies de sapins argentés doivent être assainies arec soin, dans les parties humides, par des fossés pour donner l'écoulement aux eaux; par des mares ou de très-larges fossés en croix, quand il ne sera pas possible de donner de l'écoulement aux eaux. Lorsqu'on crée une futaie, ce travail s'exécute en même temps que le tracé des chemins.

Il est on ne peut plus important de débarrasser les futaies de sapins argentés de tous les arbres morts, pourris à l'intérieur, dépérissans, ayant des chancres on des maladies, brisés on déformés de manière à ne pouroir jamais acquérir unc grande valour; molin, des arbers sur le retour, car ce soml ces arbres sur 
lesquils on roit paraitre d'alord les insectes. Cela est facile pour tout ce qui est apparent, et est an contraire souvent fort difficile et même quelquefois impossible lorsque ces arbres sont altaqués de la pourriture à l'intérieur' j'entrerai dans quelques détails à ce sujet quand je parlerai des maladies du sapin argenté.

Les troncs des sapins argentés du même âge qui se trourent dans des situations semblables, sont, à une très-petite différence près, des solides semblables. Ainsi, des sapins qui ont crù dans le même sol et à la mème exposition, qui se trourent dans un massif de futaie à l'état serré, qui ont à peu près la même hauteur, et qui ont perdu leurs branches inférieures à peu près dans le mème rapport relativement à leur lauteur; des sapins qui se trourent dans ces conditions, présenteront sensiblement le même rapport entre leur circonférence à 1 mètre du sol et leur circonférence à 7 mètres, par exemple. Si ces sapins, au lieu d'avoir crù à l'état serré, ont crù isolés, si ce sont, par exemple, des arbres d'allée, ce rapport sera différent, mais il sera aussi à peu près le même pour chacun d'eux. Cette observation conduit à trouver avec une exactitude suffisante la solidité des arbres sur pied, et par conséquent à en estimer la valeur. Je ne puis mieux faire pour expliquer ce procédé que de raconter comment je l'ai. mis en pratique dans ces dernières années.

Dans ma sapinière, les sapins argentés ne dépassaient guère alors 20 mètres de hauteur, du sol à la cime, et ils avaient de 14 à 15 mètres de longueur propre à la rente. Je fis mesurer sur dix-lunit sapins pris dans un massif à l'état serré, la hauteur totale, la lauteur propre à la vente, la circonférence à 1 mètre au dessus du sol et la circonférence à 7 mètres, et je dressai le tableau suivant:

\begin{tabular}{|c|c|c|c|c|c|}
\hline Numeros. & $\begin{array}{l}\text { llauleur } \\
\text { tolale de } \\
\text { l'arbre. }\end{array}$ & $\begin{array}{l}\text { Hauleur } \\
\text { propre } \\
\text { à la venle. }\end{array}$ & $\begin{array}{l}\text { Circonference } \\
\text { a } 1 \text { mètre } \\
\text { du sol. }\end{array}$ & $\begin{array}{l}\text { Circonférence } \\
\text { à } 7 \text { métres } \\
\text { du sol. }\end{array}$ & OBSERVAT1ONS. \\
\hline $\begin{array}{r}1 \\
2 \\
3 \\
4 \\
5 \\
6 \\
7 \\
8 \\
9 \\
10 \\
11 \\
12 \\
13 \\
14 \\
15 \\
16 \\
17 \\
18\end{array}$ & $\begin{array}{l}\text { m. } \\
18,00 \\
19,50 \\
19,00 \\
18,00 \\
19,50 \\
19,70 \\
19,00 \\
17,00 \\
17,00 \\
17,40 \\
17,45 \\
20,00 \\
20,00 \\
19,50 \\
19,00 \\
17,00 \\
20,30 \\
19,00\end{array}$ & $\begin{array}{l}\text { m. } \\
13,00 \\
14,50 \\
14,00 \\
14,00 \\
14,50 \\
15,00 \\
14,00 \\
13,00 \\
14,00 \\
14,00 \\
14,00 \\
15,00 \\
15,00 \\
14,00 \\
14,50 \\
12,50 \\
15,00 \\
14,00\end{array}$ & $\begin{array}{l}\mathrm{m} . \\
1,33 \\
1,50 \\
1,19 \\
1,35 \\
1,25 \\
1,28 \\
1,20 \\
1,20 \\
1,23 \\
1,23 \\
1,25 \\
1,76 \\
1,75 \\
1,37 \\
1,38 \\
1,1 \pm \\
1,45 \\
1,27\end{array}$ & $\begin{array}{l}\text { m. } \\
0,99 \\
1,10 \\
0,90 \\
100 \\
0,95 \\
0,98 \\
0,90 \\
0,92 \\
0,90 \\
0,90 \\
0,90 \\
1,35 \\
1,31 \\
0.94 \\
0,97 \\
0,80 \\
1,17 \\
1,02\end{array}$ & 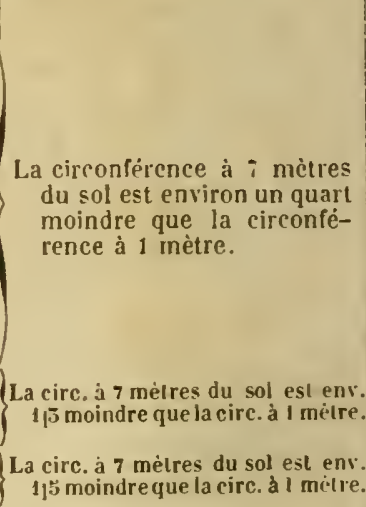 \\
\hline Moyennes. & 18,68 & 14,11 & 1,34 & 1,00 & \\
\hline
\end{tabular}

Ce tableau fait roir qu'en moyenne ces sapins avaient $18^{\mathrm{m}}, 68$ do hauteur $10-$ 
lale, $14^{\text {1n }}, 11$ de hautcur propre à la vente, et que le rapport de la circonlérence à 1 mètre au dessus du sol (toujours facile à prendre) à la circonférence à 7 mètres était à peu près comme un est à trois quarts. A insi, on opèrera a vec une exactitude suflisante pour obtenir la solidité qu'auront un certain nombredeces arbres après l'équarrissage, en calculant leur circonférence à 7 mètres au dessus du sol, d'après leur circonférence à 1 mètre au dessus du sol diminuée d’un quart, et en évaluant à $14^{\mathrm{m}}, 11$ leur hauteur propre ì la rente(1). En opérant ainsi pour un seul arbre, l'on pourrait commettre des erreurs assez fortes; mais les personnes qui ont l'habitude de ces sortes d'estimations reconnaîtront tout de suite que l'arbre mainticnt mieux ou plus mal sa grosseur que ceux qui perdent un quart a $i$ mètres, et alors ils déduiront un cinquième ou un tiers de lat circonférence à 1 mètre du sol, ou une moyenne entre ces nombres.

Il peut être utile de mesurer la hauteur des arbres sur pied dans des circonstances exceptionnelles, comme par exemple, pour savoir approximativement quelle est la hauteur des arbres d'un canton de futaie, ce que l'on sait en en mesurant quelques-uns; car les arbres du même âge, situès à lá même exposition, venus dans la même nature de terre, auront à peu près la même hauteur. J'ai fait construire deux instrumens fort simples (deux dendrometres), destines it cet usage; j'en (ionme la description chap. XII, art. III, et les dessins se trouvent pl. Vi, fig. 8, 9 et 10.

Tous les propriétaires d'une sapinière d'une certaine étendue doivent avoir une pépinière de jeunes sapins plus ou moins grande selon l'étendue de leur' sapinière; le plant qu'on en tire sert à remplir les clairières, et dans beaucoup de localités on ne manque point d'acquéreurs, si l'on n'emploie pas tout à cet usag̉e. Dans la sapinière de Raveton, dont j'ai déjà parlé, on a assaini par des fossés les parties marécageuses de la sapinière qui formaient de petites clairières, parce que le sapin argenté, craignanl l'excès d'humidité, ne pouvait y croìreavec succès; puis après l'assainissement on a mis ces terrains en culture, et l'on y a lait des pépinières de sapins. Ces pépinières, entourées de tous còtés par la futaie, sont par conséquent à mi-ombre; elles sont d'une grande beauté, fournissent lu plant pour les clairières, et on laissera dans l'emplacement où elles se trouvent la quantité de plant nécessaire pour bien garnir le terrain : on ne peut mieux faire que de suivre un tel exemple.

J'ai dit, page 12, qu'il me semblait généralement prélérable d'abattre les arbres quand ils ne sont pas en sève, parce que le bois abattu alors a, selon moi, plus de qualité que s'il l'eût été pendant la sève. Il y a encore d'autres raisons de pré-

(1) Dans la localite que j'habite, on calcule la solidité d'un tronçon de sapin, pour la rente en grume, en multipliant sa longueur par la surface que l'on obtiendrait après l'équarrissage, en faisant au milieu une section perpendiculaire à l'axe de ce tronçon. On calcule cet équarrissage en prenant le quart de la circonférence, parce qu'on n'équarrit point à vire aréte; dans d'autres localités, on calcule l'équartissage en prenant le quart de la circonférence diminuẻe d'un sirième, et dans d'autres diminuée d'un cinquième. 
férer ce lamps-la pour l'exploilation des fulties dr sapins argentés el des autres arbres résineux dont je m’occupe : les blessures aux arbres, les brisures, le piritiinage du plant par les ouvriers, le séjour des copeaux et des bourrées sur le: plant, sont beaucoup moins nuisibles alors que pendant la sève, parce que les pousses, tant qu'elles sont herbacées, sont beaucoup plus faciles à endommager et à briser que lorsqu'elles sont devenues ligneuses. 11 peut d'ailleurs être utile dans des circonstances particulières, ainsi qu'on le verra plus loin, d'abattre les sapins pendant la sève. Voici ce qui se pratique dans différens pays.

On abat en toutes saisons dans les sapinières de Laigle, et principalement penlant l'hiver. Selon Dralet (1), on abat aussi en toutes saisons dans les Pyrénées. Il est pourtant nuisible, d'après Leroy, précédemment cité, d’y couper les sapins en pleine sève, et cela ne doit jamais se faire lorsqu'ils sont destinés à la mâture; le moment le plus favorable est aux approches de l'hiver, lorsque la sève est en repos, et il ne faut pas abattre par le vent du midi qui est très-chaud, parce que les sajins abattus alors sont sujets à être piqués des vers. On peut, ditil, couper toute l'année, excepté dans le fort de la sève, pour donner de l'occupation aux ouvriers et aux scieries; cela influe peu sur la qualité des borlages et des planches.

Cet ingénieur commençait ordinairement à faire abattre les sapins pour la mâture at commencencnt d'oetobre et continuait tant que les reiges ne l'en empecchaient point; puis il recommençait après la fonte des neiges pour ne s'arrêtor que lorsque la sève commençait à partir. Quand on en avait le temps, on transportait avant l'hiver les sapins destinés à la mâture, que l'on avait coupés l'automne dans la forêt d'Issaux, jusqu'au port d'Atas, situé sur le gave. d'Aspe; on les dépouillait de leur écorce et on les mettait à l'abri jusqu'au moment de les faire flotter; on laissait dans la forêt, sans les écorcer, ceux qu'on n'avait jas eu le temps de transporter. Ces arbres, dit Leroy, qui restaient ainsi quelquefois pendant cinq mois dans leur écorce, étaient moins piqués des vers que ceux qui avaient été transportés au port.

Dans les Vosges, on exploite le sapin argenté en toutes saisons, excepté pendant les grands froids; on choisit de préférence l'hiver pour l'exploitation des parties où il y a du semis, et l'été pour l'exploitation de celles où il n'y en a pas; les scieries se trouvent ainsi alimentées pendant toute l'ammée. On pense dans les Vosges que le bois dles sapins coupés en sìve est meilleur que celui rles sapins qui sont coupẹ́s pendant que la sève est inactive, quoiqu'il n’y ait pas eu d'expériences positives faites à cet égard; mais ce n'est point le principal motif pour préférer d'exploiter l'été plutôt que l'hiver : on se propose ainsi de diminuer les ravages des insectes et particulièrement des bostriches, en écorçant les arbres ou en leur enlevant des lanières d'écorce, aussitôt après cqu'ils ont été abattus, ce qui est facile pendant la sève. On a remarqué, en effel, que peu de jours après l'apparition de la sève, tous les sappins qui auraient ćté abattus précédromment 
sont allangés patr les bostriches s'ils n’ont point été exorcés, et que cens que l'on abal pendant la sève sont attaqués au bout de quelques jours si on ne les écorce point; les ravages de cet insecte sont tels qu'ils mettent en peu de jours le tronc de l'arbre hors d'état d'être converti en planches. L'écorcentent immédiat se pratique depuis la fin d'avril jusqu'i la tin de juillet (1).

M. Mougeot, dans son Némoire, cité pages $\mathbf{1 4}$ et $5 \mathbf{4}$, sur les lorêts d’abres résineux des montagnes des Vọges, donne des renseignemens à pen près sem11) lables à ceux qui précèdent, et il émet l’opinion que le bois du sapin coupé en sève est meilleur que celui du sapin coupé hors sève. I'lusieurs forestiers allemands ont la même manière de voir sur l'exploitation du sapin argenté, et nème de tous les bois résineux.

M. Parade, directeur de l'Ecole royale forestière de Nancy, assista à Bade, en mii 1841, à un congrès forestier anquel prirent part cinquante-six forestiers de différens grades des royaumes de Bavière ef de Wurtemḅerg, des grands duchés de Bade et de Ilesse-Darmstodt, et de la principauté de Hohenzollern-Signaringen; il a rendu compte des travaux de ce congrès dans un article inséré dans les Annales forestieres de janvier 1812. On s'y occupa entre autres choses de l'abatlage des futaies de bois résineux en temps de sìve ou hors sève, et l'on demanda aux forestiers du Wurtemberg leur opinion à ce sujet. Cette opération s'exécutait dans le Wurtemberg où se trouve une partic de la Forêt-Noire, et ì dater du 15 septembre 1829 seulement, depuis la fin d'avril jusqu'à la lin d'aont; l'on écoreait les arbres aussitòt après qu'ils avaient été abattus; antéricurement à celtépoque on abattait les bois résineux depuis le mois d'octobre jusqu'au mois d'avril inclusivement. Ce changement a vait eu pour but de combattre la propagation des insectes, et en particulier du hostriche typographe, et comme on s'en était bien trouvé, on n'était point revenu à l'ancienne méthode. Les forestiers du Wurtemberg répondirent unanimement que les bois, loin de perdre de leur qualité marchande par la coupe en temps de sève, gagnaient au contraire beaucoup; que les pièces étaient plus belles, plus légères, flottaient plus facilement; que la planche était plus lisse et plus blanche; qu'on remarquait entin que les marchands de bois de la Ilollande faisaient de préférence leurs approvisionnemens dans les coupes exploitées en temps de sève. lls convenaient des dégâts qui résultent de l'exploitation pendant la sève, et que les blocs destinés au sciage, dépouillés aussitôt de leur écorce, se crevassaient quelquefois profondément; mais en définitive ils préféraient la coupe pendant Ia sève.

M. Parade fit olserver, avec raison selon moi, que sous le point de vue mercantile ce mode d'exploitation paraissait mériter la préférence, dans un petis état qui exporte une très-grande partie de ses bois d'œuvre; mais que ce qu'il lallait prendre aussi en considération, surtout dans un pays qui n'exporterail point, e’était la qualité et la durée des bois exploités pentant la sève ou en morte

(1) Ces renseignemens complètent, aree ccux qui se truuvent pages 39 , it et it6, ce que j'aj ob lenu de fobligeance de $\mathbf{1 1}$. (i. Gand sur le silpin argenti diuns les montagnes des losges. 
sève. J'ajouterai qu'il fitulrait tenir compte aussi du dommage que cause à la futaie une exploitation exícutée pendant les mois de l'année où celte opération est le plus nuisible aux jeunes sapins et au recru. Il paraît d'ailleurs que Ia direction forestière du duelé de Bade, dans lequel se trouve aussi une partie de la Forêt-Noire, était disposée à adopter, pour l'exploitation de ses futaies d'arbres résineux, la même mesure qui est en usage depuis quatorze ans dans le royaume de Wurtemberg.

Moi j'ibats pendant que la sève est inactive, et je fais débiter la bois le plus tôt possible après que lẹs arbres sont abattus. Je n'ai d'ailleurs, dans la localité que j'habite, rien vu de semblable à ee qui a été observé dans les Vosges. Le sapin mort sur pied se pique, pour me servir de l'expression consacrée, an bout d'un an environ; celui que l'on abat hors du temps de la sève peut rester fort longtemps dans son écoree sans qu’il se pique, ear je l'y ai laissé quelquefois jusqu'à einq mois, et jẹ n'ai jamais remarqué qu'il se fût piqué. J'emploie une partie des bouts de sapins, impropres à la charpente, à faire des pieux; on met trois de ees pieux unis par des ehevilles autour de jeunes pommiers et poiriers à cidre pour les préserver des hestiaux; ils durent ainsi einq à six ans, quoiqu’on ne les ait point dépouillés de leur éeoree, ne deviennent hors de serviec que paree que la partie qui est en terre pourrit, et je n'ai point remarqué que leur bois se piquât. Le chêne, an contraire, se pique régulièrement, mais légèrement, au bout d’un an après qu'il a été abattu, si on le laisse dans son écorce, et il est utile de l'y laisser un an, mais on ne doit pas tarder plus longtemps à l'équarrir. Les sapins argentés qui ont été abattus pendant la sève ne se piquent pas non plus aussi promptement que dans les Vosges, puisque j'en ai fait abattre ainsi dans mon pare que j’ai conservés six mois dans leur écorce, et qui ne se sont pas piqués.

On conelura de ce que je viens de dire relativement au temps que le sapin argenté peut rester sans inconvénient dans son écoree, que sous le climat de Paris il faut l'équarrir cinq mois au plus après qu'on l'a fait abattre, non pas paree qu'il se pique, ear j'en ai gardé plus d'un an dans son éeoree qui ne s'était pas piqué, mais de erainte qu'il ne s’échauffe. L'on a vu que les expériences que j’ai faites ne m'avaient pas prouvé qu'il fût nécessaire d'équạrrir plus tôt ceux que l'on coupe pendant la sève; eependant je crois prudent de ne pas les laisser aussi longtemps dans leur écorce. Il y a d'ailleurs un motif fort grave qui doit engager à équarrir les sapins le plus tôt possible après l'abattage; c'esı la crainte des bostriches qui commeneent orlinairement à paraître entre l'écorce et le bois des arbres morts sur pied ou laissés longtemps dans leur écorce.

Le propriétaire d'une sapinière, dans une localité où l'on trouve le débit de toutes les espèces de marehandises, peut tirer parti de sa sapinière de trois manières différentes : $1^{\circ} \mathrm{Il}$ peut vendre, sur une étendue déterminée, tous les sapins qui dépassent une grosseur convenue, sur pied, en masse, à prix défendu; $2^{\circ}$ il peut vendre une partie de ses sapins en grume et l'autre partic après l'avoir convertie en planches, en hois de charpente, en échelles, etc, et il 
peul vende ees marchandises en gros à un marchand de bois ou vendre luimême en délail; $3^{0}$ il peut entin convertir tous les sapins qu’il veut vendre en diverses marchandises, selon la facilité du débit, et vendre cu gros à un marchand ou se faire lui-même délaillant.

Lorsyu'il vend en grume, il doit d'abord faire marquer tous les arbres qu'il veut vendre; on leur enlève de l'écorce avec une plane on une hachette, de manière à ne pas atteindre le liber, et l'on met sur chacun d'eux un numéro d'ordre en commencant par le $n^{0} 1$. Puis on peut finire estimer les arbres sur pied, un à un, par un connaisseur, les acquéreurs les estiment de leur côté, et on les leur vend i prix délendu; ou on pent faire abattre ces arbres et les vendre au mètre cube : dans ees deux cas, on convient d'une époque à laquelle l'exploitation et la vidange devront être terminées. Le propriétaire pent mettre dans ses conditions qu'il se chargera de l'abattage et de l'ébranchage, ce qui lui sera toujours avantageux, car jamais acquéreur ne prendra de sa sapinière, pendant cette exploitation, le soin qu'il en prendra lui-même. En vendant en grume au mètro: ('ube et en vendaut du bois converti en marehandises, lik vente se fait avec une rutière connaissance de ce qui esı vendu el acheté, ce cui est presque toujours ì l'avantage du vendeur.

Je consignerai ici les prix du bois de sapin et des principales dépenses d'exploidation dans les sapinières de Laigle, en 1812, ces sortes de renseignemeus ćtant toujours intéressans pour les praticiens, lors même que les prix sont trèsdiflérens de ceux des localités qu'ils habitent, parce gu'ils leur fournissent des objets de comparaison.

Des sapins argentés en grume propres à faire de la grosse charpente, de la planche et des poutres, pris sur place mais abattus et ébranchés par le propriétaire, auraient été vendus en gros environ 35 fr. le mètre cube(1), et peut-être un septième de moins, si l'on avait fait une forte vente à un marchand. L'on payait aux scieurs de long 1 fr. 75 c. pour 36 mètres de planche, de $0^{\mathrm{m}}, 22$ de large. On payait aux charpentiers 1 lir. 75 c. pour l'équarrissage de 36 mètres de solive ou autre bois de charpente; on leur" payait 1 fr. 50 c. pour 36 mètres de chevron, qu'il fùt de brin ou fendu en deux. On vendait en gros à un marchand $11 \mathrm{fr}$. Les 36 mètres de planche de $0^{\mathrm{m}}, 22$ de large et de $0^{\mathrm{m}}, 027$ d'épaisseur; les planches d'une autre épaisseur étaient réduites pour la 'Iongucur de manière à avoir la même solidité que celle dont je viens de donner les dimensions; ainsi on donnait 72 mètres de la planche de $0^{\mathrm{m}}, 0135$ ( 6 lignes) au lien de 36 mètres de la planche de $0^{\mathrm{m}}, 027$. La solive et les autres bois de charpento, quel que fùt leur équarrissage, se vendaient en bloe $20 \mathrm{c}$. les $0^{\mathrm{m}}, 32$. Le

(1) Ivant l'établissement du système métrique, on comptait par marques tlans les sapinières de Laigle. La marque étail un solide de 300 pouces carrés de base ( 15 pouces sur 20 ), et de 12 pouces de haut, et elle contenait par conséquent 3,600 pouces cubes; elle se divisait en 300 cherilles; ainsi la cheville était un solide de 1 pouce carré de base ct de 12 pouces de haut. II fallait 1í marques pour faire 1 mètre cube; ainsi, en vendant 35 fi. le mètre cube, on vendait 2 fr. $50 \mathrm{c}$. la marque. 
cherrou se vendait 5 fr. 25 c. les 36 mètres. Il va sans dire que ces marchandises se vendaient plus cher en détail.

Les futaies de sapins argentés, exploitées en jardinant, semblent pouvoir durer éternellement; car les terres qui sont occupées par ces futaies ne paraissent point se lasser de proluire du sapin, comme il arrive pour les essences feuillues: néanmoins, je n'oserais affrmer que l'apparence ne soit pas trompeuse, n'ayant aucune donnée d'expérience suffisante à ce sujet. Il semblerait qu’on peut conserver une sapinière éternellement, en favorisant le sapin aux dépens des essences qui pourraient lui disputer le terrain, et le bois taillis qui se trouve dans ces sapinières favoriserait cet état de choses, d'après l'opinion de plusieurs naturalistes sur l'avantage du mélange des essences; mais en serait-il ainsi, si l'on abandonnait la sapinière à la nature? Ne pourrait-il pas arriver alors, qu'au bout d'un certain nombre de siècles, le terrain fatigué ne produirait plus des sapins aussi beaux que ceux qu'il produisait dans la jeunesse de la sapinière, ou que d'autres essences s'empareraient du terrain?

Kasthol'er dit qu'en Suisse on voit quelquefois les forêts de sapins picéas se transformer en forêts de hêtres, et réciproquement; que des forêts de sapins picéas s: changent quelquefois en forêts de sapins argentés (1), et qu'on est dans l'erreur quand on at tribue ces changemens à des causes inlıérentes à la nature du sol; que cela résulte de ce que "l'ombrage des bois d'une essence, en faisant périr ceux de "l'autre, ne tarde point à se mettre en possession dı sol. " Je crois, au contraire, que cette transformation est presque toujours la conséquence de ce que la terre étant lassée de produire une espèce de bois, d'autres espèces lui succèdent, ainsi que cela se remarque pour les essences feuillues. Je suis d'autant plus étonné de trouver, dans Kasthofer, l'opinion que je viens de citer, que plus loin, page 125, cet auteur dit: "Si pendant des siècles ou des milliers d'années, le sol forestier " n'a produit que des sapins rouges (sapins picéas) qui tirent leur nourriture de "la même couche de terre, on comprend que celle-ci doiı s'épuiser, à la fin, de " toutes les substances nutritives particulièrement propres à la vie de ces arbres; " mais que vous remplaciez le sol déboisé de cette essence par une autre dont les " racines, moins superficielles, pénètrent dans des couches plus profondes, vous " pouvez être certains que cette nouvelle espèce d'arbres croîtra, sur ce même " sol, a vec beaucoup plus de vigueur qu'une continuation de sapins rouges. "

Dralet émet la même opinion (2). "La terre se fatigue, dit-il, si elle produit " longtemps des végétaux de même espèce; tel esı le principe général de l'art des " assolemens : cet art est une imitation de l'ouvre de la nature dans ses grandes "productions. "Et il cite de nombreux exemples du remplacement naturel de quelques essences forestières par d'autres essences. "Nous voyons, dit M. G. " Gand (3), partout où la main de l'homme n'y a point mis d'obstacle, le hêtre et

(1) Le Guide dans les forits, t. I1, p. il-i3.

(2) Traité du hêtre, p. 12 !.

(3) Mémoiresur l'alternance des essences forestières, P. $3 \mathrm{i}$. 
"le sápin alterner continuellement dans des proportions et sur des étendues " diverses, et les forêts, que ees denx essences forment, être d'autant plus belles et " présenter une végétation d'autant plus vigoureuse qu'elles sont plus mélangées. " Je crois n'avoir rien omis de ce qu'il y avait à dire d'important qui soit commun aux modes d'exploitation que je vais décrire.

Je vais commencer, ainsi que je l'ai dit, par m'occuper de l'exploitation en jardinant. Je supposerai d'abord que la valeur du bois de sapin argenté et le débit de toutes les espèces de marchandises que l'on peut faire avec ce bois purmettent de domner à la sapinière tous les soins qu'elle réclame; je supposerai aussi qu'elle est situće sous un climat et dans un terrain favorables. Si l'on veut conserver toujours une futaic de sapins argentés sur le même terrain, on doit suivre une marche avant, pendant et après l'exploitation, différente selon le mode d'exploitation, et je dois choisir un point de départ. Je supposerai donc que la sapinière dont je vais m’occuper est une futaie pleine, nouvellemẹt créée, qui ue contient par conséquent que de jeunes sapins, l'âges peu diflérens, dont elle est bien garnie. Si elle est mêlée de hois taillis, on devra le couper quand il dépassera les jeunes sapins, de manière à les priver trop rigoureusement d'espace, de lumière et de soleil; il faut d'ailleurs couper, tous les neuf ans au plus tard, le taillis qui occuperait le terrain conjointement avec la sapinière, sans quoi ce laillis serait très-nnisible au junne plant et pourait même le faire périr s'il était trop épais.

Dans les parties de la sapinière oủ les jeunes sapins argentés sont si nombreux qu'ils ont détruit toute autre espèce de végétation, et alors il y en a souvent des milliers de plus qu'il n'est nécessaire, il est utile de couper une partie de ces sapins; néanmoins cet éclaircissage doit se faire avec beaucoup de réserve, car des huit espèces d'arbres résineux à hautes dimensions, ì chacune desquelles j’ai consacré un chapitre, le sapin argenté est celui qu'on peut laisser croitro le plus serré. C'est celui auquel il faut le moins d'espace pour prospérer daus sa jennesse; et quelque chétif et souffrant qu’il soit devenu, faute d'espace et de lumière, il reprend, lorsqu'on lui en procure suffisamment, la plus belle végétation, si scs racines sont saines; cela résulte principalement de ce qu'il parait alors des boutons adventifs qui donnent maissance à des branches et à des ramilles, en sorte qu'il se trouve suffisamment garni de branches et de feuilles au hout de quelques annécs. Les sept autres espèces d'arbres résineux conifères, llont je: m’occupe spécialement, même le sapin picéa, ne sauraient croìtre aussi scrrés sans périr, ou sans que leur constitution soit altérée de manière, pour les pins, ì ne jamais se rétablir entièrement. Lors done qu'on ne s'est pas pressé d'éclaircir les sapins argentés, les plus robustes dominent bientôt, et l'on distingute alors ceux qu'il faut couper pour donner de l'espace et de la lumière aux autres, parce qu’ils étaient destinés à périr un peu plus tard.

Après ce premier ćclaircissage à liı suite duquel on en fera autant de semblables qu'il sera nécessaire, on éclaireira successivement la sapinière en y prenant

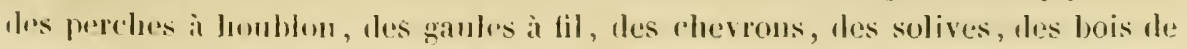


charpente et enfin des sapins de grosseur à faire des poutres ou de la planche, et ces éclaircissages produiront aussi des bourrées. On aura soin de choisir les sapins que l'on abattra dans les endroits où ils sont trop serrés, parmi ceux qui nuisent le plus aux sapins de leur voisinage par leur ombrage; et pourtant de conscrver, autant qu'il sera possible, ceux qui ont la plus belle végétation, de manière à ce que, en définitive, tous les sapins que l'on conserve assez longtemps pour qu'ils puissent atteindre la grosseur à laquelle on peut en faire de la planche, soient provenus de ces sapins d'élite. Il va sans dire que l'on doit abattre les arbres morts, brisés, dépérissans, ayant des chancres ou des maladies.

Les futaies que l'on exploite en jardinant contenant des arbres de tous les âges, les sapins n’y sont pas tous dépouillés de branches comme dans les futaies pleines, el il est utile d'élaguer ceux qui restent garnis de branches quelquefois jusqu'au sol; car, sans cela, ils étoufferaient tout sous leur gouttière, leur tronc ne maintiendrait pas sa grosseur et la planche qu'on en tirerait serait gâtée par les nœuds des branches. Néanmoins, les propriétaires ne feront guère exécuter cet élagage s'ils ne trouvent point à vendre les bourrées de sapins. C'est l'ailleurs une opération qui doit être surveillée avec le plus grand soin pour qu'elle ne devienne point nuisible; ainsi il faut la fairc exécuter à la journée et non à l'entreprise, et seulement pendant que la sève est inactive. On ne touchera point aux arbres qui seront dépouillés de branches jusqu'à 4 mètres du sol; mais à ceux qui auraient des branches plus rapprochées du sol et qui seraient âgés de plus de 40 ans, on coupera chaque année un étage et même deux étages, si les branches sont étiolées ou qu'il n’en reste que la plus petite partie. Les branches seront coupées rez du tronc, car si elles étaient coupées à quelque distance du trone, les chicots périraient, s'incorporeraient dans le bois et il se trouverait des trous dans les branches; tous les arbres résineux doivent être, par la même. raison, élagués ainsi rez du tronc. Lorsqu'une sapinière sera bien tenue, sous le rapport de l'élagage, il suffira d'y faire passer les ćlagucurs tous les cinq ans au plus : on jugera à l'inspection quand cela sera nécessaire.

Ce travail sera exécuté par deux ouvriers élagueurs qui travaillent ensemble; ils seront porteurs chacun d'une serpe trempée exprès, les branches du sapin étant fort dures (1), d'une échelle légère de $3^{\mathrm{m}}, 50$ de haut, d'un maillet et d'uu ciseau ( Pl. VI, fig. 4) emmanché soliılement et garni d'une virole de fer au bouı du manche : ce manche aura sept pieds de loug. Le ciseau coupe très-difficilement les grosses branches et fatigue beaucoup l'ouvrier qui frappe de côté et de bas en haut, avec son maillet, sur le bout du manche; cela se remarque surtout lorsque ces branches sont un peu longues, parce qu'elles exercent alors, par leur poids, une forte pression sur le ciseau; le poids de la branche favorise au contraire l'action de la serpe. On ne se servira done du ciseau que pour couper de

(1) Les branches du sapin argenté, à l'endroit où elles s'attachent au trone, sont plus dures qu'aucunc de celles des huit espéces dont je m'occupe spécialement dans cc Traité; aussi les menuisiers redoutent-ils les planches de cet arlire, qui contiennent des nouds. 
petites et de moyennes branches, et éviter l'applieation de l'échelle. J'ai dù indiquer eet instrument que l'on emploie avec succès en Normandie, conjointement arec la serpe et unc hachette pour tailler les pommiers ì cidre. Mais les branches de cet arbre ne sont pas pendantes comme celles des sapins argentés, et elles sont beaucoup moins dures à leur naissance. Ainsi, en définitive, je crois géućralement préférahle de n’employer que la serpe.

L'èlagage des sapins des allées demande plus de précantions encore, parce que, si ces allées sont isolées, les arbres qui les forment conscrvent toutes leurs branches el de toute leur grosseur; et lors même qu'elles seraient dans une futaie, les sapins, si elles sont larges, y conservent la plus grande partie de leurs branches. On ne doil alors couper gu'un étage de branches tous les deux ans, ou un demi-étage par an. On commencera l'élagage lorsque les sapins auront 5 mètres de haut, et on l'arrêtera selon le goût, si l'on ne consulte que l'agrément; mais on ne doit point dépouiller le trone de branches à plus de la moitié de sa hauteur, et on ne doit terminer alors l'élagage que lorsque l'arbre ap)proche de sa maturité. Conduit avec ces précautions, l'élagage sera toujours utile; les silpins sur lesquels on l'aura pratiqué auront un tronc plus gros, qui maintiendra mieux sa grosscur, qui n'aura pas de nouds, et qui aura par conséquent beaucoup plus de valeur que si on ne lui eût point coupé de branches.

Si l’on coupait à la fois plusieurs étages de branches sur un sapin, on nuirait ì sa végétation par la déperdition de la sève, mais je ne pense pas que l'arbre en souffrît d'ailleurs, à moins que le nombre des étages coupés ne fùt trop grand. J'ai fait élaguer les sapins d'une allée de mon parc, ils étaient âgés alors de 6ł :uns environ, n'avaient jamais été élagués à plus de cinq pieds de haut et avaient des branches fort longues qui gênaient pour passer sous leur gouttière; on a coupé, malgré ce que j’avais preserit, plusieurs élages à la fois ì plusieurs l'entre eux, el l'un de ces sapins, que j'ai abaltu pour expérience cinq ans après, était parfaitement sain. On élague ainsi les sapins qui sont à l'entrée des habitations dans plusicurs parties de la Normandie, et je n'ai point entendu dire 'fu'il en résultât d'autres inconvéniens que de retarder beaucoup leur végétation guand on les élague trop laut ou trop vite.

Il me parait utile de conserver antour des sapinières cxploitées en jardinant, même lorsqu'elles sont situées en plaine, une lisière mieux garnie de haut bois que le reste de la futaie. Elle aura 10 mètres de large; les sapins qui la formeront, particulièrement ceux de la bordure, ayant plus de lumière, plus de terrain pour étendre leurs racines, étant plus exposés à l'action des vents, seront mieux enracinés que les arbres de l'intérieur de la futaie. On élaguera les sapins de la bordure à raison d'une couronne de branches tous les deux ans, en commençant à vingt ans, jusqu'à 4 mètres de haut seulement; on les abattra de 70 à 90 ans, lorsqu'il s'en présentera à côté d'eux qui pourront les remplacer. Si la sapinière n'occupe fu’une petite étendıe, on n’aura de lisière que du còté vì soufflent les vents les plus violens; el dans une sapinière en palys de monta-

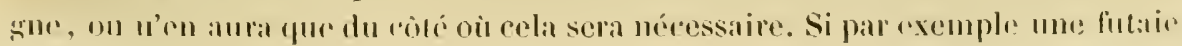


occupe un côté d'une vallée jusqu'iu sommet de la montagne, il laudrat une lisière au sommet et ordinairement une lisière à chacune des extrémités. Karsthofer (1) dit qu'il faut réserver la lisière supérieure de la largeur de 100 pieds; cette largeur dépend évidemment des circonstances locales.

Les éclaircissages et les élagages successifs ayant été exécutés de manière à aménager la futaie pour l'exploiter en jardinant, il devra se trouver dans toutes les parties de cette futaie des sapins le différens âges et surtout de l'âge de 60 ans au moins pour porte-graines. S'il y a des clairières, on y plantera de petits sapins âgés de huit ans au plus, levés en motte dans les parties les plus aérées de la sapinière, par exemple dans les bordures; ou, ce qui scrait préférable, pris dans une pépinière que doivent ávoir tous les propriétaires d'une futaie importante de sapins. On ne cherchera point à donner aux sapins, quel que soit leur âge, un espacement régulier, ces arbres aimant à croître plus ou moins rapprochés, selon que la veine du terrain où ịls se trouvent leur convient plus ou moins; l'on peut dire du sapin argenté qu'il aime à croitre par houquets.

Je ne donnerai point de renseignemens plus précis que ceux qui précèdent sur les travaux successifs à exécuter dans les sapinières que l'on exploite en jardinant; on acquerra bientôt l'habitude de juger, à l'inspection de la sapinière, les parties qui ont besoin d'ètre éclaircies.

Après avoir maintenu ainsi la sapinière en lon état par des éclaircissages et par des élagages successifs, et cn la déharrassant, altant que cela aura été possible, des arbres sans avenir, jusqu'à l'époque où une partie des sapins anront atteint la grosseur nécessaire pour qu'on en puisse litire des poutres ou dẹ la planche, la futaie approchera de l'âge où l'on commencera, à proprement parler, l'exploitation en jardinant. Cette exploitation consiste à abattre chaque :mmée les arbres qui ont atteint l'âge ou les dimensions au delà desquelles il y aurait de la perte à les laisser dans la sapinière. C'esı au propriétaire à prendre une détermination à ce sujet en ayant égard au prix de vente, à la perte d’intérêt résultant de l'attente et au dommage que causent les arbres qu'il veut abattre aux arbres qui les entourent.

I)ans les pays où le bois de sapin se vend bien et où l'on trouve le débil de toutes les espèces de marchandises que l'on peut fairc avee ce bois, on n'a jamais intérêt à attendre la maturité complète, parce que l'accroissement du sappin argenté est fort lent pendant les dernières années qui précèdent cette époque. Mais on at ordinairement intérêt à attendre que les sapins aicnt atteint les dimensions qui permettent d'en faire des poutres ou de la planche. Il peut arriver aussi que le prix du bois de sapin augmente par des circonstances extraordinaires (2), et alors on a intérêt ì avancer les coupes. Il y at d'ailleurs des localités où l'on ne peut tirer parti que des pièces de belles dimensions, tandis

(1; Le Guide dans les forêts, t. II, p. 6i.

(2) Une guerre maritime qui empêcherait l'arrivée des bois de sapin picéa et de p'n d'Écosse, qui nous viennent du Nord, augmenterait la valeur du bois de sapin argenté dans plusieurs lieux, par exemple en Normandie. 
fue dans d'antres on trouve à vender toute espece de marchandise, depuis l'humble perche à houblon et gaule à fil, jusqu'aux plus belles pièces de charpente, et e'est des localitis qui se trouvent dans ce dernier cas que je m'oceupe actucllement, ainsi que je l'ai dit. 11 va sans dire que l'on doit continuer a éclaircir la lutaie, quand il est nécessaire, comne on le lérait avant qu'ello ent l'âge auquel a commencé l'exploilation en jardiuant à proprement parler.

Sous le climat de Paris, dans une sapinière aménagée ainsi que je viens dr. l’indiquer, un certain nombre de sapins argentés atteindront à 60 ans la grosseur nécessaire pour que l'on puisse en tirer de la planche, et la circonférence de quelques-uns d'entre eux aura dépassé $1^{\mathrm{m}}, 60$. Je pense que dans les circonstunces favorables dont j'ai fait la supposition, on aura intérêt à ne jamais laisse'l les arbres de la sapinière dépasser 70 à 80 ans, et il y en aura qui à 75 ans auront plus de 2 mètres de circonférence. La sapinière devra contenir par hectare environ 200 arbres ayant de 60 à 70 ans, et il faudrạ en abattre environ trois par an l'un dans l'autre; on continuera en outre à abattre des arbres de différeus âges, lorsqu'on le jugera utile, de manière à maintenir la sapinière suffisamment meublée d'arbres de tous âges et bien vivamte.

Dans une sapiuière située sur un terrain très-favorable ì la production du sapin, ces trois arbres auront en moyenne $1^{\mathrm{m}}, 80$ de circonférence à 1 mètre au dessus du sol, et 22 à 23 mètres de haut. En supposant même qu'il n’y ait que 16 mètres du tronc propres à être employés pour bois d'oeuvre, cette partic de l'arbre contiendrait environ $1^{\mathrm{m}}, 8$ cube, ce qui, an prix de $31 \mathrm{fr}$. le mètre cube veudu en gros, d'après le cours du pays que j'habite, produirait $57 \mathrm{fr}$. 35 c., ou $172 \mathrm{fr}$. 5 c. de revenu net annuel par hectare; car les éclaircissages produiraient d'ailleurs assez, je crois, pour payer les impóts et les frais de garde. É cette évaluation est loin d'être exagérée, puisque les bois de sapin argenté de cet échantillon se paient plus de 31 fr. le mètre cube, et que je n'ai tenu compte ni de 6 mètres qui restent du tronc, ni des branches, supposant qu'on ferait cet avantage au marchand qui achèterait en gros. On voit quelle énorme différence il y a entre le revenu qu'on peut tirer d'une sapinière et lo revenu qu'on tire ordinairement de la même terre par la culture des céréales, surtout lorsque celle terre, étant très-propre à la culture du sapin, est peu favorable à celle des céréales, comme il s'en trouve dans les environs de Laigle.

II. Noirot dit (1) "que l'on coupe annuellement dans les forêts de sapins ar") gentés du Jura trois sapins au moins et quatre au plus par hectare de la gros") seur moyenne de 2 mètres, de l'âge de 60 à 130 ans et d'une valeur moyenne: "de $20 \mathrm{fr}$.") ; mais on a vu, par ce que j'ai dit plus haut, que ces arbres auraient une valeur beaucoup plus grande dans la localité que j'habite. Leur circonférence ayant été prise au gros bout après l'abattage, ils ne devaient pas avoir beaucoup plus de $\mathrm{I}^{\mathrm{m}}, 80$ à un mètre au dessus du sol. Dralet.(2), après avoir dlit

(1) Traité de la culture des forêts, p. 16:.

(2 Traité des forêts diarbres risineux, p. Ii?. 
que toutes les futaies de sapins argentés de l'Etat sont exploitées en jardinant, et que la plupart l'ont été on ne peut plus mal, cite quatre forêts dans les départemens de la Loire, de l'Aude el des Pyrénées-Orientales qui ont été mieux exploitées; il dit qu'elles contiennent 2,700 hectares, et donnent un revenu annuel de 194,500 fr. ou $\mathbf{7 2}$ fr. par heetare, tandis que la masse des forêts de toute espèce appartenant à l'Etat produit à peine $15 \mathrm{fr}$. l'hectare. L'exploitation de ces forêts en jardinant n'était probablement point encore aussi bien exécutée quelle aurait pu l'être, et le bois d'œeuvre y était sans doute moins cher alors qu'il ne l'est aujourd'hui dans la localité que j'habite; tout le terrain n'y est d'ailleurs pas de première qualité pour la production du sapin.

Pour donner une idće du capital que représente une sapinière exploitée en jardinant, je rapporterai ce que dit II. Noirot d'un hectare de la sapinière de la commune de Riquervich, exploitée jusqu'alors (1832) en jarlinant, et que l'on allait soumettre à la méthode allemande des éclaircies. "Nous avons essayé, " dit-il (1), de compter les arbres dans un hectare de cette sapinière. 11 y en a " environ 1,400 qui valent chacun 15 fr., terme moyen, ce qui donne une valeur " de 21,000 fr. par hectare en calculant sur 7ŏ c. le pied cube (métrique)." Dans la localité que j’habite, le pied cube métrique de bois d'ouvre de belles dimensions vaudrait 1 fr. 15 c. Je suis d'ailleurs disposé à croire qu'une partic de ces sapins n'avaient pas des dimensions telles qu'on pût les estimer 15 fr. en ınoyenne dans la localité où il se trouvent. Quoi qu'il en soit, je sonhaite que la méthode des éclaircies conserve à cet hectare l'état de prospérité dáns lequel il se trouvait lorsque la méthode du jardinage le lui a livré.

Il est quelquefois nécessaire de faire ébrancher les sapins sur pied, jusqu'à une grande hauteur, avant de les abattre, quand ils ne sont pas situés près d'une allée ou d'une clairière où l'on puisse les faire tombèr; sans cette précaution ils briseraient beacicoup de jeunes sapins en tombant. On emploiera pour cet ébranchage la serpe dont j'ai déjà parlé, qui sera portée en ceinture derrière la hanche droite, suspendue à un crochet fixé à une lanière en cuir ( Pl. VI, frg. 2 et 3). Il serait préférable sans doute de commencer l'élagage des arbres sur pied par les branches les plus rapprochées de la terre, ainsi que le conseille 1I. Lorent\% (2); mais comme cette opération déjà dangereuse pour les élagueurs, le deviendrait alors beaucoup plus, qu'elle serait plus longue et en quelque sorte impraticable, on commencera l'élagage par le haut de l'arbre; les branches causeront encore moins de dommage en tombant que si l'on eût élagué l'arbre après sa chute, parce qu'elles occuperont moins d'espace. Le branchage doit, dans tous les cas, être disposé en bourrées, et les bourrées placées le long des chemins le plus promptement qu'il sera possible.

Avant que d'abattre un sapin on ploie les très-jeunes sapins qui se trouveraient sur l'emplacement où il doit tomber et on les fixe daus cette position

1) Traité de la culture des foréts, p. 285.

'2) Coiurs élrmentairc de eulture des bris, p. 183. 
avec une petite fourche, faite sur lo lien même, on en les altachant à un autre petit sapin on à un brin de bois du taillis. On ne doit abaltre que par un temps calme. Cette opération est exécutée a vec la cognée (PI. VI, fig. 5 et 6) et par deux

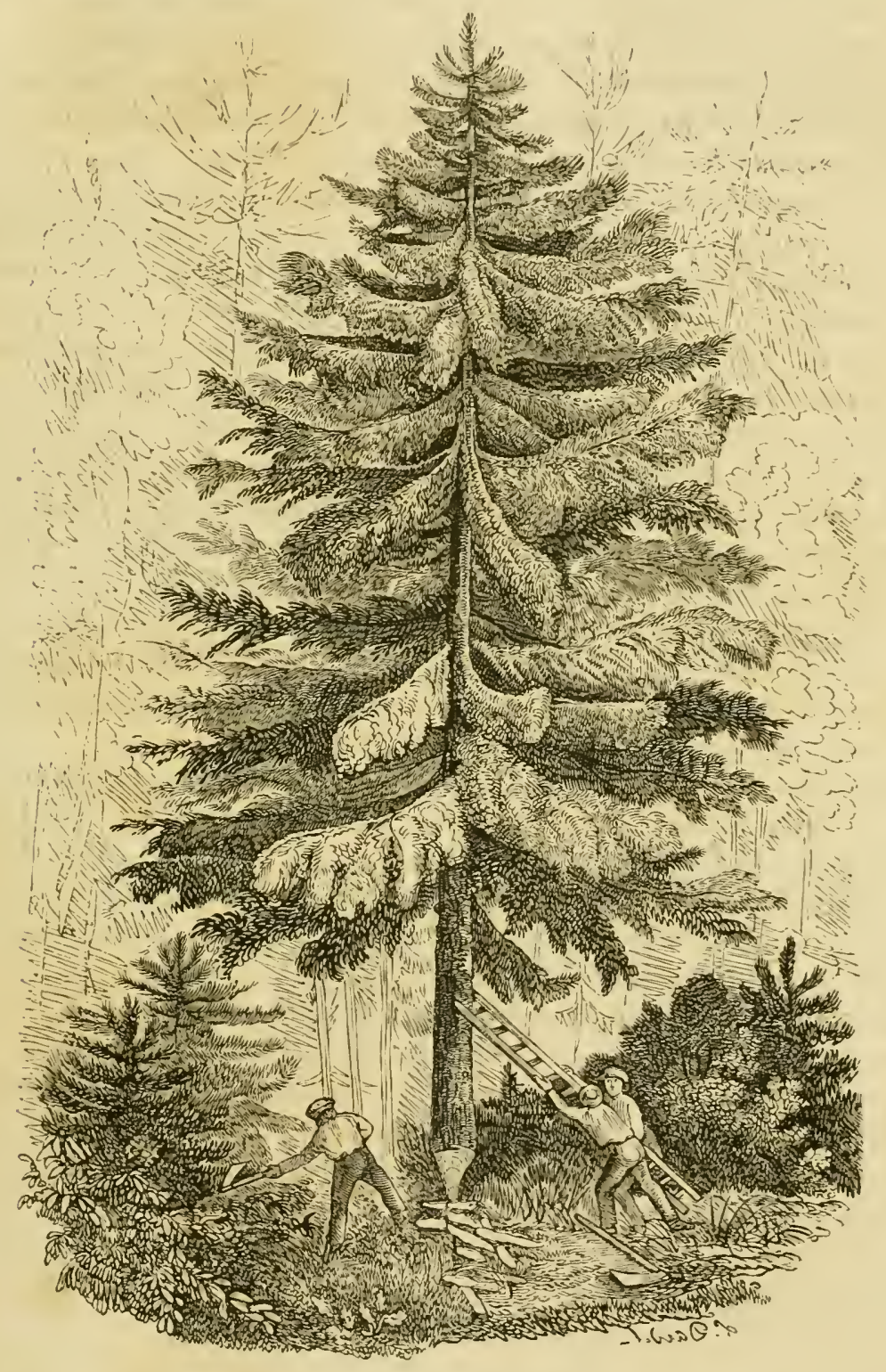

brìcherons; ils font à l'arbre deux entailles opposées rez terre, dont l'une est du cò té où ils veulent faire tomber l'arbre et l'autre du côté opposé; mais il est ordinairement nécessaire, particulièrement pour l'abattage des arbres de fortes dimensions, de commencer par faire quatre entailles, ce qu'on appolle meillir les 
racines, el l'on finit toujours par se lixer aux entailles qui se trouvent dans la direction où doit tomber l'arbre. Lorsqu'il ne tient presque plus à la souche, l'un des bûcherons le pousse dans la direction où l'on veut le faire tomber, soit avec la main, soit arec sa hache qu'il pique dans l'arbre, pour augmenter le bras de levier, à la hauteur de cinq pieds environ, tandis que l'autre donne les derniers coups de hache pour déterminer la chute. Arec ces précautions deux bûcherons habiles, par un temps calme, pourront presque toujours faire tomber l'arbre où ils roudront, à quelques pouces près.

Si l'on veut apporter encore plus de soin à cette opération, on se procurera une échelle légère, quoique solide (Pl. VI, fig. 7 ), d'une largeur de $0^{\mathrm{m}}, 32$ entre les montans el de 4 mètres de long; le dernier échelon de cette échelle sera en fer carré, sera arrêté solidement à l'extérieur par une tête d'un côté et un écrou de l'autre, et ne se trouvera qu'à $0^{\mathrm{m}}, \mathbf{1 2}$ de l'extrémité des montans, qui seront garnis de pointes en fer solidement fixées. Quand l'arbre sera près de sa chute, l'un des bûcherons le poussera en fixant le barreau du haut de l'échelle contre cet arbre sous une branche ou sous un noeud, s'il est possible, ou en enfonçant la pointe d'un des montans dans l'arbre; si l'arbre a un diamètre plus forl que l'intervalle compris entre les montans de l'échelle, les pointes s'engageront dans le bois. On peut enfin, et cela est préférable, employer à cet abattage trois ouvriers; il y en aura alors deux qui pousseront l'échelle an moment de la chute quand il sera nécessaire. L'emploi de l'échelle est particulièrement utile si l'on abat par un temps qui ne soit pas calme, et si les arbres penchent ou sont chargés de branches du côté oủ l'on ne veut pas qu'ils tombent.

Ordinairement tous les arbres de la futaie doivent être abattus à la cognée, parce que cela est plus prompt et qu'on les fait tomber ainsi à peu près exactement où l'on veut; et je répèterai qu'ils doivent être abattus rez terre, parce que s'il en élait autrement, les bostriches, qui préfèrent au bois vif les bois tarés et les chablis, pourraient s'établir entre le bois et l'écorce, et causer, par leur propagation, de grands ravages, ainsi que je le dirai plus loin.

Mais pour les arbres propres à faire de la planche, s'il est possible de les faire tomber sans causer de dégât, par exemple, lorsque ce sont des arbres d'allées ou de bordures, et que le prix du bois d'œuvre soit élevé, il y aura toujours de l'arantage à les déraciner. On y gagnera la souche, et de $0^{\mathrm{m}}, 20 \mathrm{à} 0^{\mathrm{m}}, 50 \mathrm{et}$ au delà de longueur du tronc, selon le diamètre des arbres, dans la partic où le tronc a le plus de valeur. Pour que cette opération puisse s'exécuter avec toute la promptitude dont elle est susceptible, il faut au moins trois ouvriers, dont l'un doit pouvoir monter dans les sapins pour les ébrancher, s'il est nécessaire, et pour attacher un grand câble avec lequel les trois ouvriers tirent ensuite l'arbre, avant. même que l'on ait coupé toutes ses racines. Si l'on n'a pas de câble, l'opération sera plus longue; on poussera l'arbre à la main et avec une échclle, ainsi que je l'ai dit, mais on n'a pas alors la même clıance pour le faire tomber où l'on veut.

Lorsqu'on abat à la hache, les souches se pourrissent promptement, et l'avidile aree latuelle les racines des jeunes sapins envahissent l'emplacement oì 
se trouvent ces sonches prouve que le terreau provenant de leur técomposition convient parfaitement à la végétation de ces arlores. Il arrive pourtant quelquefois que la souche du sapin ne pourrit qu'à l'intérieur, qu'il se forme de nouvelles couches ligneuses régulières, et qu'elle se couvre d'un bourrelet d'icorce. Le sapin argenté est, je crois, le seul des arbres dont je m'occupe dans ce Traité qui présente ce phénomène. Lorsqu'une sonche végète ainsi, e’est que l'une de ses principales racines est greffée par approche avec la racine d'un sapin de son voisinage. 11 ne me paraît d'ailleurs pas possible d'expliquer cette formation régulière de couches ligneuses, sans formations de bourgeons ni llo fenilles, par les principes des botanistes.

Je ferai observer relativement à l'ébranchage sur pied, sans lequel les sapins causeraient souvent beaucoup de dégâts en tombant, que les marchands qui achèteront les sapins sur pied, en ébrancheront ainsi le moins qu'ils pourront, parce qu'il est plus prompt de ne couper les branches que quand l'arbre est à bas; et parce que, en tombant, les arbres ébranchés sur pied se cassent quelquefois vers la partie où l'on a cessé d'ébrancher, ce qui n’arrive, pour ainsi dire, jamais aux arbres qui n'ont point été ébranchés avant que d'être abattus. Aussitòt que les arbres seront abattus, on achèvera de les ćbrancher et l'on dégagera les jeunes sapins qu'on aurd ployés par précaution, ou qui auraicnt été ployés par ceux que l'on a abattus. S'ils ont brisé des sapins en tombant, ce qui arrive rarement lorsqu'on prend les précautions que je viens d'indiquer, ces sapins reformeront des flèches s'ils sont jeunes et vigoureux. Il est d'ailleurs rigoureusement exact de dire que dans les endroits ou il y a surabondance de plant et de jemes sapins, ceux que l'on abat ne causent souvent, pour ainsi dire, ancun dommage en en brisant quelques-uns.

L'équarrissage s'exécute sur le lieu même oì l'arbre a étẻ abattu, s'il est possible; relativement an sciage de la planche, quand il n'y a pas de scieries, les charpentiers trouvent plus d'avantage à transporter à leur atelier les pelotes qu'ils convertissent en planches, que leur atelier près de chaque pelote, du moins dans une certaine étendure. On transporte ensuite les diverses espèces de marchandises sur le bord des allées; on les classe par échantillons et on les étiquette avec de la pierre noire on rouge.

Les soins à prendre pour la reproduction consistent dans les éclaircissages successifs, dans les élagages, et daus la coupe de ce taillis d'essence feuillue et les arbustes, qui se trouvent toujours dans les sapinières exploitées en jarlinant; cette coupe doit se répéter tous les neuf ans au moins : dans la sapinière de Raveton, le dessous se coupe tous les six ou sept ans. Le dessous des sapinières exploitées en jardinant présente d'ailleurs une composition différente sclon le climat et la nature du terrain; j’ai fait comaîtte, pages 53 et 54, quelle est cett: composition en Nomnandie et dans Jes montagnes des Pyrénées. Dans une sapinièrr déjà anciemne, on doit conserver, par exception, pour porte-graines les sapins qui auraient dépassć leur maturité, s’il n’y a pas de porte-graines dans le

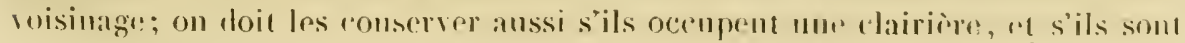


utiles pour rompre l'action des rents auxquels on donnerait passige en les abattant.

Il se forme dans toutes les sapinières des clairières, c'est-à-dire des parties entièrement dégarnies de sapins et qui se seront recouvertes de taillis d'essence feuillue, d'arbustes, d'arbrisseaux ou de gazon; on pourra y semer de la graine de sapin, diuns des potets, mais il sera toujours préférable d'y planter du plant de pépinière, et si l'on n'a point de pépinière, du plant arraché dans la sapinière avec toutes les précautions que j’ai indiquées; on se conformera pour ce semis ou pour cette plantation à ce que j'ai prescrit dans l'article VII. Dans les clairières de péu d'étendue, il suffit de façonner la terre, avant la chute des graines, lorsqu'il y a abondanee de cônes pour qu'elle se couvre de semis naturel; mais on ue peut obtenir ce résultat que dans le voisinage de la futaie, dans les grandes clairières. J'ai vu le rejet des terres de fossés d'assainissement faits dans des clairières où le terrain était marécageux, se couvrir ainsi d’une innombrable quantité de plants provenant de semis naturel.

Si la sapinière se trouvait située dans une localité oǹ l'on ne pût tirer parti que des sapins, qui ont au moins la dimension nécessaire pour que l'on puisse en faire de la planche; si l'on ne trouvait même point à donner les bourrées pour la façon, et qu'on fût contraint de brùler le menu bois sur place, on se contenterait d'abattre les sapins à mesure qu'ils auraient atteint la grosseur que l'on jugerait la plus avantageuse pour li vente. Mais ne pouvant faire alors les travaux ordinaires pour favoriser la végétation et la reproduction dı sapin, on n'en abattrait qu'avec beancoup de réserve, de manière à ce qu'ils fussent to̊njours assez serrés, dans la sapinière, pour étouffer ou du moins pour dominer les antres essences.

J'ai dit que la sapinière dont je viens d'indiquer l'aménagement, pour l'exploiter en jardinant, avait été nouvellement créée; ainsi l'on ne commencera guère à y voir du semis naturel que lorsque les arbres les plus âgés qui la composent auront atteint 50 aus. Et comme le plant provenant de ces arbres ne donuera dı semis naturel que quand il aura lui-même atteint 50 ans, si l'on n'avait pas pris les précautions que j’ai indiquées page 61, il faudrait conserver pour portrgraines les arbres de la création, justu'ì l'âge de 100 ans; sans cela il y aurait interruption dans la proluction du semis naturel : ces précautions ne seront plus nécessaires par la suite, puisque la sapinière se trouvera garnie de sapins dis différens îges.

A vant de passer à un autre mode d'exploitation, je ferai quelques réflexions sur l'expression exploitation en jardinamt ou jardinage. Inalet dit, page 139 de son Traité des arbres résineux : "Tellìs d'Acosta (1) définit le jardinage un modr

(1) Tellès d'Acosta était grand-maitre des eaux et forèts de France. li a publié deux onvrages : l'un intitulé Instruction sur les bois de marine et autres, en 1789, avec deux supplémens, en 1784 et 1786 ; l'autre, Plan d'une nouvelle administration pour les forfts de France, en 1791 : la citation de Dralet duit s'y trouver, je n'ai pas pris la peine de la chercher. 
"d'exploitation d'après lequel, lorsqu'un bois est en coupe, on choisit èt et là "les plus beaux arbres. Suivant d'antres éerivains, ce sont les arbres les plus " forts qui doivent être enlevés par le jardinage. L'une et l'autre de ces défini. "tions, prises ì la lettre, ont autorisé bien des bévues et occasioné bien des " désastres. Une forêt dans laquelle on a coupé, pendant une longue suite d'an. " nees, les arbres soit les plus heaux, soit les plus forts, doit abonder en arbres "défectueux, languissans ou tombés de pourriture; elle doit renlérmer beau" coup de elairières, beaucoup de parties trop fourrées. Et malheureusement tel " est le triste état où sont réduites une partie de nos forêts."

Cet auteur cite pourtant quelques forêts qui forment exception, particulièrement celles des Yosges, où l'on avait continué les sages prescriptions de l'ordonnance du duc Léopold de Lorraine, de novembre 1707. Cette ordonnance prescrivait de couper des arbres de tout âge et de toute grosseur, pour éclaircir les parties trop serrées, et de conserver les arbres les plus beaux et les plus mûrs, quand il était nécessaire, pour servir de porte-graines, et pour tenir la futaic dans un état serré el prévenir ainsi la formation rles elairières. Dralet donne à ce dernier mode d'exploitation le nom de furetage (1), et je pense que c'est à tort : ce dernier mode est un jardinage bien entendu qui consiste à abattre, indépendamment des plus beaux arbres, ceux qui sont mûrs, vieiés, dépérissans, nuisibles ou inutiles à la bonne tenue de la futaie.

Le furetage a, en silviculture, une acception bien déterminée qu'il faut lui conserver. On donne ce nom à une exploitation des taillis qui consiste à ne couper ces taillis qu'en partie, parce que les circonstances locales et celles du climat dans lesquelles ils se trouvent rendraient très-préjudiciable de les couper à blanc-étoc. Ainsi, par exemple, on coupe tons les dix ans, sur elaque souche, la moitié ou un tiers des brins, selon que l'on veut que les brins que l'on coupe aient 20 ou 30 ans; ce sont les taillis de hêtre que l'on exploite le: plus communément de la sorte. C'est en furetant que l'on exploite une partie des taillis du Morvan, des Alpes et des Pyrénées; la plupart de ces bois périraient, au bout d'un petit nombre d'exploitations, si un les exploitait à blancétoc.

L'aménagement des futaies qui doivent être exploitées par coupes rases, par coupes rases par bandes étroites ou par éclaircies, est d'aborıl le même; on peut donc, lorsqu'elles ont été aménagées ainsi que je vais le dire et que le moment de l'exploitation est arrivé, employer l'un de ces trois modes à volonte.

Je supposerai que la valeur du bois de sapin argenté et le débit le toutes les marchandises que l'on peut faire avec ce bois, permettent de donner à la sapinière tous les soins qu'elle réclame, qu'elle est située sous un climat et dans un terrain très-favorables, que la coupe, dont je vais tracer l'aménagement, lait partie d'une futaic pleine nouvellement créée et qui ne contient, par conséqurnt, que de jeunes sapins d'ìges pou différens, dont ello rst bien garnir. 
On celarircira d'abord exlte jeune sapinière à des époques irrégulières, lorsque lo besoin s'en fera sentir, en conservant, autant qu’il sera possible, les arbres de la plus forte dimension et de préférence ceux qui ammoncent la plus belle régélation; on ne tiendra donc pas à ce qu’ils se trouvent trop régulièrement à la même distance les uns des autres, mais à ce qu'il y en ait à peu près le même nombre par chaque espace de 10 ares carrés. Ce nombre et leur disposition doivent ordinairement être tels que les branches de la partie inférieure des sapins soient arrètées l'aborl dans leur accroissement et périssent ensuite, fautr. de lnmière el de soleil. Il doit résulter aussi de cés éclaircissages successifs que la tète de tous les arbres conservés se trouvera, quand ils approcheront de leur maturité, sinon entièrement à la même hauteur, du moins à une hauteur telle qu'ils puissent jouir des bienfaits du soleil; ainsi l'on doit supprimer tous ceux de ces arbres qui se trouveront dominés par leurs voisins, de manière à ce que leur tête soit dans l'ombre, ear ils sont destinés à périr après être restés longtemps langouissans et ils causent du dommage sans utilité. Ces travanx ne demandent que de l'habitude, du soin et ne présentent pas de grandes dilficultés d'exirution.

Si les éclaircissages ont été bien condnits, les trones des sapins seront privés de branches vivantes dans les deux liers environ de leur partic inféricure. Les branches mortes qui s'y trouveront, ayant été étiolées avant que de périr, 10mbent successivement et ne s'incorporent pas dans le tronc; il n'est donc pas nécessaire d'élaguer une telle futaie, néanmoins il est utile de débarrasser les arbres de leurs branches mortes, ce qui facilite la circulation de l'air; et s'ils en sont bien garnis, on trouvera à faire faire cet élagage, pour le bois, dans les pays ou le bois est cher.

A 60 ans, la sapinière présentera déjât un aspect majestueux; les arbres seront éloignés de 4 mètres au plus les uns des autres, terme moyen, et il y en aura par conséquent au moins 62 par hectare. Eı comme je sujpose que cette sapinièr se trouve située dans des circonstances très-favorables à la végétation des sapins, c'est à cet âge qu'ils prendront l'accroissement le plus profitable, particulièrement en grosseur, et l'on ne doit point encore songer à l'exploitation; il faudra donc continuer à exécuter des éclaircissages, de manière à ce que les branches des arbres se touchent seulement par leur extrémité ou ne se croisent qur lort peu.

Les Allemands sont les premiers qui aient pratiqué l'aménagoment des filtaies par éclaircies; mais c'est, je crois, Varenne de Fenille qui l'a décrit et conseillé le premier, dans un mémoire intitulé Aménagement des futaies, qui se trouve dans son ouvrage intitulé Mémoire sur l'Administration forestière, 1. 1, p. 83.

J'ai dit que le sapin argenté atteignait ordinairement sa maturité sous le climat de Paris, dans les terrains (pui lui sont le plus larorables, à environ 90 ans; mais, même dans ces terrains, je pense qu’il sera presque toujours avantagr.ux

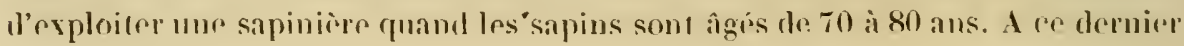


ige et jusfu'it 100 ans el an deli, les arbres devront ètre eloignés, terme muy en, de 5 mètres environ les uns des autres, ainsi il y en aura au moins 400 par heetare; je présume qu'ils auront, en moyenne, 2 mètres de circonférence du côté du pied après l'abattage, c'est-à-dire à environ $0^{\mathrm{m}}, 32$ du sol et 24 mètres de haut du sol à la cime. Si donc l'on suppose que les arbres aient en moyenne $16^{\mathrm{m}}$, 50 de: longueur, propre à liare de la planche ou du bois de charpente, et $1^{\text {m }}, 34$ de, circonférence à $8^{\mathrm{m}}, 25$ du sol, éest-à-lire $0^{\mathrm{m}}, 335$ d'équarrissage, chaque arbre conliendra environ $1^{\mathrm{m}}, 85$ cube de bois, non compris les $7^{\mathrm{m}}, 50$ du tronc du còté de la tète, dont je n’ai pas tenu compte, et qui donneront de la solive, du chevron et des bourrées. Dans la localité oì jè me trouve, des bois d'une telle dimension ne: vatudraient pas moins de $31 \mathrm{fr}$. le mètre cube vendus sur pied en gros, et je suppose qu'on donne le haut de l'arbre par dessus le marché; ainsi chaque arbre vaudrait $57 \mathrm{fr} .35 \mathrm{c}$, et l'hectare rapporterait $22,940 \mathrm{fr}$.

Supposons donc que l'on tire $21,500 \mathrm{fr}$. de l'hectare d'une futaie de sapins, ì gés de 80 ans, et située sur un terrain très-favorable à la production de cus arbres, déduction faite des frais de transplantation el autres, pour repenplement de la sapinière; on aurait obtenu un revenu net de $268 \mathrm{fr}$. 75 c. par an, par heclare, car les éclaircissages successifs, pendant les 80 ans, auraient, je pense. servi à payer l'impôt et les frais de garde. Une futaie de 80 hectares, en terrain extrêmement favorable, rapporterait done plus gu'aucune futaie d'une autre espèce, sous le climat de Paris, et il n'y a point de terres arables qui, loućes en corps de lerme, puissent en produire un semblable. Mais, je le répète, lanis des terrains moins favorables à la production du sapin on n'obticndrait point un revenu si élevé, et clans des terrains qui lui seraient contraires il serait presque 1uul. S'il y avait plus de 400 arbres par hectare, ils seraicnt d'un plus laible echantillon et l'hectare contiendrait une moindre quantité de mètres cubes de bois, il produirait par conséquent un revenu moins élevé.

En supposant même qu’il y ait de l'exagération dans cente évaluation, que les salpins n’aient pas atteint, en moyenne, 2 mètres de circonférence près lu sol; fue ne tronvant point à vendre tout le bois en grume on soit obligé d'en faire lébiter une partic, et qu'on-n'y trouve point le même avantage; que les éclaireissages ne couvrent point les frais de garde et d'impôt, que le revenu ne soit entin que la moitié de mon évaluation; ce serait encore un très-beau revenu, surtout dans des terres argileuses, difficiles pour la culture des céréales, ed propres à celle du sapin.

Ilartig, cité par Bandrillart (1), règle ainsi qu'il suit, dans son Instruction pour les forestiers, les éclaircies, dans une futaie parlaitement bien garnic par suite de l'ensemencement naturel, et que l'on veut exploiter par la méthode des eclaircies : On fera la première éclaircie à 40 ans et l'on ne conservera, par hectare, que 4,500 ì 5,000 des plus beaux brins; ì 60 ans on fera une secontele aclaircie el l'on n'en conservera que 1,500 a 2,000 ; it 80 ans, une troisième, n 
l'on n'en conservera que 800 à 1,000; à 100 ans, une.guatrième éclaircie, ct l'on n'en laissera que 600 à 800 jusqu'ì 120 ans, époque de l'exploitation. Si l'on conserve la futaie plus longtemps, on ne laissera subsister à 120 ans que 500 à 600 tiges, à 140 ans que 400 à 500 tiges, à 160 ans que 300 à 400 . Ce que je viens de citer de Hartig étant fort différent de ce que j'ai dit, je ferai observer que le sapin se trouvant en Prusse, à la limite nord où il parvient en Europe, y a une régétation plus lente qu'en France, et qu'il n'y parvient à sa maturité qu'à un âtre plus avancé; j’ai d'ailleurs bien de la peine à croire qu'un accroissement régulier jusqu'à 160 ans ne soit pas un cas exceptionnel.

Le inême auteur dit, dans son Instruction sur la culture du bois, page 81 : - L'exploitation des forèts d'arbres résineux a lieu plus tôt ou plus tard, selon "que les circonstances l'exigent. Quand on veut avoir du bois de charpente ou " du bois de chauffige, on doit les exploiter à 100 ans, si d'ailleurs elles sont " situées sur un terrain de bonne qualité et qui convienne à cette essence. Quand, " au contraire, le sol est mauvais, il faut les exploiter à 60 et 70 ans, parce que " passé cette époque l'accroissement se ralentit et cesse quelquefois tout-ì-fait. "Si l'on veut se procurer du fort bois de construction pour la marine ou pour " faire des poutres, on doit attendre 120 à 180 ans et choisir pour cela les meil"leurs terrains, parce qu'un mauvais sol ne produira jamais des arbres propres " à cet usage, les laissât-on sur pied jusqu'à ce qu'ils aicnt atteint leur plus haut " degré d'accroissement."

Je suppose que la sapinière dont je m’occupe soit divisée en 80 coupes, afin qu'il y en ait une à exploiter par chaque année, et que l'une de ces coupes, après avoir subi des éclaircissages successifs, ainsi que je viens de l'indiquer, ait atteint l'âge où l'on trouvera avantageux de l'exploiter; cette exploitation pourra s'exécuter par coines rases, e'est-à-dire à blanc-étoc, en style de forestier, et alors il fiut repeupler les coupes par la plantation; por coupes rases par bandes étroites pour les repeupler par le semis naturel, et par éclaircies pour les repeupler aussi par le semis naturel. Je décrirai ces trois différens modes d'exploitation dans l'ordre oǹ je viens de les nommer. Mais je vais indiquer d'abord des dispositions qui sont les mêmes dans les trois cas.

On commencera l'exploitation de la sapinière par le côté opposé aux vents les plus violens, pour que la coupe que l'on exploitera et le jeune plant qui remplacera les arbres que l'on abat soient abrités de l'action de ces vents par le reste de la forêt; ainsi, sous le climat de Paris, on dirigera les coupes du nord-est au surl-ouest, la première sera done située au nord-est et la dernière au sud-ouesta Cette disposition sera d'ailleurs avantageuse parce qu'une partie de la coupe sera ombragée par le reste de la futaie, et parce que les sapins argentés étant exposés à perdre quelquefois leurs jeunes pousses, par suite des gelées tarlives lu mois de mai, ceux qui sont abrités du côté du midi souffrent moins de ees grelées que les autres. Dans les montagnes les vents suivent souvent la direction les vallíes; il faudra consulter les circonstances locales pour déterminer l'ordre dans lequel doit s'exícuter l'exploitation des coupes. 


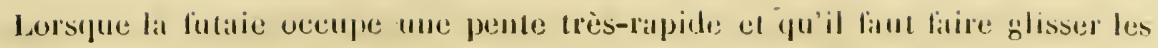
arbres jusqu'au has de cette pente, on commence l'exploitation par lat partic supérieure; si on lat commenteait par le bas, le passage des arbres, endescendant, lerait beaucoup plus de tort aux jeunes plants et l'on ne pourrait planter qu'après avoir achevé l'exploitation du haut. On doit toujours faire tomber les arlures du còté du sommetode la pente, paree que tombant de moins haut ils ine sont pals exposés à se lriser et causent d’ailleurs moins de dlégât.

Il y a des situations en pays de montagnes oi il est indispensable de laisser une lisière sur les côtés de la futaie, et il en faut toujours laisser sur la crète de la montagne, lorsque la futaie ne la dépasse point, pour la protéger contre les vents; sans cette précaution, ils raseraient, dans la jeune futaie qui remplacera celle que l'on va exploiter, les sommets des sapins qui dépasseraient la crète de cette montagne et en feraient des chablis : cette lisière sera plus ou moins large selon les circonstances locales; on l'exploitera en jardinaut.

Je vais m'oceuper actuellement de l'exploitation par conpes rases. Si l'on desline le terrain qu'occupe la coupe que l'on va exploiter à être mis en culture, on exécutera la coupu rase en déracinant tous les arbres, ce qui fera gagner be:tucoup de hois et beancoup de temps, parce que les souches sont plus ficiles à arracher quand les arbres sont debout, et l'on pourra alors labourer tuut de suite en employant une charrue à défricher.

Si, au contraire, on destine le terrain à être occupé encore par unc lutaic de: sapins argentés et que l'on veuille repeupler la sapinière en y plantant du pliut, on abattra tout de suite la totalité des arbres de la coupe; et comme cette coupe ue sera pas suffisamment garnie de plant, puisque j’ai supposé que la futaic était belle; qu'une partie de ce plant, étant trop petit, serait d'ailleurs élouffic par les plantes et arbustes qui couvriront le sol après l'exploitation, on aura eu la précaution d'élever du plant de pépinière, neuf ans d'avance, pour remplacer les arbres que l'on vient d'abattre : c'est ainsi qu'était aménagée la belle futaic de sapins picéas de l’abbaye de Vallombreuse (1), siluée en Toseane, dans les Apennins, et qu'elle l'est cncore, je crois.

Si l'on me plantait pas aitisi du plant après l'exploitation, la futaie se trouverait détruite; c'est ce qui est arrivé en France dans les futaies de sapins argentés de l'État, oì l'on a voulu applifuer ce mode d'exploitation sans remplacer par

(1) Louis Fornaini, abbé de Vallombreuse, en parlant du repeuflement des coupes de la sapinière de cette abbaye après leur exploitation, aı moyen de la plantation avec $d$ ts arbres de pépinière, dans sa brochure intitulée Dissertation sur la culture des sapins, page 23, traduite par des Acres-Fleırange, dit : "On environnera les picćas nouvellement plantés d'une palissade, pour les préserver de "l'atteinte des animaux; préeaution d'autant plus indispensable, répète Dulaamel (Traité des arbres

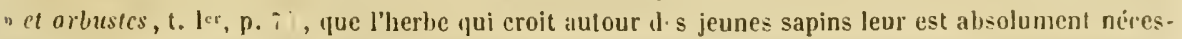
"saire pour les garantir du soleil," Je n’hésite pas í afirmer que l'abbé Fornani et Juhanel somt dins l'erreur ; il est très-utile de hiner plusieurs fois claqque année les jeunes sapins dans la pépinière. et dans la futaie au moins une fuis pendant l'année qui suit celle où on les a plantés à demcure: lorsque l'on néglige ces façons, on aperẹoit une dillèrence notable dans leur accroissenjeut. 
du plant : de tels finits pataissent incroyables, mais ils sont rapportés par Draleı (1); cet auteur cite des forêts de sapins qui ont élé detruites de la sorte.

L'abattage des sapins argentés s'exécutera à la cognée, ainsi que je l'ai dit, en ménageant soigneusement les plants de semis naturel de $0^{\mathrm{m}}, 32$ et plus de hauteur qui se trouveraient dans la futaie. Le plant de pćpinière quie l'on emploiera devra avoir un mètre au moins de haut, dans la crainte qu'il ne soit étouffé ou opprimé par les plantes et arbustes qui croîtront autour en innombrable quantité, le deuxième printemps après l'exploitation. Les plants seront placés, autan $q$ qu'il sera possible, en quinconce, à $2^{\mathrm{m}}$,, o de distance les uns des autres; ainsi il en faudrait 1,600 par hectare, s'il n'y avait point du tout de plant assez haut provenant de semis naturel, mais il y en aura ordinairement, ne fût-ce que sur les lisières. Il sera suffisant que les trous aient un mètre de côté, mais préférable qu'ils aient $\mathbf{1}^{\mathrm{m}}, \mathbf{1 4}$, et l'on a vu, page 56 , ce qu'ils coûteront; il ne mourra, pour ainsi dire, aucun de ces sapins si la plantation a été faite avec des arbres de pépinière ayant été élevés ainsi que je le dirai, chap. XI, art. 11. On les binera pendant le printemps qui suivra la plantation, par un temps de luâle.

Les sapins pousseront médiocrement l'année de leur plantation, mais les plantes et arbustes ne pousseront aussi que faiblement et ne paraitront qu'en petite.quantité; l'année suivante, les sapins pousseront aussi vigoureusement que s’ils fussent restés dans la pépinière, et pourtant ils seront enveloppés de plantes et d'arbustes de la plus magnifique végétation. Mais pour peu que leur tête dépasse ce fouillis qui les enveloppera de toutes parts et semblera leur disputer le terrain, ils auront une si belle végétation, que je słrais tenté de croire que cette situation leur est avantageuse ou du moins ne leur est pas nuisible. J'expliquerai ainsi ce fait : les plantes et arbustes qui viennent de paraître, pour ainsi dire spontanément, ne peuvent pas encore nuire benucoup aux sapins, par leurs racines, et ils forment sur le terrain une sorte de converture qui peut être utile dans les grandes chaleurs, en empêchant le sol de se dessécher, autant que s’il était découvert; plus tard les sapins étouffent tout sous leur gouttière et leurs branches protégent ainsi leurs racines. On remplacera, pendant les premières années, les arbres qui auraient péri, et le nombre en sera très-petit; plus tard on ne remplacera point, puisqu'au contraire il faudra faire des éclaircissages.

Il résulte des renseignemens que je viens de donner, qu'il faut planter les jeunes sapins destinés à reproduire une sapinière, dans l'emplacement oì l'on vient d'en abatre une, avant le printemps qui suit l'exploitation, alin qu'ils puissent profiter de la fécondité extraordinaire de la terre, et disputer le terrain aux plantes et aux arbustes qui paraitront, en innombrable quantité, au deuxième printemps après l'exploitation. Ainsi, je suppose que l'on commence l'exploita-

1. Traite des forcts d'urbes resineux, p 120-123 


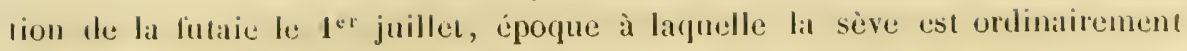
terminée depuis plus d'un mois; on abattra les arbres, on les débitera, et l'on fera en sorte de terminer la vidange de la compe avant le $1^{\text {er }}$ mai suivant, époque ì laquelle on cesse ordinairement de planter. Les bois de charpente et autres seront débités sur place, et entassés ensuite avé soin le long des chemins. On condırira les pelotes destinées à être converties en planches à la seierie, ou, s'il n’y en a pas, près des ateliers des seieurs de long; dans le même cemps on transportera ies copeaux họrs de la coupe. La plantation s'exécutera successivement à mesure que l’on débarrassera le terrain; il ne devra rester de terrain qui ne soit point planté, avant le premier printemps qui suivia l'exploitation, que les emplacemens occupés le long des chemins par les marehandises (1) qui n’auraient point encore été vendues ou livrées mux acquéreurs; mais on plantera ces emplacemens avant le second printemps qui suivra l'exploitation. Que si le temps manque pour exécuter la vidange el les plantations, avant le premier printemps qui suivra l'exploitation, il faudra toujours s'efforcer d'avoir terminć a vant le second.

On peut ordinairement planter avec certitude de suecès, en y apportant le soin convenable, depuis le 15 octohre jusqu'au $\mathbf{1}^{\text {er }}$ mai, tant que la geléc ou les pluies ne s'y opposent point. L'antomne est la saison la plus favorable, sous le climat de Parris, pour planter le sapin argenté, quoique l’on ait publié et répété tant de fois qu'on ne devait planter les arbres résineux conifères que lorsqu'ils entrent en sève. (Voy. eliap. XI, art. 1.)

J'ai dit gu'il faudrait 1,600 plants pour planter chaque hectare, en supposant qu'il n'y ait pas du tout de plant provenant de semis naturel, mais il y en a toujours le long des lisières, les allées et des clairières; et quelque belle que fìt la futaie au moment de son exploitation, elle devait pourtant contenir quelques plants provenant de semis natmel étiolés à la vérité et n'ayant qu’un bien petit nombre de feuilles, situées vers la lête senlement. Nianmoins, presque tous ces jeumes sapins, lorsqu'ils auront $1^{\mathrm{m}}, 33$ de haut, quelque chétive que soit leur apparence, résisteront aux plantes et aux arbustes, se couvriront de branches et de feuilles, et au bout de trois ou quatre ans ils auront repris une telle vigueur, que la llèche poussera quelquefois de plus do: $0^{\mathrm{m}}, 65$ en une annéc. On ne plantera donc point de plant de pépinière quand il se trouvera du plant de semis naturel de $1^{\mathrm{m}}, 33$ de haut ou même d'un mètre soulement, s'il est assez serré pour oceuper le terrain. Il est d'ailleurs possible 'fue des plants moins hauts parviennent ì se faire jour, par exemple ceux qui se trouveraient sous des ronces, car là il ne vient point d'herbes; les jeunes sapins y sont ombragés, mais ils ne sont pas très-serrés par les runces; ils parviennent souvent ì les dépasser, et ils les ćtouffent ensuite.

P'uisqu'il ne doit rester qu'environ 400 sapins par lsectare, lorsqu'on fera une

(1) Le bois vendu en grume aura été livré dans le plus bref délai; mais il pourra rester de la plan 'he, des hois de rlarpente, des échelles el des saules ì lil el à houblon. 
nouvelle coupe délinitive, de 70 à 80 ans après leur plantation, il latudra procéder à des éclaircissages successifs non point régulièrement, mais en se conformant à ce que j'ai prescrit ; et ordinairement lorsqu'on procédera pour la première fois à cette opération, une partie des sapins auront 40 ans et seront déjà de grosseur à faire des chevrons ou de la solive.

Les futaies de sapins argeutés exploitées par coupes rases à blanc-étoc présentent toujours un remarquable aspect. Dans les annécs qui suivent l'exploitation, le sol y est couvert de plantes et d'arbustes qui forment un épais massif' de verdure au dessus duquel on distingue les flèches des sapins; mais à mesure qu'ils croissent, ils étouffent cette végétation si belle qui se convertit en terreau et sert à leir nourriture; puis leurs branches inférieures meurent et éprouvent le même sort; lesol entièrement dépouillé de plantes est tapissé de leurs feuilies; lout périt à l'ombre des sapins, et les sapins eux-mêmes, quand ils sont longtemps exposés à un trop épais ombrage; on peut alors circuler librement dans ces lieux naguère impénétrables. Enfin, quand on approche de l'époque de l'exploitation, les branches des cimes des sapins qui se touchent forment des voûtes impénétrables aux rayons du soleil soutenues par des milliers de colonnes; on ne saurait alors trouver, au sein des forêts, rien de plus magnilique et de plus majestueux que ces belles solitudes.

Si l'on veut exploiter la futaie par coupes rases par bandes étroiles, afin de repeupler la sapinière au moyen du semis naturel, on divisera la coupe qu'on va exploiter en bandes étroites, parallèles et en ligne droite quand il sera possible; ces bandes seront numórolées, et leur largeur sera telle qu'en en faisant exploiter alternativement une sur deux, par exemple toutes celles qui portent les uuméros pairs, le terrain des bandes que l'on vient d'exploiter se trouve aroir justement assez de lumière et de soleil, après l'exploitation, pour que le semis naturel de sapin puisse pruspérer; mais pas assez pour favoriser l'occupation du terrain par les plantes et arbustes qui pourraient lui nuire. Cette condition se trouve remplie en donnant pour largeur à ces bandes un peu plus de la hauteur moyenne des sapins; si done cette hauteur est de 25 mètres on leur donnera 30 mètres de large. On a vu que l'exploitation de la forêt devait commencer par le nord-est et se terminer au sud-outest; mais les bandes, (juand il u'y aura pas d'obstacle ou d'inconvénient, seront dirigées de l'est à l'ouest. Quelle que soit l'ailleurs leur direction, le ternin s'y trouvera toujours à mi-ombre, et, par conséquent, bien disposé sous ce rapport pour favoriser la naissance dı semis. Si la sapinière est située sur une pente très-rapide qui oblige à faize glisser le bois jusqu'au bas, les bandes seront établies dans la direction des pentes.

L'exploitation ne s'exécuter: que par une année d'abondance de cônes, ce lont on sera instruit à la lin de l’antomne qui la précédera, parce que les cònes seront céjà annoncés par de's boutons. (Toy. page 18.) Aussitôt done que l'on aurat acquis la certitude de cette année d’abondance, on préparera la coupe, si on le: juge nécessaire, en arrachant des épines et autres arbustes s'il y en a, et en fac:on- 
nant la terre avec une houe par places ou par bandes. Les gardes auront dù observer les endroits oì ils croiront que l'on doit faire ce travail préparatoire, rt ce seront ceux où il ne lève point de semis naturel; car dans les endroits où il lève bien et périt ensuite à cause de l'ombrage, il ne sera pas nécessaire de l'exécuter, puisque par l'exploitation on val diminuer cet ombrige. Les auteurs allemands yne j’ai préeédenment cités preserivent, dans les pays où l'on nourrit des trouperaux de cochons dans les bois, d'introduire dims la sapinière, avant l'exploitation, un troupeau de ces animaux, ce qui dispense de faire façonner la lerre; mais ce moyen ne peut être employé lorsque la sapinière contient du plant; rémmoins, ce n'est pas un obstacle quand elle n'en contient que sur les lisières, ceux qui conduisent le troupeau pouvamt le fatre passer assez promptement pour qu'il n'ait pas le temps d'y fouiller.

Les bandes que l'on doit exploiter seront indiquées en marquant les arbres de leur pourtour à la racine'avec le marteau, et au tronc, en l'entourant d'une ligne rouge ou noire très-apparente, à $1^{\mathrm{m}}, 30$ au dessus du sol; ou en enlevant de l'écorce jusqu'au liber avec une plane; on abattra tous les arbres que l'on anra marqués et tous ceux qui se trouvent dans l'enceinte qu'ils lorment. On ne doit commencer l'exploitation que lorsque la graine de sapin est tombée, ce qui arrive ordinairement au commencement d'octobre; le travail exécuté pour l'exploitation suffit pour enterrer les graines ou du moins pour les presser contre terre assez pour favoriser leur levée; il serait très-utile que la vidange des bandes que l'on vient d'exploiter fùt terminće quinze jours avant l'ápoque où peuvent lever les premières graines, c'est-à-dire le $1^{\text {er }}$ mars sous le climat de Paris; et pourtant cela sera rarement possible. On remarque que la partie les bandes qui est la plus cxposće au soleil se garnit ordinaircment moins bien que celle qui est plus ombragée, et que les hordures des bandes réservées se garnissent mieux que l'intérieur de ces bandes. Si quelques parties ne se couvraient pas tle semis naturel dans l'amnée de l'exploitation, il faudrait l'annce suivante y semer de la graine à la volée, ou y faire des potets dans lesquels on sèmerait, ou enlin, ce qui est préférable, y planter du plant de pépinière de 4 à 5 ans. Cette première coupe s'appelle coupe d'ensemencement.

Le grand avantage qu'il y a à ce que le semis naturel s'opère l'année même où se fait l'exploitation, résulte de ce que la terre, se reposant depuis longlemps, améliorée par le détritus des feuilles pendant tant d'années, débarrassée enfin en partie de l'ombrage qui la couvrait, a une force de végétation extraordinairc dont le semis profite; mais ce plant nouvellement né a besoin d'ombrage, et si le terrain ćtait entièrement découvurt, il serait probablement tué par le soleil, s'il n’élait étouffé par les plantes et arbustes qui naitraient alors abomdimment. Arec les dispositions que je viens de preserire, non-seulement on pent esprirer qu'il naitra abondamment du semis maturel, mais les plants qui existaient dejja • dans les bancles qui ont éléexploitérs, aussi bien que cenx qui se trouvalient dans les bandes qui ne l'ont point éte, ayant obtenu du soleil on de la lumière, et presque partout l'un et l’antre, sortiront de leur état de léthargie, si je puis 
m'expriner aiusi, pour prendre une végétation aclive. Nóammoins il sera peutêtre nécessaire d'éclaircir un peu les bandes impaires que l'on a conservées intactes deux ou trois ans après cette première exploitation, pour domner un peu plus de lumière au jeune plant qu'elles contiendront.

Ordinairement, au bout de six à dix ans, les bandes qui ont été exploitées aussi bien que celles qui ne l'ont pas été seront suffisamment garnies de plant; et ce plant aura acquis assez de force pour ne plus craindre ni l'action permanente du soleil, ni la rivalité des plantes et arbustes qui trouveront d'ailleurs le terratin moins apte à les produire et occupé en grande partie par du plant de sapin. On achèvera alors l'exploitation, c'est-à-dire que l'on coupera toutes les bandes portant des numéros impairs qui avaient été réservérs : cette scconde coupe s'appelle coupe définitive. On ménagera le jeune plant le plus qu'il sera possible, surtout dans les parties où il n'y en a pas surabondamment; ainsi cette exploitation sera exécutée pendant le temps oì la sève est inaclive, et pendant que la neige couvre la terre, si on le peut, car c'est alors que l'on cause le moins de dommage au jenne plant. Mais cela arrive assez rarement sous le climat de P'aris et seulement penilant fort peu de temps, tandis que dans d'autres climats, fal exemple dans le nord de l'Allemagne, une neige abondante couvre régulièrement la teire tous les hivers et pendant à peu près le même temps.

Le moment le plus dangereux pour exécuter cette exploitation est celui pendant lequel pousse le sapin, et l'on a vu que cet arbre n’a qu'une sève, que cette sive commence ordinairement au commencement du mois de mai sous le climat de Paris, et que les pousses du sapin ont pris toute leur longueur au bout le cinq à huit semaines environ; mais il faut compter en outre un mois pendant lequel les pousses étant encore herbacérs se cassent aussi très-facilement; e'est donc pendant les mois de mai, de juin et de juillet qu'il faut éviter principalement de faire la coupe délinitive.

Quelle que soit d'ailleurs l'époque à laquelle s'exécutera la coupe définitive, on détruira toujours beaucoup de plant, moins pourtant qu'on ne le croirait; car, délivré des géans qui l'opprimaicnt, ce plant repousse ordinairement, quoiqu'il ait été meurtri ou brisé.

Dans les grandes exploitations où l'on n'a souvent la certitude de vendre ses marcluandises que lorsqu'on n'en met en vente qu’à peu près la mème quantité tous les ans, on ne peut atlendre une année d'abondance de cônes pour exéruter less coupes d'ensemencement; et comme on aurait presque la certitude d'échouer si on les exécutait plusieurs années d'avance, parce que le terrain se couvrirait plus ou moins de plantes ou d'arbustes, on se contente d'abord de faire des coupes préparatoires qui consistent ì n'abattre qu'une partie des arbres des coupes d'ensemencement, le tiers on la moitié, par exemple : lorsque l'ammée d'abondance de cònes se présente, on achève d'abattre les arbres restans pour mettre toutes les coupes daus lesquelles il avait étí fait des coupes préparatoirrs laus l'itat ou clles doivent se trouver après la coupe d'ensemencenent.

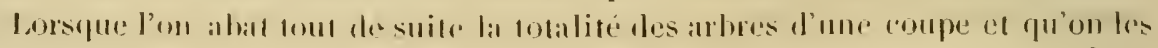


remplace par du plant do pépinière, si l'on a ì expluiter une coupe par chanus année, les exploitations se suivent régulièrement; mais lorsque l'on exploite par bandes et qu'il y a plusieurs bandes par chaque coupe, on ne termine définitivement l'exploitation d'une coupe qu'au bout de six à dix ans; il fatut donc entamer autant de coupes qu'il est nécessaire, en y faisant des coupes préparatoires ou des coupes d'unsemencement, pour que l'on puisse abattre à peu près la même quantité de hois par chaque année, et il faut ensuite rentrer dans l’ordre habituel. Je ferai connaìtre plus loin les inconvéniens des'coupes préparaloires en parlant de celles qu'on est souvent aussi contraint de faire exícuter dans les exploitatious par éclaircies.

Le mode d'exploitation par bandes est en usage en Allemagne, où on l'emploie beaucoup plus pour le sapin picéa que pour lo sapin argenté; je ne sacho pas qu’il ait été mis en usage en France. 11 a été décril dans les ouvrages de. Intrigg et de Cotta, qui ont été, je crois, les premiers à l'employer.

Il y a des montagnes élevées et froides, exposées d'ailleurs à de violens coups de vent, dans lesquelles le recru périrait si on le privait trop tôt d’abri, et oì les vents feraient plus tard de grands dégâts. Il fiut alors, si l'exploitation s'exécute à 80 ans, attendre 40 ans lorsque l'on a coupé une bande, pour couper les deux bandes qui la touchent. Ainsi, chaque bande, lorsqu'on en fait l'exploitation, est bordée de chaque côté par des bandes dans lesquelles les sapins sont moitié moins âgés que ceux que l’on coupe : j’appellerai celte exploitation exceptionnelle, exp'oitalion par bandes permanentes.

Dans l'exploitation par éclaircies on se propose, comme dans l'exploitation par bandes, de renonveler la sapinière au moyen du semis naturel. Les forestiers allemands ont été les premiers à employer re mode d'exploitation que l'on a commencé ì imiter en France depuis quelques années; il repose sur l'observation, qui avait été faite, que le plant ne peut croitre sous l'ombrage des arbres des futaies pleines bien gatrnies; qu’il y lève pourtant, mais qu’il y périt bientòt, à moins qu’il ne se trouve près des allées, des lisières ou des clairières. Hartig, grand-maitre des forêts de la Prusse, et Cotta, conseiller supérieur des forêts du royaume de Saxe, sont les premiers, je crois, qui aient enseigné le modr. d'exploitation des futaies par éclaircies, et ils sont aussi, je crois, les premiers qui l'aient mis en pratique (1); ils expliquent avec détail ce mode d'exploitation, pour les futaies de hêtre, et se contentent de dire, lor'squ'ils parlent du sapin argenté, qu'on doit le traiter absolument comme le lıêtre : je vais décriro ce mode d'exploitation d'après ces'auteurs.

Les coupes de la futaic scront disposées, en ce qui concerne l'ordre de leur ex-

(1) Hartig a enseignè l'exploit tion par bandes el par éclaircies dans sol Irstruction sur la cullure $d u$ bois à l'usage des forestiers, qui a été traduit, et dans son Instruction pour les forestiers et ceux qui veulent le devenir, qui ne l'a pas été; Henri Cotla l'a enseigné dans son Traité de culture fortslière, qui a èté traduit, dans ses Principcs fondamentaux de la science forestière, qui ont été traduits, et dans son Irstruction pour l'aménagement el l'estimation des foréts, qui ne l'a pas été. J'ai donne aree tétail te titre de ece ourrages tans la liste qui se trouve au commenecment le ce Traite. 
ploitation, ainsi qu'il a été dit page 86; c'est-à-dire que l'exploitation commencera par le nord-est et finira au sud-ouest. Une coupe ayant atteint l'âge auquel on jugera avantageux de l'exploiter, qui est de 70 à 80 ans sous le climat de Paris, et contenant, ainsi que je l'ai dit, environ 400 arbres par hectare; on préparera la coupe, s’il est nécessaire, comme je l'ai indiqué page 90 , en parlant de l'exploitation par bandes étroites, pendani l'annèe qui précédera une année d'abondance de cônes. L'année suivante, lorsque la graine sera tombée, ce qui arrive à la fin de septembı ou au commencement d'octobre, on abattra une partie de ces arbres, de manière à rendre au terrain assez de lumière et de soleil pour que le semis naturel qui périssait dans les années qui suivaient sa naissance, par suite de l'ombrage, puisse au contraire prospérer du moins pendant quelques années : cette coupe partielle s'appelle coupe sombre ou coupe d'ensemencement.

Il n'est pas possible de déterminer, d'une manière précise, le nombre d'arbres qu'il faut abattre, pour mettre la coupe en exploitation dans la situation la plus favorable à la naissance du semis naturel et à sa prospérité, pendant les années qui suivent celle où l'on a exécuté la coupe d'ensemencement; effectivement cela dépend de circonstances variables telles, par exemple, que la nature du terrain, l'exposition, le plus ou le moins d'obscurité de la futaie. "Cette coupe, dit Har" tig, dans son Instruction sur la culture du bois à l'usage des forestiers, page 35, doit " être plus ou moins claire, selon qu'elle a lieu sur le revers septentrional des " montagnes, et dans les endroits qui sont d'ailleurs humides et ombragés, " selon que les semis existans sont plus ou moins épais et que l'on a à craindre "la crue des mauvarses licrbes et plantes nuisibles. "

Cotta dit (1) : "On ne reconnaît pas toujours, au premier abord, l'espacement " qu'il convient de domner aux arbres dans les coupes d'ensemencement. Si, " dans un canton exploitable, il se trouve quelques parties claires, dans lesquelles " le repeuplement naturel a lieu, il faut se guider d'après ces parties, choisir la " place où le recru est le plus beau et le plus complet, et donner à la coupe d'en" semencement qu'on veut faire, un espacement semblable. "

Dans une grande futaie, où je suppose que l'on exploite au moins une coupe par chaque année, on finira par être à peu près fixé à cet égard; ordinairement il faut qu'après la coupe d'ensemencement les branches se touchent à peu près lorsque le vent balance la cime des arbres. Je présume qu'en abattant 150 sapins sur les 400 que je suppose exister par chaque hectare, un peu plus ou un peu moins, ce qui se fera en tâtomnant, on atteindra ce résultat. On procédera ainsi qu'il suit: la coupe ayant été nettoyée l'année précédente des arbustes qui gèneraient la vue et préparée s'il est nécessaire, ainsi qu'il a été dit, on marquera environ le tiers cles arbres que l'on veut abattre en entourant le trone d'une ligne rouge; quand ils auront été abattus et ébranchés, on marquera un second liers que l'on abattra aussi, et enfin on marquera et l'on abattra le troisième tiers. Cette opé- 
ration est d'allenrs fort délicate el exige pour être bien exécutée qu'on y apporte la plus grande attention el qu'on ait des comnassances pratiques; car si l'on a trop éclairci, les plantes el arbustes, poussant avec trop d'activité, étoufferont le plant, et si l'on n’a pas assez éclairci, l'ombrage lo fera périr comme par le passé.

Daus les grandes exploitations, on sera obligé de faire des coupes préparatoires, par le motil que j’ai domé et comme je l'ai indique page $92 \mathrm{cn}$ parlant de l'exploitation par bandes; ainsi elles consisteront dans l'abaltage d'une partic des arbres des coupes d'ensemencement, du liers ou de la moilié, par exemple; l'on achèvera d'abattre les arbres de ces coupes lorsqu'il se présentera une année d'aboudance de cònes. Les coupes préparatoires, auxquelles on sera pourtant contraint d'avoir souvent recours, présentent d'ailleurs de grands inconvéniens, quand l'annće d'abondance de eònes que l'on attend pour achever d'abattre ce qui fait partie de la coupe d'ensemencement tarde trop à arriver; en elfet, lorsque cette ammée d'abondance arrivera, on aura ordinairement plus de bois a abattre qu'on ne peut en vendre ou qu'on ne peut en exploiter faute d'ouvriers, et si l'on n’abat pas, le jeune recru pourra périr; le même inconvénient peut se présenter relativement à la coupe claire et à la coupe définitive dont je vais parler.

J'examinerai plus loin les avantages et les inconvéniens que présente le mode d'exploitation par éclaircies, et je comparerai à la tin de cet article les cinq modes d'exploitation que je décris; mais, pour l'intelligence du mode d'exploitation dont je m'occupe actuellement, je dois supposer d'abord que l'on réussit, ainsi qu'on se le propose. Je supposerai donc que la coupe d'ensemencement se trouvera suffisamment garnie de plant, par le semis naturel, dans l'annee qui suivra l'exploitation.

Lorsque le semis uaturel a atleint environ $0^{\mathrm{m}}, 32$, il a besoin d'un peu plus de lumière, et il périrait si l'on n'éclaircissait point de nouveau; on fera donc cunper la moitié environ des arbres réservés, choisis parmi ceux qui ont le phus de volume, de manière pourtant à ce que ceux que l'on conserve soient à peu près à une égale distance les uns des autres; néanmoins, s’il y a des parties oì le recru soit plus abondant et plus élevé, on y laissera un peu moins d'arlres que dans les parties où il est plus clairsemé. On marquera les arbres que l'on doit abattre avant que la neige, qui empêche de bien distinguer le plant, ne couvre la terre, et l'on exécutera cette exploitation pendant la neige, si on le peut; car c'est alors qu'elle cause le moins de dommage an jeune plant. Si l'on est contraint de laisser du bois dans la coupe plus longtemps qu'on ne l'aurait voulı, on l'entassera dans les endroits où il causera le moins de dommage el d'où l'on pourra le tirer plus facilement : celte seconde coupe s'appelle roupe claire. Enffu, lorsque dans cette coupe claire le plant aura de $0^{\mathrm{m}}, 32$ a $1^{\mathrm{m}}, 30$ de haut, on achèvera l'exploitation; cette dernière coupe s'appelle coupe définitive; elle sera exécutée avec les précautions que j’ai prescrites pour les deux coupes qui la précèdent.

Les hauteurs anxquelles je dis que doit ime parronu le plant, lorsqur lon exi- 
cute la coupe claire et la coupe définitive, soni eelles que donnc Colta pour le hêtre, dans son Traité de culture forestière, pages 38 et 41 ; mais, page 54 de ce mème ouvrage, il renvoie, en ce qui conccrue l'exploitation du sapin, à ce qu'il a dit du hêtre: "Il y a parité, dit-il, entre ces deux essences pour la révolution, "l'état scrré lors de l'ensemencement, l'enlèvement retardé des arbrès d'abri, " ainsi que pour les règles de prévoyance; mais, lors des coupes claires et "définitives, l'exploitation doit être faite pendant l'hiver plutôt que pendant "l'antomne, parce que, pour les feuilles du sapin, il n'y a de différence à au" cume saison de l'amnée, et que si la chute des arbres a lien pendant la neige, " celle-ci protige les jeumes plants."

Dans l'ourrage qui est intitulé Instruction pour les forestiers ct ceux qui v'culent le devenir, traduit par Baudrillart dans son Dictionnaire des eaux et forêts, en ce qui concerne les exploitations par éclaircies, on trouve (1. II, p. 125 et 126) ce qui suit sur l'exploitation du sapin argenté : Quand, dit Hartig, une forêt de sapin " commun est arrivée à l'âge où il convient d'en faire la coupe et que l'on veut " y favoriser le repeuplement par l'ensemencement naturel pendant l'exploita"tion, on doit alors observer exactement toutes les règles que nous avons don" nées pour l'exploitation par éclaircissement des forêts de hêtre, parce que les " forêts de sapin commun doivent être traitées absolument de la même manière." Cet auteur prescrit ensuite de faire la coupe claire lorsque le senis naturel a 3 ou 4 ans, et la coupe définilive lorsque le plant a de 9 i 12 pouces $\left(0^{\mathrm{m}}, 24\right.$ à $\left.0^{\mathrm{m}}, 32\right)$ de haut. Ainsi, Hartig et Cotta sont d'accord pour assimiler les futaies de sapin argenté aux futaies de hêtre, en ce qui concerne leur exploitation; mais ils ne sont pas d'accord relativement aux époques auxquelles doivent être exécutées la coupe claire et la coupe définitive. L’opinion de ces deux forestiers sur l'assimilation des futaies de sapins argentés aux futaies de hêtres, en ce qui conceme leur cxploilation, n’a d'ailleurs pas été généralement adoptée; ainsi, elle a élé combattue, page 109 du Traité des arbres résineux, publié par Dralet, lorsqu'il étiil inspectem principal des forêts clu midi de la France, où le climat est si différent de celui du centre de l'Allemagne.

On peut espérer que, dans l'espace de six à dix ans, la coupe que l'on aura exploitée par les procédés que je viens de décrire se trouvera parfaitement repenplée. Mais cela est incertain, et l'on se verra très-souvent contraint de suppléer il l'insuffisance du semis naturel par des semis artificiels, ou, ce qui est bieu préférable, par des plantations de jeunes plants; aussi je ne saurais trop insister sur l'avantage d'avoir abondamment à sa clisposition du plant de pépinière. Il y aura d'ailleurs de grandes différences, selon les localités, dans le temps qui doit s'écouler entre la coupe d'ensemencement et lá coupe délinitive, car cela dépendra et de la manière dont profitera le plant et de la nature du terrain; il y a, en effet, des terrains sur lesquels on pourra faire la coupe définitive, quoique les plants les plus hauts u'aient encore que $0^{\mathrm{m}}, 32$, tandis qu'il y en a d'autres où il faut attendre qu'ils aicnt $1^{m}, 30$ si l'on ne veut s'exposer à les voir ćtouffés par les plantes ut allustrs qui y naituont en quantilé. Malgró tous les soins qur. 
j'ai preserits, il arrivera encore trop souvent qu'on sera obligé de procéder an repeuplement par lo sẹmis artificiel ou la plantation.

L'exploitation par éclaircies est, ainsi que l'exploitation par conpes rases par bandes étroites, impraticable dans quelques montagnes exposées à des vents violens et à des froids rigoureux; les années d'abondance de cônes y sont d'ailleurs plus rares; il fiut donc y employer l'exploitation par bandes permanentes, ou le jardinage, on entin la méthode mixte, que je décrirai après celle dont je moccupe actuellement.

Le grand avantage qu'on se propose d'obtenir en employant l'exploitation par éclaircies dont je viens de parler, est le repeuplement an moyen du semis uaturel; mais il est incertaiu que l'on puisse atteindre ce résultat. En effet, il peut arriver que la coupe d'ensemencement soit trop claire, et qu'il poussis assez. l'herbes et de plantes pour empêcher la graine de lever ou pour étouffer le jeune. plant; il peut arriver encore qu'elle soit trop sombre et que le jeune plant meure parce qu'il est trop ombragé. Une circonstance fâcheuse se présente aussi assez souvent après que le plant a bien levé : on voit disparaître le jeune plant l'année suivante sur quelques points, tandis qu'il prospère sur d'autres, ce qui tient quelquefois à ce que des insectes mangent les feuilles séminales, ainsi que je l'ai ćprouvé.

Lorsque le plant n’a pas levé, ou qu'il at péri par une cause quelconque, si l'on veut attendre une nouvelle annće de cônes, on aura moins de clrances encore que la première fois d'obtenir du semis naturel en quantité suffisante; si l'on veut exécuter dès semis artificiels, cela ne sera pas toujours possible, parce qu'on ne peut se procurer de la graine que dans les ammées d'abondance ét qu'une grande partie ou la totalité de cette graine a déjà perdu sa faculté germinative la seconde année; il faudra donc alors avoir recours à la plantation, qui n'est sùre qu'avec du plant de pépinière, et l'on ne peut s'en procurer, du moins en quantité suffisante, qu’en l'élevant soi-même. Des retards dans le repeuplement peuvent d'ailleurs causer de grandes pertes; ainsi, par exemple, un retard de huit ans dans unc sapinière exploitéc à 80 ans enlèvera un dixième du revenu, et la terre aura perdu cette fécondité extraordinaire qu'on lui remarque toujours immédiatement après qu'on a abattu une futaie, ce qui sera très-nuisible à la jeune sapinière. Mais, lors même que le semis naturel réussirait à souhait, la futaie serait toujours exposée aux ravages des vents pendant le temps qui s’écoulera entre la coupe claire et la coupe définitive; et à tel point que ce mode d'exploitation serait impraticable dans beaucoup de lieux exposés à de violens coups de vent, particulièrement dins les montagnes et sur les plateaux élevés.

Je rapporterai à ce sujet ce qui fut dit dans le congrès forestier tenu à Bade. en mai 1811, congrès tlout j’ai dájì parlé page 69. Il fut recommu, par suite d'observattions faites dans les sappinières de diverses parties de l'Allemagne, que les coupros d'ensemencenent, exécutées d'après la théorie des éclaircies nonvellement mises en pratique, élaient loin de produire tonjours les resultats qu'on en allendait; qua la vérito les jeumes plants y levaient nedinairement avere abondaner. 
mais qu'après la prentière ou la seconde année on les voyait souvent disparaitr: sans qu'aucune circonstance particulière pùt expliquer pourquoi on attribuait cette mortalité du plant à ce qu'il lui fallait encore plus de lumière deux ans après sa naissance qu'on ne lui en accortait. Il fut donc proposé de fairè les compes d'ensemencement plus claires que par le passé, et de procéder à l'exploitation de la conpe claire teux ou trois ans après, sauf les exceptions que demandaient des expositions chaudes. Cette proposition parul d'abord obtenir l'assentiment de la plus grande partie de l'assemblée, et l'on parla même de substituer à l'exploitation par éclaircies l'exploitation par bandes, fort pratiquée en Allemagne pour le sapin picen; mais cette dernière proposition ne fut point accueillie.

Il fut en définitive décidé qu'il ne fallait apporter aucune modification à ee qui se pratiquait pour la coupe d'ensemencement; et que, quoiqu'il parùt probable, en ce qui concernait la coupe chaire, qu'il serait prétérable de la rapproclier de la coupe d'ensemencement, il était pourtant prudent de ne prendre à ce sujet ancune décision jusqu'i ce qu'un plus grand nombre d'observations et l'expériences eussent tixé l'opinion des forestiers à cet égard.

La cause à laquelle on attribuait la mortalité du plant ne me semble d'ailleurs pas pronvée, puisque cette mortalité était irrégulière, et que je me suis assuré que le plant de sapjin argenté est quelquefois détruit en totalité ou en partie par des insectes. Quoi qu'il en soit, si l'on exécutait la coupe claire deux ans seulement après la coupe d'ensemencement, il y a des terrains où le plant serait étouffé par les plantes el arbustes qui naîtraient alors, et l'on exposerait ce jeune plant à l'action des geelées tardives dı printemps.

Le mode d'exploitation par éclaircies n’ayant guère encore été employé qu'en Allemagne, que depuis un petit nombre d'années et pas généralement, on devait s'attendre que les opinions seraient d'abord différentes sur le mérite de ce genre d'exploitation; c'est aussi ce qui ust arrirci, et l'on n'est pas encore entièrement fixé. Néanmoins on tombe d'accorl que le repeuplement au moyen du semis naturel, qui est le grand avantage que l'on se propose d'obtenir, est incertain; que dans les lieus soumis ì de violens coups de vent, surtout lorsque le sol étant peu profond les arbres sont mal enracinés, ce mode d'exploitation est impraticable, parce que les vents rasent alors des parties entières de lutaies; qu'enfin, dans les montagnes ì une ccrtaine lıateur, même dans les parties abritées, cette méthode est aussi en quelque sorte impraticable, parce que les années d'abondance de cônes ne s'y présentent que de loin en loin. Ajoutons que ce inode d'exploitation pourrait réussir en Allemagne et dans les climats analogues, é échouer ailleurs, par exemple dans le midi de la France. On trouvera dans le chapitre suivant un remarquable exemple de l'insuccòs de cette mèthole que l'on avait appliquée anx futaies de sapins picéas du Riesengebirge, chaine de montagnes qui se trouve sur les frontières de la Silésie et de la Bohême.

On conclura de tout ce que je viens de dire de l'exploitation par éclaircies, que ce mode d'exploitation n'est autre chose qu'un tâtomnement pour obtenir ('n assez grande quantité du plant de semis naturel on abattant los arbres à trois 


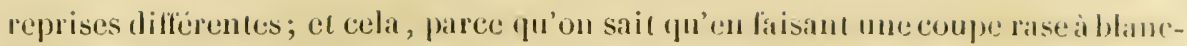
étoc, la futaie se trouverail détruite ou réduite au plus triste état. Na is le climat, le terrain, l'exposition, la nature des essences, apportent de telles différences dans la manière dont ce genre d'exploitation doit être conduit, qu'il ne me paraît pas sans danger de prescrire rigonreusement de quelle manière doivent être exécutées la coupe d'ensèmencement, la coupe claire et la coupe délinitive. de preférerais dlone me borner à l'instruction suivante.

Lorsque l'on voudra exploiter une futaie de sapins argen tés à l'élat serré, dins laquelle il ne se trouve par conséquent de recru qu'en quantité insuffisante, et si l'on désire pourtant là repeupler cu même essence au moyen du semis naturel, en employant le mode d'exploitation par éclaircies; on ne fera pas de coupes rases, on abattra la coupe que l'on veut exploiter en trois fois, en se conformant à ce qui vient d'être dit. Mais en ce qui concerne le nombre d'arbres que l'on abattra dans chacune des trois coupes partielles, et l'intervalle de temps qu'il y aura entre elles, chaque localitẹ établira sa règle basée sur l'expérience.

11 me reste à parler de l'exploitation par la méthode mixte; elle tient de l'exploitation en jardinant et de l'exploitation par coupes rases. Je supposerai que la sapinière dont je vais m’occuper a été nouvellement créce, et qu'elle ne contient, par conséquent, que de jeunes sapins d'âges peu différens, dont elle est bien garuie. On la traitera absolument de la même manière que si elle était Ilestinée à être exploitće en jardinant, jusqu'à l'âge où commencerait, à proprement parler, cette exploitation, e'est-ì-dire jusqu'ì ce que les sapins les plus âgés aient atteint de 70 à 80 ans. A cette époque la sapinière devra être garnic de sapins de tous âges; mais on y aura maintenu les arbres un pen plus serrés que si l'on voulait l'exploiter en jardinant, et il faudrait l'éclaircir encore, si l'on ne se décidait a l'exploiter ainsi que je vais le dire.

Une coupe ayant atteint l'âge auquel on jugera avantageux de l'exploiter, on

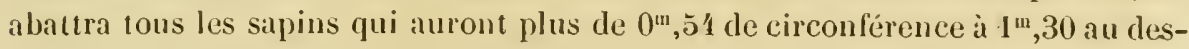
sus du sol, en prenant toutes les précautions que j’ai précédemment indiquées. Les arbres de $0^{\text {m, }}, 54$ de circonférence, d'une végétation ordinaire et qui n’ont éprouvé aucun obstacle dans leur accroissement, ont ordinairement environ 40 ans; mais s'ils ont été retardés daus leur jeunesse par l'ombrage et le défaut d'espace, ce qui arrive fréquemment dans les sippinières, une partie d'entre eux seront d'âge à donner du semis naturel efficace, et il s'en trouvera presque tonjours assez dans ce cas. On doit d'ailleurs conserver quelques porte-graines que: l'on abat plus tard. I vec ce genre d'exploitation on fait du chevron, des échelles, de la solive, du bois de charpente et de la planche; ainsi on ne pourrait l'employer dans les localités oi l'on ne trouve à vendre que le bois de charpente de fortes dimensions et la planche.

Il serait préjudiciable aux intérêts du propriétaire d'abattre pendant cette exploitation des arbres plus petits que ceux qui ont $0^{\mathrm{m}}, \mathrm{b} 4$ de circonférence à $1^{\mathrm{m}}, 30$ au dessus du sol. Ces arbres pouvant avoir une valeur décuple vingt ans plus tard, on ne doit le faire qu'entre deux exploitations quand il y a nécessite 
pour eclaircir. Il faut au contraire, si l'on croit pouvoir le tinire, réserver tuefques arbres qui auraient dépassé cette dimension et qui seront désignés parmi ceux qui auront la plus belle régétation, afin d'aroir à l'exploitation suivante un petit nombre d'arbres d'une dimension beancoup plus forte, ce qui peut être :tvantagenx; ce sont d’ailleurs ces arbres de la plus belle végétation, qui procurent le plus de bénéfice lorsqu'on les attend.

Pendant les premières années qui suivent l'exploitation, les sapins de différens âges que l'on aura conservés, ayant obtenu de l'espace et de la lumière, auront une végétation magnitique; on en remarquera qui avaient perdu presque toutes leurs branches, et par conséquent presque toutes leurs feuilles; qui n'en avaient conservé que vers le haut de leur tige, et étaient restés stationnaires pendant de longues années; et qui pourtant, après a voir reformé des branches et une flèche au moyen de boutons adventifs, auront quelquefois, à la quatrième sève après l'exploitation, des flèches de plus de $0^{\mathrm{m}}, 65$ de long.

Au bout de dix années environ après l'exploitation, il faudra recommencer ì éclaircir et continuer les éclaircissages quand il sera nécessaire; et de 25 à 3 j ans après l'exploitation, plus ou moins selon la nature des terrains et l'état de la coupe, on en recommencera une nouvelle entièrenent semblable à celle que je viens de décrite.

Ce genre d'exploitation est en usage dans une partie des sapinières des environs de Laigle, et e'est celle quel'on suit dans la sapin ière de Raveton. Je n’ai point de données d'expériences assez précises pour pou vonr me permettre d’éval uer le revenu que l'on tirera de chaque heetare en suivant ce mode d'exploitation, ainsi que je l'ai filt pour les autres modes; mais les recherches auxquelles je me suis livré à ce sujet me font présumer qu'en en tirera au moins autant de revenu que par le jardinagoe. Ce mode d'exploitation présente d'ailleurs l’a vantage, lorsque les futaies de sapins argentés sont d'une grande étendue, que la surveillance de l'exploitation est plus faeile que lorsqu'on exploite en jardinant, et que les arbres ayant crù dans une situation un peu plus serrée, sont moins branchus et conservent mieux leur grosseur.

Récapitulons sommairement les avantages et les inconvéniens des cinq modes l'exploitation que je viens de décrire.

L'exploitation par coupes rases en repeuplant la sapinière au moyen de la plantation, n'a peut-être jamais été employée sur une grande échelle que dans la futaie de sapins picéas de l'abbaye de Vallombreuse, dont j’ai parlé page 87; cependant ce mode de reproduction me paraît présenter des avantiges incontestables. En effet, si l’on emploie dı plant de pépinière élevé avec soin, arraché et planté de même, il n'en manquera pour ainsi dire point, et les sapins seront tous de même âge; ils auront une végétation aussi active, et acquerront d'aussi belles dimensions que s’ils étaient provenus de semis naturel; on giagne ainsi dix années qu'il aurait fallu au semis naturel pour atteindre aux dimensions qu'a le plant, en supposant que ce semis naturel n'eìt éprouvé aucun retard dans sa naissance of dians sa végétation. Ces avantages sont me compen- 


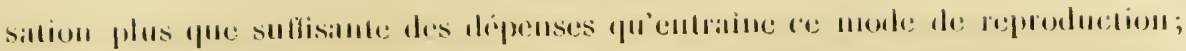
néanmoins, il sera difficilenent alopté à canse de la précantion qu’il lintu prenIre d'élever une pépiuière, plusieurs années avant l'exploitation, et des alvances qu'il force ì laire.

L'exploitation par coupes rases par baudes étroites et l'exploitation par éclaircies, ont pour but de repeupler la sapjuière an moyen du semis naturel; mats on a vu que dans plusicurs situations on ne peut obtenir ce résultat el que toujours il est incertain qu'on l'obtienne, du moins complètement, surtout par ls: second mode d'exploitation. On a vu qu'il faut souvent, lorsque le repeuplement n'a pas réussi, ou n'a réussi qu'en partic, avoir recours au semis artiliciel, qui est lıi-même incertain, ou à la plantation, et qu'il est rare qu'on puisse se procurer de la graine el du plant, du moins en quantité suffisante. L'exploitation par éclaircies est plus gênante et plus conteuse que l'exploitation par coupes rases à blanc-étoc; la compensation est, dit-on, un repeuplement frar le: semis naturel, mais on n'est pas entièrement fixé sur les circonstances où ce mode d'exploitation est praticable et sur celles ou il ne l'est pas; on ne l'est pas davantage sur les chances que l'on a d'obtenir le repeuplenent dins les circonstinces où on le juge applicable : il faut donc attendre encore pour se prononcer' sur ce mode d'exploitation.

Dans les exploitations en jardinant et par la méthode mixte, conduites avee soin et intelligence, le repeuplement se fait régulièrement et avec cerlitude; ces deux exploitations sont pratieables dans toutes les situations, et l'on peul facilement passer de ces modes d'exploitation aux trois autres, en abattant les arbres trop âgís et les arbres trop jeunes, pour ne conserver que des arbres qui soient à peu près de mêmes dimensions; quinze ans environ suffisent pour cette Iransformation : tels sont les avantages de ces deux modes d'exploitation. Les inconvéniens sont qu'on n'obtient pas ainsi une anssi grande quantite de bois et d'ume aussi bome qualité, pour bois d'ouvre, que par les trois autres modes; que, si l'on en excepte les futaies de sapins argentés d'une petite étendue, la surveillance de ces deux modes d'exploitation, et de l'aménagement qui en est la conséquence, est difficile; enfin que les vents; dans quelques localités, exercent des ravages dans les futaies exploitées ainsi.

On conclura de ce qui précède que l'on peut employer partout l'exploitation en jardinant, l'exploitation par la méthode mixte et l'exploitation par coupes rases, en renouvelant la sapinière par le moyen de la plantation; mais que si l'on emploie l'exploitation par bandes ou par éclaircies, dans lesquelles on se propose de renouveler la sapinière par le semis naturel, la réussite est incertaine, et qu'il est indispensable d'avoir alor's du plant à sa disposition pour suppléer, par les plantations, au défaut de réussite du semis naturei ou ì son insuffisance : il est d'ailleurs exact de dire que les forestiers ne sont pas encore dixés sur ces deux derniers modes d'exploitation, particulièrement sur l'exploitation par éclaircies.

Les exploitations par coupes mases, par coupes rases par handes étroites, el par 
iclaircies, paraissent dunner un revenu plus élevé, dans les situations entièrtment favorables au sapin argenté, que les exploitations en jardinant et par la méthode mixte; les trois premiers de ces cinq modes d'exploitation sont d'ailleurs plus faciles à surveiller. Il semble donc qu'il serait préférable d'employer les deux derniers de ces trois modes d'exploitation dans les grandes forêts, s'il était possible d'obtenir alors, avec certitude, le repeuplement par le semis naturel; mais comme on n'y est pas parvenu, il ne me parait pas sans danger de les adopter. Si je devais pourtant faire un choix, celui des deux que je préférerais est l'exploitation par coupes rases par bandes étroites en complétant le repeuplement par la plantation, partout où il serait nécussaire, avec du plant de pépinière. Voici d'ailleurs comment je conduirais cete exploitation.

Soit une forêt de sapins argentés, situéc en plaine sous le climat de Paris; je suppose que cette forêt contienne 1,200 hectares divisés en 80 coupes de 15 hectares chacune, et qu'on en coupe une chaque année. Ces coupes seront tracées de manière à former des bandes qui n'aient pas moins de 30 mètres de large, et elles seront numérotées depuis 1 jusqu'à 80, dans la direction dı nord-est au sud-ouest, s'il est possible, e'est-ì dire que le $1^{\circ} 1$ sera an nord-est et le no 80 au sud-ouest de la forct.

Pour fixer les idées, je supposerai que cette forêt forme un parallélogramme, Iont deux côtés aient 3,000 mètres chacun et les deux autres 4,000 mètres; on la divisera par bandes ayan 13,000 mètres de long, s0 mètres de large et par conséquent une superficie de 15 hectares. On exploitera ces coupes, à raison d'une par chaque année, dans l'ordre suivant: $\mathcal{N}^{\circ 4} 1,9,17,25,33,41,49,5 \check{7}, 65,73,2$, $10,18,26,34,42,50,58,66,74$, etc. Il résultera de cet ordre d'exploitation que chaque coupe aura, pendant dix ans, une lisière de 3,000 mètres de long qui se garnira plus ou moins do: plants provenant de semis naturel, ce qui diminuera beaucoup le nombre de plants de pépinière qu'il faudra planter pour repeupler la coupe.

Il y a d'ailleurs, dans les montagnes et dans les vallées, des sapinières qui occupent des terrains en pentes excessivement rapides, parsemés quelquefois de rochers et de pierres, soumis à des vents violens, et dans lesquels il n'y a de praticable que l'exploitation en jardinant, l'exploitation par la méthode mixte et quelquefois l'exploitation par bandes permanentes. Si un propriétaire n'a qu'une sapinière d'une médiocre étendue, je préférerais la méthode mixte; ainsi, par exemple, je suppose qu'il possède une sapinière de 30 hectares; on couperait un hectare tous les ans, ou deux tous les deux ans, ou cinq tous les cinq ans, etc., un se conformant à ce que j'ai prescrit. Le revenu se trouverait peut-être ainsi moins élevé, dans les terrains de bonne qualité, que si l'on eùt employé l'exploitation par coupes rases, ou par coupes rases par bandes étroites, ou l'exploitation par éclaircies; mais il se ferait moins attendre et le repeuplement serait assuré.

On ne cultipe point assez le sippin argente en France, sons le climat de Paris, 


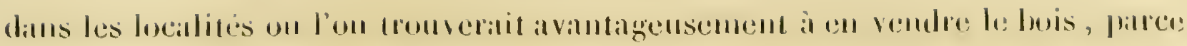
qu'il n’y a pas d'ouvrage pratique à bas prix qui ant enseigné avec détail cette culture; parce que les terres, dans lesquelles on pourrait cultiver avec sueces cet arbre, sont également propres à la culture des céréales; parce que l'on peust généralement gu’on ne peut créer une sapinière sans perdre, pendant de longues ammées, le revenu du terrain qu'on y coisacrerait; parce qu’ulin le sappin argenté étant l'arbre des huit espèces dont je me suis oecupé spécialement, qui met plus de temps à alteindre la hauteur à laquelle les pépiniéristes sont dans l'usage de vendre leurs plants, ils en cultivent moins que des autres espèces. Mais j'ai fait voir qu'il n'y a, pour ainsi dire, point de culture en grand qui puisse domner un revenu aussi élevé, sons le climal de Paris, que celle du siphin argenté dans les terrans qui lui conviennent, lorsque le débit des marchandises que l'on fail avec son bois est assuré, quoiqu’ì des prix modérés d'ailleurs; qu'il y a des terrains argileux qui rapportent peu pour la culture des céréales et dans lesquels celle du sapin argenté réussit fort lien; et qu'enfin on peut créer une sapinière dins un bois taillis, pour ses héritiors, avec me dépense de quelques liranes seulement par hectare, ot sans éprouver, en quelque sorte, aucume diminution dans le revenu.

IX. Qualtés et usages du bots; produtts divers. - Le pied cube $\left(0^{m}, 031\right)$ de bois d'un sapin argente de 80 ans pèse vert, d'après Hartig (1), 66 livres 14 onces (32 kil. $728 \mathrm{gr}$ ), et sec, 41 livres 8 onces (20 kil. $313 \mathrm{gr}$ ); il est moius pesant dans la jeunesse de l'arbre. Dralet dit, page 12 de l'ouvrage précédemment cité, que le pied cube de ce bois pèse vert 60 livres et sec 32 . Leroy dit, page 24 du Mémoire précédemment cité, relativement aux sapins qu’il laisalit exploiter, dans les Pyrénées, pour être employés à la mâture : "Un pied " cube de bois pris dans le milien d'un arbe vigoureux et fraichement coupé " pèse depuis 62 jusqu'ì 64 livres; le même morceau de bois, exposé à l'air jen" dant un an, ne pèse plus que 36 à 38 livres; le même pied cube, pris auprès de " la sonche, pèse jusqu’à 84 livres et se réduil, en un an, à 46 livres. „ Dans mon parc te pied enbe de bois d'un sipin de 60 ans, abattu le 7 septembre 1813 , pris près de la souche, pesait vert 32 kilogrammes; le 5 aoùt 1844 , il ne pesait plus (jue 18 kil. $320 \mathrm{gr}$; le $1^{\mathrm{er}}$ mars 1815 , il pesait toujours 18 hil. 320.

Le bois de sapin argenté est d'un blane terne, il est élastique et nerveux tout it la fois, il est facile a fendre, il se conserve longtemps sain lorsqu'il est it l'abri, et assez longtemps à l'arr; il n'a point t'aubier, et l'on prélè̀re mêne ha planche qui ne conticut point de hois du cour de l'arbre à celle qui en contient; il est à peu près de la même qualité que le bois du sapin picéa, pour ceux des usages auxquels ils sont propres tous les deux, cependint l'un est quelquefois préférable à l'autre pour certains usages que j’indiquerai ; il est supérieur en qualité au bois du pin maritime, mais infériemr, dit-on, an bois dlu pin sylestre ed du

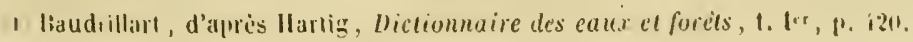


mélèz. Je ne puis comparer le bois du sapin argenté au bois des pins laricio et Weymouth, la qualité du bois que produisent ces pins, en France, n'étant pas encore suffisamment connue. Dans le congrès forestier qui se réunit à Stultgard, en 1842, congrès dont j’ai parlé page 57, on examina si le sapin argenté devait ètre préféré au sapin picéa, ou le picéa au sapin, et l’on domna généralement la préférence au sapin picéa. Cependant un membre dit que, dans la Thuringe, on prélérait effectivement le picéa pour les constructions, mais que le sapin l'emportait comme bois de fente et de racleric, et pour faire de la planche. Je ferai observer que le climat exerce ordinairement une influence notable sur la qualité du bois; ainsi, de ce que le picéa que l’on trouve jusqu'au nord de l'Europe, serait préférable au sapin dans certaines localités, par exemple dans la Thuringe, qui est presque la limite nord de ce dernier arbre en Allemagne, ce ne serait pas une raison pour qu'il en fût ainsi sous le climat de Paris; c'est ce que j'examinerai dans le chapitre du sapin picéa.

On emploie le bois de sapin argenté pour la mâture, la charpente, les échafaudages; pour les pilotis, selon M. Mougeot (1); pour des conduits ou des tuyaux te fontaine, selon Kasthofer (2); on fait avec ce bois de la planche, des madriers, de la volige, des pieux aussi durables que ceux de chêne, des échelles dont on peut faire les échelons avec les branches de cet arbre, des perches pour la culture du houblon, des gaules pour les blanchisseurs, des manches d'outils, des Lomneaux pour le transport du sel et d'autres denrées, de la boissellerie, du bardeau (3), que l'on appelle aussi aisseaux, aissandre, essione et ganivelle dans le pays que j'habite; enfin, on emploie aussi le bois de sapin argenté à la construction des iustrumens ì corde, mais celui du sapin picéa est préférable pour cet usage.

Un passage de Leroy suffira pour faire voir quelle peut être l'importance dı sapin argenté en France, pour la marine: "Les mâts des Pyrénées, dit-il, de" mandent à être traités avec beaucoup plus de précautions que ceux du Nord, " parce que la qualité des bois est naturellement inférieure; maís avec ces pré" cautions, prises régulièrement, on les mettrait presque de niveau pour le ser" vice que l'État peut en tirer dans les arsenaux pour mèches, jumelles, beau"prés, etc.; fitisant même abstraction de mâture, ils peuvent encore suppléer " aux bois du Nord pour les aiguilles de carène, les poutres, pour toute espèce " d'échafaudages, matériaux, bordages, planches, épars, etc." Dralet dit, page 51 de l'ouvrage précédemment cité, que " depuis 167ŏ, ces montagnes "fournirent plus de trois millions de pieds cubes de bois de mâture. "

L'emploi du bois de sapin argenté, pour la charpente, présente de grands avantages, parce que les pièces de charpente qu'on en fit sont longues et parfaitement droites; les poutres et solives de ce bois ne se tourmentent point,

(1) Nouveau Duhamel, p. 319.

(2) Le Guide dans les forêts, t. Jer, p. 79, art. du Sapin blane.

(3) Petite planche pour courrir les hâtimens romme aver, de lir fuile. 
comme il arrive souvent à edles que l'on fait aver du chène; de la le proverhe: Chêne debout, stapin de trurers. Il dlure extrêmement longtemps quand il est à couvert. "Les forêts de la vallée d'Aure et des Quatre-Viseatux, dit Lapeyrouse (1), "ont longtumps fourni, à Toulouse et à Bordeaux, des poutres du plus grand " échantillon; jen ai vu qui avaient 24 mètres de longueur en bois de serviec " et près d'un mètre d'équarrissage. Les entraits des fermes de la toiture de nos " anciennes iglises sont de sapin argenté; les siècles rui se sont éconlés depuis "qu'ils sout en place ne leur ont porté aucune atteinte."

llarlig place le sapin argenté, relativement à sa valeur, comme bois de chauflage et pour la fabrication da charbon, après lo pin sylvestre, le mélèze et le sapin picéa; il est supérieur, sous ce rapport, au pin maritime. Kasthofer dit que 16 toises de sapin argenté équivalent, pour le chauffage, à 11 toises et demie de hêtre. J'ai brùlé souvent du bois de sapin argenté, surtout dans ma cuisine; quand il est sec, il me parait brùler aussi vite que le hêtre, mais donner un pen moins de chaleur; je le croirais, sons le climat de Paris, égal sinon supérieur au sapin picéa comme bois de chauffage; je ne l'ai point comparé, sous ee rapport, au bois du mélèze ni à celui des pins dont je m’occuperai.

On extrait du sapin argenté un produit qui est ventu, dans le commerce, sous le nom de térébenthine de Strasbourg, quoiqu'on te tire des sapinières des Vosges, du Jura, de la Forêt-Noire et de la Suisse; c'est une substance liquide de consistance de sirop, employée, ainsi que l'huile essenticlle de térúbenthine, dans la médecine et dans les arts. Elle se trouve dans de petites vessies placées sous l'épiderme de l'écorce des sapins lorsque eette écorce est encore lisse, et chacune de ees vessies n'en renferme que quelques gonttes; la quantití de térébenthine qu'elles contiennent étant d'ailleurs plus grante, quand l'arbre a atteint un âge où son écorce devient rugueuse dans la partie inférieure dı trone, les ouviers qui recueillent eette substance sont obligés de monter dins les sapins. Ils portent, suspendu ì une ceinture, un petit cylindre de fer-blanc, le $0^{\prime \prime}, 22$ a $0^{\prime \prime \prime}, 27$ de long, terminé en pointe tranchante ou une corne terminée le même et une bouteille suspendue à leur còté; ils montent dans les sapins au moyen de crampons qui entrent dans l'écorce de l'arbre et qui sont fixés à leurs souliers; ils percent les ressies avec la pointe de leur cylindre ou de leur corne et recueillent la térébenthine qu'ils versent ensuite dans la bouteille suspenduc a leur cóté. Duhamel-Dumonceau a décrit avec heaucoup de détail cette exploitation (2). On n'est pas dans l'usage d'extraire la térébenthine des sapins dans les salpinières de la Normandie.

M. G. Gand m’a confirmé l'cractitude de ces détails : ce sont des Alsaciens qui viennent extraire la térébenthine des sapins dans les Vosgres, et l'on ne s'oppose point à cette extraction, quoiqu'ils ue paient aucune rétribution pour en obtenir l'autorisation. Selon M. G. Gand, un hectare bien peuplé peut dunner en-

(1) Histoire alrígée de's plantes des Pyrénées, p. 590.

(2) Traite des arbres of arbustes qui se cultivent en France en pleine terre, 1 |⿰, [. 8. 
viron 8 a 10 litres de térébenthine par an, et un homme peut en récolt r environ un tiers de litre par jour : on ne remarque pas que les sapins souffrent de celte extraction.

On trouvera chap. IV, art. IX, l'indication des auteurs qui se sont occupés particulièrement des produits et des qualités des bois, par exemple, du charbon et de sa labrication, de la force de résistanee des bois, de leur combustibilité, de leur corruptibilité, elc; sujets qui ne pouvaient trouver place dans ce Tritité.

X. Accidens, maladies, animaux nuisibles. - Dans les climats où la marche des saisons est irrégulière, comme, par exemple, sous le climat de Paris proprentent dit, les gelées tardives causent quelquelois le grands dommages dans les sapinières, en détruisant les jeunes pousses qui viennent de paraître; ces pousses deviennent alors noires et tombent; il en est de même des fleurs fentelles qui précèdent les cônes, ainsi que je l'éprouvai au printemps de 1843. Cet accident résulte de ce que le sapin argenté conmence souvent à poussur avant le: $1^{\text {er }}$ mai, el de ce que les gelées tardives se font quelquefois sentir jusqu'à la fin de ce mois; ce sont les plus jeunes sapins qui éprouvent ordinairement ainsi le principal dommage : la flèche élant celle de toutes les pousses qui part la dernière, est un peu moins exposée; car les boutons, tant qu’ils restent à l'état de boutons, ne souffrent point des gelées, quelque rigoureuses qu’elles soient, parce qu'ils sont couverts d'une couche de résine.

En 1840, on remarqua dans les sapinières de Laigle ce que l'on n'avait point cucore observé de mémoire d'homme : le mois de février avait été si doux, yue la sève s'était mise en mouvement; le mois de mars fut au contraire très-rigoureux; la nuit le thermomètre centigrade descendit quelquelois à 7 degrés au dessous de zéro, tandis que pendant le jour un soleil ardent réchauffait l'atmosphère; par suite de ces alternatives, des branches de sapins et même de jeunes sapins périrent; on les reconnaissait à la couleur de leurs feuilles qui élaient devenues d'un rouge brun.

Les sapins isolés sont si bien enracinés qu'ils ont peu à craindre d'être renversés par les vents et même d'avoir leur trone brisé, du moins dans les pays de plaine, parce qu'ils sont garnis de branches depuis le sol jusqu'au sommet; mais lorsqu'on exploite une sapinière, les sapins sont exposés à être déracinés et brisés en très-grand nombre, particulièrement dans les pays de montagnes, si l'on n'a pas pris les préeautions nécessaires, parce qu’ils sont moins bien enracinés que les sapins isolés, et qu’ils sont dépouillés de branches dans la partie inférieure du tronc.

La neige el le givre peuvent occasionner des dégâts très-considérables dans les pays de laates montagnes, en chargeant des branches de manière à les faire casser, et quelquefois aussi assez pour briser de jeunes sapins; mais ces aceidens sont rares sous le elimat de Paris; je les ai pourtant vus arriver dans mon pare pendant l'hiver pen rigureus de 1812-1813; une neige abondinte qui 
tomba en février 1843, me cassa beaucoup de branches de sapins et beaucoup) de jeunes sapins. J'ai olsservé aussi quelques accidens semblables, causés par la neige et le givre réunis, au commencement de mars 1845.

Je n’ai point remarqué et je n’ai point entendu dire que la sécheresse pùt faire périr des sapins, de manière à causer de grands dommages dans les sapinières, dans les terrains qui conviennent à cet arbre. L'annće 1803, qui fut très-sèche, ne causa pas d'autres dommages dans les sapinières de la Normandie que de retarder la végétation. En 1834 el en 1835, il périt beaucoup de pommiers dans nos champs par suite de la sécheresse, et il ne périt point de sapins dans les sapinières de Laigle, ni dans celle de Chambray, situće sur un terrain qui craint la sécheresse; on remarqua senlement, dans cette dernière sapinière, que plusieurs sapins cessèrent de croître en hauteur, mais depuis la plupart ont recommencé à croître. Je trouve pourtant dans le 1. V du Nouveau Duhamel, p. 317, dans le Mémoire de M. Mougeot, déjà cité, le passage suivant: "Si les sapins " ne redoutent pas les froids les plus rigoureux, les grandes sécheresses causées "par les chaleurs de l'été leur sont très-nuisibles : l'élé de 1803, qui a été très" sec, a fait périr dans les Vosges de vastes forêts situées an midi, et où l'on " avait 1rop éclairei les hois. On a vu les années suivantes les feuilles jaunir, " tomber, et le tronc se dessécher insuite."

Qu'il ait péri des forêts de sapins argentés dans les montagnes des Vosges, c'est un fait dont M. Mougeot a probablement acquis la certitude; mais est-ce bien la sécheresse qui a fait périr ces forêts? Je ne saurais le croire, et voici pourquoi : les sapinières de la Normandie n’ont rien éprouvé de sembiable en 1803, ainsi que je viens de le dire; les sapins isolés, les sapins plantés dans les haies ou dans les clottures, quelquefois sur les levées de terre en forme de: mur, non plus. Je pense donc que la destruction des forêts dont parle M Mougeot doit être attribućc non à la sécheresse, qui ne pourrait d’ailleurs faire mourir gu'me partie de leurs arbres; mais à ce que des insectes auront fait périr les feuilles, soit en les suçant ou en les perçant, soit en s'y introduisant pour en manger l'intéricur, sans altérer en rien leur forme. Une telle cause peut faire mourir tous les sapins argentés d'une forêt; car les feuilles de cet arbre étant persistantes, et de nouvelles feuilles ne paraissant jamais qu'avec de nouveau bois, si on le dépouille complètement de ses feuilles plusieurs années de suite, on le fiit mourir. Je rapporterai, à l'appui de cette opinion, un fait qui s'est passé sous mes yeux, lans mon pare, lorsque je parlerai des insectes nuisibles an sapin argenté; on verra que les ravages cxercés par l'une de ces espèces l’insectes auraient bien pu être aturibués à la sécheresse, à n'en juger que par l'apparence.

Le tronc des sapins est sujet à la gelivure, maladic qui est occasionnée par l'action d'une gelée forte et subite. Voici ce que je trouve relativement au dommage que cause quelquefois la geléc anx sapins; page 21 du lémoire de Leroy, précédemment cite. "Le sapin, quoique ami des pays froils, llit-il, est cepen" daut sujet antant qu'nn autre à être gaté par la gelie; ceda arrive surtout ì 
" ceux qui bordent les ravins qui commencent au hant des montagnes. L'im" pression de la gelée se marque par de longues ouvertures à l'écorce, lesquelles " pénètrent plus ou moins dans le bois, et elles rendent les arbres absolument " inutiles pour le service.

Le tronc des sapins est sujet à la roulure, qui est la disjonction des conches concentriques ligneuses qui le composent; cette dernière maladie ne se remarque que très-rarement dans les sapinières de la Normandie.

Les sapins sont plus sujets que beaucoup l'autres arbres à être attaqués par des chancres, et ces chancres s'étendent quelquefois tout autour du tronc en forme de bourrelet; il faut abattre les arbres attatqués par celte maladic, qui est incurable et arrête ou diminue leur accroissement. Il serait possible que des insectes fussent quelquefois la cause première de ces chancres, e'est ce que j'ignore; mais on sait qu'il nait aussi des chancres par suite d'écorchures résultant de la chute des arbres sur ceux de leur voisinage, ou de blessures occisiomnées par le choc d'essieux de voitures; on doit donc éviter ces accidens.

La maladie à laquelle les sapins argentés mont paru le plus sujets, est li pourriture des racines et de l'intérieur du trone dans sa partie inférieure; je l'ai remarquée sur des arbres de différens âges. La pourriture à l'intéricur de l'arbre est presque toujours déterminée par la pourriture des racines; si toutes les racines sont pourries, l'arbre périt bientòt; mais s'il n'y en a que quelquesunes qui soient alteintes, et qu'il lui en reste asse\% de saines pour l'alimenter, il peut virre longtemps encore. Les sapins situés daus un lieu trop humide ou trop sec, ou qui se trouvent trop serrés dans la futaic, sont le plus sujets à cetle maladie, qui peut aussi résulter de la vieillesse. Cutte maladie ne se manifeste pas vrlinairement dans son début par des signes extérieurs, et lorsque plus taral elle se manileste ainsi, ces signes ne sont pas toujours faciles à distinguer pour les yeux pen exercés.

Je ripporterai à ce sujet ce que j’ai observé moi-même. Il y avait sept ans que j'étais propriétaire de la sapinière du pare de Chambray, et j'avais remarqué que les arbres abattus par les vents étaient presque tous pourris dans leurs racines, et qu'il se trouvait aussi un assez grand nombre d'arbres pourris de même parmi ceux que j’abattais. J'observai ces arbres, aidé de mon garde et du charpentier qui travaillait habituellement dans ma sapinière, pour tâcher de reconnaitre à des signes extérieurs les arbres qui étaient altaqués ainsi, afin d'en purger ma sapinière, car on ne peut faire une opération plus utile. Nous parvinmes à les distinguer assez bien, et je les fis abattre; nous ne nous trompions point de plus d'un sur six. Les signes auxquels nous les reconnaissions peuvent d'ailleurs mieux s'indiquer pour la plupart sur le terrain, que se décrire dans un livre. Voici pourtant quelques circonstances qui indiquent d'une manière à peu près certaine que les sapins sont attaqués de la pourriture : lorsqu'ils sont sur la mêne souche qu'un sapin aurciennement abaltu, car cette souche pourril, et celle pourriture peut se prolonger sous leur trone; lorsque l'on voit leurs raci-

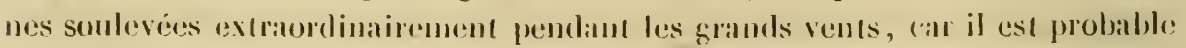


que ces racimes itant pourries se sont hrisées, et que e'est pour esla fue le vint peut les soulcver ainsi; enfin, lorsque leur trone frappé avec un marteau rent un son particulier qui amnonce qu'ils sont entièrement crenx. La couleur de l'écorce, la forme de la tête, l'aspect de l’arbre considéré dans son ensemble, suffisent d'alilleurs souvent pour faire reconnaitre qu'il est attaqué par la pourriture, mais cela ne peut se décrire; j’ai abaltu des sapins déjà creusés par la pourriture qui avaient encore d’assez belles flèches. Le dommage que peurent éprouver les sapinières par suite du très-grand nombre d'arbres pourris qu'elles contiendraient, et qu'on laisseraut subsister faute de pouvoir les distinguer, peu ètre fort considérable. Les signes de cette maladie, souvent si peu apparens, présentent d'ailleurs des différences selon les causes qui y ont donné naissance et la situation de la sapinière, en terrain humide ou en terrain sec par exemple; on devra done fatire une élude particulière de ces signes sur les lieux mêmes.

Les dommages occasionnés par les animaux dans les sapinières sont de diverses espèces. Tous les quadrupèdes pesans y nuisent en foulant aux pieds t. tout jeune plant; en frotant el en endommageant celui qui est plus âgé, et en foulant ses racines; en faisaut ébouler les terres dans les terrains en pentes rapides, et en délonçant les terrains mons et humides. On ne doit jamais faire paìtre les bêtes à cornes, les chevaux et surtout les ânes dans les sapinières; ces derniers animaux sont très-malfaisans, ils broutent souvent les flèches des jeunes sapins. Les vaches ne broutent orlinairement point les sapins argenlés; cependant l'on m’a dit avoir remarqué qu'elles les broutaient dans quelques localités, ce qui pourrait tenir à ce qu'elles y étaient mal nourries, et ì la mature des herbes qu'elles y mangeaient habituellement : il est d'ailleurs incontestable que lorsque le plant est trop petit, elles le broutent en mèmu temps que l'herbe qui l'entoure, et que partout elles écrasent les jemes sapins sous leurs pieds. Quant aux moutons, ils causent toujours un grand dommage dans les sapinières, et encore plus dans celles de sapins argentés que dans celles de sapins picéas, parce que c’est le feuillage du premier qui leur convient lo micux on qui leur est le moins désagréahle. Les chères sont encore plus muisibles que les moutons. Les cochons causent, en fouillant la terre, beaucoup de dégîts dans les endroits où il y a du jeune plant; des forestiers allemands preserivent pourtant, ainsi que je l'ai dit, d'introduire des troupeaux de cochons pour préparer le terrain à recevoir les semences avec succès avant que l'exécuter une coupe d'ensemencement; mais si la futaic contient du plant, ces animaux seront beaucoup plus nuisibles qu'utiles.

Les lapins, quand ils sont en grand nombre, sont excessivement nuisibles, parce qu'ils broutent les jeunes sapins pendant que la terre est converte de neige; mais cela n'est pas sensible si ces animaux sont peu nombreux, et s'ils ont d'ailleurs d'autres alimens qu'ils préfèrent. Ils attaquent presque tonjours les jeunes sapins nouvellement plantés et en coupent souvent la tête, quant ils peurentlattrindre en se dressant sur leurs pattes de derrière. Je donnerai chap. XI, art. I. ralivemrnt aux dignts que commottont ces animaus sur les plintations nou- 
velles d'arbres résineux conifères, tous les renseignemens qu'on peut désirer. Les lapins causent aussi de grands dégâts dans les semis en potets, parce qur: jusqu'à ce que la terre, nouvellement remuée, soit devenue aussi dure qu'elle: l'était auparavant, ils la grattent avec leurs pattes. Les lièvres sont trop peu nombreux, du moins en France, pour occasionner des dégâts sensibles, et je les crois d'ailleurs moins malfaisans que les lapins. Les chevrenils, les daims et les cerfs sont nuisibles, parce qu'ils broutent les pousses, fonlent aux pieds le semis naturel, écrasent et brisent de jeunes plants, mais surtout en en rongeañt l'écorce. Les sangliers détruisent du semis en fouillant la terre, broutent le jeune plant, le mutilent, le brisent et le foulent aux pieds. Les écureuils épluchent les cônes, même avant la maturité, pour en manger les graines, et ils mangent aussi, dit-on, les pousses des sapins, des pins et des mélèzes; s'ils ne les mangent point, il est certain qu'ils en coupent beauconp. Le rat d'eau et le mulot peuvent causer des dommages dans des localités où ils sont abondans, ce qui n'est pas ordinaire dans les sapinières, en rongeant l'écorce des jeunes arbres, particulièrement quand la terre est couverte de neige; le rat d'eau détruit en outre des racines dans le voisinage des eaux, mais on y trouve rarement le sapin argenté. La taupe coupe et ronge des racines de petites dimensions.

Des oiseaux se perchent quelquefois sur la flèche des saipins, et lorsque ce sont de gros oiseaux, et que cela arrive avant que cette flèche soit devenue ligneuse, ils la brisent ou l'endommagent; ce sont les pies qui m'ont paru être les plus nuisibles sous ce rapport. Des oiseaux appclés bec-croisé m'arrivent l'automne par bandes, mangent les graines qui se trouvent dans les cônes des picéas, des mélèzes et des pins, et ramassent sans doute aussi les graines des sapins argentés qui sont déjà tombées alors. Les pinsons, oiseaux indigènes, les eolombes et les pigeons ramiers, oiseaux de passage, mangent la graine des sapins argentés et ne sont sans doute pas les seuls. Le pic-rert perce les sapins argentés comme beaucoup d'autres arbres, ee qui les détériore et les fait quelquefois pourrir.

Il n'existe pas d'autres moyens d'arrêter ou de diminuer le dommage que le propriétaire d'une sapinière éprouverait des quadrupèdes ou des oiseaux sauvages dont je viens de parler, que de tâcher d'en diminuer le nombre ou de les détruire; et quant aux animaux domestiques, il laut leur interdire l'entrée de la sapinière, ce qui est ordinairement facile. Les quadrupèdes et les oiseaux ne causent d'ailleurs, dans les sapinières, que de bien faibles dommagés en comparaison de cenx que leur font quelquefois éprouver certains insectes; je vais parler succinctement de ceux qui sont le plus à redouter.

La larve du hanneton, vulgairement appelée ver blanc on man, qui cause quelquefois de si granls dégâts dans les pépinières, attaque aussi les sapins unuvellement plantés ou provenant de semis, et en général tous les jeunes plants des espèces dont je m’occupe dans ce Traité; elle mange leurs racines et ils périssent ou devienumt languissans. Je vais donmer quelques détails succincts sur l'his- 
toire naturelle du hatumeton, paree que cela est nécessaire à l'intelligence de ce que je dirai plus loin, non pas pour enseigner à les détruire, ce que je ne crois pas possible dans une cullure en grand, mais pour s'en préserver, quand cela est possible. La femelle du hamneton dépose dans la terre, depuis la fin d'avril jusqu'au milieu de mai environ, une vingtaine d'oufs qui éclosent au bout de: quelefues semaines et donnent naissance à des larves que l'on appelle vers blanes on muns; ces larves, qui sont encore petites, se nourrissent de racines et ne causent pourtant pas de grands dégîts cette première anmée, à moins qu'elles ne soient en nombre très-considérable. L'année suivante les mans acquièrent toutes leurs dimensions et e'est pendant cette année qu'ils causent le plus de ravages. La troisième année, ils reprennent le cours de leurs dévastations; mais ils font moins de mal, parce qu'il en est mort l'hiver, ou par tout autre cause, et à la fin tle l'été ils se transforment en chrysalides. Au bout d'un ou deux mois ils sont passés à l'état d'insectes parfaits, mais ils ne sortent de la terre que vers la tin d'avril ou dans le commencement de mai de l'année suivante, ordinairement à la suite d'une pluie douce; six ou sept jours après, les femelles, ayant été fécondées, s'enfoncent dans la terre et y déposent leurs oufs : elles choisissent, de préférence, les terres nouvellement labourées ou remuées, les prairies artifiriclles et les prairies qui ne sont pas trop humides.

J'ai adopté l'opinion des naturalistes qui pensent que la larve du hanneton passe trois ans en terre, parce qu'elle est conforme au petit nombre d'olsservations que j'ai pu faire. lls ne sont d'ailleurs pas d'accord entre eux : M. Ratzeburg dit (1) qu'elle y reste quatre ans; M. Oswald Heer, dans une histoire naturelle de cel insecte, qui a été traduite dams les Annales forestières de novembre 1841, prétend qu'elle y reste trois ans; Audouin, dans le Dictionnaire classique-d'histoire muturelle, t. VIll, p. 4t, dit qu'elle y reste denx, trois et même quatre ans; M. Duméril, dans le Dictionnaire des sciences unturelles, t. XX, p. 267, dit qu'elle y reste trois ì quatre ans, cic.

J'ai remarqué deux espèces de pucerons qui occasionnent an sapin argenté des maladies graves. Je n'ai vu le premier que sur de jeunes arbres; c'est un puceron lanigère, qui est un peu plus petit que le puceron lanigère du pommier, et que je n'ai pu bien distinguer qu'avec une loupe; il s'attache anx branches, qui se couvrent alors d'excroissances, l'écorce devient noirâtre et le dessous des loranches où se trouvent les pucerons paraît couvert, en plusieurs points, d'un duvet blane; les ramilles qui terminent les branches se dépouillent de feuilles vers le bout et meurent; cette maladie que je n'ai observée, ainsi que je l'ai dlit, que sur de jeunes sapins, peut les faire périr. J'ai remarqué le second puceron dans les sapinières de Laigle; il altaque le trone des sapins, qui devient d'un bleu noir, et ils périssent au bout de quelques années, ce qui fait qu'on doit les abattre aussitòt qu’ils sont attaqués de cette maladie, qu'on appelle la muludie du ben. La premiem fois que je vis des arbros altaqués ainsi,

(1) Les hilophllhires of leurs ennemis, p. 3.s. 
je présumai que c'était l'ouvrage tle pucerons trop petits pour être distingués à l'œil nu; effectivement, en examinant le tronc de ces arbres avec une loupe, je vis parfaitement qu'ils étaient couverts d'une innombrable quantité de pucerons lanigères.

Des insectes de la famille des bostriches (1) peuvent s'introduire entre l'écorce de l'arbre et le bois, et former, dans le liber, des galeries qui, lorsqu'elles sont assez nombreuses, arrêtent entièrement la circulation de la sève, ce qui fait périr l'arbre; ces insectes peuvent se multiplier au point de détruire des forêts entières. Je n'ai d'ailleurs remarqué la présence de ces insectes ni dans mon parc, ni dans les sapinières des environs de Laigle. Des chenilles auxquelles des papillons (des lépidoptères) ou des mouches (tenthrèdes et sirex) ont donné naissance, peuvent manger les feuilles en cntier ou les faire mourir en en mangeant l'intérieur, en les suçant ou en les perçant, et détruire ainsi des forêts entières, lorsque leur multiplication est extraordinaire.

M. Ratzeburş, page 80 de l'ouvrage déjà cité, n'indique qu'un insecte particulier au sapin argenté, le Bostrichus curvidens; mais il dit que tous les insectes nuisibles au sapin picéa le sont aussi au sapin argenté, ce dont je doute fort, du moins pour quelques-uns; car chaque arbre a des insectes qui lui sont particuliers et qui n'atta(quent point les autres arbres. Ratzelourg intitule Ic tableau des insectes nuisibles au sapin picéa Calendrier entomologitue pour les forèts d'épicéas (et de supins bluncs).

Je terminerai ce que j’ai à dire des insectes nuisibles au sapin argenté par lo récil des ravages qu'une de leurs espèces a exercés, lans mon parc, pendant les années $1839,1840,1841,1842$ et 1843.

En 1839 , je remarquai dans la futaie d'arbres résincux conifères qui occupe environ 20 hectares de mon parc, et dans laquelle le sapin argenté domine dians ume très-forte proportion, que sur un seul point les feuilles de la cime de quelques sapins devinrent jaunes, moururent, ct tombèrent successivement par l'action des vents et de la pluie : je fis peu d'attention à cet accident.

En 1840, les boutons des sapins qui avaient éprouvé ce dommage donnèrent naissance à des pousses nouvelles, couvertes te feuilles, sclon les lois de la nature pour ces arbres : le même symptôme reparut d'ailleurs, non pas seulement sur quelques sapins, mais sur la plus graude partic des sapins de ma sapimère; et au lieu de cet aspect sombre qui la faisait remarquer, elle était dans quelques parties devenue jaunâtre. Je ne pouvais attribuer cet accident ì li sécheresse, quoique ee fùt l'opinion la plus répandue; car les années 1839 el 1810 avaient été ordinaires sous éc rapport, et l'on n'avait jamais, pendant des années

(1) Il est fort gènant pour les praticiens que MM. les entomologues aient donné diffẻrens noms aux mèmes insectes; ainsi, par exemple, celui que Fabricius appelle Bostrichus lypographus, bostriche typographe, est appelé Dermestes typographus, dermeste typographe, par Linné ; Scolytus typographus, scolyte typographe, par Latreille; Ips typographus, ips lypographe, par le baron de Geer, etc. 
beaucoup plus sèches, remarqué rien de semblable diuns ma sapiniere ui dims celles de Laigle, qui n’en sont éloigmies que de: 24 à 36 hilomètres. D’ailleurs la parlie die la sapinière attaquée était la moins exposéc à la sécheresse, puisquelle est située au nord et a l'exposition du nord, tandis que la partie situce an midi était cucore intacte. Il faut ajouter, ce qui est conchuant, que la fieche el les extrémités des ramilles poussaient, et que les jeunes pousses restaient presque par$10 u t$ couvertes de: feuilles, tandis que les fruilles des anuées précédentes, et sur les mêmes ranilles, devenaient jaunes et périssaient: cela ne serait point arrivé ainsi, si la mort de ces feuilles eut été le résultat de la sécheresse, car alors éest jar la flèche et par les extrémités des branches que l'arbre aurait commencé à perdie ses feuilles.

Je pensai enfin que cette maladie des feuilles pouvait résulter de ce que des insectrs les suçient ou les perçient; j'examinai donc avec unc loupe ces feuilles mortes, et je vis qu'elles étaient toutes percées par dessous d'un trou que les personnes qui avaient une bonne vue distinguaient à l'ocil nn, el que l'intériem de: ees fenilles était creux, tandis que dans celles qui sont saines, l’intérieur est pleiu: jo rentarquai d'ailleurs sur les ramilles qui avaient pordu leurs feuilles, beancoup d'excrémens semblables à ceux des chenilles. Ces olscervations n’ayant été faites que dans la dernière quinzaine dlu mois d'anoùt, je ne trouvia point de chenilles; il n'existait probablemen! plus alors que des chrysalides, ou que dles oeufs trop petits pour être aperẹs ave une loupe, et jo ne m'occupai point de cette recherche. Je présumai que ces insectes n’avaient point attarqué les feuilles de l'amnée, parce que la pousse ayant été chétive, l’intéricur de ces feuilles n’élait probablement point encore garni de la substance dont ils se nourrissatent; mais les feuilles de quelques sapins picéas ayant été altaquées, et aussi vers le sommet de l'arbre, ce fut, au contraire, par les feuilles de l'amnéc que ces insectes commencèrent leurs ravages.

Lorsque le vent et lit pluie eurent fait tomber les funilles mortes des sapins argentés, ceux de ces arbres qui avaient le plus sonffert, dépouillés presque entièrement de feuilles, présentaient un triste aspect; aussi en fis-je abattre plnsieurs, dans la crainte de les voir périr. J'ai dit que ces insectes altaquaient de préférence les cimes des arbres, ce qui porte à croire que la lumière el le grand air leur étaient nécessaires; et ce qui me contime dans celte opinion, c'est que, dans une partic du pare où le taillis dispute le terrain à de très-jeunes sapins, mais où l'ou venait de couper ce taillis, ils avaient atlaque aussi quelques-uns de ces jemes sapins. Ces insectes, qui m’élaienb encore inconnus, n’avaient atlaqué que des sapins argentés et des sapins picéas, quoique tous les arbres résineux conifères de pleine terre, de grande et de moyenne dimension, qui sont cultivés sous le climat de Paris, se trouvent dans mon pare, et ils n'avient attaqué qu'un très-petit nombre de picéas, quoique cet arbre y soit toujours mêlé avec le sapin argenté.

Ln 1811, daus la première quinzaine de mai, je vis mo imumuluable quantiti

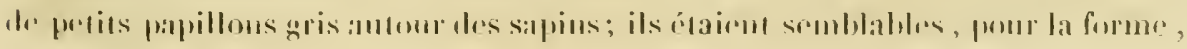




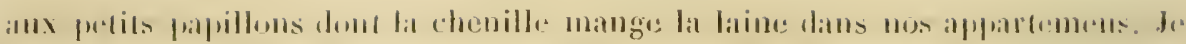
craignais qu’ils ne fussent les précurseurs des insectes qui avaicnt, lannév pre-

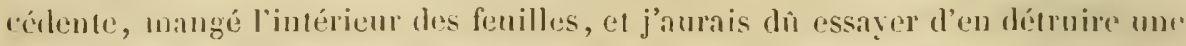
partir en allumant des fux crépusculaires dans les allées; mais ce moyen est insuffisant, "l jespérais que l'hiver, qui avait été rigoureux, et surtout le givre, yui avait, pendant plusieurs semaines, cuvoloppé les branehes et les feuilles des sippins, les auraient détruits. Quoi qu'il en soil, lo 3 juin, je m’aper!ns que les ferilles de la cime des sapins commughaient ì changer de couleur, et, en huit jours, le sommed de la sapinierre devint jaune comme un champ de blé qui a attuint sal maturité.

Aussitol que partrent les symptomes qui annonçaient l’apparilion dles insectes. j'examinai les fenilles et jo vis que l’intérieur en était mangé par dos chenillus d'un vert pâte quand elles sont prelites, el d'un vert de prairic quand elles ont

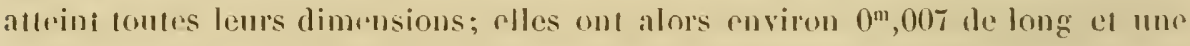
grosseur telle que, si on ne Ies tromvait dans l’intérieur des fenilles, on ne croirait point qu'elles pussent y ôtre contenues; dlles y entrent par un trou qu'dles font dessous les leuilles, près de l'entroit ou ces fouilles sont fixées sur le bois, ot rlles en sortent ì proulons. Elles commencent leurs ravages, ainsi que je l’ai dit, par los cimes des sapins qui regoivent les layous du soleil, el les pousses de l'anuce ayant été lort belles, ce furent les feuilles de ces pousses, qu'clles avaient délaissées l'ammóo précédente, qu'elles allatuèrent d’aboril. Lorsqur l'intéricur des fenilles d'une branche est mangé, less chenilles allapuent les lenilles de la branche immédiatement infílieure, sur laquelle elles si rendent

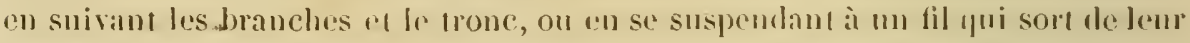
corps et an moyen duquel deles peuvent deseendre et remonter; rlles détruiraient ainsi toutes lés feuilles, si elles ne périssairnt ou si nlles ne se transtormairnt ('n chrysalides avant qur d’a voir eu le temps d’opérer entièrement celte destruction. J'ai remarqué plusicurs fois de ces chenilles suspendues sous les sapins, el j’en ai vu aussi qui montaient sur le trone de ces arlores. Au bout de quinze jours, c'est-à-llire vers Ir 18 juin, le nombre des chenilles parut décroître; le 10 juillet, il y en avait encore beaucoup; le 18 juillet, il n'y en avait plus qu'une trèspetite quantité; le $1^{\text {er }}$ aout, il n'y en avait jour ainsi dire plus, car j’on cherchai fort longtemps et jo n'un trouvai gu'me scule. Le nombre des chenilles lut infiniment plus grand cette année que l’année précédente, cl tous les sapins argentés, à l'exception de quelques jeunes sapins entièrement ombragés, furent plus on moins attaqués; ils .conservèreut d'ailleurs heureuscment des fenilles sur un nombre plus ou moins grand des branches les plus ripprochées du sol.

En 1812, les sapins de mon pare furent encore altaqués par les mêmes insectes; il mo sembla qu’il y en avait un peu moins que l’année précédente, mais ils attaquèrent un plus grand nombre de sapins picéas. En 1813 , je vis encore, dans la première quinzaine du mois de mai, de ces petits papillons que je présumais être les précurseurs des chmilles, mais en moindlre quantité; aussi Irs chenilles furenterllos ancorr moins nombreuses que l'anmén précédente. En 


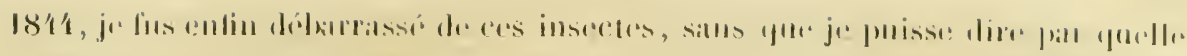
rallse.

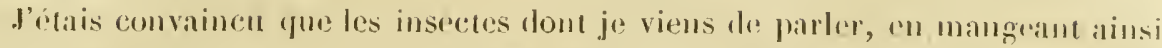
Jus fruilles des sapins, particulièrement dans le haut de l'arbre, leur cansairnt un très-grand dommage; et cela d'autant plus qu'il ne se formait point sur l's branches dépouillées de tenilles des boutons adventifs, ainsi que je l'avais es-

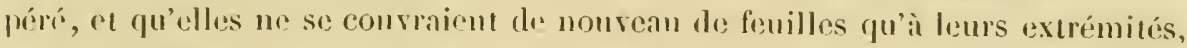
sur les pousses nourelles qui paraissaicnt lorsque les houtons ratent restés sains. Mais les chenilles mangeant de nouvcau ces feuilles, je fis abuttre en très-grand nombre los arbres qui avaient été le plus attaqués, et, dans le mêmu: tomps, je faisais abatre aussi les arbres moirs, dépérissans, attaqués par la pourriture, les chancres, elc., ce qui n’avait pas été fait par mon père; car, ainsi que je l'ai dit, inclépeudamment de ce que ces sortes d'arlores nuisent aux arbres bien venans, ils sont en ourr la cause et l'aliment des insectes. Eu éclaircissant aimsi la sapinière, par les motifs que je viens de lommer, j'espérais non pas mmir anx chenilles, qui paraissaient préférer me situation aérée, mais pentètre à leurs chrysalides, que je présmmais être ılans la mousse, au pied des arlırus, "l que je privais ainsi d’un abri qui pouvaiı lour être nécessaire.

Je présume que l’insecte dont je viens de parler passe l'hiver à l'état de clurysalide, puisque, après que les chenilles ont disparu, on n'apercoit point de pa. pillons autour des sapins; je n'oserais, d'ailleurs, l'affirmer, n'ayant pu m, procurer aucune de ces chrysalides : j’ai pourtant examiné des branches dépouillíes de leurs feuilles; j’ai conservé des chenilles sur des lranches pendant plusicurs jours, el elles sont toutes mortes successivement; j'en ai souvent remarqué qui s'envelop)paient d'unc coque, mais cette coque n'était pas entièrement forméc, et elles la quitaient quelquefois pour en former une autre, comme si ce n’èt été qu’un abri momentané. Ces chenilles se laissent probablement tomber jusqu'à terro lorsqu'elles sont au moment do se transformer, et y opèrent lem transformation. (Onoi qu'il en soit, comme je ne moccupe point d'entomologie; fue l'insecte dont je viens de parler n'a attiré mon attention que par le mal yu’il me faisail; que je ne croyais pas possil)le de le détruire dans mon parc par des moyens humaims, puisqu'il s'y trouvait 'u quantilé innombrable; j'ai abandonné cotte recherche qui m’inspirait pourtant de l'intérèt, parce que cet inscete n’a point encorr été décril, du moins par les auteurs qui se sont occupés l'arhres résineux conifères.

Il y a probablement aussides insectes, pucerons ou autres; qui n'attaquent qu. les très-jeumes sapins, ot qui pourraient par conséquent causer do grands dommages dans les pépinières de sapuins argentés et dans le jeune recrn provenanı de semis naturel; mais il n'm est point fait mention dans les auteurs, ol je n'ai observé que le puceron dont j’ai parlé pagre 111.

Je terminerai par indiquer ce que je sais des moyens de détruire les insectes,

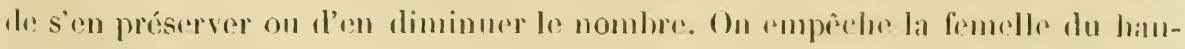

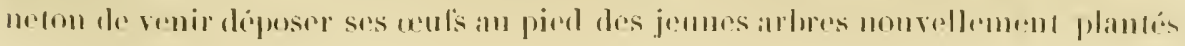


b.l y mellant une couverture. Si l'on doit biner une jeune plantation, el que les bois voisins soient couverts de hannetons, il faut allendre pour faire cxécuter ce binage que les hamnetous aient disparu. Si une terre arable destinée à un semis de pins maritimes ou de pius sylvestres, espèces dont le semis n'a pas besoin d'ombrige, porte une récolte de printemps, de l'avoine par exemple, pendant l'auncé qui précède celle du scmis, el que les bois voisins aient élé couverts de lannetons au printemps, il sera prudent de retarder le semis d'un an ef de faire une jachère, parce que si la terre conticnt des mans ils mourront de faim pendant cette année de jachère, surtout si l'on donne un ou deux labours par un temps chaud. Lorsque la récolte d'un champ destiné à être semé l'amée suivante en pins est dévasté par des mans âgés de denx ans, on retardera son semis d'un an, parce que l'année suivante les mans exerceraient encore leurs raviges.

Un a vu que des pucerons qui se fixent sur l'écorce, des bostriches qui font des gateries entre l'écorce et le bois, et les diverses chenilles qui mangent ou sucenc les feuilles, peuvent occasionner de grands ravages lorsque leur muliplication devient extraordinairc. La propagation des deux pucerons lanigères dont j’ai parlé m'a paru lente; ainsi on pourra facilement l'arrêter en abattaut les arbres qui sont attaqués par ces insectes. 11 u'en est pas de même de la propagation des bostriches et de celle des chenilles, qui jeut être très-rapide.

En ce qui concerne les bostriches, je ne vois que deux moyens dont l'efficacité ne puisse être contestée pour diminuer leurs ravages et tenter de les détruire : Ie premier est d'abattre les arbres dans lescuels ils se sont élablis, et de les transporter aussitôt hors de la forêt. On choisit pourexécuter ce travail les cing mois, depuis novembre jusqu'à mars inclusivement, pendant lesquels ces insectes, qu'ils soient à l'etat de larve, de chrysalide ou d'insecte parfitit, sont cachés sous l'écorce; on distingue presque toujours, an premicr aspeet, les arbres attaqués à leur état maladif, car les bostriches, quand ils sont cncore peu nombreux, attaquent de préférence les arbres chetifs, mal venans, nalarles, ou rendent tels les arbres de belle apparence qu'ils ont attaqués; on s'assure ensuite de leur présence en examinant l'écorce. Le second moyen est d'abattre les arbres pendant l'existence du couvinin, de les écorcer si l'on n'a pas le temps de les enlever de la forêt, et de brûler l'écorce. Il faut done s'assurer de la présence du couvain dans ces arbres, sans quoi on pourait en abaltre qui n'en contiendraicnt pas : c'est ordinairement pendant le mois de juin, selon Ratrclung (1), que le couvain se trouve daus les arbres, entre l'écorce ê le hois.

Je ne connais aucun moyen de détruire les chenilles lorsqu'elles se sont multipliées extratordinairement; il serait possible qu'on pùt effectuer la destruetion de certaines espèces en abatıant assez de sapins dans une sapinière qui serait dans un état très-scré pour y introduire de la lumière, des courans d'air et y donner accès a!x pluies; jo rapportc d'ailleurs ce moyen dans le doute, n'ayant

(1) Les hylophthires et leurs ennemis, p. 68. On trouvera un article sur edt obvrige dans le chapitre XII. 


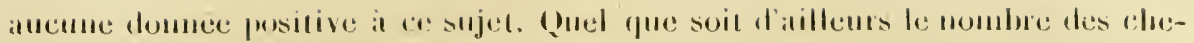
nilles, efles tinissent toujours fall disparatre, mais quelquefeis après avoir exercé de grands ravages. lilies sont délruites par quelpues circonstances atmosphérigues, felles que de brusques altermatives de température, des phuies fréfunoules el froides, l'action dı fluide éloctripue qui se développe pendant les orages; mais le plus communément elles sont détruites par des ichucumons (1), el funelyuefois avec une telle rapidite que leur disparition est pour anusi dire instantance : toujours lorsque la propargation des chenilles est extraordinaire, qu'elle dure plusieurs ammées et cause de grands ravages, on voit paraitre entin des ielneumons qui les délruisent.

Lorsque des sapins onl eu une grande partie de leurs feuilles détruites par les chenilles, ainsi qu'il arriva daus ma sapinière, on ne doit pas hésiler à abattre tous les arbres qui, ayant élé atlaques ainsi, ont alteint leur maturité, ou qui en approchent, ou dont l’aceroissenent en hauteur est arrêté; car s'ils ne meurent point dans l'année mềne on dans les suivantes, ils dépériront centanenent, ne pouvant phus se gamir suffisamment de fenilles. Si les arbres qui ont elí allatués sont jeunes, poussent de très-belles flèches, malgré lat perte d'une partlie de leurs feuillss, el premnent par conséfuent de l'accroissement en hauteur, en grosseur, el en pourtour, relativement à l'ensemble de leur feuillage, ils se rétabliront; car les feuilles qu’ils auront perdues aurajent alors été étouffées quelques années plus lard patr l'ombrage des feuilles nouvelles. Si, au contraire, les jeunes arbres qui ont éte allatués ont des pousses chétives, des leuilles d'ume: couleur jamnâtre et restent languissans, il ne faudra pas hésiter à les abaltre.

Ralzeburg dil (2) : que lorsque la chenille de la nome a dévoré des feuilles du sapju rouge (picéa), "cel arbre, sauf quelques exceptions résultant de la tempé"rature et du lieu où il se trouve, meurt sans rémission, hion que conservant la " moitié, le ticrs ou le quart de son teuillage. "Le sapin argenté me parait êlre phus robuste sous ce rapport que le picéa; il doit d'ailleurs y a voir des différences selon les lieux, les termins ef les elimats; chanue proprićtaire d'une futaie de sippins argentés dont les arbres auront éprouvé ee genre de dommage, devra done faire des observations parliculières à sa localité.

(1) Mutches qui deposent leurs aufs sur le eorps des chenilles, el dont les larves vivent dre res chenilles, t les funt pill conséquent périr.

(2) Les hylophlhire's ef leurs cnnemis. ए. 1:52. 


\section{CHAPTRE III.}

SIPII PICLA. Abies picea.

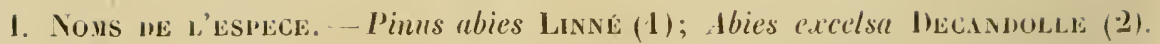
On l'appelle aussi Epicea, Picea, Pesse, Senente on Serento, Sipin douge, Sipin de Nord et Sapin de Norwège.

J'adopte de préférence la dénomination de Sapin picéa, parce qu'elle exprime un caractère particulier à ce sapin, celui de donner de la poix. Le nom de Limné, Pimus abies, aurait mieux convenu, selon moi, au sapin argenté, que les latins appelaient Lbies fémina, et le nom de Pinus picea au sapin picéa, qui cionne la poix, et que les latins appelaient P'icea. Inecandolle croyait, ainsi qu'il le dit dans sa Flore francaise, que le sapin picúa atteignait à de plus belles dimensions que le sapin argenté : voilà pourquoi il atopte pour cel arbre le nom d'Abies cxcelsa; on verra dans cet ouvrage que c'est probablement le contraire, quoique ces sapins acquièrent d'ailleurs tous les deux de magniliques dimensions.

II. Boutons et sève. -- Le sapin picéa a des boutons ì bois el des boutons à fleurs; ses feuilles naissent en même temps que los pousses lu bois sur lesquelles elles somi fixées.

Cet arbre n'a qu'une seule sève (3) qui commence ordinairement, sous le climat de l'aris, dix ì quinze jours atprès celle du sapin argenté, c’est-è-dire dans la fremière ou chns la deuxième quinzaine du mois de mai, el qui s'arrète, en ce (jui concerne la longurur des pousses, au bout de six à neuf semaines, selon la température qui a régné. Lorsque la sève est arrêtée, en ce qui concerne: la longueur de la flèche et des pousses, les boutons fui donneront naissance à la llèche et aux pousses de l'année suivante sont parfailement formés, mais les pousses premment uncore de l'accroissement en grosseur et elles dericnment lianeuses d'herbacées qu'elles étaient.

La sève fait d'abord pousser les boutons dos hranches qui sonf placées le plus

1) Specirs plantarum, 3e édit, t. 11, p $\$ 25$.

(2) Flore française, 1. 1II, p. 275.

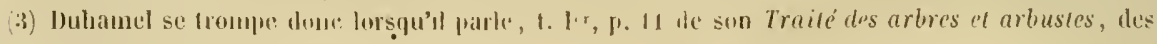
Inux sèves du saping jicéa 


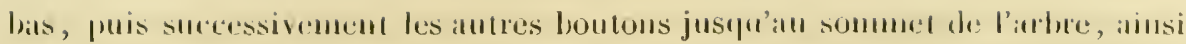

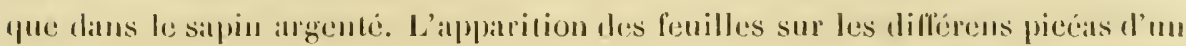
mine canton est d'ailleurs moins regulière que sur be sapin argenté; on en renarque, patr exemple, qui se convernt de feniltes aussitot que lui, mais ordihatirement la sève suit la marele que j’at décrite.

Lorsque laation de lat sève est atrêtéc on est devenue insensihle, on rentarque: sur:puelgues parties des prousses de l'année, et toujours à leur extrémite, alu boul

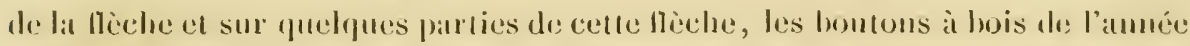
suivante qui sont plus petits el plus nombreux que dans le sapin argenté. Cenx qui sont atu bout ou tont près du bout de la flèche sout au nombre de trois à six, le plus communément an nonbre de cinq dans les arbres bien venans qui ont déplassé 12 ans, non compris celui qui ust situé dans le prolongement de la flèche; ces boutons donneront naissance, l'annce suivante, à la lleche el aux branches nouvelles. Les lioutous à bois funi se trouvent sur le reste de la llèche, sur les parties latérales "t sur le dessus des autres pousses, ne doment ordinairement maissance qu' di dess ramilles : il ne pousse, pour ainsi dire, point de: boutons adventifs sur lo silpiu piceil.

L.s boutons à fleuts paraissent en même lemps que les houtons à bois; crux fui domneront naissance aux fleurs femelles sont d'ilhord scmblables aux boutons à bois, mais à l'antonnc ils en difterent scusilitement parce qu'ils sunt devenus plus gros; ils se rouvent à l'extrémite de quelques pousses de l'anuée et (n) plus grand nombre vers le haut de l'arbre. Les houtons qui contiennent le rudiment des fleurs malles, beancoup plus petits que les boutons à bois, sont seuls ou rémis an nombre de deux et frois cutre les fenilles et sont dispersis sur toutes les parties de l'arbre. Les boutons qui donneront naissance aux lleurs lemeltes se distinguent liacilement dès le jer octolsere.

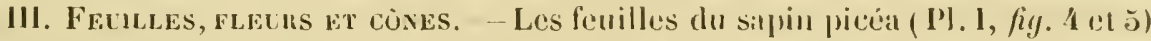
‘ommencent à patratre, ainsi que je l'ai dit, daus l. rourant du mois de mai, en mème temps que les pousses sur lesfuelles elles sont fixées; elles sont linéares, pointues, fermes, fuadrangulates, d'un vert fonce, moins puntant

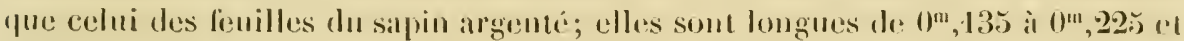
sont lixées irrégulièrencot, une à une, sur les parties supétieures el latérales des rameaux et des ramilles, excepté vers le sommet de l'arbre où elles les contourent sourent et sur la fleche qu'elles couvent entierenent. Elles persistent tant que l'ombrage, le grossissement de la partie des hranches sur lesquelles elles se trouvent, ou des maladies ne les lont point périr; in Kin Kisthofer (I) el Lorentz (2) se trompent en disant, l'mn, qu'elles persistent pendant trois ans; l'atutre, de trois à cing ans. Les feuilles qui couvrent la thèche ue jersistent que: ferndant six on huil ans, lant que l'arbre croil; c'est sentement au boul de ce

1) Le Guide dans le's forets, 1. 1'. 1.28.

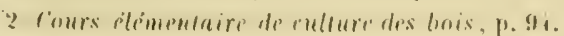


temps que le trone en est débarrassé, probablement par suite de l'oubrage qu'elles éprourent à mesure que l'arlore s'élève et du grossissement du tronc. Les leuilles qui garnissent les ramilles tixées sur le tronc, et sur la partie des branches qui avoisinent le tronc, périssent aussi successivement par la mêne cause, el les ramilles qui portaient ces feuilles, privées de lumière, périssent ensuite; mais de nouvelles pousses, couvertes de feuilles nouvelles, paraissent annuellement dans les parties qui jouissent des bienfaits de la lumière, et ces pousses sont plus nombreuses daus le sapin picéa que dans le sapin argenté. Il ne repousse jamais de feuilles sur les rameax on sur les ramilles qui en ont été dépouillés, parr quelque cause que ce soit, à l'endroit où étaient ces feuilles; mais ils peuvent pourtant se couvrir de feuilles au moyen des houtons, qui donnent naissance à de nouvelles pousses, s'ils sont restés sains.

Les fleurs du sapin picéa (Voy. page 10) commencent à paraitre en même temps plusieurs jours avant l'apparition des pousses, c'est-a-dire pendant la deuxième quinzanè du mois d'arril ou la première du mois de mai.

Les chatons mâles (P. 1, fig. 4) sont dispersés entre les feuilles sur le bois de l’année précédente. Ces chatons, souvent très-nombreux, sont seuls ou réunis au nombre de deux et trois, et ils sont en plus grand nombre vers la partie supérieure de l'irbre; ils sont rougceitres et ont la forme d'une fraise des bois trèsrégulière, avant que d'avoir alteint leur maturité; lorsqu'ils l'ont atteinto, environ dix jours après leur apjatrition, ils sont de couleur cannelle, occupent plus de volume, sont plus allongés et laissent échapper une poussière jaune fort abondante : c’est peu de jours après que partent les pousses.

L.es chatons femclles du sapin picéa, annoncés dès l'automne précédent par des boutons plus gros que les boutons à bois, se trouvent principalement vers le: haut de l'arbre, à l'extrémité et dans le prolongement de quelques ramilles; ils sont oblongs et sont d'abord verts; leur pointe est tournée vers le ciel et leurs feuilles florales sont appliquées sur l'axe et sont dirigées vers son sommet; mais au bout de deux ou trois jours elles se retournent entic̀rement, sont alors dirigées vers la base de l'axe et prennent une couleur d'un rouge ćclatant, puis elles deviennent violettes, et enfin, au bout de trois semaines environ, ces mêmes bractées, en une couple de jours, se retournent de nouveau, sont alors dirigées vers le sommet de l'axe el se transforment en écailles : le chaton devient un còne et la couleur rouge, après avoir passé par la couleur violette, est remplacée par une couleur vert pâle.

Les cônes ( PI. 1, fig. 5) sont lixés immédiatement sur le bois; leur pointe est d’abord, ainsi que je l'ai dil, tournéc vers Je ciel, mais elle baisse à mesure qu'ils grossissent, et elle finit par se tourner vers le sol pour rester fixée dans cette position. J'ai dit que la fleur femelle, après avoir passé par le veri, le rouge éclatant et le violet, se transformait en un cône d'ume couleur vert pâle. Celte couleur n'est d'ailleurs pas constante : il y a des cònes qui sont d'un vert brun, d'autres l'un vert violacé; mais tous finissent par devenir d'un rouge canHrllr 'n allrignant leur maturité, ce qui arrive orlinairement au commence- 
ment de novembre; ils ont alors de $0^{m}, 11$ a $0^{m}, 11$ de long. lls sont oblongs, quelpucfois légèrement courbes et se composent d'écailles serrées les mes contre les autres, adhérentes à un axe commun, plus épaisses à la base fixée à l’axe, qu'à là partio extérieure; à la base interne de ces écailles se trouvent deux graines munies d'me aile.

La graine que contiennent les eònes atteint ordinairement sa maturité dans la première quinzaine de novembre, mais ce n'est que dans le courant du mois d'avril de l'année qui suil celle où ont paru ces cônes que l'action du soleil tait soulever leurs écailles, et que la graine qu'ils contiennent commence à tomber; cependant j’ai remarqué qu'il en tombe aussi quelquefois, mais en très-petito quantité, dès l'automne de l'ammée où ils sont nés. Colta, qui habitait la Saxe, fait la même observation (1); j'ignore s'il en est de même dans le Nord, où les étés sont courts et les hivers longs. Ainsi, ce n'est ordinairement que 10 mois et demi environ après que les cònes ont paru, que la graine qu'ils contiennent commence a tomber, et elle tombe non pas en quelques jours, comme celle du sapin argenté, mais en quelques semaines. Cette fraine, étant très-légère et munie d'une aile, est quelquelois transportée au loin par les vents. Les cònes commencent à tomber successivement, par suite des secousses des rents, dès l'année même pendint laquelle sont tombées les gratnes qu'ils contenaient: mais ce n’est qu'au bout de plusieurs années que les picéas en sont entièrement débarrassés.

Le sapin picéa le plus jemne que j’aie vu porter des cônes, avait de 13 à 14 ans, el provenait de pépinière; c'est d'ailleurs une exeeption, ces arbres ne portent ordinairement point de cỏnes aussi jeunes. En 1843, année d'abondance de cònes dins mon pare, quelques-uns des picéas d'une allée, qui étaient îgós de 15 a 16 ans, eurcnt assez abondamment des cones, et il y en avait aussi quelques-uns qui portaient des fleurs mâles; ainsi c'est à cel âge que les picéis de pépinière commencent à porter des cônes. Je n'ai pas de données positives relativement à l'àge aucquel les picéas, provenant de semis naturel, commencent it en porter, je présume que e'est quelques années plus tard. La graine dle picéa, récoltée sur des arbres trop jeunes, n’esı d'ailleurs pas toujours féconde et présente beaucoup de déchet; elle n’atteint toute sa force germinative que sur des picéas plus âgés encore, aussi est-il prudent de ne récoltcr les cônes, pour en extraire la graine, que sur ceux de ces arbres qui sont âgés de plus de כ̌0 ans. Mais il ne suffit point de se procurer de la graine féconde; il faut aussi la tirer, autant qu'on le peut, des plus beaux arbres; car il est à craindre que des graines lirées de sujets rabougris ne donnent naissance qu'ì des arbres qui se ressentent de leur origine.

On commence à voir des lleurs mâles, pour la première fois, sur les jeunes picéas au même âge environ oủ l'on commence à y voir des cônes; quelques années plus tòt ou quelques années plus tard. Cet arbre ne porte pas toujours en 


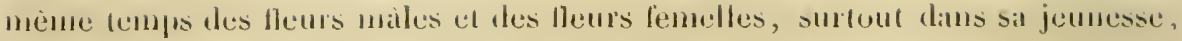
rar lorsqu'il approche de sa maturite ou qu'il l'a alteinte, il a presque toujours des lleurs mâles pendaut l'amnée qu'il porte des flenrs femclles; mais il porte sonvent des fleurs mâles, sims avoir des fleurs fomelles ni par consérquent des cònes. Lors done qu'on veut récolter de la graine sur un picéa isolé, il laut s'assurer qu'il a eu des lleurs mâles en mème temps que les fleur's fémelles qui ont domné naissance aux cônes, puisque sans cela celle graine serait stérile.

Le sapin picéa ne porte pas des cònes tous les ans, et les ammées d'abondancer de cones sont encore plus rares pour cet arbre que pour le sapin argenté, du moins sous le climat de Paris; car dans le Norl et dans les montignes, dans les lieux enfin où il est indigène, il peut en ètre autrement. Dins mon pare, où les picéas sont nombreux, depuis le jeune plant jusqu’à l'arbre qui a dépassé 80 ans, j’ai cru remarquer qu'il y avait au plus une ammée d'abondance tons les sept ans environ. Dans ces années d'abondance, indépendamment des cònes yui se trouvent agglomérés vers la eime de l'arbre, ainsi que je l'ai dit, on en rennarplus: aussi quelques-tuns, quand ils sont isotés, jusqu'aux teux tiers de l'arbre, i

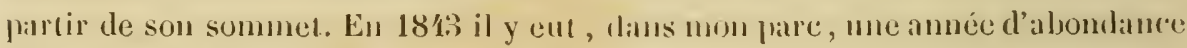
de cònes; en 1844 , il n'y avait ni une flemr mâle ni une fleur fomelle.

IV. Grunes et semis n.tunel. - Les graiues du silpin picéa (P’l. I, fig. (i) sunt ovaies, d'un brun roussâtre (couleur puce), et sont munies d'une ailı; elles ont environ $0^{\mathrm{m}}, 004 \mathrm{de}$ longueur moyenne. Nous a vons vu que cet arbe, lorsqu'il provient de semis naturel, ne porte des cònes qu’après avoir dépassé 16 ans; mais ces graines n'acquierent ordinarement assez de foree germinative pour tomer du semis naturel que lorsque l'arlore a atleint 35 ans, et ee n'est encore qu'en très-petite quantité; il laut que le sapin picéat ait 50 ans pour domner abondamment du semis naturel efficace. Les sapins picéas qui alprochent le plus de leur maturité ou qui l'ont atteinte sont ceux qui, pour la même quantité de graines, doment lo plus de semis naturel, déc'est par conséquent la graine de ces arbres que l'un doil preférer pour linire des semis.

Pour se procurer de la graine, on peut linire cureillir des comes depuis la pemière quinzaine de novembre jusqu’ì l'époque où celle graine doit s'échapper des cones, c'est-ì-dire jusque dans le courant du mois d'avril de l'annéc: suivante.

La manière d'extraire la graine des cònes du sapin picéa, est la mème que celle 'fu'on emploie pour extraire la graine des cones du pin sylvestre; soit (pu'on venille en extraite une pelite quantité pour son usage, soil qu'on veuille l'exuraire en grand, au moyen d'une chaleur artilicic!le. Ce que je dirai de l'extraclion de la graine des cỏnes du pin sylvestre el de son désailement, dans le chapitre suivant, sappliquera done, de tout point, an picea, et j’y renvoie mes lecteurs. J'ajouterai seulrment qu'on peut récolter les cones du piééa quinze

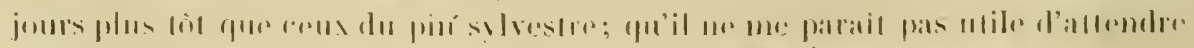




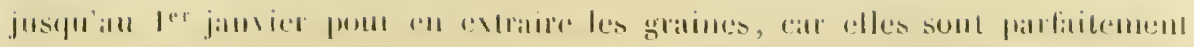

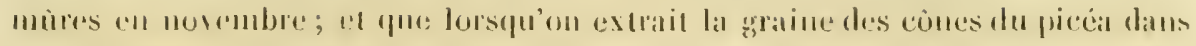
me sécherie, on doil la chanfler moins que pour l'extratelion de la grane du pin sylostre, partec gac les cònes du premicr s'ourrent phus litcilement que: reux du seromb. Níammoins, lant gu’il n’y a pas de nécessité de procéder à l'exIraclion de la gratine, il est prérérable de la laisser dans les cònes oir elle se conserve mienx; matis on doit avoir l'allention de remuer les las de cónes, atutant 'fu'il rst nécessatre, pour qu'ils ne s'échauffent point, « qui atriverail s'ils nétaient pas parlaitement ser's. Lorsqu'il y a ahondance de cónes on se procure licilement dre la grane de picéa, pares que chaque cone en contiem beancoup, flusieurs centaines, je crois; aussi est-elle moins chère 'n Allemagne que celle du pin sylvestre, dont les couses sont plus petits at me contiennent chacun, terme moyen, que vingt graines.

Il faut, selon Cotta (1), six it dix boisseaux de cònes pour obtcnil un boisscau de graine ailie, et il dil que la graine ailée se garte quatre ou cinq ans. Sulon IIarlig (2), wne partie de la graine de sapin picia ronserve sa faculte germinalise pendant guatre ans, si l'on a le soin de l'étundre clair sur un plincher acré et de la remuer de tomps en temps, surtont pendant l’élé; mais plus tót on l'emploiera après a voir été récoltée, moins dilde donnera de déchet.

IIartig dit (3) que 4 décalitres de graines de sapin picéa sans ailes pèsent 1 J̇ kilugrammes, c’ust-à-dlire qu'un litre pèse 375 grammes; sclon Colta (4), un litre pisse 433 grammes. IIoi, j’ai trouvé qu’il pesail 41 ŏ grammes el contenait 52,600 gratines; ainsi le kilogramme de cette graine occupait un volume de 2 litres 11 dérilitres et contenait 126,747 graines. Il est d'ailleurs ívident que eo n'est qu'mu: approximation, el que l'on n'obtiendrait jamais de résultats idlentiques de celle rxpérience en la répétant plusieurs fois, lors mênequel'on emploierait de la graine lirée du même sac; à plus forte raison, si l'on employait chaque fois dus graiurs de différens degrés de netteté, des graines tirées de différens pays, ou sutement si l'expérience était faite dans des annees différentes, on enfin, si on la laisail avec des graines lirées de picéas de différens âges. A P’aris, la graine do: sippin picéa se tire de l’Allemagne; clle se vend ordinairement, daus la maison Vihnorin-Andrieux, i lir. le kilogramme.

Lat gratine du sapin picéa tève dans l’annéc mème oú elle est tombéc, et l'on a vu qu'elle ne commence ordinairement ì tomber que dans le courant du mois l'avril, et fue s'il en tombe quedguefois pendant l'automme de l'année où sont nés les cònes, ce n’est qu’en très-petile fuantité; celle grane étant plus légère que celle du sapin argente ost emportée plus loin par les vents. Ce yne j’a dit

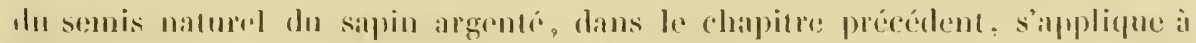

(1) Traité de culture forestière, p. 255-251;.

(2) Hartig, cité par Baudrillat, Dictionnaire des eaux et forits, 111,11 . isi.

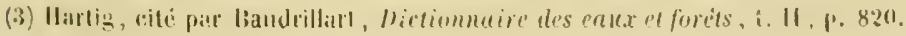

i) Trater do cullure forestuire, p, 3ii. 
celui du sapin picéa ; ces deus sapins ont la laculté de résister longtemps à un épais ombrage, tandis qu'il en est autrement des pins et même du mélèze, dont je m’occuperai dans les chapitres suivans : le picéa venu de semis naturel peut, ainsi que le sapin argenté, résister à l'ombrage d'un taillis que l'on coupe tous les dix ans, mais moins bien pourtant.

Voici ee que j'ai remarqué dans mon parc, c'est-ì-dire sous le climal de Paris proprement dit. Les sapins picéas qui ont dépassé 50 ans y donnent abondamment du semis naturel qui lève très-bien, mais au bout d'un an il n'en reste qu'une très-petite quantité, beaucoup moins que de sapins argentés. Cela tient-il à ce que cet arbre n'est pas dans le climat qui lui couvient le mieux? Sont-ce les lapins, qui tondent si bien les picéas de pépinière que je plante dans les allées, qui les détruisent? c'est ce que j'ignore. Quoi qu'il en soit, ceux qui dans le bois taillis ont résisté pendant les premières années, ont beaucoup de chances de devenir des arbres s'ils n'éprouvent point d'accidens ou ne sont point étouffés sous l'ombrage; dans les massit's de la futaie qui sont bien garnis, ils finissent, ainsi que le sapin argenté, par périr, après avoir lutté longtemps, si on ne leur procure pas enfin de la lumière et de l'espace.

Mon père ayant racheté, en janvier 1803 , peu après son retour de l'émigration, le château et le pare de Clıambray, qui avaient été vendus pendant la révolution, fit, dans l'automne même de cette année, planter en bois d'essence feuillue et d'essence résincuse un terrain silico-argileux maigre, d'environ un liectare, sépraré seulement du pare par un chemin. Au nombre dés plants d'arbres résinenx qu'il planta se trouvaient des sapins picéas, âyés tleuviron 8 ans, qu'il avait pris dans son pare, parmi ceux qui provenaient de semis naturel. Cés picéas ont commencé à domner du semis naturel lorsqu’ils étaient âgés d'environ 35 ans, mais én bien petite quan(ité; tandis qu'il a levé dans ee terrain un très-grand nombre de sapins argentés, dont la graine, qui est pourtant plus lourde que celle du picéa, a dù, pour arriver jusque-là, franchir le chemin de 16 mètres de large qui sépare ce massif du parc. Une personne de mon voisinage, qui a cultivé des picéas en massif, m’a dit én avoir obtenu du semis naturel, mais en petite quantité, dès l'âge de 22 ans.

V. Mode De végétation, descripton, duenstons. - Le mode de végétalion du sapin picéa a été décrit au commencement de ce chapitre, en ce qui concerne la marche de la sìve daus cet arbre, ses boutons, ses feuilles, ses fleurs et ses cônes, et l'on trouvera, chap. XI, art. III, des détails sur sa végétation et son accroissement, depuis te semis jusqu'au moment de la plantation à demeure. Je n'essaierai point de domner de semblables détails relativement au plant provenant de semis naturel, parce qu'il présente beaucoup de variété dans son accroissenent, selon les circonstances différéntes dius lesquelles il se troure placé. Je me contenterai de dire qu'il at un accroissement plus lent que le plant que l’on èteve on pépinière; il ne m'a pals paru avoir un accroissement plus frompl que le plant de semis naturel du sapin argente, of pourtanl le plant dr. 


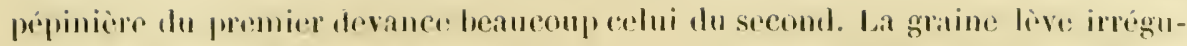

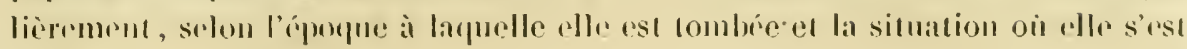
Iromvión.

A l’âge oì l’on plante ordinairement ì dememr le sapin picéa élevé en pépinière, e'est-ì-dire à 7 ans, le picéi de semis naturel n’a pas orlinairement plus le $0^{\prime \prime}, 65$ de haut; mais il commence alors ì pousser avec vivacite, ce, quand il a dépassé 16 ans, on remarque quelquelois, pendant des années privilégiées, des flèches d'un mètre de long. J'en ai mesuré, en 1814, de $1^{\mathrm{m}}, 10$ rans los allíes de mon pare. C’est orlinairement de 15 à 40 ans que le picéa prend annuchlement le plus d'accroissement en hauteur; la longueur ordinaire de la llèche, pendant ce laps de temps et daus des circonstances favorables, me paraît être de $0^{m}, 32$ ì $0^{m}, 65$, en moyemme: $0^{m}, 50$, comme pour le sapin argenté; mais cet accroissement ne se soutient pas aussi longtemps, toutes choses égales d'ailleurs, sous le climat de Paris, dans le sapin picéa que dans le sapin argenté. Les branches du picéa et même le trone, dans la partie où il est jeune, étant couverts d'une rrès-grande quantité de ramilles, cet arbre a, jusqu'ì environ 15 ans, la formo. d’un épais lunisson que l'on aurait taillé en pain de sucre; sa tète conserve cette. forme cl est semblable à un jeme picéa pendant tout le temps qu'il prend son principal accroissement en hauteur. Enfin l'arbre cesse de croître en hauteur, mais ordinarement il contiume à angmenter en grosseur.

Voilà ce que j’ai remarqué dans la sapinière du pare de Chambray, dont le terrain léger, silico-argileux, souvent caillouteux, me parait convenir un peu mieux au sapin picéa qu'au sapin argenté; on voit que sa végétation est plus rapide, dans les premières amnées, que celle diu sapin argenté; que, jusqu’à 35 ans, elle ne le còle guère à celle de ce sapin; mais plus tard, toutes choses égales d'ailleurs, elle lui est inférieure. On devait, au reste, s'attendre à ce résultat, car ces deux arbres, atteignant à peu près aux mêmes dimensions daus des circonstances également farorables, celui-là qui n’est pas indigène du climat de Paris doit s'y trouver, par rapport à l’autre, dans une infériorité relative.

Le sapin picéa a ordinairement deux étages de racines el souvent un pivot; les racines du premier étage partent du collet; elles sont à fleur de terre et quelquefois même il y en a qui soirtent entièrement de terre pour y rentrer bientöt après; le pivot n'est pas la racine dominante, quand il y an a un, comme dans d'autres espèces; ce sont les racines latérales, et c'est principalement par elles que cet arbre se maintient. La plupart des auteurs qui ont parlé du picéa disent qu'il est sujet à être renversé par los vents, mais il suffit qu'un auteur dé réputation ait émis cette opinion pour qu’elle ait été reproduite par beaucoup d'autres; il est possible que cet arbre, pouvant croître dans des terrains moins substantiels que ceux qui sont nécessaires au sapin argenté pour y développer sa belle régétation, et ponvant croitre aussi daus des terrains moins profonds, y soit exposé à être renversé par les vents; mais je pense que, lorsqur: cos deux arhres croissont daus le même terrain, le sapin pieca ust ordinarement

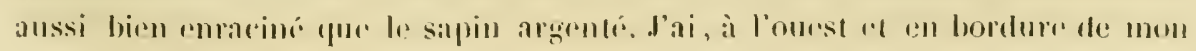




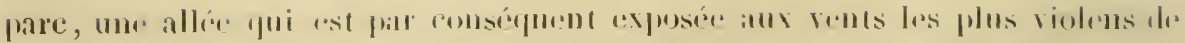
la localité; il s’y truence des sapins argentés, des sapins pịcéas, des pins sylrestres et des pins maritimes qui ont été plantés de 1785 à 1789, "1 atucun puicria n’y a été renversé par les vents. J'avais un quinconce de picéas qui avait é.. planté en 1765-1766, el dont je parlerai plus loin; il n'était couvert, du còté du sud-ouest, d'où nous arrivent les vents les plus violens, que par un bois taillis de mauvaise qualité que l'on coupait tous les neuf ans; ce quinconce a été tellement éclairci à différentes époques, qu’il n’en reste plus que quelques picéas que je conserve pour porte-graines, et pourtant je n'ai jamais vu le vent en renverser un seul, quoique la plupart de cenx que j'ai fait abattre dans ces demiers temps fussent attaqués de la pourriture au cœur.

Le tronc du sapin picéa est toujours droit, soit qu'il croisse isolé, soit qu'il croisse à l'état serré; dans le premier cas, il est garni de branches depuis le sol jusqu'à la eime; dans le second, il se dépouille de branches jusqu'aux deux tier's emviron de sa hauteur. L'écorce du picéa, qui est d’abord rougeâtre et unie, d'où Ini vient probablement le nom de sapin rouge, qu'on lui donne particulièrement en Allemagne of en Suisse, devient grise ot rugneuse à mesure que l'arbre approche de sa maturité. Tant que l'arbre est jeune, sain et vigoureux, son trone 'st toujours terminé par une flèche; lorsqu'il approche de l'âge de sa maturité ou que sa croissance a été arrêtée par une cause quelconque, il n’a plus de flèche; sa tète s'élale et forme une espèce de buisson d'une très-petite étendue, mème: lans les picéas des plus belles dimensions : si la cause qui a arrèté la croissance de l'arbre en hauteur cesse, il repart quelquefois une flèche. Le tronc est en queue de rat quand le sapin picéa croît isolé ; il maintient au contraire beaucoup mieux sa grosseur, jusqu'à environ les deux tiors de sa hauteur, quand il croît on futaie; mais, dans mon pare, je l’ai trouvé inférieur, sous ce rapport, au sap̧in argenté. Ainsi, lorsque deux de ces sapins y ont erù en futaie à l'état serré, dans des circonstances également favorables, et ont la même hauteur et la même circonférence à un mètre au dessus du sol, e’est ordinairement le tronc du sapin argenté qui a lo plus fort volume de bois. Il en est de même dans une allée composée do sapins argentés et de piréas, plantés par mon oncle, in $1787-1788$.

Si l'on brise le trone du sapin picéa dans sa jeunesse, unc ou deux des branches les plus rapprochées de la brisure continuent le trone; il parait quelquefois des boutons adventifs sur le trone, par exception, mais ils ne parviennent point à former une flèche. Lorsque l'arbre est très-jemne, qu'une seule branche s'empare de la sive ef continue le trone, il me reste quelquefois point do traces de we accident; mais si le sapin approchait de sa maturité lorsque cet accident arrive, le tronc resterait mutilé, et si la cassure était trop rapprochéc du sol, l'arbre périrait.

Lorsque, dans sa jeunesse, Io sapin picéa est longemes privé d'espace et de: lumière par des arlures de son roisinage, sa régétation devirnt insensible, les.

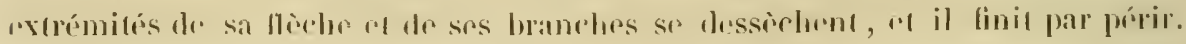




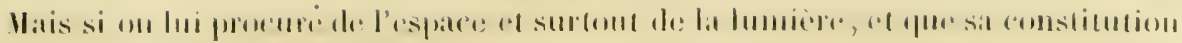

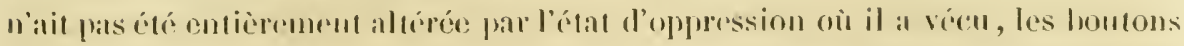
fui lui restent se raniment, et il paraît mêmr quelquefois des boutons adrentlitis; il se forme de nombreuses ramilles, une flèchr part d'un bouton de la deruiere hèche ou de l'extrémite d'une branche et continue le trone, de noweans bages de luanches se formont successivement chaque anner : Iorsque quolques: ammés se sont écoulces, l'arbre présente l'aspeet le la plus belle végétation at He ronserve plus ancune trace des sonffrances qui l'avaient róluit à un si tristr ital. Toutefois, quelle que soit l’appinence el toutes choses igales d'ailleurs,

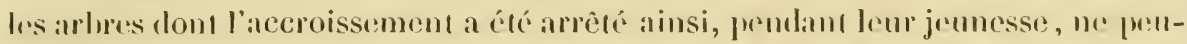
vont alleindre aux mêmes dimensions que si feur (roissance n'avait pas subi

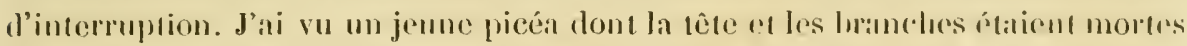
ì lours extrémités, el qui pourtant reprit une belle végétation, lorsque l’on ent alatlu de grands sapins argentés qui, par lenr ombrage, l'avaient mis dans co Iriste ćat ; mais i] ne follut pas moins de dix ans pour cela el jaurais en beanroup d’avantage ì l'arracher prour le remplacer par un aslore de pépinière.

Ies brancles du sapin picéa sont disposées par élages, au nombre de trois i six par chaque chage, mais fas aussi régulièrement que celles du sapun

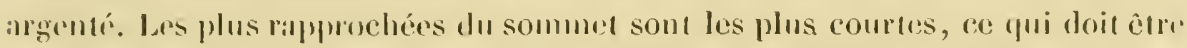
puiseu'dlas sont les plus jemmes. I at disposition des branches par élages dis-

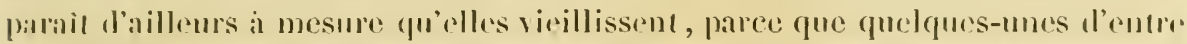
rlles s'ólexent pendaut que d’autres s'abaissent, el elles ne conservent presque blus alors de traces de cette disposition régulière de leurs premières années. Dans les jeunes piréas, el vers la cime des picéas qui onl encore une végébalion vigourense, les branches sont érigées; mais les branches les plus rapprochérs du sol qui sont plus âgérs, surtont quand le picéa approche de sa matun ité, fléchissint sous to poids, des rimilles et des feuilles ef ne se redressent un jen four virs lo bout; les ramilles pendent alors de chaque cóté des branches.

Le sapin picéa, considéré dans son ensemble, conserve torjours la forme. coniqur: quand il n'est pas trop serré par d'autres arbres; mais l'axe de ce conne s'allouge dians une proportion plus grame que sa base ne s'agrandiı. La c'oulcur verte des fentlles de cet arbre est moins foncéc que celle des linulles du sapin argenté; mais la forme pendante de ses hranches inférieures, co surtout des ramilles qui les couvent, lui donnent un air de tristesse; il partage aree l’il, le cyprès pyramidal et les thuyas, lo priviléne d'orner les cimetiores.

L'accroissement annuel en diamètre du sapin picéa ne doit être examiné que sur dles arbres dont l'aceroissement u’a jamais ćté inferrompu (Joy. page 32): je. n’ai pu réunir à ce sujet, sous le climat de Paris, qur les fails suivans.

Dans la plantation dont j’ai parlé page 124, Jes picéas ćlaient âgés d’environ As ans ì l'autommo de 1811; le plus gros de ces arbres a vill un diamètre de $0^{\mathrm{m}}, 50$, lo plus laut avait $13^{m}, 50$; ils avairnt en moyemo un diamètre de $0^{\mathrm{m}}, 41$, er qui

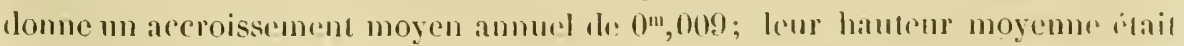

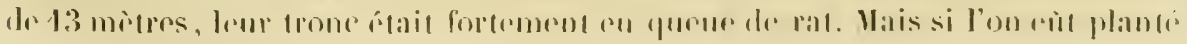


des arbres de pépinière au lieu de planter du plant de semis naturel, il est probable que l'accroissement aurait élé plus grand; il aurait été plus grand aussi, si ces picéas étaient provenus de semis naturel, et il aurait été plus grand aussi, je crois, si ces arbres, au lieu de se trouver dans un taillis de bois fenillus, s'étaient trouvés dans un massif de futaie ayant entre eux l'espacement Ie plus favorable. La dimension des picéas, à cet âge, ne peut d'ailleurs point servir à asseoir un calcul même approxima tif sur leur accroissement annuel en cliamètre, depuis leur naissance jusqu’à leur maturité, ni sur le produit qu'on peut en tirer, parce que c'est alors que le tronc commence à prendre beaucoup plus de valeur, et que e'est alors aussi que l'accroissement annuel en diamètre commence à être moins fort, du moins sous le climat de Paris : c'est done à l'époque où l'arbre approche de la maturité qu'il est utile de faire ce calcul, et ce n'est que le volume et la forme qu'a alors la partie du tronc propre à la vente, qui peuvent faire connaître quel intérêt on peut avoir à cultiver cet arbre.

Le plus gros des picéas qui restent du quinconce (1) dont j'ai parlé plus haut a aujourd'hui (1845) un diamètre de $0^{\mathrm{m}}, 56$ et 19 mètres de haut; mais on avait abattu les plus beaux de ces arbres qui auparavant opprimaient ceux qui ont été conservés; ces derniers sont d’ailleurs presque tous atlaqués de la pourriture au cœur et ne prennent plus d'aceroissement depuis plusieurs années, aussi n’en ai-je conservé que comme porte-graines et pour ornement. Si l'on suppose qu'ils n’avaient cessé de prendre de l'aceroissement qu'à 80 ans, le picéa dont je viens de parler aurait eu un accroissement annuel de $0^{\mathrm{m}}, 007$. J'ai, dans le taillis tout près de ces vieux arbres, un picéa que j’ai vu jeune el que je crois être l'un deleurs nombreux enfans, mais qui pourraic aussi avoir été planté, par mon oncle, de 1786 à 1789; cel arbre, qui n'a pas encore atteint sa maturité et qui prend tous les ans de l'accroissement, avait déjà, à l'automne de $1841,0^{\mathrm{m}}, 60$ de diamètre el 19 mètres de haut : on pouvait alors évaluer son âge à 60 ans au plus, s'il provenait de semis naturel, puisque, en lui supposant cet âge, il aurait cu pour pèr un arbre de 25 ans, ce qui serait, selon moi, un cas exceptionnel; il aurait pu avoir de 65 à 66 ans s'il avait été planté de 1786 à 1789. A l'automne de 1814 il avait $0^{\mathrm{m}}, 64$ de diamètre; ainsi, en le supposant âgé alors de 63 ans, il aurait el! un accroissement annuel de $0^{\text {in }}, 01$.

On a planté, en 1792, dans un jardin anglais appartenant à Mme de Buhorel, situé à Breteuil, petite ville qui se trouve à 6 kilomètres de chro moi, des sapins picéas, des pins sylvestres et des pins Weymouth, qui sont isolés ou peu serrés et en bonne terre; le plus gros picéa avait, à l'automme le 1814, un diatmètre de $0^{\mathrm{m}}, 57$, ce qui, en le supposant âgé de 60 ans, donne un accroissement

(1) Ce quinconce fut planté par mon grand père en 1765-1766, et si l'on suppose que le plant de picéa que l'on emplloya avail 7 ans, ces arbres auraient aujourd'hui $\$ 6$ ans; il occupait environ un hectare dans un champ de tere lahourable qui se frouvait alors dans le pare et quon planti en bois; les picéas y étaient à 4 métres les uns dts autres en tout sens, et ils auraient été trop serris, apròs avoir

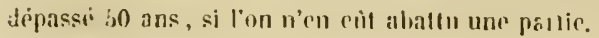




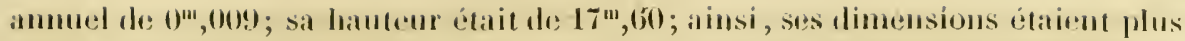
fortes que celles du pluš gros des pins sylvestres et du plus gros des pins du lord W cymouth, qui avaient été plantés en mème temps. (Voy. thap. IV a III, art. 1.)

On a planté, en 1810, dans le pare de Glissoles, qui appartient à M. Ir duc de Clemont-Tonnerre, à 20 kilonètres de che\% moi, des sapius picéas, des pins sylvestres el des mélèzes, au bas d'un cotean qui borde la vallée de l'lton; ces arbres sont isolés ou peu serrés ef ron bomne terre. Le plus gros des picéas avait,

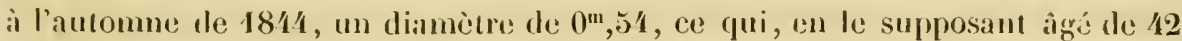
ans, dome un accroissement anmuel de $0^{\mathrm{m}}, 012$; j'évalue sa hauteur à environ 19 unètres; ainsi, ses dimensions en grosseur étaient moindres que celles du plus gros des pins sylvestres et du plus gros des mélèzes plantés en mêmo temps. (Voy. chap. IV et VIII, art. V.)

M. G. Dickie donne, dans un article (1) Sur les forêts et les arbres du comté l'Aberdeen, en Ecosse, un tableau de l'accroissement moyen anmuel de quelques sapins picéas que je vais reproduire, quoiqu'il ait calculé l'âge d'après le nombre des eouches ligneuses du trone, (Voy. page 13); il a pris le dianètre des arbres an gros bout après l'alattage.

\begin{tabular}{|c|c|c|}
\hline YOMBRE DES ARBRES. & AGE. & $\begin{array}{l}\text { ACCROISSEMENT HOYEN } \\
\text { ANNUEL. }\end{array}$ \\
\hline 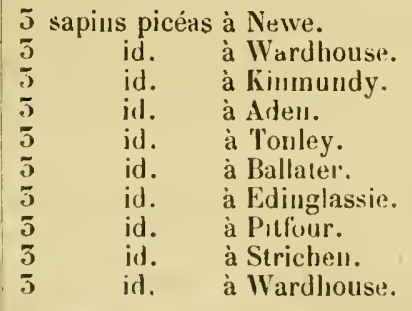 & $\begin{array}{l}28 \text { alls. } \\
40 \text { id. } \\
40 \text { id. } \\
50 \text { id. } \\
60 \text { id. } \\
70 \text { id. } \\
90 \text { id. } \\
100 \text { id. } \\
100 \text { id. } \\
100 \text { id. }\end{array}$ & 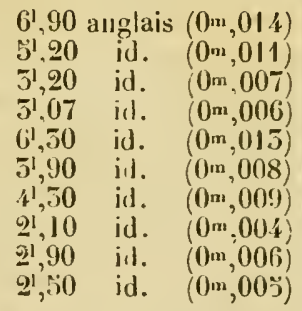 \\
\hline
\end{tabular}

l'ai d'ailleurs la conviction que, sous le climat de Paris proprement dit, toutes choses égales d'ailleurs, il y aura toujours plus d'avantage à cultiver le sapin argenté que le picéa; que, si l’on cite des terrains oì le premier reste chétil et rabougri, tandis que le second y vient passablement, e'est que ces terrains ue conviemnent pas au premier : cela se remarque, par exemple, dans un quartier de mon parc qui était couvert de bruyères et de tristes cepées de chêne, el que mon père et moi avons converti en pinière. Le sapin argenté y reste chétil et rabougri, le sapin picéa y vient passablenent, lo pin sylvestre, le pin maritime al le pin laricio y viement bien.

(n) ue peut ćvaluer l'ìge du sapin picéa, même approximativement, par les

(1) Guarterly Journal of agricullure, n" 60, mars $1893, \mathrm{p} .3994$. 
étages de ses branches, parce que ces étages se téforment bicntòt et qu’il pousse quelquefois des branches entre les étages.

La maturité du sapin picéa n’arrive, comme celle du sapin argenté, que quand il a cessé le croître en hauteur; mais sa croissance en hauteur peut être suspendue ou arrêtéc par des circonstances particulières, comme, par exemple, une sécheresse ou la présence d'un sous-sol imperméable. Burgsdorf dit (1) que le sapin picéa atteint sa maturité à 110 ans. Baudrillart dit, d’après Ilartig (2), que cet arbre, dans des circonstances favorables, acquiert en 100 et 120 ans toutes ses qualités; que Hartig en a fait couper de 150 ans sur des terrains de bonne nature, et qu'un grand nombre étaient gâtés; qu'on en a pourtant coupé de 200 ans qui étaient encore sains; qu’il y a peu de différence entre l'accroissement des deux sapins d'Europe. On remarquera que ce que disent Burgsdorf of Hartig est évidemment ce qu'ils ont observé en Prusse, où ils étaicnt grandsmaîtres des forêts; mais le sapin argenté ne se trouve qu'au midi cle ce royaume, c'est la limite nord où il atteint en Allemagne; le sapin picéa, au contraire, semble y être, sous le rapport du climat, dans les conditions qui lui sont le plus favorables. Ainsi, il est probable que des observaltions faites en Prusse, relativement à l'époque de la maturité et aux dimensions des picéas, ne sont pas applicables à ce qui se remarquerait à cet égard sous le climat de Paris. Cotta (3) st. contente de dire que la révolution du sapin picéa, c'est-à-dire l'époque où il est le plus avantageux de l'exploiter, est de 60 à 140 ans, moindre par conséquent que celle du sapin argenté, qu'il dit être de 80 à 160 ans. Je ne saurais dire à quel àge le picća atteint sa maturité sous le climat de Paris, puisque les faits me manquent pour émettre unc opinion à cet égard; dans mon parc, il ne me paraìt pas l'atteindre plus tòt que le sapin argenté, mais j’ai déjà dit que ce dernier arbre n'y est pas dans les conditions les plus favorables.

Le sapin picéa acquiert de magnifiques dimensions lorsqu'il se trouve dans des circonstances de tout point favorables à sa végétation. Je rapporterai ce qu'en disent différens auteurs: Baudrillart dit, l'après llartig, dans le passage que j’ai cité plus laaut, que parmi ces picéas de 150 ans dont un grand nombre étaient

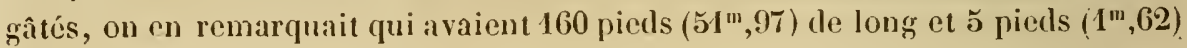
de diamètre à la base. Burgstorf dit (4) que, "presque semblable au sapin com" mun, il s'accroît de plus rn plus en grosseur, de manière à être employé à des "usages extraordinaires." M. G. Dickie, dans l'article cité plus haut, Süles forêts et les arbres du comté d'Aberdeen, donne un tableau que je vais reproduire le la circonférence de quelques sapins picéas à différens âges; cel âge y est calculé par le nombir des couclies ligneuses.

(1) Nouceau .Ianucl forestier, tableau à la fin du t. Ler.

(2) Dictionnaire des eaux et forêts, t. II, p. 785.

(3) Traité de culture forestière, p. 61.

(i) Vonvea Manuel forestier, 1. Ier, p. 11i. 


\begin{tabular}{|c|c|c|c|}
\hline LOCALIT E.S. & AGE. & 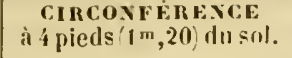 & NATURE WU SOL.. \\
\hline $\begin{array}{l}\text { Philorll. } \\
\text { Pitfotr. } \\
\text { Kinmundy. } \\
\text { Striclien. } \\
\text { Kemndy. } \\
\text { T'unley. } \\
\text { Wardhouse. } \\
\text { id. } \\
\text { Leilh-Hall. } \\
\text { lireda. } \\
\text { Wilehaugh. } \\
\text { Newe. } \\
\text { Eninglassic. } \\
\text { Ballaler. } \\
\text { Invercauld. } \\
\text { Aboyne. }\end{array}$ & $\begin{array}{l}46 \text { ans. } \\
100 \text { idl. } \\
45 \text { id. } \\
100 \text { id. } \\
60 \text { id. } \\
100 \text { id. } \\
40 \text { id. } \\
67 \text { id. } \\
70 \text { idl. } \\
97 \text { id. } \\
28 \text { id. } \\
90 \text { idl. } \\
70 \text { id. } \\
75 \text { id. } \\
80 \text { id. }\end{array}$ & $\begin{array}{cc}4 \mathrm{p} .3 \mathrm{p}^{\mathrm{rs}} \text { angl. } & \left(1^{\mathrm{m}}, 29\right) \\
4-6 & \left(1^{\mathrm{m}}, 37\right) \\
3-4 & \left(1^{\mathrm{m}}, 01\right) \\
(\mathrm{i}-4 & \left(1^{\mathrm{m}}, 93\right) \\
5-11 & \left(1^{\mathrm{m}}, 80\right) \\
6-10 & \left(2^{\mathrm{m}}, 08\right) \\
4-7 & (1 \mathrm{~m}, 39) \\
4-2 & \left(1^{\mathrm{m}}, 27\right) \\
6-3 & \left(1^{\mathrm{m}}, 90\right) \\
5-4 & \left(1^{\mathrm{m}}, 62\right) \\
10-6 & \left(3^{\mathrm{m}}, 20\right) \\
4-4 & \left(1^{\mathrm{m}}, 32\right) \\
8-4 & \left(2^{\mathrm{m}}, 54\right) \\
4-10 & \left(1^{\mathrm{m}}, 47\right) \\
9-n & \left(2^{\mathrm{m}}, 74\right) \\
8-5 & \left(2^{\mathrm{m}}, 56\right)\end{array}$ & $\begin{array}{l}\text { Sol de l,ruyère, sablonneux. } \\
\text { Fond d'argile. } \\
\text { Loam liger sur rnc. } \\
\text { Terreau noir, profund, sur argile. } \\
\text { Terre marécageuse. } \\
\text { Gravier sur fond d'argile. } \\
\text { Terreau léger sur gravier. } \\
\text { Sol léger aigre sul fond dur. } \\
\text { Bon sol, sur roc et glavier. } \\
\text { Sol pauvre. } \\
\text { Surface noire, fond jaune. } \\
\text { Loam sablonneux léger, sur gravier. } \\
\text { Gravier riche. } \\
\text { Bon abri, en sol riche. }\end{array}$ \\
\hline
\end{tabular}

Loudon dit, au commencement de l'article Abies excelsu de son Arboretum et frutiretum britumicum, 1. IV , p. 2295, que "le sapin de Norwège s'élève à la hau" teur de 12 à à 150 pieds $\left(37^{\mathrm{m}}, 50\right.$ à 45 mètres $)$, et même quelquefois à 180 pieds " (5't mètres), a vec un tronc droit, vertical, de 2 à 6 pieds $\left(0^{\mathrm{m}}, 60\right.$ à $\left.1^{\mathrm{m}}, 80\right)$ de " diamètre." II donne, à la fin de cet article, les dimensions de plusieurs sapins picéas situés dans les pares de la Grande-Bretagne; je vais reproduire ce qu'il dit de ceux de ces arbres qui avaient les plus belles dimensions, en choisissant de préférence ceux dont il donne l'âge (Yoy. page 38).

En Angleterre. A Kingsweston, un sapin picéa a 9ð pieds anglais $\left(28^{\mathrm{m}}, 50\right)$ de. haut et son tronc un diamètre de 3 pieds $\left(0^{\mathrm{m}}, 90\right)$. - A Claremont, un picéa a 95 pieds $\left(28^{\mathrm{m}}, 50\right)$ de haut, son tronc un diamètre de 2 pieds $\left(0^{\mathrm{mu}}, 60\right)$. - A Cowdrey, 80 pieds (24 mètres) de haut, son tronc un diamètre de 3 pieds 9 pouces $\left(1^{\mathrm{m}}, 12\right)$. -A Longleat, planté depuis 80 ans, 99 pieds $\left(29^{\mathrm{m}}, 70\right)$ de haut, son tronc un dliamètre de 4 pieds $\left(1^{m}, 20\right)$. - A IIaffield, âgé de 105 : ans, $7 \cdot 1$ pieds $\left(21^{\mathrm{m}}, 30\right)$ de haut, son tronc un diamètre de 2 pieds 6 ponces $\left(0^{\mathrm{m}}, 75\right)$. - A Trentham, 90 pieds $(27$ mètres) de haut, son tronc un diamètre de 3 pieds 4 ponces ( 1 mètre). - A Finborough Hall, planté depuis 60 ans, 100 pieds (30 mètres) de haut, son trone un diamètre de 3 pieds $\left(0^{\mathrm{m}}, 90\right)$. - En Ecosse. A Kilkerran, planté depuis às ans, 95 pieds $\left(28^{\mathrm{m}}\right.$, ว̆0) de haut, son tronc un diamètre de 3 pieds 6 pouces $\left(1^{\mathrm{m}}, 0.5\right)$. -- A Invermay, 84 pieds $\left(2 \breve{2}^{\mathrm{m}}, 20\right)$ de haut, son trone un diamètre de 5 pieds ? ponces $\left(1^{\mathrm{m}}, 72\right)$. - A Taymouth, 100 pieds (30 mètres) de haut, son trone un diamètre de 4 pieds $\left(1^{\mathrm{m}}, \mathbf{2 0}\right)$. - A Sauchie, 96 pieds $\left(28^{\mathrm{m}}, 80\right)$ de haut, son trone un diamètre de 2 pieds 6 poucẹs $\left(0^{\mathrm{m}}, 75\right)$. -- A Blair Drummond, îgé de 120 ans, 98 pieds $\left(29^{\mathrm{m}}, 40\right)$ de haut, son tronc un diamètre de 2 pieds 6 pouces $\left(0^{\mathrm{m}}, 75\right)$.

- En Irlande. A Mackree Castle, 96 pieds $\left(28^{\mathrm{m}}, 80\right)$ de haut, sou trone uñ diamètre de 2 pierls 8 pouces $\left(0^{\mathrm{m}}, 80\right)$. - A Barons Court, planté il y a 60 ans, 100 pieds (30 mètres) de haut, son trone un diamètre de 2 pieds 6 pouces $\left(0^{\mathrm{m}}, 7 \mathrm{~T}\right)$.

Ju tiens de: I. G. Gand que, dans les montagnes des Vosges, oule sapin picria 
llexiste qu'rn tres-pelite quantite, comparativement all sappin algente, il atequiert à peu près la mème hauteur que bui, avee une circonférence un pru moindre.

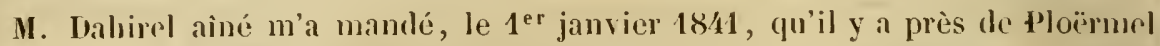
(Morbihan) des sapins picéas, au nombre de sept ou buit, auxquels on donnait près de 100 ans; que ces arbres avaient la même hauteur que les sapins argentŕs, situés près de la même ville, lont il m’avait envoyé les dimensions (Voy. page 33), mais qu'ils étaient un peu moins gros; qu'on en avait trouvé un fort bon prix lors de la guerre maritime, sous l'empire, et qu'on ne voulut pas les vendre. Ainsi, le rapport entre les dimensions des denx sapins d'Europe, dans les Vosges et en Bretagne, so trouve êtru le même.

Le sapin picéa a été introduit par la culture sous le climat de Laris: il ne s'y trouve point en furaies; il y est épars dans les jardins anglais et dans les pares, et il n'y a pas très-longtemps que cotte culture y a pris de l'extension, ear il est lien rare d'en trouver qui aient dépassé 80 ans. Il en résulte qu'il n'y a pas, sous te climat de P'aris, un assez grand nombre de sapins picéas ayant atteint leur maturité pour que l'on puisse savoir quelles sont les plus belles dimensions que cet arbre peut y acquérir, surtout en futaic; mais il est indubitable qu'il serait inférieur, sous ce rapport, au sapin argenté, puisqu'il atteint à peine aux mêmes dimensions que cet arbre sous le climat et dans les siluations qui lui sont le plus favorables. Voici les dimensions de quelques sapins picéas sous le climat de Paris.

On remarque dans le parc de Vrigny (Loiret) plusicurs sapins picćas qui se trouvent en sable substantiel mêlé de terre de bruyère, dans le même emplacement où sont les beaux cèdres dont je parlerai chap. $I X$; ils ont été plantés en 1730, d’après des renseignemens que $\mathbf{H}$. Dubamel de Fougeronx, propriétaire de ce parc, tient de son père, ainsi ils avaient 114 ans en 1814. Le plus gros de ces picéas a $2^{\mathrm{m}}, 32$ de circonférence; je n’ai point eru pouvoir caleuler son accroissement annuel, parce que je présume qu’il y a déjà longlemps qu’il a alteint sa maturité el qu'il a cessé de prendre de l'accroissement.

Il y a dans le pare du Désert, qui appartient à Mr. Bayard, et est sifué à 8 kilomètres de Saint-Germain (Seine-et-Oise), 5 sapins picéas qui ont alleint de belles dimensions; à l'automne de 1843 , ces arbres avaient en circonférence, à $1^{\mathrm{m}}, 25$ au dessus du sol, le premier $2^{\mathrm{m}}, \mathbf{4 3}$, le second $2^{\mathrm{m}}, \mathbf{2 5}$, le troisième et le quatrième $1^{\mathrm{m}}, 98$, et le cinquième $1^{\mathrm{m}}, 92$. Ils ont été plantés de 1770 à 1780 , par M. de Monville, fermier-général; ils se trouvent dans une vallée au bas d'un cotcau, lans un terrain d'alluvion; ils sont garnis de branches du sol à la cime, ont encore une végétation active et ne paraissent pas avoir atteint leur maturité; ils ont dépassé en grosseur les pins sylvestres dont je parlerai dans le chapitre suivant, qui se trouvent au dessus d'eux sur le même cotean.

On trouve dans le parc de Courtomer, qui appartient à M. le marquis de la Coste, et qui est situé à 12 kilomètres de Séez. (Orne), dans une de ces lerres. d'herbages si fertiles des vallées d'Auge, plusicurs espèces d'arbres résineux, parmi lesyuels se trouvent des piéas dont los trois plus gros avaient en 1840: 


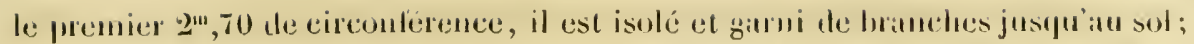
le secont $2^{m \prime}, 10$, il est aussi isolé; le troisième $2^{m}, 11$, il est dans un massil. On leur dome approximativement 23, 27 et 30 metres de laut (Voy. page 38); on innore fuel est exactenent l'âge de ces arbres, on sait seulement qu'il y a all plus 80 ans qu'ils ont été plantés. On voit que, diuns ce pare, l’aceroissement innuel en grosseur du picéa, du pin sylvestre et du pin Weymoutlı, les plis gros, ('hacun dans leur espèce, a élé le même et celui du mélèze un peu maindre. (Voy. chap. IV, VII et VIII, art. V.)

Il y a daus le parc de Trianon, près de Versailles, en terre lianche, plusieurs sapins picéas qui datent, dit-on, de la création de ce pare, qui est postéricure au mariage de Louis XVI, en $\mathbf{1 7 7 0}$, et qui ont par conséguent environ 74 ans. l'ai mesuré plusieurs de ces picéas le 7 aoù 1844 ; le plus gros avait $2^{m}, 28$ ،l: circonférence et miron 20 mètres de haut, ainsi il aurait eu un accroissement annuel en diamètre de $0^{\mathrm{m}}, 0 \mathrm{I}$. En comparant les dinensions de ce picéa arec: celles du plus gros des pins sylvestres, des pins Weymouth et des mélèzes de ce pare (Voy. chap. IV, VII et VIII, art. V) qui y avaient été plantés en mèms: temps, on verra qu'il avait été déjassé en circonférence par un pin sylvestre pommier et un pin Weymouth, mais qu'il avait dépassé le mélèze.

J'ai donné précédemment, en parlant de l'aceroissement anmuel des silpius picéas, les dimensions de plusieurs arbres de eette espèce de diflérens âges, farrliculièrement sous le climat de p'aris.

11. Chinat, exposttion, terrans - Le sapin picéa croìt spontanément diuns le nord et dans la partie centrale de l'Europe; il compose, avec le pin sylvestre, la masse des forêts du nord de l'Allemagne, de la Pologne, de lia Russie et de la Scandinavie, mais il y entre dans une bien moindre proportion que ce pin. On le trouve aussi en plaine dans quelques parties de l'Nllemagne méridionale, el plus au midi, dans les chaines de montagnes seulement. Ainsi it est commun lians les Alpes, mais on ne le trouve en France, croissant spontanément, que dins les montagnes des Vosges, dans celles du Jura, dans celles des Alpes, et il y occupe beaucoup moins d'étendue que le sapin argenté. Dans les Pyrénées il u'y en a pour ainsi dire point, car Lapeyrouse dit (I) qu'il n'y en a vu que quelques individus qui se trouvaient au pied de la montagne de la IIaladetta, et le capitaine S. L. Cook (2) prétend qu'il ne s'y en trouve pas. Il n'existe point dans les Apennins du royaume de Naples, puisque Tenore n'en parle pas dans sa Flora nupolitura; il ne se trouve point non plus dans les Apennins des États-Romains, mais je présume qu'il s'en trouve daus la partie de ces montagnes qui touche aux Alpes. Les moines de l'abbaye de Vallombreuse, située dans les Apennins, non loin des sources de l'Arno, en ont eréé ume telle futaic, dont j'ai 
parlé page 87 , et qu'ils entretiennent par la plantation; mais je ne crois pas qu'il existe croissant spontanément dans ces montagnes.

Loudon dit, dans l'ourrage précédemment cité, page 2302, que le picéa n'est point indigène de la Grande-Bretagne, où il n'est considéré que comme arbre d'ornement, mais qu'il y a très-longtemps qu'il y a été introduit, et il cite à ce sujet un ouvrage de Turner, publié en 15̌48, dans lequel il en est question. Il ajoute d'ailleurs que plusieurs des anciens auteurs ont confondu cet arbre avee le pin d'Écosse, et que ce n'esı que du temps de Miller, pendant le xvir siècle, qu'il a été introduit dans les parcs de la Grande-Bretagne.

Le sapin picéa n'est point indigène du climat de Paris, et il n'est cultivé nulle part en grand sous ce climat, mais seulement comme arbre d'ornement; il n'y a d'ailleurs pas très-longtemps que la culture de cet arbre s'y est introduite, et je pense qu'il n'en existe guère de plus âgés que ceux qui me restent du quinconce ‘lont j’ai parlé précédemment, qui out aujourd'hui (1845) 86 ans.

L'exposition au nord est celle qui convient le mieux au sapin picéa, dans les climats tempérés, et cela doil être, puisque c'est principalement dans les climats froids qu’il croìt spontanément.

On ne peut indiquer, d'une manière précise, quels sont les terrains qui conviennent le mieux à la culture du sapin picéa sous le climat de Paris, puisque sa culture n'y a pas encore été exécutće en grand; je présune qu'un terrain silicoargileux, mêlé de terre végétale, frais et perméalıle aux racines, est celui qui lui convient le mieux. Le sapin picéit peut d'ailleurs croitre passablement sur des terrains maigres, siliceux ou sablonneux, où le sapin argenté resterait chétif; mais pourtant pas sur des terrains de cette nature aussi maigres que ceux sur lesquels on peut encore cultiver avec succès le pin maritime, le pin sylvestre et le pin laricio. Dans le nord de l'Europe, oủ la plupart des forêts sont composées de pins sylvestres et de sapins picéas, on a remarqué que le pin sylvestre occupe les parties les plus sablonneuses et les plus sèches, mais que dans les parties où le sol est moins sec, est humide ou devient argilenx, il est ordinairement remplacé par le sapin picéa.

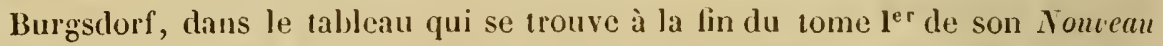
Mancel forestier, indique un sol moyen comme étant celıi qui convient au sapin picéa. Baudrillart dit, d’après llartig (1) : Le picéa est moins délicat sur la na" ture du sol que le sapin commun, il se plait beaucoup dans un terrain.com" posé d’argile, de terre végétale el de gravier ou de petites picrres, et un peu " frais, mais on peut le cultiver aussi avec succès sur un sol de médiocre qualité. "Il n'exige pas beaucoup de profondeur, parce que ses racines s'enfoncent peu, " cependant il vient bien mieux dans les terrains qui ont du fond et qui, par con" séquent, conservent mieux l'humidité que dans les sols superficiels. Les ter" rains fangeux et limoneux ne lui conviennent pas et il vient mal dans les sables " secs, où d'ailleurs il est exposé à être renversé par les vents."

(1) Dictionnaire des eaux et forêts, t. II, p. 784. 
Daus les monlagmes des Vosges, on ne le tronve que daus les hatules Vusges; et, saul quelques rares exceptions, que dans le voisinage des lacs élevés, sur des flatean tourbeux ou sur des versans humides et tourbeux (1). M. le capitaine S. E. Cook, dans l'article Sur les yenres P'in et Sapin, précédemment rité, dit qu’il résiste mieux à l'humidité qu’aucun des arbres de ces deux geures. M. Laing Meison dit (2) qu’il réussit bien en Écosse dans les terrains stériles, s’ils sont humicles et ont quelque profondeur, tels que les terrains tourbeux et marécageux. Il paraît donc que le picéa peut être cultivé avee succès dans les terraius humides et tourbeux, à un point que je ne puis d'ailleurs indiquer.

l'air des grancles villes est contraire au sapin picéa, un peu moins pourtant qu'au sapin argenté; l'on en a plante successivement un assez grand nombre an Jardin-(les-Plantes de Paris; la plupart sont morts, les autres ont le plus triste aspect. Je n'en ai jamais vu dans les jardins de Laris, excepté guand ils sont tris-jeunes, qui eussent une belle végétation.

Vil. Creation dove futale de sapins picéas. - Lie que j’ai dit dims le chapitre précédent, pages 48-65, de la création d'une futaie de sapins argentés, s'applique entièrement à lit création d'une futaie cle sapins picéts ; j'ajouterai seulement les modilications et les faits suivans.

Le plant du sapin picéa ne supporte pas autaut d'ombrage et ne peut pas croitre aussi serré, sans périr, que celui du sapin argenté; ainsi, si l'on plante du plant de picéa dans une futaic ou dans un taillis de bois feuillu, avec l'intention de le: transformer dans l'avenir en une forêt de picéas, il faudra procurer au plaut un neu plus de lumière et d'espace qu'à celui du sapin argenté. On ne peut pas espérer que, sous le climat de Paris, ce sapin domera autant de semis naturel que le sapin argenté, du moins si j'en juge par ce que je remarque dans mon parc; et cela me paraît être une conséquence de ce que cet arbre n'est point indigène de ce climat, et n'y est pas par conséquent dans les conditions les plus favorables a sa reproduction spontanée. On n'aura donc, je pense, une entière certitude de réussir à transformer une futaie ou un taillis de bois feuillu en une futaie de sapins picéas, que par la plantation.

Relativement à la création d'une forêt de sapins picéas par le semis artificiel, je me contenterai de dire que le semis de ce sapin n’a pas tout-ì-fiait besoin d'autant d'ombrage que celui du sapin argenté; néammoins un demi-ombrage lui est nécessaire, du moins sous le climat de P'aris. On a vu, page 58, que j'avais échoué dans un semis de graine de picéa sur labour, comme pour le sapin argenté; el l'on trouvera, à la suite du récit de ce semis, le résultalt d'une expérience de II. de Boisdhyver, à ce sujet, dans la forêt de Fontaincbleau.

En appliquant ce que j’ai dit, daus le chapitre précédent, de lis création d'une futaie de sapins argentés par la plantation, à la création d'une fulaie de sapins

(1) Note communiquece pall M. G. Ciand

?) Le la plantation du méleze, p. 1\%. 
picéas, on assimilera, pour lá dimension des trous, le plant de sapin picéa de (f) à 7 ans au plant de sapin argenté de 8 à 9 ans, et celui de 3 ans du premier ì celui de 5 ans du second.

S'il est vrai que le sapin picéa puisse être cultivé avec succès dans les terrains humides, sous le climat de Paris, ce dont je n'ai aucune certitude, et ce que je présume seulement, par analogie avec ce qui a été observó dans le Nord et en Angleterre, ainci que je l'ai rapporté dans l'article précédent; il serait préférable de ne planter, dans ces sortes de terrains, qu'au printemps. Si ces terrains étaient marécageux l'hiver, il serait nécessaire d'y faire des fossés d'assainissement, et l'on planterait de préférence sur les berges de ces fossés; il est d'ailleurs toujours avantageux de planter sur les berges des fossés, quand elles sont assez fortes, à moins qu'elles ne soient situées à une exposition lorûlante.

VIII. Amexageuent, exploitation et reproduction. - Ce que j'ai dit, dans le chapitre précédent, pages 6ذ-103, sur l'aménagement, l'exploitation et la reproduction du sapin argenté, s’applique entièrement au sajpin picéa, sauf quelques légères modilications que je rais indiquer; ainsi je me contenterai d'y renvoyer mes lecteurs; je rapporterai aussi quelques faits d'expérience.

On peut élaguer le sapin picéa comme le sapin argenté; mais il faut le faire avec encore píus de ménagement, parce qu'il coule beaucoup plus de résine des plaies qu'on lui fait ainsi, et que l’élagage lui est plus nuisible.

J'ai prescrit, dans l'exploitation par bandes et dans l'exploitation par éclaircies, d'attendre une annće d'abondance de cônes; elle se trouve annoncée, pour le sapin picéa, par la quantité des boutons ì lleurs en octobre et, six mois après, par l'apparition des fleurs femelles en avril, environ un an avant la dispersion des graines l'année suivante. Les forestiers allemands ne sont d'ailleurs pas l'accord sur la meilleure manière d'exploiter les futaies de sapins picéas; il y en a qui proserivent la méthode d'exploitation par éclaircies, dans la crainte que les picéas ne soient renversés par les vents, et qui n'admettent que l'exploitation par bandes; mais Hartig et Cotta ne partagent point cette opinion: ces forestiers conviennent d'ailleurs de l'incertitude du repeuplement quand on emploie l'exploitation par éclaircies (1), quoiqu’ils en aient été les propagateurs. Depuis ces opinions contradictoires, des faits d'expérience éclairent peu à peu les forestiers. Je vais rapporter quelques-uns de ces faits, qui se trouvent consigonés dans les Mémoires de la Société forestière de la Silésie prussienne, et auxqueís II. T. Lanier, inspecteur des éudes à l'Ecole royale forestière de Nancy, a dunné de la publicité dans le numéro de janvier 1845 des Annales forestières.

La Socièté dont je viens de parler avait proposé la solution de la question suivante: " Dans les régions des hautes montagnes de la Silésie prussienne, fant" il préférer les coupes à blanc-étoc aux coupes sombres, el ne devrait-on pas " quelquefois recourir au mode jarlinatoire? Je rappellerai d'abord que ces 
montagnes sont principalement la Riesengobirge, thane de montagnes qui su trouvent sur les frontières de la Silésie el de la Bohême, et dont les plus haules ne s’älèvent qu’à 1,290 mètres au dessus du nivenu de la mer, excepté l’une d'elles, qui alleint 1,608 mètres. Elles sont convertes en grande partic de bois dont l'essence dominante est le sajoin picéa, qui fome des massifs purs ou mêlés arec le hêtre. On remarque qu’̀̀ 900 mètres au dessus du niveau de la mer, la croissance du picéa se ralentit beaucoup; aussi n'y est-il plus cullivé que pour procurer m abri aux forêts sitmées à mo moindre élévation el pour prévenir lat détérioration des montagnes et l'affitblissement des sources.

On répondit unanimentent à la question qu'avait proposéc la Société qu'il fallait proscrire les coupes d'ensemencement dius les lautes montagnes, et qu'il lillait quelquefois recourir à l'exploitation en jarlinant. Mais l'on conseillait surtout les coupes par bandes étroites à blanc-étoc, repeuplées par le semis artificiel, qui ne présente que peu de difficultés d'exécution dans cette partie de l'Allemagne, parce qu'on s'y procure facilement el ì bas prix d'excellente graine de picéa. Les causes principales qui avaient fait abandonner l'expluitation par éclaircies dans ces montagnes, étaient que les anmées d'abondance dus cònes y arrivent à de plus grands intervalles que dans les plaincs, ce qui contraignail à exécuter, en les attendant, beaucoup de coupes préparatoires; que les vents exerçaient des ravages dans les futaies où l'on avait fint des coupes d'ensemeneement ou sculement des coujes préparatoires; et qu'en définitive ce morle; de repeuplement n’avait point eu de succès, car il n'avait réussi que par exception et seulement sur des terrains prolonds, abrités, mêlés de quelques hêtres. Ju vais d'ailleurs reproduire des opinions qui furent émises alors, par des hommes l'une autorité incontestable, dans la question proposée.

l'inspecteur liottenberg dit que si le terrain est très-peu profond, humiele, marécageux ou qu'il renferme de nombreuses sources, il est tout-à-fait impossible, fùt-il même peuplé de hêtres, de régénérer la futaie de picéas par la voie naturelle, parce qu'un seul coup de vent, par un temps duux, lorsque le sol n'est pas encore raffermi par le froid, suffirait pour bouleverser une coupe d'eusemencement, quelque sombre qu'on l'en̂t disposée; mais que la présence du hêtre, à la hauteur de 7 à 800 mètres, indiquant toujours un sol profond et argileux; quand les futaies de picéas, placées à cetle élévation, seront mélangées de hêtres bien venans, on pourra établir des coupes d'ensenencement avec quelque chance de succès, sans qu'il soit permis néammoins de les conserver durant 7 ou 8 ans en atlendant mne année d’abondance de cônes. Selon lui, l'usage des coupes ordimaires d'ensemencement, daus les régions élevées, me peut être appliqué-aux futaies de picéas purs que daus un petit nombre de: circonstances; des coupes étroites à blanc-étoc procurent soment un repeuplement complet et méritent la préférence. Que si certaines coupes d'ensemencement ont fourni, en l'absence de ces circonstances, un repeuplement complet,

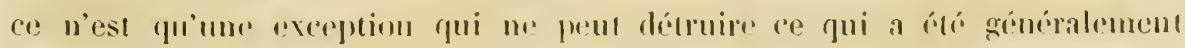
oliseris. 
IM. les inspecteurs Bormann et Haas, qui atministrent 75,000 arpens de forêts dans la partie la plus élevée du Riesengebirge, proserivent d'une manière absolue l'emploi des coupes d'ensemencement dans les futaies de picéas situées à 7 ou 800 mètres au dessus du niveau de la mer. L'inspecteur Rucker prétend qu'on ne doit pas employer les coupes d'ensemencement dans les hautes montagnes, parce que l'économic de semence que l'on fait ainsi ne saurait compenser les nombreux dangers qui résultent de l'emploi de cette méthode, et parce que la semence n'atteint jamais, à cette hauteur, une maturité complète.

L'inspecteur Wegner de Zotten a renoncé, depuis 1833, à employer les coupes d'ensemencement dans les futaies de picéas, ses essais ayant tous échouć; depuis cette époque, il ne propage plus cette essence que par le semis artiliciel, et il trouve dans les sonches extraites dans les coupes à blanc-étoc une entière compensation des frais de culture et d'achats de graines. Il conteste que l'abri procuré par la coupe d'ensemencement soit indispensable, sur les hautes montagnes, à la prospérité des jeunes plants de picéa, surtout si l'on prend la préeaution de faire les coupes à blanc-étoc assez étroites pour que les parties conservées en massifs puissent leur procurer quelque abri. La meilleure méthode de semis artificiel est, dit-il, d'ouvrir avec un instrument en fer des sillons d'un ponce à 6 lignes $\left(0^{\mathrm{m}}, 02 \mathrm{t}\right.$ à $\left.0^{\mathrm{m}}, 013\right)$ de profondeur et de largeur, d'y répandre la semence et de la couvrir d'un pouce à 6 lignes de terre; il est utile que la graine soit couverte ainsi pour la préserver des oiseaux et pour la protéger, au moinent de la germination, contre le froid et la chaleur.

Quoique le bois du sapin picéa soit à peu près de même qualité que celui du sapin argenté, l'estimation que j'ai donnée du, revenu que peut produire une sapinière de sapins argentés, sous le climat de Paris, n'est point applicable à une sapinière de sapins picéas. De deux sapinières de ces sapins, qui anront crù chacune dans les conditions les plus favorables, celle de sapin argenté produira toujours davantage : c'est une conséquence de ce que jai dit précédemment, que le sapin argenté, sous le climat de Paris, atteint à de plus belles dimensions que le sapin picéa, de ce que le premier peut y croître plus serré que le second, et de ce que son trone maintient mieux sa grosseur. Il faut donc faire une diminution à l'estimation que j'ai donnée du revenu que peut produire une futaic de sapins argentés pour obtenir celui que peut donner une futaie de sapins picéas; mais je manque de données pour indiquer quelle doit être celte diminution.

IX. Qu.atités et usages de bors; prodetrs divers.-- Le pied cube de bois d'un silpin picéa de 100 ans pèse vert, d'après Hartig (1), 64 livres 11 onces (31 kil. $664 \mathrm{gr}$.), et sec 3 İ livres 2 onces (19 kil. $193 \mathrm{gr}$ ); le pied cube d'un autre picéa de 60 ans pesait sec, d'après le même auteur, 33 livres 9 onces (16 kil. $128 \mathrm{gr}$.). Dans mon parc, le pied cube de bois d'un picéa le 60 ans, abattu le

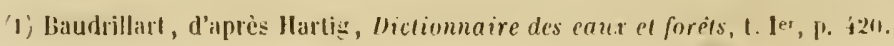


7 septembre 1813, pris près de la sruche, pesait vert 25 hil. 2000 g̈r.; le J̆ septembre 1814 , il ne pesait plus que $15 \mathrm{kil} .920 \mathrm{gr}$, et le $1^{\mathrm{er}}$ mars 1845 , étant sec, que 15 kil. $810 \mathrm{gr}$.

Le bois du sapin picéa n'a point d'aubier; il est d'un blane mat, plus blane, par conséquent, que celui du sapin argenté, et il a à peu près les mêmes qualités que celui de ce dernier arbre. Le sapin picéa que l'on lire du Nord l'omporte pour la mâture, et peut-être aussi pour la charpente, sur le sapin argenté; mais, sous le elimat de Paris, si j'en juge par ce que j'ai observé dans mon pare, où j’ai fait abattre des picéas qui avaient de 60 à 80 ans et au delà, et où mon père en a fait abattre pour la charpente d'une fẻrme, le bois du sapin picéa est tout au plus égal à celui du sapin argenté : je suis même disposé à croire qu'il a moins de nerf et que la planche en est moins bonne.

Le bois du sapin picéa est employé absolument aux mêmes usages que celui du sapin argenté; mais il est préféré pour la construction des instrumens à cordes, et je n'ai point trouvé qu'il fùt employé, comme l'autre, à faire des pilotis et des tuyaux de fontaine; comme bois de chauffage, il m'a paru avoir les mèmes qualités que le bois du sapin argenté. Kasthofer dit que 16 toises de picéa valent 12 toises $\mathbf{1 / 2}$ de hêtre. Je renvoie d'ailleurs à ce que j’ai dit, page 104, des usages du bois du sapin argenté.

On extrait du sapin picéa une résine qui est vendue en France sous le nom de poix de Bourgogne, quoiqu'il n'y ait point de forêts de picéas en Bourgogne : c'est particulièrement en Allemagne et en Suisse qu'on se livre à cette extraction. Pour obtenir la poix, on fait aux picéas une entaille, en observant de ne point entamer le bois; la poix suinte de l'écorce, et transsude entre le bois et l'écorce; elle se fige et reste attachée à la plaie en grosses larmes ou flocons. On ramasse la poix plus ou moins souvent, selon que l'arbre donne ce produit plus ou moins abondamment, mais au plus tous les quinze jours, et chaque fois qu'on fait cette récolte on rafraîchit l'entaille. Le même instrument sert pour faire l'entaille, pour la rafraichir et pour récolter la poix; il a d'un côté la forme du fer d'une hache et de l'autre celle d'une gouge. Un arbre vigoureux planté en bou fond peut rendre par an de 30 à $\mathbf{4 0}$ livres de poix, dit Duhamel, mais cela doit ètre un cas exceptionnel. On ne doit point faire les entailles du còté où vient habituellement la pluie; si l'on n'en fait qu'une ì un arbre, son bois n'en est point altéré, et il peut fournir de la poix pendant vingt-cinq à trente ans; un prétend même que cette opération prolonge la durée des picéas qui sont plantés dans des terrains trop gras. Si, all contraire, l'on fait plusieurs entailles an même arbre, il peut arriver que son bois en soit altéré; il devient alors rouge, te blanc qu'il est ordinairement, et n'est plus propre qu'au chauffage.

Les personnes qui recueillent la poix lui font subir une préparation avant que de la livrer au commerce : ils la mêlent avec de l'eau et la lont fondre dans une grande chaudière à un feu modéré; puis ils la versent dans des sacs de toile lorte et claire, et l'on porte ensuite ces sacs sous des presses pour en faire couler li pois, qui en sort bien nettovée: la poix ainsi préparée se met dans dres barils. 
el on la vend sous le nom de poix grasse vu poix de Bonryogne. Lia liuilite d'entraire la poix du picéa est cause que des délinquans cherchent quelquefois à s'eı procurer; ils ont, par ce motif, fait des entitilles à presque tous les picéas des Vosges.

On tire aussi des résidus que l'on obtient en fabriquant la poix du noir de fumée, en faisant brûler ces résidus. Mais je m’arrête; car la description des procédés que l'on emploie pour tirer diverses substances de la résine, ainsi que du goudron que l'on extrait des pins, n'appartenant qu'accessoirement au sujet que je traite dans cet ouvrage, je ne contenterai d’indiquer les auteurs qui ont décrit ces procédés : c'est ce que je ferai à la lin de l'article $\mathbf{I X}$ du chapitre suivant, consacré au pin sylvestre, el j'y renvoie mes Jecteurs. On y trouveri aussi les noms des auteurs qui ont traité avec détail des produits et des qualités des bois, comme par exemple du charbon et de sa fahrication, de la force de résistance des bois, ete.

X. Accidens, maladies, animaux nusmbes. - Ce que j'ai dit, dans Je chapitre du sapin argenté, des accidens et des maladies auxquels cet arbre est sujet, s’applique au sapin picéa, sanf quelques légères modifications; j’y renvoie dunc mes lecteurs, et je me contenterai de faire connaître ces modifications.

Les gelées tardives causent moins de dommage aux picéas qu'aux sap)ins argentés, parce que leur sève part un peu plus tard.

Les auteurs qui se sont occupés du sapin picéa lombent d'accord qu'il est moins solidement enraciné que le sapin argenté, et par conséquent yu’il est plus exposé à être renversé par les vents; mais, ainsi que je l'ai dit précédemment en parlant des racines de cet arbre, il m’a pourtant paru bien enraciné, et, dans mon pare, il résiste aussi bien aux vents que le sapin argenté.

La neige et le givre causent moins de dommage dans les futaies de sapins picéas que dans celles de sapins argentés, parce que les branches du picéa sont plus llexibles et que ses ramilles sont pendantes.

Le dommage que peuvent occasionner les quadrupèdes et les oiseaux dians les sapinières de sapins picéas est absolument semblable ì celui qu'ils peuvent causer dans les sapinières de sapins argentés. J'ajouterai seulement que les lapins broutent beaucoup plus le sapin picéa que le sapin argenté.

En parlant, dans le chapitre du sapin argenté, des insectes nuisibles à cet arbre, j’ai indiqué le moyen de prévenir ou de diminuer leurs ravages, quand cela est possible; je ne pourrais que répéter ce que j’ai dit à ce sujet, je me contenterai donc d'y renvoyer, et de parler succinctement ici des insectes nuisibles an sapin picéa.

La larve du hanneton peut causer absolument les mèmes dégâts lans les jeunes plantations de sapin picéa que dans celles de sapin argenté. Je présume qu’i existe un puceron du sapin picia comme il en existe un qui allaque le sapin arwenté; mais je n'ai pas eu oceasion de le remarquer.

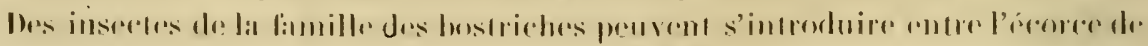


l'arbou lo bois, at former daus le liber des galeries qui, lorsqu'elles sont assez nombreuses, arrêtent entièrement la circulation de la sève, ce qui lait périr l'arbre; ces insectes peuvent multiplier au point de détruire des forêts entières. Lo sapin piréa est plus exposé à ces sortes de ravages que le sapin argenté. Des chenilles, anxyuelles des papillons ou des monches ont dommé naissance, penvent manger les feuilles, ou les laire monrir en en mangeant l'intérieur, en les sugant on en les pergant, et détruire ainsi des forêts entières lorsque leur mulliplication est extraordiuaire. Ratzeburg indique (1), comme causant le plus hallituellement des ravages dans le's forêts de picéas du nord de l’Allemagne, le bostriche typogriphe, Bostrichus typographus, et la nonne, Phalena bombyx monacha.

Je n’ai remarqué sur ma propriété que trois insectes unisibles au sapin picéa: d'aborl une chenille verte qui mangeait les f'uilles des pousses de l'année, re qui faisait périr ces pousses; mais elle n'attaqua que quelques jeunes arbrus a disparut l'année suivante. Elle ressemblait parfaitement à celle que Ratzeburg: appelle tenilhrède du pin, Tenthredo pini, et dont il donne le dessin colorié; cet anfeur dit pourtant que celle tenthrède ne vit que sur les feuilles du pin sylvestrr. Le second insecte est la chenille dont j’ai parlé fort en détail pages 112-115, et qui faisait mourir les fenilles du sapin argenté en en mangeant l’intérieur; elle allaqua aussi les fenilles du sapin picéa, mais beaucoup moins que celles de l'autre sapin. Le troisième est un puceron que j'observai dans l'intérieur des excroissances rugueuses, grosses comme une petite noix, qui se trouvent trèssouvent ì la naissance des pousses des picéas plantés depuis peu; ces excroissances, vertes pendant la sève, dont elles s'emparent, deviennent sìches et noirâtres pendant l'hiver; il est très-rare que cette maladie, qui est très-commune, fasse périr les picéas, mais elle ralentit beaucoup leur accroissement; heureusement ces excroissances annuelles finissent prestue toujours par disparaître. Il serait pourtant possible qu'elles fussent les conséquences, et non la cause de l'état maladif de l'arbre.

J'il vu quelquefois, au sommet d'un picéa encore jeune, tous les bouts des branches se dessécher et périr, y compris la flèche, et l'arbre succomber alissi, mais rarement : c'était probablement l'ouvrage d'un puceron; c'est ce que je n'ai pas eu le temps d'observer.

(1) Les hilophthires ef lewrs ennemis, p. Gi cit 113. 


\section{CHAPITRE IV.}

\section{PIN SILUESTRE, Pinus syluestris.}

1. Nous de l'espèce. - Pimus syluestris Liné (1). On l'appelle aussi PiN sauvage, Pin d’écosse, Pin du Nord, Pin de Riga, Pin de Hlaguenau, Pin ie Genève el Dallle (2).

Je donne la préférence au nom de pin sylvestre, parce qu'il est le plus répandu et qu'il est en même temps scientitique el vulgaire. On voit que, selon moi, le pin sauvage, le pin d'Écosse, le pin du Nord, le pin de Riga, le pin de Haguenau, le pin de Genève, la daille ne sont qu'un seul et même pin qui peut subir des changemens, excepté en ce qui concerne la forme des feuilles, des tleurs et des cônes, en raison du climat, dans les différens pays-où on lui a donné ces noms. Malesherbes, dans un mémoire inlitulé Observations sur les pins en général el en particulier sur le pin maritime (3), émet la même opinion; il dit que Duluamel a semé du pin de Haguenau et qu'il n’a remarqué aucune différence spécitique entre ce pin el les vilains pins de Tarare et de Genève; qu’il a semé lui-même de la graine de pin d'Écosse, achetée à Londres, et de la graine des pins de Tarare, que lui avait procurée Bernard de Jussieu, et que les deux pins provenus de ces semis lui paraissent être entièrement semblables. Fougeroux de Bla veă, neveu tle Duhamel, dans son Mémoire sur les espèces de pins qui sont ì préférer pour réparer les parties de nos forêts légamies de chênes, mémoire inséré dans les Mémoires de la Société d'agriculture de P'aris, année 1785, trimestre d'automne, page 5̌, dit que Duhamel a semé des graines de pin de Riga, apportées par Barbé, maître mâteur à Brest,

(1) Species plantarum, 3c édit.. t. 11 , p. 1418.

(2) Le nom de Pin d'Ecosse qu'on dorne à cet arbre en Angleterre, parce qu'il est commun en Ecosse, est le plus répandu en France; le nom de Pin de Riga résulte probablement de ce que l'on fait à Riga un grand commerce de bois de pin sylves!re, arbre le plus commun dans les provinces voisines de Riga et dans celle que traverse la Dwina, qui passe par cette ville. Le nom de Daille est le nom vulgaire en Suisse. Les autres noms sont ceux de lieux où le pin sylvestre est commun.

(3) L.e mẻmoire de Lamoignon de Malesherbes se trouve L. II, p. 301-357 de l'ourrage de Virenne de Fenille, intitule Mémoire sur l'administration foresticre, elc., ctc. Il est digne de remarque que ces deux savans, qui s'occupaient si activement de prrfectionner la sylviculture en France, fiérirent sur l'échafaud révolutionnaire dans l’année ģii suivit la pullication de leur onvrage. 
"' qu’il est difficile de distingure les plants qui en sont nés de eeux du pind'Écosse: il fit la meme remaryue sur des semis faits, dans les environs de Brest, avec la même graine, et il conclut que le pin connu sous le nom de pin de Riga lui parait entièrement semblable au pin d'Écosse; il ajoute que Miller, dans un. lettre ì Duhamel, émettait la même opinion.

I1. Boutons et sirve. - Le pin sylvestre n'a que des boutons à bois qui contiennent en même temps le rudiment des feuilles et des fleurs; dlu moins, bois, feuilles, fleurs, tout part des mêmes boutons.

Cet arbre n'a qu'une seule sève qui commence ordinairement, sous le climat de Paris, dans les dix derniers juurs du mois de mars, par le bouton qui se trouv' dans le prolongement de la flèche de l'année précédente, contrairement à ce qui se remarque dans les sapins, et qui s'arrête, en ce qui concerne la longueur des pousses, au bout de deux à trois mois environ; ainsi en 1842, annéc chaude, la sève ne dura que deux mois; en 1843, annéc humide et froide, elle dura trois mois; en 1844, elle dura deux mois et demi.

Les pousses sont d'abord couvertes d'une pellicule de couleur rousse et sont serrées les unes contre les autres; sous celtc pellicule, et autour du bas des pousses, sont les lleurs mâles, quand il y en a, et au dessus les feuilles naissantes collées contre les pousses; cette disposition des fleurs mâles au bas des pousses est un caractère génćral dans les pins. Au bout d'un mois, environ vers to 20 avril, la forme des fleurs mâles, malgré la pellicule qui les couvre, se distingue parlaitement et l'on voit naître les boutons à hois, et à côté, au bout des pousses qui doivent porter des fleurs femelles, le petits boutons qui en contiennent le rudiment, et qui se trouvent quelquefois sur les mêmes pousses que les fleurs mâles. Quinze jours après environ paraissent les fleurs; et quelques jours plus tard les pousses, qui étaient restées jusqu'alors serrées les unes contre les autres, et qui ont déjà atteint une partie de leur longueur, s’écartent; la pellicule qui les couvre tombe, en commençant par le bas des pousses, et l'on aperçoit alors les bourgeons des feuilles, lesquelles paraissent environ quinze jours plus tarıl. Enfin, ainsi que je l'ai dit plus haut, au bout de deux à trois mois environ les pousses ont atteint toute leur longueur, et elles sont terminées par les boutons destinés à produire les pousses de l'année suivante qui sont alors complètrment formés; mais cnsuite elles augmentent encore un peu en grosseur, ainsi que les boutons, et elles deviennent ligneuses d'lerbacées qu'elles étaient. La végétation des boutons ne s'arrête d'ailleurs jamais entièrement; ils prennent de l'accroissement en longueur, mais avec une extrême lenteur, jusq̣u'au moment où partira la sève au printemps suivant.

IiI. Fechles, fleurs et cônes. - Les bourgeons des feuilles du pin sỵlvestre commencent à paraître, ainsi que je viens de le dire, dans la première quinzaine du mois de mai, lorsque les pousses, qui ont paru depuis environ sept semaines, ont déji acquis ume parlie de leur longueur el que la pellicule qui les 
convrait est tombée. Environ quinze jours après on commence à voir les fenilles sortant deux à deux ( elles sont géminées) de gaines cylindriques fixées autour des pousses. Quand ces feuilles ont atteint toutes leurs dimensions (Pl. J, fig. 7 et 8), elles sont dures, linćaires, pointues, d'un vert blenâtre, longues de $0^{\mathrm{m}}, 027$ à $0^{\mathrm{m}}, 068$, selon l'âge des arbres, le terrain et l'exposition. Chaque feuille a sensiblement la forme d'une moitié de cylindre qu'on aurait coupé en deux suivant son axe; les faces aplaties de deux feuilles contenues dans une même gaine se regardent, et ces feuilles ont, si on les reunit, la forme d'un cylindre. Les feuilles ne persistent ordinairement que pendant deux ans et tombent pendant la troisième année; ainsi elles tombent après la troisième sève, y compris celle qui leur a donné naissance, et plus particulièrement à l'automme.

Les fleurs du pin sylvestre (Voy. page 10 ) commencent à paraître en même temps dans la première quinzaine de mai environ, ainsi qu'on l'a vu au commencement de ce chapitre.

Les chatons mâles (Pl. I, fig. 7 ) sont serrés autour de la partie inférieure des pousses de manière à former une sorte de grappe. Les fleurs qui les composent ont atteint leur maturité quinze jour's environ après qu'elles ont paru, ordinairement dans la deuxième quinzaine de mai, environ huit jours après celles du pin maritime; elles sont alors d'un jaune citron et répandent en très-grande quantité une poussière jaune soufre (le pollen). Le pin sylvestre porte des lleurs mâles en plus ou moins grande quantité, et il peut arriver qu'il en porte sur toutes les branches, comme aussi qu'il n'en ait pas du tout, ce qui une parait d'ailleurs être l'exception sur des arbres ayant dépassé 20 ă ans et convenablement espacés.

Les chatons femelles sont amnoncés, ainsi que je l'ai dit, environ quinze jours d'avance, par de très-petits boutons qui sont au bout des pousses, au nombre d'un à quatre et quelquefois plus, par exception, et se trouvent en plus grand nombre vers le haut de l'arbre. Ils sont ovoïdes, ne sont d'abord pas plus gros qu'une trèspetite graine de vesce, sont d'un rouge-violet et ont la pointe tournée vers le ciel (sont érigés). Au bout de quelques semaines les fenilles llorales (les bractées) se transformant en écailles, les chatons deviennent des eônes, et à la couleur rougeviolet des fleurs succèle la couleur rouge-brun, qui est bientôt remplacée par la couleur gris-ver. Cette transformation est déjà très-apparente vers le milieu du mois de juin, et e'est pendant qu'elle s'opère que les cônes s'inclinent et prennent la position qu'ils conserveront; ils ne sont pas plus gros alors qu'un pois.

Les cònes sont toujours placés au bout de la pousse sur laquelle ils se trouvent (ils sont terminaux), à côté des boutons, au nombre d'un ì quatre ẹt quelquefois plus, par exception; ils sont fixés sur le bois par une quene très-courte (ils sont pédonculés). $\Lambda$ la fin de septembre les cônes ont acquis tout le développement qu'ils prendront cette première année; ils sont alors oblongs, gros comme tunc petite noisette et d'un gris vert. L'annće suivante, immédiatement avant la sève, ils sont d'un grris clair ( Pl. V, fı. 2), et ils commencent à grossir dès qur part la sive; ì la fin do mai ils devienment d'un vert pribie et conservent celle 
couleur jusqu’a la tin de septembre, époque à laquelle ils ont atteint tout heur accroissement; puis ils passent peu ì peu i la couleur gris-cendré, lorsque les premiers froids commencent, et dans le courant de mars de l'amnée suivante, peu avant qu’ils ne laissent échapper les graines qu'ils contienuent, leur couleur varic du gris brum au brun finue.

Les connes du pin sylvestre ( Pl. I, fig. 8, et Pl. V, fig. 2) ont de $0^{\mathrm{m}}, 027$ ì $0^{\mathrm{m}}, 05 \mathrm{~s}$ de longr; ils sont coniegues et se composent d'écailles serrées les unes contre les autres, allhérentes à un axe commun, plus minces ì la base fixée à l'axe qu’à la partie qui en est le plus éloignée; à la base interne de ces écailles se trouvent deux graines munies chacune d'une aile. La graine que contiemnent les cônes n'a atteint une complète maturité qu’à la fiu de novembre, et ce n’est que daus le mois l'avril de l'année suivante, e'est-à-dire 22 mois environ après qu'ils ont paru, que le soleil fait soulever leurs écailles et que la graine qu’ils contiennent commence à tomber; cette graine étant munie d'une aile, comme celle des sapins, peut aussi être transportée au loin par les vents; cette dispersion de la graine s'opère en un petit nombre de jours. Les cônes commencent à tomber successivement, par suite des secousses des vents, dès l'année mène pendant laquelle sont tombées les graines qu'ils contenaient; mais ce n'est qu'au bout de plusienrs années que les pins sylvestres en sont entièrement débarrassés.

Le pin sylvestre le plus jeune auquel j'aie vu porter des cônes, était un arbre tiré d'une pépinière et âgé de 10 ans, ce que je considère comme une exception; mais dans une allée de pins sylvestres de mon parc, plantée en 1837, ils commencèrent, pour la plupart, à en porter en 1812, c'est-ì-dire lorsqu'ils avaient ì peu près 12 ans; je présume que les arbres provenant de semis naturel en portent un peu plus tard. Lne partic des graines de ces jeunes arbres sont fécondes, s'ils ont porté des fleurs mâles en même temps que des cònes; mais ce n'est que lorsque les pins sont plus âgés que leur graine a acquis toute la force germinative dont elle est susceptible; je pense done que, lorsqu'on le peut, l'on ne doit récolter les cònes, pour en extraire la graine, que sur des arbres âgés le 40 ans an moins.

On ne commence à voir des fleurs mâles pour la première fois, sur les jeunes pins sylvestres, que deux on trois ans environ après que l'on a commencé à y voir des cônes. Cet arbre porte plus souvent des fleurs mâles et des cònes que les sapins; néanmoins, on remarque, par exception, des années sans fleurs mâles, d'autres sans cônes; on remarque aussi des anućes d'alondance de cônes, qui sont ordinairement ausși des amnèes d'abondance de fleurs mâles, et même, mais plus rarement, des années de stérilité.

Il est d'ailleurs digne de remarque que les fleurs ne commencent pas à paraitre dans le même ordre que les feuilles, dans les quatre espèces de pins à chacune desquelles j’ai consacré un chapitre. Lesfleurs du pin maritime paraissent et mûrissent les premières, puis celles du pin sylvestre, et enfin celles du pin laricio a du pin du lord Weymouth à peu près en même temps. Les feuilles du pin sylvestre paraissent les premières, relles du pin laricio quelques jours après, celles 
du pin du lord Weymouth suivent, et enfin celles du pin marilime très-pen de jours après celles du pin Weymouth.

1Y. Granes et sems naturfel- - Les graines du pin sylvestre (Pl. l, fig .9) sont ovales, d'un brun noir, et sont munies d'une aile; elles ont environ $0^{\mathrm{m}}, 004$ de Jongueur moỵenne. J'ai indiqué, dans l'article jrécédent, à quel âge les jeunes pins commencent à porter des cônes; les graines qu'on en tire peuvent être fécondes, mais ce n'est guère que lorsque l'arbre a dépassé 20 ans qu'il'lonne du semis naturel, et il n'en donne d'abord qu'en petite quantité; il faut que le pin sylvestre ait dépassé 40 ans pour domner abondamment du semis naturel efficace. Ce sont les pins sylvestres qui approchent le plus de leur maturité, ou qui l'ont atteinte, qui, pour la même quantité de graine, donnent le plus de semis naturel, et c'est par conséquent la graine de ces arbres que l'on doit préférer pour faire des semis.

On peut, pour se procurer de la graine, faire cueillir des cônes depuis le commencement de novembre jusqu'à l'époque où cette graine doit s'échapper des cônes, dans le courant d'avril de l'année suivante; mais, quoique la plus grande partie des graines soient bonnes au commencement de novembre, les cônes étant encore gris-vert, je pense qu'il est préférable de ne les récolter qu'après le $1^{\text {er }}$ décembre, et même plus tard encore si on le peut; la graine est alor's meilleure, donne moins de déchet et on l'extrait plus facilement des cônes; il y a l'ailleurs de l'avantage à la laisser le plus longtemps possible dans les cônes, parce qu'elle s'y conserve mieux.

Lor'squ'on n'a besoin que d'une petite quantité de graine que l'on récolte che\% soi, il ne faut faire cueillir les cônes qu'en mars, peu avant l'époque à laquclle elle serait tombée; on les expose au soleil, sur des vans ou sur des draps; les cònes s'ouvrent, et en les secouant la graine tombe; si l'on peut les mettre dans une serre ou sous une bâche, on récoltera la graine encore plus promptement. Par ce moyen, on n'obtient guère, en moyenne, qu'une vingtaine de graines par còne, mais ordinairement elles sont toutes bonnes. Si l'on veut se procurer une plus grande quantité de graine, il y a nécessité de cueillir plus tôt les cônes et d'employer d'autres procédés d'extraction, afin de l'obtenir assez. tôt pour pouvoir la semer au moment le plus favorable. On peut atteindre ce but en employant la chaleur du soleil, ce qui est préférable, mais n'est pas toujours suffisant, ou une chaleur artificielle. Il arrive d'ailleurs presque toujours, lorsque l'on emploie le premier moyen, que l'on obtient les graines trop tarl pour semer au moment qui serait le plus avantageux, et cela arrive toujours dans le Nord, puisque Burgsdorf dit, dans son Nonveau Manuel forestier, t. II, p. 238, que "l'opération qui consiste à fáre ouvrir les cônes au soleil serait sans " contredit la meilleure, si elle n'était pas si longue et si elle n'obligeait pas à " garder les semences pendant une année entière."

Pour extraire la graine des cônes en employant la chaleur du soleil, on établit rontre un mur exposí au mirli des cohafaurlages, de manière à pouvoir pla- 
cer des claies mobiles les unes au dessus des autres, i une distrnce telle quilles puissent etre frappées en grande partic par les rayons du soleil. Ces claies on $1^{\mathrm{m}}, 30$ de long, $0^{\mathrm{m}}, 6$ o de large, el des bords de $0^{\mathrm{m}}, 16$ de haut; le foud ast en til de fer ou en baguctles de hois espacées de telle sorte qu'elles retiennent les cones et laissent passer facilement les graines ailées. Au dessus des claies de l'élagr: le plus élevé on place un toit mobile dont les charnieres se trouvent près du mur, et au dessous de celles de l'étage le plus rapproché du sol des tiroirs dont le fond est en toile grossière, afin que s'il tombe de lit pluie, elle puisse passer ì travers. On charge les claies de cônes quand il fait du soleil, et on les remuc de temps en temps lorsqu'ils commencent à s'ouvrir. On relire les cônes quand ils ne contiennent presque plus de graine; deux ouvriers les secouent une dernière fois dans une claie plus grande ([ue celles de l'échalinudage, et plus fortement que cela n'avait encore été lait; enfin on les met en magasin pour servir de combustible.

Lorsque l'on extrait la graine des cònes de pin sylvestre au moyen de la chaleur du soleil, par le procédé que je viens de décrire, on ne peut, si l’on reut exécuter un semis de quelque importance, se procurer assez tòt la quantité de graine nécessaire pour semer ì l'époque la plus favorable, et si l'on sème trop tard, la sécheressé peut compromeltre la réussite du semis. Dautre part, si l’on emploie de la graine qui a été récoltée l'année précédente, elle présente plus de déchet, parce qu’il y en a déjà une partie qui ne lève plus, et que celle qui lève n'a plus la même furce de germination. Si enfin on emploie de la graine extraite dans des sécheries pendant l'hiver, ainsi que je vais le dire, il est à craindre qu'elle n’ait été altérée, et il y a beaucoup de déchet dans cette graine:, tandis qu'il n’y en a pour ainsi dire point dans celle qui a été extraite au soleil. Il serait done très-utile de pouvoir se procurer de la graine extraite au soleil arant

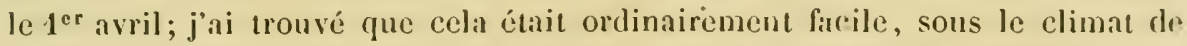
l'aris, et pouvait. être exécuté économiquement sur une assez grande échelle.

Le moyen que j’ai employé consiste à placer les cônes sous une bâclıe ljien close et abritíe du côté du nord et de l'est; il suffit de les y mettre du $1^{\text {er }}$ au 15 férrier, et quelquefois mème plus tard, pour que, presque toujours, ils se soient ouverts et aient laissé échapper leurs graines avant le $\mathbf{1}^{\text {er }}$ avril. lour opérer en grand, on ferait construire une bîche d'une largeur convenable et d'une longueur dépendant de la quantité, de cònes qu'on voudrait y mettre. Elle scrait garnie de claies, telles que je les ai décrites, sur lesquelles on placerait les cônes, et elle serait pavée, pour qu'on pủt facilement retirer les graines avec un balai; on ne donnerait à cette bîche que la profondeur strictement nécessaire pour le service auquel elle serait destinée. Le meilleur abri serait de hautes murailles, mais une furaie, un taillis assez âgé ou une linge et forte haie suffirait. J'ai lenu note d'une extraction de graines que je fis ainsi en 1814. Le 20 février, je mịs sous une bâche des graines de picéa, de mélèze, de pin sylvestre, de pin laricio et de pin maritime; le 8 mars, jajoutai les cones de pin sylvestre et de mélèze qui s'ouvirent aussi tò que ceux qui avaient èté nis 
le 20 lévrier. Le fer avril, les eônes de pin laricio avaient achevé de laisser tomber leurs graines, les cônes de picéa, de mélèze et de pin sylvestre les eurent laissć tomber en même temps, quelques jours plus tard, et enfin les cônes de pin maritime le $1 f$ avril seulement.

Pour extraire la graine des cônes au moyen d'une chaleur artificielle, lorsqu’on veut opérer en grand et avec toute l'économie possible, on fait construire une sécherie. J'en connais de deux espèces que je vais décrire sommairement: relle que l'on emploie habituellement en Allemagne, et une autre espèce de sécherie, dont il n'existe, je crois, que deux en Europe, l'une à Haguenau, l'autre ¿ Fontainebleau. La sécherie de Fontainebleau, construite, d’après celte de IIaguenau, par les soins de M. Marrier de Boisdhyver, inspecteur de la forêt de Fontainebleau, a ćté terminée à la lin de 1843, et elle a déjà produit, depuis qu'elle est ell activité, 6,000 kilogrammes de graine de pin maritime, 2,000 des graine de pin sylvestre et 100 de graine de pin laricio. Ainsi, il sera bientôt facile de multiplier le pin laricio, dont on ne pouvait exécuter des semis en grand, à cause de la difficulté que l'on éprouvail à s'en procurer le la graine; cela sera facile, dis-je, puisque les nombreux sujets que MM. de Larminat et de Boisdhyver ont obtenus, par la greffe du pin laricio sur le pin sylvestre, commencent à fournir abnodamment des cônes.

I.es sécheries allemaudes sont composées de deux chambres, dont l'une est placée au dessus de l’autro; la chamlsre inférieure est destince à servir d’éluve: elle est plus on moins grande, selon que l'on veut donner plus ou moins d'extension à l'extraction des graines; la chambre supérieure sert de dépôt momentané pour les cônes que l'on veut faire passer à l'étuve; le séjour qu'ils y font les dispose ì s'ouvrir plus facilement, parce qu'ils y sont plus chandement que dans le grand dépôt d’où on les tire. On garnit les parois de l'étuve de claies semblables à celles dlon j’ai parlé plus hảut, et l’on met les étages de claies à une distance relle qu'on puisse facilement secouer les cônes et les remuer avec des râteaux.

La chamlre ou magasin qui se trouve immédiatement au dessus de l'étuve est percée de deux ouvertures carrées de $0^{\mathrm{m}}, 40$ à $0^{\mathrm{m}}, 50$ de côté ; l'unede ces ouvertures, houchées toutes deux par un couvercle, est destinée à faire passer une partie de la chaleur de l'étuve dans le magasin, lorsqu'elle est trop forte ou quand il n'y a plus de cônes dans l'étụve; à l'autre onverture est adapté un conduit en grosse toile qui s'arrête à un pied du plancher de l'étuve : ce conduit sert à faire passer les cònes de la chambre supérieure dans l'étuve, où on les reçoit dans les claies, que l'on place successivement sous le conduit. L'étuve est chauflée au moyen d'un poêle auquel il est avantageux d'adapter des tuyaux et des houches de chaleur; les cònes, après qu'on en a extrait les graines, fournissent assez le combustible pour l'alimenter; la chaleur est poussée jusqu'au point où elle peut ètre supportée par les hommes qui travaillent dans l'étuve. On arrose les cônes uṇe première fois, lorsque la chaleur les a bien desséchés, car ils sont encore très-verts, s'ils ont été récoltés avant les grands froids, et on les arrose ume sreonde fois s’il est néressitire, après les awoir remués. Jo ne parlenai du dé- 


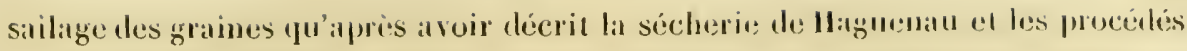
d'extraction qui y sont en usigge.

M. Rich, gérant de Ia sécherie royale de llaguenau, a donné, lans les Amutes forestieres de, septembre 1813, une description de cette sécherie, accompangnés: de planches; jextrais de cette description ce yui va suive.

Lat sécherie de llaguenau se compose d'un bâtiment rectamgulatire formini

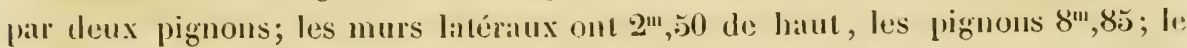
bâtiment a 10 mètres sur 13 de dedans m dedans; il est divisé en trois piòes qui aboutissent sur les pignons el qui ont par conséquent 10 mètres de long; celle: du milieu est une éluve. La pièce de droite a $3^{\mathrm{m}}, 70$ de large, une porte d'outrés sur le pignon avec une fenêtre au dessus et une autre porte au milieu du mur the refend, laquelle est l'entrée de l'étuve; cette pièce est carrelée en pierres, sert :II nettoiement des graines, et l'on y dépose les ustensiles, tels que vans, cribles et moulin ì nettoyer les graines. La pièce de gauche a $2^{\text {m }}, 70$ de large et un: porie d'entrée sur le pignon avec une fenêtre au dessus; on a placé dinns le unur de refend les portes de deux calorifères qui se trouvent dans l'étuve; on mel dans eette piece un lit pour les onvriers el l'on y dépose les cones qui ont passé à l'éture el qui servent à chanffer les calorifères.

L'élure a 6 mètres de large et $7^{\mathrm{m}}, 25$ de hatut; elle est divisée en trois étiges; il y a entre le rez-de-chaussée et le premier étage $1^{\mathrm{m}}, 80$, entre le premier élage et le second $1^{\mathrm{m}}, 50$, entre le second étage et le troisième $1^{\mathrm{m}}, 50$, et entre le troisième el son plalond $1^{\mathrm{m}}, 80$. Le rez-de-chaussée, éclairé par une fenètre percée dans le pignon, est carrelé en pierres et contient deux calorifères desquels sortent des tuyaux qui chauffent les trois étages; des chapeaux en tôle sont suspendus au dessus de ces calorifères pour empêcher que les graines ne tombent dessus. Les trois ćlages sont construits avec des lattes espacées de $0^{\text {mn }}, 02$, reposant sur des poutrelles qui sont supportées par des poutres; chaque élage est éclinié par une fenètre pratiquée dans le pignon. La fenêtre du troisième étage sert en vutre à y introdure des cònes au moyen d'une poulie qui est placée au dessus; il est divisé en deux grandes cases égales, destinées à recevoir chacune 20 hectolitres de cônes. 11 y a une cheminée d'appel dans un angle pour donner issue à la vipeur; elle est ouverte au rez-de-chaussce et à chacun des étages. Dans un autr: angle se trouve une échelle qui règne depuis le rez-de-chanssée jusqu'au troisième étage el par laquelle on communique de l'un à l'autre; des ouvertures servent à faire descentre les cònes d'un élage dans l'étage inférieur.

Pour procédèr à l'extraction de la graine, on charge la sécherie de cònes en usctant 20 hectolitres de cònes sur le premier étage, autant sur le second el 20 hectolitres dans chacune des eases du troisième étage : en tout 80 hectolitres. On allume alors les calorifères et l'on entretient pendant 36 heures un feu tent ét égal, si les còne's, ayant été récoltés avant les grands froids, sont encore verts. Lorsque ceux du premier étage commencent à s'ourrir, on les arrose, on les retourne, on les change de place au besoin et l’on élève la chaleur jusqu ì iš et an

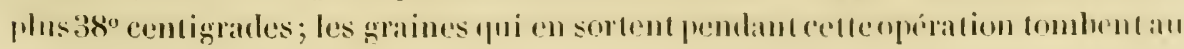


rez-de-chaussée. Au bout de quelques heures, on arrose encore les cònes et on les retourne de nouveau en remplaçant ceux du milieu, qui s'ouvrent toujours les premiers, par ceux des côtés; puis, lorsqu'ils sont entièrement ouverts, on les lait tomber par une ouverture pratiquée exprès dans une caisse en laltes à claire-voie, en forme de carré long, qui est suspendue sous le plancher; cetfe caisse sert à les transporter dans Ja pièce destinéc au nettoiement des graines. On pile ces cònes avec des dames pour en extraire ce qui y reste de graines; mais celles que l'on obtient ainsi, étant ordinairement en petite quantité et de mauvaise qualité, je croirais préférable de laire passer tout de suite les cônes. dans la pièce de gauche, par une ouverture qu'on pratiquerait au mur de refend, pour y être employés à la combustion.

Le plancher du premier élage étant débarrassé des cònes qu'on y avait mis, on le nettoie et l'on y fait tomber les cônes qui se trouvent sur le second étage; on les étend uniformément et on les arrose, puis on les couvre d'une toile destinée à recevoir les graines qui sortent pendant que l'on fait tomber les cône̊s de l'une des cases du troisième étage sur le deuxième étage, où on les étale; on remplit ensuite cette case avec des cônes frais. On rallume alors le feu, et douze heures après on arrose, on retourne et l'on change de place au besoin les cônes du premier étage; on fait subir la même préparation à ccux du deuxième étage, après avoir couvert ceux du premier étage d'une toile. Après ce travail sur. les planchers, on ramasse les graines et on les porte dans la chambre où l'on en fait le dépôt. Par ces opérations successires, qui une fois en train se répètent tuutes les vingt-quatre heures, les graines s'obtiemnent au fur et à mesure de l'ouverture des cônes.

Pour nettoyer la graine, on la fait passer par trois cribles de différentes dimensions : le premier, placé sur une laisse lestinée à en recevoir la graine, sert à en séparer les cônes et les parties les plus grossières qui s'y trouveraient mélangées; au moyen du second, on en sépare les parties ligneuses, les leuilles et autres débris; le troisième sert à la nettoyer du sable et de la poussière. C'est aussi pendant que la graine est sur ce crible que l'on retire à Ia main les débris ligneux qui restent encore. Mais, quelque soin que l'on preme, on ne parvient jamais à rendre la graine ailée entièrement propre.

La graine ailée se conserve mieux que celle qui est désailée; néanmoins, comme elle occupe plus de volume et qu'elle est plus difficile à bien semer è à enterrer, on est dans l'habitude de la désailer. J'emprunte textuellement à M. Rich ce qu'il dit à ce sujet :

"Le meilleur moyen pour désailer les graines de pin sylvestre est de les frot" ter entre les mains, mais il n'est praticable que pour de petites quantités; "pour de grandes, on se sert de fléaux à battre le grain. A cet effet, on étend la " graine par lits de $0^{\mathrm{m}}, 20$ à $0^{\mathrm{m}}, 2$ อ̆ d'épaisseur sur une aire, puis on la bat, en " ayant soin de la conserver tónjours en couclıes assez épaisses pour qu'elle ne " soit pas écrasée. Dès que les ailes sont détachées, on passe le tout dans un mou" lin à vent, et on achève le nethoiement au moyen de cribles de différentes di- 


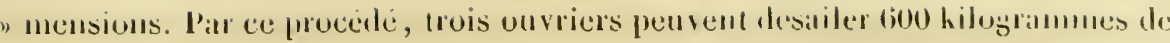
"graines en un jour.

"La quantité de graines mèlées fournie par mue mène quantité de cônes, ét h. "prix de revient, varient très-sensiblement, suivant la plus on muins grande "abondance de la récolte et la qualité des cônes. Les linites de rendement do: " 1 hectolitre de cônes sont de 1 kilogramme a 1 kil. $250 \mathrm{gr}$, et le prix de revient "varie entre $1 \mathrm{fr} .70 \mathrm{c}$. el 2 fr. $80 \mathrm{c}$. La quantité de parties étrangères, d’ailes ê " de vaines graines varie selon les amées; cette variation peut être, pour des "graines préparées el nettoyées avec le même soin, de 28 à 35 pour 100 él "poids.

"Les graines ailées se conservent longtemps (quatre ans) sans autre soin qur: " celui de les placer dans des endroits secs et aérés. Les graines désailées exi"gent plus de précautions: elles ont besoin d’ètre retournées souvent, surtout " si l'opération du désailement a eu lieu avee beaucoup d'eau, ce qui se pratique "fort souvent dans le commerce. Ces dernières graines paraissent à l'ueil prélé"rables à celles obtenues par le procédé indiqué plus haut : elles ont une cou"leur plus foncée, sont plus propres; aucun fragment d'aile n'y reste adhérent " comme aux autres; mais elles sont bien inféricures en qualité, et il suffit de " décrire le mode de désailement employé pour en domner la conviction.

"Ce mode consiste ì mouiller les graines assez fortement pour que la fermun"tation s'y établisse. Alors la graine gonfle, rompt le frein qui retenait l'aile " adhérente à son enveloppe, et l'en détache entièrement. Cette férmentation ") altìre nécessairement la qualité des graines et leur procure une angmenta" tion de poids; aussi, peu de jours après, remarque-t-on déjà un déchet de 8 à " 10 pour 100. Les graines ainsi désailées ne se conservent qu'étendues en cou" ches minces dans des greniers bien aérés, et encore faut-il les y retourner ma" tin et soir dans les premiers temps. Sans cette précaution, les graines moisis" sent et se détériorent, ce qu'on reconnaît aisément par l'anande, qui se durcit " et prend une couleur rougeâtre. Alin de dissimuler cette détérioration, et pour "donner aux graines une apparence plus favorable, on les frotte dans les mains "humectéces d'huile. L'enveloppe reprend alors sa conleur noirâtre, et l'amande " son aspect huileux. C'est aussi par ce procédé et le secours de quelques agens "chimiques que l'on parvient à teindre la graine d'épicéa, pour en faciliter le " mélange a vec celle du pin sylvestre, dont le prix est toujours au moins de 65 ì "70 pour 100 plus élevé. Mais ces fraudes se recomaissent facilement aux signes " suivans :

"Lat graine de pin sylvestre est aplatie, unie, émoussée à sal pointe, tandis " que celle de l'épicéa est presque toujours conique, strice, et a la pointe aiguè. " En outre, en pressant une graine de pin sylvestre par ses deux extrémités en" Tre les doigts, on l'écrase facilement, tandis que celle de l'épicéa résiste, el pe" nétrerait dins la chair assez a vant plutòt que de céder (1). Enfin le gonit de ces 
"graines diffère : celui de la graine de pin resstmble ì l'amande, el celui de liı " graine d'épicéa est tout-ì-fait résineux.

"Le mode de préparation, de nettoiement, de désailement et de conservation " que nous venons de décrire est celui que l'on emploie pour le pin sylvestre; " celui qui est utile pour l'épicéa en diffère peu. Seulement, les cônes d'épicéa " s'ouvant plus facilement, il faut employer beaucoup moins de chaleur pour " en extraire les graines. "

Je sais qu’on a témoigné la crainte que la graine obtenue dans les súcheries ne fùt altérée par ce mode d'extraction; je crois donc utile de consigner dans ce Traité qu'une persomne de ma connaissance, qui avait eu à se plaindre des graines de pin sylvestre qu'elle avait achetées chez des grainetiers, en tira ensuite directemient de la sécherie de Haguenau, et en a toujours été parfaitement contente.

Indépendamment des moyens que donne M. Rich pour désailer les graines de pin et de picéa, l'on peut átussi les désailer en les mettant dans un sac que l'on ne remplit pas entièrement, et en les frottant et secouant dans ce sac.

La sécherie de Haguenau a coùté 3,000 à $3,500 \mathrm{fr}$, et peut produire 8 à 9,000 kilogrammes de graines par an.

Un propriétaire qui ne veut extraire de la grainc des cônes que pendant une seule année, ou que pendant un petit nombre d'années, ne fera pas construire une sécherie comme s'il voulait se livrer à une exploitation permanente; mais il pcut disposer une chambre pour cet usage, puisqu'il sulfit d'y placer un poêle et des claies, ainsi que je l'ai dit; il peut même se contenter d'y faire étaler des cônes sur le plancher, de les faire arroser et remuer quand ils s'ouvrent, et d'en ramasser les graines. 11 peut aussi se servir d'un four à pain, en ayant soin que la chaleur y soit iclle qu'on puisse y tenir la main; on y place des claies remplics de cônes, on les arrose légèrement quand ils sont secs, et on les retire quand ils sont ouverts pour les secouer sur un drap : la même opération se répète jusqu'ì ce que les cônes ne contiennent plus de graines.

Hartig indique, dans son Instruction sur la culture du bois, page 189, un moýen d'exıraire la graine des cônes du pin sylvestre, qui a le mérile de pouvoir être employé partont : "Je pris, dit-il, des sacs de grosse toile, que j’emplis à demi "des cônes que je voulais faire ouvrir; je les liai bien serrés par le haut, et je "les étendis sur la surface extérieure d'un four chauffé longtemps; je les re" muai plusieurs fois par jour, et aussitôt que les cônes commencèrcnt à s'ou" vrir, ce qui arriva quelques jours après, je les versai dans une huche, où je les " agitai fortement avec un râteau de fer; après quoi je ramassai la graine qui en " était tombée."

C'est en employant la chaleur du soleil que j’ai extrait des cônes de pin sylrestre les graines qui m’étaient nécessaires; néanmoins, par exception, j’en ai

méme tems, en les pressant entre mes doigts par leurs deux extremịtés, ct toutes deux pénétraient dans la chair plutỏ que de céder. 
extrait aussi en mettant les cònes dans un four assez longtemps après qu'on en avait retiré le pain pour qu'on pùt y tenir la main, et les graines que j’ai obtenues ainsi étaient bonnes, du moins en trìs-grande partie.

Quel que soit le procédé d'extraction que l'on emploie, si l'on a commencé à cucillir les cônes dès la fin du mois de novembre, il est préférable d'attendr: jusqu'au commencement de janvies pour en extraire la graine; le plus tard serat le mieux, paree que celle qui n'est pas parfaitement mùre achève de mủrir daus les cônes, et que celle qui est mure s'y conserve mieux. Il fant d'ailleurs, lorsque les cônes ont été récoltés avant la fin de février, surtout si l'on n'a pas encoré éprouvé de froids rigoureux, remuer souvent les tas de cônes; car cess cônes sont encore verts alors, fermentont facilement, moisissent, tiniraient par pourrir, et leurs écailles ne s'ouvrent plus à aucun degré de chaleur. Ce n'est que lorsqu'ils sont parfaitement secs, tant intérieurement qu'extérieurement, qu'on peut se contenter de ne remuer les tas de cònes que de loin en loin.

Il faut, selon Cotta (1), 10 à 16 boisseaux de cônes pour obtenir un boisscau de graine ailée, et il dit que la graine ailée se garle quatre à cinq ans; celle qui est désailée ne se conserve que trois ans, en prenant les précautions qui ont été indiquées plus haut; mais plus tòt on l'emploiera après qu'elle a été récoltée, moins elle donnera de déclıet. Hartig dit (2) que 3 décalitres de graine de jin sylvestre sans ailes pèsent 12 kilogrammes, e'est-à-dlire qu'un litre pèse 400 grammes; selon Cotta (3), un litre pèse 440 grammes. Moi, j'ai trouvé qu'un litre pesait 485 grammes et contenait 65,300 graines; ainsi le kilogramme contenait 134,815 graines et occupait un volume de 2 lit. 06 . Delamarre dit (4) qu'un kilogramme de graines de pin sylvestre en contient, terme inoyen, 150,000. Il est d'ailleurs évident que ce ne sont que des approximations, puisque la grainc peut être plus ou moins nette et peut même présenter de légères différences dans ses dimensions. J'ajouterai que les graines extraites des cônes des jemes pins m’ont paru généralement plus grosses que celles que l'on extrait des cônes des pins qui approchent de leur maturité ou qui l'ont atteinte. A Paris, la graine du pin sylvestre se tire de la sécherie de Haguenau ou de l'Allemagne, et se vend ordinairement, dans la maison Vilmorin-Andrieux, 7 fr. le kilogramme.

La graine du pin sylvestre lève dans l'année mêne oì elle est tombée, et l'on at vu quiclle ne commence ordinairement ì tomber que dans le courant du mois d'avril; elle lève facilement, mais le plant ne supportw point l'ombrage conme celui des sapins. Si donc l'on a des pins sylrestres dans un taillis, ou dans le voisinage d'un taillis de bonne qualité, on verra lever cluplaut, ma is il périra, à moins qu'il ne se trouve dans une elairière, comme, par exemple, une place à charbon. Les jeunes pins me semblent pas trop souffrir, dans leurs racines, par le voisinage des racines du bois feuillu, car ils ont une belle apparence tant que

1) Trailé de culture forcstière, p. 25i.

2. Hartig, citẻ par Baudrillart, Dictionnaire des eaux et foréts, 1. 11, p. \$20.

3 Trailé de cullure foreslière, p. 3 i:3.

- Traite pratipue de la cullure des pins à grandes dimensions, 1. s:!. 
leur tète dépasse le taillis, aussi voit-on de fort beaux pins sylvestres sur taillis; lorsque au contraire leur tête est dépassée par ce taillis, ils périssent bientìt. Lat même observation s'applique au plant qui lève dans les futaies de pins sylvestres ou autres; ce plant a besoin de plus de lumière que celui des sapins pour prospérer, du moins sous le elimat de Paris.

V. Mode de végétation, description, mmensions. - Le morle de végétation du pin sylvestre a été décrit au commencement de ce chapitre, en ce qui concerne la marehe de la sève dans cet arbru, ses boutons, ses feuilles, ses fleur's et ses cônes; et l'on trouvera, clıap. XI, art. IV, des détails sur sa végétation el son accroissement, lepuis le semis en pépinière jusłu'au moment de la plantation à demeure. Je n'essaierai point de donner de semblables détails relativement au plant provenant de semis naturel, parce qu’il présențe beaucoup de variété dans son aceroissement, selon les circonstances différentes dans lesquelles il se trouve placé; je me contenterai de dire que la graine lève irrégulièrement, selon l'époque à laquelle elle est tombée et la situation oỉ elle s'est trouvée, et que l'accroissement du plant de semis naturel est ordinairement plus lent que celui du plant que l'on cultive en pépinière. Cependant il peut l'égaler et même le dépasser, dans des circonstances de tout point favorables, à cause du retard que la transplantation fait éprouver au plant de pépinière. J'ai dit, dans l'article précédent, que le plant de pin sylvestre ne supporte point l'ombrage comme celui des sapins, et qu’il périt bientôt s'il est trop ombragé; mais il réussit très-bien sans ombrage, même dans l'année de sa naissance.

Pendant les premières années, le jeune plant de semis naturel pousse un peu plus lentement que le plant du pin maritime, mais un peu plus promptement que le plant du pin du lord Weymouth et surtont que celui du pin laricio. Lorsque le pin sylvestre a dépassé 15 ans, j’ai remarqué quelquefois, pendant des années privilégiées, des flèches qui avaient jusqu’à $0^{\mathrm{m}}, 90$ de long : je ne saurais indiquer quelle est la longueur moyenne de la flèche pendant les années où il conserve une végétation très-active, n'ayant pas assez de données pour cela.

Le pin sylvestre a une racine principale pivotante et de fortes racines latérales; toutes s'enfoncent en terre, aussi est-il fortement enraciné.

Lorsque cet arbre croît en futaic à l'élat serré, son tronc est droit et dépouillé de branches jusqu'aux deux tiers environ de sa hateur; il conserve alors une tlèche et des étages réguliers de branches, tant que, n’approchant point de sa maturité, il a une végétation vigoureuse. Lorsqu'il croît isolé, son tronc est chargé de branches jusque près du sol, et ces branches sont quelquefois trèsgrosses; le tronc est en queue de rat, il se bifurque, se contourne ou se cambre quelquefois, et finit par se diviser en plusieurs branches; l'arbre alors n'a plus de lièche, sa tête s'étale, et il s'élève moins haut que lorsqu’il croît ì l'état serré. M. G. Dickie, dans son article (1) Sur les foréts el les arbres du comté d'iberilceni,

1) Quarterly Journal of agriculture, $11^{\circ} 60$, mars 19.33, p. 393. 
partic de l'Ĺcosse ou la pin sylvestre est le plus commun, dit que dans quelques lieux ou ces arbres ne se trouvent point dans ume situation favorable, on observe fréquemment que leur tronc est contourné, que leur aspect est quclquefois des plus bizarres, et que la lettre S représente la forme qu'ils prenuent alors le plus souvent. Néanmoins, dans les lieux favorables à la culcure du pin sylvestre, on pourra toujours, par un élagage bien entemlu commencé daus la jeunesse de l'arbre et continué assez. Iongtemps, à raison d'un demi-ćtage par chaque annéce, lui former un beau tronc, conme s'il eût crû à l'état serré. Le tronc du pin sylvestre qui a crù à l'état serré m’a paru maintenir aussi bien sa grosseur que celui du sapin argenté et peut-être mieux; mais je n’ai pu faire d'expériences précises à ce sujet, car je ne crois point qu'il existe, sous le climat de Paris, des futaies de cet arbre à l'état serré, approchant de leur maturité ou l'ayant atteinte.

Si l'on brise le tronc du pin sylvestre dans sa jemesse, une ou deux des branches de l'étage immédiatement inférieur continucnt le tronc. Il parait pourtant sur le trone des boutons adventifs qui donnent naissance ì des pousses, lorsque e'est la tlèche qui a été briséc ou que la brisure a été faite dans un endroil du tronc où le bois ı'a que deux ans; mais ces pousses uc parvicment point ì former une flèche, elles périssent parce que c'est une branche, ainsi que je l’ai dit, qui forme cette flèche et s'empare de la sève. Dans les pins sylvestres plus âgés ont qui approchent de la miturité, si le tronc est brisé l'arbre reste mutilé, et si la brisure est trop rapprochée dı sol, ou que l'arbre conserve trop peu de feuilies ou de bourgeons, il périt.

L'écorce du trone du pin sylvestre est moins épaisse que cellé du pin maritime; elle est grise pendant les premières ammées et devient ensuite rougeâtre; dans un âge plus a vancé elle redevient grise sur la partie du tronc dépouillée de branches qui est près dı sol, et se couvre de larges écailles : le reste du tronc et les branches conservent une conleur rougeâtre fort apparente, ce qui domne: à cet arbre un aspect particulier qui le fait tout d'abord recommaître. C'est sans doute la couleur de son écore qui a linit domner à ce pin le nom de Pinus rubra par Miller. Il peut arriver que ce caractère ne se remarque point sur des arbres mal venans et que leur écorce reste grise, mais on reconnaît toujours ce pin à ses fleurs, à ses cônes et à ses feuilles.

Les branches du piu sylvestre sont disposées par étages (sont verticillées) et au nombre de cinq à six par chaque étage; elles sont érigées dans les jeunes pius et vers la cime des pins, tant qu'ils ont une flèche, c'est-ì-dire tant qu’ils sont dans leur période d'accroissement; les branches qui sont plus âgécs et par conséquent plus rapprochées du sol, surtout quand le pin approche de sa maturité, lléchissent sous le poids des rameaux et des ramilles, et se trouvent quelquefois au dessous du plaut horizontal qui passerait par l'étage auquel elles appartiennent.

La végétation des plantes est sujette à des modifications, selon l'action des agens qui exercent sur elles de l'influence, et ceux de ces agens qui exercent la principale influence sunt le sol, le calorique et l'atmosplière. Les résultats qu'ils 
produisent sont surtout remarquables sur les arbres à grandes dimensions, puisque le même arbre, dans des circonstances différentes, portu sa lête dans les nues ou rampe sur la terre. Le pin sylvestre me paraît être celui des arbres dont je m’occupe spécialement dans ce Traité qui présente le plus de variations, el e'est sans doute par cette raison que. des botanistes en nomment plusieurs variétés; mais ces variétés ne sont probablement autre chose que de simples modifications dues à des différences de situation. Le même pin sylvestre qui alteinı aux plus belles dimensions, dans des circonstances de tout point favorables, aurait été chétif, rabougri, rampant même dans un climat trop chaud, sur un point trop élevé au dessus du niveau de la mer, à une trop petite distance du pôle, ou enfin dans un sol ou dans une situation qui lui serait entièrement contraire : son écorce aurait été noirâtre; ses l'euilles, ses fleurs et ses cônes auraient été plus petits, mais l'arbre aurait présenté d'ailleurs les mêmess caractères botaniques.

Le pin sylvestre est celui des arbres dont je m'occupe dans ce Traité qui s'approche le plus du pôle, mais ce n'est pas celui qui s'élève le plus au dessus du niveau de la mer dans les hautes montagnes; il s'y trouve toujours au dessous du mélèze et du pin picéa et très-souvent mème plus bas encore que le sapin argenté. Dans les Alpes, le pin sylvestre se trouve ordinairement à une altitude moindre que le mélèze et que le sapin picéa, et il s'élève-à peine à celle du sapin argenté; sa végétation y est généralement médiocre. Dans les montagnes des Vosges, le pin sylvestre occupe environ le vingtième du terrain des forêts d'essence résineuse (1). On le trouve principalement sur les contreforts de la grande chaîne, dans les parties rapprochées de la plaine, presque jamais dans les hautes Vosges; s'il y paraît, e'est à l'état rabougri, en forme d'arbrisseau, et il n'y dépasse guère 1,000 mètres au dessus du niveau de la mer.

On a semé, il y a dix-huit ans, un mélange de graines de pins sylvestres et de pins laricio sur le sommet du Donon, montagne situéc dans le départenent des Vosges, arrondissement de Saint-Dié. Cette montagne est èlevée de 1,000 mètres au dessus du niveau de la mer, domine toutes celles des environs et est par conséquent dans une situation très-exposée aux rigueurs du froid et à la violence des vents. Les pins sylvestres sont restés presque tous à l'état rabougri; les pins laricio ont mieux résisté d'abord, mais depuis la neige en a brisé ou ployé un grand nombre. Un autre semis de pins laricio, cxécuté à trois lieues du Donon, à 800 mètres au dessus du niveau de la mer, sur un are de mauvaise terre exposće au nord, a eu une bonne végétation pendant les seize premières années, puis la neige ou les vents en ont brisé une boune partie.

Le pin sylvestre a généralement une chétive végétation dans les montagnes des Vosges; il prend pourtant de l'aceroissement dans quelques localités peu élevées, jusqu'à 80 à 100 ans, et l'on en trouve par exception qui ont, à $1^{\mathrm{m}}, 33 \mathrm{au}$ dessus du sol, une eirconférence de $1^{10}, 50$ el qui s'éièvent à une hauteur de 20 ì

(1) .rotecau Duhamel, p. 315 (Mémoire de M. Muggeol). 
25 mètres; ainsi, il ne parvient que par exeeption ì des dimensions qui permettraient seulement de l'employer pour la petite mature. Cet arbre est trèscommun dans la plaine du Rhin, entre la chaine des Vosges et ce fleuve, au nord de Strashourg à partir de Ilaguenau, et il y atteint de beaucoup plus belles dimensions que dans les montagnes des Vosges (1). Le sapin argenté est beaucoup) plus rommun dans ces montagues que le pin sylrestre; le sapin picéa ỳ est, an contraire, moins commun; tous les deux y acquièrent de plus belles dimensions que le pin sylvestre (Voy. [. 39, 41 et 131).

L'arrondissement de Tournon, situé au nord du département de l’A rdèche, s'étent depuis le Rhơne jusqu’au mont Mézin, la plus haute montagne des Cévennes; on y remarque quatre zônes bien distinctes par l'espèce des plantes qui s'y trouvent et les caractères de la végétation, et dans toutes il y a des pins sylvestres.

La première zône, comprenant la plaine da Rhỏne et le coteau de la rive droite, s'élève depuis 100 jusçu’à 300 mètres au dessus du niveau de la mer; on y tronve le noyer, le mûrier, la vigne, le chêne vert, etc., et quelques boutquets de pins sylvestres chétifs et rabougris. La seconde zône, à peu près aussi large, est élevée de 300 à 600 mètres au dessus du nivean de la mer; on y cultive aussi le noyer, le murier, le châtaignier el la vigne, mais avec moins de succès; on y trouve des pins sylvestres dont la hauteur moyenne est d'environ 10 mètres et dont la plupart sont tortus et biscornus; leur principal mérite est de fournir de la litière, et e'en est $m$ très-grand. La troisième zòne, d'une étendue à peu près égale aux deux premières, est élevée de 600 à 900 mètres au dessus du niveau de lat mer; on n'y cultive plus ni la vigne, ni le mûrier; le pin sylvestre, qui s'y trouve mêlé avee le sapin argenté, y parvient à une hauteur moyenne d'environ 13 mètres at est propre à être employé comme bois d'ouvre. La quatrième zòne, qui n’a guère plus d'étendue que les trois autres, s’élève généralement de 600 à 900 mètres au dessus du niveau de la mer, quelquefois de 15 à 1,600 mètres, une fois à 1,800 mètres, au mont Mézin. On y trouve beaucoup de pins sylvestres et de sapins argentés, ces derniers y sont mème plus communs et occupent la partie la plus élevée; le pin sylvestre y parvient en moyenne à une hauteur d'environ $16^{\mathrm{m}}, 24$, et il y en a qui dépassent 26 mètrés; mais le maximum de grosseur n'est que d'environ 2 mètres de circonférence rezlerre (2).

J'emprunte à Cotta le dernier fai que je vais eiter : "On remarque, rlit-il dans " son Traité de culture forestière, page 240 , dans le pare de Weimar des pins nains, "venus de semence franche, qui perdent déjà leur caractère distinctif. J'ai re" cueilli de leur graine et jen ai fait un semis, il y a plus de 30 ans, dans le " jardin forestier de Zillbach; les arbres qui en sont provenus, arrivés à l'âge

(1) Renstignemens communiqués par M. G. Gand, inspecteur des forçts.

(2) Renseignemens communiqués par M. A. de Saint-Priesl, propriétaire dans l'arrondissement de Touruon. 
" où ils portent semence, ne diffèrent plus des pins ordinaires que par la fleur; " quant à leur croissance, elle est aussi rapide. On a fait de nouveaux semis " avec de la graine provenant des arbres de Zillbach, et l'on peut déjà recon" naître qu'en grande partie le port des jeunes plants est semblable à celui du pin "sylvestre."

Les massifs de pins sylvestres sont sombres, moins pourtant que ceux de sapins argentés; mais l'arbre isolé, quand il a une belle végétation, ne l'est point, parce que l'on distingue facilement son tronc et ses grosses branches, dont la conleur rouge forme un contraste avec le vert sombre de son feuillage; l'aspect du pin sylvestre, quand le bas de son tronc est dégagé de branches, est tout à la fois majestueux et pittoresque.

Je vais actuellement m'occuper de l'accroissement annuel du pin sylvestre, en commençant par ce que j'ai à en dire sous le climat de Pilris proprement dit. Il y a dans mon parc une allée qui le borde du côté du couchant et dont les arbres ont été plantés en 1787-1788; il s'y trouve sept pins sylvestres mêlés àvec des pins maritimes, des sapins argentés et des sapins picéas de leur âge, et avec d'autres pins sylvestres et d'autres arlores résineux plus jeunes. Ces sept pins ont eu par conséquent environ 63 ans à l'automne de 1843 ; ils étaient garnis de branches jusque près du sol, et quelques-unes dle ces branches étaient fort grọsses, d'où il est résulté qu'ils sont peu élevés. Lorsque je devins propriétaire du parc, il y a neuf ans, je fis couper, à raison d'une ou deux par an, celles de ces branrhes qui, étant trop bas, empêchaient de passer, et il n'en est pas résulté d'inconvéniens. Le plus gros de ces pins, non compris l'un d'eux qui se bifurque à un mètre du sol, avait, à l'automne de 1843 , un diamètre de $0^{\mathrm{m}}, 57$ et une hauteur de 14 mètres, le plus petit un diamètre de $0^{\mathrm{m}}, 48$; ainsi, en évaluant leur âge ì 64 ans, ils auraient eu un accroissement moyen annuel cle $0^{\mathrm{m}}, 008$.

J'ai, dans la plantation d'environ un hectare attenant à mon parc ( $V$ oy. p. 124 et 127), quatre pins sylvestres qui ont été plantés en 1803-1804; le plant que l'on employa provenait de semis naturel du parc et avait environ 4 ans, ainsi, ces arbres avaient, à l'automne de 1843 , environ 44 ans; ils ne sont pas aussi branchus que ceux dont je viens de parler, à cause du taillis et de quelques arbres qui les ont serrés. Le plus gros avait, à l'automne de $1813,14^{\mathrm{m}}, 32$ de haut et $0^{\mathrm{m}}, 43$ de diamètre; ainsi, il avait eu un accroissement annuel de $0^{\mathrm{m}}, 01$; l'accroissement annuel des trois autres pins est peu différent.

On a planté, en 1792, dans un jardin anglais qui se trouve à Bretenil, petite ville située à 6 kilomètres de chez moi, des pins sylvestres, des picćns et des pins Weymouth, qui sont isolés ou peu serrés et en bonne terre; le plus gros des pins sylvestres avait, à l'automne de $\mathbf{1 8 4 4}$, un diamètre de $0^{\mathrm{m}}, 55$, ce qui, en le supposant âgé de 60 ans, donne un accroissement annuel de $0^{\mathrm{m}}, 009$; sa hauteur était de $17^{\mathrm{m}}, 15 \check{\text {; }}$ il avait été élagué jusqu'ì une certaine hauteur (Voy. p. 128 ).

On a planté, en 1810, dans le parc de Glissoles, à 20 kilomètres de chez moi, des pins sylvestres, des sapins picéas et des mélèzes, au bas d'un coteau quî horde la vallée de l'Jton; ces arlores sont isolés ou peu serrés et en bonne terre. 
1.e plus gros des pins sylvestres avait, ì l'antommo de 184t, un diametre de 0'm,60, ee qui, en le supposant àgé de 41 ans, domne un aceroissement anmuel de $0^{m,}, 015$, accroissement évidemment exceptionnel; jévalue la hauteur de cet arbre à environ 19 mètres (Voy. p. 129).

Dins le pare de Condé, à 3 kilomètres de clrez moi, il y a un massif de 152 pins sylvestres qui ont élé plantés en 1813-1814, et qui ont en par conséquent 35 ans environ en 1813 ; ils se tronvent sur un cotean exposé à l'ouest, dans un terrain silico-argileux, sans calcaire, de qualité ordinaire; les plus lauts avitient, à l'automne de cette année, $16^{\mathrm{m}}, 50$; leur grosseur était fort incgale, parce qu’ils étaient déjà trop serrés dans quelques parties; le diamètre du plus gros était de $0^{\mathrm{m}}, \mathbf{1 1}$, mais ils n'avaient, terme moyen, qu'un diamètre de $0^{\mathrm{m}}, 30$; ainsi, ils avaient eu un accroissement moyen annuel de $0^{\mathrm{m}}, 009$.

Les premiers semis de pins sylvestres, dans la forêt de Fontainebleau, ontété exícutés en 1785, sur un sol de sable siliceux mêlé d'un peu d'humus, dans une épaisseur de $0^{\mathrm{m}}, 20$ a $0^{\mathrm{m}}, 2 \breve{.}$. Le tableau ci-joint fait comnaître quelle était la dimension de ces arbres à l'automne de 1813; le maximum est la moyenne des dimensions des 10 plus gros arbres, et la moyeme est la moyeme des dimensions de 20 arbres de grosseur moyeme (1); la circonférence a été prise à un mètre dlu sol.

\begin{tabular}{|c|c|c|c|c|c|c|}
\hline \multirow{3}{*}{$\begin{array}{l}\text { DESIGNATION } \\
\text { DES LIEUX. }\end{array}$} & \multicolumn{5}{|c|}{ 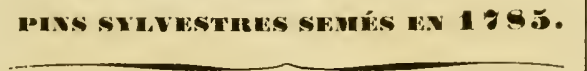 } & \multirow{3}{*}{ OBSERVATIONS. } \\
\hline & Maxi & mus. & MOYE & NNE. & \multirow{2}{*}{$\begin{array}{l}\text { Accroisse- } \\
\text { menl } \\
\text { moyen } \\
\text { annuel. }\end{array}$} & \\
\hline & Hanteur. & Circonf. & Hauteur. & Circonf. & & \\
\hline $\begin{array}{l}\text { Plaine des Pins. . . } \\
\text { Mont-Chauvet. . . } \\
\text { Rucher d'Avou. . . }\end{array}$ & $\begin{array}{l}\mathrm{m} ., 00 \\
19,00 \\
21,00 \\
20,00\end{array}$ & $\begin{array}{l}\mathrm{m} . \\
1,86 \\
1.26 \\
1,59\end{array}$ & $\begin{array}{l}\mathrm{m} . \\
17.00 \\
18.00 \\
19,00\end{array}$ & $\begin{array}{l}\mathrm{m} . \\
1,50 \\
0,81 \\
1,02\end{array}$ & $\begin{array}{l}\mathrm{m} ., 007 \\
0,003 \\
0,006\end{array}$ & $\begin{array}{l}\text { Pins isolés. } \\
\text { Pins à l'étal serré. } \\
\text { id. }\end{array}$ \\
\hline
\end{tabular}

On trouvera dans le chapitre suivant, consacri an pin maritime, un tableau de pins maritimes qui ont élé semés aussi en 178 dans la forêt de: Fontainebeau, dans trois endroits dont deux sont aussi la Plenine-des-Pins et le Rocher"Arou; on pourra donc comparer les dimensions auxpuelles y sont parvenues ces deux espèces de pins. Mais on deva avoir égard à la grosseur de l'écorce du pin maritime, et l'on ne pourra d'ailleurs tirer aucune conséquence de cette comparaison, parce que les terrains dans lesquels ont élé exécutés les semis sont évidemment meilleurs pour le pin maritime que pour le pin sylvestre.

Ce n'est qu'en 1818 que le pin sylvestre a été introduit dans la forêt de Com-

1) Renseignemens communiquis par M. de Boisdhyver, inspectom de la foril de Fontainebleau. 
piègne, et l'ou a employé le semis et la plantation. Le tableau ci-joint fait connaître quelle était la dimension de ces pins à l’automne de $\mathbf{1 8 4 3 .}$

\begin{tabular}{|c|c|c|c|c|c|c|c|c|}
\hline \multirow{3}{*}{$\begin{array}{l}\text { DESIGNATION } \\
\text { DES IIEUX. }\end{array}$} & \multirow{3}{*}{ TERRAINS. } & \multirow{3}{*}{$\begin{array}{l}\text { Mode de re- } \\
\text { pcuplement. }\end{array}$} & \multirow{3}{*}{ Age. } & \multicolumn{4}{|c|}{$\begin{array}{l}\text { DIMENSIONS DES SUJETS } \\
\text { en } 18: 4 .\end{array}$} & \multirow{3}{*}{$\begin{array}{c}\text { Accroisse } \\
\text { ment } \\
\text { mojen } \\
\text { annuel. }\end{array}$} \\
\hline & & & & \multicolumn{2}{|c|}{ y. X XIMUN. } & \multicolumn{2}{|c|}{ MOYENNE. } & \\
\hline & & & & IIautr. & Circ. & Hautr. & Circ. & \\
\hline $\begin{array}{l}\text { Bruyères de Verberie. } \\
\text { Beaux-Monts. } \\
\text { Bruyères Ifathieu. }\end{array}$ & $\begin{array}{l}\text { Sable sec blanc. } \\
\text { Calcaire. } \\
\text { Sable sec gris. }\end{array}$ & $\begin{array}{l}\text { Plantation. } \\
\text { Plantation } \\
\text { Semis. }\end{array}$ & $\begin{array}{c}\text { Ans. } \\
25 \\
23 \\
21\end{array}$ & \begin{tabular}{c|}
$\mathrm{m}$. \\
12,00 \\
12,00 \\
12,00
\end{tabular} & $\begin{array}{l}\mathrm{m} . \\
0,72 \\
0,70 \\
0,70\end{array}$ & $\begin{array}{c}\mathrm{m} . \\
10,(10 \\
10,00 \\
10,00\end{array}$ & $\begin{array}{l}\mathrm{m} . \\
0,62 \\
0,64 \\
0,60\end{array}$ & $\begin{array}{l}\mathrm{m} . \\
0,00 \mathrm{~s} \\
0,009 \\
0,009\end{array}$ \\
\hline
\end{tabular}

On trouve dans les archives de l'inspection de la forêt de Compiègne une réformation générale, en 1549, qui présente la situation du peuplement de la forêt i cette époque, triage par triage, et dans laquelle il n'est nullement question de bois résineux. L'on a pourtant tronvé, en 1833, daus cette forêt, en faisant des fouilles dans un terrain tourbeux, près di'un ruisseau et à 2 mètres de prolondeur, une grande quantité de trones de pins sylvestres, couchés dans le sens du cours de ce ruisseau. Ces troncs, quoique entiers, étaient dans un état de décomposition qui prouvait qu’ils étaient bien antérieurs à la réformation dont je viens de parler. Linsi le pin sylvestre aurait existé autrefois dans la forêt de Compiègne et en aurait disparu (1).

M. Seurat, l'un des premiers propriétaires qui aient cultivé le pin sylvestre en Sologne, en avait planté, en 1812, 5 hectares dépentant de sa terre du Trey, commune de Saint-Aubin (Loiret), dans un sable d'assez. bonne qualité. Il avait placé le plaut daus des lignes parallèles, espacées de 5 mètres l'une de l'autre el fort rapproché dans les ligrnes; entre ces lignes on avait semé du chêne et planté du bouleau. On n'avait commencé à éclaircir cette plantation, qui avait très-bien réussi, qu'en 1831, e'est-à-clire beaucoup trop tarl; cependant ces pins avaient, à l'automne de 1813 , à $1^{\mathrm{m}}, 50 \mathrm{du}$ sol, de $0^{\mathrm{m}}, 66$ à $0^{\mathrm{m}}, 90$ de circonférence et de 14 ì 17 mètres de haut.

M. de Mainville a exécuté en grand, dans sa terre d'Alosse, commune de Marcilly-en-Villette. (Loiret), des semis de pius sylvestres mélangés tantôt avec des pins maritimes, tantòt avec des bois feuillus; ces semis ont été faits dans un sable de bonne qualité pour la Sologne. Dans l'un de ces semis âgés de 16 ans, composé d'un mélange de „pins sylvestres et de pins maritimes, el qui occupe une pente exposéc au midi, les pins sylvestres ont, à $4^{\mathrm{m}}, 50 \mathrm{du}$ sol, de $0^{\mathrm{m}}, 40$ à $0^{\mathrm{m}}, 50$ de circonférence et 8 mètres de hauteur moyenne. Dans un autre semis composé des mêmes essences, situé à la même exposition, mais âgé seulement de 13 ans, les pins sylvestres ont une circonférence moyenne de $0^{\mathrm{m}}, 40$ et une hauteur

(1) Renseignemens communiqués par M. Poirson, inspecteur de la forèt de Compiègne. 
Ie $6^{\mathrm{m}}$, 60 à 8 mètres. Euffu, dans un autre somis âgé de 13 ans, sur un coteau exposé an nord, et où le pin sylvestre est mêlé avec le pin maritime, lep pin laricio et le bouleau, il a en moyenne $0^{\mathrm{m}}$, 3 š de circonférence et de 6 mètres à $6^{\mathrm{m}}, 33$ de haut; il est plus élevé que le pin maritime (1).

Parmi les semis et plantations que M. Dahirel ainé a fait exécuter dans le Morbihan, et dont j’ai déjà eu l'occasion de parler page 33, on en trouve de pin sylvestre; l'un de ces semis a été exécuté; en 1821, sur 12 hectares d'un terrain plat, ayant $0^{\mathrm{m}}, 32$ de terre végélale sur $\mathrm{m}$ sons-sol argileux; on a éclairci cette petite futaic avec soin. Les pins sylvestres dont elle est composée, îgés par conséquent d'environ 20 ans, en 1841, avaient alors de 7 à 8 mètres le hauteur et $0^{\mathrm{m}}, 15$ de diamètre, terme mnyen, ce qui donne un accroissement innuel le $0^{\mathrm{m}}, 007(2)$.

M. Dickie, dans l'article cité quelques pages plus haul, Sur les forêts ct tes arbres au comté d'Aberdecu, dome un tableau de l'accroissement moyen amuel de quelques pins sylvestres de différens âges, tableau que je vais reprocluire, quoique l'auteur ait calculé l'àge d'après le nombre des couches ligneuses (Voy. page 13); il a fait ses calculs, dit-il, sur te plus gros diamètre de l’arbre, probablement après l'abattage.

\begin{tabular}{|c|c|c|}
\hline NOMBRE DES PINS SYLYESTRES. & AGE. & $\begin{array}{l}\text { ACCROISSEMENT MOYEN } \\
\text { ANSCEL. }\end{array}$ \\
\hline 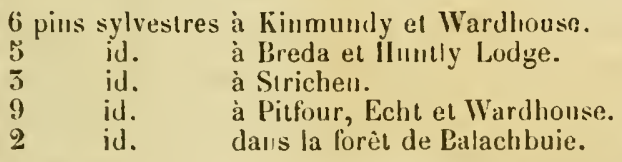 & $\begin{array}{l}40 \text { ans. } \\
70 \text { id. } \\
90 \text { id. } \\
100 \text { id. } \\
120 \text { id. }\end{array}$ & $\begin{array}{lll}4^{1}, 1 & \text { anglais } & (0 \mathrm{~m}, 009) \\
4^{1}, 3 & \text { id. } & (0 \mathrm{~m},(109) \\
5^{1}, 9 & \text { i.l. } & (0 \mathrm{~m},(108) \\
2,76 & \text { id. } & (0 \mathrm{~m}, 0006) \\
2 !, 9 & \text { id. } & (0 \mathrm{~m}, 006)\end{array}$ \\
\hline
\end{tabular}

Loudon s'exprime ainsi qu'il suit (3) relativement à l'accroissement du pin sylvestre: "En 10 ans, sous le clinat de Londres, les pins sylvestres peuvent " attcindre la hauteur de 20 à 25 pieds $\left(6\right.$ mètres à $\left.7^{\text {mo }}, 50\right)$ et en 20 ans celle de 40 " ì 50 pieds ( 12 à 15 mètres)..... 150 on 60 ans l'arbre est consiclérí comme - propre à être employé pour bois d'oeuvre. Mais dans les endroits oì il croît " lentement, comme dans le nord de l'Écosse et autres climats froids, il continue - à prendre de l'accroissement pendant trois ou quatre siècles. "

On trouve dans un mémoire de MM. A. Bravais et Ch. Martins, intitulé Recherches sur la croissance du pin sylvestre dans le nord de l'Europe, des tableaux desquels il résulterait ce qui suit: Le pin sylvestre aurait, dans les environs de Grefle, en Suède, sous la latitule nord de $60^{\prime \prime} 40^{\prime}$ (calcul fait sur des pins âgés de 117 à 436 ans ), un accroissement anmel moyen, pendaut les cent premières années,

1) Renseignemens communiqués far M. Jacquinot de Presle.

(2) Renseignemens communiqués par .M. Dahilel.

(3) Arhoretum el fruticenum britannirum, I. IV, p. 2161, art. Pinus sỵluestris. 


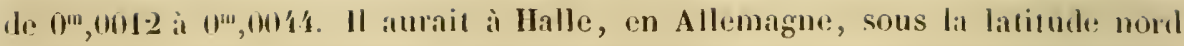
de $51^{\circ} 30^{\prime}$ (calcul fait sur des pius âgés de 83 à 88 ans), un accroissement moyen annuel, pendant les quatre-vingts premières années, de $0^{\mathrm{m}}, 0026$ i $0^{\mathrm{m}}, 0016$. Il aurait à II:iguenau, sous la latitude nord de $48^{\circ} 43^{\prime}$ (ealcul fait sur des pins âgés Ie 100 à 130 ans ), un accroissement moyen annucl, pendant les cent premières anuées, de $0^{\mathrm{m}}, 0066$ à $0^{\mathrm{m}}, 0086$. Plus au nord que Geflle, l'aecroissement annuel du pin sylvestre en hauteur et en grosseur, aussi bien que les dimensions auxquelles il peut parvenir, vont toujours en diminuant.

Je trouve aussi, dans le mème mémoire, que deux pins des environs de Gefle, âgús dle 60 ans et de 119 ans, avaient, le premier, une hauteur de $15^{\mathrm{m}}, 04$, le second une hauteur de $19^{\mathrm{m}}, \mathbf{1 3}$. Je dois d'ailleurs faire observer que les autcurs du mémoire auqual j’emprunte les renseignemens que je viens de donner n’ont calculé l'âge des arbres que par le nombre des couches, et je conteste l'exactiIule de ce moyen (Voy. p. 13). Comment d'ailleurs compter sans se tromper, 'n plus on en moins, des couches ligneuses si petites qu'elles se confondent presque; telles sont, par exemple, celles que suppose un accroissement do $0^{\mathrm{m}}, 008$ en 25 ans.

Je ne puis rien dire de précis sur l'âge auquel les pius sylvestres atteignent leur maturité sous le climat de Paris; mais je ne crois pas que ce soit avant 100 ans, dans des circonstances qui leur soient de tout point favorables. BurgsJorf (1) indique 140 ans pour l'âge auquel cet arbre a atteint tout son accroissement. Colta dit (2) que la révolution du pin sylvestre, c'est-à-dire l'âge où il est le plus avantageux de l'exploiter, varie de 70 à 140 ans. Baudrillart dit, d'après IIarlig, t. 11, p. 578 de son Dictionnaire des eanx et forêts, qu'à 100 et 120 ans ces arbres ont acquis toutes les qualités qui les rendent propres aux grandes constructions, et qu'on en a abattu qui avaient 180 ans, et dont la tige longue de 120 pieds $\left(38^{\mathrm{m}}, 88\right)$ était saine dans toute son étendue. Dans le même ouvrage, I. II, p. 875, il rapporte ce que lui a dit $\mathbf{1 1}$. Steffens, inspecteur des forêts en Hollande, de la forèt de Masbach, créée il y a quelques siècles sur des bruyères, dans le voisinage de Breda. Le sol peut y être divisé en bon, médiocre et presque stérile; les termes de la croissance des pins somt de 100 ans dans la première classe, de 40 à 50 dans la seconde, et de 20 à 25 dans la troisième.

Le pin sylvestre acquiert de très-belles dimensions quand il se trouve dans des circonstances de tout point favorables, mais il est pourtant, sous ce rapport, inférieur aux deux sapins dont j’ai parlé dans les chapitres précédens. Selon Burgsdorf (3), sa tige peut acquérir, quand il croît à l'état serré, de 70 à 80 pieds ( 22 à 25 mètres) de haut, et un diamètre de 3 pieds $\left(0^{\mathrm{m}}, 97\right)$ et au delà. I'feil (1) reprorluit l'opinion de Burgsdorf.

(1) .oureau Manucl forestier, t. IÆr, p. 394.

(2) Trailé de culture forestière, p. 75.

(3) Noursau Manuel forestier, 1. Џer, p 394.

i) Cours complet d'agrirulture pratique, p. 382. 
M. Dickie, dans l'article Sur les forêts et les arbres ulu comté d'Aberdeen, cité plus haut, donne, dans un tableau, la circonférence de quelques pins sylvestres a 4 pieds $\left(1^{\mathrm{m}}, 20\right)$ au dessus du sol; je reproduis ce tableatr, quoique l'âge y ait élé calculé par le nombre des couches ligneuses: on peut comparer ce tableau avec les tableaux analogues qui ont été donnés pour les sapins pages 37 et 131.

\begin{tabular}{|c|c|c|c|}
\hline LOCALITÉS. & AGE. & $\begin{array}{l}\text { CIRCONFÉlácice } \\
\text { à } 4 \text { pieds }(1 \mathrm{~m}, 20) \text { du sol. }\end{array}$ & NATURE DU SOL. \\
\hline $\begin{array}{l}\text { Park llill. } \\
\text { Philorth. } \\
\text { Pitfour. } \\
\text { Kinmundy. } \\
\text { Strichen. } \\
\text { Echt. } \\
\text { lerith Hall. } \\
\text { lireda. } \\
\text { Wirlh iugh. } \\
\text { Huntly Lodge. } \\
\text { Ballaler. } \\
\text { Mar Forest. } \\
\quad \text { id. } \\
\text { id. }\end{array}$ & $\begin{array}{r}95 \text { ans. } \\
46 \text { id. } \\
100 \text { id. } \\
40 \text { id. } \\
90 \text { id. } \\
100 \text { id. } \\
95 \text { id. } \\
70 \text { id. } \\
97 \text { id. } \\
70 \text { id. } \\
70 \text { id. }\end{array}$ & $\begin{array}{cc}\left.5 \text { p. } 6 \text { pes angl. }^{\text {(1m }}, 68\right) \\
3-10 & \left(1^{\mathrm{m}}, 16\right) \\
4-9 & \left(1^{\mathrm{m}}, 44\right) \\
3-5 & \left(1^{\mathrm{m}}, 04\right) \\
7-6 & \left(2^{\mathrm{m}}, 28\right) \\
7-9 & \left(2^{\mathrm{m}}, 36\right) \\
8-2 & \left(2^{\mathrm{m}}, 49\right) \\
6-0 & \left(1^{\mathrm{m}}, 83\right) \\
8-2 & \left(2^{\mathrm{m}}, 49\right) \\
7-0 & \left(2^{\mathrm{m}}, 13\right) \\
5-8 & \left(11^{\mathrm{m}}, 72\right) \\
12-10 & \left(3^{\mathrm{m}}, 91\right) \\
11-9 & \left(3^{\mathrm{m}}, 58\right) \\
13-0 & \left(3^{\mathrm{m}}, 96\right)\end{array}$ & $\begin{array}{l}\text { Sable sur gravier. } \\
\text { Terre narécageuse et sable. } \\
\text { Fond d'argile. } \\
\text { Sous-sol de gravier. } \\
\text { Loam noir sur argile. } \\
\text { Bon sol sur le roe. } \\
\text { Sol pauvre. } \\
\text { Loam argileux riche. } \\
\text { Loam sablonneux, fond de gravier. }\end{array}$ \\
\hline
\end{tabular}

M. Dickie donne ensuite les renseignemens suivans, qui sont plus détaillés, sur quelques pins sylvestres des forêts d'Invercauld et de Mar.

De deux arbres de la forêt d'Invercauld, Ie premicr avait 8 pieds 2 pouces anglais $\left(2^{\mathrm{m}}, 90\right)$ de circonférence à 4 pieds $\left(\mathbf{1}^{\mathrm{m}}, 20\right)$ an dessus du sol, et 6 pieds 9 pouces $\left(2^{\mathrm{m}}, 05\right)$ à 27 pieds $\left(7^{\mathrm{m}}, 10\right)$; le second avait 7 pieds $\left(2^{\mathrm{m}}, 10\right)$ de circonférence à 4 pieds $\left(1^{\mathrm{m}}, 20\right)$ au dessus du sol, et 6 pieds 2 pouces $\left(1^{\mathrm{m}}, 88\right)$ à 16 pieds $\left(4^{\mathrm{m}}, 80\right)$, et son tronc était dépouillé de branches jusqu’à la lıauteur de 40 à 50 pieds (12 à 15 mètres ); il avait une hauteur totale de 70 à 80 pieds (21 à 24 mètres). Il y avait des centaines d'arbres des mêmes dimensions que celles du second arbre clans son voisinage. Trois arbres de la forêt de Mar, dont l'un était abattu depuis trois ans, l'autre depuis un an, le troisième depuis huit mois, ayant environ 2 pieds 4 pouces $\left(0^{\mathrm{m}}, 71\right)$ de diamètre à la base et une longueur de 50 pieds ( 15 mètres) de bois d'ouvre, ont été comparés avee un pin de Riga de très-bonne qualifé. On a soumis ces quatre arbres aux mêmes épreuves et l'on a trouvé que les trois pins sylvestres d'Écosse étaient supérieurs en qualité au pin sylvestre de Riga, auquel on les avait comparés. La forêt de Mar, de laquelle on avait expédié ces arbres, est la propriété du comte de Fife, et contient au delà de 60,000 pins sylvestres semblables à ceux dont on vient de parler, outre un nombre immense de pins de moindres dimensions. Malgré l'expérience que rapporte M. Dickie, je persiste à croire que les pins sylvestres du Nord sont généralement supérieurs à ceux de l'Écosse, particulièrement pour la mâture.

Loudon dit, an commencement de l'article Pinus syluestris de son Arboretum et fructicetum britannicum, 1. IV, p. 2159 , que "les pins sauvages ou pins d'Écosse "alteignent, dans les positions favorables, la lauteur de 80 à 100 pieds (24 à 30 


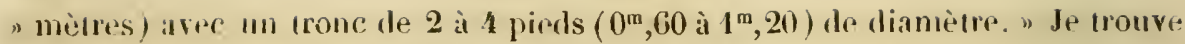
dans ee même article, page 2161 , que "le plus bean pin sylvestre qui ait ji" mais été coupé en Écosse est, dit-on, un pin de la forèt de Gleenmore, que l'on "appelait la dame du Glen; on trouve une planche de ce pin à l'entrée du ves" tibule de Gordon Castle, elle a 6 pieds 2 pouces $\left(4^{\mathrm{m}}, 85\right)$ de long et 5 pieds 5 "ponces $\left(1^{\mathrm{m}}, 62\right)$ de large. "Loudon donne, à la fin de cet article, les dimensions d'un grand nombre de pins sylvestres silnés dans les pares de la Grande-Bretagne; je vais reproduire ce qui est relatif à cenx de ces arbres qui avaient les plus belles dimensions (Voy, page 38 ).

En Angleterre. Dans les environs de Londres, à Whitton, il y a plusieurs pins sylvestres, plantés depuis 100 ans, qui ont de 70 à 80 pieds ( 21 à 24 mètres) de haut avec des trones de 2 à 3 pieds $\left(0^{\mathrm{m}}, 60\right.$ à $\left.0^{\mathrm{m}}, 90\right)$ de diamètre. - A Melbury park, un pin sylvestre, âgé de 100 ans, a 76 pieds $\left(22^{\text {wa }}, 80\right)$ de haut, et son trouc un diamètre de 3 pieds $\left(0^{\mathrm{m}}, 90\right)$. - A Kidbrooke, un pin sylvestre, planté depuis 60 ans, a 80 piels (24 mètres) de haut, et son tronc un diamètre de 4 pieds $\left(1^{\mathrm{m}}, 20\right)$. - A Harlingford, un pin sylvestre, âgé de 160 ans, a 70 pieds ( 25 mètres) de baut, et son trone, dépouillé de l,ranches jusqu'à 40 pieds (12 mètres ), un diamètre de 5 pieds $\left(1^{\mathrm{m}}, 50\right)$; près de ce pin sont cinq autres pins ayant 4 pieds $\left(1^{\mathrm{m}}, 20\right)$ de diamètre. - A Melbourne Il:ıll, un pin sylvestre a 81 pieds $\left(24^{\mathrm{m}}, 30\right)$ de haut, et son tronc un diamètre de ś pieds $\left(4^{\mathrm{m}}, 50\right)$. - - A Ilaffielo, un pin sylvestre, âgé de 105 ans, a 100 pieds (30 mètres) de haut, et son trone un diamètre de 3 pieds $\left(0^{\mathrm{m}}, 90\right)$. - A Tredegar park, un pin sylvestre, âgé de 110 ans, a 70 pieds ( 21 mètres) de haut, et son trone un diamètre de 3 pieds 6 pouces $\left(1^{\mathrm{m}}, 05\right)$.-A Croome, $u$ pin sylvestre, planté depuis 6 ă ans, a 70 pieds (21 mètres) le haut, "t son tronc un diamètre de 3 pieds $\left(0^{\mathrm{m}}, 90\right)$. - En Écosse. A Gorion Castle, un pin sylvestre a 90 pieds (27 mètres) de haut, et son tronc un diamètre de 3 pieds 6 pouces $\left(1^{\mathrm{m}}, 05\right)$. - A Castle Huntley, un pin sylvestre avait, en 1796 , 19 pieds $\left(5^{\mathrm{m}}, 70\right)$ de circonférence près du sol, 13 pieds 6 ponces $\left(4^{\mathrm{m}}, 05\right)$ à 3 pieds $\left(0^{m}, 90\right)$ au dessus du sol, et il était considéré comme le plus gros du pays. - A Bargally, un pin sylvestre avait, en 1780,90 pieds (27 mètres) de haut, dont 22 pieds $\left(6^{\mathrm{m}}, 60\right)$ sans branches, et son tronc 9 pieds 3 pouces $\left(2^{\mathrm{m}}, 7 i\right)$ de circonférence. - En Irlande. Près de Carrick, sur Suir, un pin sylvestre a 86 pieds $\left(25^{\mathrm{m}}, 80\right)$ de haut, dont 60 pieds (18 mètres) dépouillés de loranches, et son tronc un diamètre de 5 pieds $\left(1^{\mathrm{m}}, \breve{0} 0\right)$.

Dans la forêt d'Haguenau, située au nord et à 30 kilomètres de Strasbourg, les pins sylvestres, qui composent en grande partie cette forêt, parviennent à d'aussi belles dimensions qu'en Allemagne. L'on a vu au commencement de cet article, lorsque j’ai parlé des variations du pin sylvestre, que dans les Cévennes les pins sylvestres acquièrent jusqu'à 26 mètres de haut et 2 mètres de circonférence près du sol; il en est de même dans les montagnes de l'Auvergne.

II nous arrive de la Suède, de la Russie, de la Pologne et du nord de la Prusse des bois des plus belles dimensions, propres à la mâture, à la charpente, otc.; a sont des pins sylvestres, dres sapins picras at quelguefois des málizes, mais 
surtumt des pius sylvestles. Ce's bois sont conmus dius le commerce sous fe nom de sapins du Yord; ils sont ordinairement supérienrs en qualite aux bois des mèmes espèces coupés en France, parce qu’ils ont élé tirés de belles lutaics et parce qu'ils ont en une croissance plus lente el plus régrulière, les saisons ayant dẹns le Nord plus de régularité que sous notre elimat tompéré; ils ont plus de: force et plus d'élasticité qu'eux, ce qui les rend particulièrenent propres ì ètre employés pour la mâture et pour pièces de charpente de fortes dimensions.

Malesherbes, dans le mémoire précédenment cité, explique, ainsi qu’il suil, comment lexpression sapins du Nord a été appliquée aux bois que la France tirait du Nord: "De tous les arbres de France, dit-il, ceux qui domnent les mcil" leurs mâts sunt les sapins; mais on sail de temps immémorial que les málures "du Noril valent mieux que les nòtres. On allait les acheter dans les ports de D la Baltique, et nos marchands n'allaient pas dans les forêts du Nord, d'où on " tirait cet arbre. Ils l'appelaicit sepin du Nord, ne croyant pas qu'un autre " arbre qu'un sapin pùt produire de beaux mâts. Il n'y a pas plus de 40 aus que "l'on satit que l'arbre de la mâture est un pin, et e'est seulement depuis que: " M. Barbey, maître mâteur de Brest, fut envoyé dans le pays, où il a vu l'arbre " et d'où il en a rapporté la graine."

Je pense que le pin sylvestre pourrait, sous le climat de Paris et dans des situations qui lui seraient entièrement farorables, parvenir à d'aussi belles dimensions qu'en Allemagne. Mais on ne l'y cultive guère en futaies, depuis longtemps, que dans le Maine, sur des terrains sablonneux plus ou moins maigres, souvent en société avec le pin maritime, et on l'abat sans lui laisser le temps d'alteindre toutes les dimensions dont il est susceptible; on ne peut donc être éclairé par les faits. De nombreux semis et de nombreuses plantations de cet arbre ayant été exécutés dans les forêts de Fontaineblean et de Conpiègne, voisines de la capitale, on y pourrait faire par la suite des observations précises it ce sujet si quelques-uns de ces semis avaient élé exécutés dans des terrains de tout point favorables au pin sylvestre, ce que je ne présume pas. Voici les dimensions de quelques pins sylvestres sous le climat de Paris.

Il y a, dans le parc de Trianon, en terre franche, des pins syliestres qu'on dit avoir été plantés lors de la création de ce parc, et qui doivent par conséquent être: âgés d'environ 74 ans. Le plus gros de ces pins avait, lorsque je le mesurai le 7 aoùt 1844 , une circonférence de $2^{\mathrm{m}}, 37$ et environ 16 mètres de haut, mais il a une tête de pommier composée de quatre branches principales. Le pin sylvestre le plus gros, après celui dont je viens de donner les dimensions, avait une circonférence de $2^{\mathrm{m}}, 28$ et environ 20 mètres de haut (Foy. 1) 133).

On trouve, dans le parc dı Désert (Seine-et-Oise), plusieurs pins sylvestres qui ont été plantés de 1770 à 1780 . Les trois plus gros de ces arlores avaient, à l'automne de 1813 , à $1^{\mathrm{m}}, 2 \mathrm{~J}$ au dessus du sol, une circonférence de $1^{\mathrm{m}}, 70,1^{\mathrm{m}}, \mathbf{7}$ et $1^{\mathrm{m}}, 93$; ils sont à mi-còte et croissent dans un sable substantiel reposant sur un sous-sol argileux (Voy. 1). 132).

Il y a, dans le parc de Comrtomer (Orne), dans une tire d'herbages tris-fer- 
tile, un pin sylvestre isolé, branchu, donı la plantation ne remonte pas à plus de 80 ans; il avait, à l'automne de 1840, une circonférence de $2^{\mathrm{m}}, 22$ et environ 14 mètres de haut (Voy. p. 132).

Malesherbes dit, dans le mémoire précédemment cité, qu'il vit à Brest, en 1780 , M. Barbey, qui avait apporté de la graine de pin de Riga, et M. de Kergariou, officier de marine, qui avait avec ces graines, semé à quelques lieues de Brest un bois qui venait fort bien. Ce bois aurait été semé vers l'année 1752, d'après ce que dit Malesherbes qu'il y avait quarante ans en 1792, que M. Barbey avait apporté ces graines; ainsi, il aurait aujourd'hui 92 ans; s'il existe encore, il serait intéressant de saroir quelles dimensions y ont atteintes ces pins sylvestres de Riga, et à quel usage on pourrait les employer.

J'ai donné précédemment, en parlant de l'accroissement annuel des pins sylvestres, les dimensions de plusieurs arbres de cette espèce de différens âges, particulièrement sous le climat de Paris.

V. Clibat, exposition, terlian. - Le pin sylvestre est celui des arbres dont je parle dans ce Traité qui occupe en Europe le plus grand nombre de degrés de latitude, puisqu'on le trouve depuis le $44^{\mathrm{e}}$ jusqu'au $70^{\circ}$ degré de l'hémisphère septentrional. Il croit spontanément dans le nord et dans la partie centrale de l'Europe, ainsi que dans quelques-unes des chaines de montagnes de l'Europe méridionale. Il est l'arbre le plus commun daus le nord de l'Allemagne; dans la Russie, dans la Pologne el dans la Scandinavie, il compose souvent seul, quelquefois en société avec d'autres arbres, la masse les forêts de ces pays. Loudon regarde le pin sylvestre comme le seul des arbres résineux conifères qui soit indigène de la Grande-Bretagne; il est l'arbre le plus commun dans les forêts de l'Écosse. On trouve aussi le pin sylvestre croissant spontanément dans les montagnes des Alpes, dans celles des Vosges, du Jura, des Cévennes et des Pyrínées. Nous avons vu, page 160 , que l'on a trouvé sous terre, dans la forêt de Compiègne, des troncs de pins sylvestres qui étaient d'une époque antérieure à 1549, et il y a dans le Maine des charpentes de ce bois qui ont plus de 200 ans (1); il serait donc possible que cet arbre fùt indigène du climat de Paris, et qu'il en eût été expulsé par les bois feuillus et par la culture.

I. le capitaine S. E. Cook dit (2) qu'il a trouvé le pin sylvestre dans la Sierra de Guitlarrama, ou grande chaine centrale de l'Espagne, et plus à l'est, dans la sierra de Cuença, à peu près à la même lalitude. Cet arbre occupe les sommets de la Sierra de Guadarrama, et au dessous se trouve une zône de pin unaritime identique, dit-il, avec le pin maritime des landes de Bordeaux; dans la Sierra de Cuença, le pin sylvestre n'occupe que les sommités septentrionales des montagnes.

On trouve des pins sylvestres dans les moutagnes du nord de l'ltalie, mais

(1) Renseignement communiqué par M. Renard, régisst ur des prupriçtés de $\boldsymbol{M}$. le comte de Nicolai.

(2) Annals of natural history, t. II , p. 163, annce 1839. 
j'ighore s'il en existe dans les montagnes des Apennims, de la Tuscince des

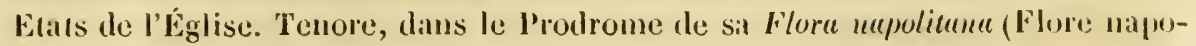
litine), 1. I, p. LV, qui a paru, ainsi que les quatre preniers volumes, en 18111813, nomme le P'iuns sylecstris; daus le 1. IV, 1). 136, il nonme un Pinus pinus-

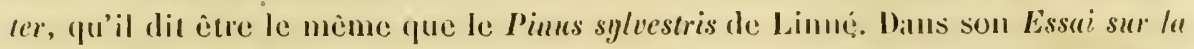
geographic physique et botureipne du roynume de Nuples, paiges 76 et 77, il dit que be pin sylvestre est abondant dans les Apemnins du royamme de Naples; mais, dans le 1. V, p. 266 de sa Flore napolitanu, tome qu'il ne fit paraitre qu’en 1835-1836, il recommait s'ètre trompé, et il alpuelle Pinus nigrescens, pin noirâtre, l’arbre auquel il avait domé le nom de P'inus syleestris; il dit que e’est eelui qui es conum des Allemands sous le nom de Schu'arzache (pin noir), ce qu'il a recomm près de Vienne, où il examina ce pin, élant accompagné de M. Hosı, l'auteur de la Flora Austriaca; ainsi, ce serait le pin que nous appelons I'in d'Autriche.

La culture a introduit le pin sylvestre dans plusieurs parties des plaines de lit France, par exemple dans le Mane, et depuis dans l'Orléanais. On peut citer les forèts de Fontainebleau et de Compiègne, dans le voisinage de Paris, on il en al élé lait, sur une graude échelle, des semis et des plantations qui, dans lin première de ces forèts, sont antérieurs à la révolution française. Quoique le pin sylrestre soit un arbre du Nord et des climats tempérés, on peut le cultiver dims le midi de la France, jusque sous le climil de l’olivier, mais il y vient tripu et rabougri.

Le pin sylvestre réussit à toutes les expositions dans le Nord el dans les cli. mats tempérés; dans les localités les plus méridionales où l'on puisse le culti. ver, il prélère l'exposition du Nord. Cet arbre redoute les grands vents, qui brisent ses branches, plus grosses que celles des sapins mais beaucoup moins flexibles, et il vient mal lorsqu'il est soumis lréquemment à leur action; il redoute, par la même raison, les lieux exposés à d’abondantes neiges et au givrè, qui fon casser ses branches, garnies surtout de feuilles aux extrémités. Toutefois, dans les plaines du Nord, il ne parait pas souffrir autant de la neige et du givre que dins les hautes montagnes, telles que celles des Alpes, par exemple, non pas seutement parce que la neige et le givre y sont moins abondans, mais aussi parce qu'ils s'y attachent moins aux branches, ce dont je ne puis assigner la cause. Ces deux circonstances som probablement la principale cause pour laquelle on ne trouve pas le pin sylvestre sur des points aussi élevés des hautes montagnes que le picéa et que le mélèze, quoiqu’il s'approche plus qu'eux du pôle; on le trouve à peine, sur ces montagnes, à la hauteur du sapin argenté, qui n'atteint pas même, dans le Nord, les rivages de la mer Baltique.

Je ferai remarquer aussi que le sol doit souvent exereer de l'inlluence sur le lait que je viens de rapporter, parce qu'il a ordinairement très-peu de profondeur dans les parties élevées des hautes montagnes, ce qui est trìs-muisible à la végétation du pin sylvestre. Burgsdorf, qui était grand-maitre des forêts de la l'russe (1), dit, en parlant du pin sylvestre: "Toutes les situations panaissent 
- lui convenir, puisque nous le voyons réussir partout; cependant la cime des " hautes montagnes présente un inconvénient, en ce que ces arbres ont à y " souffrir du poids des neiges et des frimas qui surchargent la grande quantité "de leurs longues feuilles toujour's vertes. "Le pin sylvestre étant le seul pin qui se trouve en Prusse, il est évident que Burgsdorf ne parle de ses longues feuilles que par opposition à celles des sapins, qui sont plus courtes.

Irarlig dit (1), en parlant du terrain qui convient au pin sylvestre: "Il se " plait particulièrement dans un sol mêlé de sable et de bonne terre et un peu "profond, mais il vient encore passablement dans toute autre, même dans les "plus mauvais fonds sableux, pourvu qu'il s'y trouve un peu de terre végétale. "Il n'y a que les terrains argileux aquatiques el marécageux qui ne lui convien"nent pas. Il aime les coteaux et les plaines sablonneuses. Sur les montagnes, " il a beaucoup à souflrir par les neiges et le girre, qui s'attachent en grande " quantilé à ses longues feuilles et qui rompent souvent sa cime et ses branches. " Selon Burgsdorf (2), dont Pfeil reproduit l'opinion, le pin sylvestre peut être cultivé dans les silbles purs, soit en plaine, soit sur les montagnes, mais il préfère un terrain sec de meilleure qualité, sableux, mêlé d'argile et recouverl d'une couche de terre végétale. Dans le nord de l'Allemagne, le pin sylrestre occupe ordinairement des terrains sablonneux plus ou moins argileux, plus ou.moins substantiels. Le sol de la grande forêt de pins sylrestres de IIaguenau, située à 25 kilomètres au nord de Strasbourg, est un sable siliceux, frais, recouvert d'un peu d'humus.

Loudon donne les renseignemens suivans sur les terrains qui conviennent au pin sylvestre en Écosse(3) : Il se troure, dit-il, sur les sols sees, sablonneux, graveleux, granitiques ou argileux, rarement sur ceux qui sont calcaires; et les plus beaux pins sylvestres, dans les llighlands (4), se trouvent sur un loam léger, d'un brun clair. Lorsque le vent porte les graines du pin sylvestre sur les terrains marécageux et tourbeux, elles lèvent quelquefois, mais elles ne donnent naissance qu'ì des arbres d'une triste régétation et d'une cuurte durće. On remarque, dans l'Aberdeenshire, dans le roisinage de la Dee et de la Spey, ou se trouvent les terres les plus élevées de l'Écosse, que c'est dans les vallécs, sur les bords de ces rivières et de leurs affuens, sur un sol d'alluvion ou sur les pentes douces qui forment le pied des collines, ou encore dans les renfoncemens élevés des montagnes, que le pin sylvestre croissant spontanément prospère et donne le meilleur bois d'œuvre. L'anteur, pour montrer les effets du sol et du climat sur la croissance du pin sylvestre, donne ensuite une courte description de cing des principales forêts de pins sylvestres de l'Écosse.

En Suède, les belles forêts de pin sylvestre des environs d'Upsal croissent

(1) Instruction sur la culture du bois a l'usage des forestiers, p. 203.

(2) Nouveau Manuel forestier, t. Ler, p. 39'.

(3) Arboretum et fruticeluın brilannicum, t. W, p. 2164, art. Pinus sylcestris.

(i) La traduction litterale du mot highland est haut pays ou haute terre; mais ce mot exprime en anglais la partie montagneuse de l'beosse : j’ai donné page 37 une définition du mot loam. 
dans un sol sablonneux : on y remarque, ainsi que dans le nord de l'Allemagne, que cet arbre occupe les partics les plus sèches du terrain, et que dans les parties où le sol est humicle il est ordinairement remplacé par le picéa. Dans le Maine et dans l'Orléanais, au contraire, on a remarqué que c'était dans les terrains frais, sans être mouillés, que le pin sỵlvestre a vait la plus belle végétation; mais peutêtre ces terrains n'étaient-ils frais que comparativement aux sables secs et aritles consacrés à la culture du pin maritime; peut-ètre aussi ees terrains étaient-ils en même temps plus substantiels et très-facilement pénétrables aux ritcines des pins sylvestres, et alors on pourrait croire que c'était principalement par ces raisons que leur végétation y était plus belle : il n'y aurait d'ailleurs rien d'extraordinaire à ce que les conditions l'unc belle végétation fussent différentes, pour le même arbre, sous des climats très-différens.

II. Jacquinot de Presle a vu le pin sylvestre réussir passablement en Sulognne, dans des terrains oì régnait une humiclité stagnante, et sur la glaise, lieux où l'on ne pouvait cultiver le pin maritime.

Le pin sylvestre donne encore de bons produits dans les terres de bruyères et diuns les sables qui ne sont pas trop arites, mais il ne peut être cultivé avec succès dans des sables aussi arides que ceux où l'on peut cultiver le pin maritime. Dins le llaine cl dans l'Orléanais, par exemple, on remarque de grandes étendues de sables sur lesquels le pin maritime a une assez belle végétation et où l'on ne parviendrait point à cultiver le pin sylvestre; le peu de sujets qu'on y obtiendrait y resteraient chétifset rabougris : les nombreuses expériences qui ont été fatitus ne laissent aucun doute à ce sujet; I. le baron de Morogues en a rapporté plusieurs, dans une brochure intitulée ine la préférence ì accorder en Sologne ct dans les sols d'alluvion quartzense à la culture lu pin maritime sur celle des pins d'Ecosse et laricio.

Le pin sylvestre peut donuer de beaux produits dans les terrains calcaires, et l'on parvient même à le cultiver dans ceux qui le sont extraordinairement; alinsi, dans le département de la Còte-d'Or, on est parvenu à couvrir de pins sylrestres des coteaux calcaires arides, et j'en ai vu aussi, dans une semblable position, chez MI. Gazan, clont la proprićté n'est située qu'à six lieues de la mienne. Il n’a alors, à la vérité, qu’une paurre végétation, mais éest déjà un magnifique résultat quand il remplace l'aridité. Cet arbre est le seul des arbres résineux conifères, de pleine terre en France, que l’on soit encore parvenu à cultiver sur les terres crayeuses de la Champagne, et quoique sa végétation y soit languissante, il y rend de grands services; il fournit du combustible dans une localité où il n'y en avait point du tout, et à la longue, par l'accumulation du détritus de ses feuilles, il rend des terrains, jusqu'alors stériles, propres ì la culture des céréales. Cette propriété dı pin sylrestre de croitre sur les terrains calcaires avait déjà été signalée par Rozier, dans son Cours complet l'agriculture, t. VI, p. 685̆, à l'article Pux sauvage, Pimns syltestris Linnć : "Il est reconnu, dit-il, que le pin "sylvestre a la propriété de croitre dans de très-mauviais terrains, même dans les "terres calcaires el crétacées. "Elle avait été signalée aussi par Malesherbes, 
dans le mémoire cité à la première page de ce chapitre: "En Suisse, et en par" ticulier dans le Valois, j’ai souvent vu, dit-il, des pins sylvestres sur des côtes " escarpées calcaires, el qui, sans la présence du pin, auraient été totalement stériles. "

VII. Crigation d'une futale et d'Un talllis de pins sylvestres. - Les semis el les plantations de pins sylvestres n'ont pas besoin d'ombrage, et ne peuvent supporter le même ombrage, que les semis et les plantations des deux sapins d'Europe; ainsi il n'est pas possible de transformer les taillis el les futaies de bois feuillus en futaies de pins sylvestres, en suivant les procédés (Voy. p. 49) au moyen desquels on peut les transformer en futaies de sapins. Les semis, aussi bien que les plantations de pins sylvestres, peuvent souvent, au contraire, être employés avec succès et avec un trìs-grand avantage à repeupler les clairières de terrains siliceux qui se trouvent dans les forêts de bois feuillus.

Ordinairement ces clairières résultent de ce que le terrain est de trop mauvaise qualité pour que le clıêne et les autres bois feuillus puissent y avoir une belle végétation; ils y viennent chétifs et rabougris; la bruyère, le genêt, le jonc marin ou d'autres arbustes y couvrent le sol. Le pin sylvestre réussit presque toujours dans ces sortes de terrains, s'iln'est point dominé par d'antres arbres et qu'il puisse y enfoncer ses racines; car si le sous-sol y est impénétrable aux racines à peu de distance de la superficie, on l'y cultiverait sans succès en futaie; sa tête se couronnerait au bout d'un petit nombre d'années. Cet arbre, qui ne paraît pas souffrir d'être mêlé avec des bois d'essence feuillue tant que sa tête les domine, est retardé dans son accroissement lorsque le terrain est couvert de ces arbustes dont je viens de parler, mais sa végétation n'en est point arrêtée, et s'il a été planté assez serré, il linit par les étouffer. Le pin laricioet le pin maritime présentent le mêmea avantage que le pin sylvestre pour le repeuplement de ces clairières. Il y avait clans un bois, à 3 kilomètres de chez moi , une clairière de 6 hectares dont le terrain, couvert de bruyère et de mousse, était si mauvais que mon père, quoiqu'il l'eùt entièrement défoncé, n'avait pu y faire réussir le bouleau; mon frère y a créé, par le semis en potets, une pinière où se trouvent mêlés le pin sylvestre, le pin laricio et le pin maritime.

On peut créer une futaie de pins sylvestres par la plantation et par le semis. Il est généralement plus coûtcux d'employer la plantation, mais cela estordinairement plus prompt, et l'on obtient ainsi un bois qui marque tout de suite; aussi est-ce le moyen que l'on emploie, presque toujours, quand on n'a principalement pour but que l'ornement; on emploie, au contraire, beaucoup plus souvent le semis lorsqu'on ne se propose, en eréant une futaie, que de tirer un revenu de la terre. Il y a d'ailleurs des terrains et des situations où l'on échouerait toujours en employant le semis, ainsi que je l'ai dit page 11, même pour les essences telles que le pin sylvestre, qui est l'une de celles dont le semis à demeure réussit le mieux. Je l'ai éprouvé à mes dépens, ear ayant semé un hectare de terrain argiloalcaire, dépendant d'une propriété que j’ai près de l'ougues (Nièvre), en pin 
sylvestre, en pin maritime et en pin laricio, après que la terre eut été bien préparée par des labours et des hersages, les graines levèrent très-bien, mais le plant périt presque entièrement pendant les trois années qui suivirent le semis; il périt parce qu'il fut déchaussé par l'action successive des gelées et des dégels.

A vant de s'oceuper de la plantation ou du semis, le premier soin doit être de tracer les chemins de la futaie luture et d'assainir les parties qui auraient besoin d'être assainies; on so conformera, à cet égard, à ce que je dirai au commencement de l'article suivant.

Si l'on veut créer une futaie en employant la plantation, on élèvera d'abord du plant, ainsi qu'il sera dit chap. XI, art. IV, et l'on pourra le planter à demeure, lès l'automne de la deuxième année après celle ou l'on a exécuté le semis; mais on ne plantera pas plus tard que la sixième année, parce que lorsque le plant est plus âgé il reprend moins bien et que la plantation est plus coûteuse; il faut ajouter que le pin sylvestre, élevé en pépinière, étant chargé de branches vers la tête, est sujet à ètre ébranlé par les vents, ce qui, quand on le plante trop grand, rend, toutes choses égales d'ailleurs, sa reprise plus diflicile encore que celle des arbres, comme les sapins et le mélèze qui ont, dans leur ensemble; une forme conique. On trouvera, chap. XI, art. II, tous les détails de la plantition à demeure. Je me contenterai done de dire que pour planter du plant de deux ans, qui a au plus $0^{\mathrm{m}}, 20$ de haut, il faut des trous de $0^{\mathrm{m}}, 32$ de côté; pour dı plant de trois ans, qui a au plus $0^{\text {m }}$, 55 de haut, il faut des trous de $0^{\mathrm{m}}, 50$ de côté, et pour du plant de 5 à 6 ans, des trous de un mètre de côté au moins. On voit, par ce que j'ai dit page 49 , que j'assimile pour les dimensions des trous le plant du pin sylvestre de 5 à 6 ans au plant du sapin argenté de 8 à 9 ans, celui de 2 ans du premier à celui de 3 ans du second, et celui de 3 ans de l'un à celui de 5 ans de l'autre.

Quant à la distance à mettre entre les plants, si l'on plante du plant de $20 u$

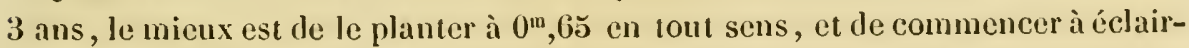
cir lorsque les branches commenceront à se croiser, en supprimant, autant qu'il sera possible, les plants les moins bien venans. Voilà ce qu'il y a de mieux, parce que plus tòt le terrain est occupé par les pins, de manière à étouffer les plantes et arbustes qui les couvrent, plus tôt ces arbres acquièrent toute la force de végétation dont ils sont susceptibles, dans le lieu où on les a plantés (Voy. p. 12); mais il est fort coûteux de planter aussi serré, et si l'on n'éclaircissait pas aussitôt qu'il est nécessaire, la plantation en éprouverait un grand dommage, et il aurait été préférable alors de planter moins serré. On peut diminuer beaucoup la dépense en ne plantant pas en plein, mais seulement par bandes parallèles de 7 mètres de large, entre lesquelles on laisse une distance de 4 mètres; cette disposition est préférable si l'on n'éclaircit pas aussitòt qu'il est nécessaire; les sentiers de 4 mètres servent tout à la fois à l'exploitation des bourrées provenant des éclaircissages et à procurer de l'air et de la lumière à la jeune pinière. Il arrivera d'ailleurs rarement que l'on plante aussi serré, excepté dans les pantations d'agrément et daus les sables, où la plantition est beatucoup plus facile, 
moins coùteuse, et qui sont dans un cas particulier, dont je m'occuperai plus loin; on pourra donc planter à 1, 2, 3 et même 4 mètres en tout sens. Si l'on plante du plant de 2 ou 3 ans, il ne faut pas le mettre à plus de 2 mètres en tout sens, sans quoi il aurait le temps de devenir branchu arant que ses branches ne fussent gênées par suite de l'accroissement de la plantation; il n'en est pas ainsi du plant de 6 ans, parce que ses branches les plus basses ont été étouflées ou étiolées dans la pépinière.

Quel que soit d'ailleurs l'âge du plant que l'on plantera, si on le place à moiṇs de 2 mètres en tout sens, on pourra planter par bandes de 7 à 10 mètres de large, ayant entre elles des intervalles de 4 mètres; mais lorsqu'il sera placé à plus de. 2 mètres, on plantera en plein. Si l'on a trop peu de plant pour occuper tout le terrain qu'on veut planter, même en le mettant à 4 mètres en tout sens, on pourra laisser entre les massifs des bandes de terrain non planté plus ou moius larges; tant que ces bandes ne dépassent pas ŏ mètres de large, il n’y a aucun inconvénient, car, lorsque la futaie approchera de la maturité, le terrain y sera aussi ombragé qu'ailleurs; on pourrait alors aussi planter par houquets. Si l'on plante du plant de 5 à 6 ans, âge qu'a ordinairement le plant des pépiniéristes, le mieux serait de le mettre à 2 mètres en tout sens et d'échaircir aussitôt qu'ii serait nécessaire, mais cela serait lort coûteux : en le mettant à 3 et même ì 4 mètres, la futaie s’élaguera cncore suffisamment d'elle-même, quelques années après la plantation, si le pin sylvestre se trouve dans des circonstances lavorables, car il finira encore par être trop serré, cet arbre exigeant plus d'espace que les sapins.

Dans les plantations en grand, c'est à l'âgre de 3 ans qu'il me paraît généralement le plus avantageux et le plus économique de planter le pin sylvestre, mais cela n’est possible que si ce jeune plant n'est pas exposé à être dominé par des plantes ou par tes arbustes, puisque alors il n’a encore au plus que $0^{\mathrm{m}}$, ̌̌ de haut et qu'il boude la première année de sa plantation; il est donc possible que l'on soit obligé d'employer du plant plus âgé; c'est d'ailleurs le moyen d'avoir tout de suite un bois qui marque.

Les sables, parmi lesquels il y en a de très-favorables à la culture du pin sylvestre, et les terres rendues aussi meubles qu'eux par la culture, se trouvent dans un cas particulier. On peut y planter du plant de l'année, depuis l'automne jusqu'au moment où part la sève l'année suivante, en le repiquant au plantoir après avoir préparé la terre par des labours et des hersages; on peut aussi, au lieu de labours, remuer la terre avec la fourche-bêche à chaque endroit où l'on veut repiquer, ou enfin on peut planter dans de petits trous faits avec une houlette ou avec la petite fourche à deux dents (Pl. VII, fig. 7 et 8). On prendra pour arracher et pour repiquer ou pour planter le plant les précautions qui seront prescrites chap. XI, art. II; le plant doit être mis en terre le plus tôt possible après qu'il a été arraché. Le mieux est de planter ce plant lierbacé à $0^{\text {m, }}, 32$ de distance en tout sens et d'éclaircir aussitôt qu'il sera nécessaire; cependant on pourra le puetle à $0^{\mathrm{m}}, 65$ et mème à un mètre. 
Les craies se tonvent, comme les sables, dans un cas particulier; les semis y úchouent, les plantations y réussissent difficilement. Je trouve dans le tome $\mathbf{X V}$ (année 1812) des Ḿmoires de la Société d'agriculnure du département de la Seine. dans un rapport de Mr. François de Neufchâteau sur un mémoire de M. de Villarsy, relatif aux plantations dans le département de la Marne, que la méthode qui a le mieux rénssi dans les plus mauvais terrains de la Champagne, oǹ l'on a planté des pins sylvestres, est la suivante : on fait des fossés d'un mètre de large à la distance de $3^{\mathrm{m}}, 25$ les uns des autres; on étale la terre tirée des fossés sur les intervalles qui se trouvent entre eux, et l'on y fait des trous dans lesquels on plante; le plant que l'on emploie a toujours été levé en motte. Lorsque ces plantations couvrent le sol, elles y forment un terreau par le détritus de leurs lenilles, et le terrain finit par devenir propre à produire du semis naturel et ì la culture des céréales.

On trouve dans les Mémoires de la Société royale et centrule d'agriculture, qui sont la continuation de ceux que je viens de citer, année 1831, page 135, un rapport de M. le vicomte Iféricart de Thury, sur les plantations de M. de Guinaumont, dans le même département, entre Vitry et Châlons, sur des craies; voici le procélé qu’il employait. Il exécutait ses plantations de préférence à l'automne; les plants de pins sylvestres élevés en pépinière, levés en motte à 5 ou 6 ans, ćtaient plantés à 4 ou 5 mètres en tout sens les uns des autres. Ces plantations se sont couvertes de plants provenant de semis naturel, et 30 à 40 ans après la plantation, selon qu'on l'a jugé nécessaire, on a abattu des pins afin dé domner de l'espace et de la lumière au jeume plant, qu'on éclaircit d'ailleurs quand il est nécessaire. M. de Guinammont a planté ainsi 2,700 hectares, situés dans quatorze communes dilhérentes, et a transformé en -bois, dans un pays où l'on en manquait, des terrains auparavant incultes et qui ne se vendaient que $12 \mathrm{fr}$. l'hectare. D'autres propriétilires ont exécuté de semblables travaux dans le même département et dans des terrains de même nature : on cite dans ce rapport MII. Dozon, Not, Ruinard de Brimont, Moët, de Thuisy, Arnoulsenart, Meunier, Consin-Joli et le général Tirlet.

S'il est vrai que l'on puisse planter le pin sylvestre avec succès dans des terrains très-humides, ce dont je doute, on se conformera à ce que j’ai prescrit pour le sapin picéa dans une semblable situation (p. 136).

Je vais rapporter sommairement quelques exemples de créations de futaies de pins sylvestres par la plantation, avec du plant de 1, 2 et 3 ans. M. Couturier, propriétaire à Ampilly-le-Sec, près de Châtillon-sur-Seine (Còte-d'Or), a donné, dans le Monitenr industriel du 23 janvier 1840 , des détails relatifs à ses plantations de pins sylvestres sur des coleaux de friches jusqu'alors improductives; il ne fait point connaître de quelle nature est le sol de ces friches; il se contente de dire que les semis y réussissaient mal et qu'il était préférable d’y employer la plantation. Il achetait à Semur, pour 15 fr. le millier, du plant de 2 ans, qu'il avait payé auparavant $150 \mathrm{fr}$. à Epernay, et il le faisait planter à la pioche. On faisail en doux on trois roups de pioche des trous qui avaient en largeur deux 
fois la largeur de la pioche et 6 pouces $\left(0^{\mathrm{m}}, 16\right)$ de profondeur; puis on plaçait le plant, on remplissait le trou et l'on buttait la terre contre le plant avec le talon de la pioche. Les plants étaient placés à $\mathbf{2}$ mètres les uns des autres; ils réussissaient à toutes les expositions, et ils n'offraient d'ailleurs pendant les quatre ou cinq premières années qu'un développement insensible, mais ensuite leur végétation devenait rapide; des pins plantés en 1826 avaient déjà, en 1840, 18 à 20 pieds $\left(5^{\mathrm{m}}, 84\right.$ à $\left.6^{\mathrm{m}}, 49\right)$ de haut, et 15 pouces $\left(0^{\mathrm{m}} 40\right)$ de circonférence à 1 mètre au dessus du sol; ils commençaient à donner du semis naturel. Les picéas et les pins du lord Weymouth n'avaient pas réussi sur ce terrain; mais il est probable que le pin laricio, que j'ai vu prospérer sur de si mauvais terrains, y aurait réussi. M. Couturier trouve la plantation d'automne préférable à celle du printemps, et il était tellement satisfait de ses plantations qu'il avait déjà planté 100,000 pieds et se proposait de continuer à en planter tous les ans.

Je ferai observer, relativement à ce fait que les plants de M. Couturier boudent pendant quatre à cinq ans, que cela tient à ce qu'ils sont placés dans des trous très-petits et plantés avec très-peu de soin; j'ai des terrains de terre de bruyère très-maigres où le pin sylvestre réussit, et je serais certain d'échoner si j’y plantiais de la même manière. Je suis d'ailleurs loin de le blâmer; sa plantation est économique, puisqu'elle ne lui conte, dit-il, qu'une journée de $1 \mathrm{fr} .50 \mathrm{c}$. pour faire les trous et planter 500 plants, et en définitive il réussit. Je conclurai aussi de ce qu'il réussit très-bien en plantant avec si peu de soin, et des dimensions qu'ont ses pins sylvestres de 17 ans, que le terrain convient passablement à cette essence.

J'extrais ce qui suit d'un article que M. C. Marsaux, planteur de la forêt de Compiègne, a fait insérer dans le numéro de décembre 1843, des Annales forestières : Les plants de pépinière sont préférables à ceux que l'on extrait des forêts. Le plant de 2 à 3 ans reprend mieux qui celui qui est plus âgé et n'exige que des trous de $0,{ }^{\mathrm{m}} 30$ à $0^{\mathrm{m}}, 40$. 11 est avantageux de planter assez serré (1 mètre sur $\left.1^{\mathrm{m}}, 33\right)$ pour que le plant couvre rapidement le sol et y étouffe les herbes parasites; il se trouve alors 7,500 plants par hectare, ce qui est suffisant. On peut planter les pins sylvestres aux mêmes époques où l'on plante les bois feuillus; cet arbre est celui de tous les arbres verts dont les plantations réussissent le mieux. La plantation exécutée ainsi qu'il vient d'être dit revient à 25 fr. pour planter un millier de plant; ainsi la dépense s'élève par hectare à $187 \mathrm{fr}$. $50 \mathrm{c}$, , et avec les regarnis le prix moyen par hectare ne dépassera pas $250 \mathrm{fr}$. M. Marsaux a fait planter ainsi 48,000 pins sylvestres pendant l'hiver de 1842-1843 qui fut très-cloux; le nombre des regarnis s'éleva à 8,000 , et il est impossible, dit-il, de faire une perte moindre. M. Marsaux parle aussi d'une plantation dans des

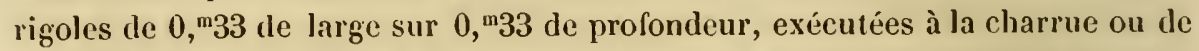
main d'homme, et dit que la première manière est bien préférable ì la seconde.

Je pense que dans les sables ou dans les terrains sablonneux, dans lesquels a planté M. Marsaux, il aurait été préférable de semer ou de repiquer du plant de l'annće. Les plantations de pin sylvestre ne sont pas celles qui réussissent le micux; olles ne réussissent pas mieux que celles de sapin argenté el surtont 
que celles de sapin picéa , ce qui peut tenir à ce que ces deux sapins ont plus de clevelu et sont moins ébranlés par les vents que les pins sylvestres; elles ne me paraissent pas réussir beaucoup mieux que celles de pin Weymouth, mais il faut que le plant soit élevé et planté à demeure, ainsi que je le dirai chap. XI, dans la situation et dans le terrain favorables à chaque espèce. M. Marsaux a oublié, dlans l'évaluation de la dépense, de tenir compte du prix du plant, ce qui augmente pourtant beaucoup cette dépense, même lorsque l'on a une pépinière. La perte d'un sixième, en plant de 2 ou 3 ans, au lieu de me paraître la plus petite possible, me paraît au contraire très-forte, à moins que le terrain ne fùt l'une aridité extrême. On verra, chap. XIl, art. II, quelles ont été mes pertes pour les plantations que j'ai exécutées, pendant ce même hiver de 1842-1813, avec dı plant de 5 à 7 ans, qui reprend toujours moins bien que du plant de 2 à 3 ans. Relativement à la plantation en rigoles, je renvoie à ce que j'en ai dit page 52.

J'emprunte à une brochure de M. Hubert (1) des détails sur la manière dont il a fait exécuter, en 1824, de nombreuses plantations dans les sables des dunes et autres de la province d'Utrecht, en Hollande, par un procédé qui n’y était pas encore en usage, dit-il, et qui est à peu près conforme à celui que j'ai précédemment indiqué.

Après avoir élevé du plant en pépinière et en lignes, sur un terrain sablonneux préparé exprès, ou sur les dunes mêmes, également en lignes, mais à $0^{\mathrm{m}}, 30$ de distance (et dans ce dernier cas une partie du plant est destinée à rester en place), on le plante à demeure dans l'année même; on peut ordinairement exécuter cette plantation dès le quarantième jour après la germination, et cette opération peut se continuer pendant le printemps, l'été, l'automne et mème l'hiver, tant que le temps est doux. On lève le plant avec une spatule ou une petite bêche, qu'il faut avoir le soin d'enfoncer jusqu'à la profondeur des racines, qui ont quelquefois de $0^{\mathrm{m}}, 25$ à $0^{\mathrm{m}}, 30$ au bout de deux mois après la germination; ce travail ne s'exécute qu'au moment de planter; on tient le plant renfermé et couvert, et on l'arrose, s'il est nécessaire, pour le maintenir humide; on évite ainsi que les racines de ce jeune plant ne souffrent du hâle et du soleil. On se sert, pour planter, d'une houlette légère, à manche court; les plants se placent à $0^{\mathrm{m}}, 35$ les uns des autres en tout sens dans les landes et friches, et à $0^{\mathrm{m}}, 30$ dans les lunes. Le plant est placé aussi serré pour occuper le terrain et pour que les jeunes pins se protégent les uns les autres. La plantation est exícutée par trois planteurs, qui opèrent en échelons et à reculons, et auxquels un enfant dounc le plant, qui est renfermé dans une petite hoîte ou dans un panier; cet atelier peut planter en un jour 12 à 1,500 plants, et, lorsque la plantation a été faite avec soin, il en manque fort peu. Sur les dunes, on commence la plantation par leur sommet et l'on enterre le plant jusqu'à la plumule. Il est digne de remarqu. que dans ces dunes on trouve l'humidité à $0^{\mathrm{m}}, 02$ au dessous de la superficir du sol; il en est de même dans celles des lancles de Bordeaux.

(1) Traite ou meithode de rultiver les pins saurages (Pinus sylvestris de linné). 
On commence à éclaircir la plantation de 5 à 7 ans, et le bois qu'on se procure ainsi est employé pour chevilles à tabac, pour claies, pour tuteurs do fleurs, etc.; de 9 à 10 ans, on pratique un second éclaircissage clont le produit est employé pour perches à haricots et à houblon; quelques pins ont déjà de 4 à 5 mètres de haut; le troisième éclaircissage s'exécute de 12 à 15 ans; l'on en fait des échalas et des chevrons, etc.

Le même auteur dit aussi, comme l'ayant pratiqué avec succès, que pour planter sur les landes, lorsqu'elles sont fortement convertes de bruyères ef de mousses, il faudra les brûler s'il est possible ou les faucher; que sur les friches, qui sont des pâtures, on ne fera aucune préparation; que, dans ces deux espèces de terrains, on plantera à $0^{\text {m }}, 35$ en tout sens, et qu'on emploiera pour faire les trous une forte houlctte à long manche ou une bêche.

La méthode de M. Hubert différait de celle qui était en usage dans le pays en ce qu'il plantait à demeure, à une faible distance, du plant de l'année, tandis que l'on plantait à demeure du plant de 5 ans à environ un mètre de distance, on que l'on semait 8 à 9 kilogrammes de graines par hectare. Cette méthode me semble fort bonne dans les sables et surtout dans ceux des dunes, parce que le plant de l'année y reprend très-bien; qu'étant serré, il est moins ćbranlé par les vents, et qu'on ne conserve que les sujets d'élite, les moins bons étant enlevés par des éclaircissages successifs; mais elle n'est praticable que dans les sables ou dans les terrains sableux. Il me semblerait d’ailleurs plus économique de repiquer an plantoir, et l'on réussirait aussi bien; on devrait labourer et herser la terre auparavant, ou, si le labour n'était pas praticable, il fauchait la remuer avec la fourche-bêche dans chacun des endroits où l'on repique, ce qui serait encore plus prompt que la plantation à la houlette. Le fauchage des ln'uyères n'est praticable que lorsque ces plantes sont très-chétives.

Si l'on veut exécuter des plantations de pin sylvestre en grand, ainsi que je viens de l'indiquer, il faudra, quel que soit l'âge du plant que l'on veut employer, l'élever chez soi, non pas seulement à cause de l'économie, et parce que l'on n'en trouverait probablement pas autant qu'on devrait en employer chez les pépiniéristes, mais parce qu'on pourra ainsi avoir avec certitude du plant bien garni de chevelu, l'arracher et le planter dans la journée même ou le lendemain, ce qui est fort important.

Loudon décrit, t. IV, p. 2180 de l'ouvrage précédemment cité, une méthode fort expéditive employée en Angleterre pour planter à demeure du pin sylvestre de 2 ans. Un ouvrier fait, arec une bêche ordinaire, deux entailles dont l'une aboutit sur l'autre à angle droit; il soulève légèrement la terre en faisant la seconde entaille au point où ces deux entailles se rencontrent; une femme ou un enfant, qui suit l'ouvrier, place un plant dans l'ouverture et la ferme ensuite en foulant avec le pied. Un' homme et un enfant peuvent planter ainsi 1,000 plants dans un jour d'hiver de six heures; on en plante 5,000 par acre ( 40 ares). Les saisons pendant lesquelles on plante sont l'automne et le printemps, mais l'automme est préférí; on plante les mólìgs de la même manière. Il est évident que 
cette méthode expéditive, mais imparfaite et rustique, ne: peų réussir dans toutes les espèces de terrains. Il existe une manière do planter encore plus prompte el plus économique que celle que je viens de décrire, c’est la méthode qui a élé employée en Écosse, sur une très-grande échelle, par le second due John d'Athol pour créer des futaies de mélèzes; il se servatit de plant d'un an ou de 2 ans, que l'on plantait avec la lance ì planter (Voy. chap. VIII, art. VII). Je suis persuadé que cette méthode réussirait aussi bien pour le pin sylvestre que pour le mélèze, dans les circonstances tontes particulières où elle est applicable; mais il faudrait employer du plant de pin sylvestre de 2 ans, celui d'un an étant trop petit.

Il est digne de remarque que les Anglais ue créent des futaies de pins syyvestres que par la plantation, et point au moyen de semis sur place, car Loudon cite, 1. IV, p. 2178 de son Arboretum, et comme un fait extraordinaire, qu'en France et en Allemagne on crée souvent les forèts de pins sylvestres en semant la graine dans le lieu même oủ les plants doivent rester.

Pour évaluer la dépense de ces plantations, on consultera, en ce qui concerne les trous, ce que j'en ai dit pages 48 et 56 . Quant au plant, celui de 5 ou 6 ans coùterait $40 \mathrm{fr}$. le cent dans la localité que j'hahite; le plant de 2 ans repiqué coùtcrait $1 \mathrm{fr} .50 \mathrm{c}$. a Orléans, où lat terre est si favorable aux semis, $2 \mathrm{fr}$. 50 c. ailleurs; il serait préférable de planter du plant de 3 ans élevé ansi que je l'ai dit, mais il coùterait plus cher : le plant des pépiniéristes n’a pas toutes les dimiensions qu'il devrait aroir, paree qu'ils repiquent ordinairement trop serré, pour épargner le terrain. Je le répète, il y a un très-grand avantage à élever du plant chez soi, et c'est une nécessité pour peu que l'on veuille exécuter une plantation de quelque importance, puisqu'on ne trouverait point chez les pépiniéristes la quantité de plant dont on aurait besoin. Je vais m’oceuper actuellement de la création d'une futaic de pins sylvestres au moyen du semis.

J'ai dit, au commencement de cet article, que le plant du pin sylvestre ne peut supporter le même ombrage que les sapins, mais il peut lever à mi-ombre et réussir parfaitement, si l'on a soin de domer ensuite successivement à ce plant l’espace et la lumière qui lui sont nécessaires. Il lève anssi et réussit très-bien sur un terrain entièrement découvert; je ne saurais dire d'ailleurs ce qui lui convient le mieux, l'annće où il lève, d'une exposition à mi-ombre ou d'une exposition entièrement découverte. J'ai donné, pages 146-153, les moyens de se procurer de bonne graine, et la bonne grainc lève pour ainsi dire toujours lorsqu'elle a été semée en saison convenable, sur une terre bien préparée.

Avant de semer la graine de pin sylvestre, on peut préparer le terrain ainsi qu'il suit : $1^{\circ}$ par des labours et des hersages; $2^{\circ}$ en faisant des potets (Voy. p. 58); $3^{\circ}$ en faisant écobuer le terrain destiné au semis ou en faisant brùler les plantes qui le convent; $4^{\circ}$ en arrachant les bruyères ou autres arbustes qui couvrent le terrain après avoir préalablement semé; $5^{\circ}$ on peut enfin semer à la volée, sans donner aucune préparation an terrain. Quelle que soit la préparalion quon ail donnée à la terre, on sime du fer mars an fer mai, exepté daus 
une circonstance particulière que j'indiquerai; on pourrait sans doute semer plus tard et réussir, mais on risque d'échoner si l'été esı sec. La graine se sème avec trois doigts comme celle du trèfle.

La préparation par des labours et des hersages peut être exécutée sur des terrains qui avaient d'abord été cultivés en céréales, nu qui étaient couverts d'une futaie que l'on a exploitée à blanc-étoc et dont on a arraché les souches, ou enfin sur des terrains qui étaient couverts de bruyères, de genêts, de joncs marins ou de toute autre plante; il faut quelquefois, dans les deux derniers cas, employer la charrue à défricher et de forts attelages. La terre ayant été préparée par des labours et des hersages, on sème à la volée, flu $1^{\text {er }}$ mars all $1^{\text {er }}$ mai, et l'on enterre la graine avec une herse faite avec des épines auxquelles on donne la forme d'un éventail, on avec une herse en hois très-légère; on pourrait se dispenser d'enterrer la graine ou se contenter de la presser contre terre, au moyen d'un rouleau, si l'on ne craignait qu'elle fût mangée par les oiseaux. La quantıté de kilogrammes de graine qu'il faut employer par chaque hectare doit être telle que le plant occupe le terrain après la troisième sève; elle dépend d'ailleurs du nombre de graines fertiles contenues dans chaque kilogramme et de la quanlité de plants qui survivront après les trois premières années, ce qui varie selon la nature des terres et selon les climats. Je me contenterai donc d'indiquer ce qui se pratique dans les pays où l'on exécute orlinairement le semis sur labour.

Dans le Maine, pour ce semis en plein, on emploic 6 kilogrammes par hectare. Delamarre (1) dit que 3 kilogrammes par hectare sulfisent. Les forestiers allemands ne sont pas d'accord : Hartig, page 235 de son Instruction sur la culture du bois, dit qu'il faut employer 7 à 8 livres (3 kil. $426 \mathrm{gr}$. à 3 kil. 916) par hectare pour le semis sur labour; mais, dans un autre ouvrage, il dit (2) qu'il faut en employer de 12 à 14; Cotta dit (3) qu'il faut en employer 13; Burgsdorf, 15 (4); cet auteur ajoute que " si l'on sème par rayons tracés à la charrue on à la " houe, il ne faut que 5 à 6 kilogrammes de graine, et que les semis de pins syl"vestres ne doivent nullement être recouverts. "Cela peut réussir sur les sables qui occupent une si grande partie de la Prusse : il en est autrement lorsque l'on sème sur des terrains pius substantiels; je pense seulement qu'il ne faut couvrir la graine que très-peu, ainsi que je l'ai dit. La nature des terres doit d'ailleurs ètre prise en considération en ce qui concerne la quantité de graines à employer; ainsi, il en faudra moins pour semer sur un sable doux et fertile que sur um sable aride ou sur une terre forte. Dans les pays où l'on peut cultiver le pin maritime, il serait avantageux et économique d'employer moins de graine de pin sylvestre et de la mélanger avec de la graine de pin maritime, qui est moins chère

(1) Traité pratique de la culture des pins a grandes dimensions, p. 94.

(2) Harlig, cité par Battrillart, Dictionnaire des caux el forits, 1. 11, p. 597 et 820 .

(3) Traité de culture forestière, p. 343.

(1) Nouveau Maunel forestier, 1. II, p. 23i. 
et lève mieux; on supprimerait ensuite successivement le pin maritime à mesure qu'il serait nécessaire.

Lorsqu'on transforme en pinière une terre qui avait éte cultivéc en céréales, on peut semer d'abord de l'avoine, la moitié de ce qu'on en sème ordinairement, et l'on sème ensuite la graine du pin sylvestre; on récolte l'avoine de manière à ne pas atteindre le plant; le piétinage des moissonneurs ne lui cause pas un grand dommage. Le chaume de l'avoine procure au jeune plant un ombrage qui ne me paraît pas lui être nécessaire, mais, ce qui est essentiel, il empêche le terrain de se gazonner; l'avoine pent être utile aussi dans des terrains remplis de pierres et par conséquent brùlans; nonobstant ces avantages, je préférera is ordinairement ne point semer d'avoine, car je pense que jusqu'à ce qu'on l'ait coupée, elle est nuisible au plant, et même fort nuisible si on l'a somée trop épais; le piétinage des moissonmenrs cause aussi un léger dommage. Dans le Maine et dans l'Orléanais, on a remarqué que les semis faits sur une terre qui avait d'abord été cultivèe en céréales étaient ceux qui réussissaient le mieux et qui étaient les plus beaux, ce qui résulte probablement de ce que la terre est alors mieux préparée.

Si l'on veut cultiver le pin sylvestre sur un terrain très-maigre où sa végétation serait languissante, on peut, après avoir bien préparé ce terrain par des labours et des hersages, le diviser en planches parallèles de 7 mètres, entre lesquelles on réserve des sentiers de 4 mètres, et faire jeter la couche de terre végétale de ces sentiers sur les planches; cela est surtout praticable dans les sables, mais la dépense en est fort augmentéc. Le mieux, à moins que ce ne soit pour ornement, est de ne pas semer de pins sylvestres dans des terres qui ne leur conviennent point. Ces sentiers, loin d'être musibles, seront d'ailleurs utiles, et lorsque la pinière approchera de sa maturité, les arbres qui les bordent seront encore trop serrés et seront les plus beaux.

Si le semis a manqué sur quelques points, on y sèmera de nouveau au printemps suivant et l'on enterrera la graine au râteau; si, au contraire, le semis est trop épais, on y arrachera du plant. On pent aussi, sur les sables, regarnir les parties où le semis a manqué en y repiquiunt du plant que l'on prend dans les endroits où il est trop épais; la terre se trouve encorc alors en assez bon état pour n'avoir pas bésoin d'être préparée de nouveau; cette opération peut s'exécuter depuis le mois d'octobre jusqu'au moment où part la sève l'année suivante. Une transplantation de ce jeune plant, à la même époque, dans les terres où le repiquage n'est pas possible, réussirait aussi; on ferait les trous avec une houlette ou avec la petite fourche à deux dents (Pl. VII, fig. 7 et 8). Le semis est ordinairement plus économique que le repiquage on la plantation, mais il est possible que les clairières résultent de ce que le semis ne réussit pas sur les emplacemens où elles se trouvent, et l'on peut manquer de graine.

Après la première année, on éclaircira à mesure qu'il sera nécessaire, d'abord en arrachant du plant, ce qui peut se faire jusqu'ì la quatrième année dans les sables, les annérs suivantes en le coupant rez. terre; mais je trouve très-utile 
d'éclaircir tous les ans, s'il est nécessaire, pendant les quatre on cinq premières années. On doit tenir d’abord les jeunes pins assez rapprochés pour que leurs branches se croisent un peu, les espacer ensuite successivement, de manière à ce qu'elles se croisent un peu moins, et entin, dès la sixième année, de manière à ce qu'elles se touchent seulement par leurs extrémilés; dans un âge plus avancé, elles ne devront point se toucher, ct il faudra laisser entre les branches un intervalle que j'indiquerai dans l'article suivant : chez moi, oil le bois se vend bien, les éclaircissiges seraient coûteux pendant les quatre premières années environ; ils couvriraient an moins la dépense pendant la cinquième année et donneraient plus tard du bénéfice.

Je rapporterai ce que j'ai lait exécuter ainsi, en petit, dans le semis d'expérience dont j’ai parlé page 57 , semis dans lequel le pin sylvestre occupait 30 ares. L'on ne donna qu'un seul liabour et des bersages comme pour faire de l'avoine, mais la terre était déjà en bon état de culture; le $1^{\text {er }}$ mai 1837, on sema plus de pin sylvestre qu'il n’aurait été rigoureusement nécessaire, et sans avoir auparavant semé de l'avoine, ainsi que cela se fait quelquefois. J'ai perdu la note de ce que j'employai de semence; je puis seulement dire que la graine étant bonne, le semis se trouva trop épais, ct que je fus olligé de commencer à éclaircir dès le printemps suivant. Il y a toujours de l'avantage à semer un peu épais et à éclaircir aussitòt qu’il est nécessaire, parce que le plant, occupant le terrain, l'empèche de se gazonner et qu'on supprime les plants les plus chétifs; mais quand on opère en grand, on doit avoir égard au surcroit de dépense. Je fis éclaircir ainsi jusqu’à la cinquième année (1811) inclusivement, puis on éclaircit en 1843 , et l'on éclaircira par la suitc à des époques variables, lorsque le besoin s'en fera sentir. Les jeunes pins avaient en moyenne $1^{\mathrm{m}}, 50$ à l'automne de $1841,4^{\mathrm{m}}, 83$ à l'antomne de $1812,2^{\mathrm{m}}, 39$ à l'automne de 1843 , et $2^{\mathrm{m}}, 92$ à l'aucomne de 1814. L'accroissement eût été encore plus prompt si, pendant les années1810,1811, 18'12 et 1813, des bostriches n'eussent pas mangé à même les pousses, pendant la sève, de manière à briser ou à altérer la plupart des flèches et une partie des autres pousses; mais leur végétation était si active, que si une pousse n'était pas rompue ou ployée, elle se cicatrisait, et que si une hèche était brisée, la pousse d'une branche la remplaçait bientôt; on avait d'ailleurs le soin, quand on éclaircissait, de supprimer les plants qui avaient le plus souffert.

La dépense du semis sur une terre qui était cultivée en céréales, en préparant le terrain par des labnurs et des hersages, serait, dans ma localité, de 16 à 20 fr. par hectare pour un labour et des hersages, et il faut semer de 6 à 12 kilogrammes de grainc. Celte graine a coûté, à une personne de ma connaissance, $5 \mathrm{fr} .60 \mathrm{c}$. en 1842, à la sécherie de IIagucnau; elle coùtait $4 \mathrm{fr}$. $30 \mathrm{c}$. à Strasbourg en 1843 , elle coûte ordinairement $7 \mathrm{fr}$. dans la maison Andrieux-Vilmorin, on la paie 8 à $9 \mathrm{fr}$. dans le Maine. Les labours pour défricher ou le labour d'un défriché, lors même qu'on ne serait pas obligé d'employer des attelages extraordinaires, seraient plus conteux, parce qu'ils seraient d'une exécution plus lentr. La dépense 
sera moindre pour celui qui fitit labourer par ses propres chevaux, paree qu'il les y emploie quand ils sout inoccupés.

Le senis en potets est particulièrement employé sur des terrains que l'on the pourait labourer : par exemple, sur des pentes rapides, des clatirieres parsemées de cepées, ou sur des terrains que l'on ne pourrait labourer qu'après avoir fait des travaux préparatoires fort coñteux. Si les pentes étaient trop rapides, d’un sol peu consistant, et qu'on trouvât de l'inconvénient à liaire des potets, on se contenterait de semer de la graine à la voléc ou de planter yà et là des branches garnies de eỏnes, ou culin de poser ces branches sur la terre. Je renvoie, relalivement à la construction et à la dimension des potets, à ce que j'en ai dit fage 58, et j’ajouterai ce qui suit. Il est encore plus nécessaire pour le pin sylvestre que pour le sapin argenté de faire des potets d'un mètre de diamètre lorsque le terrain que l'on veut semer"est couvert de plantes, telles que des joncs marins et de grandes bruyères, qui couvriraient bientò les potets s'ils n'avaient que $0^{\mathrm{m}}, 65$ de diamètre ou de cóté, et feraient périr le plant. Si pourtant on ne veut donner aux potets que cette dernière dimension, il faut les laire visiter tous les ans, pendant les premières années, par un ouvrier qui coupera avec une petite faucille les branches qui couvriraient les trous.

Ce que j'ai dit de la distance à laquelle on cloit faire les trous lorstue l'on $\mathrm{em}$ ploie pour la plantation du plant de 3 ans et au delà, s'applique à la distance à laquelle on fera les potets. On sèmera 10 graines environ par potel el l'on n'y Iaissera que 4 à 5 pins au printemps de la denxième anméc, que 3 à 4 au printemps de la troisième, que 2 à 3 au printemps de la quatrième, et qu'un seul au printemps de la cinquième annéc; par ce moyen, on pourra faire un choix. On calculera facilement ce qu'il faudra de graines par hectare, selon que les potets seront plus ou moins rapprochés. Ainsi, par exemple, en supposant fu'on les ait placés à un mètre les uns des autres, il y aura 10,000 potets par hectare, ce que je considere comme un maximum, et il faudra 100,000 graines pour les sener, e'est-ì-dire moins d'un kilogramme, puisqu'un kilogramme en contient environ 134,8 1 5. Il faut pourtant compter alors sur un kilogramme par hectard, car l'ouvrier qui sème sera plus enclin à semer trop que trop peu. J'ai compté dans un seul potet de 0 ", 6 de cỏté jusqu'à 70 plants de pin maritime, dans un autre jusqu'à 40 de pin sylvestre, dans un autre jusqu'à 45 de pin laricio; cela lat roir à quel point mon semeur, qui était pourtant mon jardinier, gaspillait la graine.

Jamais, à terrain égal, les pins n'auront une végétation aussi rapide lorsqu'on les aura semés dans des potets que lorsqu’ils l'auront étê sur une terre prépircéce par des labours, surtout si les plantes qui occupent le terrain peuvent les dominer dans leur jeunesse el que les racines de ces plantes occupent le sol à quelque profondeur. Dans ce dernier cas, le semis en potets, quelque soin qu'on 'n prenne, m'a paru en retard, pendant les premières ammées, de quatre à cinq ans au moins sur le semis exécuté sur un labour. Néinmoins, si l'on fait des potels tels que je les ai indiqués, plus ou moins grands, sclon les cas; s’ils sont 
assez rapprochés pour que le plant occupe promptement le terrain; si l'on éclaircit, ainsi que je l'ai dit, le plant qu'ils contiendront; les jeunes pins prendront enfin une végétation aussi active que s'ils avaient été semés sur un labour, et la pinière aura un aussi bel aspect.

La dépense par hectare, pour un semis dans des potets sur un terrain libre, en supposant qu'on leur donne $0^{\mathrm{m}}, 65$ de côté et qu'on en mette 10,000 par hectare, ce qui est le maximum, sera de $250 \mathrm{fr}$. pour les potets, à raison de $2 \mathrm{fr} .50 \mathrm{c}$. le cent, et de $7 \mathrm{fr}$. pour un kilogramme de graine, à quoi il faut ajouter $30 \mathrm{fr}$. pour la semer, en totalité $282 \mathrm{fr}$.; mais on peut meltre plus d'un mètre entre les potets, surtout si on leur donne un mètre de côté ou de diamètre, et alors on obtient une grande diminution dans la dépense. En mettant, par exemple, les potets à 2 mètres en tout sens, il en faudra $\mathbf{2 , 5 0 0 ~ p a r ~ h e c t a r e , ~ e t ~ i l ~ n ' e n ~ c o u ̂ - ~}$ tera que $77 \mathrm{fr}$.; quels que soient d'ailleurs le mombre de potets que l'on emploiera par hectare et leur dimension, on fera lacilement le calcul de la dépense avec les bases que j’ai posées page 61 .

On peut préparer le terrain que l'on veut semer en pins sylvestres en le faisant écobuer, si e'est un terrain gazomné. Dans le courant de l'été, on lève le gazon avec une écobue; on en forme des fourneaux que l'on fait brùler; on étale ensuite le mẻlange de terre brùlée et de cendres, obtenu ainsi; au printemps suivant, on herse avec une herse de fer pesante; on sème en employant un cinquième de graine en sus par hectare de ce qu'il en faut sur un labour, et l'on enterre ensuite avec une herse d'épines. Ce procédé est bon, je l'ai vu employer avec succès, mais il est coûteux; car; pour l'écobuage seulement, on ne peut compter moins de $100 \mathrm{fr}$. par hectare, même dans des circonstances favorables; je n'engage done point à l'employer : on pourra presque toujours alors le remplacer en préparant le terrain par un labour et des hersages, ce qui sera préférable, ou en y faisant des potets, si le labour n'est pas praticable.

Lorsque le terrain que l'on veut convertir en pinière est entièrement couvert de plantes, par exemple de bruyères et de joncs-marins, et que les bourrées de ces plantes se vendent bien, on a un moyen excellent et très-économique d'exécuter le semis. On sème 12 à 15 kilogrammes de graine par hectare, et ensuite, avec une houe plate, on coupe entre deux terres les plantes qui couvrent la terre; les graines se trouvent suffisamment enterrées par le piétinage des ouvriers et par la terre qui s'échappe des racines des plantes que l'on arrache et que l'on doit seconer; j'appellerai ce semis semis rustique.

M. de Boisdhyver a fait exćcuter, dans la forêt de Fontainebleau, de semblables semis arec un entier succès, tant avec de la graine de pin sylvestre qu'avec de la graine de pin maritime, sur 1,400 hectares de cette forêt, et la dépense a élé plus que couverte par la vente des bourrées; il faisait semer 15 à 20 kilogrammes de graine de pin sylvestre ou 20 à 25 kilogrammes de graine de pin maritime par hectare; ce semis rustique s'exécutait dı $1^{\text {er }}$ décembre au 15 avril. On voit que M. de Boisdhyver faisait semer un peu plus cle graine de pins sylvestres que je ne le preseris; mais il raut mieux pécher par excès que 
parr défaut, il y a d'ailleurs des terrains qui exigent plus de semence que d'intres.

Lorsque, an contraire, les bourrées des plantes qui convent le sol n'ont ancune valeur, on lait brùler ees plantes sur place. Si l'on ne craint pas que le fen se communique à des plantes semblables qu'on ne vouirait pas brûler ou à des bois voisins, cela n'exige d'autres précautions que de saisir, pour y mettre le feu, le moment d'un grand hâle ou d'une grande sécheresse; on allume alors le feu, lar un temps calme ou peu agité, du côté d'où vient le vent, et quelques ouvriers sont présens pour activer ou rallumer le feu s'il est nécessaire. Si l'on craint que Ie leu ne se communique à des termins voisins, couverts de plantes ou de bois, on isolera le terrain que l'on veut brüler pour le convertir en pinière; on coupera donc les plantes qui le couvrent dans tout son contour sur une largeur suffisante et on les jettera sur ce terrain. On mettra alors le feu, par un temps calme, du côté opposé au vent, et un nombre sulfisant d'ouvriers surveilleront le feu pour l'activer s'il est nécessaire et l'étouffer avec des battes ou des branches de jin s'il se propageait où l'on ne veut point. On sèmera après avoir fait préparer le terrain, ainsi que je l'ai dit de ceux que l'on fait écobuer, et en employant un cinquième de graine en sus par hectare de ce qu'il en faut sur un labour. Ce semis sur brilis ne réussit d'ailleurs ordinairement pas aussi bien que le sem is rustique, parce que les bruyères et autres plantes repoussent vivement et unisent à lat prospérité du jeune plant. Quel que soit celui des trois procédés que je viens de décrire que l'on emploie, s'il y a des parties ou le semis ait manqué, on y lera des potets dinns lesquels on sèmera.

On trouve dans la brochure de M. Hubert, que j'ai précédemment citće, qu'il laisait exécuter des semis de pin sylvestre sur place, dans des dunes de la province d'Utrecht, ansi qu'il suit : on traçait des rayons à $0^{\mathrm{m}}, 35$ les uns des iutres, au moyen d'un petit chariot à deux roulettes, et derrière claque roulette ćtait adapté un semoir qui semait très-clair; on couvrait la graine au râteau; quatre ou cing ouvriers faisaient un demi-hectare en un jour; on établissait des haies factices de menus branchages à des distances convenables. Aree de bonne graine, ce semis ne manquait jamais; on traitait le jeune plant, relativement aux éclaircissages successifs, ainsi que je l'ai dit page 176 , en rapportant le procédé de M. Ilubert pour créer des pinières sur ces mêmes terrains par la plantation.

On emploie dans les landes de Bordeaux, pour semer le pin maritime, un procédé qui est fort économique, puisque la dépense ne s'élève qu'ì 6 fr. par liectare, et il pourrait, je crois, être employé aussi a vec succès pour le pin sy̆lrestre, dans les mêmes circonstances; mais je présume qu'elles ne se présenteraient pas communément, le pin sylvestre ne pouvant prospérer dius des terrains de sable quartzeux sur lesquels on peut encore cultiver avec succès le pin maritime. On trouvera la deseription de ce procédé chap. V, art. VIl.

On pourrait enfin, imitant la nature, semer de la graine à la volée sur les lerrains qute l'on veut convertir en pinières, lorsegu'ils ne sont point trop éunerte 
de plantes on d'arbustes. Mais alors il faut employer beaucoup de graines, la plupart ne levant point, et l'on n'a aucune certitude de réussir; les arbres se trouvent espacés irrégulièrement, ont un accroissement fort lent, et, s'ils ne, sont pas assez. serrés, ils deviennent branchus; les jeunes plants, trouvant la terre dure et quelquefois garnie de plantes, ont un accroissement très-lent pendant les premières années. On ne doit done jamais employer ce procédé pour créer une pinière; il réussirait d'ailleurs mieux dans des terrains qui seraient facilement pénétrables aux racines, tels que les sables ou les terrains sableux, que dans des terres plus compactes. Il y a pourtant un cas ou cette méthode doit être employéc, c'est lorsqu'on sème sur des sables nouvellement fixés (1). "II „ faut alors se contenter, dit Burgsdorf, d'y passer la herse, et même on n'y fait " rien s'ils sont recouverts, dans la crainte de leur rendre leur première molsilité. " Delamarre dit (2), relativement à ce genre de semis, "qu'il a fait des semis de " pins maritimes el de pins sylvestres à l'aventure, dans des clairières plus ou * moins garnies d'herbe et de bruyère, el qu'il a obtenú trop peu de succès pour " ne pas regarder les semis faits à l'aventure dans des landes ou friches, sans au" cune sorte de préparation.du sol, et par imitation de ce que fait la nature, " comme n'étant pas susceptibles d'être mis au rang des pratiques à adopter."

En délinitive, les semis de pins sylvestres, aussi bien que ceux des autres pins dont je m’occuperai, réussissent d'autant mieux, généralement parlant, que la terre a été mieux préparéc, contrairement à ce qui a été dil par plusieurs auteurs, et même par celui que je viens de citer, qui prétend qu'une préparation pour ainsi dire ébauchée esı bien préférable à une préparation soignée.

L'on peut, au lieu de graines, semer des cônes entiers, mais cette méthode ne peut être employée avec succès que sur des sables nus, sans abri contre le soleil; j'en emprunte la description à Burgsdorf. Il faut, dit cet auteur dans son Nouveau Manucl forestier, t. II, p. 281, 24 hectolitres le cônes par hectare. "On " transporte en sacs la quantité de semence nécessaire à l'ensemencement du "terrain qu'on se propose de mette en nature de bois et dont on aura fait au"paravant gratter la superficic. On place à l'une des extrémités du champ une " voiture d'osier ou un tombereau, qu'on remplit de cônes tirćs des sacs. La per" sonne chargée de semer se munit d'unc pelle à remuer le blé et se place sur la "voiture, en tournant le dos aux chevaux. Une autre persome conduit la voi" ture au pas. Le semeur jette ses pelletées avec force, en décrivant un demi" cercle et faisant en sorte de les répandre le plus également possible sur la sur" face du terrain. Quand cette première course est linie, on compte le nombre

(1) Dans le Nouveau Manuel forestier, t. II, p. 158, Burgsdorf parle des moyens de fixer les sables. Il n'entre pas dans mon plan de traiter ce sujet; je me contenterai de dire qu'il conseille l'emploi des haies en clayonnagrs, par rangées formant un angle droit avec la ligne de direction des ensablemens, et de couvrir les intervalles entre les haies de deux cents charretees de branches de pin par hectare. Après l'hiver, on enfonce ces branches par rangées parallèles aux haies, de manière que les bouts des branches soient inclinés du còté où se portent les débordemens.

(2) Traité pratique de la culture des pins à grandes dimensions, p. 82. 
" de pas qui a été semé, y compris la largeur de la voiture, pour se porter sur "le côté, à un éloignement égal dans les deux bouts de la pièce. Là , on continue " l'ensemencement, soit avec une autre voiture, soit avec la même, qu'on rem"plit de temps en temps avec les sacs de cônes, qu'on a eu l'attention de dis" tribuer de distance en distance.

"Lorşue les cônes sont parfaitement ouverts, on fait pisser sur le terrain où "ils se trouvent une herse de branchages. Cette herse consiste dans un vieil " avant-train de voiture avec ses deux roues et à l'essieu duquel on a fiché des " chevilles sur la partie supérieure, à la distance de 6 pouces entre elles. A ces " chevilles sont attachées de longues branches qui pendent derrière l'avant"train. On fait trainer celte lierse par un clievil, dans un temps sec; il en ré" sulte que les cònes qui sont bien ouverts répandent, en roulant, la semence " qu'ils contiennent encore et opèrent un ensemencement uniforme dont on "abandonne ensuite le succès aux hasards de la température."

Burgsdorf cite des sables de la Marche de Brandebourg, qui éprouvent presque toujours en été des chaleurs considérables, d’où il résulte que les semis que l'on y lait le printemps échonent ordinairement; les semis de cònes y réussissent mieux. On les sème lorsque les chaleurs arrivent et on les remue quand ils sont ouverts, ainsi qu'il a été dit; la germination a lieu lorsque le temps est rederenu propice à la végétation, et le jeune plant a encore assez de temps pour se fortifier et bien passer l'hiver. Je doute que ce genre de semis eût autant de sucè̀s en France qu'en Prusse, ou la neige couvre la terre pendant plusieurs mois de l'hiver, à cause des alternatives de gelées et de dégels de nos hivers. Au lieu de semer les cònes en été, on peut les semer sur la neige, peu avant qu'elle ne fonde, ce qui fait qu'on distingue mieux l'égalité de la distribution; on les retourne avec des râteaux de fer quand ils se sont ouverts. Houss, dans sa Monographie der Schwar: fahre (Monographie du pin noir), dit que dans le voisinage des massifs, sur des emplacemens nus, meubles, plats ou d'une pente peu rapide, ce genre de semis est le plus économique; et ce qu'il dit du pin noir d'Autriche s'appliøueévidemment, dans ce cas, au pin sylvestre.

L'éclaircissage sera exéculé, quel que soil le mode de semis que l'on aura employé, ainsi que je l'ai dit pare 179 , en parlant de l'éclaircissage d'un semis sur labour.

Je trouve dans Baudrillart, 1. II, p. 875 de l'ouvrage déjì cité, des renseignemens, que je vais reproduire, sur la manière de cultiver les pins sylvestres sur les bruyères de la Hollande; il les tenait de M. Steffens, qui avait été inspecteur des forèts dans ce pays. "Le sol, dit-il, qui y est généralement sablomneux, "peut être divisé en trois classes : bon dans quelques parties; médiocre dins " l'autres, et presque stérile dans tout le reste des bruyères. Le pin saurage est "l'essence que réclament également la nature du terrain et les besoins du pays. "Le gouvernement en a fait des semis, il y a quelques siècles, sur des bruyères, "près de Bréda. La forèt de Masbach, qui est le produit de ces semis, fournit des "pins que les constructeurs de lit marine hollanditise estiment antant, pour leur 
"qualité et pour leur beituté, que le pin de Rigit. Cet exemple, imité par quel" ques riches propriétaires et par des corporations religieuses, a eu le mème " succès. Les termes de la croissance des pins, dans les trois classes te terrains "dont nous avons parlé, sont cenx ci-après : dans la première classe, 100 ans; "dans la seconde, de 40 à 50 , et dans la troisième, de 20 à 25 . Mais, dans l'in" tervalle du semis à la plantation, on tire des produits par l'enlèvement des " Jrins surabondans. Les exploitations des forêts de pins ne se font point en Hul"lande comme dans les autres pays, où on laisse des réserves en quantité suffi" sante pour opérer le réensemencement naturel; on y suit un autre procédé qui " consiste à couper à blanc-étoc et à réensemencer à la main après la coupe; le " second semis prospère déjà mieux que le premier, et la végétation est plus forte, " par la raison que le sol s'est amélioré par la décomposition des feuilles tombées " des arbres du premier semis. C'est ainsi qu'au bout de trois ou quatre révolu" tions, on élève de belles futaies de bois résineux dans un terrain qui était pré" cédemment stérile. n Ce que dit M. Steffens de l'amélioration qu'éprouve le sol sur lequel on cultive plusieurs générations de pins sylvestres, est en opposition, ainsi qu'on le verra, avec ce que l'on a remarqué dans le Maine pour les futaies de pins maritimes; il esı vrai qu'on y eulève les feuilles.

Dans le Maine et dans l'Orléanais, où l'on ne fait des pinières que sur des sables, on emploie habituellement le semis, après avoir préparé la terre par un labour et des hersages. Quelle que soit d'ailleurs la methode que l'on emploiera pour créer une futaie de pins sylvestres, on éclaircirit celte futaie, pendant les premières années, en se conformant à ce qui a été dit page 179.

ll y a des localités où le pin sylvestre ne pourrait être cultivé en futaie, paree que le climat, des circonstances atmosphériques, ou un sous-sol impénétrable aux racines y mettent obstacle; mais dans lesquelles on peut lecultiver avec succès et très-a vantageusement en taillis, pour en obtenir du bois de chauffage ou de la litière. La culture de cet arbre en taillis, pour en obtenir du bois de chauffage, est pratiquée sur plusieurs milliers d'hectares, dans un rayon de 8 kilomètres, autour du Puy, en Auvergne; les terrains que l'on y consacre à cette culture sont médiocres ou de mauvaise qualité, souvent peu profonds, avec une roche pour sous-sol, et l'on en tire ainsi un revenu plus élevé que de toute autre manière; il y en a mẻme qui sont de si mauvaise qualité qu'ils ne produisaient rien, il vant qu'on en eût tiré parti ainsi. J'emprunte à M. Bertrand de Doue (1) ce que je vais dire de cette culture.

Le moyen le plus économique de créer une pinière est, ainsi que je l'ai dit, celui du semis; mais, dans les environs du Puy, la plantation a mieux réussi; ce qui résulte probablement de ce que les terrains consacrés à cette culture étant

(1) Mémoire sur l'aménagement et le mode d'exploilation des bois de pin dans les entirons du l'uy. Decandolle avait déjà parlẻ de cette culture, mais sommairement, dans son Rapport sur un voyage botanique et agronomique dans les departemens du centre, inséri dans le tome $\mathbf{A l}$ de's Hémoires de la Suciété d'agriculture du département de la Seine, annce 1812. 
ordinairement brùlans, le plant a besoin d'ombrage la prenière année; e'est par la même raison que l'on échoue si souvent en semant au printemps, dans les sables de la Marche de Brandebourg. On se contente, dans les environs du Puy, pour crécr par la plantation une pinière destincée à être exploitée en taillis, de prendre du plant le $0^{\mathrm{m}}, 08$ à $0^{\mathrm{m}}, 10$ de haut dans les anciennes pinières exploitées en taillis, où il s'en trouve ordinairement beaucoup, parce que plusieurs parties des terrains brùlans qui sont consacrés à ces pinières se trouvent à ni-ombre, et on le plante ainsi qu'il suit :

"L'ouvrier qui est chargé de celte plantation, dit M. Bertrand de Done, "page 14, ouvre, en trois ou quatre coups de pioche, une petite fosse plus pro"fonde que large. Il ramène vers ses pieds la terre qu'il a renuée et la dispose " en dos d'âne sur le bord mème du trou. Il prend ensuite un pin dans le petit " paquet ou dans le panier qu'il a déposé près de lui et le place le plus d'aplomb " qu'il est possible, de manière que les racines attcignent le fond du trou, et "que sa tige s'appuic contre le petit tas de terre qu'il a retiré. Alors, s'avan"cant d'un demi-pas, il clonne en avant du trou quelques autres coups de pio" che, ramène la terre contre le jeune pin, en ayant soin que la plus meuble soit " immédiatement placée sur les racines, et après l'avoir ainsi couveri, il con"solide le tout en pressant avec le pied et plaçant dessus une pierre ou deux, " s'il y en a à sa portée. Lorsque la terre n'est pas trop endurcie, un ouvrier peut „planter jusqu'ì 3 et 400 pins par jour. 11 en forme des lignes ou rangées qu'il " lirige en allant de bas en haut, dans les terrains en pente. S'ils sont plu"sieurs ouvriers, chacun fail sa rangée et dispose ses pins en échiquier, par "rapport à ceux de son voisin. On laisse ordinairement un intervalle de 5,6 ou " 7 pieds $\left(1^{\mathrm{m}}, 62,1^{\mathrm{m}}, 95\right.$ ou $\left.2^{\mathrm{m}}, 27\right)$ entre les rangées et autant d'un pin à l'autre. "Cette distance pourrait, sans inconvénient, être portée jusqu’à 8 ou 9 pieds " $\left(2^{\mathrm{m}}, 60\right.$ ou $\left.2^{\mathrm{m}}, 92\right)$ dans les terrains un peu profonds où l’on prévoit que les pins "acquerront une certaine grosseur."

Ces plantations s'executent depuis le mois de novembre jusqu'au mois d'arril, quand le temps le permet; ainsi, malgré ce que prescrivent tant d'auteurs, de simples paysans, qui ont adopté ce mode de culture, plantent le pin sylvestre l'automne aussi bien que le printemps. L'usage de placer une pierge au pied du jeune pin me parait fort bon, surtout pour de tels terrains; car la terre se maintient fraiche sous les pierres, ce dont on pourra s'assurer en regardant sous de grosses pierres, pendant les sécheresses. Il en coùte 6 à 7 fr. pour faire planter un millier de plants par un ouvrier qui se clıarge de fournir le plant.

Ce qui est relatif à l'exploitation et à l'aménagement des pinières, dans les environs du Puy, levrait être classé dans l'article qui va suivre; mais je crois qu'il sera plus commode, pour mes lecteurs, que je complète ici ce que j’ai ì dire sur la culture exceptionnelle des pinières en taillis, pour en obtenir du bois de chauflage et de la litière.

Si l'on abandonnait ì la nature les pinières que l'on a créées, ainsi que je viens te le dire, sur de mauvais terrains, dont le sous-sol, placé près de la superticie, 
est souvent une roche impénétrable aux racines du pin, ees arbres cesseraient de s'élever lorsqu'ils auraient atteint une hauteur de $2^{\text {rn }}, 60$ ì $3^{\text {m }}, 25$. "Com" bien de fois, dit M. Bertrand de Doue, ai-je épargné les pieds les plus re" marquables par leur belle venue, pour les voir, peu de temps après, diminuer " de vigueur et perdre entièrement leur jet avant qu'ils eussent atteint 15 pieds " $\left(4^{\mathrm{m}}, 8 \mathrm{i}\right)$ de hauteur? " Non loin de.ces chétives pinières, on remarque de magnifiques futaies de pins sylvestres, mais sur des terrains plus substantiels et plus profonds. Il faudrait couper les pins cultivés sur ces mauvaises terres, lorsqu'ils cesseraient de croître, si.l'on suivait les méthodes généralement adoptées, et l'on ne se procurerait ainsi qu'un bien mince revenu : la méthode que l'on suit est fort différente et procure un revenu plus élevé.

Lorsque la pinière a 10 à 12 ans de plantation, les pins ont $1^{\text {m }}, 95$ à $2^{\mathrm{m}}$, 60 de haut et sont dans leur plus grande vigueur; on rabat alors leur tige à une hauteur de $0^{\text {m }}, 50$ à $0^{\text {m }}, 65$ du sol, c'est-à-dire au dessus des deux premières couronnes de branches; on appelle cette opération le dépointage. A u bout de 4 à ă ans, on commence la première coupe et l'on répète ces coupes tous les 4 ou õ ans. On supprime, à chaque coupe, les branches les plus fortes, celles surtout qui ont pris une direction rerticale; on ménatge au contraire les branches qui sont faibles ct basses, particulièrement lorsqu'elles ont de la tendance à prendre la direction verticale. On ne coupe les branches du bas de l'arbre que successivement et à mesure qu'elles acquièrent une cerlaine grosseur. On augmente le nombre des branches bifurquées à mesure que les souches prennent de l'accroissement, alin d'élargir la tête de l'arbre. On mainticnt ainsi, et c'est le but qu'un doit se proposer l'atteinclre, l'équilibre nécessairc entre les branches féuillues ou nourrices et les parties limneuses qu'elles ont à alimenter.

L'exploitation de la pinière étant conduite, ainsi que je viens de l'indiquer, les pins n'emploieront pas moins de 50 à 60 ans pour atteindre leur maxinum de hauteur, qui ne dépasse gruère $1^{\mathrm{m}}, 95$ ou $2^{\text {nn }}, 27$. Ils domnent de bons produits jusqu’à 70,80 et même 100 ans. On déracine les souches lorsque, par suite de l'âge ou de quelques fautes graves dans la taille, elles cessent de donner de bons produits, el l'on choisit pour les remplacer les plants les meilleurs et le mienx placés, parmi le recrû qui les entoure; on olıtient par hectare et par chaque coupe quinquennale, dans les meillemres de ces pinières, où les terres ont un peu de fond, 13 à 1,500 fagots, liés avec deux liens de seigle; sur les plus mauvaises, 350 à 400, sur cellesqui sont entre deux, 750 à 850 ; ces fagots se vendent 12 à 16 fr. le cent, pris sur place. Telle est la méthode d'exploitation el d'aménagrement que l’instinct ou le hasard a suggérée aux cultivateurs des environs du I'uy, pour tirer parti, par la culture du pin sylvestre, de ces terrains qui avaient été jusqu'alors, pour ainsi dire, improductifs.

d'ai parlé, page 15\%, des différences que présente la végétation du pin sylvestre dans les diverses parties de l'arrondissement de Tournon, département de l'Arleche. On y cultive le pin sylrestre en taillis, sur les plus mauva terrains, dans la partie de cel arrondissement qui se trouve entre les montagnes el la vallée du 
Rhône; l'on se procure ainsi, en mème temps, des firgots t' de menu hranchage pour servir de litière; ce dernier produit y est si important, que les terres consacrées à cette culture donnent un revenu plus élevé que celles qui portent toute autre espèce de hois et un revenu aussi élevé qu'une terre à froment. Je n'ai point obtenu autant de renseignemens sur cette culture que j'en ai donné sur celle des pinières des environs du l’uy, a vec laquelle elle a tant de ressemblance; mais je sais que, dans l'arrondissement de Tournon, on rabat aussi la tige des pins, qu'on en coupe aussi les branches tous les quatre on cinq ans, et la taille doit être la même, sans quoi ces pinières périraient bientòt. Je ne sache pas que ce mode d'exploitation se pratique ailleurs que dans ces deux endroits, et pourtant il pourrait certainement être adopté a vee avantage dans beaucoup d'autres lieux, tels, par exemple, je crois, que la Champagne Pouilicuse, où l'on a, depuis plus d'un siècle, commencé la culture du pin sylvestre, sur des terrains excessivement mauvais.

Tous les terrains de peu de profondeur ne sont d'ailleurs pas propres ì la culture du pin sylvestre en taillis, quelle que soit la nature du sons-sol. Je vis, chez M. Descolombiers, en $\mathbf{1 8 1 2}$, dans sa terre de Pontlung(Allier), près de son chatteau, des pins sylvestres âgés de 18 ans; ils avaient été plantés sur un sable substantiel el avaient en une très-belle végétation pendant les premières années, mais Jours têtes, entièrement mortes alors, avaient commencé ì se dessécher dès leur dixième année. Cet accident tenait sans doute à ce que l'on trouvait à $0^{\mathrm{m}}, 20 \mathrm{du}$ sol un sons-sol impénétrable aux racines, qui était une sorte de tuf composé de sable mêlé d'oxide de fer; je présume que les racines pourrissaient Jorsqu'elles étaient parvenues à ce tuf, sans quoi la tête des pins n'aurait pas péri : il serait seulement arrivé, comme dans les terrains dont je viens de parler, où l'on exploite le pin sylvestre en taillis, que la croissance en hauteur se serait arrêtée et que les pins seraient devenus rabougris. 11 me paraitrait d'ailleurs intéressant d'essayer la culture en taillis sur ce terrain; elle pourrait peul-être y réussir, du moins pendant un certain nombre d'anncées, car en rabaltant le tronc on empêche les racines et surtout le pivot de s'enfoncer aussi profondément. Des pins laricio, des pins Weymouth el des sapins picéas, qui se trouvaient mêlés avec les pins sylvestres, avaient éprouvé le même accirlent; les pins laricio avaient été atteints les premiers, ce qui devait être puisqu'ils ont un pivot encore plus prononcé que le pin sylvestre.

Vill. Amfingement, explottation et repronection. - Les généralités qui se trouvent an commencement de l'article VIII du chapitre 11 sur les chemins d'exploitation dans les futaies de sapins argentés, sur les allées devant les habitations, sur l'assainissement dn terrain, sur le nettoiement des sapinières, sur l'estimation et sur le mesurage des sapins sur pied, sur le temps le plus fivorable pour l'abattage des sapins, et sur le mode de rente dans les sapinières; ces généralités s’appliquent en très-grande partic aux futaies des arbres dont jo m’occuper spécialement daus er Traité. La deseription fur je fais, dans ee même 
article, des cinq modes d'exploitation que l'on peut employer pour les futaies de sapins argentés, et des soins relatifs à l'aménagement et à la reproduetion qui doivent les accompagner, s'applique au pin sylvestre, sauf d'importantes modifications que je vais indiquer : je supposerai qu'on a lu eet article.

Le pin sylvestre peut rester plusieurs mois dans son écorce, après qu'il a été abattu, sans en éprouver de dommage, et il est utile qu'il y reste quelques semaines; j'en ai laissé pendant quatre mois, du 10 décembre au 10 avril, qui ne s'était point échauffé et qui commençait seulement alors à être légèrement piqué des vers, ce qui n’a aucun inconvénient; néanmoins on doit l'équarrir plus tôt, dans la crainte des bostriches qui s'établissent de préférence entre l'écorce et le bois des pins abattus depuis quelque temps.

On peut exploiter les futaies de pins sylvestres en jardinant comme celles de sapins, et c'est encore le mode qui est le plus usité en Allemagne et en Écosse lans les forêts naturelles. Ce mode d'exploitation ne présente pas autant d'avantage pour le pin sylvestre que pour les sapins, parce que ce pin ne supporte pas de croître aussi serré. Une futaie de pins sylvestres que l'on exploite en jardinant ne peut donc contenir autant d'arbres qu'une futaie de sapins et ne peut donner le même revenu. Si l'on fait des élagages, qui sont d'ailleurs moins nuisibles aux pins sylvestres qu'aux sapins, ils doivent être exécutés rez du tronc (Voy. p. 74).

L'exploitation par la méthode mixte ne me paraît pas convenir pour les futaies de pin sylvestre, parce que cet arbre ne pouvant croitte aussi serré que les sapins, le repeuplement ne serait pas successif, comme dans l'exploitation en jardinant; il ne se ferait qu'après l'abattage de tous les arbres ayant plus de $0^{\mathrm{m}}, 54$ de eirconférence à $1^{\mathrm{m}}, 30$ au dessus du sol; il y aurait perte de temps dans le repeuplement et par suite dans le revenu.

L'exploitation par coupes rases peut être employée avec d'autant plus de succès et d'éeonomie, pour les futaies de pin sylvestre, que les semis de cet arbre réussissent très-facilement. Ainsi, on peut déraciner tous les arbres, mettre la terre en eulture par des labours, lui demander même quelques récoltes de céréales et y semer ensuite de la graine de pin sylvestre; on peut se contenter d'abattre les arbres à la hache et semer dans des potets; on peut enfin employer la plantation : j'ai indiqué, dans l'article précédent, ce qu'il y a à faire dans ces trois eas. Dans le Maine et dans l'Orléanais, on fait des coupes rases des futaies de pins sylvestres et de pins maritimes et l'on repeuple par le semis sur labour.

Le mode d'exploitation par coupes rases par bandes étroites, peut être employé avec succès pour les futaies de pin sylvestre. Lorsqu'une futaie a atteint l'âge d'être exploitée, on attend qu'une année d'abondance de cônes se présente et elle est annoncée par l'apparition des jeunes cônes 21 mois avant que ces cônes ne laissent échapper leurs gıaines. On exécute alors la coupe d'ensemencement, et si le plant de semis naturel ne garnit pas suffisamment le terrain, on y supplée par le semis dans des potets ou par la plantation. Au bout de trois ans on abat les bandes qui avaient été réservées; si l’on attendait plus longtemps, on cause- 
rait un grand dommage au recru qui devient cassant quand il a plus de 3 ans.

II me reste à parler le l'exploitation par éclaircios. Les forestiers allemands, qui ont été les premiers à employer ce mode d'exploitation, tombent d'accorl que dans les lutaies de pius sylvestres on ne doit faire pue deux coupes: la coupe d'ensemencement et la coupe léfinitive; mais ils diffèrent d'opinion relativement au nombre d'arbres que l'on doit abattre dans la première de ces coupes. J'emprunterai ce que je vais dire à Cotta, qui me paraît avoir bien résumé, page 75 de son Traité de culture forestière, ce qui concerne l'application de ce mode d'exploitation au pin sylvestre.

On a plus de chances de réussir en appliquant l'exploitation par éclaircies aux futaies de pins sylvestres qu'en l'appliquant aux futaies de sapins, parce que les annés d'abondance du pin sylvestre sont plus fréquentes que celles des sapins, qu'elles s'annoncent clairement 21 mois d'avance, que les graines de ce pin lèvent plus facilement et que cet arbre résiste mienx aux vents que les salpins; les vents lui cassent plus souvent des branches, mais ils ne le renversent pour ainsi dire jamais.

La coupe l'ensemencement sera exécutée pendant le temps qui s'écoulera depuis le moment où l'on aura pu distinguer les cônes qui annoncent une année d'abondance, jusqu'au moment où tomberont les graines qu'ils contiennent; et comme le semis et le plant de pin sylvestre n'ont pas besoin d'ombrage, et qu'un trop) fort ombrage leur serait très-nuisible, on réservera seulement 30 à 60 pins par hectare selon les circonstances. Avant de commencer l'exploitation on préparera la coupe, s'il est nécessaire, ainsi qu’il a été dit page 90. Il sera toujours avantageux de déraciner les pins, parce que les emplacemens où ils se trouvaient sont alors parfaitement préparés pour qu’il y lève du semis naturel; et cela présentera aussi de l'avantage sous le rapport pécuniaire, a moins que le bois ne soit à très-bas prix. On abattra les arbres qu'on ạvait riservés et on les enlèvera pendant les trois années qui suivront la coupe d'ensemencement, parce que si l'on attendait plus longtemps, on causerait en enlevant ces arbres un grand dommage au jeune recru, car il devient cassant quant il a dépassé 3 ans, lcin d'être flexible comme le plant de sapins. Colta s'exprime d'ailleurs ainsi qu'il suit, dans le passage auquel j'ai emprunté ce qui précède : "La certitude d'avoir de bonne semence et l'économic dans les " frais, sont à mes yeux les seuls motifs en faveur des coupes d'ensemencement; " et j'avoue que je préférerais en g'énéral pour cette essence les coupes à blanc" étoc, si chaque annéc j'étais sûr de pouvoir me procurer de bonme semence. "

Relativement à ce que j'ai dit, d'après Hartig, pages $\mathbf{9 2}$ et 95, qu’il était avantageux d'exploiter les futaies de sapins argentés pendant que la neige couvre la terre, ce qui serait applicable à celles de pins sylvestres, mais que cela arrive rarement et pour peu de temps seulement sous le climat de Paris, je dois ajouter re qui suit, qui a été oublié. Dans le Nord une neige abondante couvre la terre pendant plusicurs mois, elle a toujours une cerıaine épaisseur, et elle est toujours dureir par un froid rignureux; sous le climat dr Paris, il tombe rarement 
de la neige; elle ne couvre ordinairement la terre que d'une couche pẹ épaisse et que pendant peu de temps; elle n'est jamais durcie par le froid, qui n'y est point assez rigoureux pour cela. Il en résulte que lorsqu'il arrive par extraordinaire que la neige y couvre la terre, l'exploitation devient fort difficile, el quelquefois pour ainsi dire impraticable, ainsi que je l’ai éprouvé moi-même.

Ce que j'ai dit de l'incertitude du repeuplement par le semis naturel dans les futaies de sapins argentés, pages 97 et 101, en employant l'exploitation par coupes rases par bandes étroites et l'exploitation par éclaircies, s'applique aux futaies de pins sylvestres particulièrement en ce qui concerne l'exploitation par éclaircies; j'y renvoie done mes lecteurs. Il laut ajouter que le plant de semis naturel de trois ans, ordinairement très-chétif, peut lacilement être étonffé par les plantes ou les arbrisseaux qui poussent souvent si abondamment après que l'on a abatuu une futaie.

J'ai indiqué dans l'article précédent eomment devait être dirigé l'éclaircissage d'une futaie de pins sylvestres pendant les premières années; on le conduira ensuite ainsi que je l'ai dit, pages 73 et 74 , pour les futaies de sapins ar'gentés, selon le mode d'exploitation que l'on se jropose d'employer, mais avec cette différence que les pins sylvestres doivent être un peu plus espacés que les sapins.

Loudon dit dans l'article précédemment cité, t. IV, p. 2181, que " dans les " forêts naturelles de pins d'Ecosse, la nature sème les graịnes, nourrit les ar" bres, les éclaireit et les élague; et que la main de l'homme n'est employée " qu'à les couper lorsqu'ils sont devenus propres à être employés comme hois " d'œuvre; " qu'il arrive pourtant quelquefois qu'on les éclaireit dans les lieux où le bois de chauffage a de la valeur; mais que dans les forêts créées par la main de l'homme, les arbres étant de même âge il faut éclaircir, et que l'on y fait des éclaircissages successifs quand il est nécessaire. Quelques personnes, lit cet auteur, pratiquent aussi l'élagage, mais avec une grande réserve, et au nombre des partisans de l'élagage il cite le duc de Bedford, qui le faisait exécuter dans des futaies de pins sylvestres el s'en trouvait bien.

Relativement à l'exploitation des taillis de pin sylvestre, je renvoie à ce que j’en ai dit à la fin de l'article précédent, page 187, ayant cru devoir y réunir ce qui était relatif à la culture exceptionnelle du pin sylvestre en taillis et à l'exploitation de ces taillis.

Quant au revenu qu'on peut tirer des futaies de pins sylvestres, il eșt très-liffírent selon les diverses manières de les exploiter, et par suite de la très-grande différence qui exisı dans la végétation de ces arbres, selon les sols, les latitudes ou les altitudes, et les eirconstances atmosphériques. Mais si l'on compare le revenu qu'on peut tirer de deux futaies de même étendue, l'une de sapins argentés, l'autre de pins sylvestres, se trouvant toutes les deux dans des situations très-favorables, on verra que la première produit un revenu plus élevé que la seconde. C'est une conséquence de ce que le sapin argenté peut croitre plus serré que le pin sylvestre, tout en atteignant de plus belles dimensions et en moins dr temps. 
I'IN SIITESTRL.

Je trouve, dans l'Agriculteur praticien de mai 1843, un article relatif aux dimensions de 60 pins sylvestres qui occupaient, en 1839, 15 ares de la forêt de Weinberg; cet article provenait dı Journal de la Société d'agriculture de Vienne, auquel il avait été fourni par M. C. de Pausinger : je le reproduis ci-dessous.

"Le sol de cette vente est un loam sableux, profond, modérément humide, " un peu calcaire, renfermant peu de pierres, et qui est pourvu d'une couche " d'humus d'épaisseur moyenne, recouverte partie de mousse, partie d'aiguilles "de pins. La roche sous-jacente est un grès marneux. Il est placé sur le pen" chant d'une montagne qui l'abrite du côté de l'ouest, el à une hauteur absolue " d'environ 500 mètres. Les pins sylvestres abaltus provenaient d'ensemence" ment naturel, et ont tous pu jouir, dès leur jeunesse, de beaucoup d'air et de " lumière. Leur distance entre eux était en moyenne de 5 mètres, de façon que " elıaque tige occupait un espace de 25 mètres carrés de surface."

DIVENSIONS DES PINS.

\begin{tabular}{|c|c|c|c|c|c|c|c|}
\hline 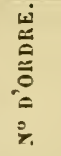 & $\begin{array}{c}\text { Nombre de } \\
\text { couches li- } \\
\text { gneuses an- } \\
\text { nuelles à } \\
0^{\mathrm{m}, 60} \text { du sol. }\end{array}$ & $\begin{array}{c}\text { Diamètre } \\
\text { moyen } \\
\text { de la partie } \\
\text { inférieure de } \\
\text { la tige. }\end{array}$ & $\begin{array}{l}\text { Hauteur de la } \\
\text { lige, y com- } \\
\text { pris la flèche. }\end{array}$ & 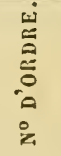 & $\begin{array}{c}\text { Nomise de } \\
\text { couclies li- } \\
\text { gneuses an- } \\
\text { nuelles à } \\
0 \text { m, } 60 \text { du sol. }\end{array}$ & $\begin{array}{c}\text { Diamètre } \\
\text { moyen } \\
\text { de la parlie } \\
\text { inférieure de } \\
\text { la lige. }\end{array}$ & $\begin{array}{l}\text { Hauteur de la } \\
\text { lige, y com. } \\
\text { pris la fleccle. }\end{array}$ \\
\hline 1 & 63 & ${ }_{0,4915}^{m}$ & $\begin{array}{l}\mathrm{m} . \\
22,750\end{array}$ & 51 & 54 & $\mathrm{~m}_{0,5188}$ & $\mathrm{~m}_{18,960}$ \\
\hline 2. & 70 & 0,5754 & 21,802 & 32 & 52 & 0.5754 & 20,291 \\
\hline 5 & 41 & $0, \overline{5} 82 \overline{3}$ & 21,486 & $5 \overline{3}$ & 55 & $0,49] 5$ & 18,950 \\
\hline 4 & 48 & 0,4642 & 20,221 & 54 & 53 & 0,5754 & 20,856 \\
\hline 5 & 68 & 0,5734 & 23,698 & $5 \%$ & 54 & 0,5754 & 18,960 \\
\hline 6 & 66 & (),5461 & 20,856 & 56 & 54 & $0,575.4$ & 25,582 \\
\hline 7 & 50 & 0,5754 & 20,220 & .57 & 55 & 0,6280 & 21,802 \\
\hline 8 & $6 \overline{3}$ & 0,5188 & 21,802 & .58 & 51 & 0,5461 & 21,800 \\
\hline 9 & 50 & 0,5754 & 20.856 & 59 & 58 & 0,5 ม 61 & 22,118 \\
\hline 10 & 57 & $0,57 \overline{3} 4$ & 22,118 & 40 & 56 & 0,5461 & 22,750 \\
\hline 11 & $5 \overline{3}$ & 0,6007 & 21,486 & 41 & 50 & 0,4915 & 22,750 \\
\hline 12 & $5 \overline{5}$ & 0,5188 & 20,549 & 42 & 54 & 0,6007 & 21,486 \\
\hline 15 & 57 & 0,5188 & 21,802 & $4 \overline{3}$ & 70 & 0,6553 & 22,118 \\
\hline 14 & 57 & 0,5161 & 22.750 & 44 & 54 & 0,6000 & 22120 \\
\hline 15 & $6 \overline{3}$ & 0,6007 & $2 \pi, 698$ & 43 & 52 & 0,5754 & 21,170 \\
\hline 16 & 70 & 0,6280 & $2 \overline{5}, 698$ & 46 & $5 \overline{3}$ & 0,6280 & 22,119 \\
\hline 17 & 51 & 0,3461 & 21,486 & 47 & 54 & 0,6003 & 21,485 \\
\hline 18 & 62 & 0,6826 & 22,750 & 48 & 46 & 0,4910 & 20.224 \\
\hline 19 & 56 & 0,6007 & 21,802 & 49 & 67 & 0,5461 & 22,750 \\
\hline 20 & 48 & 0,5754 & 20,224 & 50 & 61 & 0,6007 & 25,582 \\
\hline 21 & 56 & 0,5461 & 21,486 & 51 & 55 & 0,5754 & 22,118 \\
\hline 22 & วั8 & 0,5754 & $22,4 \overline{3} 4$ & 52 & 54 & $0,5 ั 460$ & 21,486 \\
\hline 23 & 60 & 0,4915 & $21,-187$ & 55 & 44 & $0, \overline{5} 550$ & 20,540 \\
\hline 28 & 62 & 0,6007 & 22,750 & 51 & $43 ั$ & 0,5550 & 19,908 \\
\hline 25 & 32 & 0.57 .54 & 21,583 & $5 \%$ & 52 & 0,5462 & 20,223 \\
\hline 26 & 52 & 0,5161 & 20,510 & 56 & 48 & 0,4642 & $18,9.40$ \\
\hline 27 & 60 & 0,5461 & 22,118 & 57 & 55 & 0,5188 & $20,2 \geq 0$ \\
\hline 28 & 61 & 0,5734 & 21,802 & 58 & 52 & 05464 & 20,860 \\
\hline 29 & 5.5 & 0,5754 & 20.836 & 59 & 62 & 0,5751 & 22,750 \\
\hline 50 & 60 & $0,5: 61$ & 22,120 & 60 & 54 & $0,5 \div 60$ & 21,486 \\
\hline
\end{tabular}

Ces 60 pins se trouvaient, d'après ce qui a été dit, dans une situation très- 
favorable; tous pouvaient domner de la planche; leur hauteur moyenne était de $21^{\mathrm{m}}, 53$, leur circonférence moyenne de $1^{\mathrm{m}}, 65$, à $0^{\mathrm{m}} 60 \mathrm{du}$. sol. Si donc l'on suppose qu'il y avait 15 mètres de la longueur de chaque arbre propre à la vente pour hois d'œuvre, on trouvera, en supposant que la circonférence moyenne à $7^{\mathrm{m}}, 50$ était de $1^{\mathrm{m}}, \mathbf{2 4}$, que chaque arbre contenait $1^{\mathrm{m}}, \mathbf{4 4}$ cube (1). En évaluant donc le mètre cube à $31 \mathrm{fr}$., prix approximatif en gros dans ma localité, chaque arbre aurait valu $14 \mathrm{fr} .68 \mathrm{c}$., la coupe $2,680 \mathrm{fr}$. $80 \mathrm{c}$., et l'hectare $17,875 \mathrm{fr}$. $44 \mathrm{c}$. Quant à l'âge, on n'a donné le nombre des couches ligneuses des pins que pour le faire connaître; mais, ainsi que je l'ai dit page 13, je conteste l'exactitude de ce moyen. Je dois d'ailleurs faire observer que si le bouquet de pins était isolé, ou si c'était le plus beau bouquet d'une grande futaie, la quantité de bois qu'il contenait ne peut ètre considérée que comme un cas exceptionnel.

IX. Qualites et usages du bois; pronuts divers. - Le pied cube de hois d'un pin sylvestre de 100 ans pèse vert, d'après Hartig (2), 67 livres 14 onces (32 kil. $763 \mathrm{gr}$.), et sec 41 livres ( $20 \mathrm{kil}$. $049 \mathrm{gr}$.). Le bois du pin sylvestre n'a pas d'aubier, il est d'un blanc terne, ordinairement veiné de rouge; on l'emploie aux mêmes usages que celui du sapin argenté (Voy. p. 104). On tombe d'accord qu'il est d'une excellente qualité; il est bien supérieur au bois du pin maritime, et il est généralcment plus estimé que le bois des sapins; néanmoins, dans les Vosges, on préfère la planche du sapin argenté à celle du pin sylvestre. Les bois de pin sylvestre pour mâture, que l’on tire du Nord, sont les plus estimés; cépendant l'on a vu, pages 163 et $\mathbf{1 8 5}$, que dans l'opinion de quelques personnes, ceux que l'on tire de l'Écosse et de la Hollande, pour cet usage, ne le cèdent point en qualité à ceux que l'on tire du Nord. En Allemagne, on emploie indifféremment le pin sylvestre et le chêne pour la charpente.

IIartig indique (3) comme étant également bons el comme étant les meilleurs bois à employer en pieux : le chêne, l'acacia, le mélèze, le pin sylvestre, le sapin argenté, le sapin picéa, le pin du lord Weymouth, le pin cembro, le pin bérissé, le thuya, le genevrier commun et le genevrier de Virginie; on peut y ajouter le châtaignier et le pin maritime, dont cet auteur n'a point parlé, parce que ces arbres n'existent puint en Prusse.

D’après Hartion, le bois du pin sylvestre, comparable pour le chauffage à celui du hêtre, est supérieur au bois des sapins et du mélèze, et son charhon leur est aussi préférable. D'après Kasthofer, 16 toises de pin sylvestre valent, pour le chanffage, 14 toises 1/5 de hêtre. Baudrillart, dans son Dictionnaire des eaux el forêts, à l'article Bois, t. 1, p. 415-447, rapporte des expériences de Duhamel, Buffon, Varennes de Fenille, Hartig, Werneck, etc., sur la pesanteur spécifique, la force de résistance, la corruptibilité et la combustibilité des bois. A l'article Charbon,

(1) Voir pages 55, 67 et 85 pour l'explication de ces calculs.

(2) Baudrillarl, d'après Ilartig, Dictionnaire des caux et foréts, 1. Jer, p. 419.

(3) Annales forestières d'eonit 18:3, p. 411, Expériences sur la durée des bois, traduit de l'aliemand de llallig. 
t. I, p. 555 , il domne des renseignemens étendus sur les qualités du charbon et sur les diverses manières de le fabriquer, d'après Dulıamel, Fleuriau de Bellevue, Rumfort, IIartig, Werneck, etc. Je me contente d'indiguer les sources où l’on pourra trouver ce qui a été publié sur ces matières, n'ayant pas cru dévoir m’en occuper spécialement.

On peut extraire de la résine du pin sylvestre par le même procédé que l'on emploie pour en extraire du sapin picéa (Voy. p. 24); mais on en oltient beancoup moins; ces deux résines se confondent dans le commerce, quoique la première soit d'une qualité supérieure à la seconde. Il en est de même du noir de fumcée.

On extrait du bois du pin sylvestre du goudron, dont on se sert dans la marine, et c'est celui qui est le plus estimé. Les racines, surtout celles qui sont restées plusieurs années cn terre après l'abattage de l'arbre, les nouds, et certaines partics du bois que l'usage apprend à distinguer, en contiennent le plus; cette substance paraît être un mélange de résine et de sève. Pour obtenir le gondron on soumet le bois, coupé en petites bûches, dans des fourneaux qui ont ordinairement une forme ovale on la forme d'un cône renversé, à une combustion lente qui le réduit en charbon; le goudron coule, pendant l'opération, par un tuyau qui s'adapte à un trou pratiqué au bas du fonrneau. Ce qui coule au commencement de l'opération est un goudron trop liquide et de mauvaise qualité que l'on met à part, et.qui sert, en Allemagne, à graisser les charrettes, surtunt celles dont l'essieu est en bois.

On peut tirer de la résine et du goudron différentes substances: ce sont le brai sec, le brai gras, la poix noire, le noir de fumée, l'huile de pin appelée aussi huile de résine, et de la lérébenthine qui est fort différente de celle que l'on tire du sapin et du mélèze. Je n'ai parlé que sommairement de l'extraction de la résine du sapin picéa et du pin sylvestre, et de l'extraction du goudron du bois de pin sylvestre; je ne pense point que le sujet que je traite exige que je fasse connaître les procédés en usage pour tirer, de la résine el du goudron, les sulsstances que je viens de nommer, je me contenterai done d'indiquer les anteurs dans lesquels on peut trouver ces renseignemens : Baudrillart, dans son Dictionnaire les eaux et forêts, à l'article Résine, 1.. II, p. 719, reproduit en grande partie ce qui a été dit, sur ces matières, par Duhamel, dans son Traité des arbres et arbustes; par IIartig, dans son Leherbuch für Forster (Instruction pour les foresticrs); par Burgsdorf, dans son Nonvean Mamel forestier, el par II. Badeigts-Laborde, dans un Hémoire sur les brais et goudrons de France. Duhamel a traité avec détail toutes ces matières, dans son Traité des arbres et cubustes, aux articles Abies, S.PIN, 1. I I r , p. 8, et Pinus, PıN, 1. Il, p. 141. Cotta parle, dans ses Principes fondamentaux de la science forestière, de l'extraction de la résine, page 153, de celle lu gondron et de la fabrication de la poix, page 451. La Maison rustique du $\mathrm{xix}^{\mathrm{e}}$ siècle donne, t. III , p. 393, dans un article intitulé Des prothuts résineux, la préparition des térébenthines, de l'huile de résine, les goudrons et du noir du fumée. te ne trouve point, dans les auteurs que je viens de citer, la description d'un 


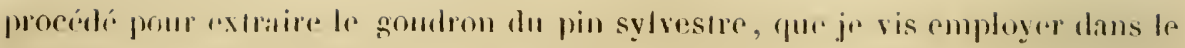
wisimage ale Pforrkirchen, petite ville de Bavière, daus lacuelle je fus en eantonnemont, en 1806, pendant une partie du temps qui s'écoula contre la campagno
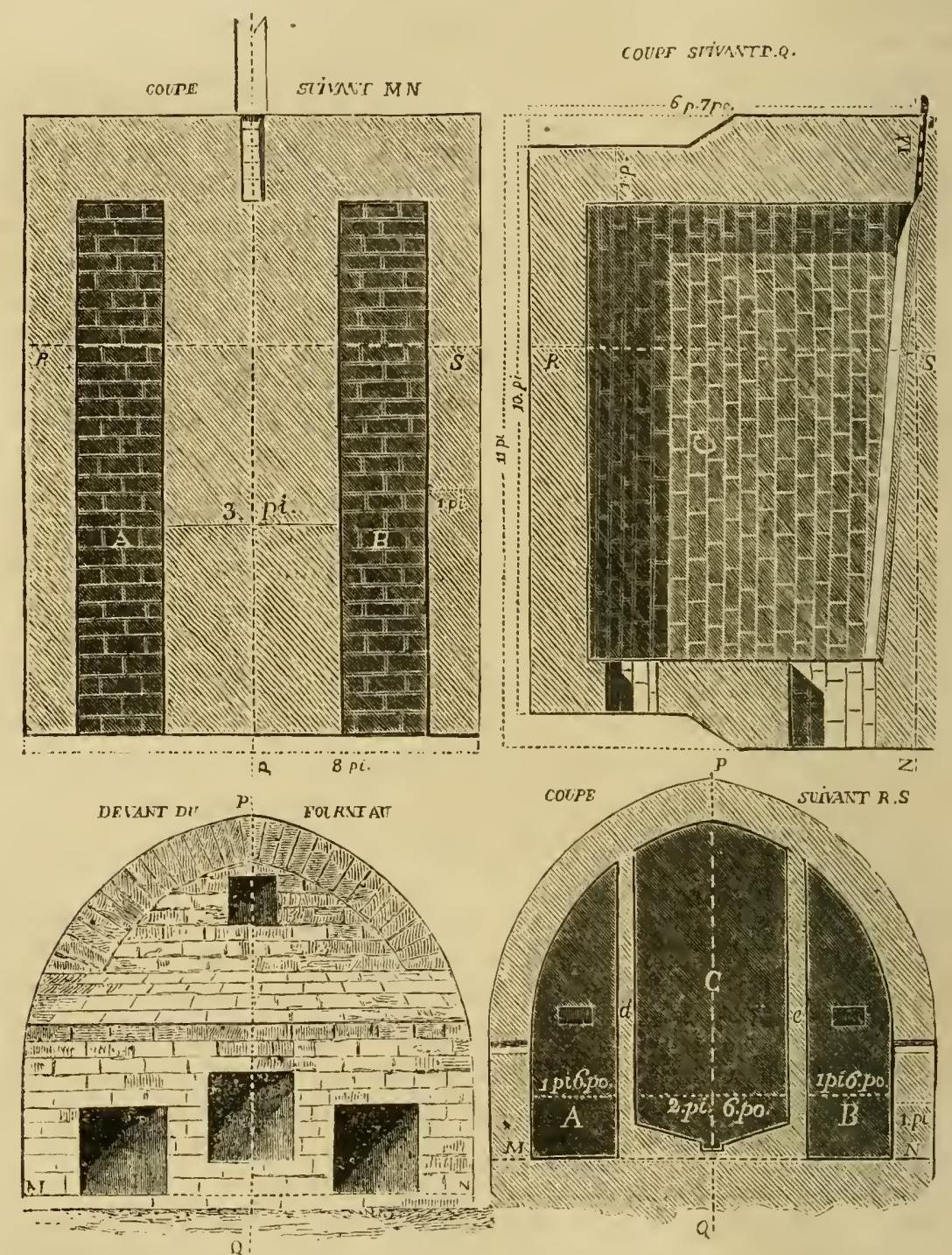

d'Austerlity ce celle d'léna. Je consacrai alors quelques-nus des nombreur loisirs dont jouissent les officiers qui sont en cantonnement, à faire les dessins d'un fourneau que l'on employait à cel usage el it décrire ce procédí; je ne me

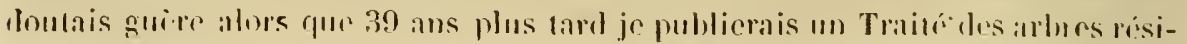


neus conteres. Je vais fomner eelle description el je reproduis les dessins du fourneau rédnits à l'échelle de 3 lignes pour pied; je conserverai les nestres anciennes que j'employai alors pour faire ces dessins.

L'élévalion et les trois coupes ci-jointes, avec les explications qui vont suivre, font commaitre la forme el les dimensions du fourneall assez exictement pour que l'on puisse en fitire construire un semblable. Ce fourneau est construit en briques jointes avec du morticr de terre argileuse; les bases des loyers I et b, aliusi fue celle du four G, sont formées par des briques mises it plat. Les cloisons qui séparent les foyers du four sont faites avec des briques, poscés de champ, qui ont 3 pouces d'épaisseur. La base du four a une pente de 8 pouces du devant an derrière et est formée par deux plans inclinés qui aboutissent à une rigole de; 2 pouces de large et 2 pouces et $1 / 2$ de profondeur, dins laquelle lo goudron coule et eśt conduit hors du four. A l'extrémité de ectle rigole on allapte un tuyau en bois, long de 10 pieds, dans lequel se trouve un petit tron par tessous el à 2 pouces du derrière du lour ; e'est parr ce petit tron que coule le groudron, et, de l'extrémité du tụyau, il en sort aussi, qui était à l'étalt gazeux èt qui s’est contlensé. Les quatre suppiraux que l'oi voit dans la coupe lis, pratiqués dans les murs des foyers, sont destinés à produire un courant d’air et à laisser échapper la fumée; ils ont 6 pouces sur 4 ; c'est par ceux qui se trouvent dans le mur de derrière que l'on allume le feu, on les bouche a demi lorsque le leu est bien allumé. La voùte el les murs de côté ont un pied d’épaisseur; on élève de la terre contre ces derniers murs pour empècher le dégagement du calorigue.

Après chaque cuisson on visite avec soin l'intéricur des deux foyers et du four, et l'on rebouche avec de la terre argileuse les trous et les gerçures qui se seraient formés dans les murs et dans les cloisons. Le foumeau dont je donne les dessins avait coùté environ $100 \mathrm{fr}$, tant pour l'achat des matériaux que pour la main-d'ocuvre; il durait environ six ans, en y faisant de légères réparations.

Le bois du pin sylvestre est le seul que l'on cmploie, en Bavière, pour en extraire du goudron; celui du picéa ne produirait qu'un goudron très-épais qui ne serait propre qu’i faire de la poix. Les vieilles racines qui se sont en parlie pourries en terre produisent lit plus grande quantité de goutron et le meilleur; le bois près de l'écorce, les noeuds et les branches sont ensuite reconnus plus abondans en résine que les autres parties de l'arbre. Les ouvriers arrachent les racines et préparent le bois au fur et ì mesure qu'ils en ont besoin; on coupe le bois en morceaux de 18 pouces de long sur 2 pouces d'équarrissage, les racines se coupent en plus petits morceaux, et l'on a soin d'òter toutes les parties pourries; on choisit, en fendant le bois, toutes les parties résineuses que l'expérience apprend bientôt à distinguer.

Avant de charger le four, on en balaie le fond et l'on y jette de l'eau pour en fitire sortir le charbon qui pourrait s'y trouver; on place ensuite sur la rigole, et daus le sens de sa longucur, des lattes élevées et soutentes par des traverses, aliu que le goudron puisse y arriver ficilement de chaque còté. Le bois se place debout, sur atutant de rangs que le permet la hauteur du lour, et serré de ma- 
nière qu'il en entre le plus possible; les morceaux noueux el ceux qui sont difficiles à fendre se mettent au haut, dans la partie voûtée, où la chaleur est la plus forte; on remplit les trous et l'on achève de charger avec les petits morceaux et les racines. Le four, étant bien rempli, contient 950 à 1,000 livres de bois; on en rebouche les portes a vec des briques et de la terre glaise; on place le tuyau et les tonueaux ou vases destinés à recevoir le goudron.

Tout ayant été préparé ainsi que je viens de le dire, on met dans les foyers des copeaux bien secs et le bois qui ne se serait pas complètement carbonisé dans l'opération précédente; on allume le leu par les soupiraux; quand il est bien pris, on l'alimente avec des bùches, de manière à ce que le four soit également chauffé dans toute sa longueur, et l'on bouche en partie les soupiraux. On pousse le feu vivement pendant les donze premières heures, c'est-àdire jusqu'à ce que le goudron commence à couler; on diminue ensuite successivement le feu, jusqu'à ce qu'il cesse de couler, et alors on ferme hermétiquement, avec de la terre argileuse, l'extrémité de la rigole pour empêcher le charJon de s'enflammer; on n'ouvre le four que 48 heures plus tard et pas plus tôt, dans la crainte que le charbon ne s'enflamme.

On allume ordinairement le fen vers six heures du soir; le goudron commence à couler le lendemain vers six heures du matin; depuis dix heures jusqu'à deux heures, il coule abondamment; l'écoulement diminue ensuite successivement, jusqu'à six heures du soir, qu'ị cesse ordinairement. On brûle environ 600 livres de bois dans les deux foyers pour cette opération. Le goudron runi coule au commencement de l'opération est d'une qualité inférieure à celui qui coule vers le milieu : on est dans l'usage de les mêler; celui qui coule vers la fin est de mauvaise qualité, il est plus épais et plus noir; on le met à part pour en faire de la poix noire lorsqu'on en a 200 livres. Pour faire la poix, il suffit de chauffer ce goudron à petit feu pendant trois heures, en le remuant continuellement.

Les dépenses et les recettes d'une opération étaient alors évalucees ainsi qu'il suit :

Le bois que l'on met dans le four.

DEPENSE. RECETTE.

Le bois que l'on brûle pour chauffer le four. . . . . . . .

Six journées pour arracher les racines, couper et fendre le bois, charger le four et conduire l'opération, à $2 \mathrm{fr}$. l'une.

Reconstruction d'un four tous les six ans; par chaque

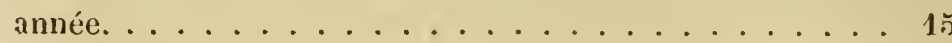

Le charbon qu'on tire du four vaut environ. . . . . . "

Deux quintaux environ de bon goudron. . . . . . . . . . . . .

20 livres de poix. . . . . . . . . . . . "

Totaux. ............ . $37 \mathrm{fr}$

$8 \mathrm{fr} . \quad n \mathrm{fr}$.

$2 n$

$12 \quad$ o

15

11

40

5

$56 \mathrm{fr}$.

Ainsi, l'on gaguait par chaque opération 19 tr. 
IX. Acchens, mathes, animux nuishles. - Ce que j'ai dit, dims le chapitre 11 , article $X$, des atceidens et des maladies anquel la sapin argenté est sujet, s'applique au pin sylvestre, sauf quelques modifications fuu; je vais indiquer.

l.es gelées tardives ne mont paru causer aueun dommage au piu sylvestre, du moins sous le climat de Paris.

Les auteurs qui se sont occupés du pin sylvestre tombent d'accord qu’il est plus solidement enraciné que les_sapins, surtout que le picéa, el par conséquent moins exposé à être renversé par les vents; néanmoins, les grands vents lui sont plus unisibles qu’à ces arbres, parce qu'ils lui brisent quelquefois des branches et mème le trone, surtout quand il est isolé; la neige et le givre lui causcnt aussi plus de dommages par la même raison.

Le dommage que peuvent causer les quadrupèdes et les oiseaux dans les pinières de pins sylvestres est absolument semblable à celui qu'ils peuvent causer dans les sapinières. Les lapins le broûtent moins que le sapin picéa, mais plus que le sapin argenté; les moutons le broùtent très-volontiers et s'en trouvent bien, dit-on.

Je renvoie à ce que j'ai dit, chapitre $\mathbf{I}$, article $\mathbf{X}$, des moyens de diminuer ou de prévenir les ravages des insectes, et je vais indiquer ceux qui sont particulièrement uuisibles au pin sylvestre.

La larve du hanneton peut causer absolument les mêmes dégâts dans les jeuncs plantations de pins sylvestres que dans celles de sapins. Des insectes de la fitnuille des bostriches peuvent nuire au pin sylvestre de la même manière qu'aux sapins, c'est-à-dire en formant des galeries entre l'écorce de l'arbre et le bois, les faire périr ainsi et même détruire des forêts entières lorsque leur multipliętion est prodigieuse. J'ai indiqué, page 145, les moyens, sinon de les détruire, du moins d'en diminuer le nombre. D'autres bostriches se nourrissent de la moelle des pousses des jeunes arbres. D'autres enfin mangent les pousses des jeunes arbres, ainsi que je l'ai vu de mes yeux, et pourtant les auteurs, tels que Ratzeburg, qui se sont occupés des insectes nuisibles aux arbres résineux, n'ont point parlé de ce dernier insecte. Des ehenilles, auxquelles des papillons (des lépidoptères) ou des monches (tenthrèdes el sirex) ont donné naissance, peuvent manger les feuilles, faire mourir ainsi des arbres et mème détruiré des forêts entières si leur multiplication devient prodigicuse.

Ratzeburg indique (1), comme causant le plus habituellement des ravages lans les forêts de pins sylvestres du nord de l'Allemagne, le seolyte des pins, Iylesinus piniperla; le bostriche sténographe, Bostrichus stenographus; la petite tenthrède du pin, Tenthredo pini; la fileuse du pin, Phalcena bombyx pini, qui ne vit que des feuilles du pin sylvestre, n'attaque ordinairement que ceux qui ont dépassé 60 ans et cause quelquefois de très-grands ravages; la nonne, l'halcent bombry.x monaca, qui se nourrit de préference des feuilles dı picé:ı, mais yni 
mange aussi celles du pin sylvestre et même celles de plusieurs espèces de bois feuillus; la noctuelle, Phalana noctua piniperda, et l'arpenteuse du pin, Phalona geometra piniaria.

Je n'ai observé chez moi que deux insectes nuisibles au pin sylvestre, et c'étaient deux bostriches : l'un, que je n'ai pas trouvé, mangeait la moelle des pousses; l'autre, de couleur brune, mangeait à même, et je ne l'ai trouvé que sur des pins âgés au plus de 15 ans. Ces sortes d'observations exigent d'ailleurs un soin tout particulier; ainsi, par exemple, on croira au premier aperçu qu'un insecte qu'on n'a remarqué que sur de très-jeunes arbres n'attaque point ceux qui sont beaucoup plus âgés, parce qu'on ne l'a pas vu sur les feuilles des branches inférieures, mais si l'on eût observé les branches de la cime de l'arbre, dont les feuilles ont le plus d'analogie avec celles des très-jeunes arbres, on l'y aurait peut-être trouvé. 


\section{CHAPITRE V.}

\section{PIN MARITIUE, Pinus maritima.}

1. Nons de l'espìce. - P'inz meritima Lamark (1). On l'appelle aussi Grand rin mamtime, Petit pin marithe, Pin a trochets, Pin de Bondeadx, Pin des landes he Bombiux, P’in du Maine.

Linné n'il point parlé du pin maritimé, quoi qu'en ait dit Decandolle, ainsi que je l'ai lait voir page 8 . J'adopte le nom de Pin maritime, parce que ee pin croit de préférence dans le voisinage de la mer, et que ce nom est le plus répandu et le plus généralement adopté par les praticiens et par les botanistes (2). On voit quue, selon moi, les dénominations Grand pin maritime et Petil pin maritime, données à des arbres qui présentent les mêmes caractères botaniques, ne sont relatives qu'à leur dimension; ainsi, la première pourrait s'appliquer i cet arbre daus les landes de Bordeaux et en Corse, la seconde au même arbre dans le Maine et dans l'Orléanais. L'expression Pin à trochets exprime une anomalic qui se remarque sur quelques sujets. Ies autres noms sont ceux de lieux où le pin maritime est commun.

11. Boutons er sève.--Le pin maritine n'a que des boutons à bois, qui contienuent en même temps le rudiment des fenilles et des fleurs; du moins bois, feuilles, neurs, tout part des mêmes boutons.

Cet arbre n'a qu'une seule sève, qui commence ordinairement, sous le climat de Paris, dans les dix derniers jours du mois de mars, par le bouton qui se Irouve dans le prolongement de la flèche de l'année précédente, et s'arrête, en (e) qui conceme la longueur des pousses, an bout de deux mois et deni à trois

1) Flore francaise, 1. 11, p. 201.

(2) Je sais que Lambert, dans l'ouvrage intitulé 1 Description of the genus Pinus, donne le nom de Pinus marilima à un pir qui, par les dessins qu'il en donne et la description qu'il en fait, est evidemment le pin d'Alep, el qu'il a adopté, ainsi que Loudon dans l'Arborelum el frulicelum brilannicum, le nom de P'inus pinaster, d'après Aiton, pour le pin dont je vais m'occuper dans ce chapitre; ma's ce nom, inconnu des praticicns, I'a point été adopté par les botanistes : on a va, page 6 , que le non de Pinaster a été clonné à ditlërentes espèces de pins par diflérens autruts. 
mois el demi environ. Il arrive quelquefois, par exception, qu'une seconde sève se manifeste en mème temps que la seconde sève des bois feuillus, mais elle ne donne naissance qu'à des pousses très-courtes; ce cas exceptionnel est d'ailleurs rare; je ne parlerai done que des pins maritimes qui n'ont qu'nne seule sève.

Les circonstances de la végétation, en ce qui concerne l'apparition et la disposition des boutons, des feuilles et des fleurs, sont les mêmes dans le pin maritime que dans le pin sylvestre (Voy. p. 143), avec cette différence que les fleurs du premier paraissent et mûrissent un peu plus tôt que celles du second, et que ses pousses sont beaucoup plus grosses. On remarque que, pendant les premières années du pin maritime, sa flèche est plus longue que celle du pin sylvestre, mais que, sous le climat de Paris, lorsque ces arbres ont dépassé 12 ans, clle est, en moyenne, de la même longueur pendant un assez grand nombre d'années, toutes choses égales d'ailleurs; enfin, sous ce climat, le pin sylrestre tinit par dépasser le pin maritime.

1II. Feullees, flevps et cônes. - Les bourgeons des feuilles du pin maritime commencent à paraître daus le courant du mois de mai, quelques jours plus tard que ceux du pin sylvestre, lorsque les pousses, qui ont paru depuis environ deux mois, ont déjà acquis une partie de leur longueur el que la pellicule qui les couvrait est tombée. Quelques jours après, on voit les feuilles sortant deux à deux de gaines cylindriques fixées autour des pousses; les feuilles du pin sylvestre, du pin laricio et du pin du lord Weymonlı les ont déjà devancées. Lorsqueces feuilles ont atteint toutes leurs dimensions (Pl. II, fig. 10 et 11), elles sont dures, linéaires, pointues, longues de $0^{m}, 08$ à $0^{m}, 16$, sclon l'âge des arbres, le terrain et l'exposition; elles sont d'un vert clair dans les jeunes arbres et d'un vert terne dans ceux qui sont plus âgés. Chaque feuille a sensiblement la forme d'une moitié d'un cylindre qu'on aurait coupé en deux suivant son axe; les deux faces aplaties de deux feuilles contenues dans une même gaîne se regardent, et elles ont, si on les réunit, la forme d'un cylindre. Les feuilles du pin maritime ne persistent ordinairement que pendant deux ans et demi, c'est-àdire qu'elles tombent après la troisième sìve, y compris celle qui leur a donné naissance, el elles commencent ì tomber dìs l'automne.

Les fleurs du pin maritime (Voy. p. 10) commencent à paraître en même temps, dans la première quinzaine de mai environ.

Les chatons mâles (Pl. II, fig. 10) sont serrés antour de la partie inférieure des pousses, de manière à former une espèce de grappe comme ceux du pin sylvestre; mais ils sont beaucoup plus gros. Les fleurs qui les composent ont atteint leur maturité dix jours environ après qu'elles ont paru, et environ huit jours avant celles du pin sylvestre; elles sont alors d'un rouge orange et répandent en si grande quantité ume poussière jaune soufre, que la terre en est quelquefois couverte. 11 m'a paru que les pins maritimes âgés de plus de 20 ans, el convenablement espacés, portaient tous les ans des fleurs mâles.

Les chatons femelles sont amnoncés, environ quinze jours d'avance, par de 
très-petits boutons qui sont au bout des pousses, ordinairement au nombre de deux à six, mais quelquefois jusqu'au nombre de vingt-cinq, et qui se trouvent en plus grand nombre vers le sommet de l'arbre. Ils sont ovoïdes, ne sont d'abord pas plus gros qu'un pois, sont d'un rouge violet et ont la pointe tournée vers le ciel. Au bout de quelques semaines, les feuilles florales se transformant en écailles, les chatous deviennent des cónes, et la couleur rouge est remplacée par la couleur gris vert. Cette transformation est déjà très-apparente vers le milieu du mois de juin, et c'est pendant qu'elle s'opère que les cônes s'inclinent et prennent la position qu'ils conserveront; ils ne sont pas alors plus gros qu'une noisette; la transformation des fleurs femelles en cônes m'a paru s'opérer quelques jours plus tard dans le pin maritime que dans le pin sylvestre.

Les cônes sont toujours placés vers le bout de la pousse sur laquelle ils se trouvent à côté des boutons, et sont lixés immédiatement sur le bois. Ordinairement ils sont au nombre de deux à six, mais quelquefois il n'y en a qu'un seul, et quelquefois aussi il y en a jusqu'à vingt-cinq agglomérés. J'ai vu un de ces trochets composé de vingt-deux cônes qui avaient l'apparence d'avoir atteint unc complète maturité. Le prolongement de la branche sur laquelle se trouve unc telle quantité de cônes est ordinairement chétif et meurt, soit parce que la sève absorbéc par les cônes a manqué, soit parce qu'ils u'ont pas laissé à cette partic de la branche une place suffisante pour se développer : ces sortes d'aggloméralions de cônes sont d'ailleurs des cas exceptionnels; c'est donc à tort, ainsi que je l'ai dit, que des stuteurs ont fait des arbres qui les portent une variété sous le nom de Pin maritime à trochets. Les cônes, quel que soit leur nombre, ont leur axe plus ou moins incliné, par rapport à lil branclıe sur laquelle ils se trouvent, de manière à ne pas gèner le développement des boutons qui produiront les pousses de l'année suivante. Ils ont acquis à la tin de septembre tout le développement qu'ils prendront cette première année; ils sont alors oblongs, gros comme une petite noix et d'un rouge brique foncé. L'année suivante, inmédiatement avant la sève, ils sont roux ( $\mathrm{Pl} . \mathrm{V}, \mathrm{fg}$. 4), et ils commencent à grossir dès que part la sève; ils se trouvent alors entre les pousses et.sous les pousses de l'annće. Ils deviennent, à la fin de juin, d'un gris roux par dessus et d'un gris vert par dessous; à la fin de septembre ils ont atteint tout leur accroissement, et sont vert pâle; puis ils changent successivement de couleur jusqu'à ce qu'ils deviennent couleur de chocolat et luisans, ce qui n'arrive complètement que dans le courant de mars de l'année suivante, peu de jours avant l'époque où ils laissent échapper les graines qu'ils contiennont. Ces ğraines sont d'ailleurs mûres au commencement de décembre et peut-être avant, et l'on peut cueillir alor's les cônes pour cn extraire la graine, dans les sécheries.

Les cônes du pin maritime (Pl. 11 , fig. 11 et Pl. V, fig. 4) ont alors de $0^{\mathrm{m}}, 10$ à $0^{\mathrm{m}}, \mathbf{1 6}$ de long; ils sont coniques et se composent d'écailles serrées les unes contréles autres, adhérentes à un axe commun, plus minces à leur base fixée à l'axe qu’à la partie extérieure qui est terminée en massue; ì la base interne de 
ces ecailles se trouvent denx grtaines munies chacune d'une aile. La grante gur conticnuent les cònes n'atteint une complète maturité qu'à la lin de novembre, et ce n'est que dans le mois d'avril de l'annće suivante, c'est-í-dire 22 ì 23 mois environ après qu'ils ont paru, que le soleil fait soulever leurs écailles et que la graine qu'ils contiennent commence à tomber : cette grainc étant munic d'une aile, comme celle du pin sylrestre, peut aussi être transportéc au Join part les vents, mais moins facilement, parce qu'elle est plus grosse; la dispersion de celte graine s'opère en un petit nombre de jours. Les cônes commencent à tomber successivement, par suite des secousses des vents, dès l'annéc même pendant laquelle sont tombées les graines qu'ils contenaient; mais ce n'est qu'au lout de plusieurs années que les pins maritimes en sont entièrement débarrassés.

Le pin maritime porte des cònes encore plus tôt que le pin sylvestre; on peut en voir, par exception, sur des arbres îgés de 8 ans seulement. J'en ai souvent remarqué beaucoup, dès la quatorzième année, sur des pins maritimes, provenant de semis en grand, qui avaient été tenus suffisamment espacés; une partie des graines que produisent ces jeunes arbres sont fécondes, s’ils ont porté des tleurs mâles en mème temps que des cônes, mais ce n'est que lorsque ces pius sunt plus àgés que la graine a acquis toute la force germinative dont elle est susceptible. Je pense donc, lorsqu'on le peut, que l'on ne doit récolter les cònes pour en extraire la graine, que sur des arbres âgés de 30 ans au moins. II m'a semblé que l'on ne commençait à voir des fleurs mâles sur les jeunes pins maritimes que deux ou trois ans après que l'on avait commencé à y voir des cones. Cet arbre m’a paru porter des lleurs mâles tous les ans, quand il a atteint 20 ans, et des cônes presque tous les ans, mais en plus ou moins grande quantité. 11 a, comme le pin sylvestre, des amnées d'abondance et des amuées de stérilité.

1V. Graines et semis xatcrel. - Les graines du pin maritime ([1]. 11, fig. 12) sont ovales, gris foncé d'un còté, d'un brun luisant de l'autre, et elles sont munies d'une aile; elles ont environ $0^{\mathrm{m}}, 008$ de longueur moyenne. J'ai indiqué, dans l'article précédent, à quel âge les jeunes pins commencent à porter des cônes; les graines qu'on en tire alors peuvent ètre fécondes, mais ce n'est guère que lorsque l'arbre a dépassé 15 ans, qu'il commence à donner du semis naturel, et il n’en donne qu'en petite quantité; il faut que le pin maritimo ait alteint 25 ans pour donner abondamment du semis naturel efficace, et c'est la graine: des arbres qui approchent de leur maturité, ou qui l'ont atteinte, que l'on doit préférer pour en faire des semis.

Pour se procurer de la graine de pin maritime, on peut faire cueillir des cônes ilepuis le commencement de décembre jusqu'au moment où elle doit s'échapper. des cones, dans le courant d'avril. Dans le Maine, d'où l'on tire la plus grande partie des graines qui se vendent à Paris, on récolte les cùnes en janvier, février et mars, soit en montant dans les arbres pour les cueillir it la main, ou les ábattre aver une gatule terminéc par un crochet en bois, suit en les arrachant a vec de 
lomgurs produes armers à l'extromite d'me petite fourche en fer, are qui est un travilil très-pénilıle: on doit éviter en cueillant les cònes d’endommager les boutons ou de casser le houl des branches, car on causerait ainsi un grand dom-mige aux pins.

II. Marcellin Vétillart, dans un mémoire auquel j’anrai recours plusieurs fois, rapporte (1) que le's ouvriers qui cueillent les cônes en montint daus les arbres passent quelquefois d'un arhre dans l'arlore voisin sans descendre, en balan!:anı relni sur lequel ils se tronvent pour saisir une branche de l'arbre voisin, l'atlirer à cux el s'y transporter. "Lorsqu'une pinière est à peu près également es"pacée, dit-il, el qu’il n'y a pas de grandes lacunes, les ouviriers, me fois " montés, ne redescendent que pour prendre leurs repas et courent ainsi des " journées entières du sommet d'un arbre à l'autre. "Ce royage, à la manièr: des écureuils, doit être difficile et dangereux, et je suis disposé à croire que des arbres sur lesquels des ouvriers peuvent voyager ainsi sont plus serrés qu'ils ne devraient l'ètre.

On n'esı pas dans l'usage d'extraire la graine des cônes du pin maritime dans des séclueries, ainsi que cela se fait pour les cônes du pin sylvestre, quoique cêli soit praticable; on emploie tonjours la chaleur du soleil. Cependant il est aussi facile d'extraire la graine tes cônes du pin maritime, dans les sécheries, que celle: des cones du pin sylvestre; et l'on y trouverait l'avantage de semer cette graine: l'année mème oì elle a été récoltée, tandis qu'on ne la sème que l’année suivantr, A u moins d'après l'usage suivi dans le Haine, puisque l'on u'extrait la graine des rônes que pendant l'été et qu'on ne la sème qu'au printemps suivant. On a commencé avec succès l'extraction de la graine des cones du pin maritime dans la sécheric nouvellement crée à Fontainebleau (Voy. p. 148). I. Delamarre rapporte (2) qu'il a extrait de la graine an four con n'y mellant les cones que le soir du jour oì, le matin, on avait cuit le pain, et qu’elle était excellente; j’ai ohtenu le même résultat.

Dans le Maine, on entasse les cunes, après les avoir cueillis, et on les ćtale an soleil, pendant lété, sur une aire bien exposéc oil le sol a été nettoyé et battu, on les remue souvent pour présenter toutes leurs fices au solcil; les écailles se soulèvent alors et les graines tombent. Lorsque tous les cônes sont ouverts et ne laissent plus tomber de graines, on les enlève et l'on ramasse la graine qui est tombée à terre. Pour débarrasser cette graine de ses ailes on la met en tas de $0^{\text {nt }}, 20$ à $0^{\text {ma }}, 2$ ó d'épaisseur, sur une aire à battre le blé, et on la bat légèrement au fléau ou avec un bâton flesible; puis, on achève de la nettoyer en la vannant et en la criblant. Delamarre dit, page 51 de l’ouvrage déjì cité, que, dans le Maine, on desaile aussi la grainc en la plaçant dans une cuve et en la remuant avec une pelle, dont on se sert comme d'un levier, en prenant le bord de la cuve pour point d'appui. On suit ce mème procédé d'extraction dans l'Orléanais et dans les

1) Olisrrations rratirius sur la culnure du pin moritime dans le dípariomont de la Sarlher, p is.

" Truilei protique de la culure des pins à grandes dimensions, ze cidit., p. 3i9. 
landes de Bordeaux : il est possible que dans ce dernier endroit, ou sous un climat plus chaud encore, on puisse se procurer ainsi de la graine assez tôt pour la semer au printemps. On pourra, sous le climat de Paris, et comme pour le pin sylvestre, se procurer de la graine extraite au soleil assez tôt pour semer au printemps, en plaçant, dès le 15 février, des cônes sous une bâche bien close (Voy. p. 147). La graine que l'on se procure dans le Maine, et qu'on ne sème par conséquent que plus d'un an après qu'elle a atteint sa maturité, est d'ailleurs trèsbonne; mais elle présenterait encore moins de déchet si on la semait un an plus tôt.

J'ai trouvé qu'un litre de graine de pin maritime pesait 520 grammes et contenait 12,512 graines; ainsi le kilogramme contenait 24,061 graines et occupait un volume de 1 litre 92 décilitres, et l'hectolitre pesait 52 kilogrammes et contenait 1,251,200 graines. Selon Delamarre (1), qui faisait ses expériences au Vieil-Harcourt, dans le département de l'Eure, un kilogramme de graine de pin maritime contient, terme moyen, 20,000 graines, et chaque cône donne, terme moyen, 140 graines. Ainsi, d'après mon évaluation de la quantité de graines que contient un hectolitre, et en admettant que chaque cône donne, terme moyen, 140 graines, il faudrait 8,937 cônes pour obtenir un hectolitre de graines, et comme un hectolitre de cônes contient environ 400 cônes, 8,937 cônes occuperaient un volume d'environ 22 hectolitres.

Selon M. Vétillart, la graine de pin maritime ne vaut que 12 à $15 \mathrm{fr}$. les 50 kilogrammes au Mans; Delamarre dit, page 253 de l'ouvrage déjà cité, l'y avoir payée de 20 à 60 centimes le demi-kilogramme, selon les années. M. de Béhague l'évalue (2) à 60 centimes le kilogramme dans l'Orléanais. M. Dallier l'évalue (3) à $30 \mathrm{fr}$. l'hectolitre dans les landes de Bordeaux, c'est-à-dire à 29 fr. les 50 kilogrammes, d'après ce que je viens de dire du rapporı entre le volume et le poids de cette graine.

La graine de pin maritime lève dans l'année même où elle tombe de l'arbre; celle que l'on extrait des cônes lève plus facilement qu'aucune des graines des arbres dont je m’occupe spécialement dans ce Traité, mais le plant du pin maritime ne supporte pas mieux l'ombrage que celui du pin sylvestre (Voy. p. 153).

V. Mode de régétation, description, dimensions. - Le mode de végélation du pin maritime a été décrit, au commencement de ce chapitre, en ce qui concerne la marche de la sève dans cet arbri, ses boutons, ses feuilles, ses fleurs el ses cônes; et l'on trouvera, chap. XI, art. V, des détails sur sa végétation et son accroissement, depuis le semis en pépinière jusqu'au moment de la plantation à demeure. Le plant de semis naturel présente beancoup de variété dans son accroissement, selon les circonstances particulières dans lesquelles il se trouve

(1) Traité pratique de la culture des pins à grandes dimensions, 3 édit., p. 89 et 241.

(2) Nate sur quelques traqaux agricoles exécutés sur la terre de Iampierre, p. 9.

(3) Vérités sur les landes de Gascogne el sur la culture forestière des pins, p. 7. 
placé; cet aceroissement, qui est ordinairement plus lent que celui du plant de pépinière, peut l’égaler pourtant et mème le dépasser dans des circonstances de tout point favorables, à cause du retard que la transplantation fait éprouver au plant dans les pépinières. La graine lève irrégulièrement selon l'époque à larquelle elle est tombée et la situation où elle s'est trouvée. J'ai dit, dans l'arlicle précédent, que le plant de pin maritime ue supporte point l'ombrage, comme celui des sapins, et qu'il périt bientòt s'il est trop ombragé; mais il réussit très-bien sans ombrage, même dans l'année de sa maissance, et je présume que l'ombrage lui est toujours nuisible, du moins sous le climat de Paris.

Le plant de pin maritime pousse plus promptement, pendant les premières années, que celui de pin sylvestre, de pin laricio et de pin du lord Weymouth. J'ai remarqué quelquefois, pendant des années privilégićes, lorsqu'il a lépassé 12 ans, des flèches de $0^{\mathrm{m}}, 94$; mais je ne puis indiquer quelle est la longueur moyemne de la llèche, pendant les années où l'arbre conserve une végétation très-active. II. Vétillart, en comparant, page 32 de son mémoire, une pinière mal tenue, îgée de 7 ans, à ses pinières et à celles de M. Bérard, faites à peu près à la même ćpoque, dit que les pousses ont, dans ces dernières pinières, 1 pied et 1/2 a 2 pieds $\left(0^{\mathrm{m}}, 49\right.$ i $\left.0^{\mathrm{m}}, 65\right)$ de longueur.

Le pin maritime a une racine pivotante qui s'enfonce à une grande profondeur dans les terres facilement pénétrables, d'autres racines latérales moins grosses et peu de chevelu; par suite de cette disposition de ses racines et de ce qu'il est chargé de branches vers la tête, pendant ses premières années, il est alors sujet à être ébranlé et penché par les vents lorsqu’il croît isolé; car, plus tard, le vent le brise plutöt que de le renverser.

Lorsque le pin maritime croît en futaie à l'état serré, son trone est droit et dépouillé de branches jusqu'aux deux tiers environ de la hauteur de l'arbre; il conserve alors une flèche et des étages réguliers de branches, tant que, n'approchant point de sa maturité, il a une végétation active. Lorsqu'il croît isolé, il est exposé, ainsi que je viens de le dire, à être ébranlé et penché par les vents; il ne périt pourtant point ordinairement, étant nourri par son long pivot, et il finit par se raffermir, mais il reste penché, courbé ou tortu. J'ai une allée qui borde mon pare, au couchant, dans laquelle 28 pins maritimes sont mêlés avec des sapins argentés, des picéas, des pins sylvestres, des pins du lord Weymouth et des pins laricio; 21 de ces pins maritimes ont été plantés en 1787-1788, les 7 autres antérieurement à cette époque; il n’y a que 4 de ces arbres qui soient droits, encore pas parfaitement, les autres sont courbes, tortus, crochus, et il y en a qui affectent les formes les plus bizarres. Le pin maritime, quoiqu'il ait crù isolé, perd successivement toutes ses branches inférieures, qui meurent et tombent; il ne conserve que celles de la partie supérieure de l'arbre, qui prennent dans leur ensemble une forme arrondie : ainsi, qu'il croisse isolé ou à l'état serré, son trone se déponille également de branches, mais à une moindrr lanteur dans le premier eas. 
Si l'on brise le tronc d'un pin maritime dans sa jumesse, une ou deux des branches de l'étage immédiatement inférieur continuent le trone; si l'arbre approche de sa maturité ou que lá brisure soit trop loin de la tête, il reste mutilé; si la brisure est trop rapprochée du sol ou que l'arbre ait conservé trop peu de fenilles et de bourgeons, il périt.

L'écorce du pin maritime est persistante et très-épaisse; lorsque l'arbre a dépassé les premières années; elle s'accroît tous les ans, ainsi que le bois, d'une couche ligneuse, et comme elle n'est point élastique, elle est obligée de se fendre; de là résultent les nombreuses fissures irrégulières que présente l'écorce dı trone d'un vieux pin maritime : cette écorce, qui est d'abord grise dans les jeunes pins, devient ensuite brune.

Les branches du pin maritime sont disposées par étages et au nombre de cinq à six par chaque étage; elles sont érigées dans les jeunes pins ô vers le sommet des pins, tant qu'ils ont une flèche, c'est-à-dire tant qu'ils sont dans la période d’accroissement; les branches qui sont plus âgées, et par conséquent plus rapprochées ılu sol, s'abaissent jusqu'à devenir presque horizontales, mais elles se redressent à leur extrémité et ne pendent jamais comme celles du pin sylvestre.

Les massifs de pins maritimes, moins sombres que ceux de pins sylvestres, sont d'un vert terne, peu agréable selon moi. Quant à l'arbre isolé, lorsqu'il a atteint toutes les dimensions dont il est susceptible, ce qui n'arrive que dans les climats et dans les situations qui lui conviennent parfaitement, comme par exemple sur les dunes des landes de Bordeaux, il a ce genre de beauté qui résulte de la surprise que cause son aspect. Car il semble qu'avec cette masse de branches garnies de feuilles qui se trouvent à la partic supérieure de son tronc, il devrait être renversé parles vents; mais ses racines, qui pénètrent à une grande profondeur, le maintiennent; les vents le briseraient plutôt que de le déraciner. Chez moi, quoique ceux qui ont atteint leur maturité ne dépassent pas $16^{\mathrm{m}}, 30$ de haut, ils me font éprouver ce sentiment quand je les regarde pendant la tempête; le plus gros, qui est en même temps le plus haut, a eu la tête briséc par un cuup) de vent.

L'accroissement du pin maritime sons le climat de Paris est fort irrégulier. Des 28 pins maritimes dont j’ai parlé ci-dessus, qui avaient été plantés en même temps, qui étaient âgés de 62 ans au moins à l'automne de 1843, et qui me paraissaient avoir atteint leur maturité, le plus gros avait $16^{\mathrm{m}}, 30$ de lıut; et $0^{\mathrm{m}}, \mathbf{7 6}$ de diamètre y compris l'écorce, qui occupait $0^{\mathrm{m}}, 10$, ainsi il avait eu un accroissement annuel de $0^{\mathrm{m}}, 012$; le moins gros n'avait que $0^{\mathrm{m}}, 35$ de diamètre, el 10", 70 de haut : ces pins étaient dans un terrain silico-argileux où le chênr réussit bien. J’ai remarqué la même irrégularité dans la végétation des arbres provenant de semis.

Il y a dans cette plantation attenant à mon pare, dont j’ai déjà parlé (Voy. p. 124, 127 et 158), 12 pins maritimes qui ont été plantés en 1803-1804, en mème inmps que les picéas et les pins şrlrestres qui s’y trourent, et dont j’évalue l'äge 
a 44 ans; le plus gros de ces pins avait, ì l'automne de 184.3, $0^{\mathrm{m}} 5$ 5̆ de diametrey compris l'écorce, et $11^{\mathrm{m}}, 70$ de haut; ainsi il avait eu un accroissement annur:l de. $0^{\mathrm{m}}, 012$; le moins gros n'avait que $0^{\mathrm{m}}, 21$ de diamètre el $10^{\mathrm{m}}, 10$ de haut, ainsi il avait eu un accroissement annuel de $0^{\mathrm{m}}, 005$. On peut comparer les dimensions de ces pins avec celles des pins sylvestres et des picéas qui ont crû a côté d'eux sur ce même terrain; mais il faut tenir comple de l'épaisseur de l'écorce du pin maritime, de ce que son trone n'etait pas droit, et de l'infériorité de son bois.

Il y avait à un quart de lieue de mon habitation des pins maritimes, plantés par mon grand père, qui n'avaient pas moins de 72 ans en 1837, lorsque mon beau-frère les lit abattre; ils se trouvaient sur un coteau exposé au midi en terrain silico-arghileux oủ le chêne réussit hien. Ils avaient dépassé l'âge de leur maturité el étaient sains en apparence, cependant le bois de quelques-uns de ces pius était altéré; aucun d'eux n'était droit, parce qu'ils n'avaient pas été assez serrés; ils ne profitaient plus depuis bon nombre d'années. Le plus beau de ces pins avait $0^{\mathrm{m}}$, ̌̌ de diamètre et 14 mètres de haut; le plus petit avait des dimensions beaucoup moindres; je les ai perdues.

Les premiers semis de pin maritime dans la forêt de Fontainebleau ont été cxécutés en 1785, en même temps que ceux de pin sylvestre, sur un sol de sable siliceux mêlé d'un peu d'humus, dans une épaisseur de $0^{\mathrm{m}}, 20$ ì $0^{\mathrm{m}}, 25$. Le tableau ci-joint fait connaitre quelles étaient les dimensions de ces arbres à l'automne de 1843; le maximum est la moyenne des dimensions de 10 des plus gros arbres, et la moyenne est la moyenue des dimensions de 20 arbres de gros. seur moyenne (1).

\begin{tabular}{|c|c|c|c|c|c|c|}
\hline \multirow{4}{*}{$\begin{array}{l}\text { DÉSIGNATION } \\
\text { DES LIEUX. }\end{array}$} & \multicolumn{5}{|c|}{ 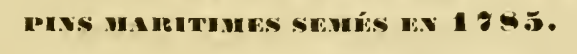 } & \multirow{4}{*}{ OBSERVATIONS. } \\
\hline & \multicolumn{4}{|c|}{ DIMENSIONS EN 18 " T. } & \multirow{3}{*}{$\begin{array}{l}\text { Accroisse- } \\
\text { ment } \\
\text { moyen } \\
\text { aniuel. }\end{array}$} & \\
\hline & \multicolumn{2}{|c|}{ maxixc). } & \multicolumn{2}{|c|}{ MOYFNAE. } & & \\
\hline & Hauleur. & Circonf. & Ilauleur. & Circonf. & & \\
\hline Champs Ninette. & $\underset{17,00}{\mathrm{~m} .}$ & $\begin{array}{c}\mathrm{m} . \\
\mathrm{a}\end{array}$ & m. 14.00 & ${ }_{1,65}^{m}$ & m. & Pins isolés. \\
\hline Plame des Pins. & 21.00 & 2,15 & 18.00 & 1,25 & 0,007 & id. \\
\hline Rocher d'A vou. & 21,00 & 1,50 & 17,00 & 1,16 & 0,006 & Pins à l'état serré. \\
\hline
\end{tabular}

En comparant ces dimensions avec celles des pins sylvestres semés en même temps (Voy. p. 159), on trouve que le pin maritime a acquis un peu plus de volume que le pin sylvestre, mais il faut avoir égard à ce que l'écorce lu pin maritime est plus grosse que eelle du pin sylvestre; i ce que son trone n'est jamais droit que quand il croît à l'état serré; à ce que son bois est bien inférieur à celui du pin sylvestre; et encore ne peut-on tirer aucuue conséquence de cette

1) Renseignemens communiques par M. de Roisdhyver, inspecteur de la forct de Fontainebleau. 
romparaison, parce que les terrains sur lesquels a été pxécutée celte culture sont évidemment meilleurs ou moins mauvais pour le pin maritime que pour le pin svlvestre.

Ce sont MM. de Boisdhyver et de Larminat qui, pendant qu'ils ont successivement administré la forêt de Compiègne, y ont introduit la majeure partie des bois rósineux qui s'y trouvent aujourl'hui; avant eux il n'existait que trois petits massifs de pins maritimes qui avaient été semés par un planteur, en 1774 el 1775̆, au Mont-du-Tremble et à la Muette, sur un sable pur impropre à la culture des ilutres essences : le dépérissement de ces pins en détermina la coupe en 1838, c’est-ì-dire lorsqu'ils avaient 69 et $\mathbf{7 0}$ ans; les plus élevés avaient alors environ 20 mètres de haut el étaient propres à faire du bois d'œuvre. Les pins maritimes semés il y a 12 aus dans le lieu diı Carendeau, dans un sable quarıeux, avaient, à l'automne de 1843 , en moyenne $0^{\mathrm{m}}, 34$ de circonférence, et $5^{\mathrm{m}}, \mathbf{7 0}$ de haut; I's plus beaux avaient $0^{\mathrm{m}}, 40$ de circonférence et $6^{\mathrm{m}}, 50$ de haut (1).

Dans le Maine, sur ces sables arides oì l'on ne peut cultiver ancune autre espèce d'arbres, le pin maritime acquiert sa maturité de 35 à 40 ans, et sur les ierrains qui lui sont le plus favorables de 80 is 90 ans. Le petit nombre d'observations que j'ai pu faire à ce sujet dans la localité que j’luabite, me fait croire que dans les terres qui lui conviennent le mieux et qui ne sont d'ailleurs point sablonneuses, il atteint sa maturitú de 60 à 80 ans. Dans les dunes des landes de Bordeaux, il l'alteint de 80 à 100 ans.

Pour connaître les plus fortes dimensions auxquelles peut atteindre le pin maritime, il faut l'observer dans les pays d'où il est indigène et non loin des rivages de lá mer, car c'est une situation qu’il paraît affectionner; il me paraît évilent qu'il a été introduit par la culture sous le climat de Paris, où il a sonvent tant à souffrir des hivers rigoureux et des gelées tardives dans ses premières années. On ne l'y cultive d'ailleurs en futaie, pour en tirer un revenu, que sur des terrains siliceux très-maigres, et qui ne sont quelquefois propres qu'à ce genre de culture. Dans les dunes des landes de Bordeaux, les pins maritimes qui onı acquis toutes les dimensions dont ils sont susceptibles, peuvent aroir jusqu'à 3 mètres de circonférence et jusqu’à 30 mètres de haut. On peut voir de ces arbres dans la forêt de la Teste, près dı rivage de la baie d'Arcachon, qui ont 1 mètres et jusqu'à 5 mètres de circonférence, ce que l'on considère comme des cas exceptionnels. Les mêmes arbres n'acquièrent que des dimensions beaucoup moindres dans les plaines de ces landes. M. Vétillart, dans le mómoire précédemment rilé, parle d'un royage qu'il fit en Corse, par amour des plantations, et dit que les pins laricio et les pins maritimes y prennent un développement surprenant; il y a vu, dir-il, des pins maritimes de 12 a 17 pieds $\left(3^{\mathrm{m}}, 89\right.$ i $\left.5^{\mathrm{m}}, 52\right)$ de circonfírence (probablement près du sol); ce sont là évidemment des dimensions exceptionnelles.

Quant aux dimensions auxquelles peuvent atteindre les pins maritimes sous

1) Renseignemens communiqués par $\mathbf{M}$. Poirson, inspecteur de lil forêt de Compiègne. 
le climat de Paris, on a vu que dans mon pare un pin maritime a 2 "w, 28 de: ritconférence el $16^{m}, 30$ de haut. A deux lienes de che\% moi, dims le millis oi si Ironve la jeune sapinière dont j’ai parlé page 21 , il y a trois pins maritimes anssi îgés peut-être que les sappins qui ont lonné naissance ì celte sapinière, el l'un d’eux a 2 mètres de circonférence et 15 mètres de lıut. M. Vétillart dit, pago 5 de son mémoire: "Dans le Maine, le pin maritime atteint ordinairement 35 à 40 " pieds $\left(11^{\mathrm{m}}, 37\right.$ à $\left.12^{\mathrm{m}}, 99\right)$ d'élévation, très-rarement il dépasse 50 pieds $\left(16^{\mathrm{m}}, 2\right.$ 亿). "La grosseur du tronc varic beaucoup; il attein tordinatrement de 20 à 50 pouces " $\left(0^{\mathrm{m}}, 5{ }^{\prime} 4\right.$ i $\left.1^{\mathrm{m}}, 35\right)$ de circonférence; on en voit de 2 pieds et demi $\left(0^{\mathrm{m}}, 8\right)$ de dia" mètre dans les terres qui lui conviennent parfaitement, mais ils sont lort "rares. "Je rappellerai que $\mathbf{H}$. Vétillart ne s'occupe dans ce mémoire que des pins maritimes du département de la Sarthe. Je tiens d'ailleurs de M. Vétillart et de M. Renard, qu'on en peut citer, comme cas exceptionnels, qui y parviennent à 26 mètres de haut du sol à la cime.

London, à la fin de l'article Pinus pinaster de son Arboretum, 1. IV, p. 2221, donne les dimeusions de plusieur's pins maritimes situés dans les pares de la Grande-Bretagne; je vais reproduire ce qu'il dit de ceux de ces arbres qui avaient les plus belles dimensions (Voy. p. 38).

En Angleterre. A Fulhiam P'ilace, un pin maritime âgé de 150 ans a 80 pieds anglais (24 mètres) de haut, et son tronc un diamètre de 4 pieds $\left(\mathbf{1}^{\mathrm{m}}, \mathbf{2 0}\right)$. - $\mathbf{A}$ Syon, il y a plusieurs de ces arbres de 60 piels (18 mètres) de haut. - A Carclew, 82 pieds $\left(24^{\mathrm{m}}, 60\right)$ de haut, son tronc un diamètre de 3 pieds 6 pouces $\left(1^{\mathrm{m}}, 05\right)$. A Barwood Park, 50 pieds ( 15 mètres) de haut, son tronc un diamètre de 4 pieds 6 pouces $\left(\mathbf{1}^{\mathrm{m}}, 3 \mathrm{3}\right)$. - A Southend, planté il y a 40 ans, 60 pieds (18 mètres) de laaut, son tronc un diamètre de 3 pieds $\left(0^{\mathrm{m}}, 90\right)$. - $\Lambda$ Croome, planté il y a 70 ans, 90 pieds (27 mètres) de haut, son trone un diamètre de 2 pieds 6 pouces $\left(0^{\mathrm{m}}, \mathbf{7 5}\right.$ ) - En Écosse. A Brahan Castle, un pin maritime a 35 pieds $\left(10^{\mathrm{m}}, 50\right)$ de haut, et son trone un diamètre de 1 pied 6 pouces $\left(0^{\mathrm{m}}, 45\right)$. - En Irlande. A Woodstock, un pin maritims, planté il y a 80 ans, a 72 pieds $\left(21^{\mathrm{m}}, 60\right)$ de haut, et son trone. un diamètre de 2 pieds 9 pouces $\left(0^{\mathrm{m}}, 82\right)$.

VI. Cumat, exposition, terran. --Le pin marilime est indigène des parties méridionales de la France; il est abondant et croît spontanément dans les landes de Bordeaux, dans la Provencé et dans la Corse. Le capitaine S. E. Cook l'a tronvé (1) dans les montagnes de Guadarrama, en Espagne, formant une zône an dessous du pin sylvestre; Quer en parle d’ailleurs dans sa Flora espagnola. Savi, dans sa Flora pisana, parle de l'arbre dont je m'occupe dans ce cliapitre en le désignant sous le nom de pin laricio, et Santi, dans son Viaggio terzo per la Toscana, en parle aussi sous le mème nom (Voy. clıap. VI, art. 1). Il paraît que le pin maritime ne se trouve point dans le royaume de Naples, car Tenore n'en parle point dans sa Flora napolitana. On l'a trouvé sur plusieurs points de l'A Igérie, particuliè- 
rement dins la grande forè de l'Eydough, non loin de Bone. Le pin maritimeacé introduit par la culture dans les provinces occidentales et centrales de la France, particulièrement dans les parties sablonneuses du Maine et de l'Orléanais, où il y en a de nombreuses futaies. Son introduction dans la première de ces provinces date do loin; elle est beaucoup moins ancienne dans la seconde.

Malesherbes dit, dans ses Observations sur les pins en général et en particulier sur le pin maritime, déjà citées (Voy. 1. 112) : "1l y a peu de bois dans la Sologne et " ils y sont de la plus mauvaise qualité. Cependant c'est en Sologne que M. Bou"L lin a imaginé de semer dı pin maritime, qui y était inconnu avant lui, " dans une terre qu'il avait près d'Orléans, nommée la Source, et il y a si "bien réussi, qu'aujourl'hui l'exploitation de ces bois est un bon revenu pour "M. de Muntaudoin, à qui il a vendu sa terre. M. de Boisgibault a une terre voi" sine, oủ il a pareillement semé un bois de pin à l'imitation de M. Boutin. Peut" être, de proche en proche, la Sologne entière se serait hoisée en pins, si le, " malheur arrivé dans l'hiver de 1788 à 1789 n'avait point mis obstacle au pro"grès de cette culture." Cet auteur donne ensuite des renseignemens précis et très-intéressans sur l'aptitude du pin maritime à supporter les hivers des provinces centrales de la France. "Dans les provinces de l'intérieur de la France, " dit-il, le pin maritime supporte le froid de nos hivers, même des froids très"rigoureux, puisqu'il a résisté, sans avoir éprouvé aucun échec, à l'hiver de v 1775 a 1776. Il faut donc, pour qu'il périsse, un clegré de froid pareil à celui de "1788 à 1789. Dans mon pays (en Gâtinais), presque tous les pins maritimes on t " été fortement attaqués par l'hiver de 1789; la plus grande quantité des vieux " arbresa péri, quelques-uns viven tencore, mais paraissent languissans; quelques " autres, mais en petit nombre, ont peu souffert. A l'égard des jeunes pins ma" ritimes, le plus grand nombre a péri, excepté les plus petits, que la neige avait "entièrement couverts avant la forte gelée. "Malesherhes émet le vou que la Société royale s'informe de l'effet qu'a produit le terrible hiver de 1789 sur les pins maritimes du Maine, des côtes de Bretagne et même des landes de Borleaux; j’ignore si ê vœu, émis en 1792, a été accompli.

M. G. Gand dit (1) qu'on a fait des semis assez consitérables de pin maritimo: en Alsace, dans la vallée de Munster et dans la plaine de l'Ochsenfeld, et qu'il réussit bien dans les parties chaudes et abritées de cette province et de la Lorraine, mais que le rude hiver de 1829 à 1830 le̋rur a fait le plus grand mal; je doute, en effet, qu'on puisse le cultiver avec succès dans ces localités. On en trouve des futaies jusqu'à Ghéluvelt, dans la Flandre occidentale; c'est le point le plus septentrional où l'on puisse le cultiver sur le continent, mais on n'y réussirait point à la même latitude en s'éloignant de la mer.

Le pin maritime réussit à toutes les expositions dans toute cette partie ouest de la France, où on le cultive; néanmoins, en s'éloignant des climats où il croît spontanément, une exposition abritée des vents froids, c'est-à-dire l'expo- 
sitionaumidi el an couchant, lui est ou phus lavorable que les antres, ou mème nécessaire; cela a été remarqué en $\mathbf{\Lambda}$ sace el en Lorraine, ainsi que je l’ai dit plus haut. J'ignore quelle exposition cet arbre préfère daus les haules montagutes où il croît spontanément, par exemple, en Corse; il n'y occupe d'ailleurs que les parties basses des montignes.

Le pin maritime ne peut réussir dans les terrains calcaires; cette observation avait déjà été laite par liozier, daus son Cours complét d'uyriculture, théorique, preliqu", économique, cte., t. VI, p. 683 et 685 ; il y dit "qu’il végète faiblentent el périt " lemisère s'il est semé dans les terres eal leares." Rozier ajoute " qu'il a vainement " tâclé de le multiplier dans son habitation près de Beziers, paree que le sol y est " tenace et calcaire. "Malesherbes, dans le mémoire déjì cité, dit "qu’il n’y a " aucun arbre à qui les terrains calcaires et crétacés soient plus contraires; qu’il "en a lait l'expérience chez lui, et que plusieurs de ses amis l'ont fitite aussi; " et il reproduit le passage de hozier que je viens de citer. Le pin maritime réussit, sous le climat de Paris, dans tous les terrains autres que les terrains cateaires pourvu qu'il puisse y enfoncer ses racines et que l'humidité n'y soit pas stagnante. Dans le Maine, où l’on ne sème guère le pin maritime que sur des sables plus ou moins arides, plus ou moins sulstantiels, il réussit très-bien dans un sable prolond, onctueux, couvert d'une couche de terre de bruyère ou d'une 'wouche de terre végétale. Dans les landes de Bordeaux, c'est sur les dunes qui sont composées de sable pur que le pin maritime acquiert les plus belles dimensions, et ses racines, qui s'y enfoncent à une grande profondeur, y sont plongées dans une humidité constante, ce qui paraît lui être nuisible dans d'autres situations; mais cette humidité est légère, et ces dunes ne sont point exposées ì des gelées aussi rigoureuses que les terrains qui se trouvent sous le climat de Paris.

Le pin maritime présente cet avantage inappréciable qu’on peut le cultiver sur des sables quartzeux si arides qu'aucun arbre, mène le pin larieio el le pin sylvestre, ne ponrait y croitre; l'on a tiré parti ainsi, dans le Iatine et daus l'Orléanais, de terains qui aviaent été jusqu’alors entièrement improduetils.

VI. Creation d'une rutale de pins mamtues. - l'resque tout ce que j'ai dit de lat création d'une futaic de pins sylvestres dans l'article VII du chapitre précédent s'applique à la création d'une futaie de pius maritimes; je me contenterai done d'y renvoyer mes lecteurs et d'indiquer les moditications qu'il faudrait y apporter, et ce qu'il y aurait à y ajouter.

Le pin maritime peut être employé, ainsi que le pin sylvestre, à rejeupler diıns les forêts les clairières dont le terrain maigre et siliceux serait si mauvais que les bois feuillus u'y pourraient prospérer; il peut mème réussir, ainsi que je l’ai dit dans l'article précédent, sur des sables si arides qu'on ne pourrait y culliver ni le pin sylvestre, ni le pin laricio. Il ne supporte pas plus l'ombrage que le pin sylvestre, mais il réussit aussi bien que lui dans les taillis de bois leuillus tant que sal lète les domine. 
On peut creer une futaie de pins maritimés, par la plantation, de la mème manière qu'une futaie de pins sylvestres; mais le plant de pin maritime reprend moins facilement que le plant de pin sylvestre, parce que ses racines ont moins de chevelu et que sa tête est plus chargée de branches; il faut pourtant en excepter le plant herbacé, c'est-ì-dire qui n'a qu'une sève, celui du pin maritime reprenant encore plus facilement que celui du pin sylvestre. On plante ou l'on repique le plant herbacé de pin maritime pendant les mois de mars et d'avril, par un temps couvert, et l'on doit avoir soin de n'arracher le plant qu'à mesure lles besoins; j’ai indiqué page $\mathbf{1 7 2}$ et chap. XI, art. II, comment s'exécute cette opération. Le semis de pin maritime ne manquant pour ainsi dire jamais, et étant le moven le plus économique de créer une futaic de cette essence, on n'emploie guère le plant herbacé que pour regarnir les clairières des pinières pendant l'annće où on les a semées; cependant ce plant peut être employé, je crois, à fixer les dunes, ainsi que je le dirai plus loin. II. Vétillart rapporte qu'il a vu exécuter par des femmes, sur des sables et pendant l'année du semis, des repiquages de plusieurs milliers de plants de pin maritime, que l'on prenait dans les endroits où le semis était trop épais pour en garnir les clairières; il ajoute que ces repiquages avaient si bien réussi qu'on ne distinguait point les parties où les pins avaient été repiqués de celles où ils avaient été semés.

Quoique, généralement parlant, les plantations de pin maritime soient d'une reprise moins facile que celles de pin sylvestre, elles réussissent pourtant très-bien si le plant que l'on emploie a été élevé ainsi que je l'indiquerai chap. XI, art. V, mais on ne doit employer que du plant de 4 à 5 ans au plus; le plant plus âgé reprend plus difficilement, toutes choses égales d'ailleurs, que celui des autres espèces dont je m'occupe spécialement, parce que, étant chargé de branctres vers la tête, il est plus exposé à être ébranlé par les vents. Les plantations d'automne arec une couverture sont préférables à celles du printemps; sans couverture, je préférerais planter au printemps.

Si les plantations de pin maritime réussissent ordinairement moins bien que celles des autres arbres résineux dont je m’occupe spécialement dans ce Traité, les semis de cette essence sont ceux qui réussissent le plus facilement; aussi estce presque toujours par le semis que l'on crée des pinières de pins maritimes. Ce que j’ai dit dans le chapitre précédent pages 177-184, relativement à la création d'une pinière de pins sylrestres par le semis, s'applique aussi à la création d'ume pinière de pins maritimes, cxcepté en ce qui concerne les semis de cónes, impraticables en quelque sorte pour le pin maritime, parce que ses cônes sont beaucoup plus gros et contiennent beaucoup plus de graines que ceux du pin sylvestre.

Dans le Maine, Jorsqu'on veut transformer en pinières de pins maritimes des sables couverts de bruyères, on laboure à petites raies en octobre ou novembre, le plus profondément qu'on peut. Au commencement de février, après les fortes gelées, on donne un hersage en travers des raies, puis on sème et l'on enterre les graines au moyen d'un léger hersage donné dans le sens des raies. 


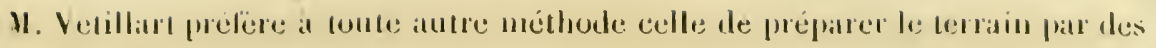
labours el des hersanes, el de le partager en planches el en sentiers; on jelle i la bèche la couche de terre végétale des sentiers sur les planches, el l'on sème: ensuite sur ces planches seulenent. J’ai décrit cette mélhode dans le ehapitre précédent. "Toutes les pinières que j’ai senées el va semer par" ce procédé, diı " II. Vétillart, page 1.1 de sa brochure, ont un tel avanlinge sur celles du mème "igge semées autrement, que je n'emploierai janais d’autre mode de semis, " malgré le surcroil de dépense. "Je concois les a vamtages que l'on se procure. ainsi fuand on erée une piniere sur de maigres sibles, tels fu'il y en at dans le Maine; mais sur des terrains plus substantiels on pourrait, en suivant ce proéélé, faire une dépense inutile on dont on ne serait pas convert.

le marquis de Turbilly (1) conseille, lorsque l'on veut créer une fulaie de pins maritimes sur des sables vifs, de les metre d'abord en bon élat de culture par des labours, ę en faisant brûler les racines des petites landes on bruyères ‘ui s’y trouveraient; d'y semer une première année du sarrasin, el l'annéc suivante, en mars, le pin maritime, après avoir mis de nouveau la terre en bun état de culture par des labours. Il appelle sables vifs ceux sur lesquels il ur: pousse rien ou yui ne produisent que de la mousse, ou de petites landes eh th: petites bruyères mêlées de quelques brins d'herbes.

On n’est point d'accord sur la quantité de graines que l'on doit semer par heclare sur un terrain qui a élé préparé par des labours, el celte quantité éprouve l'ailleurs quelques variations en raison de la nature des terres. Delamarre dit, page 91 de l'ouvrage déjà eité, qu'il faut employer pour ce semis 15 à 20 kilugrammes. Baudrillart indique (2) 17 à 20 kilogranmes. M. Vétillart, page 26 de son mémoire, s'exprime ainsi qu’il suit à ce sujet : "Il n’y a pas, dit-il, un poin " de culture sur lequel on soit moins d'accord que sur la quantité de graine de "piu à semer par liectare : depuis l'énorme quantité de 25 kilogramunes que la " direction des eaux et forèts et les hospices civils du Mans lont ensenencer. "jusqu’a la quantilé trop minime de 3 kilogrammes par hectare quemploic ".ll. Lérard aìné, il n’est pas un propriétaire qui n’ait son poids déterminé pour "ses semis, el qui ne s’imagine mieux faire que les autres. Les observations que "j'ai faites sur les semis de toute espèce, m’ont convaineu que pour semer dans " du seigle ou de l'avoine, ou sur des planches bien préparées, 12 hilogrammes "élaicnt suffisans par hectare : dans les terres oủ le pin maritime réussit ordi" nairement bien, et lorsque l'on est assuré de la bonne qualité de la graine, il y " iurait beaucoup moins d'inconvénient ì diminuer cette quantité qu'à l'auor"menter."

Je pense a vec $\mathbf{M}$. Vétillart, que 12 kilogrammes de graines parlitement bonnes, far hectare, sur une terre favorable à la culture du pin maritine, et bicn prépilrée par des labours, sont une quantité suffisinte; mats si le terrain n'est pils

(1) Pralique des défrichemens, 1. 1?.

:) Dictionnaire des caux el forets, 1. II . 1. j\$9 el $8: 0$. 
farorable au semis ou s'il n'est pas bien préparć, il est prudent d'en semer davantage; il n'y a d'ailleurs jamais d'inconvénient à semer un peu épais lorsqu'on est décidé à faire en temps utile les éclaircissages ainsi que je l'ai prescrit.

Pour faire connaître à quelles dimensions pent parvenir le pin maritime dans la localité que j'habite, pendant les premières années, lorsqu'on le sème sur une terre préparće par des labours, je rapporterai ce que j'ai observé sur ce semis d'expérience dont j’ai précélemment parlé(Voy. p. õ cl 180). La graine de pin maritime et celle de pin laricio y avaient été semées le ler $^{\mathrm{r}}$ mai 1837 , l'une après l'autre, sur un terrain excessivement pierreux, et en semant du pin maritime, je n'avais d'autre but que de m'assurer que le terrain serait promptement occupé si la graine de pin laricio ne: levait pas bien; car j'avais l'intention de supprimer peu à peu le pin maritime et de ne conserver que le pin laricio. Mais ce dernier pin ayant occupé très-promptement le terrain, il fallut, dans les éclaircissages successifs des premières années, supprimer de l'une et de l'autre espèces, et les pins maritimes disparurent bientôt; néanmoins, je conservai les dix plus beaux de ces arbres jusqu'en 1811-1812, pour comparer leurs dimensions avec celles du pin laricio. Le plus grand de ces dix pins avait à l'automne de 1811, c'est-à-dire après la cinquième sève, $2^{\mathrm{m}}, 21$ de haut, et ils avaient en moyenne $\mathbf{1}^{\mathrm{m}}, 95$.

Le semis sur une terre préparéc par des labours, qui est le procédé que l’on emploie habitucllement dans le Maine et dans l'Orléanais pour créer les pinières de pins maritimes, est employé aussi très-souvent dans les landes de Bordeaux, surtout lorsque l'on veut d'abord se procurer des échalas, mais lorsqu'il n'y a pas de débouché pour les échalas on emploie un procédé beaucoup plus économique; j'en prends la description dans une lsrochure attribuée à M. Dallier (1):

"Des femmes, placées à 2 mètres de distance les unes des autres, marchent " de front et parallèleınent; elles s'arrêtent après avoir marché 4 pas (2 mètres " environ), et font, avec une petite bêche de $0^{\mathrm{m}}, 08$ de hauteur et $0^{\mathrm{m}}, 05$ de lar"geur, une entaille dans le sable de $0^{\mathrm{m}}, 0$ a de profondeur; elles jettent dans l'ou"verture un peu béante de cette entaille 3 ou 4 graines de pin, passent leur " sabot ou leur orteil sur l'orifice de ce trou, et continuent leur marche et leur "manouvre. Jamais les bruyères auxquelles on a mis le feu, a vant ce semis, ni " les autres plantes, n’offrent une difficul té aux travailleurs; ces plantes laissent " entre elles des interstices qui présentent plus de sol nu que de sol couvert; il " leur suffit done de déranger leur bêche de quelques centimètres pour trouver " du vide, et ce vide est toujours un sable désagrégé comme celui des dunes, où " les pins se plaisent tant. Ces frais d'ensemencement sont à peine de 6 fr. par " hectare.

"Admettons qu'il vienne seulement deux arbres dans chacun des 2,500 trous, " ce qui serait trop, il suffit pour les éclaircir d'infléchir ceux qu'on voudra dé" truire, et de les casser à une partie quelconque de leur tronc : les conifères, on "Je sait, ne repoussent pas. Cette opération exigerait à peine une demi-journée

(1) Vérilés sur les landes de la Gascogne et sur la cullure forestière des pins, 1'. 6. 
"de travail. Les pins ainsi semés ont, dnamt les trois ou quatre premières an"nées, une croissince moins vigoureuse que s’ils cussent été semés dins les " dunes ou dans les landes défrichées, labourées el hersées; mais avant leur "huitième année, lorsque les racines ont plongé dans le sable et vaincu les ré" sistances que pouvaient leur oflrir les autres plantes, et que les arbres ont " étouffé ces plantes sons leur umbrage, cette différence disparait et ils arrivent,

" dès la dixième année au plus tard, à la mêne hauteur et grosseur que s'ils eus" sent été semes dans des terres próparées, bien qu’il y ait eu économie de $100 \mathrm{fr}$. "au moins par hectare. "

Le moyen économique que je viens de rapporter, employé pour créer les pinières dans les landes de Bordeaux, réussirait probablemęnt aussi bien dạs les sables du Maine et de l'Orléanais; cependant je ne sache pas qu'on l'y ait jamais employé.

Ce que j’ai dit de l'éclaircissage des futaics de pins sylvestres, crées par le semis sur une lerre préparće par des labours et des hersages, pendant les premières années, s’applique de tout point ì celles de pins maritimes créées prar la même méthode; néinmoins, je teproduirai ee que M. Vétillart dit, page 29 du mémoire déjà cite, de la manière dont s’exécute cette opération dans le Maine, praree qu'il décrit les bons et les mauvais procédés, et qu'il fait bien connaitre combien les résultats que l'on obtient, dans les deux cas, sont diflérens.

"Lorsque le semis de pin maritime est bien levé, dit-il, il ne s'agit plus, "pendant 3 ou 4 ans, que de le préserver du parcours des bestiaux, suriout des " chèvres et des moutons, qui ne manqueraient pas d'en brouter les sommités.

"La troisième ou quatrième annéc, selon la vigueur des plants, on doit conn"mencer à supprimer tous les sujets fourchus ou mal venans et mème une "partic de ceux qui sont beaux, lorsfu'ils sont trop serrés les uns contre les "autres : à cet âge, on les arrachera facilement à la main. La seule règle que "I'on puisse assigner à cette opération, qui est essentielle et de laquelle dé"pend beaucoup le succès de la pinière, c'est de la confier à un ouvrier intelli"gent, qui conserve les arbres les plus beaux et les mieux venans : ils doivent " être espacés, après l’opération, de manière que leur's branches latérales se "touchent sans se croiser. Les pins qui ont été repiqués seront traités de même "à mesure qu'ils en auront besoin.

"L'éclaircissage doit se répéter tous les ans ou tous les deux ans; les arbres se "Lrouveront beaucoup mieux d'ètre espacés peu à peu, à mesure de leur ac" croissement, que de rester pressés plusieurs ammées et de se trouver ensuite, " par un éelaircissage trop abondant, isolés et livrés à l'inlluence du grand air et " de la lumière, auxquels ils ne sont pas accoutumés; ils seraient étiolés, au" raient peu de branches latérales et ne pourraient résister aux grands vents, " qui les inclineraient. C'est pour cette raison que l'on voit tant d'arbres arqués " dans les pinières, où l'éclaircissage a été fait trop tard et sans intelligence. "Q Quelques proprićtaires n’éclaircissent qu’au bout de 10 à 12 ans; ils prétendent " que leurs pins deviennent plus longs el plus droits lorsyn'ils sont pressés, 
" qu'ils en tirent phus de revenu et qu'ils ont moins de dépense à fiare. Ciatte me" thode a sun beau côté, qui pourrait séduire quelques persommes; mais, comme " elle est contraire aux principes d'une bonne culture, je vais la combattre par "l'expérience.

"D’après ce procédé, il n’y a aucune dépense à liaire pendant les 10 à 12 pre" mières années : à cette époque, on tire de la pinière, par le premier éclaircis" sage, un bien plus grand nombre de bourrées; ces bourrées sont très-longues, " elles contiennent peu de feuilles et se vendent plus cher que celles d'une " pinière qui est souvent éclaircie. Jusque là, l'avantage parait évident; mais " que reste-t-il sur le terrain après l'éclaircissage? des arbres étiolés, très-longs, "très-grêles, presque sans feuilles et aussi gros du haut que du bas. Une telle * pinière languira pendant plusieurs années, la plupart des arbres seront arqués " par le vent et reprendront d'autant plus difficilement de la vigueur que l'éclair" cissage aura été fait plus tard; enfin, à peine au-bout de 17 ou 18 ans les arbres " seront assez gros pour faire de la corde à brùler : encore, pour cela, faudra-t-il " que la terre convienne bien à cct arbre; car que serait-ce qu'une pinière ainsi " traitéedans un terrain ingrat? Il est facile de le voir : on peut examiner une pin ière " appartenant aux hospices du Mans, située au bout du chemin de Perquois, com" mune de Pontlieue; elle a été semée en 1828 et abandonnée à elle-même de"puis celte époque : les entrepreneurs qui l'ont ensemencée réponclaient, pen"dant trois ans, du semis; dans la crainte de ne pas réussir du premier coup, " ils ont semé beaucoup plus de graine qu’il n’en fallait. Dès la seconde amée, le "terrain eùt été facilement pris pour un pré, tant il y avait de pins, qui tous se " touchaient: ceux qui n'y connaissaient rien tronvaient ce semis magnifique; " mais, au bout de quelques amnées, le sol a été épuisé, les arbres se sont man"gés les uns les autres : maintenant il en est mort une grande partie, on voil les " autres périr par milliers; à peine quelques-uns, d'endroit en endroit, ont-ils " pu étouffer leurs voisins el s'élever au dessus de ce fouillis impénétrable. Lia "pinière, âgée maintenant de 7 ans, a ì peine 4 ou 5 pieds de hauteur; et quand " même on éclaircirait, le sol est trop épuisé pour que cette plantation vaille " jamais quelque chose.

"Que l’on examine ensuite, à quelques cents pas de là, les pinières de M. Bé"rard ainé et les miennes, faites à peu près à la même époque? La question sera "résolue de la manière la plus positive en laveur de celle-ci : on y verra des alr" bres convenablement espacés, tous de même force et de même hauteur, "grands déjà de 10 à 12 pieds et ayant ă à 10 pouces de circonférence. Les pous" ses vigoureuses de chaque année ont de 1 pied $1 / 2$ a 2 pieds de longueur; les " branches latérales nombreuses sont garnies d'un feuillage êpais et d'un beau "vert qui abrite le tronc et nourrit de nombreuses et fortes racines, qui affer" missent solidement l'arbre sur le terrain et le mettent dans le cas de résister " aux plus grandes tempètes.

"Lors de l'éclaircissage des premières années, on arrache facilement les al" hres en les tirant à la main; res qu'ils sont devenus toop gros, on se contente 
"de les conper rez terre à lat serpe, ce qui se pratique jusqu'à la dixiène ou don" zième année; les arbres a cet âge sont assez espacís pour pouvoir ètre arrachés " il la pioche sans endommager ceux qui restent : le remuement de la terre, occa" sionné par cette opération, est salutaire à ceux-ci et favorise le développement " de leurs racines.

"L'éclaircissage s'opère ordinairement depuis le mois d'octobre jusqu'à la fin " le mars, parce que e’est le moment de repos de la sève. Si l'on éclaircissait "pendant l'été, il serait à craindre que les jeunes pins ne fussent saisis trop su" bitement par le soleil et la chaleur. La sève pourrait être arrètée dans les pous" ses tendres, et les arbres en éprouveraient alors un grand préjudice; et quant " au produit, les bourrées faites en été ont moins de valeur que celles qui sont " faites en liver."

Si l'on veut créer une futaic de pins maritimes en semant dans des potets, ainsi que je l'ai dit dans le chapitre précédent, il suffira de semer cinq ou six graines par potets, et l'on n'y laissera que 3 ou 4 plants au printemps qui suivra celui où l'on aura semé; on n'en conservera que 2 ou 3 le printemps suivant, et enfin qu'un seul.

Si l'on sìme sur un terrain que l'on a fait écobuer, il faut employer un cinquième de graine en sus de ce qu'il en faut sur un labour; il en est de mème pour le semis rustique et pour le semis sur brûlis. II. de Boisdhyver faisait employer, daus la forêt de Fontainebleau, de 20 à 25 kilogrammes de graines pour le semis rustique. I. de Béhague dit, dans la brochure déjà citée, qu’il employait, dans l'Orlé:mais, sur des sables maigres couverts de lnuyères, 20 kilogrammes par hectare pour le semis sur brùlis.

Le semis à la volée, sans qu'on ait fait subir aucune préparation au terain, ne doit jamais être employé, pour le pin maritime, par les raisons que j’ai données, page 183, pour ne pas semer ainsi le pin sylvestre; il présente d'ailleurs encore plus d'inconvénient pour le pin maritime que pour le pin sylvestre, parce que yuand cet arbre n'est pas maintenu à l'état serré dès sa jeunesse, il est ordinairement courbe ou crochu.

Le pin maritime a une très-belle végétation sur les dunes des landes de Bordeaux, ce qu'on attribue à leur voisinage de la mer', et à ce que le sable désagrégé, dont elles se composent, est, à 0,02 au dessous de la surface du sol, dans un état constant de légère humidité; aussi la création de futaies de pins maritimes a-t-clle été employée avec succès à la fixation des dunes dans les landes de Bordeaux. Les futaies de cet arbre semblaient propres à cet usage, non-seulement parce qu'il se trouve sur les dunes dans des circonstances très-favorables à sa végétation, mais parce qu’il y enfonce ses racines pivotantes à une grands prolondeur, et parce qu'aucun de ses congénères d'Europe n'a une végétation plus rapide que lui, pendant les premières années, d'où il résulte qu’il s’empare promptement du terrain.

La méthode pour semer sur les dunes mobiles est très-simple : on sème à raison de te kilogrammes par hechare, e'est-i-dire très-épais, ef l'on couve ce 
semis avee une couche de branches de pin maritime sur les bouts despuelles on place des perches de pin que l'on fixe à chaque bout avee de petits crochets en bọis; on protège ce travail, si cela est nécessaire, par des lignes de clayonnages fixcs, ou, ce qui a paru plus économique, par des barrages en planches. Ces travaux sont dispendicux à cause du prix élevé des transports dans des sables où il n'existe point de chemins entretenus. Le procédé que je viens de décrire a été mis en pratique avec succès, près de la baie d'Arcachon, par Bremonticr, ingénieur des ponts-et-chaussées. Il commençait par un travail préparatoire qui consistait à semer en pins, ainsi qu'il vient d'être dit, une zône de 60 à 100 mètres au pied des dunes, sur cet espace de surface plane, ordinairement de 200 à 250 mètres de large, qui se trouve entre les dunes et la ligne de laisse des plus hautes marées. Ce travail préparatoire n'est pas indispensable, on peut y suppléer par des lignes de clayonnages ou de barrages en planches.

11 me semble qu'on devrait réussir à fixer les duncs en y repiquant du plant herbacé de pin maritime, ainsi qu'on le fait avec du plant herbacé de pin sylvestre sur les dunes de IIollande (Voy. p. 175), et en protégeant ces repiquages au moyen de lignes de clayonnages fixes, ou de barrages en planches.

Je vais rapporter sommairement quatre excmples de créations de futaies de pins maritimes, par le semis, dans des circonstances particulières.

Dubamel dit (1) que l'on sema en 1756, 1757 et 1759, dans la forêt de Rouvray, près de Rouen, de la graine de pin maritime sur une plantation de bouleau ainsi qu'il suit : Le terrain était un sable assez aride sur un sous-sol de grus gravier mêlé de sable, et il était couvert de courtes bruyères. On mit le feu à la bruyère, on laboura le terrain en plein, et l'on creusa davantage les sillons, dans lesquels on planta du bouleau pendant l'automne; quatre mois après, on sema sur cette plantation de la graine de pin maritime et l'on hersat dans le sens des sillons, ce qui ne causa aucun dommage sensible au plant de bouleau. Ce semis réussit et domna naissance à une pinière que l'on a exploitée, à blanc-étoc, en 1803; je parlerai de celte exploitation dans l'article suivant. Je pense d'ailleurs qu'il aurait été prélérable de ne point mêler le bouleau et le pin maritime, qui ne pouvaient que se nuire réciproquement, et de cultiver l'unc on l'autre de ces espèces, selon ce que réclamait le terrain.

M. J. Rieflel a fait connaitre dans une revue trimestrielle, intitulée Ayriculture de l'ouest de la France, les travaux qu'il a exécutés sur' l'établissement agricole de Grand-Jouan (Loire-Inférieure), particulièrement pour mettre en culture des landes; il parle, 1. II , p. 29 , des bois pour chauffage, et de l'utilité des abris pour les cultures dans certaines situations, et en particulier dans celle où il se trouve. Il dit que le pin maritime est, à Grand-Jouan, l'arbre qu'il faut cultiver pour obtenir le plus promptentent du bois de chauffage et des abris, en créant des rideaux d'une largeur moyenne de 15 mètres. Selon $M$. Rielfel, il y a une trèsgrande différence, à Grand-Jouan, entre les semis laits sur un terrain écobué et

(1) Des semis el planlations de's arbres, p. iss. 
cultivé ensuite comme pour y semer une céréale, et ceux que l'on fait sur un simple labour ou sur un simple hersage après un écobuage ou un brùlis; il a donc adopté la première méthode. "Quand on se sert, dit-il, de l'écobuage, " On fait une récolte de seigle, et c'est daus cette récolte, au printemps, que l’on "sène la graine de pin, absolument de la même manière fu'une prairie artili" cielle. On pisse sur le semis une simple herse d'épines que l'on promène dans " la cérúale. La graine de pin demande à peine d’être enterrée. Voici les détails "des frais, sur un hectare, d'un semis de pins maritimes, avec l'emploi de l'i" cobuage :

"E. Éoluage et brûlis. . . . . . . . . . . . $90 \mathrm{fr}$.

"Un lahour. . . . . . . . . . . . . . . . . 12

" Main-d'œuvre pour répandre les cendres et casser les mottes. 15

"Semence de seigle, 2 hectolitres ì $11 \mathrm{fr} . \ldots . . . . .29$

"Graines de pins, 20 kilogrammes ì 60 cent. . . . . . . 12

"Chemins et fossés d'écoulement. . . . . . . . . . 5

"Frais de la récolte de seiglo. . . . . . . . . . . . 36

"Total pour un hectare. . . $1912 \mathrm{lr}$.

"Ians la plupart des cas, cette récolte de seigle, sur écobuage, donue au moins " 18 hectolitres à l'hectare." Ainsi les frais sont couverts, et l'on a encore la paille en bénéfice. Le fait que j'emprunte à M. Rieffel vient encore à l'appui de ce que j’ai dit, page 181, que, généralement parlant, le semis du pin maritime, ainsi que celui du pin sylvestre, réussit d'autant mieux que la terre est mieux préparéc.

Dans le même recueil, t. 11 , p. 571, M. le baron dı Taya dit que la méthode qui lui a le mieux réussi pour convertir les landes arides et les terres élevées presque improductives en futaies de pins maritimes, est une méthode qu'il appelle semer à poteaux, et qui n'est autre que celle que j’ai décrite sous le nom de semis en potets. Elle consiste à cultiver dle petites surfaces circulaires d'un mètre de diamètre, dont les centres soient à la distance de 3 mètres en tout sens les uus des autres; on les débarrasse d'abord des bruyères, ajoncs ou mousses qui les couvrent, en se servant de l'écolue; on les défonce ensuite profondément à la pioche, on dispose la terre en butte, vers le milieu, et l'on y sìme quelques graines. M. du Taya ne paie que 25 centimes par chaque poteun, prix auquel il serait difficile de les faire exécuter ailleurs qu'en Bretigne.

II. J. L. Trochu a fait exécuter en Bretagne, dans l'ile de Belle-lsle-en-.ller, des semis de pin maritime sur des défrichemens de landes, par un procédé qui me paraît bon et économique; il commença à le mettre en pratique en 1811 (1). 11 partageait son terain en planches parallèles et ayant alternativement, les unes, 3 pieds $\left(0^{\mathrm{m}}, 97\right)$ de large, les autres 10 pieds $\left(3^{\mathrm{m}}, 25\right)$. 11 défrichait toutes les plan-

(1) Du défrichement et de la plantation des landes et truyères, article insérí dans te 1. XI, 2e sćic,

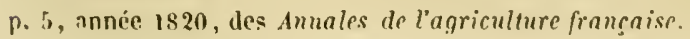


ches de 3 pieds de large et y semait du pin maritime qui finissait par étouffer les landes qui se trouvaient sur les planches de $\mathbf{1 0}$ pieds de large. Pour défricher les petites planches, il procédait ainsi qu'il suit : Il employait une forte herse rectangulaire de 3 pieds de large sur 6 de long, ayant sept rangées de dents en fer, longues de 3 pouces $\left(0^{\mathrm{m}}, 08\right)$, tranchantes comme un coutre, recourbées du côté du tirage, espacées de 4 pouces $\left(0^{m}, \mathbf{1 1}\right)$ les unes des autres et disposées en quinconce. Cette herse avait des mancherons, comme une charrue, pour quion pût la diriger et augmenter ou diminuer la pression sur le sol. On coupait rez terre les landes des planches les moins larges qui devaient être défrichées, et celles-lì seulement, en octobre et novembre; on faisait passer quatre ou cinq fois la herse sur chacune de ces planches; on recommençait la même opération au mois de mai et au mois de septembre de l'année suivante, et enfin une dernière fois au mois de février suivant. Aussitôt après ce dernier hersage, on semait épais et l'on faisait passer un rouleau en bois sur le semis pour fixer la graine; quelquefois I. Trochu semait, en même temps que la graine de pin maritime, deux fois autant de graine d'avoine. Les semis de pin sylvestre et de pin laricio réussiraient très-bien par ce procédé.

Le bas prix de la graine du pin maritime, la facilité avec laquelle elle lève, le peu de chevelu qu'ont les racines de cet arbre qui s'enfoncent profondément en terre, l'engrais que le détritus de ses feuilles procure à la terre, rendent son emploi très-avantageux pour occuper momentanément le terrain, lorsque l'on fait des semis d'autres espèces d'arbres; on le sacrifie ensuite par des éclaircissages successifs à mesure que le plant qu'on a voulu protéger, prenant de l'accroissement, s'empare du terrain: on peut alors semer une moindre quantité d'une graine qui serait plus chère, qu'on n'a pas autant de certitude d'avoir bonne que celle du pin maritime ou dont le semis ne réussit pas aussi bien. On évite ainsi que le terrain ne se gazonne ou ne se recouvre des plantes que l'on avait voulu extirper, ce qui est on ne peut plus important.

Il me paraît in téressant de rapporter comment on protége par ce moyen les semis de gland, en Orléanais, dans des sables où peut croître le chêne : on emploie les deux procédés suivans. On sème an printemps, et l'une après l'autre, la graine de chêne et celle de pin maritime; le gland d'abord, parce qu'il faut l'enterrer plus profondénent avec la herse de fer; la graine de pin maritime ensuite, et on la couvre très-légèrement, ainsi que je l'ai dit. D'après Hartig (1), il faut de 18 a 24 hectolitres de gland pour semer un hectare, selon que le terrain est plus ou moins favorable; Baudrilları dit, à l'article Chêne (2), qu'il en faut 16 à 18, mais il en faut beaucoup moins lorșue l'on sème en même temps de la graine de pin maritime. On emploiera 9 à 10 kilogrammes de cette dernière graine par hectare. On éclaircira successivement pendant les années qui suivront le semis quand il sera nécessaire, en sacrifiant le pin maritime, qui a une croissance beạucoup plus

1. Baudiblarl, d'aptès Ilartig, Dictionnaire des eaur el forfts, t. II, p. $\$ 20$.

2) Diftionnare des saux et forfits, 1. Ier, p. (124. 
rapide que le chêne pendant les premières ammées. P’ar la sceonde méthode, on sème de la grainr de pin maritime, el l'on oblient une pinière qui a bientô élouffé toute rspèce de végétation; six à lunit ans après le semis, on éclaircit dr manière à ce que le sol se trouve à mi-ombre, et l'on sème du gland l'automne ì III mètre de distance en tont sens; quatre ans après, on recèpe les chênes el l'on coupe tous les pins. La première mélbode est généralement préférable, et l’on olltient le taillis de chêne six ou lunt ans plus tôt; mais il faut employer la seconcle, qui améliore le terrain pendant six ou huit ans, par la chute des feuilles 't lil décomposition des racines, quand on juge celle préparation nécessaire.

Cette opération pourrait s'exécuter aussi en semant en lignes à la charrue, er yui procurerait une légère économie de semence; on metlrail les lignes à $0^{\mathrm{m}}, 32$ au moins les unes des autres, et l'on alternerait les lignes de chêne et le pin; on sèmerait la graine de pin maritime sur la raie, car si on la semait dessous elle serait trop enterrée, et l'on passerait un rouleau sur le semis pour l'appuyer, ainsi que l'on fait quand on sème de la carotte à la cloarue. On pourrait aussi semer d'abord le pin maritime par lignes ì $0^{\mathrm{m}}$, fro les unes des autres, et dans les Irois années qui suivent le semis, quand arriverait une année de gland, on en simerait lautomne entre les lignes à la pioche; on ferait porter les éclaircissages sur lı's pins, ainsi qu’il a été dit plus haut.

Vill. Exploitation, aminagement et riprondction. - Ce que jai dit dans l'art. VIII, du chapitre du pin sylvestre, peut s'appliquer en grande partie au pin maritime; j'y renvoie done mes lecteurs, et je ne consignerai dans cet article que ce qui est particulier au pin maritime.

Le pin maritime ue peut rester aussi longtemps que le pin sylvestre dans son écoree apròs qu'il a éte abattu; il se gâte au bout de peu de mois, ce qui est indiqué par la couleur noirâtre que prend alors son bois; j’ai conservé du pin maritime pendant plusieurs mois dans son écorce, et au bout de quatre mois apris l'aballage il était déjà gâté. Ainsi s’il est utile de laisser le pin maritime dans son écorce, comme les sapins et le pin sylvestre, pendint quelques semaines avant que de l'équarrir; on ne doit jamais l'y laisser longtemps et je crois prudent de le débiter au plus tard dans le second mois qui suit l'abattage.

La futaie de pins maritimes qui fut semée dans la forêt de Rouvray, près de: Rouen, en 1756, 1757 el 1759, ainsi que je l'ai dit page 220, d'après Duhamel, fut exploilée en 1803, 1804 el 1805 par M. Lebon, auquel on l'avait venduc. Delamarre rapporte (1), d'après M. Ricard, qui avait alors cette forêt dans son inspection, que ces pins dépérirent si promptement après l'aballage, que M. Lebon n’en trouva aucune offre, malgré le prix élevé des bois à Rouen. Il attribue la perte que fił cet acquéreur à ce qu’il avait laissé les pins maritimes des mois entiers sur le sol sans les faire débiter, et à ce qu’il n’avait eu égard ni aux phases de la lume, ni à la sève, aỵant abattu une partie te son bois penckant l'élí. 
Mettant de còlé les phases de la lune, il suffit, pour expliquer le désastre de I. Lebon, de dire qu'il avait laissé les pins maritimes trop longtemps dans leur écorce sans les équarrir. Je pense aussi, et c'est une opinion généralement accréditée dans le Maine et dans l'Orléanais, qu'il est nuisible à la qualité du bois de cet arbre de l'abattre pendant qu'il est en sève.

Il y a les mêmes inconvéniens a exploiter les futaies de pins maritimes en jardinant, et par la méthode mixte, que celles de pins sylvestres; et il faut ajouter que les pins maritimes sont toujours courbes ou crochus lorsqu'ils ne croissent pas à l'état serré; cependant la forme de la tête des pins maritimes contraindrait, si l'on employait ces modes d'exploitation, à les tenir moins serrés encore que les pins sylvestres, pour favoriser la naissance et l'accroissement du recru. Ainsi on ne doit employer pour les futaies de pins maritimes aucune de ces deux méthodes d'exploitation; on doit maintenir les futaies de cet arbre à l'état serré par des éclaircissages successifs, et les exploiter lorsqu'elles ont atteint leur maturité par l'un des trois autres modes d'exploitation que j'ai décrits pages 83-99. L'exploitation par éclaircies réussirait encore moins bien, je pense, pour le pin marilime que pour le pin sylvestre; l'exploitation parcoupes rases par bandes étroites présente les mêmos chanees de réussite pour ces deux pins. Mais celle qui convient le mieux pour le pin maritime est l'exploitation par coupes rases. On crée ensuite une nouvelle futaie sur l'emplacement de l'ancienne par le semis, ainsi que je l'ai dit pages $214-219$, si l'on veut y continuer la culture du pin maritime.

Les pins maritimes, dans les futaies maintenues à l'état serré par un éclaircissage successif et bien conduit, s'élaguent seuls comme les sapins et le pin sylvestre, et leurs branches inférieures meurent même plus promptement que celles de ces arbres; il semblerait done qu`il n’est pas plus nécessaire de les élaguer qu'eux. Mais les branches inférieures des sapins et du pin sylvestre, lorsqu'ils ont crù en futaic à l'état serré, meurent, tombent, et il n'en reste aucune trace sur le tronc; dans le pin maritime au contraire, dit I. Delamarre (1), d'après II. de Menjot d'Ebenne, propriétaire dans le Maine, une partie des chicots s'incorpore dans le trone, ce qui y forme des vides lorsqu'on le débite. S’il en est ainsi, il est nécessaire, lorsqu'on se propose d'obtenir du bois d'œuvre, d'élaguer les futaies de pin maritime. Je pense d'ailleurs qu'il suffit, ainsi que dans les futaies des trois espèces d'arbres dont j’ai déjà parlé, de débarrasser les trones des branches mortes et de celles qui, étant étiolées, sont destinées à mourir un peu plus tard; il est toujours utile aussi d'élaguer les arbres les lisières, ainsi que je l'ai dit page 7 ó. Quoiqu'il me paraisse nuisible d'élaguer plus que je ne viens de le dire les pins des futaies de pins maritimes tenues à l'état serré, je rapporterai ce qui se pratique dans le Maine, où l'on élague les arbres de ces futaies, pour tirer un produit de cet élagage, de manière à leur causer, selon moi, un véritable dommage; je suis d'ailleurs disposé à croire que ce qui a été généralement adopté clans un pays est sinon utile, en n'envisageant que l'améliora-

(1) Traite piratique de la culture des pins ì grandes dimensions, r. I (6S. 
tion de la fuaie, du moins avantagenx sous le rapport pécuniaire. Je me contenterai de rapporter à ce sujel ce que pratique M. Renard dans les propriétés de II. Ie comte de Nicolai, qui contiennent beaucoup de pinieres, et ce que preserit M. Vétillart dans son mémoire.

Le premier lait marcher de frout l'éclaircissage et l'élagage, et conduit ces ıleux opérations différemment, selon que la futaie, occupant ces sables arides dont on ne peut tirer un revenu que par la culture du pin maritime, est destince ¿̀ être abattue a 30 ans pour être convertie en bois dle chauffage; on qu'occupant un terrain plus substantiel, on vent la conserver assez longtemps pour en obtenir du bois d'ocuvre. Dans le premier eas, il éclaircit de manière à ce que les pins se trouvent à l'àge de 7 à 8 ans à la distance moyenne de $0^{\mathrm{m}}, 60$ à $0^{\mathrm{m}}, 80$; à l'âge de 9 à 10 ans, il éclaircit et élague, en laissant à la cime quatre ou cinq étages de branches; à l'âge de 14 à 15 ans, mêmes opérations; et à 20 ans on l'épiete, pour la dernière fois, ces deux opérations, qui produisent de 15 à 18 stères de bois par hectare. Les pins doivent conserver alors huit étages de branches an moins, et doivent être éloignés l'un de l’autre de 2 ì 3 mètres en tout sens, quelquefois de 4 mètres par exception. Dans le second eas, les échaircissages doivent être plus largement faits même dès les premières années et continués plus longtemps.

Jai déjà reproduit textuellement ce que M. Vétillart dit, dans son mémoire, de l'éclaircissage; je vais reproduire aussi ce qu'il dil de l'élagage : "Les pius "semés et éclaircis successivement peuvent se passer de l'úlagage jusqu'ì l'îge " de 15 ans, parce qu'à cet âge les arlores en massil' ont à peine quelques bran" ches qui puissent, par leur grosseur, faire du tort au tronc; et cela paree que " heaucoup de branches inférieures se sont desséchées, sont tombées naturelle:" ment, ou bien ont été enlevées sans précaution par les indigens auxquels les "propriétaires ont coutume de les abandonner : il reste autour du tronc heau" coup de chicots de 6 ponces à 1 pied $\left(0^{\mathrm{m}}, 16\right.$ à $\left.0^{\mathrm{m}}, 32\right)$ de longueur, secs el cassés " inégalement. On doit faire couper avec soin, el le plus près possible du trone, " tons ces restes de branches mortes, et supprimer en même temps toules celles " (qui n’ont pas une grande vigueur et qui ne sont pas bien garnies tle feuilles, cn " laissant au sommet de l'arbre huit ì neuf couromnes de branches. J'ai tou" jours reconnu que l'élagage était extrêmement uuisible dans la jeunesse des ar" bres, et je recommande de le faire le plus tard possible et avec grande modé"ration.

"Après cette opération, des pins de 20 ans doivent a voir 20 ì 25 pirds $\left(6^{m}, 50\right.$ ì " 8 mètres) de tige avant la première couronne. Je ne conseille pas d'élaguter " une seconde fois : la valeur du hois d'ouvrage étant plus considérable à raison " de son diamètre qu'à raison de sa longneur, et l'aceroissement en grosseur " élaut proportionné à la quantité de branches et de fenilles, plus les arbres an"ront de branches, phus ils gagneront de grosseur et de valeur. Les pins isolés, " placés sur le horld des rontes ou sur les lisières des bois, réclament l'élagage "plus lit yue reux yui sont ro massif, soil pour supprimer les hranches latéra- 
"les, qui prendraient trop d'extension aux dépens de la tige principale, soit pour " dégager les lisières des bois et permettre à l'air, ainsi qu'à la lumière, un " accès plus facile dans l'intérieur des massifs; dans cette circonstance, on "élague les pins plusieurs fois, en supprimant seulement une ou deux couronnes " de branches à chaque fois.

" Lorsque l'on coupe un trop grand nombre de branclues aux pins, en ne lais" sant que trois ou quatre couronnes au sommet, conme le font beaucoup de "propriétaires, l'arbre déponillé d'une partie de ses funilles grossit lentement; " et, lorsque l'opération est répétée plusieurs fois, l'arbre s'épuise et le bois perl " une partic de sa qualité : j’ai en l'occasion de faire souvent cette remarque "dans le département de la Sarthe, dont presque toutes les pinières sont soi"gnées par des procédés différens, et clont plusicurs proprićtaires font élagner "tons les sept ou huit ans. Je recommande aux propriétaires qui ont des pins

" de conserver, comme je le fais, huit ou neuf couronnes de branches ì tous les " arbres lorsqu'on les élague.

"L'élagage des pius peut se pratiquer depuis le mois de novembre jusqu'au " mois de mars; le très-grand froid n'a d'autre inconvénient que de rendre le bois "plus cassant et l'opération plus difficile pour les ouvriers: je n'ai jamais pu re" marquer, malgré l'attention que j'y ai apportée, que la gelée ait eu aucune: " action malfaisante sur le corps des arbres nouvellement élagués. J'ai aussi " coupé des branches de pin pendant l'été, sans que les arbres aient paru en "souffrir : cependant la résine a coulé beaucoup plus abondamment, et, sans " doute, il y a eu une plus grande déperdition de sève; aussi il est convenable " de s'abstenir de couper aucune branche lorsque la sève est en pleine activité. "

On a remarqué dans le Maine que le terrain sur lequel il y a eu une futaie de pins maritimes, que l'on a exploitée à blanc-étoc pour la remplacer par une autre futaic de mème essence, n'est plus aussi propre à cette culture, puisque la nouvelle futaie est toujours moins belle que celle qu'elle remplace. Aussi est-on dans l'usage de laisser reposer la terre pendant deux ou trois ans avant de l'ensemencer de nouveau, el il est très-utile de la labourer pendant qu'elle est livrée à ce repos. Cette observation est en opposition avec celle qu'avait faite M. Stephens relativement à des futaies de pins sylvestres dans les environs de Breda (Voy. p. 186); il est vrai que dans le Maine les branches mortes, les cônes et les feuilles, qui sont destinés par la nature à enrichir le sol, sont enlevés par les propriétaires ou par les pauvres, ce qui doit exercer une fâcheuse influence, et qu'il n'en est péut-être pas ainsi dans la forêt de Breda.

Le revenu que l'on peut tirer des futaies de pins maritimes dépend d'abord de la facilité d'en vendre les produits, ce qui u'est pas toujours possible, parce que les terres arides où on le cultive de préférence, comme seul moyen a'en tirer un revenu, sont souvent situées dans des pays peu peuplés. Ainsi, dans une partie des landes de Bordeaux, on ne peut tirer un revenu des pins maritimes que par l'extraction de la résine; on peut citer des pinières de pins maritimes, dans l'Orlíanais, qui naguère ne prodnisaient pour ainsi dire point de revenu, 
à cause de la difficulté des transports. Sous le climat de Paris, il n'y a guère encore que le Maine et l'Orléanais où l'on puisse trouver des exemples d'un revenu régulier produit par des futaies de cet arbre. Dans la première province, oì il est cultivé depuis plus longtemps, on coupe à trente ans les lutaies de pin maritime qui se trouvent sur des sables arides, of on convertit le bois en corles à brùler ou en charbon. Sur des terrains où il pourrait atteindre à des dimensions qui permettraient de l'employer comme bois d'ouvre, il est presque toujours plus avantagenx de le vendre comme combustible lorsqu'il a de 30 at 35 ans, le bois d'ouvre de cet arbre ayant peu de qualité.

Les pinières de M. le comte de Nicolaï, situćes à quatre lieues du Mans, produisent à trente ans 160 à 200 stères de bois par hectare, selon la qualité du terrain, non compris les racines et la cime de l'arbre, dont le produit couvre les frais d'exploitation; le stère se vend ordinairement 3 fr. 33 c. Ce capital se renouvelle tous les trente-trois ans, parce qu'on laisse reposer la terre pendant trois ans entre l'exploitation et le semis qui la suit. Le bois de pin maritime qui a son écorce est désagréable à brûler, parce qu'il pétille et en lance au loin des morceaux. Ce bois est principalement employé pour les usines, telles que tuileries, boulangeries, fours à chaux, blanchisseries, etc. Le charbon du pin maritime est bien inférieur à celui du chêne, et même à celui du pin sylvestre; mais il s'emploie avantageusement dans les forges, ayant la propriété de rendre le fer plus ductile.

M. Vétillart résume ainsi qu'il suit les revenus que l'on peut obtenir d'uinc pinière bien conduite et qui a réussi dans les environs du Mans, c'est-à-dire daus des circonstances de tous points favorables :

"Les landes ou mauvaises terres dans lesquelles on sème le pin ma" ritime valent communément $450 \mathrm{fr}$. l'hectare. . . . . . . . . 450 "

"Il en coûte pour le labourage et le hersage 50 fr. par hectare. . . 50 "

- "Façon pour relever la terre des allées sur les planches, pour semer " et enterrer la graine, $30 \mathrm{fr}$. par hectare. . . . . . . . . . " 20 livres de graine de pin maritime à $15 \mathrm{c}$. la livre, une livre de pin " d'Ecosse à 3 fr., ou un quart de livre de pin laricio à $12 \mathrm{fr}$.; total pour " ensemencer un hectare, $6 \mathrm{fr} \ldots \ldots \ldots \ldots$

"Clôture et autres menus frais, environ $20 \mathrm{fr}$. . . . . . . . . .

"Total, $556 \mathrm{fr}$. pour l'achat et l'ensemencement d'un hectare de terre.

"Une pinière ainsi semée-ne donnera de revenu qu'au bout de cinq " áns : dans les cinq premières années les soins d'éclaircissage coûtent "plus que ne valent les pins enlevés; je compte pour ces soins $10 \mathrm{fr}$. "par hectare qui sont plus que suffisans. . . . . . . . . . .

n Il faut ajouter à cette somıne l'intérêt à 5 p. $0 / 0$ de la première mise

: de fonds, on 28 fr. $30 \mathrm{c}$. par an; pour cinq ans l'intérêt sera de. . . 14150

"Un hectare de pins maritimes mélangés de pins d'Ecosse et de pin laricio, 
" cultivé et semé avec tou le soin possible, contera done an propriétaire envi" ron 707 fr. à l'âge de cinq ans.

"Voici le revenu que l'on peut en tirer:

"De cinq à douze ans, on obtiendra tous les ans d'un hectare 5 à 600 bourrés, qui vaudront, nets de frais, 6 à 7 fr. le eent; on peut les compter pour. 3̌ fr.

"De douze à scize ans, on fera deux charrctées de corde à brûler, à 7 fr. la corde. ............................ 11 "

"Plus 250 à 300 bourrées à $10 \mathrm{fr}$. le cent. . . . . . . . 25 "

Tolal par an. .............. 39 ".

"De seize à trente ans, les éclaircissages fourniront tous les ans deux charre"lées de bois de toise, à $10 \mathrm{fr}$. . . . . . . . . . . . . . . . . 20

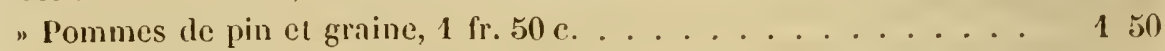

" 200 bourrécs, à $10 \mathrm{fr}$. le cent. . . . . . . . . . . 20 "

Total par an................. 1150

"Je néglige le revenu de la bruyère, qui rapporte souvent 3 fr. par hectare; " mais elle se consomme le plus sonvent par les fermiers, qui s'en servent en "place de paille pour mettre sous les bestiaux; elle croit naturellement sous les "pins, et doit être mise en coupe réglée de trois ou quatre ans.

"Lorsqu'une pinière mélangée de pins d'Ecosse el de pins laricio a plus de "trente ans, le revenu augmente chaque année; car si l'on enlève moins de " sujets, ils ont chacun une bien plus grande valeur. Arrivé à l'âge de trente ans, ") un pin doit valoir $1 \mathrm{fr}$. כ̃o c. ì $2 \mathrm{fr}$.; à quarante ans, il vaut $3 \mathrm{fr}$. à $6 \mathrm{fr}$. ; de cin"quante à soixante ans, il y en aura de 10 à 12 fr. ; de quatre-vingts à cent ans, " il doit y avoir des pins d'Ecosse et des laricio, dont quelques-uns peuvent val" loir $100 \mathrm{fr}$. Dans une pinière mélangée de pins d'Ecosse el de laricio, el où ceux" ci trouvent une terre et un elimat convenables, le revenu à un certain âge est " considérable, et la coupe à blanc-étoc inappréciable. Je ne fais ici que laisser. " entrevoir cet avantage pour encourager la multiplicalion de ces espèces pre" cieuses, et je laisse à l’expérience de nos descendans le calcul de la jusıe "valeur.

"J'ai dit $1^{\circ}$ qu'un hectare de pins maritimes, ensemencé, bien cultivé et ar"rivé à l'âge de cinq ans, coûtail environ $707 \mathrm{fr}$. $2^{\circ}$ qu' un hectare de pins mari" limes rapportait ammuellement de 35 à $\mathbf{~} \mathbf{1}$ fr. depuis l'âge de cinq ans jusqu'à "l'âge de.trente ans. Le propriétaire retire donc au moins 5 p. 0/0 par an d'une " culture bien entenduc et bien réussic.

"Examinons maintenant quelle est la valeur d'une pinière de trente à qua" rante ans. Je vais citer un exemple récent, qui est de notoriété publique et qui " est propre à éclairer la question. Un cultivateur de pins maritimes, très-dis" lingué, et dont les commaissances et les bons exemples ont beaucoup contri" bué à perfectionner la culture des arbres résineux, M. Bérard aînć, a vendu, " en 1832, la superficie d'une pinière de 12 hectares, âgéc de trente-cinq ans, "pour la sommo de 2 t,000 frances. . . . . . . . . . 21,000" 
Iriporl.

21,000

"Le fonds vaul encore 5,100 linincs. . . . . . . . . . . . 5, 100"

"Total de la villeur eles 12 liechares. . . . . . . . . . . . . . . 400"

"O॥ 2,150 fr. l'hechare; or si de celle somme nous déluisons 700 l'r. pour pre" nlière mise de fonds, il reste 1,750 fr. que $\mathbf{~ 1 t . ~ B e ́ r a r d ~ a ~ r e t i r e ́ s ~ d e ~ b e ́ n e ́ f i c e ~ n e t ~}$ " de sa dernière coupe : ce qui lail deux fois et demic sa mise.

"La pinière dont nous venons de parler a toujours été soignée avee une intel" ligence dont on n'avait pas encore eu d'exemple dans le Maine. Le sol est un " Sable très-siliceux, maigre, profond, quelquefois caillouteux et arès-cunve" nable au pin maritime. Cliteue arbre élail très-vigoureux el très-beau à voir. "Ils onl été vendus sur pied de 2 fr. l'un dans l'autre, mais il y en avait qui "Valaient 8 el 10 fr. pièce. On croil généralement que celle pinière a élé vendue "fort cher : il est vrai que la beauté de tous les arbres a séduit l’acquéreur; " inais quand même elle cut été vendue un einquième au dessus de sa rigonteuse " valeur, il serail encore vrai que le propriétaire aurait retiré un bénélices net "égal à deux fois sa première mise de fonds. Ce résulıt esı bien loin d'ètre " aussi merveilleux que le résultat promis par M. Delamare, mais il a le mérite " de la réalité. Je ne préténds pats néammoins que la terre vaudra partout 450 fr. ") l'hectare, que les bourrées et le bois d'ouvrage auront toujours la valeur que " je leur assigne; la qualité du sol el la position locale de la pinière feront né" cessairement varier beaucoup celte valeur, et par conséquent celle du revenu.

"La proximilé des grandes routes, des villes, des forges, des fours à chaux, " des usines en général, la rareté des autres bois, le bas prix du sol el de la " main-d'oeuvre sont des faveurs de localité qui donneront de grands avantages " aux cullivateurs de pins. Mais les ravages des insectes, le sol peu convenable " et peu profond, l'éloignement des usines, la difficulé ét le prix élevé de la " main-d'oeuvre et des transports, enfin la matuvaise culture, sonl des chances " loul-à-fait désavantageuses el mème désastreuses. Les caleuls que j’ai présenlés " ne peuvent donc pas être exacts pour loules les localités; mais ils serviront de " base certaine et de modèle à tous les cultivateurs qui, d'après leurs propres " connaissances, pourront caleuler les chances de leur semis de pins et sauront " comment s'y prendre pour en tirer parti.

"L̈intérêt force quelquefois les propriétaires à abattre, au bout de ırente-cinq „ou quarante ans, les pinières dont l'essence est seulement de pins maritimes. "La pinière do M. Bérard, que j’ai cilée, me servira encore à établir des cal" culs qui prouveront cela évidemment. Cette pinière a été vendue 24,000 fr., " et contenail 12,000 pius; ils avaient, par conséquent, une valeur de 2 fr. pièce. " Si M. Bérard eùt laissé crô̂tre cette pinière pendant vingı ans de plus, il cù " fallu nécessairemont supprimer les deux tiers des arlures par des éclaircissages " successifs. J'admets que les huit mille pins enlevés pentant ces vingl ans aient "pilyé l’intérè de 24,000 li., valeur de la pinière; il restera, au bout de ces n) vingh ans, 1,000 pins seulenemt : pour qu'ils représentent le capilal de 
„24,000 fr., il faut qu'ils aient une valeur de 6 fr. l'un dans l'autre, ce qui peut

"être considéré comme un maximum.

"Admettons encore ce nec plus ultri, la position de M. Bérard se trouverait, " dans vingt ans d'ici, ce qu'elle est aujourd'hui; il eùt perçu 5 p. 100 de ses

" fonds sans avoir eu d'augmentation de capital, et il eût couru les chances dé-

"favorables à sa plantation pendant vingt ans. La position de M. Bérard est

" beancoup plus avantageuse par le parti qu'il a pris de vendre. Il est rentré dans

" un capital de 24,000 fr. qui lui produiront intérêt; il a ensemencé de nouveau

"son terrain, qui, au bout de vingt ans, se trouvera garni d'une nouvelle

"forêt dont la valeur sera alors de 10 à $12,000 \mathrm{fi}$. : cette somme est un béné-

"fice réel qu'a fait $\mathbf{M}$. Bérard en vendant sa pinière à l'âge de trente-cinq ans.

"Cette pinière avait donc acquis le maximum de sa valeur avant que les pins

" maritimes eussent atteint le développement auquel ils pouvaient parvenir. Cet

" exemple suffira pour convaincre les cultivateurs de pins qu'il faut, dans la

" pratique agricole et forestière, calculer l'accroissement de la valeur des ré" coltes et l'intérêt des fonds qu'elles représentent, pour maintenir toujours une " Lalance avantageuse de valeurs."

Je vais actuellementreproduire des renseignemens que M. le baron de IIorogrues a vaitadressés à $\mathbf{M}$. Vilmorin sur le revenu des pinières de pin maritime dans ]'Orléanais, et que ce dernier a placés dans une note de la troisième édition duTruité pratique de lu culture des pins à grandes dimensions, de Delamarre, page 300.

"Convaincu plus que personne, dit M. de Morogues, de la nécessité des notes " que vous ajoutez à l'ouvrage de M. Delamarre, pour désabuser le public des " principales erreurs qu'il renferme, je m'empresse de vous transmettre le ré"suitat de mes observations. Possesseur par moi-même, ma famille et mes " anis, de plusieurs mille hectares de pins dans la Sologne, et m'étant beau" coup occupé de leur culture et de leur exploitation, je crois que les renseigne" mens ci-après sont aussi exacts que possible.

"Nos pins maritimes, espèce la plus répandue et la plus productive dans nos " cantons, où il y en a peu d'autres en très grandes tenues, sont presque tou" jours semés sur des terres arables, usées par un maurais assolement et une " mauvaise culture; c'est sur ces terres qu'ils réussissent le mieux quand le sol "d'alluvion sur lequel nous les semons n'est pas trop mouillé, ou quand il peut " être égoutté; les semis sur défrich is et sur bruyère réussissent moins bien. Les "terrains quartzeux sont les meilleurs pour le pin maritime; les terrains calcai"res et marneux ne lui conviennent pas.

"Jusqu'à ce moment, nos bois de pins ne se ressèment pas d'eux-mêmes " d'une manière profitable; nous les semons à la charrue sur labour: plus la "terre est meuble et nettoyée d'herbes, mieux ils réussissent; 17 kilogrammes " de graine de pin maritime sont très-suffisans pour un hectare; 12 kilogr. " même suftisent quand la terre est bien labourée.

"La valeur de nos bois de pins dépend uniquement de la facilité des débou" chés. $\Lambda$ Orléans, la corde de clıêne vauı $52 \mathrm{fr}$; ; elle en vaut 40 à une ou cleux 
"Lienes d'éloignement. La corde de pin se vend de 30 à 32 fr. à Orléans, el de 201 " à 22 fr. à une ou deux licues, à cause de la voiture et des entrées. Notré corde " est celle de forèt, équivalant à deux voies de Paris, ou 3 st. 839. Près de lit "ville, à une ou deux lieues d'Orléans, au dessus du coleau du Loirer, l'hectare " de nos bois de pins maritimes produit en grande tenne :

Cordes. Collels. Bourres.

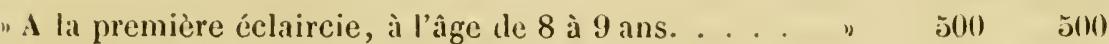

"A la denxième éclaircie, à l’âge de 12 à 13 ans. . . " 5̆00 Ju)0

" $A$ la troisième éclaircie, à l'âgue de 16 à 18 ans. . . $10 \quad 1,000 \quad 1,000$

" $\Lambda$ la quatrième ćclaircie, à l'âge de 25 à 30 ans. . . 1 š $1,000 \quad 1,000$

"Total des quatre éclaircies. . $\overline{25} \quad \overline{3,000} \quad \overline{3,000}$

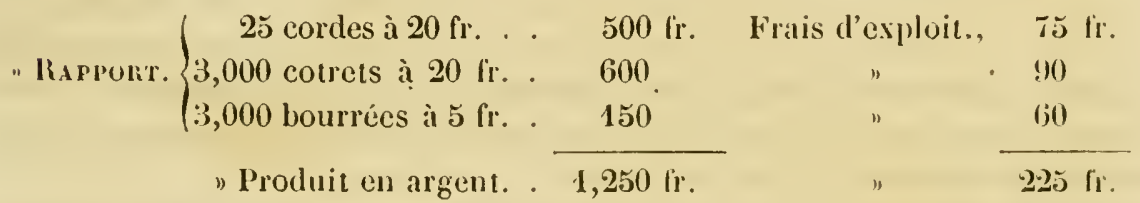

"Le bois de quarante-cinq à cin-

" quante ans vaut la coupe rase. . . 2,500

" P'roduit brut en cinquante ans. . $3,750 \mathrm{fr}$.

"Frais de garde en cinquante ans. . . . . . . . . . . 5t)

"Semence et labour. . . . . . . . . . . . . . . 50

"Fossés et clôture. . . . . . . . . . . . . . . . . 50

"Valeur locative du sol à $8 \mathrm{fr}$ par an. . . . . . . . . . . . 400

"Frais à déduire. . . . . . . . . . . . . . 775775 ir.

"Produit de l'hectare en 50 ans. . 2,975 fr.

"Produit net de l'hectare à deux lieues d'Orléans, par an, 59 fr. 50 c. .

" I quatre ou cinq lieues d'Orléans, la valeur du bois est réduite d'un quari "par les frais de voiture; le produit en cinquante ans est de. . 2,812 fr. 50 c.

"Les frais de location du sol et de garde diminuent d'un " (quart, et sont, a vec ceux d'exploitation, de. . . . . 66250

"Reste net en cinquante ans. .......... 2,150 fr. "

"Ce qui donne, par an, 43 fr.

"De six à huit liecies d'Orléans, les frais de voiture diminnent le produit de " moitié, et il en est de même de la valeur locative du sol et des frais de garde : " dès lors le produit brut de l'hectare est de. . . . . . . 1,875 fi.

"Frais à cléduire. ................ . . . . 550

"Produit net en cinquante ans. . . . . . . . . 1,325 fr.

"Ce qui dlonne, par all, $26 \mathrm{fr}$. äll $c$. 
"De dix à quinze lienes d'Orléans et des grands débouchés, les frais de voi"ture absorbent la totalité de la valeur du bois de pin conduit en nature; la " corde de chêne ne se vend que 10 à $12 \mathrm{fr}$., et la bourrée de chêne de 2 à $3 \mathrm{fr}$. " le cent : le bois de pin ne pourrait se vendre que réduit en charbon, cn résine " et goudron, ou exploité en bois de charpente el en planches. En conséquence, " j'ai vu des bois de pins très-beaux, âgés de 16 à 18 ans, situés à Chou, à douze " lieues d'Orléans, oflerts pour rien à des tuiliers, à condition qu'ils exploite" raient le bois et arracheraient les souches pour rendre le terrain propre à la " culture : cette offre a été refusée! A cette distance, les produits des éclaircies " sont donc amnulés par les frais, et l'on ne peut compter que sur la valeur du " produit de la coupe à 45 ou 50 ans, valeur qui ne peut s'élever, au maximum, " à plus de $500 \mathrm{fr}$. l'hectare; ce qui donne $10 \mathrm{fr}$. par an, pour les bois de pin en " grande tenue el en coupe réglée, à dix ou quinze lieues des délıonchés.

"Je dois encore vons faire observer que je n'ai pas fait entrer dans mes cal" culs la chance des gelées, et celle des mortalités par suite des piqûres de vers, "chances qui, par les pertes qu'elles mont fait éprouver, me semblent devoir "être apprécićes au dixième du produit. »

Dans les landes de Bordeaux, l'aménagement adopté pour les futaies de pins maritimes dépend de la possibilité de tirer parti des produits. Si, par exemple, un terrain sur lequel on veut créer une pinière est situć de manière à ce qu'on puisse en vendre tous les produits, on sèmera sur une terre préparée par des labours et des hersages, et l'on vendra successivement des échalas, des bourrées, de la corde, du charbon, de la résine et des bois d'œuvire; mais dans les landes de Bordeaux, une pinière se trouve rarement dans une situation qui permette la vente des échalas, et souvent même on est réduit à ne pouvoir en tirer un revenu que par l'extraction de la résine. Ainsi, pąr exemple, I. Dallier rapporte, page 9 de la brochure déjì citée, que dans les dunes où sont situées les plus belles futaies de pins maritimes, "l'administration n'a pu trouver aucun entre" preneur qui voulùt se charger des travaux de l'éclaircie, moyennant l'abandon, "à son profit, des bois à abattre, bien que ces bois eussent 20 ans d'âge et qu'ils "pussent fournir de la bùche et du clıarbon. " Dans les localités où l'on ne trouverait pas à vendre les échalas, mais où l'on pourrait placer tous les autres produits, on crée les pinières par le procédé économique que j’ai décrit page 216; il se trouve alors environ 2,500 pins par hectare, auxquels on ne donne aucun soin jusqu'à l'âge de 15 ans.

"A cet âge, dit M. Dallier, page $\mathbf{1 1}$ de la brochure déjà citée, les arbres au"ront une hauteur moyenne de 10 mètres; leur circonférence, encore un peu " filiforme, sera de $0^{\mathrm{m}}, 40$ à $0^{\mathrm{m}}, 50$ à un mètre au dessus du sol. On opérera alors "l'abattage d'un cinquième; on aura donc, par hectare, 500 arbres dont le bois " pourra être converti en charbon. Ce bois, il faut le reconnaître, sera inférieur " au vieux bois, parce qu'il sera moins dense et moins résineux. On peut néan"moins, et sans exagération, estimer chacun de ces arbres 15 cent. net de " tous fratis d'abatlage et de distribution. 
" .20 ans, on fera l'éclaircie d'un second cinfuieme; les arbres abattus an"ront 12 mètres de hauteur, et à un mètre lu sol, 0 m",̌̀ de circonférence; cha"que arlore vautra 2 ź cent. net au moins.

" A 25 ans, troisième éclaircic. Cette opération produira 500 arbres, tous pou"vant fournir des solives, des planches, de la bùche de bonme qualité et du " charbon. Ces arbres, hauts de 13 mètres el d'une circonférence de $0^{\mathrm{m}}, 69$ à $0^{\mathrm{m}}, 7$ it ") ì un mètre du sol, produiront net 60 cent. au moins. Immédiatement " après cette opération, on incisera les 500 arbres destinés à être abattus à la " trentième année, pour en obtenir des récoltes de résine. Ces arbres donneront " un produit annuel de 4 cent. On forcera le rendement en résine jusqu’ì " épuisement des arbres. Cet épuisemeut, loin de nuire à la qualité du bois soit " comme combustible, soit comme bois de charpente, ne fait au contraire que "l'améliorer.

" A 30 ans, âge où la croissance des arbres se ralentit, et où la végétation agit " avec le plus de force vers la circonférence, on abattra les 500 arbres résinés " depuis la vingt-cinquième année, et formant la quatrième et dernière série des " éclaircies. Ces arbres, hauts de 15 mètres, et d'une circonférence de $0^{\mathrm{m}}, 85$ " ì $0^{\text {m}}, 90$, à un mètre du sol, vaudront un franc au moius chacun. La produc" tion ligneuse sera suspeudue, après cette éclaircie, jusqu'à la coupe à blanc" étoc de la forct ; car on n'aura de bois que celui provenant des arbres abattus " par le vent (circunstance fort rare et dont les effets ont peu d'étendue); mais " on entrera alors dans la période de la production résineuse. A cet effet, on in" cisera les 500 arbres restans destinés à former la forêc. Ces arbres, clégagés "par les éclaircies successives de tout ce qui faisait obstacle ì leur complet dé"veloppement, puiseront copieusement dans la terre et dans l'air tous les thuides " nécessaires, se renfleront vers la base, et, dès l'îge de 50 ans, auront acquis, ") à un mètre du sol, une circonférence moyenne de $1^{\mathrm{m}}, 50$ ì $\mathbf{1}^{\mathrm{m}}, 7 \mathrm{7}$. On peut, salns " exagération, évaluer le produit résineux de chaque arbre jusqu'à l'âge de 60 " ans, époque où les arbres ont atteint leur maximum d'accroissement et de "production, et où ils commencent à péricliter, à 10 cent. au moins, soit s0 fr. " par hectare.

" A 60 ans, époque de la coupe à blanc-étoc, chaque arbre vaudra 5 fi. au " moins, soit 2,500 fr. par hectare.

"Résumé en chiffres de ces divers produits :

" A 15 ans, produit de 500 arbres de la première éclaircic, à tó cent. $7 \mathrm{c} \mathrm{lr}$.

" A 20 ans, produit de 500 arbres de la deuxième éclaircie, à 25 cent.

n $\mathbf{A} 25$ ans, produit tle 500 arbres de la troisième ćclaircie, à 60 cent.

"De 2 à 30 ans, produit du résinage des 500 arbres qui seront " abatlus à la trentième amméc, à raison de 4 cent. par arbre, soit " par an $20 \mathrm{fr}$. el pour ż années. . . . . . . . . . . . . " $\ 30$ ans, produit de 500 arbres de la quatrième éclaircie, à 1 fr. 
licport. . . . 1,100 $\mathrm{fr}$.

"De 30 ì 60 ans, produit anuuel de résine, à 10 cent. par arbre, " soit $50 \mathrm{fr}$. par an, et pour 30 ans. . . . . . . . . . 1,500

n Enfin, valeur des כ00 derniers arbres de la forêt, à 5 fr. l'un. . . 2,500

"Ainsi, on aura obtenu par hectare, en 60 ans, pour une mise pre-

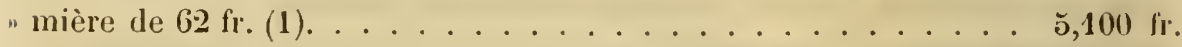

"De tels résultats présentent une si énorme supériorité sur ceux qu'on obtient "par toute autre sorte de culture, des bénéfices si extraordinaires, si exception"nels, que la première réflexion semble devoir commander le doute sur leur " véracité; on objectera naturellement ensuite que, s’ils étaient aussi exacts, " aussi faciles à obtenir, aussi réguliers et aussi continus qu'on l'a établi, agri" culteurs et commerçins, ceux qui ont peu et ceux qui ont beaucoup, tout lo " monde se serait rué sur ce pays, l'aurait défriché et boisé, et qu'on n'y trou" verait plus de terres à acheter au vil prix de 50 fr. l'hectare! Répondons, tour " à tour, à l'incrédulité des uns et à la prudence des alutres.

"Nous avons dit que l'ensemencement des pins ne coûtait, au maximum, "dans les landes, que $12 \mathrm{fr}$. l'hectare; les semis de plusieurs milliers d'hectares, "opérés depuis quelques années sur divers points de l'arrondissement de Nérac "(Lot-ct-Garome), dans le canton de la Teste (Gironde), et dans un grand " nombre de communes du département des Landes, à ce prix et par les moyens "que nous avons indiqués, sont un fait sans réplique. On trouverait bon nombre " d'entrepreneurs qui se chargeraient, à de telles conditions, de faire, sur de "vastes surfaces, des semis dont ils garantiraient les résultats : obligation très" peu onéreuse; car il est sans exemple qu'un semis de pins n'ait pas réussi "lorsque la graine n'était pas altérée. Or, cette altération ne peut exister que "lorsqu'on met les cônes de pin dans un four trop chaud; la graine, en tombant " sur l'âtre, se torréfie et le germe périt. Mais toutes les fois que la graine aura " été extraite des cônes dans lesquels elle est emboitée, par la dessiccation solaire - ou par une chaleur modérće d'éture, il suffira de la jeter dans les sables pour " qu'elle pousse. Tout ce que nous venons de dire est de notoriété dans les "Landes. "

Les localités desquelles on peut tirer le revenu que vient d'indiquer M. Dallier, par la culture du pin maritime, sont, dans les landes de Bordeaux, des localités privilégiées, car il y a beaucoup de lieux où l'on n'al d'autre moyen de tirer un revenu des pinières que par l'extraction de la résine. En admettant même l'exactitude de ses évaluations, on trouve que plusieurs causes peuvent détourner les spéculateurs de ce genre d'entreprise : ce sont la nécessité de faire garder les jeunes futaies pour qu'elles ne soient pas dévastées ou détruites par les bestiaux, si mal garlés dans les landes de Bordeaux; l'impôt qui se paie pour les futaies, comme pour les autres bois; l'absence de revenu pendant quinze ans;

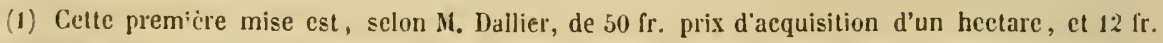
pour la mise en culture el l'ensemeneement, par le procedé économique que j'ai decrit page 216. 
entin, la tristesse et l’insalubrité des landes, oủ la tièvre est, pour ainsi dire, endémique dans beancoup de lieux.

IX. Qualtés et usages du rols; proneits divers. - Jai trouvé que le pied cube de bois d'un pin maritime âgé de 44 ans, que je fis abattre exprès le 25 septembre 18/3, jris près de la souche, pesait vert 25 kil. 0.10 gr. ; le 5 août 18:1',

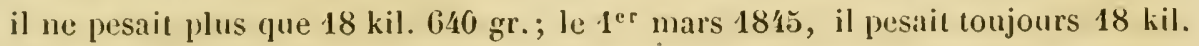
$640 \mathrm{gr}$. Le bois du pin maritime est d'un blane terne, ordináirement veiné de rouge, plus ou moins, selon la nature des terres où il a crû; on l'emploie aux mêmes usages que celui du pin sylvestre, excepté à la mâture : il est d'ailleurs inférieur en qualité, comme bois l'oeuvre, au bois des sapins et du pin sylvestre, quand il n'a pas été résiné; dans le Maine, on ne paie le pin maritime, pour cet usage, que la moitić du prix du chêne. Employé à l'intérieur, en menuiserie, le pin maritime dure quarante à cinquante ans; employé en charpente, il ne lure que trente ans; s'il est exposè à la pluie, il ne dure que sept à huit ans. J'ai fait faire des contrevents avec le bois d'un pin maritime qui avait atteint sa maturité, on les avait peints à l'huile et cependant, sept ans après, ils étaient piqués des vers et pourris de manière à être hors de service.

11. Vétillart convient " que l’on a, dans le Maine, des exemples très-nombreux " de charpentes entières de maisons qui ont élé, au bout de douze ou quinze ans, "rédnites en poussière par les insectes; " mais il prétend que " cet inconvénient "provient moins de la nature du bois que du mode vicieux d'exploitation. "On les abit, dit-il, trop jeunes et il conseille o de n'employer en charpente que des " pins matritimes bien ligneux et ayant atteint leur maturité, âgés de 40 à 50 ans " au moins, et de les abattre pendant l'hiver, par le vent du nord et le plus grand "froid. "Il ajoute que " le pin maritime venu à matmrité et abattu sous l'in" fluence de toutes les circonstances arantageuses, est susceptible de faire d'ex" cellente charpente et de durer fort longtemps; qu'il a sous les yeux plusieurs " exemples de charpentes fort anciennes et très-bien conservées. "II indique d'ailleurs, comme moyen de donner à ce bois les qualités qui lui manquent, de le tremper dans l'eau après qu'on l'a équarri et de l'y laisser pendant plusieurs mois; il est présumable que c'est ce qui avait été fait pour les charpentes, (lont parle M. Vétillart, comme s’étant conservées longtemps. Ces précautions prouvent suffisamment que le bois dlu pin maritime est fort inférieur à celui des Sapins et du pin sylvestre qui se conservent si longtemps en charpente. A Laigle et dans les environs, par exemple, on n'emploie que des chevrons faits avec de jemnes sapins sciés en deux, et pourtant ils se conservènt très-longtemps. J'ai un bâtiment fort ancien où se trourent des remises et des greniers; les cherrons du toit, parmi lesquels il y en a qui conservent encore quelques parties de leur icorce, et les solives des planchers sont en bois de sapin provenant indubitablement de mon pare; tous ces bois sont en fort bon état.

Le bois tles pins maritimes qui ont été résiués arec mesure est beaucouo meilleur que celui dles pins qui ne l’ont jas éte; on prétend qu'il raut presque celui 
du chêne. Le challbon du pin maritime est bien inférieur à celui du chène; mais employé dans les lorges, il a le mérite de rendre le fer plus ductile.

On tire du goudron du bois de pin maritime comme de celui de pin sylvestre, mais le premier est d'une qualité inférieure au second.

On extrait de la résine du pin maritime el avec cette résine on fabrique différens produits. Jusqu'à ce jour on n'a recueilli ces diverses matières en grand, dans les futaies de pins maritimes, que dans les provinces méridionales de lit France, particuliềrement dans cette partie de la Guyenne que l'on appelle les landes de Bordeaux; on ne l'a point encore fait dans le Maine et dans l'Orléanais, ou l'on cultive pourtant le pin maritime depuis fort longtemps. Cependant il résulterait d'une expérience qui a été faite dans la forêt de Fontainebleau, que cet arbre peut domner ces mêmes produits, sous le climat de Paris, aussi bien que dins le midi; mais il serait possible que l'extraction de la résine diminuât le revenu au lieu de l'augmenter, lorsque le bois est eher, parce que cette extraction cause une diminution dans la production ligneuse. J'emprunte le récit Je l'expérience faite dans la forêt de Fontainebleau à un article de I. I'oiteau, inséré dans le Journal d'agriculture pratique de mars 1838; et j'ajoute que l'exaclitude de ce qu'il rapporte un'a été contirmé par M. de Boisdhyver.

"En 1822, M. de Lauriston, ministre de la Maison du roi, fit venir de La Teste " deux résiniers, pour essayer si, par le gemmage des pins de la forêt de Fontai" nebleau, on en obtiendrait de la résine comme dans les landes de Burdeaux. "Ces deux hommes, adressés à $\mathbf{H}$. Larminat, ont soumis au gemmage, en deux v ans, environ 4,000 pieds de pins maritimes, et en obtinrent à peu près autant " de résine que dans les landes, c’est-à-dire un kilogramme par ardore, terme " moyen. M. Larminat a suivi avec soin les détails el les résultats de celte opé"ration, qui était encore inconnue aux environs de Paris; voici ce qu'il a bien "voulu m’en communiquer :

"Deux hommes peuvent suffire au gemmage de 8,000 pins, qui produisent " annucllement 16 milliers de matière à 12 ou 15 fr. le quintal, ce qui est assu" rément un très-beau revenu, quand on pense que les pins dont on l'obtient " croissent dans des sables qui se refusent à toute culture et dont beaucoup " d'arpens se sont vendus à raison de 3 ou $4 \mathrm{fr}$. Cependant reste à calculer s'il ne " vaudrait pas mieux conserver les pins intacts pour en tirer de beaux et bons " sciages, que de les mutiler par le gemmage, apres lequel les pins ne son "plus propres qu'à faire des échalas qui sont, il est vrai, de première qualité.

"On n’a tiré de la résine que des pins maritimes; les pins sylvestres soumis " au gremmage n'ont rien produit, quoique ayant 4 pieds de tour' peut-être qu'ils " étaient encore trop jeunes. Mais, chose étonnante! le ministre qui avait fait " entreprendre ce gemmage avec beaucoup de chaleur a fini par n'y plus penser, " et par refuser à M. Larminat les moyens de faire manipuler les produits bruts " qu’il avait obtenus. Après plusieurs demandes restées sans réponses, M. Lar" minat reçut l'ordre d'envoyer toutes ses résines à l'entreprise générale des galz " de Parris; et six nois après fu'il eut envoyé là son dernier tonneau de résine, 
" il reçu un autre ordre qui lui enjoignanit d’avoir bien soin de ses résines, el de ". prendre garde que les grandes chaleurs de l'été (1825) n’en tissent évaporer " les parties essenticlles. De ce fait, et de cent autres bien connus, on peut con" clure que quanl des expériences et des entreprises n’ont pas l'intér l person" nel pour promier mobile, elles réussissent tris-rarement. "

On peut consulter sur les procédés que l'on emploie pour extraire de la résine du pin maritime et du goudron du bois tle cet arbre, et pour la fabrication des produits qu'on peut tirer de cette résine, les ouvages suivans : le Dictionnaire des eaux et forêts de Baudrillart, à l'article Résine, t. II, D. 719 oǹ il reproduit en partie ce qui a été dlit par Dulaımel, dans son Traité des arbres et arbustes, et par 11. Barleigts-Laborte, commissaire de marine, dans un Mémoire sur les brais et goudrons de France; le Traité des arbres et arbustes de Duhamel, à l'article Pims, Pin, 1. 11, p. 141; la Mrison rustiune du xix siècle, 1. III, p. 393, à l'article intitulé Des produits résincux. Je vais cmprunter à Baudrillart ce qu'il dit de l'extraction de la résine, t. 11, p. 724, et je me contenterai de renvoyer aux ouvrages que je viens de citer, pour la fabrication des produits qu'on peut tirer de ecte résine, ct pour l'extraction du goudron du bois de pin maritime.

" Quand le pin maritime a de 20 ì 2 s ans et une grosseur l'environ 4 pieds, on " enbeve la grosse écorce sur une liargeur de 4 à 6 pouces $\left(0^{\mathrm{m}}, 11\right.$ à $\left.0^{\mathrm{m}}, 16\right)$ de large " et une bauteur de 12 à 18 pouces $\left(0^{\mathrm{m}}, 32\right.$ à $\left.0^{\mathrm{m}}, 18\right)$. Le résinier (l’ouvrier) fait en " même temps au pied de chaque arbre, et dans le corps même du trone, une " fosselte ou petite auge de la capacité d'une demi-pinte d'eau. Cette opération "préliminaire finie, le résinier fail ensuite une entaille d'environ 6 pouces de " hauteur, 4 pouces de large, et de la profondeur nécessaire pour mettre le Jiber a " déconvert; car le suc résineux ne coule presque que du corps ligneux, et d'entre "le bois et l'écorce. La hache dont il se sert a le fer légèrement recourbé daus " sa plus grande largeur, et son tranchant est creusé cu gouge d'un cùté. Toutes " les semaines le résinier rafraichit les plaies en les agrandissant en hauteur et " jamais en largeur, et sans dépasser 18 pouces de hauteur dans le courant de la " saison. Ces entailles successives sont nécessaires, parce que le suc résineux " coule toujours plus abondamment des plaies récentes que des anciennes; mais " comme le plus mince copeau suffit pour donner la liberté au suc de couler, " l'ouvrier chargé de faire les eutailles doit ménager l'arbre autant qu'il est pos" sible, el n'enlever que des copeaux très-minces toutes les fois qu'il rafraichit " les plaies. Ce travail exige de l'activité, car la tîche d'un homme est ordinai" rement de 2,500 ì 3,000 pieds d'arbres. Les entailles, vulgairement appelées " quarres, se prolongent les années suivantes, jusqu’à ce qu’elles aicnt atteint la " hauteur de 12 a 14 pieds $\left(3^{\mathrm{m}}, 89\right.$ à $\left.4^{\mathrm{m}}, 55\right)$; ce qui arrive au bout de 7 à 8 ans.

"A celte époque, on commence une nouvelle cutaille au pied du même arbre; " on la lait parallèle et presque contiguë à la première, ne laissant tout an "plus que 2 pouces d'écorec entre deux, et on la conduit jusqu’à la même haı" teur. Après cette nouvelle entaille, on en fait une troisième, puis une qua-

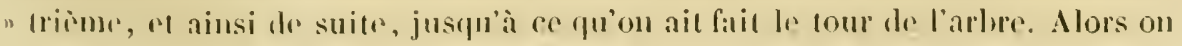


" entaille sur les cicatrices, vulgairement appelées ourles, qui ont recouvert " presque entièrement les vieilles entailles, si le résinier a bien ménagé l’arbrc " en le taillant.

"Quelquefois on laisse reposer un pin pendant un an quand il a résiné, e'est" à-dire quand il a fourni de la résine pendant 7 à 8 ans de suite. Si, au eontraire, " un pin est très-vigoureux, on lui fait deux entailles en même temps : l'une " s'appelle la quarre haute et l'autre le basson. Quand on juge que les pins sont "trop nombreux, on taille sur tontes les faces à la fois, et chaque année, à une " hauteur triple des autres, tous les arbres qu'on veut détruire. Cette manière " s'appelle tailler à pin perhu. Les arbres, dont on a ainsi extrait la résine, sont " abattus peu de temps après pour en extraire le goudron. Pour porter les en" tailles à la hauteur de 12 à 14 pieds, comme il vient d'être dit, les résiniers " sont obligés de se servir de perehes, dans la longueur desquelles on a pratiqué " des coches ligurées en cul-de-lampe; ils y montent avee une grande dextérité.

"Arrivés à la hauteur néeessaire, ils passent leur jambe gauche entre l'arbre et " l'échelle en portant, du eôté droit, le bout du pied qu'ils appuient sur le trone " pour leur servir de point d'appui; tandis que le droit est porté sur une coehe " de l'éehelle qui s'appuie, elle-même, sur la cuisse gauehe, et esı tenue forte" ment serrée contre l'arbre par la jambe dı même rôté. Dans eette position " un résinier prend sa hache des deux mains, et il entaille le pin avec autant " d'aisanee que s'il était à terre, ou que si l'éehclle était appuyéc contre l'arbre "à la manière ordinaire. L'opération finie, et il lui faut tout au plus 2 ou 3 mi" nutes pour monter, tailler l'arbre et en deseendre, il prend sa légère éehclle "sur une ćpaule, court à un autre arbre et ainsi de suite, de manière qu'un " bon ouvrier peut tailler 2 à 300 arbres en un jour. Les résiniers sont toujours " nu-pieds pour grimper à leur échelle. Quand ils portent des sabots, ils les lais" sent au pied de l'échelle; mais il n'est pas rare d'en rencontrer qui, pour aller "plus vite, marchent toujours les pieds nus.

"C'est depuis le mois de mai jusqu'ì la lin de septembre qu'on taille les pins.

"Tout le sue résineux qui sort des arbres pendant ce temps coule liquide;

" il est reçu dans les petites auges qu'on a pratiquées au pied de leur tronc, " et qu'on a soin de vider de temps en temps. Le sue résineux coule d'antant " plus abondamment que la chaleur est plus grande, et les arbres bien exposés " au soleil en fournissent plus que eeux qui sont à l'ombre. L'écoulement rési" neux cesse vers le milieu de l'automne, et il ne sort pas des arbres une seule " goutte de résine pendant l'hiver, ou dans les autres saisons lorsqu’il fait froid. "Outre la résine qui découle des ineisions qu’on a faites aux pins, il sort en" core naturellement de leur écoree des gouttes de résine qui se dessèehent et " forment des grains que l'on emploie au lieu d'encens dans les églises de eam" pagne, et que les marehands de mauvaise foi mêlent avec l'encens du Levant. " Cette extravasation du sue propre arrive surtout aux pins qui sont près de " mourir; c'est le dernier produit de ces arbres que l'âge a affaiblis, ct que les "tailles sucerssives ont épuisés au point de ne plus douner de résiue. 
"La matière résineuse fournic par les incisions faties au pin maritime est du. " deux sortes: la première, que l'on nomme barres, est celle qui se fige fre long " des entailles où elle forme des croùtes plus ou moins épaisses. Elle est blanche " comme de la cire, avec laruclle quelques marchands la mêlent pour falmiquer " ce qu'ils appellent de lil bougie filée, afun de lui donner plus de souplesse et de: " tenacité. Le burrus se récolte une fois par an : on le détache avec un instrument " de fer en formo de ratissoire, emmanché au bout d'un bâton, et on le met en "réserve sous cles hangars, aprìs en avoir fail des pains de 60 à 80 ) livres (29 kil. " $370 \mathrm{gr}$. à $39 \mathrm{kil}, 160 \mathrm{gr}$.). La seconde espèce de résine se nomme galijiot ou ré" sine molle : elle se ramasse, comme nous l'avons dit, dans les petites auges " creusées à la base des entailles. On la récolte quatre fois dans le courant de la " saison, et on la verse dans de grands réservoirs creusés dans la terre et de la " eapacité d'environ 150 a 200 barriques. Ces réservoirs sont gamis dans le fond " et sur les côtés d'épais madriers de pins joints de manière ì ne laisser aucune " issue à la partic la plus fluide de la matière résineuse. Cette résine molle esı " destinée à être transformée en brai sec, en résine janne, ou à être distillée pour " en obtenir une huile essentielle. Dans tous les cas, on la fait fondre et on la pu"rifie de tous les corps étrangers avec lesquels elle est mêlée. "

On extrait en Provence les substances résineuses du pin maritime, et plus encore du pin d'Alep, par des procédés qui ont été décrits par Duhamel, et qui dilfèrent peu de cenx qui sont en usage aux environs de Bordeaux.

X. Accidens, maladies, animaux nuisibles. - Les gelées, surtout les gelées tardives, causent quelquefois de grands dommages dans les jeunes pinières de pins maritimes pendant les trois premières années; elles ne mont point paru causer un dommage apparent aux pins plus âgés, pendant les hivers orlinaires; mais des hivers extriondinaires, tels que ceux de 1709 et de.1789, peuvent en faire périr un grand nombre.

Les pins maritimes qui ont résisté aux vents pendant les premières années, n’en sont pour ainsi dire jamais renversés, lors même qu'ils seraient isolés, dans les terrains qui ont du fond, parce que leurs racines pénètrent à une grande. profondeur, et il est bien rare aussi qu'ils soient brisés; aussi les voit-on sur les dunes braver tes coups de vents de mer les plus violens.

lls sont moins sujets à être endommagés par la neige et le givre que les sapins et le pin sylvestre, parce qu'ils ne s'y trouvent pas aussi exposés, ne pousant supporter un climat aussi rigoureux qu'eux, et par suite de la disposition de leurs feuilles.

Le dommage que peuvent causer les quadrupèdes et les oiseaux dans les pinières de pins maritimes est absolument le mêmeque celui qu'ils peuvent canser dans les sapinières. Mais comme on n'exploite point ces pinières en jardinant, les quadrupèdes ne peuvent guère leur nuire que quand elles sont jeunes.

Les pins maritimes ne craignent point la sécheresse lorsqu'ils se trouvent dans un lerrain où ils peuvent enfoncer leurs racines; mais s'ils se trouvent sur un 
terrain pen profond à sous-sol de tuf, de rocher ou de pierre, leur croissance s'artête peu après que leurs racines ont atteint ce sous-sol, et une sécheresse peut en faire périr de grandes quantités.

Ces arbres sont sujets à la pourriture au cœur dans les terrains trop humides on marécageux, qui ne leur conviennent point; cette maladie commence par le pivot, et tant que les racines latérales restent saines, elle n'est souvent annoncée par des signes extérieurs que lorsqu’elle a fait de grands progrès; la vieillesse leur cause aussi cette maladic. Les pins maritimes sont encore sujets à une caric sèche qui s'annonce ordinairement par la présence d'un bolet (espèce de champignon); on attribue cette maladie ì la décomposition des branches coupées ou cassées loin du tronc.

Des insectes peuvent causer de grands dommages dans les futaies de pins marilimes, ainsi que dans celles des arbres dont je me suis déjà occupé. Les mans penvent manger les racines des semis; mais lorsque le plant a atteint 5 ans, ses racines étant alors résineuses, ils n'y touchent plus.

Un insecte qui parait appartenir au genre bostriche exerce quelquefois de tels ravages dans les semis, en perçant les pousses et en en mangeant la moelle, qu'il peut détruire des pinières entières; on le remarque principalement sur des pinières de 4 à 10 ans, et on ne le rencontre que rarement sur des arbres qui ont plus de 15 ans; le seul moyen de le détruire ou d'en diminuer le nombre est d'arracher les arbres dont la mutilation atteste sa présence, el de les transporter hors de la pinière pour les brûler.

Un autre insecte, également du genre bostriche, cxerce quelquefois de grands ravages dans les pinières en s'introduisant entre l'écorce et le bois, oì il forme dans le liber des galeries qui finissent par arrêter la circulation de la sève et firire périr l'arbre; les insectes de cette espèce, lorsqu'ils sont assez multipliés, peuvent détruire des forêts entières; il y en avait dans les futaies de pins marilimes que Delamarre a léguées à la Société royale et centrale d'agriculture, lorsque je fus les visiter en 1838 : M. A. Michaux, alors administrateur pour la Socićté, me les fit remarquer. Ce bostriche parait être le même qui exerce de semblables ravages dans les futaies de pins sylvestres. J'ai indiqué, page 116 , le moven, sinon de détruire ces insectes, du moins d'en diminuer le nombre.

Il y a indubitablement une chenille qui mange les feuilles du pin maritime, comme il y en a une qui mange celles du pin sylvestre; mais je ne l'ai trouvée indiquée dans aucun auteur, el je ne l'ai point remarquée. Les seuls insectes que j’aic observés chez moi sur le pin maritime, sont un bostriche qui mange la moelle des pousses, el un autre bostriche qui mange à même; ces insectes sont ies mêmes qui attaquent aussi, et plus volontiers encore, le pin sylvestre. (Voy. p. 200).

XI. Culture du pin maritiue en Sologne. - J'ajouterai à ce chapitre une note de mon ami, M. Jacquinot de Presle (1), sur la culture du pin maritime dans

(1) M. 1. de Presle, connu par un Cours d'art ef d'histoire militaires, après avoir suivi la carrière 
cette partie de la Sologne qui se trouve dans les arrondissenens d'Orlúms el dr. Romorantin, où il est proprićtaire (1811); je la reproduis textuellement.

Le sol de cette partie de la Sologne est formé en général d'un sable quartzeux très-maigre; l'épaisscur en est fort variable, mais il y a toujours un banc d'argile au dessous; assez souvent encore on trouve, à peu de profondeur, une couche de pyrite appelée mâchefer dans le pays; le pin maritime et le chêne végètent bien dans la glaise; mais dès qu'ils ont atteint le mâchefer, ils languissent, se couvrent de mousse, et ne reprennent vigueur que s'ils parriennent à le percer.

La misérable agriculture suivie en Sologne depuis des siècles a achevé de ruiner ses terres, naturellement mauvaises, et le pâturage des bestiaux en a ruiné les forêts, autrefois très-belles. Les proprićtaires ont enfin senti qu'il fallait recréer des forêts, dans un pay fy où la culture des céréales est ruineuse : une révolution a donc commencé à s'y faire vivement sentir depuis 1830; on retire successivement aux fermiers les terres usées, dont le nombre est considérable; on les convertit en pinières, puis on défriche les bruyères pour les livrer à la culture. Il faut observer ici que la Sologne est encore divisée en grandes propriétés, et qu'une ferme de 100 à 120 hectares est regardéc comme fort petite. Les propriétaires, tout en adoptant les pins maritimes, n'ont cependant pas voulu renoncer au chêne, qui croît fort bien dans une partie de cette con trée, et ils sèment souvent ensemble ces deux essences; quelquefois aussi c'est le châtaignier qu'ils sèment avec le pin maritime. Ce semis s'exécute ainsi qu'il suit:

La charrue du pays étant à billons, on laboure l'hiver le terrain qu'on doit ensemencer au printemps, et aux mois de mars el d'avril, on répand le gland dans le creux des billons, en l'espaçant de deux en deux pas, quelquefois plus, et en semant de deux billons l'un, ce qui met une distance de près de 2 mètres entre les rangées; ce semis étant terminé, le laboureur passe une grande herse de bois sur les billons et les rabat. Dès que le champ ne présente plus qu'une surface bien unie, on y sème à la volée la graine de pin maritime, soit pure, soit mélangée de pin sylvestre; on passe une ou deux fois la herse sur ce semis, et l'opération est terminée. Lorsqu'on veut créer une futaie de pin maritime sans mélange d'une autre essence, on se contente de labourer et de herser, puis l'on sème et l'on herse ensuite très-légèrement. Il est bon que la graine soit très-peu enterrée; il faut cependant la lien couvrir, car les pigcons ramiers et les tourterelles, qui arrivent au printemps, en sont fort avides, ainsi que les pies et les mulots. Si le temps est favorable, on voit les pins lever quinze jours et un mois après la semaille; mais il arrive assez souvent que la levée des pins est plus tardive: beaucoup de graines ne lèvent même que la seconde année, quelquefois encore à la troisième.

La quantité de graines employée est fort variable; elle est la mème soit qu’ou

lles armes et s'ètre occupé de littérature mililaire, rentré dans la vie prlvée, s'est llvré aux travaux de l'asriculture. 
sème la graine de pin maritime seule, soit qu'on la sènte avec dlu gland; on ćtait sans principe à cet égard, on a presque toujours semé trop épais : ainsi on mel souvent 12 et 15 kilog. à l'hectare, rarement moins; cela dépend des vues du propriétaire, qui peut vouloir d'abord des échalas, puis du bois à clıarbon; mais il est certain que cette grande quantité de plant affame le terrain et que les arbres en éprouvent une grande diminution dans leur croissance. Il faut néanmoins convenir que les jeunes pins sont si sujets à fondre par les vents secs du printemps et les chaleurs, que des semis fort épais deviennent assez souvent trèsclairs; il faut encore ajouter qu'il y a une incroyable diversité entre des terrains en apparence de la même nature, en sorte que la quantité de graines convenable pour un semis épais dans un champ, n'en donnera qu'un fort clair dans un aurre qui lui sera contigu. Je connais même des terrains où des pins semés trois années de suite, et à des époques différentes, n’ont pas levé. J'en ai un de ce genre d'environ 70 ares, entouré de parties où les pins sont fort beaux, et rien ne peut faire présumer la cạuse de cette anomalie.

Les pins viennent vite et fort bcaux sur les bruyères défrichées et écobuées; mais si le terrain n'a pas été cultivé pendant au moins trois ans, la bruyère ne tarde pas à repousser a vec une grande vigueur et fait beaucoup de mal aux jeunes pins; néanmoins, si le plant atteint sa deuxième année avant que la bruyère aiı reparu, sa croissance n'er est pas moins belle, surtout si l’on a semé épais. J'ai semé sur un pareil écobuage il y a cinq ans : la terre, couverte de bruyères et de grosses touffes d'ajoncs, fut piochée, puis brûlée et labourée; et malgré une grêle qui coupa une partie de mon semis à sa deuxième année, cette pinière a aujourd'hui près de $\mathbf{2}$ mètres de haut; la bruyère repousse avec fureur, car elle se plaît singulièrement dans la cendre; mais mes pins la dominent tellement et sont si épais, qu'ils n'ont rien à en craindre, et ils seraient beaucoup plus grands si la grêle ne les eût frappés.

J'ai lu dans un rapport de M. de Bélague, propriétaire d'une terre considérable près de Sully, qu'il semait ses pins sur des bruyères qu'il fitisaiı brùler sans les écobuer et sans aucun labour, et en enterrant simplement la graine à la herse. Je ne nie pas le succès que $\mathbf{M}$. de Béhague obtient par ce procédé, parce qu'à chaque pas qu'on fait en Sologne on trouve des exceptions; mais je puis assurer que ce mode de semis présente, en général, peu de chances de succès, et que plusieurs propriétaires qui l'ont essayé ont dû y renoncer, parce que leurs pins étaient dévorés par la bruyère, qui reparaissait aussitôt.

L'enfance du pin maritime est plus ou moins longue, selon la bonté du sol; il est fort lent à pousser dans les terres qui sont restées en genetière, ce qui est souvent le cas en Sologne; on peut dire, en général, qu'il fait peu de progrès dans les quatre premières années; il est faible et atteint rarement plus de $0^{\mathrm{m}}, 66$, excepté dans les défrichés; mais après cette époque sa croissance est rapide, et il n'est pas rare de lui voir faire des pousses de $0^{\mathrm{m}}$, $\check{0} 0$ à $n^{\mathrm{m}}, 66$, et même plus : c'est ì 7 ans qu'il commence ì montrer des cônes. 
D’après mes comptes, l'établissement d'un hectare de pins ne me revient pas à plus de 13 fir. 25 c. quand je les sème seuls.

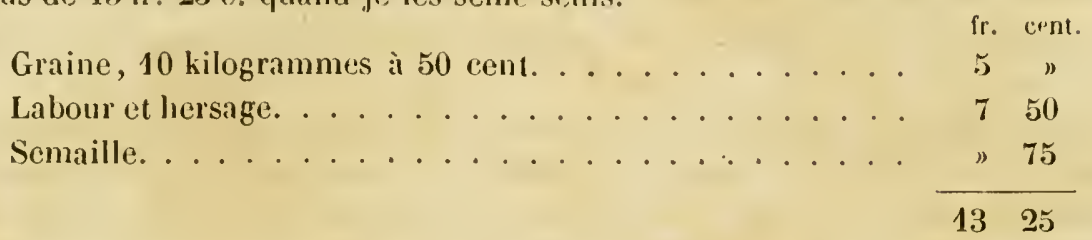

L'hectare ne me coùterait pas plus de $10 \mathrm{fr}$ à établir, en se dispensant de labourer de vieilles terres sur lesquelles la herse peut agir librement.

J'ai établi en 1841 douze hectares de pins mêlés de glands; je semai 2 š kilog. de graine seulement, parce que je voulais élever de beaux arbres et que les échalas et les fagots se vendent mal dans ma localité; j’y joignis près de 7 hectolitres de glands; mon semis est convenablement garni, et aussi beau que je pouvais le désirer. Mes frais ont été de 19 fr. 20 c. par hectare, dans lesquels je comprends 850 mètres de fossés à 8 cent. $1 / 2$ le mètre courant, le tracé des allées, une barrière, et mes frais de voyage et de séjour : si j'eusse été sur les lieux, l'hectare ne me revenait pas à plus de $17 \mathrm{fr}$. La nécessité de bien répartir les glands dans le semis cause une assez grande augmentation de dépense, car il m'a fallu onze journées de femme pour les semer.

On commence à éclaircir les pins à l'âge de 6 à 7 ans, soit en coupant, soit en arrachant : on élague en même temps les pins restans. Cette opération, abandonnée à des ouvriers sans soins et mal surveillés, se fait lort mal; on coupe beaucoup trop de couronnes à la fois et on laisse des crochets; on la pratique hiver et été. C'est à 8 ans que l'on commence à faire des échalas avec les jeunes pins; les vignerons des coteaux qui bordent la Loire vienneut en Sologne pendant l'hiver et au printemps, et y font leur provision: on leur vend le millier 12 fr. pris sur place, dans plusieurs localités éloignées; il se paie plus cher dans les pinières rapprochées des vignobles.

Les pins arrachés et les produits de l'élagage servent à faire des fagots dont le débouché est souvent difficile ou même impossible, à raison du défaut de consommateurs; aussi beaucoup de propriétaires oul-ils été en quelque sorte contraints d'établir des tuileries pour les consommer. Il en résulte que la tuile et la brique, autrefois fort chères en Sologne, où l'on n'a pas de pierres, sont levenues à bon compte, et que les constructions en maçonnerie font disparaître celles en bois et en torchis.

On continue à éclaircir les pinières, et à 12 ct 15 ans on y fait des cotrets qui ont remplacé ceux de chêne chez les boulangers des villes des rives de la Loire; le cent de cotrets rendu à Orléans s'y vend 30 à $32 \mathrm{fr}$. Les localités trop éloignées des villes convertissent le jeune bois en eharbon, et on calcule que la corde, ou 2 slìres $1 / 2$ environ, rend 4 poinçons ou 9 hectolitres de charbon. Ce charbon est léger, il se couvre de cendres et pétille quand on le souffe, s'it a conservé une partie de son écorce; il donne moins de ehaleur que celui du chène, mais on le mêle souvent maintenant à ce dernier, devenu lort cher. Le charbou 
de pin est près de moitié moins cher que celui de chêne, puisque l'hectolitre de charbon de chêne vaut $2 \mathrm{fr}$. $40 \mathrm{c}$. près l'Orléans, el que celui de pin ne vaut pas plus de $1 \mathrm{fr}$. $30 \mathrm{c}$.; on commence à employer ce charbon dans quelques forges du Berry.

Le pin maritime, comme bois de chauffage, a l'inconvénient, quand son écorce est devenue rugueuse, de brûler en faisant entendre un pétillement continuel et fitigant; il lance des étincelles dangerenses autour du foyer, c'est donc une nécessité de l'écorcer; il perd enriron un quart de son volume par cette opération, il brùle alors paisiblement et jette une flamme claire. Associé au chène, il fait un feu agréable et de durée. Le pin ne lance pas d'étincelles quand son écorce est unie.

J'ai des pins maritimes de 31 ans, ils croissent sur une colline assez élevée en terrain sec et rocailleux; les plus beaux ont $0^{\mathrm{m}}, 70$ à $0^{\mathrm{m}}, 80$ de tour à $1^{\mathrm{m}}$, , 0 au dessus du sol, et 10 mètres de hauteur mesurés exactement. J'en ai de 20 ans qui viennent sur la même colline, les meilleurs ont $0^{\mathrm{m}}, 40$ à $0^{\mathrm{m}}, 50$ de $10 u r$ el 7 à 8 mètres de haut. J'en ai un grand nombre de l'àge de 10 ans quii croissent en meilleur fond que les précédens, ils ont 5 à 6 mètres de hauteur sur $0^{\mathrm{m}}, 30$ à $0^{\mathrm{m}}, 40$ de tour.

J'en vois chez M. Gaullier, maire de Chaumont-snr-Taronne, qui ont environ 45̆ ans, quelques-uns ont 13 à 14 mètres de haut sur $1^{\text {m }}, 69$ de tour; ils sont dans un sable argileux au bord d'un ruisseau. M. Bignon, propriétaire dans la mème commune, vient d'en abattre trois dans son parc de Boucheteau, qui avaient $\mathbf{4 3}$ ans; ils avaient 2 mètres de tour à 1 mètre de terre. Chez M. de Mainville, commune de Marcilly-en-Villette, j'ai mesuré des pins maritimes en terrain sec et meilleur qu'il n'est d'ordinaire en Sologne; ils avaient à 13 ans $0^{\mathrm{m}}, 40$ de tour sur $6^{\mathrm{m}}, 66$ de haut; ̀̀ 16 ans $0^{\mathrm{m}}, 40$ et $0^{\mathrm{m}}, 50$, sur 8 mères de haul; à 17 ans $0^{\mathrm{m}}, 30$, $0^{\mathrm{m}}, 40$ el $0^{\mathrm{m}}, 50$ sur 8 mèrres el $8^{\mathrm{m}}, 33$. 


\title{
CHAPITRE VI.
}

\author{
PIN LARICIO, Pinus laricio.
}

1. Nons ue l'espice. - P'inus laricio Ponetr. On l'appelle aussi P'in de Conse. Poiret, dans le t. V, p. 339 de l'Encyclopédlie méthodique (Botanique), qui parut

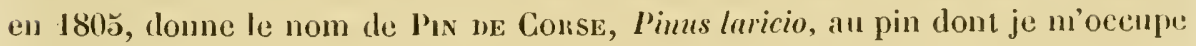
dans ce chapitre; le nom botanique que cet auteur a adopté n'est autre que la traduction en latin du nom vulgaire que porte ce pin en Corse, d'après ce que dit Rozier (1), et M. Moll, professeur d'agriculture au Conservatoire, qui s'en est assuré sur les lieux mêmes, n’a confirmé l'exactitude de cette assertion. Tenore, dans le 2 . V de sa Flora napolitana, qui parut en 1835̃, décrit un arbre qu'il dit être le pin laricio de Corse, aussi a-t-il adopté pour cet arbre le nom botanique et la phrase spécilique de Poiret; il lui domne en italien le nom de Pino laricio; si c'est le 'nom vulgaire de cet arbre dans les $\Lambda$ pennins, il y porterait le même nom qu'en Corse, ce qui serait digue de remarque. Avant Poiret, Savi, dans sa Flora pisana, t. Il, p. 353, avait donné le nom de Pinus laricio au pin maritime. Santi, dans son Viaggio per la Toscana, 1. 111, p. 60, avait, d'après Savi, donné Je même nom au même pin; mais son ouvrage est postérieur d'un an au tome de l'Encyclopédie où se trouve l'article de Poiret sur le pin de Corse. On ne peut d'ailleurs contester que ce ne soit pas le pin maritime, dont je me suis occupé dans le chapitre V, auquel ces auteurs donnent le nom de Pinus laricio, car Santi, indépendamment de la phrase spécifique de Savi qu'il reproduit, donne des dessins bien faits des lleurs, des cônes, des feuilles et des graines de ce pin, qui ne laissent aucun doute à cet égard.

Le pin laricio fut introduit en Angleterre, dit Loudon (2), en 1759, sous le

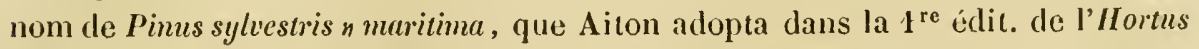
liewensis; cet anteur Jui donna ensuite le nom de Pinus maritima dans sa $2^{\mathrm{e}}$ édit.;

(1) L'abbe Rozier, dans son Cours complet d'agriculture, théorique, pratique, économique, etc.' t. VI, p. 686 , s'exprime ainsi qu'il suit : " Il serait fort à souhaiter que MM. les intendans fissent venir "la graine du pin nommé laricio en Corse, ainsi que du pin de Riga, etc. "

(2) Arboretum et fruticetum britannicum, t. 1V, p. 220', art. Pinus laricio. 
enfin Lambert, dans l'ouvrage intitulé A description of the genus Pinus, et London, dans son Arborctum el fruticctum britannicum, ont adopté le nom de Pinus laricio, d'après Poiret. Les botanistes allemands ont adopté aussi ce nom d'après Poiret. Quelques auteurs ont voulu donner au pin dont je m'occupe dans ce chapitre le nom de Grand pin maritime, Pinus maritima major, prétendant que cet arbre n'était qu'une variété du pin maritime des landes de Bordeaux; mais ce sont deux espèces fort distinctes, ainsi qu'on le verra. J'ai adopté le nom de Pin laricio, parce qu'il est adopté tout à la fois par les botanistes et les praticiens; sans celte circonstance, j’aurais préféré le nom de Pin de Corse, qui indique le lieu où l'on a observé d'aloord ce pin, et où il s'en trouve de vastes forêts.

1I. Boutons et sive. - Le pin laricio n'a que des boutons à bois qui contiennent èn même temps le rudiment des feuilles et des fleurs; du moins, bois, feuilles, fleurs, tout part des mêmes boutons.

Cet arbre, ainsi que les deux pins dont j’ai déjà parlé, n’a sous le climat de Paris qu'une seule sève qui commence ordinairement dans les dix derniers jours du mois de mars, par le bouton qui se trouve dans le prolongenent de la flèche de l'année précédente et s'arrête, en ce qui concerne la longueur des pousses, au bout de deux mois et demi à trois mois et demi environ. Quelquefois, par exception, on remarque une seconde sève sur les pins laricio, mais elle ne se manifeste que par de très-petites pousses. M. Zédé, ingénieur de la marine, qui faisait exploiter des forêts en Corse en 1822, remarqua que cet arbre y a deux sèves. On a vu, page $\mathbf{1 7}$, que Leroy, ingénieur de la marine sous Louis $\mathrm{XV}$, avait fait la même remarque dans les Pyrénées sur le sapin orgenté, qui n’a aussi qu'une sève sous le climat de Paris.

Les circonstances de la végétation, en ce qui concerne l'apparition et la disposition des boutons, des feuilles et des fleurs, sont les mêmes dans le pin laricio que dans le pin sylvestre (Voy. p. 143), avec cette différence que la pellicule qui couvre les pousses, au lieu d'être rousse, est d'un gris blanc; que les fleurs du premier paraissent et mûrissent un peu plus tard que celles du second, et que les pousses du pin laricio sont plus grosses que celles du pin sylvestre, moins que celles du pin maritime. Quand le pin laricio a dépassé 12 ans, sa flèche est en moyenne, pendant un assez grand nombre d'années, au moins aussi longue que celle du pin sylvestre, toutes choses égales d'ailleurs, et je présume que le pin laricio finit par dépasser le pin sylvestre.

1II. Feulles, fleuns et cônes. - Les bourgeons des feuilles du pin laricio commencent à paraître peu de jours après ceux du pin sylvestre; environ quinze jours après on voit les feuilles sortant deux à deux de gaînes cylindriques fixées autour des pousses, mais au lieu d'être sensiblement droites comme celles du pin sylvestre et du pin maritime, elles sont contournées. Lorsque ces feuilles ont atteint toutes leurs dimensions (Pl. III, fig. 13 et 14), elles sont fermes, linéaires, pointues, d'un vert moins foncé que celui des feuilles du pin sylvestre, 


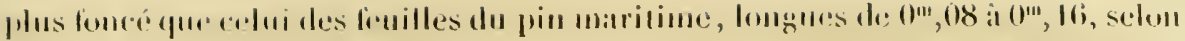
le lieu oil se trouve l'arbre, l'exposilion, le terain, l'age, la partic de l'arbre ou on les prend; la réunion de deux leuilles sortant d'une mène gaine a la forme d'un cylindre. Les feuilles ne persistent ordinairement que pendint deux ans et demi; e'est-it-rlire qu'elles tombent après la troisième sève, y compris celle qui leur a donné natissance, et elles commencent à tomber dès l'automne.

Les lleurs du pin laricio (Voy. 1. 10) paraissent l'une après l'autre; les lleurs utàles dans la première quinzane du mois de mai, les lleurs femelles quelques semaines plus tard, lorsque commencent à paraître les fenilles, ordinairement dius les premiers jours de juin.

Les chatons mâles (1'l. III, fig. 13) sont serrés autour de la partie iuférieure des pousses, de manière à l'ormer une sorte de grappe comme ceux du pin sylvestre et du pin maritime; mais ils sont plus gros que les premiers et moins que les seconds. Les fleurs qui les composent n'atteignent leur maturité qu'après celles du pin sylvestre, ordinairement dans la première quinzaine du mois de juiu, à peu près en même temps que celles du pin Weymouth; elles sont alors l'un jaune verdâtre cl répandent abondamment une poussière jaune. Le pin l:1ricio porte des fleurs mâles en plus on moins grande quantité, et il arrive quelquelois qu'il n'en porte point; mais cela me paraiı être l'exeeption sur des arbres ayaut déplassé 25 ans et convenablement espacés.

Les chatons femelles sont amnoncés, comme dans le pin sylvestre, par de pelits houtons situés au bout des pousses, qui paraissent à la fin de mai ou au commencenent de juin, en même temps que les feuilles, et sont bientôt remplacés par les lleurs; ces chatons sont au nombre d'un à trois, el quelquefois plus parr exception, et en plus grand nombre vers le hant de l'arbre. lls sont ovoüles, ne sont pas plus gros qu'une graine de vesee, sont d'un violet clair et ont la pointe tournée vers le ciel. Au bout de quelques semaines, les leuilles florales se transformant en écailles, les chatons deviemuent des cônes qui sont d’abord violets et deviemment ensuite d'une couleur gris-vert tirant sur le brun; cette translormation est déjà très-apparente dans la première quinzaine de juilled, et e'est pendant qu'elle s'opère que les cônes s'inclinent et prement la position qu'ils conserveront; ils ne sont pils alors plus gros qu'un pois.

Les cônes sont toujours placés au bout de la pousse sur laquelle ils se trouvent, à còté des boutons, au nombre d'un à trois, et quelquefois plus par exception; ils sont lixés immédiatement sur le bois et ont leur axe inclinć de manière à ne pas gèner le développement des boutons qui produiront les pousses de l'annéc suivante. A la fin d'aoùt ils ont acquis tout le développement qu'ils prendront cette première année; ils sont alors oblongs, gros comme une petite noisette et d'un gris-vert. L'annće suivante ils sont roux, lorsque part là sève, commencent dès lors à grossir et deviennent d'un vert-prairie au commencement du mois de juin; à la fin d'août ils ont atteint tout leur accroissement et sont d'une conleur gris-vert; puis ils changent successivement de couleur jusqu'ì ce qu'ils deviemnent couleur nankin et luisans, e qui n'arrive complètement que dins 
te mois de mars de l'année suivante, peu de temps a vant l'époque où ils laissent échapper les graines qu'ils contiennent.

Les cônes du pin laricio (Pl. III, fig. 14, et Pl. V, fig. 6) ont alors de $0^{\mathrm{m}}, 05 \mathbf{y}^{\prime}$ à $0^{\text {m }}, 08$ de long, sont à peu près coniques, et la description que j’ai faite des cònes du pin sylvestre leur est applicable, sauf les dimensions, et avec cette différence que les écailles des cônes sont armées de très-petites épines, excepté pourtant les petites écailles du sommet et de la base (1). Ils s'ouvrent un peu plus tôt qu'eux, c'est-à-dire à la fin de mars ou dans le commencement du mois d'avril de l'année qui suit celle dans laquelle ils ont atteint tout leur accroissement, par conséquent 21 mois environ après qu'ils ont paru, et ils laissent alors échapper leurs graines; ces graines étant munies d'une aile peuvent aussi être transportées au loin par les vents. Les cônes tombent ensuite successivement comme ceux du pin sylvestre.

ll y a dans mon parc deux allées de pins laricio provenant de graines qui m’avaient été données par le ministre de l'intérieur, en janvier 1828, el que je semai pendant le printemps de cette même année pour faire une pépinière; dans l'une dẹ ces allées ils sont mêlés avec des hêtres âgés de 68 ans, et des picéas de leur îge; dans l'autre ils alternent avec des mélèzes également de leur âge, et il y a , dans le taillis, deux rangées de pins laricio parallèles à cette seconde allée. En 1841, et pour la première fois, un seul de ces pins laricio cut pendant sa quatorzième sève des lleurs femelles, et par'suite des cônes qui mûrirent en 1812; ils étaient plus petits qu'ils ne sont sur les arbres plus âgés; en 1812, trois laricio en portèrent; en 1813, il y en ent un plus grand nombre encore, et je remarquai pour la première fois des tleurs mâles sur le laricio qui avait commencé le premier à porter des cônes. Je présume que les arbres provenant de semis naturel porteraient des fleurs et des cônes un peu plus tard.

Une partie des graines de ces jeunes pins laricio sont fécondes, s'ils ont porté des fleurs mâles en même temps que des fleurs femelles; mais ce n'est que lorsque ces pins sont plus âgés que la graine acquiert toute la force germinative qu'elle peut atteindre; je pense done qu'on ne doit récolter des cônes pour en extraire la graine, Jorsqu'on le peut, que sur des arbres de 40 ans an moins. J'ai un pin laricio qui a été planté en 1814-1815, qui avait par conséquent environ 37 ans à l'automne de $\mathbf{1 8 4 4}$, et qui donne de bonne graine depuis plısieurs années, mais avec beancoup de déchet; elle m'a paru inféricure à celle que j’ai obtenue plusieurs fois du ministre de l'intérieur, laquelle, tirée directement de Corse, provenait sans doute d'arbres beaucoup plus âgés; ainsi la première donne plus de déchet et produirait dı plant moins vigoureux.

Le pin laricio qui a dépassé 30 ans me parait présenter, en ce qui concerne les lleurs et les cônes qu'il porte annuellement, les mêmes phénomènes que les pins

(1) Quoique les épines qui se trouvent aux écailles des cỏnes du pin laricio soient très-petites, elles sont pourtant très-apparentes; cependant aucun des auteurs qui ont parlé de ce pin ne les a indiquées, et ceux qui ont donné un dessin du còne de cet arbre le rrprésentent sans épines. 
sylvestres du même âge : e'est-ì-llire qu'il en porte plus souvent que les sapins, qu’on remarque des années d'abondance et des années de stérilité, qu'il y a des années oǹ il ne porte que des fleurs mâles, d'autres où il ne porte que des fleurs femelles; il me parait un peu moins lécond que le pin sylvestre, mais chaque cône contient un plus grand nombre de graines. Il y a d'aiłleurs encore trop peu de pins laricio sous le climat de Paris qui aient dépassé 30 ans, pour que l'on puisse avoir des clonnées d'expérience bien précises à ce sujet.

IV. Granes et semis naturel, - Les graines du pin laricio (Pl. III, fig. 15) sont ovales, d'un brun clair, tachetées et munies d'une aile; celles qui sont d'un blanc jaunâtre sont ordinairement stériles; elles ont environ $0^{\mathrm{m}}, 006$ de longueur moyenne. J'ai indiqué dans l'article précédent à quel âge le pin laricio conmence à porter des cônes; il u'y a, ainsi que je l'ai dit, qu'un petit nombre des graines que conticnnent alors ces cônes qui soient fécondes, et clles ne le sout que si l'arbre qui les a produits a porté en même temps des fleurs mâles el des fleurs lemelles; mais ce n'est que lorsque les arbres sont plus âgés qu'ils donnent dlu plant de semis naturel. J'en ai remarqué en très-petite quantité qui avait un et 2 ans, dans le pare des eaux de Bagnoles (Orne), où je me Irouvais en juillet 1837; il provenait de pins laricio îgés alors de 28 ans, et qui avaient par conséquent commencé à donner du semis naturel à l'âge de 26 ans. Je présume que cet arbre pourrait en domner plus tòt par exeeption; mais je pense aussi que son semis niturel ne serait abondant et efficace que produit par des arbres plus îgés. La graine de pin laricio me paraît avoir atteint sa maturité dès la fin de novembre; cependant je crois prudent de ne cueillir les cônes, si on le peut, pour en extraire la graine qu'après le $\boldsymbol{1}^{\text {er }}$ janvier.

On extrait la graine des cônes du pin laricio absolument de la même manière qu'on extrait celle des cônes du pin sylvestre; ainsi je renvoie à ce que j’ai dit, à ce sujet, pages 146-153. J'ajouterai que les cònes du pin laricio s'ouvrent un peu plus tôt que ceux du pin sylvestre et contiennent une plus grande quantité de grraines; aussi dans les amnées favorables sous le rapport de la température, on pourri se procurer de la graine de pin laricio, en étalant les cònes au soleil, sur des claies, assez tôt pour la semer en avril, et l'on pourra s'en procurer tous les ans assez tòt pour la semer à cette époque, en plaçant les cỏnes sous une bâche préparée exprès, ainsi que je l’ai indiqué page 117.

J’ai trouvé qu'un litre de graine de pin laricio pesait 175 grammes et contenait 31,240 graines, ainsi le kilogramme de cette graine contenait 71,909 graines et occupait un volume de 2 litres 20 décilitres. Delamarre dit, page 89 le son Truité pratique de la culture des pins, que le kilogramme de cente graine contient, terme moyen, 60,000 graines. La graine de pin larieio, malgré la facilité avec laquelie on l'extrait des cones, est rare en France, et souvent l'on n'en trouve point à Paris; elle coùte $16 \mathrm{fr}$. le kilog. dans la maison Vilmorin-Andrieux. Si les ministres de l’intérieur n'en avaient pas fait distribuer, presque tous les ans, depuis dixneuf ans, ce pin, dont il serait pourtant si utile de propager la culture, seritit 
encore beatcoup moins répandu qu'il ne l'est actuellencut, quoiqu'il ne le soit encore que fort peu. On a d'ailleurs la ceritude qu'il sera bientùt plus facile d'en propager la culture, car la forêt de Fontainebleau contient actuellement une grande quantité de pins laricio, provenant de greffes sur pin sylvestre, qui commencent à donner abondamment des cônes, et l'on vient de mettre une sćcherie en activité à Fontainebleau (Voy. p. 1/48).

La graine du pin laricio lève dans l'année même où elle tombe de l'arbre; la graine que l'on extrait des cònes m'a paru lever presque aussi facilement que celle du pin maritime, mais elle éprouve plus de déchet. Le plant de pin laricio ne supporte pas mieux l'ombrage que celui de pin sylvestre et de pin maritime (Voy. p. 153).

V. Mode de végetation, description, dimensions. - Le morle de végélacion du pin laricio a été décrit, au commencement de ce chapitre, en ce qui concerne? la marche de la sève dans cet arbre, ses boutons, ses leuilles, ses lleurs, ses cônes; et l'on trouvera, chap. XI, art. VI, des détails sur' sa végétation et sur son accroissement, depuis le semis en pépinière jusqu'au moment de la plantation ì demeure. Le plant de semis naturel présente beaucoup de variété dans son accroissement, selon les circonstances particulières dans lesquelles il se trouve; placé; cet accroissement, qui est ordinairement plus lent que celui du plant de pépinière, peut l'égaler pourtant et mème le surpasser dans des circunstances de tout point favorables, à cause du retard que la transplantation fail éprouver au plant de pépinière. La graine lève irrégulièrement, selon l'époque à laquelle elle est tombée et la situation où elle s'est trouvée. J'ai dit, dans l'article précédent, que le plant de pin laricio ne supporte point l'ombrage comme celui des sapins et qu’il périt bientôt s'il est trop ombragé; mais il réussit très-bien sans ombrage, mème dans l'année de sa naissance, et je présume que l'ombrage lui est toujours nuisible, du moins sous le climat de Paris.

Le plant de pin laricio, toutes choses égales d'ailleurs, pousse plus lentement, pendant les premières années, que celui des pins à chacun desquels j’ai consacré un clıapitre; mais plus tard il les rattrape, et il finit par les dépasser, du moins d'après ce qui a élé observé jusqu'à ce moment. J'ai remarqué des flèches de pin laricio qui avaient, lorsque l'arbre a dépassé 12 ans, jusqu'à $0^{\mathrm{m}}, 90$ de long, et il m’a semblé qu'il y avait plus de régularité dans son accroissement annuel que dans celui des autres pins auxquels je viens de le comparer; il m'a semblé aussi que son tronc maintenait mieux sa grosseur que le leur.

A Bagnoles (Orne), les pins laricio, dont j'ai parlé précéelemment, qui avaient été plantés en même temps que des pins sylvestres et que des pins Weymouth, et tous, en 1812, à l'âge de 3 ans; à Bagnoles, les pins laricio l'emportent en dimension sur ces deux autres espèces de pins. Le terrain où ces arbres se trouvent plantés m'a paru siliceux et fort maigre; il est couvert d'un mélange de bruyères, de joncs marins et de fougères; il semble convenir mieux „II pin laricio el an pin sylvestre qu'au pin Weymouth. Loudon dit qu'eu An- 
gleterre l'aceroissement du pin laricio a été plus for que celui du pin sylvestre dans les mêmes sols.

Le pin laricio a une racine pivotante qui m'a paru aussi forte que celle du pin maritime, des racines latérales moins fortes que cette racine principale, et peu de chevelu; par suite de cette disposition de ses racines et de ce qu'il est chargé de branches vers la tête, pendant ses premières années, il est alors exposé à être ébranlé et penché par les vents, lorsqu'il croît isolé; car plus tard le vent le brise plutot que de le renverser. J'ai fait redresser souvent de jeunes laricio de 2 à 4 mètres de haut, provenant de pépinière, qui avaient été couchés par les vents jusque près de terre, et lorsqu'une sève les avait raffermis, il ne restait plus de traces de cet ébraulement.

Je ne puis rien dire, pour l'avoir vu de mes yeux, du trone du pin laricic qui a crû en futaie à l'état serré, n'ayant point visité les futaies de la Corse, et les futaies de cette essence qui existent sous le climat de Paris, n'ayant au plus que 16 ans ; mais je sais que le tronc de cet arbre, lorsqu'il a crû à l'état serré, est dépouillé jusqu'à plus de la moitié de sa hauteur et qu'il maintient bien sa grosseur. Lorsque cet arbre croît isolé, son trone est dépouillé de branches jusqu'ì environ 2 mètres au dessus du sol, et il se maintient droit comme le tronc des sapins.

Si l'on brise le trone d'un pin laricio dans sa jeunesse, une branche de l'étage immédiatement inférieur continue le trone; quelquelois, mais très-rarement, il se bifurque; si l'arbre approche de sa maturité ou que la brisure soit trop loin de la tête, il reste mutilé; et si la brisure est trop rapprochée du sol ou que l'arbre ait conservé trop peu de feuilles et de bourgeons, il périt. Des pies ont plusieurs fois brisé la flèche du pin laricio isolé, âgé de 37 ans, dont j’ai parlé page 248; il s'est toujours formé une nouvelle flèche, ainsi que je viens de le dire, et l'arbre s'est enfin bifurqué, mais il est resté parfaitement droit.

L'écorce du tronc du pin laricio est d'un gris-roux dans la jeunesse de l'arbre; elle devient brune dans un âge plus avancé et sc couvre de grandes écailles dins la partie du trone qui est la plus rapprochée du sol; elle est plus épaisse que celle du pin sylvestre, moins que celle du pin maritime.

Les branches du pin laricio sont disposées par étages et au nombre de cinq à six par chaque étage. Dans les jeunes pins et vers le sommet des pins, tant qu’ils ont une flèche, c'est-ì-dire tant qu'ils sont dans la période d'accroissement, clles sont peu élevées au dessus du plan horizontal, qui passerait par leurs points de jonction avec la tige, et elles se redressent vers le bout en forme de candélabre; puis elles s'abaissent à mesure qu'elles prennent des années, mais elles ne tombent guère au dessous dı plan horizontal dont je viens de parler: ces branches étant peu chargées de rameaux et de ramilles, l'arbre ne me paraît pas avoir toujours assez, de fenillage. Il résulte de la grande régularité des élages de branches du pin Iaricio, pendant ses trente premières années, et en ontre de ce que son tronc se maintient droit, que cet arlore est très-propre ¿ faire des allées; plus tard lés etagés se déforment et les branches du bas 
du trone n’ont plus la mème régularité, mais l'arbre conserve un port majestueux.

Le vert du pin laricio, qui est moins foncé que celui du pin sylvestre, plus que celui du pin maritime, me parait agréable, n'étant ni sombre comme celui du premier, ni fade comme celui du second.

Je n'ai à rapporter qu'un petit nombre de faits pour faire connaître quel esı l'accroissement du pin laricio soús le climat de Paris. J'ai parlé, page 2'18, d'unc allée de pins laricio, située dans mon parc, et dans laquelle ces arbres, qui étaient âgés de 17 ans en 1844 , alternent a vec des mélèzes du même âge qu'eux. Le plus haut de ces pins avait, à l'automne de 1844 , une hauteur de $7^{\mathrm{m}}, \mathbf{7 2}$, le plus gros un diamètre de $0^{\mathrm{m}}, \mathbf{1 5}$, et le plus haut se trouvait être en même temps le plus gros. La hauteur moyenne de ces arbres était de 6 mètres, et ils avaient, en moyenne, un diamètre de $0^{\mathrm{m}}, 12$; ainsi ils avaient eu un accroissement. moyen annuel de $0^{\mathrm{m}}, 008$, plus for $\mathrm{t}$ par conséquent que celui des mélèzes de même âge qu'eux, avec lesquels ils alternent (Voy. chap. VIII, art. V); il faut ajouter qu'ils maintiennent mieux leur grosseur qu'eux.

Le pin laricio isolé qui se trouve près de mon habitation, et qui était âgé d'environ 37 ans à l'automme de 1814, a vait alor's un diamètre de $0^{\mathrm{m}}, 38$, ainsi il avait eu un accroissement annuel de $0^{\mathrm{m}}, 01$; il n'avait que $1 \mathrm{1}^{\mathrm{m}}, 50$ de haut, mais il est placé sur le sommet d'une petite butte de terrain silico-argileux rempli de pierres et fort maigre, et sa flèche a été brisée plusieurs fois par des pies.

J'ai mesuré chez M. de Corday, à 4 lieues de chez moi, à sa terre du Baudry, un pin laricio qui a été planté en avril 1822, et qui avait, par conséquent, 30 ans environ en 1844; il avait alors un diamètre de $0^{\mathrm{m}}, \mathbf{4 7}$, ce qui donne un accroissement annuel de $0^{\mathrm{m}}, 015$; sa hauteur était d'environ 16 mètres; il se trouve dans une terre de jardin près d'une habitation. Un autre pin laricio planté en même temps, dans le même lieu, n'avait que $0^{\mathrm{m}}, 38$ de diamètre.

Il y a dans le parc de Trianon, près de Versailles, un pin laricio qui avail, lorsque je le mesurai, le 7 aoûl $1844,1^{\mathrm{m}}, 69$ de circonférence et environ 16 mètres de haut; je présume, à son aspect, qu'il aura été planté pendant les dernières années de l'Empire, ainsi il ne serait plus âgé que celui de 37 ans, qui est chez moi, que de quelques années; il a de plus fortes dimensions, mais il est en bonne terre et le mien en très-mauvaise.

I. de Mainville a commencé, en 1827, à semer en grand de la graine de pin laricio, dans sa terre d'Alosse, commune de Marcilly-en-Villette (Loiret), sur un bon sable de Sologne; le plus beau de ses pins avait en 1843, à $1^{\mathrm{n}}, 50$ au dessus du sol, $0^{\mathrm{m}}, 30$ à $0^{\mathrm{m}}, 40$ de circonférence et $6^{\mathrm{m}}, 66$ de haut.

Le plus gros des pins laricio du parc de Bagnoles, dont j’ai parlé plus haut, avait en 1837 , étant âgé de 29 ans, un diamètre de $0^{\mathrm{m}}, 38$, ce qui donne un accroissement annuel de $0^{\mathrm{m}}, 13$ par an.

Il y a dans la forêt de Fontainebleau (Seine-et-Iarne), sur le mont Chauret, en terrain de sable siliceux mêlé d'un peu d'humus, dans une épaisseur de $0^{\mathrm{m}}, 20$ à $0^{\mathrm{m}}, 25$, trojs pins laricio qui se trourent au milieu d'un massif de pins sylvestres 
et qui ont ché planlés un même lemps qu'eux en 1785; ils avaient, à l'automme, le $18^{\prime} 13,18$ à 20 mètres de haut et des diamètres de $0^{\mathrm{m}}, 27,0^{\mathrm{m}}, 30 \mathrm{cl} 0^{\mathrm{m}}, 31$; en moyenne, ils avaient un diamètre te $0^{\mathrm{m}}, 29$, ee qui donne un aceroissement annuel moyen de $0^{\text {"' }}, 005$. Ainsi, ces pins larieio qui ont crù en société avec des pins sylvestres, dans un terrain fort maigre, ont eu un aceroissement un peu plus prompt qu'eux (Voy. p. 159); le pin laricio a eu aussi un accroissement plus prompt que le pin sylvestre dans un massif resultant du semis qui a été exícuté en 1820, au lieu dit le Rocher-aux-Demoiselles (1).

Il y a ì Malesherbes (Loiret) neuf pins laricio que Malesherbes avait fail semer on planter, à mi-côte, dans un sol siliceux maigre, en mème temps et dans le même massif que des pins sylvestres et que des pins maritimes; l'opinion accréditée, dans le pays, est qu'ils ont été semés de 1775 à 1780; les neufs pins laricio, qui occupent un espace de $3^{\mathrm{m}}, 60$ de large sur 11 mètres de long, ont acquis des dimensions beauconp plus fortes que les pins des deux autres espèces. Ils avaient, à l'automne de 1813,2 I" $^{\prime \prime}, 50$ à 2 ' mètres de haut; le plus gros de ces pins avait un diamètre de $0^{\mathrm{m}}, 62$ et leur diamètre moyen était de $0^{\mathrm{m}}, 52$; s’ils n’étaient âgés que de 60 ans, ils avaient eu un accoissement moyen amnuel de $\left(0^{m}, 008\right.$. Le plus gros des pins sylvestres n'avait que $0^{\mathrm{m}}, 36$ de diamètre el 15 mètres de haut; le plus gros des pins maritimes n'avait que $0^{\mathrm{m}}, 33$ de diamètre et 14 mètres de haut. Un pin laricio, un pin sylvestre et un pin maritime, qui ont crìs isolé dans le même terrain et près de ce massif, présentent des différences analogues dans leurs dimensions: le pin laricio a $0^{\mathrm{m}}, 70$ de diamètre et 20 mètres de haut, le pin sylvestre $0^{\mathrm{m}}, 57$ de diamètre et 16 mètres de haut, le pin maritime $0^{\text {th }}, 50$ de diamètre et 17 mètres de haut (2).

On remarque au Jardin-ıles-Plantes, dans le carré consacré à l'école de botanique, en terre de jardin, un pin laricio qui a été planté fort petit, en 1774, par Laurent de Jussieu, et qui avait par conséquent, à l'automne de 1811, environ 72 ans. Je trouvai alors qu'il avait un diamètre de $0^{\text {m }}, 76$, ce qui donne $u n$ accroissement anmuel de $0^{\mathrm{m}}, 01$; je trouvai aussi que sa hauteur était d'environ 23 mètres, mesuré avec mon dendromètre, mais j'avais pour le placer un pied d'emprunt fort mauvais.

On ne peut savoir à quel âge le pin laricio atteint sa maturité sous le clịmat de: Paris, parce que les plantations de cet arbre qui s'y trouvent sont encore trop jeunes, et je n'ai pu me procurer aucun renseignement direct sur l'âge auquel il l'atteint dans les forêts de la Corse; Baudrillart dit (3) que sa croissance y dure ordinairement de 70 à 80 ans.

Le pin laricio atteint de magnifiques dimensions. "Il n'est pas rare, dit Baudril" lart dans l'article que je viens de citer, d'en voir sur les montagnes de la Corse "qui ont plus de 100 pieds de haut sur 8 pieds de circonférence, et l'on en trouve

(1) lienseignemens comnuniqués par M. de Boisdhyver, inspectcur de la forèt de Fontainchleau.

(2) Renseignemens communiqués par MM. de Boisdliyveret Bernard, pharmacien à Malesherlıs.

3) Diclionnaire des eaux ef forês, t. I1, p. 592, art. Pinus laricio. 
"qui ont jusqu’à 140 et 150 pieds. "M. Vétillart, dans le mémoire précédemment cité, parle d'un voyage qu'il fit en Corse, par amour des plantations, et dit en parlant du pin maritime et du pin laricio : Les pins maritimes et les laricio y " prennent un développement surprenant, tel que des pins laricio atteignent de n 12 à 24 pieds de circonférence et de 80 à 100 pieds d'élévation ; rien n'est com" parable à la beauté de ces arbres, dont quelques-uns contiennent 12 à 1500 pieds " cubes de bois. " Delamarre dit page 50 : " qu'en Corse, il est fort commun " que ce roi des pins d'Europe s'élève jusqu'au delà de 120 pieds, dont moins du " 20 sont en louppe, et plus de 100 sont en tige nette de branches sur 9 à 12 "pieds de eirconlérence."

A ces renseignemens un peu vagues sur les belles dimensions auxquelles peut parvenir le pin laricio, je puis ajouter un fait précis; ce sont les dimensions qu'avait en $\mathbf{1 8 2 2}$ le plus beau pin laricio de la forêt de Vizzavone, l'une des plus belles de la Corse; cet arbre fut abattu pendant une absence de M. Zédé, ingénieur de la marine, qui aurait voulu le conserver, et qui m'a donné ses dimensions. On le coupa à $1^{\mathrm{m}}, 50 \mathrm{du}$ sol, et l'on en tira une pièce de $19^{\mathrm{m}}, 90 \mathrm{de}$ long, qui, équarrie à huit pans, avait $1^{\text {m }}, 20$ de large au gros bout, 1 mètre au petit bout, et par conséquent 20 mètres cubes. Mais en équarrissant on retranche une partic du bois, surtout au gros bout, afin de dresser la pièce; on ne peut donc pas supposer que le tronc de ce pin avait moins de $1^{\mathrm{m}}, 60$ de diamètre à 1 mètre au dessus du sol, et peut-être avait-il davantage. Ce tronc était dépouillé de branches jusqu'à 30 mètres au dessus du sol, ainsi l'arbre ne devait pas avoir moins de $\mathbf{4 0}$ mètres de haut du sol à la cime. M. Zédé ayant fait eouper en biseau la partie du trone qui restait fixée à la souche, put compter à l'œil nu 800 couches ligneuses jusqu'à environ $0^{\mathrm{m}}, 12 \mathrm{du}$ cœur, où elles étaient trop rapprochées pour qu'il fùt possible de les distinguer (Voy . p. 13). La forêt de Vizzavone oceupe un sol granitique sur un sous-sol de rocher de granit.

Je reproduirai textuellement ce que dit Tenore (2) des dimensions auxquelles parviennent ces mêmes arbres dans les Apennins du royaume de Naples : "Les " montagnes des Siles, dans la Calabre, sont renommées par l'immense quan" tité et par la grandeur colossale des pins dont elles sont couvertes; ayant eu "l'occasion d'examiner avee la plus scrupuleuse attention toutes les espèces de " pins qui croissent dans ces forêts, je me suis convaincu que l'espèce la plus " Caractéristique appartient à eelle du Pinus laricio, conuu aussi sous la dénomi" nation de Pin de Corse. Ce pin, que le célèbre Lamarck a appelé avec raison al"tissima, atteint en moins de 60 ans, dans les Siles, la hauteur de 120 à 130 pieds. "Il couronne les sommets des versans occidentaux de ces montagnes, et se plait " lans la région supérieure à celle du hêtre. Il descend pourtant dans les ré" gions inférieures et quelquefois jusqu'aux plaines, mais il y reste toujours so" litaire et il n'y forme jamais de forêts. "

(1) Essai sur la géographie physique et botanique du royaume de Taples, p. 75. Trenore a écriţ cet ouvrage en français: j'ignore si le pied dout il frarle pst le noble ou la palme napolitaine, qui n'a que $0^{\text {m1 }}, 2636$ de long: 
Loudon dit (1) yu'il y a dans te jardin botanipue de Kew un pin larieio qui a de 80 à 90 pieds (24 i 27 mètres) de haut, mais il n'en dome point l'âge. Il cite aussi un pin laricio planté dans Je Berkshire, i White Kuights, il y a 37 ans, qui est âgé par conséquent aujourd'lui (1815) d'environ 41 ans, et qui a 60 pieds (18 mètres de haut) (Voy. p. 38). Enfú cet auteur domne les dimensions de quelques autres pius larició beaucoup noins âgés.

VI. Chinat, exposition, terians. - Le pin laricio croît spontanément dans la partie montagneuse de la Corse, où il se trouve de vastes forêts de cet arlore. Selon Tenore on le trouve aussi croissant spontanément dans les Apenuins du royaume de Naples et sur le mont Etna, particulièrement sur les montagnes des Siles, ainsi qu'il le dit dans le passage que je viens de citer, et il reproduit cette assertion dans sa Flora napolitana, 1. V, p. 268. D'après la description de Tenore lans ce second ouvrage, el d'après ce que m'a dit M. A. Michaux, qu'on lui avait apporté des cônes de pin laricio de l'Etna, qu'il en avait semé les graines et que les plants ol,tenus étaient entièrement semblables à ceux du pin laricio de Corse, je pense que le pin laricio du royaume de Naples est le même que celui de la Corse. Je ne partage d'ailleurs pointl'opinion des auteurs qui disent que cet arbre ou des variétés de cet arbre ont été trouvées ailleurs; ils ont confondu le pin d'Autriche, le pin taurique, le pin de Caramanie, le pin de Romanie, un seul et mème pin selon moi sous des noms différens, avec Je pin laricio; ou ils en ont lait des variétés du pin laricio. Il est vrai que le pin d'Autriche a de la ressemblance avec ce pin, mais c'est pourtant une espèce différente, ainsi que je le ferai voir dans le chapitre $\mathbf{X}$.

Le pin laricio a été introduit en France par la culture dans un grand nombre de lieux; les graines distribuées par les ministres de l'intérieur depuis 19 ans, ont beaucoup contribué à le propager. MM. de Larminat et de Boisdhyver, qui ont été successivement inspecteurs de la forêt de Fontainebleau, en ont fait greffer dans cette forêt, sur des pins sylvestres, une grande quantité qui commencent ì donner abondamment de la graine. L'administration des forêts a fait essayer des semis de pin laricio dans les Vosges, sur des points élevés de ces montagnes, entre autres sur le sommel du Donon, montagne qui domine toutes celles de son voisinage, et qui a une élévation de 1000 mètres au dessus du niveau de la mer; la graine de pin laricio y a été semée mélangée arec le la graine de pin sylvestré, en 1825. Les pins sylvestres ont bientôt été écrasés en partie par les neiges et par les vents; les pins laricio, qui avaient d’abord assez. bien réussi, ont funi par souffrir beaucoup aussi; cenx de ces derniers arbres qui avaient le moins souffert n'avaient à l'automne de 1813 que $2^{\mathrm{m}}, 20$ de haut; un autre semis, qui avait été fait à la hauteur de 800 mètres seulement, n'a guère moins souffert; ainsi il est incertain que l'on puisse cultiver arec succès le pin laricio à celte hauteur, sous celte laticude (2).

i) Arboreluin of frutictum britaunicum , 1. W, p. 220 i.

:2 lit'nscignemens communiqués par .1. (i. liand, inspecteur des fortis. 
Les pins laricio les plus âgés que je connaisse en France sont : celui du Jardiıdes-Plantes, planté en $\mathbf{1 7 7 4}$ par Jussieu; les trois pins laricio semés en 1785 dans la forêt de Fontainebleau, sur le mont Chauvet, lont j'ai dọné les dimensions; les pins laricio de Malesherbes, âgés de 60 ans, et un pin laricio au BoisGuillaume, près de Rouen, planté, dit Delamarre, en 1776.

Il y a dans le jardin de M. Guy, à Saint-Germain-en-Laye (Seine-et-Oise), des pins qui ont été semés par son père, et que Delamarre prétend, page 31 de son Traité, être des pins ronges d'Amérique; il est difficile de s'expliquer celte opinion, M. Guy, le propriétaire actuel, les ayant toujours vus sous le nom de Pin de Corse (autre nom du pin laricio) sur les catalogues de son père. MM. Vilmorin et A. Michaux, qui ont examiné ces pins, disent dans une note de la $3^{\bullet}$ édit. du Traité de Delamarre, que ce sont des pins laricio; je les ai examinés aussi, et il m'a paru aussi que c'étaient des pins laricio. Le pin laricio et le pin rouge pourraient se ressembler assez pour qu'il fùt possible de les prendre l'un pour l'autre, quand on n'a pas en même temps sous les yeux des sujets de diflérens âges pour les comparer; mais un caractère tranché les distingue : les écailles des cônes du pin laricio sont armées d'épines, celles des cônes du pin rouge n'en ont point ( $V o y$. chap. $\mathbf{X}$, art. $\mathbf{X}$ ). Les pins laricio du jardin de M. Guy ont probablement été semés peu d'années après 1775 , époque où son père créa le jardin; ils se trouvent dans un terrain composé de débris de démolition et autres provenant de la ville de Saint-Germain, et par conséquent de même nature que celui du labyrinthe du Jardin-des-Plantes de Paris; ce terrain vie paraît pas leur convenir. Le plus gros de ces arbres a $0^{\mathrm{m}}, 42$ de circonférence, et jévalue sa hauteur à $16^{\mathrm{m}}$,, on.

Loudon dit (1) que le pin laricio a été introduit en Angleterre en 1759, mais si l'on en excepte le pin laricio du jardin de Kew, il ne donne point, ainsi qu'on l'a vu, les dimensions de pins laricio dont le semis puisse dater de cette époque; il dit que ce pin réussil jusque sur les montagnes d'Ecosse; il en cite un âgé de 10 ans ì Harbecke en Hanovre; dans ce dernier lieu il se trouve à peu près à la même latitude-el dans les mêmes circonstances de température qu'un pin d'Autriche que je remarquại dans le jardin botanique de Berlin; aussi je présume que ce laricio est dans une situation abritée, ou que c'est un pin d'Autriche qu'on prend pour un pin laricio.

Je ne puis rien dire de positif sur l'exposition qui convient au pin laricio; il peut prospérer à toutes les expositions dans les pays de plaines ou qui ne sont que montueux; j'ignore l'exposition qu'il prélère dans les montagnes de la Corse. Tenore dit qu'il occupe les versans occidentaux des montagnes de la Calabre; il lui faut évidemment, comme au pin maritime, une exposition chaude et abritée, lorsqu'on le cultive près des lieux où le climat devient trop rigoureux pour qu'il puisse le supporter.

Le piu laricio me paraìt pouvoir croître dans tous les terrains siliceux où peut

(1) Arboretum ef frulicetum brilannicum, 1. IV, p. 2201, art. Pinus laricio. 
eroitre le pin sylvestre; mais, il me pourrait pats plus que ce pin être cultivé sur des sables quartzeux aussi arides que cenx sur lespuels on peut encore cultiver areesucès le pin maritime. II. dacquinot de Presle en a fait semer, en 18:32, en Sologne, sur une étendue de 12 ates d'un sable blane improductif; lo plant :ulquel ce semis a donné naissance, avait en 181 tune belle apparence. Le pin latricio présente, comme le pin sylvestre, l'avantage de pouvoir être cultive sur les terains calcaires ordinates, et j’en parle d’après ma propre expérience; je ne puis d’ailleurs dire s’il réussirait aussi bien que le pin sylvestre sur les craies de lat Champagne; l'épreuve en aura sans doute été filite, mais les résultats ue: in'en sont pas connus.

VII. Crimtion liune futale de pins lancio. - Ce que j’a dit relalivement à la eréation d'une futaie de pins maritimes, dans lis chapitre précédent, s'applique à la création d'une futaic de pins laricio, à quelques moủifications près, que je vais indiquer.

Lorsque pour créer une futaic on veut employer la plantation, si l'on se sert de plant herbacé on réussit moins bien arec le plant de pin laricio qu'avec celui de pin maritime, parce que le plant herbacé de la première espèce étant beatucoup plus petit que celui de la seconde, demanderait à être planté avec plus de soin; ce qu'il est difficile d'obtenir quand on opère en grand. Le plant de pin laricio plus âgé, ayant un peu plus de chevelu que celui de pin maritime ététunt un peu moins chargé de branches vers la tête, reprend, au contraire, un peu micux que lui. Ainsi, dans les terrains où les semis échouent ou réussissent mal, on pourra très-facilement créer une pinière de pins laricio en employant l: plantation; mais il faut cmployer du plant âgé de 3 ans an moins. Le plant provenant de semis naturel réussit rarement; il est donc très-important d'enployer du plant de pépinière, qui, étant garni de chevelu, reprend très-bien.

I. Vétillart dit, dans ses Observations sur la culture du piu maritime, citées dans le chapitre précédent, qu'il sema en 1830 du pin laricio sur 3 ares de terrain sablommeux préparé avec soin, et que deux ans après, au mois de mars, il repiyua son plant, qui réussit très-bien; mais c'est là une véritable culcure cu pépinière. M. Jacquinot de l'resle a repiqué plusieurs fois du plant de pin laricio, de 2 et 3 ans, pris dans des semis qui avaient été exécutés en grand sur des trrrains salılonneux, et il n’a réussi qu'une seule fois. Moi, j’ai repiqué plusicurs cenraines de plants de pin laricio de 3 ans, avec beaucoup de soin, dans une terre de pépinière hien préparée, et il n’en est pas resté deux sur cent; j’avais levé ee plant, dans ce semis d'expérience sur labour dont j’ai parlé page 5̄, et dout je parlerai plus en détail, en ce qui conceme le pin laricio, quand je moceuperai de sa culture au moyen du semis à demeure. Au mème endroit oì périssaitut. presque tons les plants de pin laricio tirés d'un semis sur labour, il n'en périssatit, pour ainsi dire, pas un seul de ceux du même âge que l'on plantait en mèmo lomps, mais qui avairnt áć álevés en pépinière.

Si l'on romploir le semis pour crón une futaie de pins laricio, on n’éprouver:a 
pas plus de difficulté que pour en créer une de pins maritimes. Lorsque les graines de pin laricio sont bonnes, elles lèvent aussi facilement que celles de piu maritime, mais il y en a un plus grand nombre de stériles, et il y a par conséquent plus de déchet dans les premières que dans les secondes : l'on a vu qu'un kilogramme de graine de pin maritime contient trois fois moins de graines qu'un kilogramme de graine de pin laricio; il suffirait done de semer 4 kilogrammes de graine de pin laricio par hectare, si le même nombre de ces deux espèces de grạines contenait un même nombre de graines fécondes; mais celle du pin marilime en contenant davantage, on sèmera 6 kilogrammes au moins de graine de: pin laricio par hectare.

Le pin laricio enfonce son pirot de 6 ì 8 centimètres en terre, dès la première année, mais sa tige reste chétive; il en résulte que les plantes parasites peuvent lui être beacoup plus nuisibles qu'au pin sylvestre et qu'au pin maritime, qui poussent pläs promptement que lui (Voy. chap. XI, art. IV, V ('t VI). Par cette raison, il est très-utile de semer du pin maritime en même temps que du pin laricio, afin d'occuper promptement le terrain; ainsi avec les 6 kilogrammes de graine de pin laricio on en sèmerait autant de graine de pin maritime; mais lorsque l'on sème ainsi de la graine de pin maritime, il faut commencer les éclaircissages dès la seconde année, s’il est nécessaire, en les faisant porter sur le pin maritime; sans quoi il aurait été préférable de ne pas en semer, parce que ce pin, ayant une croissance plus rapide que le pin laricio, pourrait l'étouffer. Si l'on manquait de graine de pin laricio, ou si l'on voulait l'économiser, on pourrait n'en semer que 4 kilogrammes et même que 3 par hectare, et l'on augmenterait alors la quantité de graine de pin maritime; il y a moins d'inconvénient à en semer trop que trop pen, quand on est décidé à faire éclaircir en temps utile.

Dans le terrain consacré à un semis d'expérience, dont j’ai parlé page j̄̄, j’avais semé en 1837, sur la plus mauvaise partie, un mélange de graines de pin laricio et de pin maritime; le plant provenant de ce semis s'empara du terrain, dès l'automne de la seconde année, et je commençai à l'éclaircir en supprimant le pin maritime; ce pin aurait disparu après la troisième année, si je n'eu eusse conservé une dizaine de plants jusqu'à l'automme de 1811 , pour en comparer l'accroissement avec celui du pin laricio et avec celui du pin sylvestre. J'avais semé sur une autre partie de ce terrain qui était de beaucoup meilleure qualité, du laricio seul et il n'occupait pas encore entièrement le terrain en 1811; son accroissement a été plus Jent que celui du premier, parce que le terrain étant meilleur et n'étant pas occupé à beaucoup près, s'est couvert le bruyères, de joncs marins et de gazon. Dans le premier semis, la bautcur moyenue du pin laricio, à l'automne de 1841 , était d'un mètre; à l'automne de 1812, elle était de $1^{\mathrm{m}}, 5 \mathrm{5}$; à l'automne de 1813 , de $2^{\mathrm{m}}, 22$, et à l'automne de 1844 , de $2^{\mathrm{m}}, 92$. Si donc, dans les premières années, le pin laricio prend moins d'accroissement que le pin sylvestre, il le rattrape ensuite (Voy. p. 180), et l'on a vu qu'ordinairement, sous le climat de Paris, il finit par le dépasser. Je présume que le pin laricio sera un 
jour très-répandu en France, qu’il y sera très-utile et qu'il y atceindra, toutes 'hoses égales d'ailleurs, fle plus belles dimensions que le pin sylvestre.

La greffe herbacée que je décrirai, chap. XII, art. II, réussit très-bien quand on greflo le pin laricio sur le pin sylvestre; elle peut, par conséquent, procurer des porte-graines plus promptement que le semis, et servir à transformer de jeunes lutaies de pins sylvestres en futaies de pins laricio. II suffit, pour opérer crtte transformation, de greffer dans une futaic de pins sylvestres wn nombre suffisant de sujets en pins laricio et de supprimer, par des éclaircissages successifs, les pins qui n'ont pas été greflés à mesure qu’il est nécessaire. On trouve lans la forêt de Fontancbleau de remarquables cxemples de ces deux opérations. M. de Larminat, pendant qu'il était conservateur de cette forêt, et M. de BoisIllyver, qui lui a succédé, y ayant fait exécuter, Ilepuis 1822, un grand nombre de greffes de pin laricio sur pin sylvestre, des quartiers qui étaient originairement en pins sylvestres se trouvent transformés en quartiers de pins laricio.

VIII. Aménagenent, exploitation ét neproduction. - I'après ce que j'ai vu de la culture du pin laricio, sous le climat de Paris, et d'après ce qu'on rapporte des lintaies de cet arbre dans les montagnes de la Corse el de la Calabre, je pense qu'on doit traiter les futaies de pins laricio absolument comme celles de pins sylvestres; je renvoie dlone à ce que j'ai dit à ce sujet, pages 189-192.

Le pin laricio étant peu chargé de branches dans la partic inférieure de son tronc, ayant un pivot qui s'enfonce profondément en terre et réussissant trèsbien dans les taillis de bois feuillus, est l'un des arbres que l'on peut élever en futaie sur taillis qui causent le moins de donmage à ce taillis.

1X. Qualtés et usages du bots; pronuts divers, - Je ne commais ni la couleur, ni la pesanteur spécilique, ni la qualité du bois du pin laricio sous le climat de Paris, où il n'en existe encore qu'm bien petit nombre de sujets qui soient ıssez âgés pour qu'on puisse en faire du bois d'ouvre; je sais qu'il est plus résineux que le bois du pin sylvestre, qu'il a une pesanteur spécifique plus grande, et je présume qu'il lui est généralement inférieur en qualité; il me parait d'ailleurs probable, ainsi que je l'ai dit, qu'il y acquerrait de plus belles dimensions et en moins de temps. Le bois du pin laricio est employé en Corse pour les constructions, la menuiserie et la petite mâture. Il y a fort longtemps qu'on s'en sert dans les arsenaux pour la construction des parties des vaisseaux autres que la mâture; en 1788 on l'employa pour la première fois à la mâture, et il fut trouvé moins fort et moins élastique que les bois dı Nord, particulièrement que le pin sylvestre, celui dont on se sert le plus fréquemment en France pour cet usage. Actuellement on l'emploie à Toulon en bordages et à la mâture, on en a fait souvent de beaux mâts de hune pour vaisseaux et frégates. Un fait qui a été observé dans le pare de Bagnoles (Orne) semblerait venir à l'appui de ce que je viens de dire du manque d'élasticité du pin laricio; c’est que parmi les laricio, les pins sylvestres, l's pins du lord et les mélèzes qu'on y a plantés, et qui s'y trouvent exposés à des 
vents très-violens, les pins laricio sont ceux qui ont en le plus grand nombre de trones brisés paí les vents. On ne peut pourtant pas conclure avec certitude de ce fait que cet arbre est plus cassant que ceux auxquels je viens de le comparer, parce qu'étant plus clıargé de branches qu'eux vers la tête, pendant les premières années, il est alors plus exposé à ce genre d'accident.

Tenore s'exprime ainsi qu'il suit sur l'emploi du bois du pin laricio dans le royaume de Naples, page 76 de son Essui sur la géographie physique el botanique du royaume de Naples. "On a employé de tout temps les trones des pins laricio aux " constructions navales et civiles; et il n'est pas dilficile de se procurer dans les "Siles des mâts d'environ 100 pieds de hauteur et d'environ 3 pieds de diamètre. "C'est de ces pins qu'on tire la poix fameuse que Virgile et Horace ont célébrée " dans leurs vers larmonieux, et c'est le bois résineux de ces arbres que les babi" tans des villages adjacens aux Siles brûlent au lieu de chandelles pour éclairer " leurs maisons. Par une analogic singulière avec les noms et les usages des an" ciens, on n'appelle autrement que Telae ces morceaux de bois dont la fumée " épaisse noircit de telle sorte les habitations, les habillemens et les visages " mêmes de ces pauvres villageois, qu'en les visitaut on se croit presque trans"porté au milieu des cavernes sombres et ténél)reuses des Cimmériens."

X. Acciders, maladies, animaux nuisibles. - Les gelées ne m'ont paru causer aucun dommage au pin laricio, du moins sous le climat de Paris.

Les pins laricio qui ont résisté aux vents pendant leur jeunesse n'en sont pour ainsi dire jamais renversés par la suite, parce qu'ils sont très-solidement enracinés lorsque leurs racines peuvent pénétrer dans le sol; mais leur tronc, avant qu’ils aient dépassé 30 ans, m’a paru plus exposé que celui des pins sylvestres à être brisé par les vents.

La neige et le givre peuvent causer de grands dommages dans les jeunes futaies de pins laricio comme dans celles de pins sylvestres.

Le dommage que peuvent causer les quadrupèdes et les oiseaux dans les pinières de pins laricio est absolument semblable à celui qu'ils peuvent causer dans les sapinières; mais comme je pense qu'on ne devrail point exploiter ces pinières en jardinant, les quadrupèdes ne pourraient leur nuire que quand elles seráient jeunes.

Les lapins broutent moins le pin laricio que le pin sylvestre; ils sont d'ailleurs moins tentés par les branches du bas de cet arbre qui s'étiolent et meurent à mesure qu'il grandit.

Il est très-probable que les insectes nuisibles au pin laricio sont les mêmes que ceux qui sont unisibles au pin d'Autriche, avec lequel il a beaucoup d'analogie, et l'on a remarqué en $\Lambda$ utriche que ces insectes ne sont autres que ceux qui altaquent le pin sylvestre (Voy. chap. X, art. II). Je n'ai encore remarqué sur le pin laricio que deux insectes qui y causent du dommage, et ce sont deux bostriches, les mêmés dont j’ai parlé dans l'art. X du chapitre dn pin sylvestre; l'un brun, qui mangeait les pousses en même temps qu'elles croissaient, l'autre noir, 
qui en mangeait la moelle; fe premier mª paru preférer le pin sylvestre an pin laricio, le second paraissait préférer le pin laricio. Ce dernier bostriche avilit, en 1811, causé de tels dégâts daus l'allée de mon pare dont j’ai précédemment parlé, où les laricio alternent a vee les mélèzes, que le dessous des arbres était quelquefois jonché des pousses de l'année; les pins maritimes et les pins sylvestres qui forment avec des pins laricio un massif que traverse cette allée avaient été beauconp moins attaqués. Non-seulement dans les pousses attaquées un canal remplaçait la moelle qui avait été mangée, mais un grand nombre de trous faisaient communiquer ce cantl avec le dehor's, ee qui avait occasionné la rupture et la chute d'une partic de ces pousses. Je trouvai le $27^{\circ}$ aoùt, de petits bostriches noirs dans les canaux qui remplaçaient la moelle; cependant il serait possible que ces canaux cussent été creusés par la larve de l’insecte, car II. Jacquinot de Presle me dit avoir trouvé un ver de couleur fauve à tête noire dans le canal médullaire, et jo l'y ai trouvé aussi ; cet insecte n'attaque d'ailleurs ordinairement que les pins laricio âgés de moins de 15 ans, et j’ai été élomé qu’il eût attaqué les miens qui en avaient 17. 11 y a 72 pins laricio dans l'allće où ils alternent a vec des mélèzes, et il y en a le même nombre dans deux rangées parallèles à cette allée qui sont clans la pinière et dans le taillis. Les premiers, qui se trouvent dans une situation plus aćrée, ont été beancoup plus maltraités que les seconds; j'en ai remarqué huil, au printemps de $\mathbf{1 8 1 5}$, qui étaient en si mauvais état qu’on devait craindre d'en voir périr plusieurs. 


\section{CHAPITRE VII.}

\section{PIN DU LORI) IVEYHOUTI, Pinus strobus.}

1. Nons de l'espice. - Pinus strobus Linné (1). On l'appelle aussi Pin blanc, en anglais White pine, et ce nom est le seul que lui donnent les lıabitans des ÉtatsUnis, d'où il nous est venu. Cet arbre fut d'abord cultivé, dit Loudon(2), en 1705, à Badmington, chez $\mathbf{M}^{\text {me }}$ la duchesse de Beaufort, et immédiatement après, en très-grande quantité, dạns le Wiltshire, à Longleat, résidence du lord Weymouth, d'où il s'est répandu en Angleterre et en Europe : voilà pourquoi les Anglais l'appellent Pin du lord Weymouth. Ce nom étant généralement adopté en France, jai cru devoir l'adopter aussi, quoiqu'il m'eût semblé préférable de lui conserver le nom de Pin blanc qu'il porte dans le pays où il est indigène et d'où on l'a tiré; ce dernier nom exprime d'ailleurs une de ses qualités qui est d'avoir un bois très-blanc; mais quand on écrit pour les praticiens, le premier devoir est de leur être intelligible.

11. Boutons et Sève. -- Le pin Weymouth n'a que des boutons à bois, qui contiennent en même temps le rudiment des feuilles et des fleurs; du moins bois, feuilles, fleurs, tout parı des mêmes boutons.

Cet arbre n'a qu'une seule sève, qui commence ordinairement, sous le climat de Paris, dans les dix derniers jours du mois de mars, par le bouton qui doit prolonger la flèche, et s'arrête, en ce qui concerne la longueur des pousses, au bout de deux mois et demi à trois mois et demi environ. Les circonstances de la végétation, en ce qui concerne l'apparition et la disposition des boutons, des feuilles et des lleurs, sont les mèmes dans le pin Weymouth que dans le pin sylvestre (Voy. p. 143), avec cette différence que les pousses sont moins grosses que celles des trois pins dont j'ai déjà parlé, qu'elles ne sont pas d'abord comme les leurs couvertes d'une pellicule, et que les fleurs paraissent et mûrissent plus tard que celles du pin sylvestre, à peu près en même temps que celles du pin laricio. Le pin du lord Weymouth, quand il a dépassé six ans, me paraît avoir, en

(1) Species plantarum, 3e édit., t. It, p. 1418.

(2) Arboretum et fruticetum britannicum, 1. IV, p. 2252, art. Pinus strobus. 
moyeune, des pousses a peu près anssi longues que velles du piu sylvestre. Linsi les guatre pins dont je viens de parler ont, sous le elimat de laris, quand ils unt lépassé leurs premières années, un accroissement en lıateur à peu près semblible, pendant un certain nombre d'années, plus ou moins grant, selen l'espece.

III. Feulles, revur et cônes. -- Les bourgeons des fenilles du pin Weymouth n’étant point cachés par cette pellicule qui couvre d’albord les pousses des trois pins dontjai parlé dans les chapitres précédens, paraissent en même temps que ces pousses, éest-à-dire dans la deuxième quinzaine du mois de mars. Les feuilles paraissent peu de jours après celles du piu laricio et peu de jours a vant celles du pin maritime, dans la première quinzaine de juin ; elles ont à peu près la forme d'un prisme triangulaire, elles sortent cinq à cinq de gaines cylindriques fixées autour des pousses et si on les réunit elles forment un cylindre. Quand ces feuilles ont atteint toutes leurs dimensions (Pl. IV, fig. 19 et 2(1), elles sont linéaires, pointues, douces au toucher dans un sens, rudes dans l'atutre sens, l'un vert légèrement bleuâtre et marquées sur les faces intérieures de deux petites taies blanches; elles sont longues de $0^{\mathrm{m}}, 08$ à $0^{\mathrm{m}}, 13$, selon l'âge des arbres, te terrain et l'exposition. Les feuilles ne persistent ordinairement que pendan t deux ans et demi, e'est-à-dire qu'elles tombent après la troisième sève, y compris celle qui leur a donuć naissance, et elles commencent à tomber dès l'automne: elles m'ont paru·persister un peu moins longtemps que celles des trois ¿lutles pins.

Les fleurs du pin Weymouth (Voy. p. 10) paraissent l'une après l'autre; les nleurs mâles les premières, vers le milieu du mois de mai, les fleurs femelles quelques semaines plus tard, lorsque paraissent les feuilles, ordinairement dans les premiers jours de juin.

Les chatons mâles (PI. IV , fig. 19) sont serrés autour de la partie inférieure des pousses, de manière à former une sorte de grappe, comme ceux des pins dont j'ai déjà parlé; mais ils sont plus gros que ceux du pin sylvestre, un peu moins que ceux du pin laricio. Les fleurs qui les composent atteignent leur maturité dans la première quinzaine de juin, quelques jours après que celles du pin sylvestre l'ont atteinte, à peu près en même temps que celles du pin laricio; elles sont alors d'une couleur nankin foncé et répandent abondamment une poussière jaune. Le pin Weymouth ne porte pas des fleurs mâles tous les ans, et Jorsqu’il en porte c'est en plus ou moins grande quantité.

Les chatons femelles sont annoncés, comme daus les pins dont je me suis déjit oceupé, par de petits boutons qui paraissent au bout des pousses, vers Je commencement le juin, à peu prìs en même temps que paraissent les feuilles, et sont bientôt remplacés par les fleurs; ces chatons sont au nombre d'un à quatre et quelquefois plus, par exception, et en plus grand nombre vers le haut de l'arbre. Ils sont oblongs, d'un rose clair et om la pointe tournée vers le ciel. Au bout le quelques semaines, les fenilles horales se transformant en écailles, les chatons 
deviennent des cònes et la couleur rose est remplacée par la couleur gris-vert; cette transformation est déjà très-apparente dans la première quinzaine de juillet.

Les cônes sont toujours placés au bout de la pousse sur laquelle ils se trouvent, à côté des boutons, au nombre d'un à quatre, quelquefois, par exception, en plus grand nombre, car j'en ai compté jusqu'à huit; mais le plus communément ils sont isolés. Ils sont altachés au bois par une quene et ont la pointe tournée vers le ciel, position qu'ils conservent jusque deux mois après le départ de la sève de l'année suivante. A la fin d'août les cônes ont acquis tout le développement qu'ils pren(lront cette première année; ils sont alors oblòngs, gros comme un très-petit cornichon et d'un gris-vert ( I'l. V, fig. 8). L'année suivante, immédiatement avantla sève, ils sont d'un gris-violet, et ils commencent à grossir dès que part la sève; environ deux mois après, ils s'inclinent de manière à devenir pendans, prennent une couleur vert-prairie à la fin du mois de mai, et à la fin du mois d'août ou au commencement de septembre ils ont alteint leur maturité : cette maturité est annoncée par leur changement de couleur; ils deviennent d'un brun-violet de vert-jaune qu'ils étaient. Les cônes du pin Weymouth ( Pl. IV, fig. 20 et PI. V, fig. 8) ont alors une longueur de $0^{\mathrm{m}}, 14$ à $0^{\mathrm{m}}, 16$, sont oblongs, légèrement courbes el se composent d'écailles serrées les unes contre les autres, adhérentes à un axe commun et plus minces à leur base fixée à l'axe, qu'à la partie extérieure; à la base interne de ces écailles se trouvent deux graines munies chacune d'une aile. Les écailles se soulèvent anssitôt après que les cônes ont atteint leur maturité, c'est-à-dire à la fin d'août on an commencement de'scptembre, environ 14 mois (1) après leur apparition, et laissent échapper les graines qu'ils contiennent; ces graines, étant munies d'une aile, peuvent ĉtre transportćes au loin par les vents; en fort peu de jours elles sont toutes tombées. Les cônes commencent à tomber successivement, par suite des secousses des vents, dès l'année même pendant laquelle sont tombées les graines qu'ils contenaient; mais ce n'est qu'au bout de deux ans environ que les arbres en sont entièrement débarrassés.

Le pin du lord Weymouth le plus jeme auquel j'aie vu porter des fleurs femelles, était un arbre provenant de pépinière, planté à demeure depuis quatre ans et pouvant avoir de 11 à 12 ans, mais ordinairement ils n'en portent pas si tôt: pendant les années suivantes plusieurs pins de cetle espèce, plantés en même temps, eurent aussi des fleurs femelles. Une partie des graines de ces jeunes arbres sont fécondes, s'ils ont porté des fleurs mâles en même temps que des fleurs femelles, mais ce n'est que sur des pins plus âgés que la graine acquiert toute la force germinative qu'elle peut atteindre. Je pense que l'on ne doit récolter des cônes pour en extraire la graine, lorsqu'on le peut, que sur des arbres âgés de 40 ans au moins.

(1) II L. C. Richard se trompe donc lorsqu'il dit, dans son Mémoire sur les conifères al lrs c.ycad'es, p. 108 , que a dans toutes les espèces de pins les cônes emploient trois années pour parrenir *à une maturité parfaite, et que le cèdre du Liban emploie le méme espace de temps pour mùrir ses " fruits. " Cette erreur est la plus grande pour le pin Weymouth, celui des pins dont je m'occupe qui emploie le moins de temps pour muirir ses graines. 
Le pindu lord Weymouth ne porte pas tous les ans des lleurset des eònes; il y a des années oì il ne porte que des fleurs mâles, d'autres que des lleurs femelles. Cel arbe a des années d'ahondance et des années de stérilité; les années d'abondance sont plus rapprochées que dans les sapins, et les années de stérilité sont l'exception.

Ln 1813, je rentrquai que les pins du lord Weymouth, dans un massif de 250 de ces arbres, situé à 3 kilomètres de mon habitation, dåns le parć de Condé, avaient des lleurs femelles, et pour ainsi dire point de fleurs mâles, car je lis monter sur dix de ces arbres et l'on n'y put tronver que deux fleurs mâles; quelquefois il y en a autant que de pousses. J'ai élevé en pépinière et planté à demeure un assez grand nombre de ces pins, et j’ai remarqué qu'ils portaient des cônes plusieurs années avant que de porter des theurs mâles; je suis done disprosé à penser qu’il en est ainsi partout ailleurs, sous le climat de Paris.

IV. Granes et seurs viturne. - Les grames du pin du lord Weymouth ( PI.ハ, fig. 21) sont ovales, rousses et munies d'une aile; clles ont environ (1)",, 007 de longueur moyenne. J’ai indiqué, dans l’article précédent, à quel âtge les pins Weymoulh commencent à porter des cônes, et j'ai dil qu'une partie seulement des graines que contiennent alors ces cônes étaient fécondes, mais ce I'est que plus tard que les pins Weymouth donnent du semis naturel; il m'a semblé qu'il fallait que les arbres eussent dépassé 20 ans pour en donner, el que ce n'est que vers 40 ans qu'ils le donnent abondant et efficace.

Il y a chez M. le comte de Courcy, près de son château des Haies, à 20 kilômètres de chez moi, deux allées formées par trois rangées d'arbres, dont deux de mélèzes et une de pins Weymouth au milicu; ces arlires ont été plantés au printemps de 1813, dans un terrain argilo-siliceux fort maigre, très-sec l’été, plein d'eau l'hiver; ainsi ils avaient au plus 38 ans lorsque je les visitai à l'automme de 18'13. Les mélèzes n’ont pas tonné de plant de semis.naturé, les pins Weymocith en ont donné qui se trouve dans le taillis très-clair et de mauvaise qualité que ces allées traversent. Le plus âgé de ces jeunes plants, qui étaient au $n$ ombre de plus de 300 , pouvait avoir 13 ans, les autres étaient beaucoup plus jeunes; ainsi ce n’est que lorsque ces arbres étaient âgés d’environ $2 \check{\text { ans }}$ (qu'ils ont commencé à domner du semis naturel.

M. le vicomte Iléricart de Thury me dit que dans son pare, près de Thury (Oise), oủ son pòre a vail liait exécuter de belles plantations d'arlores résincux, le pin Weymouth donnait abondamment du semis naturel qui prospérait, soit qu’on le laissât sur place, soit qu'on le levât pour le mettre en pépinière.

Deux massifs de pins IVeymouth qui sont dans le pare de Condé, à 3 kilomètres de chez moi, le premier de 250 pins, plantés en 1816 , en bordure d'un bois taillis, le long de la vallée de l'ton, qui coule en cet endroit du sud au nord; le second de 480 pins, plantés en 18I'́ sur l'autre rive, n'ont point cncore donné de semis naturel. Mais pròs du premicer se trouve un terricer de lapins ctonnamment 
bien habité; le second est borné de deux côtés par un nur élevé, des deux autres còtés par une prairie et un labour; les arbres y sont d'ailleurs trop serrés pour qu'il puisse croitte du plant de semis naturel dans ce massif.

Chez moi, j'ai remarqué aussi du semis naturel de pin Weymouth, mais seulement près des arbres qui avaient dépassé 20 ans; ce semis périssait étouffé par le taillis; j’en ai conservé un pied que j’ai protégé en éclaircissant autour de lui à mesure qu'il était nécessaire. Peut-être le plant de semis naturel de pin Weymouth ne peut-il lever que par un concours de circonstances difficile a rencontrer sous le climat de Paris; cet arbre serait dès lors très-différent sous ce rapport du pin sylvestre et du pin maritime, dont le semis naturel est ordinairement commun dans les futaies de ces pins, lorsque les arbres n'y sont pas trop serrés.

Les cônes du pin Weymouth atteignent, comme je l'ai dit, leur maturité à la tin du mois d'août ou au commencement du mois de septembre; on les cueille immédiatement avant cette maturité et l'on en extrait la graine au moyen de la chaleur du soleil, comme je l'ai prescrit dans les clapitres précédens, pour extraire ainsi la graine des cônes des pins dont je me suis déjà occupé.

J'ai trouvé qu'un litre de graine de pin Weymouth pesait 45 s̆ grammes, et contenait 26,580 graines; ainsi le kilogramme de cette graine contenait 5ั8,417 graines et occupait un volume de 2 lit. 19. Celle que l'on vend à Paris se tire ordinairement des parcs, par exemple du parc de Mortfontaine, où il se trouve de beaux pins Weymouth, que je n'ai pas eu le temps d'aller voir; elle se vend dans la maison Vilmorin-Andrieux, 16 fr. le kilogramme. Il serait préférable de la tirer de l'Amérique septentrionale où cet arbre est indigène; mais ceux qui se donneraient la peine de récolter cette graine ne trouveraient pas à la vendre, puisqu'on ne la sème pas en grand.

La graine du pin Weymouth lève au printemps qui suit l'année où elle est tombée; les jeunes plints ne supportent pas mieux l'ombrage que ceux de pin sylvestre et de pin maritime; ils prospèrent comme eux dans les taillis de bois leuillus tant que leur tête les dépasse, aussi voit-on de très-beaux pins Weymouth sur taillis.

Y. MOde De Végétation, deschuption, diuensions. - Le molle de végétation clu pin du lord Weymouth a été décrit au commencement de ce chapitre, en ce qui concerne la marche de la sève dans cet arbre, ses boutons, ses feuilles, ses fleur's et ses cônes; et l'on trouvera, chap. Xi, art. VII, des détails sur sa végétation et sur son accroissement, depuis le semis en pépinière jusqu'au moment de la plantation à demeure. Le plant de semis naturel présente beaucoup de variélé dans son accroissement, selon les circonstances particulières dans lesquelles il se trouve. La graine qui tombe en septembre ne lève, ainsi que je l'ai dit, qu'au printemps suivant; le plant réussit bien sans ombrage, comme celui de pin sylvestre et de pin maritime, même dans l'année de sa naissance; mais je serais disposé à croire qu'un demi-ombrage lui est firvorable dans les premières an- 
nées, sans avoir d'ailleurs assez de domnécs d'expérience pour me prononcer a ce sujet.

P'endant les premières années, le jeune plant de semis naturel pousse un peu plus lentement que le plant de pin sylvestre, un peu plus promptenent que eelui de pin laricio. Lorsque le join Weymouth a dépassé 15 ans, j’ai remantpué quelquefois, pendant des amées privilégiées, des flèches qui ont jusłu'i (0", 9.2 de long; je ne saurais indiquer quelle est la longueur moyeme de la llèche pendant les années où il conserve une végétation active, n’ayant pias assez de données pour cela.

Le pin Weymouth a une racine principale pirotante el de fortes racines latérales; il me parait aussi bien enraciné que le pin sylvestre.

Le tronc du pin du lord Weymouth est droit, soit qu'il croisse isolé, soit qu'il croisse à l'état serré. Dans la première situation, il est garni de branches jusłjue près du sol, comme celui des sapins; dans la seconde, il n'en conscrve quu vers la cime, comme les arbres dont je me suis déjà oecupé. Le trone du pin Weymouth qui a crû à l'état serré ne m’a pas paru maintenir aussi bien sal grosseur que celui du sapin argenté; je ne puis d'ailleurs être bien lixé à cet égard liute de domnées suffisantes. Si l'on brise le trone du pin W eymouth dans sa jeunesse, une ou deux des branches qui se trouvent immédiatement au dessous de la hrisure continuent le tronc. Dans les pins Weymouth plus àgés, ou qui appruelıunt de leur maturité, si le trone est brisé l'arbre reste mutilé; et si la brisure est trop rapprochée du sol, ou que l'arbre conserve trop peu de feuilles ou de bourgeons, il périt.

L'écorce du pin Weymouth est persistante, lisse, luisante ef verdàtre dans les jemes sujets; clle devient grise, rugueuse et se fendille à mesure pue ces arbres prennent des années; elle est tout au plus aussi épaisse que celle du piu sylvestre.

Les branclres du pin W eymoutlı sont disposées par étages et au noubre de ciny à six pill chaque étage; elles sont érigées dans les jeunes pins et vers la cinte des pins tant qu'ils ont une flèche, c'est-it-dire tant qu’ils sont dans la période l'aceroissement; les branches qui sont plus âfrées, et par conséquent plus ripprochées du sol, fléchissent sous le poids des rameaux et des ramilles et se trouvent atu dessous du plan horizontal qui passerait par leurs points de jonction avec la tige. La tête d'un pin Weymouth, pendant sa période d'aceroisscunent, est semblable à un très-jeune pin Weymoutls.

Les massifs de pins Weymouth sont d’un vert légèrement bleuttre, trèsagréable; l’arbre isolé me parait, ainsi que le pin laricio, n’avoir pas alutant de leuillage qu’il serait ì llésirer.

de viens de décrire to pin Weymouth tel que je l'ai observé sous le clinat de l'aris; je vais reproduire ce qu'en dit II. A. Michaux (l):

(1) Histoire des arbres forestiers de l'Anérique septentrionale, 1. 1.r, p. 106, art. Pinus strobus. J'rmprunterai plusicurs fois i tet ouvrage, qui jouit d'ailleurs d'une réputation justement miritic. de's renseignemens tels que les praticiens désireraient toujours en trouver. 
"Cet antique et majestueux habitant des forêts de l'Amérique du Nord n'en " esı pas moins le plus élevé comme le plus précieux des arbres qui les com" posent, et sa cime élancée dans les airs les surpasse tous de beaucoup, et le " fait apercevoir ì de grandes distances. Sa tige est sans branches jusqu'aux deux " tiers et même aux trois quarts de sa hauteur, et les branclies sont véritablement " très-courtes proportionnellement à la grosseur du tronc. Elles sont verticillées " ou disposées par étages les unes au dessus des autres, et garnissent ainsi le "reste du corps de l'arbre jusqu'à son sommet : alors les trois ou quatre der"niers rameaux se relèvent et présentent un bouquet qui semble comme déta" ché et dont on aperçoit à peine le support. Lorsqu'au contraire le Pinus stro"bus se tronve disséminé dans les forêts d'érables à sucre, de hêtres, ou parmi " les chênes de différentes espèces, comme sur les bords du lac Champlain, et " qu'il croît dans une terre forte, substantielle et propre à la culture du fromenti, " alors il présente une tête très-ramifiée qui embrasse beaucoup d'espace, et " quoique dans ces sortes de terrain il parvienne à une moindre élévation, il " n'en est pas moins encore le plus grand et le plus vigoureux des arbres au " milieu desquels il se trouve.

"Dans les jeunes individus (fui n'ont pas plus de 13 mètres (40 pieds), l'écorce " du tronc et surtout des jeunes branches est lisse et même luisante; mais à " mesure que les arbres vicillissent, elle se fendille, devient rugueuse et d'une v couleur grise; elle ne tombe pas non plus par écailles, comme dans les autres " espèces de pins. Le Pinus strobus en diffèrè aussi par son tronc, qui ne conserve ". pas, comme ces derniers, un diamètre uniforme jusqu'à une grande hauteur, " Car il diminue au contraire très-sensiblement à partir du pied jusqu'au som" mel, quoique cela paraisse moins remarquable dans les vieux arbres. "

J'ai peu d'exemples à citer de l'accroissement annuel du pin Weymouth sous le climat de Paris. Le plus âgé de ceux qui se trouvent chez moi a environ 5 ă ans, et il a été transplanté deux fois; c'est un arbre isolé, situé à l'entrée d'un massif en terre de bonne qualité, mais il est exposé à des rents d'ouest très-violens qui se trouvent resserrés, avant de l'atteindre, entre mon château et d'autres bâtimens; j'attribue à cette situation le dépérissement qu'il éproure depuis 12 ans, au lieu de continuer à prendre de l'accroissement. Son tronc a un diamètre de $0^{\mathrm{m}} 36$, ce qui fait un accroissement annuel de $0^{\mathrm{m}}, 006$, et sa hauteur est de $14^{\mathrm{m}}, 50$.

Le plus gros des pins Weymouth, situés près du châtcau des Haies, dont j’ai parlé page 265 , et qui étaient âgés de 38 ans au plus à l'automne de 1813 , a $0^{\mathrm{m}}$, $31 \mathrm{de}$ diamètre; ils ont en moyenne $0^{\mathrm{m}}, 27$ de diamètre, ce qui donne un accroissement amnuel de $0^{\mathrm{m}}, 007$; leur hauteur est de 13 à 14 mètres. Les mélèzes qui ont élé plantés en même temps qu'eux sur ce même terrain ont la même hauteur, mais sont beaucoup moins gros.

Dans les deux massifs de pins Weymouth du pare de Condé, dont j’ai parlé

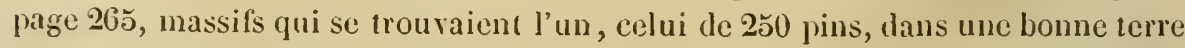
de vallée silico-argileuse sans calcaire; l'autre, celui de 480 pins, au bas du coteau qui borde la vallée; j'ai trouvé a l'automne de 1813 , que dans celui de 180 
arbes plantes en 181/, et qui sont beaucoup trop serrés, le plus gros avilit un

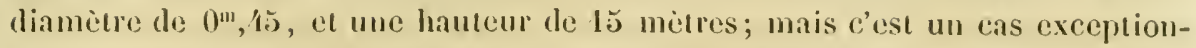
nel, puisque je u’ai trouvé pour le dianètre moyen des arbrus de ce massif que $0^{\mathrm{m}}, 23$, ce qui donne $u$ accroissement anmucl de $0^{\mathrm{m}}, 006$. Dans le massif de 200 pius plantés en 18 Iti, le plus gros piu, qui était fourclı, avait un cliamètre de (0"',36, et sa hauteur élait de 13 mètres; mais le diamètre moyen des arbres de ce massif n'était que de $0^{\mathrm{m}}, 23$, ce qui donne un aceroissement anmuel de $0^{\mathrm{m}}, 006$. (hu trouvait, parmi les pins Weymouth du premier massil, yuclques pins sylvestres ed quelıues sapius picéas; les dimensions des pius syliestres étaient un peu plus fortes que celles des pius Weymouh, celles des picéas un peu moindres. Si l'on compare les dimensions des pins du second massif avec celles des pins d'un massif de 152 pins sylvestres du même âge (qui se tronvait à còté, dans le même parc, mais sur le coteau (Voy. p. 159) et dans une terre silico-argileuse sans calcaire, moins bonne que la précédente, on voit que le plus gros pin Weymoull était plus gros que le plus gros pin sylvestre, mais que le pin sylvestre de moyenne dimeusion était plus gros que le pin Weymoutı de moyenne dimension.

L'on a planté en 1792, dans un jarlin anglais situé à lireteuil (Eure), des pins Weymouth, des pins sylvestres el des picéas qui sont isolés ou peu serrés et en bonne terre; le plus gros des pins Weymouth avait, à l'automne de 1814, un diamètre de $0^{\mathrm{m}}, 39$, ce qui, en le supposant âgé de 60 ans, donne un accroissement annuel de $0^{m}, 006$; sa hauteur était de 17 mètres (Voy. p. 128 et 158 ).

Je ne puis dire à quel âge le pin Weymouth atteint sa maturité sous le clima t de Paris, ni même en Amérique, d'où on l'a tiré, ne trouvant point ce renseiguement dans les auteurs qui en ont parlé.

Le pin Weymouth acquiert dans l'Amérique septentrionale, oì il est indigène, de magniliques dimensions. M. A. Michaux, dans l'article l'inus strobus de l'ouvrage précédemment cité, dit qu'il a mesuré deux de ces arbres que l'on avait abattus pour faire des pirogues : l'un avait 50 mètres le longueur sur $1^{\mathrm{m}}$, $4 \mathrm{~s}$ de lliamètre, à un mètre de terre, et l'autre 46 mètres sur $1^{\mathrm{m}}, \mathbf{1 4}$, à la même hauteur; il ajoute que la plus, grande élévation à laquelle parvient le pin Weymouth est d'environ 58 mètres. Lambert dit (1) qu'en Amérique il y a des pins Weymoutlı quí atteignent jusqu'à 200 pieds anglais (60 mètres); il cite deux mâts de vaisseaux en bois de pin Weymouth qui avaicnt une longueur de 108 pieds $\left(32^{m,}, 40\right)$ et formaient un cylindre dont le diamètre était partout de 3 pieds $\left(0^{\mathrm{m}}, 90\right)$ : de tels arbres, ajoute-t-il, devitient a voir eu une longueur de 200 pieds (60 mètres).

Nous ignorons encore à quelles dimensions le pin Weymouth pourra atteindre en Europe; voici les dimensions de quelques-uns de ces arbres sous le climat de Paris. II y a dans le pare de Trianon, en terre franche, plusieurs pins Weymoutl qu'on dit avoir étí plantés lors te la création de ce parc et qui, par con-

(1) A drscriplion of the genus Pinus, 1. [־, p. 37, art. Pinus strobus. 
séquent, doivent avoir environ 74 ans. Le plus gros de ces pins, non compris celui qui est bifurqué à un mètre an dessus du sol, avait, lorsque je le mesurai, le 7 août 1811, une circonférence de $2^{\text {m }}$, 3ă et environ 22 mètres de hau ( $V o y$. p. 133 el 165$)$.

On trouve dans le parc du château du Breuil, qui appartient à Ir. de Glatigny, à 6 kilomètres d'Evreux (Eure), en bonne terre, un pin Weymouth isolé, garni de branches du sol à la cime. 11 avait, lorsque je le mesurai en 1810, 19 mètres de hauteur et $0^{\mathrm{m}}, 66$ de diamètre, on le disait âgé de 80 ans environ.

Il y a dans le pare de Courtomer (Orne), dans une terre d'herbages très-fertile, plusieurs pins Weymouth dont la plantation remonte au plus à 80 ans; le plus gros de ces pins avait, à l'automne de 1810 , une circonférence de $2^{m}, \mathbf{2} 2$, et l'on évalue sa hauteur à 30 mètres (Voy. p. 132 el 165). On remarquera qu'on donne à ce pin beaucoup plus de hauteur que je n'en ai donné au pin Weymouth le 'Trianon, qui est pourtant plus gros; je suis disposé à croire qu'on s'est trompé dans cette évaluation. La hauteur du pin Weymouth de Trianon que j'ai évaluće à 22 mètres avait été évaluée à 36 mètres par une autre personne qui l'avait vu avant moi. Je ne crois pas faire ordinairement de grandes erreurs dans mes évaluations approximatives lorsque les arbres ne lépassent point 22 mètres, hauteur que ne dépassent point les sapins de ma sapinière. Je me suis exercé à évaluer la hauteur d'un grand nombre de ces sapins d'aborl approximativement, puis en les mesurant avec le dendromètre, et enfin, après qu'ils étaient abattus, pour vérification.

On remarque, dans le parc de Vrigny, plusieurs pins Weymouth en terrain de sable substantiel, mêlé de terre de bruyère, dans le même emplacement où se trouvent les beaux cèdres dont je parlerai chap. $\mathbf{I X}$, art. V. Le plus gros de ces pins a $2^{m}, 75$ de circonférence et 2.5 mètres le haut; il aurait été planté en 1730 , l'après les renseignemens que $\mathbf{M}$. Duhamel de Fougeroux tient de son père, ainsi il aurait eu 114 ans en 1814. Je présume qu'il a dépassé sa maturité.

Le pin Weymouth acquier en Angleterre les plus belles dimensions; on y trouve, dit Loudon, dans l'article Pimus strobus de son Arborctum, précédemment cité, de ces pins, provenant de graines récoltées danş le pays, qui ont de 70 ì 90 pieds (21 à 27 mètres) de haut. Cet auteur donne à la fin de cet article les dimensions de plusieurs pins Weymouth situés dans les pares de la Grande-Bretagne; je vais reproduire ce qu'il dit de ceux de ces arbres qui avaient les plus helles dimensions (Voy. p. 38).

En Angleterre. A Finborough IIall, un pin Weymouth, planté il y a 70 ans, a 70 pieds (21 mètres) de haut, et son tronc un diamètre de 2 pieds 6 pouces $\left(0^{m}, 75\right)$. -A Coombe Abbey, un pin Weymouth, planté il y a 60 ans, a 60 pieds (18 mìtres) de haut et son tronc un diamètre de 3 pieds $\left(0^{\text {m }}, 90\right)$. - A Strathfieldsaye, 95 pieds $\left(28^{\mathrm{m}}, 50\right)$ de haut, son tronc un diamètre de 4 pieds 6 pouces $\left(1^{\mathrm{m}}, 3 \mathrm{5}\right)$. - A Kingston, 95 pieds $\left(28^{\mathrm{m}}, 50\right)$ de haut, son trone un diamètre de 3 pieds $\left(0^{m}, 90\right)$, ete. - En Écosse. A Dalquharran, un pin Weymouth, planté il y a 5.) ans, a 68 pierls $\left(20^{\mathrm{m}}, 10\right)$ de haut et son trone un diamètre de 2 pieds $\left(0^{\mathrm{m}}, 60^{\prime}\right.$. 
- A Blarir Drummond, un pin Weymouth, âgé de 120 ans, a 73 pieds $\left(21^{m}, 90\right)$ de haut et son tronc un diamètre de 2 pieds 6 pouces $\left(0^{m}, 7 \dot{b}\right)$, etc. Sous le climat de Paris, le pin Weymouth atteintrait probablement d'aussi belles dimensions qu'en Angleterre, mais on l'y cultive depuis moins longtemps et en moins grande quantilé.

VI. Climat, exposition, terisan. -- Je vais d'abord extraire de l'ouvrage de M. A. Michaux ce qu'il dit du climat, de l'exposition et du terran qui conviennent an pin Weymonth, dans l'Amérique septentrionale; je rapporterai ensuite les olservations qui ont été faites à ce sujet en Angleterre et en France, où l'on a planté un grand nombre de ces arbres dans les parcs.

Le pin Weymouth ne se trouve dans l'Amérique septentrionale qu'entre le $30^{\circ}$ e le $48^{\circ}$ degré de latilude, et dans la partie méridionale des pays compris entre ces deux lignes, on ne le trouve que dans les vallons ou sur les penchans des monts Alleghanys. C'est entre le $13^{\mathrm{e}}$ et le $47^{\mathbf{e}}$ degré de latitude qu'il est le plus commun et surtout dans l'État de Maine, où l'on fatit un grand commerce de son bois; lorsque M. A. Michaux parcourut cet État, au commencement de ce siècle, on y éprouvail en hiver les froids anssi rigoureux qu'en Suède, quoiqu'il soit situé beaucoup plus au midl. L'exposition ne parait point exercer d'influence notable sur la végétation du pin Weymouth, aussi en trouve-t-on à toutes les expositions. Il paraît s'accommoder de toute espèce de terrains, excepté de ceux dont le sol serait entièrement formé d'un sable maigre et aride ou continuellement submergé. Cependant la partie la plus déclive des vallons, dont la terre est douce, friable et très-fertile, les borls des rivières oǹ elle est composée d'un sable noir, profond et toujours frais, les marais remplis de Thuyn occidentalis, dont la surface est tapissée d'un lit épais de Sphagmum et constamment humide, sont les lieux où l'on rencontre les individus qui atteignent le plus grand développement. Ce fut dans l'un de ces marais de thuya, où l'on ne peut avoir accès que dans le milieu de l'été, que M. A. Michaux mesura les deux pins Weymouth dont j'ai donné plus haut les dimensions.

Le pin Weymoutlı résiste très-luien aux hivers rigoureux, en Europe comme en Amérique, et je n’ai pas remarqué qu'il souffrit des alternatives de gélées et de diggels, ni des gelées tardives. J'en ai vu un, à l'entrée du jardin botanique de Berlin, qui m'a paru avoir un diamètre d'environ $0^{\text {m", }}$, 65 et on l'a indul,itablement cultivé encore plus au nord. Kasthofer a fait une plantation de pins du lord Weymouth (1) en même temps qu'une plantation de pins sylvestres, de sapins picéas et de mélèzes, sur la pente d'une montagne de la vallée d'Interlaken, ì 1,230 mètres au dessus du niveau de la mer; cette plantation avait bien réussi lorsqu'au bout de quelques années il survint, vers la fin d'avril, une gelée tardive, dont le: pin Weymouth seul ne souffrit point.

Sous le climat de Paris, le mélèze, le pin sylvestre, le pin laricio, le pin Wey-

11. I.e Guide dans les forêts, I, I.r. D. 200, art Pin We!month. 
mouth et même le pin maritime, excepté pour ce ternier pin pendant les deux années qui suivent le semis, ne m'ont pas paru souffrir des gelées tardives comme les sapins et le cèdre du Liban.

Je n'ai rien recueilli relativement à l'exposition que préfère le pin Weymouth en Angleterre et en France; il paraît y réussir également bien à toutes les expositions. Loudon dit, l'ạprès Sang, qu'en Écosse il demande à être abrité; j’ai cru remarquer aussi qu'en France les lieux trop exposés atux grands vents lui sont contraires, lorsqu'il croit isolé. On a remarqué en Europe, comme en Amérique, que le pin Weymouth ne peui réussir sur les terrains siliceux très-maigres, sur lesquels on peut encore cultiver le pin sylvestre, le pin laricio el le pin maritime; mais je ne sache pas que l'on ait essayé d'en planter dans des marais, où il serait pourtant si avantageux de le cultiver, s'il y réussissait aussi bien que dans ceux dont parle M. A. Michaux.

Je ne puis rapporter qu'un fait, mais qui ne me parait pas sans importance, relativement à la végétation de cet arbre dans un terrain de très-mauvaise qualité. Jo, veux parler de ces pins Weymouth qui sont prèz du château des IIaies, (Voy. p. 265), et qui ont donnć du semis naturel dans le taillis où ils se trouvent, quoique bien éloignés encore d'avoir atteint leur maturité. Le terrain dans lequel ont crî ces arbres m'a paru argilo-siliceux, et je n'y ai point trouvé trace de: calcaire; il contient de petits cailloux à sa superficie, et à $0^{\mathrm{m}}, 0$ 't de profondeur, il a pour sous-sol unc espèce de tuf qui paraît être impénćtrable ou difficilement pénétrable aux racines; ce terrain retient l'eau l'hiver et devient trèsdur l'été, aussi ne serait-on pas couvert de ses frais si l'on y cultivait des ceréales. On a vu que les pins Weymouth qui s’y trouvent avaient déjì aequis, à 38 ans, des dimensions qui permettraient qu'on en fit de la solive et du chevron, et qu'ils donnent du semis naturel efficace, ce qui prouve que ce terrain si manvais leur convient; il y aurait donc de l'avantage à planter ces sortes de terrains en pins Weymouth; les mélèzes qui se trouvent près d'eux ont de bien moindres dimensions. Je présume que le pin Weymouth ne réussil pas ou réussit mal sur les terrains calcaires.

ViI. Creation d'une futale de pins du lord Weymoutil. - On peut creer une futaie de pins Weymonth par la plantation, absolument de la même manière qu'une futaie de pins sylvestres. Quand le plant a été élevé en pépinière el quon le plante à demeure, ainsi qu'il scra dit chap. XI, art. VII, il reprend aussi bien que celui de pin sylvestre.

La création d'une futaie de pins Weymouth par le semis présente beaucoup, plus de difficultés; la graine coûte plus cher que celle du pin sylvestre, et l'on n'en trouve que de petites quantités, parce qu'il n'y a encore en France qu'un petit nombre de ces arbres sur lesquels on puisse récolter cette graine, el parce que l'on n'a que quelques jours pour eucillir les cones dont on l'extrait : aussi n'est-on pas dans l'usage de faire des semis sur place de ce pin, comme de ceux lont j’ai dléjà parlé. Je présume pourıant que si l'on pouvait se proecurer de liı 
graine de piu Wiymouth de bonne qualité, en suffisante quantité el à bas prix, le semis sur place réussirait assez bien, dans beaucoup de localités, pour ètre a vanlagenx. Le nombre de kilogrammes de graine il enployer, par lectare, devait être moindre que ce que l'on emploie de graine de pin laricio; si l'on ne considerait que la dimension de la grane; mais il m’a semblé que la graine de pin Weymouth que l'on se procure chez les grainetiers, aussi bien que celle que j'ai récoltée moi-mêne, avit plus de déché que celle de pin sylvestre et de pin laricio. Cela peut résulter de ee qu'on lat tire de France, oü probablement on la recueille très-souvent sur des arbres trop jeunes encore. Voici quels ont été les résultits d'un semis tle graine de pin Weymonth sur labour.

Dans le semis d'expérience, dont j’ai parlé page 57, j’ávais sémé de la graine de pin Weymoutl, le $\mathbf{A}^{\mathrm{er}}$ mai 1837 , sur 30 ares de terre silico-argileuse, assez bomne, préparée par des labours et des hersages. Malheureusement le terrain ne se tronva pas assez garni de plant, ce que j'attribuai à ce qu'une partic de la graine était manvaise; mais il serait possible aussi qu'une partie du plant eǹt péri après avoir levé; par une cause quelconque, sans que je m’en liusse aperçu. Quoi qu'il en,soit, le terrain n'étant pas occupé se recouvrit de gazon, de briyères et de jones marins; cependant les plants qui avaient lévé n’ont pas péri, atrisi que je le craignais, mais ils ont été fort retardés; à l'atutomne de 184h les plus hauts le ces plants n'avaient que $\mathbf{1}^{\mathrm{m}}, 50$, et il faudra encore plusieurs années pour qu'ils aient occupé le terrain. Si, âu contraire, le semis eût été assez épais pour occuper le terrain, dès la seconde ou dès la troisième ámée, je présume qu'il aurait réussi aussi bien que celui de pin sylvestre et de pin larició que j’avais fait à côté, sur le même terrain.

Loudon, en parlant dans son Arboretum, 1. 1V, p. 2285, de la culture du pin Wi eymouth, se conteinte de dire : Cet urbre procure des graines en abondance, " el quand elles sont semées au printemps, les plants lèvent la première annćc, " et doivent être traités comme ceux du pin sylvestre. "

Vill. Amsiagnent, exploitation ex reproduction. - On n'a point encore, que je sache, exploité de futaies de pins Weymouth en Europe, et l'on n'a exploité que des forèts vierges en Amérique; on ne peut donc s'appuyer sur des fitits d'expérience pour indiquer la manière la plus lavorable d'aménager, d'exploiter et de repeupler les forêts de pins Weymouth. Je présume que ce que j’ii dit à ce sujet du pin sylvestre doit s'appliquer aussi au pin Weymouth.

1X. Qualtés ét usages du rols; produits divers. - On ne me parait pas être entièrement fixé en Europe sur les qualités du bois du pin du lord Weymouth, cet arbre n'y ayant point encore été cultivé en' grand pour en tirer un produit, mais seulement dans les parcs comme arbre d'ornement. Loudon s'exprime ainsi qu'il suit, t. IV, p. 2281 de son Arboretum et Fruticetum britannicum, relativement aux qualités du bois du pin Weymouth, qui a crì en Angleterre : "Le bois " llú pin Weymouth qui a crù en Angleferre, est imployé pour les parquets at 
"par les tourneurs; mais cet arbre étant généralement eultivé comme arbre " d'ornement, est rarement exploité pour bois d'œuvre. Le bois d'œurre du pin "Weymouth continue à être exporté en Angleterre en immense quantité; il y " est considéré comme fort inférieur à celui de plusieurs autres pins d'A mérique, " et au bois d'ourve des pins du nord de l'Europe. Dans le Dictionary of com" merce (Dictionnaire du commerce) de Macculloch, cet auteur, comparant le pin "blanc d'Amérique (pin Weymouth) avec le pin de la Baltique, donne un extrait " du témoignage de M. Copland, architecte et marchand de bois d'œuvre, qui a " examiné devant le parlement la valeur comparative du bois d'œuvre européen " et du bois d'œuvre américaiı. "Le pin d'Amérique, dit M. Copland, est fort in" férieur en qualité, beauceup plus tendre de sa nature, moins durable, et fort " sujet à la pourriture sèche; aussi n'est-il permis à aucune des personnes qui " travaillent pour le gouvernement d'en faire usage, et on ne l'emploie jamais " dans la construction des meilleurs bâtimens de Londres. Ce sont seulement les "spéculateurs qui sont disposés à l'employer, parce que le prix en est fort infé"rieur (par suite de l'exemption de droits) à celui (lu bois d'oeuvre de la Baltique. "Si vous posez deux planches de ce bois américain l'une sur l'autre, dans le " cours de douze mois elles seront presque invariablement attaquées à un cer" tain point de la pourriture sèche. "Loudon reproduit d'ailleurs, en partie, ce que dit M. A. Miehaux dons l'article Pimus strobus de l'ouvrage déjà cité, des qualités du bois du pin Weymouth en Amérique et des différens usages auxquels on l'emploie, el c'est ce que je vais faire aussi.

"Parmi les nombreuses espèces de pins que possède l'A mérique septentrio"nale, dit M. A. Michaux $1 . I^{\mathrm{er}}$, p. 108, il n'en est aucune dont le bois soit em" ployé en aussi grande quantité et à des usages aussi variés : ce n'est pas cepen" dant que le bois du Pinus strobus soit sans défauts, car il en a même d'assez. " essentiels, comme de n'avoir pas beaucoup de force, de tenir mal les clous, et " d'être parfois sujet à se gonfler dans les temps humides; mais ces défauts " sont rachetés par une multitude de propriétés qui lui assurent la supériorité sur " tous les autres bois du genre des pins. Il est tendre, léger, peu chargé de nœuds " et facile à travailler; il résiste mieux qu'aucun autre aux injures du temps, el " il ne se fend pas aussi facilement aux ardeurs du soleil; il fournit des plan" ches d'une belle largeur, et des pièces de charpente de la plus grande dimen" sion; enfin il est encore abondant et à bon marchć.

"Si le bois du pin Weymouth n'est pas débité dans le courant de la même an" née, il est sujet à être attaqué par de gros vers, qui le perforent dans tous les " sens, de trous de $0^{\mathrm{m}}, 00$ ऽ (2 lignes) de diamètre; mais s'il est dépouillé de son " écorce, il peut rester exposé aux injures de l'air pendant plus de 30 ans sans " s'altérer en aucune manière (1).

(1) Celte assertion contraste tellement aree celle de Vacculloch, rapportée plus haut, qu'il est prrmis de eraindre que M. A. Michaux, qui n'a pu faire lui-même des expériences, n’ait été trompé par de faux renseignemens. 
" Dans tous les États du nord qui renferment la très-grande partie de la po"pulation des Etats-Unis, les sept dixièmes des habitans vivent encore dans des " maisons construites en bois, et les trois quarts de ces maisons, dont on peut " évaluer le nombre à plus de 500 mille, sont presque entièrement faites de Pinus " strobus, non-seulement dans les campagnes et les villages, mais dans toutes les "villes, à l'exception de Boston, New-York et Philadelphie, qui cependant ont " encore les maisons de leur's faubourgs et un petit nombre d'autres bâties de " cette manière. Dans les églises et autres grands édifices, les plus grosses pièces " de charpente sont aussi tirées de ce même arbre.

"Les moulures qui décorent les portes extérieures des maisons, les corniches " et les frises qui ornent l'intérieur des appartemens, les manteaux des chemi" nées qui sont travaillés en Amérique, avec beaucoup de soin, sont encore faits " de ce même bois, de même que les cadres des glaces et des tableaux, car il a "l'avantage, pour ces différens ouvrages, de prendre bien la dorure. Les sculp" teurs en bois qui s'occupent exclusivement de faire les figures destinées à orner "l'avant des vaisseaux, n’emploient également que le bois du Pinus strobus. A "Boston et dans les autres villes des États du nord, l'intérieur des meubles " l'acajou, les malles, le fond des chaises de Windsor de deuxième qualité, les " seatux à puiser de l'eau, une grande partie des caisses destinées à emballer les " marchandises, les cases et tablettes des magasins et boutiques sont faites en "planches de cet arbre, ainsi qu'une infinité d'autres ouvrages. Dans le district " de Mane (actuellement État de Maine), on en fait aussi des barils pour le " poisson salé. ”

"Les magnifiques ponts en bois qui sont construits l'm à Pliladelphie, "sur la Schuylkill, et l'autre à Trenton, sur la Delaware; ceux qui unissent " Cambridge et Charleston à la ville de Boston, dont l'un a 974 mètres $(3,000$ " pieds) de longueur, et l'autre 487 mètres (1,500 pierls), sont fitits en bois de "Pinus strobus, qu'on a préféré coinme résistant le mieux aux alternatives de lit "chisleur et de l'humidité.

"Il fournit encore exclusivement à la mâture des nombreux vaisseaux qui se " construisent dans les États du nord et du milien, et il serait bien llifficile de le " remplacer, pour cet objet, dans l'Amérique septentrionale. On dit même qu'a" vint la guerre de l'Jndépendance, l'Angleterre faisait venir des États-Unis les " mâts nécessaires à sa marine militaire et marchande, el encore aujourd'hui, elle " en tire de ce pays pour suppléer à ce qu'elle ne peut se procurer dans le nord " de l'Europe. C'est du districı de Maine, et notamment de la rivière de Kennev beck, que sont venus en Angleterre les plus beaux échantillons. L'avantage le " plus marqué que les mâts de Pinus strobus ont sur ceux de Riga, c'est d'ètre in" comparablement plus légers, mais ils sont moins forts et ont, à ce que l'on dit, "le défaut de s'échauffer et de pourrir plus vite à l'attache des vergues et dans "l'entrepont. Voilà ce qui donne au Pinus sylvestris la supériorité sur le Pimus " strohus, même dans l'opinion de la majorité des constructeurs américains; " mais quelques-uns d'entre eux, cependant, pensent que les mâts de cètteder- 
" nière espèce seraient tout aussi durables, si l'on avait soin de garantir exacte-

" ment leur sommet de l'humidité; c'est dans cette vue que quelques personnes,

" pour ajouter à leur conservation, ont imaginé de les faire percer d'un trou de

" plusieurs pieds à leur partie supérieure, et de boucher ce trou hermétiquement

" après l'avoir rempli d'une certaine quantité d'huile qui se trouve, dit-on,

"absorbée au bout de quelques mois. On se sert encore en Angleterre du

"Pinus strobus pour faire les vergues et les mâtş de beaupré des vaisseaux de " guerre.

"Cet arbre n'est pas assez résineux pour qu'on puisse en extraire de la téré"benthine et fabriquer du goudron avec son bois pour subvenir au besoin du " commerce. Ce travail d'ailleurs ne serait pas facile, ear il est rare qu'il cou" vre seul quelques centaines d'arpens, étant le plus souvent mêlé, en différentes "proportions, parmi les arbres à feuilles tombantes."

X. Accidens, malajies, anmaux nuisibles. - Le pin Weymoutl ne m'a pas paru souffrir du tout des gelées tardives, les seules qui pourraient lui nuire, sous le climat de Paris, qui est moins rigoureux que celui de l'F́at de Maine, où se tronvent les plus beaux pins Weymoutb de l'Amérique septentrionale. II résiste d'autant mieux aux vents les plus violens qu'il est fort bien enraciné et que son fenillage est peu épais; il en résulte aussi qu’il est moins exposé que les autres pins, dont j’ai déjà parlé, à avoir le tronc ou les branches brisées par le vent ou par les neiges et le givre. Le dommage que pourraient causer les animaux, dans les futaies de pins Weymouth, sont les mêmes que cenx qu'ils peuvent causer dans les futaies des arbres résinenx dont j’ai déjà parlé; je renvoie donc à ce que j'ai dit à ce sujet, chap. 11 , art. $X$.

J'ai peu de chose à dire des insectes qui attaquent le pin Weymouth, n'ayant eu aucun moyen de firire, par moi-même, des observations à ce sujet et n'en trouvant point dans les auteurs que j’ai lus. M. Vétillart, dans ses Qbsermutions pratiques sur lu culture du pin maritime, brochure que j’ai déjà citée, dit, en parlant de deux insectes qui attaquent les jeunes pins maritimes, qu'ils attaquent aussi les pins Weymouth en criblant leur écorce d'une infinité de retits trous, et qu'ils ont fait périr ou rendu invendable tous les arbres verts d'un pépiniéristc du Mans. En 1813, je remarquai que mes pins Weymouth, ainsi que ceux des deux massifs dur parc de Condé, dont j’ai précédemment parlé, avaient les nonvelles feuilles de leurs cimes en partic détruites et que ce qui en restait étaic devenu Jrun; je présumai que ce dégât était l’ouvrage de quelques pucerons, mais èest ce qur je n’ai pas en le temps de vérificr. 


\section{CIIPITRE VIII.}

\section{MELLZE I'ELROPL, Larix curopare.}

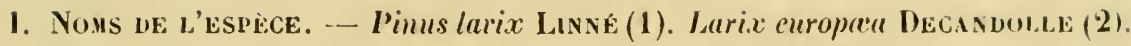

II. Boutons et sive. -- Le mélize a des boutons à l'enilles, des boutons à bois et des boutons à lleurs. Il a deux sèves : la première commence pendant la suconde quinzaine du mois de mars et s'arrète à la fin de juin ou dans le courant le juillet; la seconde commence environ quinze jours après que la première est arrêtée et finit en septembre. Les fleurs naissent environ huit jours avant les feuilles. Les feuilles sont de deux espèces; les umes sont disposées en finisceaux, les autres sont fixées une à une sur les pousses. La sève fait d'abord pousser les laisceaux de feuilles des branches qui sont placées le plus bas, puis elle fait pousser successivement les autres faisceaux de feuilles jusqu’à celui qui se trouve an sommet de l'arbre, lequel part le dernier, comme dans les sapins (3). Ce n'est ' fu'au bout de six semaines que tous ces faisceaux de feuilles ont paru, et environ quinze jours après, e'est-ì-dlire vers le milieu de mai, partent les pousses nouvelles à peu près en même temps de toutes les parties de l'arbre; ces pousses sont "nlourées de feuilles isolées. La seconde sève donne naissance à des pousses sembables à celles auxquelles la première sève a donné naissance; ces pousses ne sont pas seulement le prolongement de celles de la première sève, il s'en trouve aussi sur les pousses de cette première sève qui sont déjà devenues ligneuses. Les feuilles du mélèze tombent tous les ans et après leur chute on remarque sur les pousses, devenues ligneuses, des boutons desquels sortiront l'année suivante des faisceaux de feuilles, des pousses ou des fleurs.

(1) Species plantarum, 3e édit., 1. II, p. 1:20.

(2) Flore française , 1. 111, p. $27 \%$.

(3) Decandolle, dans sa Flore française, 1. 111, p. 277, dit que "tandis que dans tous les arbres " connus les bourgeons supérieurs de chaque branche sont les premiers qui se développent au prin" temps, dans le mélèze, au contraire, les bourgeons inférieurs sont les premiers à se développer," et il donne les raisons de ce fait qu'il appelle une anomalie. On a vu que le mème phènomène se remarque dans les sapins d'Kurope, et je l'ai remarque aussi danc.les sapins d'Amérique. 
Rien ue distingue les boutons à feuilles des boutons à bois.

Les bontons à fleurs se distinguent difficilement des boutons à feuilles et des boutons à bois; cependant, dans le courant de l'hiver, ils deviennent un peu plus gros, mais on ne peut distingner les boutons à flenrs mâles des houtons à fleurs femelles.

Si les boutons donuent maissance à une fleur mâle, ils meurent ensuite et pourrisseut; s'ils donnent naissance à une fleur femelle, ils finissent par tomber en même temps que le cône qui la remplace. S'ils donnent naissance à des faisceaux de feuilles, la partie inférieure de ces boutons devient ligneuse et porte encore des feuilles tous les ans à son extrémité, pendant un nombre d'années plus ou moins grand; ces petits corps ligneux s'allongent tous les ans un peu et deviennent de véritables dards comme ceux qui portent des fruits ì pepins; quelquefois ces dards finissent par porter des fleurs mâles ou des cônes, pourvu que le bois sur lequel ils se trouvent n'ait pas plus de cinq ans, et ils périssent alors, ainsi que je l'ai dit des boutons qui portent des lleurs.

Les boutons à feuilles, les boutons à hois et les boutons à fleurs mâles sont dispersés autour du bois; les boutons à fleurs feme!les sont placés dessus et sur les côtés.

ll se forme sur l'écorce du mélèze des boutons adventifs comme sur celle du sapin argenté, lorsque le trone d'un mélèze, jeune encore, se trouve brisé, ou quand après avoir perdu la plupart de ses branches, parce qu'il a élí privé de lumière, d'espace el de pluit, par des arbres de son voisinage, on abat ces atbres; il s'en forme jusque sur de vieille écorce devenue rugueuse. J'ai, daus mon parc, une allée de 200 mélèzes plantés en 1786-1787, et ces mélèzes ont eu par conséquent environ 57 ans en 1837; ayant fait alors couper un quartier de futaie de sapins argentés que cette allée traversait, les trones de ces mélèzes se sont recouverts de branches et de ramilles, jusqu'it un ou deux mètres de terre, au moyen de boutons adventifs.

II. Feulles, fleurs et cônes. - Les feuilles du mélèze sont, ainsi que je l'ai dil au commencement de ce chapitre, disposées sur le même arbre de deux manières différentes, en faisceaux ou une à une sur les pousses de l'année. Les premières sortent de boutons situés sur du bois d'un an, ou de dards qui se trouvent sur du bois plus âgé el qui ont déjà porté des faisceaux de feuilles les ammées précédentes. Elles commencent à paraître dans le courant de la seconde quinzaine de mars, environ deux mois avint l'apparition des pousses; elles sont d'abord disposées en faisceaux composés chacun de cinquante feuilles environ, puis elles s'étalent et prennent la forme d'un bonquet. Quand ces feuilles ont atteint toutes leurs dimensions (1'l. JI, fig. 16 e 17), elles sont linéaires, pointues, molles, d'un vert clair très-igréable; leur longueur varie dans chaque bouquet de $0^{\mathrm{m}}, 016$ à $0^{\mathrm{m}}, 025$. Ces bouquets de feuilles entourent le bois d'un an et de deux ans et l'ou en trouve jusque sur le bois de six ans, mais en bien moindre quantité, et sur le dessus des branches seulement, les dards et boutons qui se trouvent desşous 
perissint les premiers. Ce que je viens de dire de aes leuilles, melativenent alux branches, s'applique aussi au tronc; c'est-à-dire yue la lleche est couvertede lenilles et que l'on en trouve sur le trone jusque sur du bois de six ans, ma is pas sur celui qui est plus îgé. Les autres feuilles paraissent lorsque tontes celles qui sortent en láisceanx des dards et des houtons à fenilles ont paru, et en même temps que les pousses autonr desquelles elles sont lixées irrégulièrement une à une; ces fenilles ne dillèrent d'ailleurs point des premieres, mais elles sont un peu plus longues. Le mélèze perd ses feuilles à l'automne comme les bois leuillus et de nouvelles lenilles poussent an printemps suivant, ainsi que je viens de le dire.

Les fleurs du mèlèe (Voy. p. 10) commencent à paraître en même temps, daus le courant de mars, huit jours environ avant l'apparition des feuilles.

Lus chatons mâles (Pl. 111 , fị. 16) naissent, ainsi que je l'ai dit, sur des boutons qui se trouvent sur du bois d'un an; ou, lorsque le bois a plus d'un au, sur des dards qui avaient porté des bouquets de feuilles l'année précédente. Is out ì peu près la forme d'une calotte et sont placés un à un autour des rameaux et des ramilles du bois d'un an à cinq ans, sans ancune régularité, mais en beatacoup plus grand nombre sur le bois des deux dernières années. Il peut s'en trouver sur toutes les branches, mème sur celles qui sont au bas de l'arlore, néanmoins ils sont ordinairement en plus grand nombre à la partie supérieure de l'arbre. Lorsque les fleurs mâles ont atteint leur maturité, elles sont jaunâtres et Jaissent échapper une poussière jaune. Les mélèzes qui ont atteint 40 ans, et qui, n'ayant pas été trop serrés par d'autres arbres, ont une belle végétation et sont bien garnis de branches, m'ont paru porter les lleurs mâles très-souvent, mais pourtant pas tous les ans el en plus ou moins grande quantité. Le dessin ne représente la fleur mâle qu’après qu'elle a dépassé sa maturité, parce que j’ai voulu qu'on y trouvât en même temps des faisceaux de feuilles ayant déjả pris une partic de leur aceroissement.

Les chatons femelles naissent sur des boutons ou sur des dards entièrement semblables à ceux sur lesquels naissent les lleurs mâles; ils se tronvent indislinctement sur tous les rameaux et sur toutes les ramilles jusque près du sol, mais pourtant en plus grande quantité vers le haut de l'arbre, où il s'en trouve 'juelquefois jusque sur le tronc; ils sont placés sur le dessus ou sur le côté des rameaux et des ramilles, sur du bois d'un à cine aus et en bien plus grande quantité sur le bois d'un an à deux ans; ils sont ovoüdes, ont la pointe tournéc vers le eiel, et leurs l'euilles liorales sont d'abord dirigées vers la base de l'axe des chatons qui sont alors d'un rouge-violet éclatant; au bout de quelques jours les leuilles llorales se retournent, sont alors dirigées vers le sommet de l'axe, et leur couleur rouge-violet se change en un rouge-brun; ce n'est qu'au bout d'environ six semaines que leurs bractées se transformant en écailles, les chatons deviennent des cônes qui premnent alors une couleur vert-brun.

Les cônes sont lixés au bois par une queue très-courte et ils occupent une position sensiblement verticale, la pointe tournée vers le ciel; ils ont ordinairement acquis toutes leurs dimensions daus la première quinzatine du mois d’aoùt. 
de viens de dire que la fleur femelle, après aroir passé par le rouge-violet et le rouge-lırun, se transformait en un cône d'une couleur vert-brun; ces cônes finissent par prendre une couleur rouge-cannelle pâle dans le courant du mois d'octobre, et ils conservent cette couleur jusqu'à l'époque où ils s'ouvrent pour laisser échapper les graines qu’ils contiennent. Les (ônes du mélèze (P]. 111, fig. 17), lorsqu'ils ont atteint tontes leurs dimensions, ont de $0^{\mathrm{m}}, 026$ ì $0^{\mathrm{m}}, 033$ de long ; ils sont ovoïdes et se composent d'écailles serrèes les unes contre les autres, adliérentes à un axe commun, plus épaisses à la partie fixée à l'axe qu'à la partie extérieure; et à la base interne de chacune de ces écailles, se trouvent deux grainr's munies chacune d'une aile. Les graines que contiennent les cônes n'ont atteint toute leur maturité qu’à la fin de novembre, et ce n'est que dans le rourant du mois d'arril de l'année quị suit celle oủ ils ont paru, environ un an après leur "pparition, que laction du soleil fait soulever leurs écailles et que lil graine" qu’ils contiennent commence à tomber : cette dispersion dure plusieurs semaines, et les graines, étant très-légères et munies d'une aile, sont quelquefois emportécs au loin par les vents. Les cônes commencent à tomber successivement par suite des secousses des vents dès l'année même où s'échappe leur graiue, mais le plus grand nombre reste plusieurs années sur l'arbre avant de tomber.

Indépendamment de l'allée de mélèzes plantée en 1786-1787, dont j’ai parlé an commencement de ce chapitre, j’en ai une autre qui a été plantée en 183218:33. Dans cette seconde allée les mélèzes altement avec des pins litricio; ils ont eu, ainsi que ces pins, 17 ans à l'automne de 1814; ils ont commencé à porter des cônes lorsguu'ils n'étaient encore îgés que de 12 ans et ils en portent presque tous actuellement, ainsi que des fleurs mâles. Si l'on remarque des cônes sur tes mélèzes âgés de moins de 12 ans, c'est ordinairement une anomalie qui tient au malaise de l'individu qui les porte. Une partic des graines de ces jemnes arbres sont fécondes, s'ils ont porté des fleurs mâles en mème temps que des fleurs femelles; mais ce n'est que sur des mélèzes plus âgés que la grảne acquiert toute la force de germination qu'elle peut atteindre; je pense done qu'on ne doit récolter des cônes, pour en extraire la graine, que sur des arbres de $\mathbf{1 0}$ ans au moins, si on le peut, et i] est toujours préférable de la tirer des pays d'où cet arbre est indigène. M. Laing Meason dit qu’en Angleterre, ì 25 ou 30 auss, le mélèze porte des graines bonnes pour les pépinières (1).

On commence à voir des fleurs mâles, pour la première fois, sur les mélèzes, au même âge oì l'on commence à y voir des cônes. Cet arbre, lorsqu'il a dépassé 30 ans, m’a paru porter des fleurs mâles ou des flenrs femelies prosque tous les ans, mais en quantité bien différente et quelquefois pas en mêmo temps. En 1814, je ne trouvai ni une fleur mâle ni une fleur femelle sur les mélèzes de mon parc, ni sur d'autres mélèzes du voisinagge.

1V. Gratie et Semis naterel. - Les graines du mélèze (Pl. 1II, fig. 18) soll

1) De lo plantation du méleze, p i. 
oviles, blontes et mumies d'une aile; elles ont environ $0^{m}$, $(00)$ de dongueur moyenne. J’ai indiqué, dans l'article précédent, à quel âtge le mélèze commence à porter des cones, et j'ai dit qu'il u'y a qu'une partie des graines que conticunent alors ces cones yui soient fécondes, si l'arbre a porté des fleurs mâles et des flenrs lemelles; mais ce n’est que lorsque les mélèzes sont plus âgés qu’ils donnent du plant de semis naturel. M. Gazan, dont la propriété est à 6 lieues de I:t mienne, et 'pui a linit une plantation de mélèes en 1815, In'a dit qu'ils avaient domné quelques plants do semis naturel; il ne se rappelle pas quel âge ils avaient alurs : il en reste encore quelques-mus. Je crois d'ailleurs que cet arlore ne peut donner du semis naturel qu'après avoir clépassé 20 ans, et je ne pense pas qu’il puisse en donner qui soit abondant et efficace avant l'àge de 40 ans.

La graine de mélèze atteint sa maturité dès le milieu de novembre; cependant je crois prudent, si on le peut, de ne cueillir les cônes, pour en extraire la graine, que dans le courant de janvier. Cotta dit, page 256 de son Truité de culture forestiire, "qu'on ne doit cueillir les cônes que peu avant l'époque de la "dissémination, qui a lieu ordinairement au mois de mars, parce qu'alors il est "plus facile de les faire ouvrir." On doit, en récoltant les cônes, éviter soigneusement d'en cueillir de deux ans qui ne se distinguent des nouveaux que par une couleur plus foncéc.

On extrait la graine des cônes du mélèze, absolument de la même manière que l'on extrait celle des cônes du pin sylvestre, ainsi je renvoie à ce que j'ai dit à ce sujet pages 146-155; mais il faut moins de chaleur dans l'étuve de la sécherie, pour faire ouvrir les cônes du mélèze que ceux du pin sylvestre; si l'on y élevait trop la température, les écailles se colleraient et les semences ne tomberaicnt point.

M. Rich, anquel j’ai emprunté ce que j’ai dit de la sécherie de IIaguenau, 1. 1.19152 , décrit ainsi qu’il suit le procédé pour extraire la graine du mélèz: "On n’emploie pour obtenir la graine du mélise qu'une chalcur très-modérée, " autrement les écailles les cones s'enduisent de résine et ne s'ourrent phus.

"Dès qu'elles sont ouvertes on fait passer ces cônes entre deux cylindres armés "de dents inclinées en sens opposé pour en arracher les écailles; ensuite on in" troduit le tout dans des moulins à vent, et on achive le nettoiement des grai" nes en les passant par plusieurs cribles de dimensions différentes. "On noblient évidemment, par ce procédé, que de la arraine qui présente beaucoup de: lécheı. Les cônes du mélèze placés sous une bâche (Voy. p. 1/17) laissent échapper les graines qu'ils contiemnent assez tòt pour que l'on puisse les semer en arril.

La graine du mélèze peut, dit-on, se conserver pendant trois ou quatre ans, en ayant soin de l'étendre sur un grenier bien aćré et de la remuer de temps en.

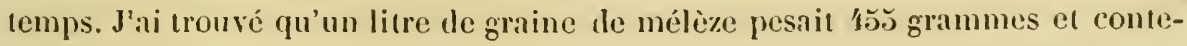
nait 26, , 00 graines, ainsi le kilogramme de cette graine contenait 58, 117 graines et oceupait un volume de 2 lit. 20. Celle que l'on trouve à Paris se tire de Suisse, elle se vend 16 fr. le kilogramme dans la maison Vilmorin-Indrieux. La grane de mélize lèr dans l'inncre mème ou elle est tombere. 
Le plant de semis naturel du mélèze ne peut réussir que par un concours de circonstances qui ne se rencontre presque jamais sous le climat de Paris : aussi en trouve-t-on heaucoup plus rarement que du plant de semis naturel des sapins et des pins dont j'ai précédemment parlé. (Quoique j'aie dans mon parc une alléc de 200 mélèzes âgés d'environ 65 ans et d'autres mélìzes plus âgés ou du même âge dans les massifs, je n'ai pats un mélèze provenant de semis naturel. En 18361837 je fis couper les plus gros arbres de la futaie de sapins argentés, dans la parlie de cette futaie que traverse l'allée de mélèze, et je vis naître, pour la première fois, une grande quantité de plants de mélèzes provenant de semis naturel; mais il en périt beaucoup dans l'année, et l'année suivante l'herbe et les plantes qui poussèrent firent périr ceux qui restaient encore; il s'en est pourtant sauvé deux que j'ai protégés, en faisant couper l'herbe et les plantes qui les eutouraient. Si l'endroit où lève le jeune mélèze est trop ombragé, il périt par l'ombrage; s'il est découvert, il périt par le soleil, par la plnie ou par les plantes qui l'étouffent. Mon grand-père a vait planté un quinconce de mélèzes qui a été abattu par la personne qui en avait fait l'acquisition; à côté de ce quinconce se trouvait une pầture dont une partie était garnie de joncs-marins, qui se coupent tous les trois ans; il a poussé, parmi ces joncs-marins, quelques mélèzes provenant de semis naturel et il s'y en trouve encore trois.

V. Mode de végétation, description, dinensions. - Le mode de végétation du mélèze a été décrit au commencement de ce chapitre, en ce qui concurne lit marche de la sève dans cet arbre, ses boutons, ses feuilles, ses fleurs et ses cônes; et l'on trouvera, chap. Xl, art. VIII, des détails sur sa végétation el sur son accroissement, depuis le semis en pépinière jusqu'au moment de la plantation à demeure. Le plant de mélèze a un accroissement plus rapide en hauteur, pendant les premières années, que celui des espèces dont je me suis précédemment occupé; mais ensuite, sous le climat de Paris, il est dépassé par le sapin argenté et sans doute aussi par quelques-unes des espèces d'arbres dont j’ai déjà parlé.

Le mélèze est fortement enraciné et cela ne saurait être autrement, puisqu’il est, avec le pin cembro, celui des arbres à grandes dimensions qui croît à la plus grande élévation sur les hautes montagnes oủ il brave kes ouragans; il a une racine principale pivotante.

Le trone du mélèze est droit, soit qu’il croisse isolé, soit qu'il croisse à l'état serré; il est garni de branches, dans la première situation, depuis le sol jusqu'à la cime; dans la seconde, il se dépouille de branches jusqu'à une certaine hauteur; il ne maintient pas mieux sa grosseur que le trone du pin Weymouth, moins bien, par conséquent, que celui des autres pins dont j'ai déjà parlé, et de nos deux sapins d'Europe; il est toujours terminé par une flèche, tanı qu'il croît en hauteur, mais sa tête s'étale quand il approche de l'âge de sa maturité. Si l'on brisc le tronc d'un mélèze, jeune encore, l'une des branches les plus rapprochées de la brisure s'empare de la sìve el prolonge le trone; néanmoins, lorsque la bri- 
sure n’a èté faite que sur du bois d'un ou deux ans, il part ordinairement une tlèche de l'un des boutons qui se trouvent alors sur ce jeune bois. Si l'on rend à un mélèze qui a crù à l'état serré de l'espace êt de la lumière, en abattant des arbres autour de lui, il paraìt bientôt sur le tronc, souvent jusque près du sol, des boutons adventifs qui dounent naissance à des ramilles et à de petites branches; j'ai eu souvent l'occision de remarquer ce fait, surtout dans mon parc. Le trone lu mélèze est moins sujet à être brisé par les vents que celui des arbres dont je me suis déjà oceupé, ce qui tient à ce que perdant ses feuilles l'hiver, il leur présente moins d'obstacle, et à ce qu'il est flexible et tenace.

l'écorce du trone du mélèze est lisse et d'un gris-blanc pendant les premières amnées; dans un âge plus avancé, elle devient grise et rugueuse, et dans la partie du tronc qui est la plus rapprochéc du sol, elle se couvre d'écailles plus petites que celles qu'on remarque sur le trone du pin sylvestre et du pin laricio; ainsi lant que l'arbre croît en laauteur, l'écorce préscnte le premier caractère vers la cime et le second près du sol.

Les branches du mélèze sont disposées irrégulièrement autour du trone, depuis lè sol jusqu'à la cime, et elles domnent à l'arbre, considéré dans son ensemble, un aspect conique; clles sont érigées vers le sommet, tant que l'arbre croit en hauteur, et pendantes vers le bas; ces dernières branches sont couvertes en partie d'une mousse blanche, du moins sous le climat de Paris. La cime d'un mélèze qui est dans sa période d'accroissement, est semblable à un très-jeune mélèze.

Le mélèze, par suite de la régularité de sa forme, cst très-propre à être employé en allées; on pourrait presque dire qu'il est nécessaire dans les massifs des pares d'agrément, où son vert clair tout particulier contraste avec celui des autres arbres et surtout avec celui de ses congénères; il est surtout remarquable lorsqu'il porte des fleurs femelles : Ieur rouge-violet éclatant, mêlé avec le vert si tendre de ses feuilles, est d'mu effet très-agréable.

On ne peut se procurer des renseignemens exacts sur l'accroissement annuel du mélèze, sous le climat de Paris, parce qu'on ne l'y cultive guère que commo: arbre d'ornement, et pas depuis très-longtemps; si quelques personnes en ont fait des plantations d'une certaine étenclue, les arbres de ces plantations sont loin d'avoir atteint leur maturité. Il faut d'ailleurs remarquer que le mélèze pousse, dans les terrains qui lui conviennent, avee une rapidité qui n'est dépassée par aucun de ses congénères, jusqu'à 20, 25 ou 30 ans au plus; mais qu'ensuite son accroissement se ralentit tellemènt qu'il reste souvent en arrière dé ceux qu'il avait dépassés d'abord. Ce que j’ai observé, sous le climat de Paris, relativement à la rapidité de l'aceroissement du mélèze, pendant les 25 promières années, et an ralentissement de cet accroissement lorsqu'il a atteint cet âge, l'a été en Suisse el en Angleterre, ainsi qu'on peut lo voir à l’article Mélizá, dins les ouvrages de Kasthofer et de Loudon précédemment cités; ainsi ce caractère est inhérent à l'espèce ct ne dépend pas d'une localité. Voici les faits que i'ai recueillis relativement il l'accroissement anmuel de cet arbre. 
L'allée de 200 mélèzes plantés dans mon parc en 1786-1787, et âgés par consiquent d'environ 65 ans en 1844, sc trouve en terrain silico-argileux, médiocre en quelques parties, assez bon dans d'autres, et qui convient à la culture des bois feuillus et des bois résineux. Cette allée traverse, dans les deux tiers de son étendue, une futaie de sapins, et dans l'autre ticrs un bois taillis que l'on coupe tous les neuf ans; le plus gros de ces mélèzes avait, en $1844,0^{\mathrm{m}}, 51$ de diamètre et le plus lıaut 20 mètres; ils avaient, en moyenne, $0^{\mathrm{m}}, 35$ de diamètre el 16 mèlres de haut : ainsi leur accroissement moyen annuel avait été de $0^{\mathrm{m}}, 005$. D'autres mélèzes, âgés en 1844 de $\mathbf{7 4}$ ans environ, se trouvent dans le même parc : le plus gros avait $0^{\mathrm{m}}, \mathbf{1 7}$ de diamètre et $18^{\mathrm{m}}, 90$ de haut, ainsi il avait eu $\mathrm{m}$ accroissement annuel de $0^{\mathrm{m}}, 006$. On peut voir, en comparant les dimensions des mélèzes de l'allée dont je viens de parler a vec celles des sapins argentés d'une allée plantée la même année, dans le même parc (Voy. p. 32), combien la dimension des sapins était plus forte; il faut ajouter que les trones des sapins maintenaient beaucoup mieux leur grosseur; aussi j'estime que la valeur d'un sapin équivalait à celle de deux mélèzes. .

Il y avait à $\mathbf{2}$ kilomètres de mon parc, sur un coteau exposé au midi qui borde la vallée de l'Iton, un bouquet d'une douzaine de mélèzes, reste de ceux qu'avait plantés mon grand-père avec du plant provenant de graines qu'il avait rapportées d'ltalie ì l'automne de 1749 , en même temps que des boutures de peuplier d'Italie (1); ces mélèzes a vaient par consíquent 94 ans lorsque mon beaufrère les fit abatıre en janvier 1844. 1ls se trouvaient sur la lisière d'un taillis de chêne, dans un terrain silico-argileux de médiocre qualité, dans lequel le bois

(1) Louis, marquis de Chambray, mon grand-père, prétendait que c'etait lui qui avait introduit le peuplier d'Italie en France; aussi dans une lettre qu'il écrivait, le 28 février 1766, au président de la Socićté d'agriculture d'Alençon, pour remercier d'avoir étć nommé membre de cette Société, il dit que c'est lui qui a introdnit en France le peuplier d'Italie, mais qu'il n'a pas réclamé l'honneur de cette in. troduction. Le fait est qu'il exécuta ses premières plantations de peuplier d'Italie en 1750 , avec des boutures qu'ıl avait rapportées du Piémont, et je ne crois pas qu'aucun auteur parle de plantations aussi anciennes en France. Valmort de Bomare dit dans son Dictionnaire d'histoire naturelle, qui parut en 1775, à l'article Peuplier : a Les pépinières où l'on peut trouver des boutures de peuplier d'Ita" lie sont à Montargis, à Nemours, à Moret, à Gron, près Sens, et à Montbar. M. le marquis de n Chambray cultive avec succès le peuplier d'Italie à sa terre de Chambray, proche Tillières, en Nor" mandie; il se fait un plaisir d'en donner des boutures aux personnes qui désirent se procurer cet " arbre. "Mais l'ouvrage dans lequel on trouve ce passage est de 1775, ct il y avait déjà vingt-cinq ans alors que Louis de Chambray avuit commencé à planter des peupliers d'ltalie. Ceux de ces arbres qui se trouvaient dans la vallée de l'Iton ont été abattus pendant la révolution française; mais on avdit conservé les seize peupliers qui étaient dans la demi-lune de l'entrée du parc; ils s'y trouvaient sur le sommet de la colline qui borde la vallée de l'Iton, en terrain silico-argileux; et quoique rette situation soit trop sèche pour ces arbres, quelques-uns d'entre eux y avaient pourtant atteint d'assez belles dimensluns. Il reste encore neuf des seize peupliers que Louis de Chambray avait plantés en 1750 à l'entrée lu parc; ainsi ils avaient, en 1844, 94 ans; presque tous ces peupliers ont été raccourcis successivement à mesure que leur tċte mourait; quatre d'entrc eux, qui dépassent beaucoup la futaic de sapins argentés et les chẻnes sur taillis, se voient de très-loin : celui qui a les plus belles dimensions a 2 mitres de circonférence et 28 melles de haut. 
lénillu vient bien; les pins maritimes dont j’ai parlé page 209, et avec lesquels on peut les comparer, se trouvaient à côté d'eux. Le plus gros de ces mélèzes n'avait que $0{ }^{m}$ ', 50 de diamètre et le plus haut que 15 mètres; mais il y avait longtemps qu'ils ne prenaient plus d'accroissement, peut-être 21 ans, et je ne puis ealculer quel avait été leur accroissement anmuel, puisque je ne sa is point exactement à quelle époque s'était arrêté cet accroissement.

J’ai parlé précédemment d'une allée de mélèzes située dans mon parc et dans laquelle ces arbres, âgés de 17 ans, alternent avec des pins laricio du même âge qu'eux. Le plus lıaut de ces mélèzes avait, à l'automne de $1811,8^{\mathrm{m}}, 33$, le plus gros un diamètre de $0^{\text {m' }}, 16$ et le plus haut se trouvait être en même temps le plus gros. La hauteur moyenne de ces arbres était de $5^{\mathrm{m}}, 66$ et ils avaient, en moyenne, un diamètre de $0^{\mathrm{m}}, 10$; ainsi ils avaient eu un aceroissement moyen annuel de $0^{\mathrm{m}}, 006$, moindre par conséquent que celui des pins laricio (Voy. [\%. 252); il faut ajouter qu'ils maintiennent moins bien leur grosseur qu'eux.

Je saisis l'occasion qui se présente pour faire voir, par un exemple, qu'on ne peut, que dans des cas exceptionnels, se former une opinion sur le mérite des différentes espèces d'arbres, en ce qui concerne Jeur accroissement, en comparant sous ce rapport ceux qui ont crû daus le même licu, parce que le terrain et la situation ne peuvent leur convenir également bien. L’allée dont je viens de parler traverse deux espèces de terrains: l'un siliceux, rempli de petites pierres et très-maigre, sur' un sous-sol de sable, l'autre silico-argileux, plus profond et d'assez bonne qualité; dans le premier le sapin argenté ne réussit point, le sapin picéa et le mélèze réussissent mal ou médiocrement, le pin maritime, le pin sylvestre, le pin laricio, etc., réussissent bien. Aussi dans le premier terrain, jusqu’à ce moment, le pin laricio dépasse le mélèze en hauteur et en grosseur; dans le second, c'est le mélèze qui dépasse encore le pin laricio, du moins en hauteur. Lors mème que deux espèces d'arbres dı nême âge se trouveraient dans un lieu qui leur conviendrait également, on ne pourrait les comparer utilement que lorsqu'ils seraient parvenus à l’âge où ils sont propres à la vente, car il y en a qui après avoir pris d'abord les devans sont ensuite dépassés.

On a planté, en 1810 , dans le pare de Glisolles, à 8 kilomètres de chez moi, des mélèzes, des pins sylvestres et des sapins picéas, au bas·d’un cotean qui borde la vallée de l'Iton; ces arbres sont isolés ou peu serrés et en bonne terre. Le plus gros des mélèzes avait, ì l'automne de 1811, un diamètre de $0^{\mathrm{m}}$, ̌s ; ce qui, en le supposant âgé (le 41 aus, donne un accroissement annuel de $0^{\mathrm{m}}, 011$, accroissement évidemment exceptionnel ; jévalue la hauteur de cet arbre à is mètres (Voy. 1. 1.29 el 1 158 ).

II y a dans le pare de Trianon, en terre franche, plusieurs mélèzes qu'on di avoir été plantés lors de la création de ce pare et qui, par conséquent, doivent ivoir environ 74 ans. Le plus gros de ces mélèzes avait, lorsque je le mesurai, le 7 : p. 133, 165 et $2(199)$.

II y a dans le pare dr Courtomer (Urue), dans un lenrain d'herbages trè- 
fertile, plusieurs mélezes dont lit plantation remonte au plus ì 80 ans; le plus gros de ces mélèzes avait, à l'automne de 1840 , une circonférence de $1^{\mathrm{m}}, 98$, et l'on évalue-sa hauteur à 22 mètres (Voy. p. 132, 165 et 270).

La plantation de mélèzes la plus étendue que l'on ait fait exécuter en France est, je crois, celle de Ir. le comte de Rambuteau dans le Charolais (Saône-et-Loire). Une Monographie du mélèze d'Europe de M. Evon, qui a été insérée dans le Journal d'agriculture pratique, de février 1839, contient à ce sujet les détails suivans: cette plantation occupe une étendue de 300 hectares d'un terrain dont une partie est un sable granitique et l'autre partic un sable noirâtre, tous deux assez profonds. Elle a été faite avec du plant de pépinière que l'on plantait dans des trous de 2 pieds $\left(0^{\mathrm{m}}, 65\right)$ de còté et de 18 ponces $\left(0^{\mathrm{m}}, 48\right)$ de profondeur, éloignés les uns cles autres de 10 pieds $\left(3^{m}, 25\right)$ en tout sens. M. Evon tenait de $\mathbf{M}$. le comte de Rambuteau, que les plus âgés de ces mélèzes, qui étaient plantés depuis 23 ans, en 1834, a vaient alors de 40 à 50 pieds ( 13 mètres à $\left.16^{m}, 24\right)$ de haut, et de 2 pieds 6 pouces à 3 pieds $\left(0^{\text {m }}, 80\right.$ à $\left.0^{\text {m }}, 97\right)$ de circonférence, mais il n'indique pas à quelle hauteur au dessus du sol avait été prise la circonlérence. Ians la mème Monographie on parle des plantations de mélèze en grand que feu M. de Lorgeril avait fait exécuter en Bretagne, dans sa terre de Lamotte-Beaumanoir, non loin de Rennes (Ile-et-Vilaine), et (ju'il avait commoncées en 1815; les plus âgés de ces mélèzes avaient, en 183 , 50 pieds $\left(16^{\mathrm{m}}, 24\right)$ de haut 613 pieds $\left(0^{\mathrm{m}}, 97\right)$ rle circonférence.

II. G. Gand rapporte dans le mémoire déjà cité, qui fut publié en 1840, qu'il existe dans les Vosges, sur une montagne du groupe du Champ-du-Feu, à environ 900 mèttes au dessus du niveau de la mer, un massif de 150 mélèzes, semés ou plantés il y a environ 55 ans, qui ont en moyenne 50 pieds $\left(16^{\mathrm{m}}, 24\right)$ de hauteur et 3 pieds $\left(0^{\mathrm{m}}, 97\right)$ de circonférence; ces arbres ont donné naissance, par le semis naturel, à un bouquet de jeunes mélèzes âgés de 12 ans environ, qui ont de 16 à 20 pieds $\left(5^{\mathrm{m}}, 20\right.$ à $\left.6^{\mathrm{m}}, 50\right)$ de haut et une circonférence de plus d'un pied $\left(0^{\text {m }}, 32\right)$ à un mètre du sol. On remarquera que ces mélèzes n'ont commencé à donner du semis naturel efficace que quand ils avaient plus de 40 ans.

Le mélè̀e a été indroduit plus tôt en Angleterre qu'en France, et y a été cultivé en beaucoup-plus graude quantité. Loudon dit (1) qu'il existait déjà en Angleterre en 1629, mais en très-petite quantité. En Écosse, les premiers mélèzes ont été plantés en $\mathbf{1 7 2}$ par un duc d'Athol, dans sa terre de Dunkeld, située dans le Perthshire; cet arbre fut ensuite cultivé, sur une très-grande échelle, par trois ducs d'Athol, sur les collines et dans la vallée de Dunkeld, et sur les montagnes de Blair; je parlerai plus loin de ces remarquables plantations.

Loudon s'exprime ainsi qu'il suit t. 1Y, p. 2354, dans l'article que je viens de citer, sur l'accroissement du mélèze en Angleterre: "La hauteur moyenne du mélèze, " sous le climat de Londres, est de 20 à 25 pieds $\left(6\right.$ mètres à $\left.7^{\mathrm{m}}, 50\right)$ dix ans après " qu'il a été planté, et il atteint presque la même hauteur sur le penchant des

(1) Arboretum ef Fruticetum britannicum, 1. IV, p. 2358 et 2359, art Larix europcea. 
" collines et des montagnes des Highlands de l'keosse. Pendant les cinquante "prenières annćes, l'arbre peut atteindre la lanteur de 80 pieds (24 mètres) et "an delà; et selon Willtenow, il vit de 150 à 200 ans dans le pays d'où il est " indigène. " Le même auteur donne, au même endroit, les dimensions en grosseur, au mois d'aoùt 1837, le cinq mélèzes qui avaient été plantés en 1767 à Ballindaloch, dans le Morayshire, et qui avaient par conséquent environ 76 ans en 1837 ; il tenait ce renseignement de $\mathbf{H}$. Macpherson, auquel ils appartenaient. Je présume que ces mélèzes étaient les plus beaux parmi un plus grand nombre de mélèzes, plantés dans une situation très-fivorable sous tous les rapports. II est facile de calculer leur accroissement annuel à $0^{\mathrm{m}}, 30$ au dessus du sol, d'après le tableau que je reproduis ci-dessous.

\begin{tabular}{|c|c|c|c|c|c|}
\hline \multirow{2}{*}{ DISTAXCE DU SOL. } & \multicolumn{5}{|c|}{ CIRGONFERRENCES } \\
\hline & du 1er méléze. & du ge mélèze. & du 50 mélèze. & du 4e mélèze. & du se métèze. \\
\hline 1 pied $\left(0^{m}, 30\right)$ & 10 pieds 6 pes & 9 pieds $6 \mathrm{p}^{\mathrm{es}}$ & 8 pieds 7 pes $^{\text {es }}$ & 8 pieds $2 p^{-s}$ & 8 pieds 6 pes \\
\hline 6 pieds $(1 \mathrm{~m}, 80)$ & $8^{(2 m, 50)} 4$ & $8 \frac{(2 m, 00)}{\left(2^{m}, 52\right)} 5$ & $7-1$ & $7-\frac{1}{\left(2^{m}, 10\right)}$ & $6-\frac{1}{\left(2^{m}, 05\right)} 10^{\circ}$ \\
\hline 12 pieds $\left(3^{\mathrm{m}}, 60\right)$ & $\frac{7}{\left(2^{m}, 12\right)}$ & $8-\frac{1}{\left(2^{m}, 50\right)}$ & $6-1 \mathrm{~m}, 90)$ & $6-\frac{1}{\left(1^{m}, 97\right)}$ & $6-5$ \\
\hline 18 pieds $\left(5^{m}, 40\right)$ & $6-\frac{1}{\left(1^{m}, 95\right)} 6$ & $6-\frac{-6}{(1 \mathrm{~m}, 95)}$ & $6-\frac{1}{\left(1^{m}, 80\right)}$ & $5-\frac{1}{\left(1^{m}, 57\right)}$ & $6-\frac{1}{(1 m, 80)}$ \\
\hline 24 pieds $(7 m, 20)$ & $5-7$ & $6-\overline{6}$ & $\frac{5-7}{(1 m, 60)}$ & $\begin{array}{c}5-1 \\
\left(1^{m}, 50\right)\end{array}$ & $5-\overline{1}-6$ \\
\hline 30 pieds $\left(9^{m}, 00\right)$ & $4-\frac{11}{(1 m, 47)}$ & $5--1$ & $4-\frac{11}{(1 m, 4 i)}$ & $4--6$ & $4-\overline{1}-9$ \\
\hline 36 pieds $\left(10^{m}, 80\right)$ & $\left.{ }^{4-1}, 30\right)$ & $\left(1^{\mathrm{m}}, 37\right)$ & $4-\frac{-9}{(1 m, 42)}$ & $(1 \mathrm{~m}, 22)$ & $4-\frac{1}{\left(1^{m}, 22\right)}$ \\
\hline
\end{tabular}

M. Dickie, dans l'article Sur les forêts et les arbres du comté đl'Lberdeen, déjà cité (Voy. p. 34, 129 et 161), donne un tableau que je reproduis ci-dessous; il a fait ses calculs sur le plus gros diamètre de l'arbre, et évalué l'âge d'après le nombre des couches ligneuses du trone (Voy. p. 13).

\begin{tabular}{|c|c|c|}
\hline NOMBRE DES ARBRES. & AGE. & $\begin{array}{c}\text { ACCROISSEMEXT MOYEN } \\
\text { ANNUEL. }\end{array}$ \\
\hline $\begin{array}{l}5 \text { mélèzes à Wardhouse. } \\
5 \text { id. à Wardhouse. } \\
5 \text { id. à Kinmundy. } \\
5 \text { id. à Aden. } \\
5 \text { id. à Breda. } \\
5 \text { id. à Iuvercauld. }\end{array}$ & $\begin{array}{l}54 \text { ans. } \\
55 \text { id. } \\
48 \text { id. } \\
60 \text { id. } \\
70 \text { id. } \\
80 \text { id. }\end{array}$ & 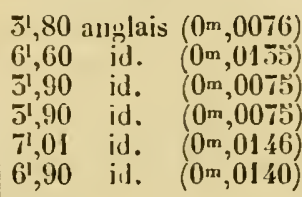 \\
\hline
\end{tabular}

Je ne puis rien dire de positif sur l'époque à laquelle le mélèze alteint sa maturité sous le climat de l'aris. Les mélèzes âgés de 94 ans plantés par mon grandpère avaient dépassé leur maturité lorsquon les abattit en janvier 1811; néanmoins ils ćtaient sains. Les 200 mélèzes âgés de 64 ans qui forment une allór 
dans mon parc me paraissent approcher de Jeur maturité. Les mélizes te Trianon, que je crois être âgés de $\mathbf{7 4}$ ans environ, me paraissent tout au plus avoir atteint leur maturité. Je présume que c'est de 70 à 80 ans que cet arbre atteint sa maturité sous le climat de Paris.

Burgsdorf(1) indique 70 ans pour l'âge anquel le: mélèze a acquis son entier accroissement. Cotta (2) dit que la révolution du mélèze varie de 50 à 110 ans.

Le mélèze acquiert de très-belles dimensions quand il se trouve dans des circonstances de tout point favorables; mais il est généralement inférieur sous ce rapport aux deux sapins d'Europe.

Kasthofer (3) dit que dans le canton des Grisons on troure des mélèzes qui, avec un diamètre de 4 pieds de Berne $\left(1^{\mathrm{m}}, 17\right)$, ont une tige de 80 pieds $\left(23^{\mathrm{m}}, 44\right)$, et qu'il a vu sur la Tête-Noire, l'un des passages qui conduisent de la vallée de Chamouny dans le Valais, à 4,000 pieds $(1,172$ intetres) au dessus du niveau de la mer, un trone creux de mélèze qui avait 21 pieds $1 / 2\left(6^{\mathrm{m}}, 15\right)$ de circonférence. Tschudy dit (4) qu'il en a vu en Suisse qui dépassaient 120 pieds $\left(38^{\mathrm{m}}, 97\right)$ de haut, et qui étaient bien loin de dépérir. Je ne présume pas que cet arbre pujsse jamais atteindre de telles dimensions sous le climat de Paris. Jai donné précédemment les dimensions auxquelles y étaient parvenus plusieurs de ces arbres en parlant de leur accroissement annuel.

Lé mélèze acquiert de belles dimensions en Angleterre. M. Dickie, dans l'article que je viens de citer, donne dans un tableau la circonférence de quelques-uns de ces arbres à 4 pieds $\left(4^{\mathrm{m}}, 20\right)$ du sol. Je vais reproduíre ce tableall, dans lequel l'âge des arbres est évalué par le nombre des couchies ligneuses'; on peut le comparer avec les tableanx analogues qui ont été donnćs pour les sapins et le pin sylvestre, pages 37,131 et 163 .

\begin{tabular}{|c|c|c|c|}
\hline LOCALITÉS. & AGE. & $\begin{array}{l}\text { CIRCONFÉRENĊE } \\
\dot{a} 4 \text { pieds }(1 \mathrm{~m}, 20) \text { du sol. }\end{array}$ & NATURE DU SOL. \\
\hline $\begin{array}{l}\text { Aden. } \\
\text { Kiunundy. } \\
\text { Tonley. } \\
\text { Wardhouse. } \\
\text { id. } \\
\text { id. } \\
\text { Leith Hall. } \\
\text { id. } \\
\text { Mar Lodge Gar- } \\
\text { den. } \\
\text { Netre. } \\
\text { Edinglassie. } \\
\text { Ballater. } \\
\text { Aboyne. }\end{array}$ & $\begin{array}{l}60 \text { ans. } \\
45 \text { id. } \\
60 \text { id. } \\
35 \text { id. } \\
32 \text { id. } \\
34 \text { id. } \\
67 \text { id. } \\
55 \text { id. } \\
28 \text { id. } \\
90 \text { id. } \\
70 \text { id. } \\
75 \text { id. }\end{array}$ & $\begin{array}{lc}5 \mathrm{p} .0 p^{\mathrm{es}} \text { angl. } & \left(1^{\mathrm{m}}, 52\right) \\
3-0 & \left(0^{\mathrm{m}}, 91\right) \\
6-9 & \left(2^{\mathrm{m}}, 05\right) \\
4-1 & \left(1^{\mathrm{m}}, 24\right) \\
3-6 & \left(1^{\mathrm{m}}, 06\right) \\
2-2 & \left(0^{\mathrm{m}}, 66\right) \\
8-1 & \left(2^{\mathrm{m}}, 46\right) \\
5-2 & \left(1^{\mathrm{m}}, 57\right) \\
10-1 & \left(3^{\mathrm{m}}, 02\right) \\
3-0 & \left(0^{\mathrm{m}}, 91\right) \\
7-2 & \left(2^{\mathrm{m}}, 18\right) \\
6-5 & \left(1^{\mathrm{m}}, 95\right) \\
7-6 & \left(2^{\mathrm{m}}, 28\right)\end{array}$ & $\begin{array}{l}\text { Fond d'argile. } \\
\text { Loam léger sur le roc. } \\
\text { Gravier rouge, fond d'argile. } \\
\text { Surface humide, fond de gravier. } \\
\text { Sol pauvre et fin, fond de gravier. } \\
\text { Terre végétale noire et fine, sur fond dur. } \\
\text { Sol d'argile sur gravier. } \\
\text { Loam fort. } \\
\text { Surface noire, fond jaune. } \\
\text { Sol léger, fond de gravier. } \\
\text { Sol aigre, sous-sol de gravier. }\end{array}$ \\
\hline
\end{tabular}

1) Noureau Manuel forestier, tableau a la fin du t. Ier.

(2) Traité de culture forestiere, p. 81.

(3) Le Guide dans les foréts, t. ler, p. 88, art Mélèze.

(4) Traité des arbres résineux conifères, p. 161. 
Loudion, ì la fin de l'article Larix europra de son Arboretum, page 2399, donue: les dimensions d'un grand nombre de mélèzes situés dans les pares des plus belles habitations de la Grande-Bretagne; je ne reproduirai que ce qu'il dit de ceux de ces arbres qui avaient les plus belles dimensions.

En Angleterre. - A Syon, un mélèze a 79 pieds auglais $\left(23^{\mathrm{m}}, 70\right)$ de haut, et son tronc un diamètre de 2 pieds 8 pouces $\left(0^{\mathrm{m}}, 80\right)$. - A Strathfieldsaye, 130 pieds (39 mètres) de haut, son tronc un dianètre de 3 pieds 6 pouces $\left(1^{\mathrm{m}}, 05\right)$. - A Ionnington Park, un mélèze, planté depuis 60 ans, a 86 pieds $\left(25^{\mathrm{m}}, 80\right)$ de haut, son tronc un diamètre de 2 pieds 6 pouces $\left(0^{\mathrm{m}}, 75\right)$. - A Hartburn, un mélèze, planté depuis 83 ans, a 89 pieds $\left(26^{\mathrm{m}}, \mathbf{7 0}\right)$ de haut, et son tronc un diamètre de 4 pieds $\left(1^{\mathrm{m}}, \mathbf{2 0}\right)$. - A Trentham, 100 pieds (30 mètres) de haut, son tronc un diamètre de 3 pieds 6 ponces $\left(1^{\mathrm{m}}, 05\right)$. - A Hagley, les troncs de plusieurs mélèzes ont 4 pieds $\left(1^{\mathrm{m}}, 20\right)$ de diamètre. -- En Ecosse. A Doonside, un mélèze, âgé de 60 ans, a 80 pieds (24 mètres) de haut, son tronc un diamètre de 3 picds 6 pouces $\left(4^{\mathrm{m}}, 05\right)$. -- A Taymouth, un mélèze, âgé de 70 ans, a 96 pieds $\left(28^{\mathrm{m}}, 80\right)$ de haut, son tronc un diamètre de 4 pieds 8 pouces $\left(1^{\mathrm{m}}, 40\right)$. - A Blair Drummond, un mélèze, âgé de 100 ans, a 105 pieds $\left(31^{\mathrm{m}}, 50\right)$ de haut, etc.

Vi. Cumat, exposition, terrain. - Le mélèze croît spontanément dans les Alpes de la Suisse, de la France, de l'ltalie ct du Tyrol; dans les monts Carpathes, dans quelques parties de la Lithuanie, dans le nord de la Russie, aux environs de la Dwina du nord; dans les montagnes de l'Oural et sur plusieurs parties des montagnes de la Sibérie. Il est digne de remarque qu'on ne trouve le mélèze ni en Suède ni en Norwège, quoiqu'il y ait dans ces pays des chaînes de montagnes qui sembleraient favorables à la végétation de cet arbre, et qu'il ne se trouve dans la partie tempérée de l'Europe que sur quelques chaînes de montagnes. Le mélèze forme quelquefois des massifs purs, mais le plus souvent il est mêlé avec d'autres arbres, particulièrement a vec le picéa, et dans les parties élevées des montagnes avec le pin cembro. Le mélèze et le pin cembro sont les arbres à grandes dimensions que l'on trouve le plus haut dans les Alpes, et ils y conservent leurs belles dimensions. Kasthofer rapporte (1) que sur le Bierenboden, à 6,225 pieds (1,825 mètres) au dessus du niveau de la mer, à l'exposition du nord et quoique le sol ne fût composé que de pierres calcaires, il trouva des mélèzes d'une belle venue et qui avaient 1 pied 6 pouces $\left(0^{\mathrm{m}}, 44\right)$ de diamètre, avec 60 pieds $\left(17^{\mathrm{m}}, 58\right)$ de haut.

Je ne puis dire quelle est l'exposition qui convient au mélèze sous le climat de Paris : je présume que c'est celle du nord; dans les Alpes, on le trouve à diverses expositions, selon la situation des montagnes.

On peut cultiver le mélèze sur presque toutes les espèces de terrains, excepté sur ceux qui sont marécageux, et il réussit mal sur cenx qui sont trop argileux et trop secs. Kasthofer dit, page 199 du Voyage que je viens de citer, qu'il en

(1) Voyage dans les Alpes Rhétiennes el dans les petits cantons, p. 149. 
a vu de superbes dans des terrains dont le sul était composé de débris dé rochers calcaires. On a réussi à le cultiver dans la Bourgogne (Côte-d’Or) sur des terrains calcaires de mauvaise qualité; néanmoins il y a des terrains très-calcaires, tels que les craies de la Champagne, où l'on est parvenu à cultiver le pin sylvestre et dans lesquels le mélèze n'a pu réussir. Les terres les plus favorables au mélèze, dit Kasthofer dans l'article Mélèze de son Guide dans les forêts, sont celles qui sont meubles et mêlées de gravier et de sable.

Selon Hartig (1) "le mélèze préfère un terrain un peu profond, mêlé d'argile, " de terre noire, de sable, de gravier ou de petites pierres, et il réussit encore "dans toute autre espèce de fond, de bonne et de médiocre qualité. Mais on doit " se garder de le semer sur un terrain composé d'une argile trop dure, dans des " sables arides, près des bancs de pierres et dans des endroits aquatiques."

J'emprunte à une lettre de Decandolle (2) les renseignemens suivans sur les circonstances les plus favorables à la végétation du mélèze : La nature du sol n'exerce pas sur le mélèze une influence très-marquée, car cet arbre ne demande pas un sol particulier, et semble seulement craindre les sols extrêmes, qui sont ordinairement rares. Les terrains marécageux sont ceux qu'il redoute essentiellement, et il ne se trouve jamais danś ces sortes de terrains. Les sols légers et pierreux ne lui conviennent pas en Suisse, où l'on est sujet à de longues sécheresses pendant l'été; mais si les sables sont médiocrement humides, le mélèze y vient bien. Ce qui peut contribuer le plus à donner au mélèze une belle végétation, c'est qu'il ait à la fois ses racines dans un sol habituellement, mais modérément humide, et sa cime exposée aux rayons directs du soleil. Cet arbre croit généralement sur le penchant des montagnes de la Suisse, rarement dans les licux plats, parce que sur les pentes des montagnes la terre conserve presque toujours une légère humidité venant des points plus élevés, et qu'en même temps les cimes des arbres ont plus d'espace et sont plus exposées à la lumière; les lieux plats sont souvent trop secs, et les arbres étant tous de la même hauteur s'ombragent mutuellement. Parmii les terrains en pente, ceux qui se trouvent au dessous de sommets converts d'une neige perpétuelle lui conviennent le mieux parce qu'ils y sont légèrement et continuellement arrosés, et qu'en même temps leur cime est exposée aux rayons du soleil. Le rédacteur du Quarterly Journal of agriculure dit que feu le duc d'Athol avait observé aussi que les situations élevées étaient meilleures pour le mélèze que les situations basses, et que les pentes étaient préférables aux terrains plats.

Vil. Création d'une futale de mélizzes. - On ne peut, sous le climat de Paris, créer une futaie de mélèzes au moyen du semis sur labour, ainsi que je l'ai

(1) Instruction sur la culture du bois à l'usage des forestiers, p. 205.

(2) La leltre de Decandolle était une réponse à des questions que lui avaient adressées des rédacteurs du Quarterly Journal of agriculture sur la culture du mélèze et sur deux maladies qui avaient détruit des plantalions di: cet arbre en Angleterre; elle se trouve dans le no 27, décembre 1834, p. 403 de ce journal. 
indiqué pour les pins. Si l’on met en bon état de eulture, par des labours et des hersages, un terrain qui convienne parfaitement au mélèze et que l'on y: sème de bonne graine, elle lève bien, mais le jeune plant périt pendant les premiers mois qui suivent sa naissance : il se dessèche au collet, se renverse et meurt, ce que l'on attribue à l'action du soleil; ou bien sês racines pourrissent quand le temps a été pluvieux, ce qui le fait également périr. Quelques plants pourraient échapper à la destruction, mais en trop petite quantité pour que le terrain en fût suffisamment garni. On ne réussirait pas mieux en semant dans des potets qui ne seraient pas convenablement ombragés.

Duhamel, qui faisait ses expériences dans l'Orléanais, avait reconnu aussi la difficulté de semer le mélèze en grand: "J'avoue, dit-il (1), que dans quelques " tentatives que nous avons faites pour avoir des semis considérables de mélèzes, or nous n'avons pas réussi, ce que nous attribuons à ce que le soleil brûle les " jeunes plantes lorsqu'elles sortent de terre; en effet, si on les sème dans des "terrines, tout périt si on les laișe exposées à l'ardeur du soleil. Nous avons " réussi à élever des mélèzes en les semant dans des terrines que nous enterrions " dans des couches : nous les couvrions soigneusement avee des paillassons " lorsque le soleil était un peu ardent, et nous les découvrions la nuit et lors"que le ciel était couvert."

M. Evon, dans la Monographie du mélèze précédemment citée, dit qu'il a essayé plusieurs fois de semer de la graine de mélèze en pleine terre et qu'il a échoué, tandis qu'il réussissait sur le même terrain en semant de la graine de sapin argenté, de picéa el de pin sylvestre. Il rapporte que près d'Épinal (Vosges), sur des coteaux qui bordent la Moselle, l'administration des forêts fit exécuter, en 1820, un semis de mélèze sur deux grands parallélogrammes et n’y obtint que quelques individus, tandis que, dans le même lieu, les semis de plusieurs autres espèces d'arbres résineux, et particulièrement de pins sylvestres, furent fort beaux.

Dans le semis d'expérience dont j'ai parlé page 57, j'avais semé, dans une. terre préparée par des labours, de la graine de mélèze mélangée avec de la graine de pin sylvestre; tout a levé, mais il n’est resté qu'un mélèze et le terrain est actuellement couvert de pins sylvestres.

Il y a, au contraire, dans les montagnes, à une élévation et à une situation convenables, des lieux où de tels semis réussissent très-bien; ainsi il y a dans les Alpes du Dauphiné et de la Suisse, dans le nord de la Russie, et dans d'autres lieux encore, des forêts de mélèzes qui se perpétuent par le semis naturel, et lì le semis artiliciel réussirait. Je rapporterai un seul exemple d'une forêt de mélèzes qui se maintient et s'accroît par le semis naturel. M. Lorentz, ancien administrateur des forêts, dans un article sur le reboisement des montagnes, qui a été inséré dans les Annales forestières de janvier 1842, dit, d’après ce qu'il a vu lui-mẻme : "La commune de Saint-Vincent, département des Basses-

(1) Traité des arbres et arbusfes qui se cultivent en France en pleine terre, t. ler, p. 333. 
"Alpes, possède une des plus belles forêts des Alpes dans laquelle domine " le mélìze. C'est à son maire actuel qu'elle doit la cortservation de cette pro"priété, sa situation prospère et sa propagation sur les pentes uues qui l'avoi" sinent. Cette propagation, dont la nature fait tous les frais, prouve que sur les " points oì ily a du mélèze il suffit d'une mise en défends pour amener le repeu"plement de tous les vides du voisinage."

Je ne puis mieux faire connaître quelle est l’importance du mélèze, dans les liautes montagnes, qu'en reproduisant un passage d'un mémoire de Decandolle (1) : "Ce bel arbre, dit-il, est le plus important et le plus utile de ceux qui "náissent dans les Alpes; c’est lıi qui, croissant de préférence sur les côtes " exposées au nord, utilise des espaces considérables qu'il serait impossible de " cultiver; cest lui, qui se plaisant dans les terrains les plus inaccessibles, " sert souvent à arrèter les glaciers et les avalanches, et fait la sûreté des mon"tagnards; c'est lui qui leur fournit la plus grande quantité de hois de clıaul"fage; c'est de lui que l'on tire, dans les Alpes de la Provence el du Dauphiné, " ces bois de construction dès longtemps employés à Toulon et qu'on vient ré" cemment d'appliquer à la construction du pont de la Durance. "

On peut parfois réussir en semant à demeure le mélèze, sous le climat de Paris, si l'on procure à ce semis de l'ombrage, ainsi que je l'ai indiqué page 60 , an parlant du semis à demeure du sapin argenté, et que le terrain pénétrable aux racines ne retienne pas l'eau. J'ai semé dans des potets un mélange de graines de mélèze et de pin maritime; les mélèzes ont bien levé, et il en est resté quelques-uns, protégés sans doute par les pins maritimes, que l'on a coupés ensuite.

Cotta, dans son Traité de culture forestiere, page 273, dit que "la semence de " mélèze coûte très-cher, et que les jeunes recrus de cette essence étant exposés " à beaucoup de dangers, il est difficile de les faire réussir sur de grandes éten" dues; qu'ainsi il vaut mieux faire les semis dans des pépinières, et en extraire " ensuite les sujets pour faire des plantations. "Cotta habitait la Saxe; ainsi l'on voit que dans cette partie de l'Allemagne qui avoisine le nord, sous un climat plus froid que celui de la France, on a éprouvé aussi de la difficulté à haire réussir les semis de mélèze sur place. Baudrillart dit, d'après IIartig, t. IJ, 1). 385 lle son Dictionnaire des eaux et forêts, art. Mélèze, que la quintité de graine nécessaire pour le semis en grand d'un hectare en mélère est de 17 à 20 kilogrammes. En Angleterre, où l'on a créé de grandes étendues de futaies de mélèzes, on a tonjours employé la plantation; mais on ne peut tirer aucune conséquence de ce fiait, car c'est aussi par la plantation seulement que l'on y a créé des futaies de pins sylvestres, quoique l'on cût pu réussir en beaucoup d'endroits en employant le semis à demeure, puisqu'il y a en Écosse de vastes futaies de pins sylvestres qui se reproduisent par le semis naturel. En définitive, la création d'une futaie de

(1) Rapport sur un royage bolanique et agronomique dans les déparlemens de l'Est. Mémoire inséré dans le 1. Xlll (annét 1810) des Mémoires de la Sociélé d'agriculture du département de la Seine. 
mélezes, par le semis idemeure, n’ayant, pour ansi dire, ancme chance de reussite, suns le climat de Paris, il laut a voir recours it la plantiltion.

Pour créer une futaie de mélèzes par le moyen de la plantition, on se conformera à ce que j’ai dit, à ce sujet, daus le chapitre du pin sylvestré, ce qui se prittique relativement à cet arbre étant de tout point applicable au mélèze. II existe pourtant entre ces deux arbres des différences auxquelles il faut itvoir égarl. Le mélèze est toujours chargé de branches vers le sol et a une forme conique régulière que u'a pas le pin sylvestre, qui esı quelquefois charge de branches vers la tête quand on le plante à 5 ans et plus. Si l'on ajoute que le prenier perd ses feuilles, on en conclura qu'il est moins sujet à être ébranlé pall les vents; à part cette circonstance, le jeune plant de pin sylvestre reprend ordinatrement encore mieux que celui de mélèze. Le plant de 3 ans, élevé ainsi qu'il est prescrit chap. XI, art. VIII, ayant, en moyenne, un mètre de haut et étant bien garni de branches, peut ètre planté dans des terrains où des sapins et des pins dı même âge, qui sont plus petits, seraient étouffés par les plantes dont ces terrains seraient couverts. Le plant de mélèze, dans la terre qui lui convient, m’a paru lutter atussi. bien que le pin sylvestre, le pin laricio et le pin maritime contre les arbustes, tels que la bruyère ou le jonc-marin, qui couvriraient le terrain où on les plante.

En Angleterre, trois ducs d'Athol, et surtout le dernier, ont exécuté en Écosse, sur les collines et dans la vallée do Dunkeld, et sur les montagnes de Blair, des plantations de mélèzes très-remarquables. Je crois utile et intéressant de parler sommairement de ces plantations; j'emprunterai ce que j'en dirai ì Loudon (1) et à une brochure de M. Shiells (2).

Le pays qui s'étend de Dunheld à Blair est de formation primitive; à Blair tomine le gueiss, à Dunkeld le schiste argileux, et l'espace intermédiaire est occupi par le mica-schiste. D'après Loudon, p. 2362, le duc James planta, de 1738 a 175!), sur les terres de Dunkell et de Blair, 1,941 mélèzes, mêlés avec d'autres arbres; le duc Johı planta sur les mêmes terres, de 1766 i 1774, 11,400 mélèzes, mèlés avec d'autres arbres; le second due John planta, de 1774 i 1826 , annéc qui précéda celle où il mourut, 1,109,000 mélèzes, mêlés avec d'autres arbres, et 12,974,380 mélèzes sans mélange; ces plantations du second duc-John occupent une étendue de 8,071 acres écossais, équivalant à 9,684 acres anglais, on 3,917 hectares 66 ares. "Il n'y a pas, dit Loudon, t. IV, p. 2363 de l'ourrage dejai cité, " de nom si élevé et à si juste titre, dans la liste des planteurs heureux, que celui " du dernier duc d'Athol. "Selon M. Shiells, les plantations du second duc Johı ont été plus étendues encore, car il dit qu’il planta, dans la propriété de Duilkeld seulement, 10,000 acres au moins en mélèzes; et que si l’on évalue à 3,000 plants ce qui en a été planté par chaque acre, tant pour la plantation primitive

(1) Arboretum et Fruticetum britannicum, 1. iV, p. 2350, art. Lurix curopacu.

(2) Report on the Athol system. M. Shiclls, qui etait charge rliez le duc al Mhol de la direction de ses bois et de ses forets, tacunte arec detail, dans cotte biorhure, comment a eite cxceutie lat de nière plantation du dur', qui fut la plus remarqualle. 
que pour les remplacemens, on voit qu'il a planté $30,000,000$ de mélèzes. II ajoute que, indépendamment des plantations de mélèze, le duc avaí fait planter plusieurs millions d'autres espèces d'arbres et que, dans ce calcul, il ne comprend point les plantations de Blair et de Strathord, qui sont si nombreuses et si étendues.

La dernière plantation de ce célèbre planteur, lorsqu'il était entìn fixé relatirement au procédé le meilleur el le plus économique pour planter en grand, sur cette partie des montagnes de l'Écosse où se trouvaient ses propriétés, fut exécutée sur une étendue de 2,231 acres écossais (1,082 hectares 92 ares); mais on ne planta réellement que 2,017 acres (978 hectares 25 ares), parce que 214 acres (103 hectares 81 ares) étaient occupés par trois étangs et par des terres trop arides couvertes de mousses sur lesquelles on ne planta point. Le terrain sur lequel on planta est situé à 8 milles (13 hilomètres) au nord de Dunkeld, à une élévation de 900 à 1,300 pieds (270 à 390 mètres) au dessus du niveau de la mer. Le climat, à cause de l'élévation du sol, est froid et humide, et cette localité est exposée à de forts coups de vent du nord-ouest.

La base du terrain est une roche schisteuse entremêlée de grenats et de veines de quartz. M. Shiells ne fait connaître la nature de ce terrain que dans la partie la moins élevée; il y est composé d'une couche de tourbe de 3 à 4 pouces $\left(0^{\mathrm{m}}, 07 \mathrm{~b}\right.$ ì $\left.0^{\mathrm{m}}, 10\right)$ d'épaisseur, sur une terre jaunâtre mêlée de pierres. Partout le sol est couvert de bruyère, généralement courte à celte hauteur, et l'on n'y trouve point d'arbustes tels que des genévriers, qui sont communs à une moindre élévation, et qu'il aurait fallu arracher; aussi l'avait-on fait dans les plantations moins importantes qu'on avait exécutées à une moindre élévation. La tolalité du terrain destiné à être planté fut entourée d'un mur en pierres sèches; on fit des fossés d'assainissement où il fut nécessaire, et des clremins de 12 pieds $\left(3^{\mathrm{m}}, 60\right)$ de large, faciles à bien tracer sur un terrain découvert, pour l'exploitation de la forèt future; le terrain ne reçut d'ailleurs aucume préparation, si ce n'est qu'on brûla la bruyère en quelques endroits.

Les terres destinées à celte grande plantation furent divisées en quarante parties d'environ 50 acres chacune, par mesure d'ordre et pour que le duc pût, de Londres, suivre les travaux sur un plan où ces divisions se trouvaient exactement tracées. Le duc avait reconnu que le mode de plantation qu'il allait employer, sur une plus grande échelle qu'il ne l'avait encore fait, était le meilleur sous le point de vue économique; ct il ne le croyait inférieur à aucun autre, considéré uniquement comme opération de sylviculture. Il avait d'abord, ainsi que ses prédécesseurs, commencé par planter dlu plant de pépinière de 5 ou 6 ans, ce qui était long et dispendieux pour une plantation en grand; il planta ensuite du plant de 3 à 4 ans repiqué, puis du plant de 2 ans; et enfin, il en était venu à planter du plant de 1 an et du plant de 2 ans, qui avait été laissé un an de plus dans la pépinière, lorsqu'il élait trop faible pour êfre planté la première année; c'est-à-dire qu'il plantait principalement du plant herbacé, ainsi que j'ai dit qu'on peut le fairc dans certaines circonstances pour tous les arbres résineux 
dont j’a parlé; mais il exécutait cette plantation dans des circunstincés ef d’une manière toutes particulières.

Les planteurs étaient divisés en trois compagnies chacune de 40 ì 70 hommes et deux jeunes garçons; chaque compagnie avait un chef chargé de diriger et de surveiller les travaux. Le seul outil dont ils se servaient était me bèche de l'invention du duc; la partie plate de cette bèche avait la forme d'une truelle de maçon, et 10 pouces $\left(0^{\mathrm{m}}, 25\right)$ de long sur 5 pouces $\left(0^{\mathrm{m}}, 125\right)$ de large au haut; la donille avait 7 ponces $\left(0^{\mathrm{m}}, 175\right)$ de long et le manche 8 pouces $\left(0^{\mathrm{m}}, 20\right)$; cet outil, que Loudon appelle lance ì planter, était constuit tris-solitement.

Les préparatifs étant terminés, la plantation conmença le 17 octobre 1825. Le duc planta lui-nême les trois premiers plants, exprimant ganment le regret de ne pouvoir, à cause de son grand âge, jouir longtemps de la vus de ces (ravaux; effectivement, il mourut daus l'année qui suivit colle où se termina cetle plantation. Sa principale occupation et ses principales dépenses avaient été de créer des forêts dont il ne devait pas jonir, dominé par cette pensée patriotique qu'il latisserait à sa patrie des bois de construction pour sa marine, et que si son exemple était suivi, il la délivrerait du tribut qu'elle payait sous ce rapport i l'étranger.

La plantation s'exécuta ainsi qu'il suit: Les ouvriers de chaque comparuic étaieut rangés en ligne à environ 5 pieds $\left(1^{\mathrm{m}}, 50\right)$ les uns des antres; les deux plus habiles étaient placés ì chaque aile; les deux jeunes gargons leur distribuaient du plant, que ces ouvriers portaient probablement dans un tablier ou dans de petits paniers. Chaque planteur faisait de la main droite, et avec sa bèche, une fente assez profonde et suffisamment ouverte; puis il y introduisait un plant de manière à ee que les racines ne fussent pas recourbées, et il refermait la fente en appuyant sur la terre avec son talon; il faisait ensuile deux pas et reconmençait la même opération; si la bruyère gènait, il en arachait une ou deux poignées avant de faire la fente. Les plants se tronvaient ainsi à environ 5 pieds $\left(1^{\mathrm{m}}, 50\right)$ les uns des autres, et l'on en plantait environ 2,000 par acre; chaque ouvrier plantait à peu près 800 plants par jour.

Ce genre de plantation n'est d'ailleurs praticable que dans des circonstances exceptionnelles; il ne serait pas praticable si le terrain était assez compact, isse\% pierreux, ou assez garni de plantes pour que l'on ne pùt y iutroduire l'iustrument; il ne le serait pas si le terrain était assez garni de plantes pour étouffer le plant; il ne peut non plus être employé qu'avec du plant assę robuste pour supporter un genre de plantation aussi rustique. Aussi y eut-il quelques partics oi il lallut employer du plant plus âgé, que l'on planta dans des trous.

On employa huit mois des années 1825 et 1826 pour exécuter cette platutition : on planta 350 acres ( 169 hectares 89 ares) en octobre, novembre et décembre $1825 ; 1,327$ acres ( 613 hectares 12 ares) en lévrier, mars et avril 1826 , el 310 acres (165 hectares 4 ares) en novembre et décenbre 1826 . Je conclus de l'évaluatiou de $\mathbf{~ I . ~ S h i e l l s ~ p r e ́ c e ́ d e m m e n t ~ r a p p o r t e ́ e , ~ r e l a t i v e m e n t ~ a u ~ n o m b r e ~ d e ~ p l a n t s ~}$ que l'on employait par acre $(3,000$ en y comprenant les remplacemens), qu'il 
fallait remplacer successivement, dans les années qui suivaient la plantation, environ la moitié des plants; cependant il dit qu'ils reprenaient d'abord presque tous. Quoi qu'il en soit, il en coûtait peut-être vingt fois moins par ce procédé que ce qu'il en aurait coûté pour planter du plant âgé de 5 à 6 ans.

Je clevrais, d'après le plan que j'ai adopté, reporter aux articles suivans ce qui me reste à dire de la méthode de culture du mélèze employée par le duc d'Athol; mais je crois préférable de ne pas diviser ce récit, auquel je renverrai par la suite lorsque je le trouverai nécessaire.

Le trone des jeunes mélèzes, dans les années qui suivent la plantation, se garnit de branches depuis le sol jusqu’à la flèche; cl, au bout de quelques années, ils prennent la forme d'un cône qui augmente tous les ans en hauteur el elı largeur. Ordinairement les branches les plus rapprochées du sol commencent, au bout de 8 ans après la plantation, à se joindre avec celles des mélèzes de leur voisinage; à 12 ans elles se croisent, et elles ont déjà étouffé les bruyères et les genêts, qui sont successivement remplacés par un beau gazon. Dans le même temps, les branches les plus rapprochées du sol périssent, et d'autres branches, situées au dessus de celles-là, périssent ensuite à mesure que les mélèzes grandissent. Le tronc des mélèzes, ainsi que celui des sapins, pousse toujours droit et n'est, pour ainsi dire, jamais brisé par les vents : il plie et ne rompt point.

On commence à éclaircir la jeune futaie environ 12 ans après la plantation, et l'on continue jusqu'à 30 ans, mais pas plus tard. On supprime les arbres les moins bien venans, autanı que cela est possible, sans craindre que les mélèzes se trouvent réunis par pelits bouquets, où ils sont quelquefois très-rapprochés les uns des autres; car puisqu'ils y ont une plus belle végétation, e'est qu'ils s'y trouvent dans des circonstances favorables; on remarque aussi que l'air circule mieux dans une futaie ainsi disposée que dans celles où les arbres, étant en même nombre, seraienı plus régulièrement espacés, el cette circulation de l'air dans les futaies de mélèzes est une des conditions nécessaires à leur prospérité. Lors du dernier éclaircissage, on fait aussi l'élagage nécessaire pour que les bestiaux puissent circuler sous les mélèzes, et les branches que l'on coupe alors sont mortes ou étiolées.

A 30 ans, les mélèzes doivent être, en moyenne, à la distance de 12 pieds $\left(3^{\mathrm{m}}, 60\right)$ les uns des autres en tout sens; ainsi il ne s'en trouve plus que 352 par acre écossais ( 733 par hectare), et ils doivent rester ainsi jusqu'au moment où l'on abat la futaic. Voilà ce que dit M. Stıiells relativement au nombre des arbres à conserver par acre. Mais je vois dans le numéro du Quarterly Journal of agriculture que j'ai précédemment cité, el dans Loudon, que le second duc Jolın d'Athol avait trouvé que 15 à 16 pieds $\left(4^{\mathrm{m}}, 50\right.$ à $\left.4^{\mathrm{m}}, 80\right)$ étaient la distance à conserver entre les mélèzes, et alors il n'y en a plus que 221 ì 192 par acre (460 à 400 par hectare).

M. Shiells a résumé dans un tableau les dépenses qu'il fau laire pour créer une futaie de mèlèzes de 100 acres ( 18 hectares 54 ares), par la méthode du duc 
d'Athol, depuis sa plantation jusqu'à la trentième année inclusivement, et les produits qu'on en tire par les élagages; je reproduis ce tableau.

\begin{tabular}{|c|c|c|}
\hline DÉTAIL DES DÉPENSES ET DES PRODUITS. & DÉPENSE. & PROHUIT. \\
\hline 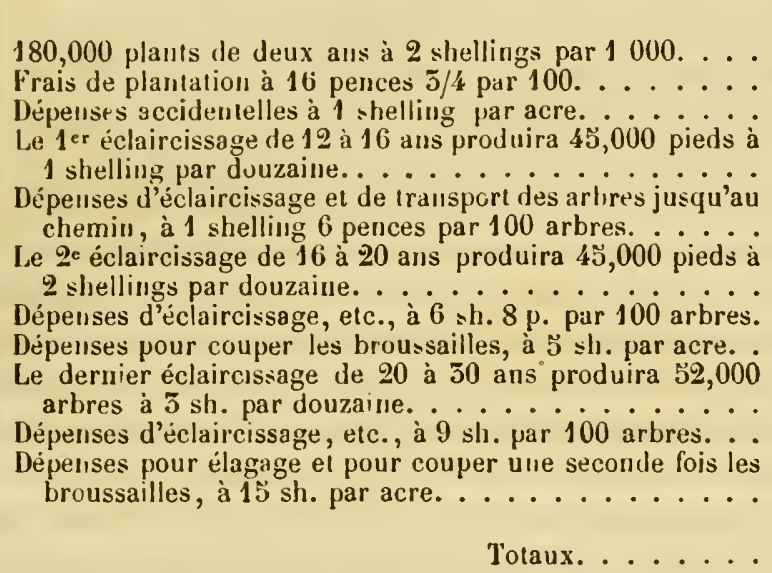 & $\begin{array}{rrr}\text { I. st. s. } & \text { p. } \\
18 & 00 & 00 \\
19 & 11 & 05 \\
5 & 00 & 00 \\
& & \\
55 & 15 & 00 \\
150 & 00 & 00 \\
25 & 00 & 00\end{array}$ & $\begin{array}{l}\text { l. st. s. p. } \\
1871000 \\
5750000 \\
6500000\end{array}$ \\
\hline
\end{tabular}

I. Shiells estime ainsi qu'il suit la valeur des 38,000 mélèzes qui restent sur les 100 acres au bout de 30 ans :

2,000 arbres contenant 15 pieds cubes chacun, ou 30,000 pieds cubes, à 1 sh. 6 p. le pied cube. . . . . . . . . . . . . 2,250

8,000 arbres contenant 10 pieds cubes chacun, ou 80,000 pieds cubes,

à 1 sl. 6 p. le pied cube. . . . . . . . . . . . . . . . . 6, . . . . . . . . . . . . . . . . .

8,000 arbres au prix de 5 sh. chacun. . . . . . . . . . . . 2,000

12,000 arbres au prix de 2 sh. 6 p. elacun. . . . . . . . 1,500

8,000 arbres au prix de 1 sh. 6 p. chacun. .......... 600

Total. . . . . . . . . . . 12,350

On réduira facilement ces quantités en francs et centimes; il suffit de savoir que la livre sterling se divise en 20 shellings, vaut 25 fr. 21 c. (1), et le shelling en 12 pences, et vaut 1 fr. 26 c. Ces résultats obtenus sur d'arides bruyères me paraissent d'ailleurs merveilleux.

M. Shiells donne la circonférence qu'avaient à l'âge de 31 et de 37 ans les cinq plus gros mélèzes d'un acre où ils se trouvaient dans une situation très-favorable, et celles des cinq plus gros mélèzes d'un autre acre, où ces arbres se trouvaient dans une situation moins favorable. Je reproduis ce renseignement.

1). Annuaire du. Bureau des longiludes. 


\begin{tabular}{|c|c|c|c|c|}
\hline \multirow{2}{*}{ 官 } & \multicolumn{2}{|c|}{ SITUATION TRES-FAVORABLF. } & \multicolumn{2}{|c|}{ SITUATION MOINS FAVORABL.E. } \\
\hline & $\begin{array}{c}\text { Circonf. a } 4 \text { pieds }(1 \mathrm{~m}, 20) \\
\text { du sol Ages de } 51 \text { ans } \\
\text { en janvier } 1821 .\end{array}$ & $\begin{array}{l}\text { Circonf. à } 4 \text { pieds }(1 \mathrm{~m}, 20) \\
\text { du sol. - Agés de } 37 \text { ans } \\
\text { en janvier } 1827 \text {. }\end{array}$ & $\begin{array}{c}\text { Circonf. a \& pieds }(1 \mathrm{~m}, 20) \\
\text { du sol. - Agés de } 31 \text { ans } \\
\text { en janvier } 1821 .\end{array}$ & $\begin{array}{c}\text { Circonf. à } 4 \text { pieds }(1 \mathrm{~m}, 20) \\
\text { du sol. - Agés de } 37 \text { ans } \\
\text { en janvier } 1827 \text {. }\end{array}$ \\
\hline $\begin{array}{l}1 \\
2 \\
5 \\
4 \\
5\end{array}$ & $\begin{array}{l}4 \mathrm{p} .2 \mathrm{p}^{\mathrm{es}}(1 \mathrm{~m}, 25) \\
5-10-(1 \mathrm{~m}, 15) \\
5-10-(1 \mathrm{~m}, 15) \\
5-7-(1 \mathrm{~m}, 07) \\
3-5-(1 \mathrm{~m}, 04)\end{array}$ & $\begin{array}{l}4 \mathrm{p} .7 \mathrm{p}^{\mathrm{s}}(1 \mathrm{~m}, 57) \\
3-11-(1 \mathrm{~m}, 18) \\
4-0-(1 \mathrm{~m}, 20) \\
3-10-(1 \mathrm{~m}, 15) \\
3-10-(1 \mathrm{~m}, 15)\end{array}$ & $\begin{array}{l}5 \text { p. } 9 \text { pes }^{\text {( } 1 \mathrm{~m}, 12)} \\
5-7-(1 \mathrm{~m}, 07) \\
5-2-(0 \mathrm{~m}, 95) \\
3-1-(0 \mathrm{~m}, 92) \\
5-0-(0 \mathrm{~m}, 90)\end{array}$ & $\begin{array}{l}4 \text { p. } 2 \text { pes }(1 \mathrm{~m} .25) \\
5-10-(1 \mathrm{~m}, 16) \\
5-5-(1 \mathrm{~m}, 02) \\
5-5-(1 \mathrm{~m} .02) \\
5-3-(0 \mathrm{~m}, 98)\end{array}$ \\
\hline
\end{tabular}

Le mode de plantation en grand que je viens de décrire, mode anquel s'était enfin fixé le second duc John d'Athol, était, selon lui, le meilleur qu'il pût adopter dans les circonstances où il se trouvait; il en donnait pour raison principale le bas prix de cette opération, comparativement à ce qu'il lui en aurait coûté s'il eût planté selon la méthode habituelle, et surtout s'il eût planté plus serré : non-seulement la première dépense aurait alors été plus forte, mais il aurait fallu faire éclaircir à une époque où les produits de l'éclaircissage auraient été sans valeur dans le licu où il plantait. Il me semble que la méthode adoptée par le duc était excellente, puisqu'elle était économique et qu'elle donnait de bons résultats dins les circonstances où il se trouvait; mais il me parait évident aussi qu’il serait préférable de planter plus serré, si l'on n'aviit point égard à la dépense, pourvu que l'on éclaircît aussitôt qu'il serait nécessaire; il me parait enfin incontestable que cette méthode ne peut avoir de succès, ainsi que je l'ai fait voir, que dans des circonstances particulières.

Loudon donne les renseignemens suivans, t. IV de son Arboretum, p. 2354, sur l'accroisscment des mélèzes à A thol et à Dunkeld : "La hauteur moyenne des mé"lèzes, 8 ans après qu'ils ont été semés, est de 11 pieds $\left(3^{\mathrm{m}}, 30\right)$; leur accroisse" ment innuel en hauteur, jusqu'à la $50^{\mathrm{e}}$ année, cst de 1 pied 4 pouces $\left(0^{\mathrm{m}}, 43\right)$ par " an; et, après cette période, il est de 10 pouces $\left(0^{\mathrm{m}}, 25\right)$ pendant les 22 années " (qui suivent; ainsi, la hauteur des mélèzes âgés de 72 ans est d'environ 85 pieds " 4 pauces $\left(27^{\mathrm{m}}, 75\right)$. " Si les dimensions que Loudon dit être une moyenue de l'accroissement des mélèzes du duc d'Athol à 72 ans sont exactes, ce dont je me sens disposé à donter, on peut dire que la végétation de ces arbres sur cette partie des montagnes de l'Ecosse est magnifique. Cet auteur donne, I. IV, p. 2392 de son Arboretum, les deux exemples suivans, pour faire voir les dimensions auxquelles peuvent atteindre les mélèzes de ces plantations : En 1806, 20 mélèzes îgés de 64 ans qui aviaient crù à l'état serré, et qui furent employés au pont de Dunkeld, avaient de 105 à 109 pieds $\left(35^{\mathrm{m}}, 50\right.$ à $\left.32^{\mathrm{m}}, 70\right)$ de long et unc circonférence de 5 pieds $\left(1^{\mathrm{m}}, \check{5} 0\right)$ à ó pieds 4 pouces $\left(1^{\mathrm{m}}, 60\right)$; ils contenaient, terme moyen, 80 à 90 pieds cubes $\left(2^{\mathrm{m}}, 265\right.$ a $2^{\mathrm{m}}, 548$ cubes $)$ de bois d'oeuvre. En 1810 et 1811, 600 mélèzes abattus à Dunkeld et à Blair furent envoyés à l'arsenal de marine de Woulwich; ils contenaien 30,300 pieds cubes $\left(818^{\mathrm{m}}, 40\right.$ cubes $)$, e'est-à-1lire 50 
pieds $1 / 2$ cubes $\left(1^{m}, 14\right)$ chatcu en moyenne; ce bois lut fort admiré des commaisseurs.

II. Shiclls dit que les plus beaux des mélèzes, les premiers plantés à Dunkeld, avaient, ì 4 pieds $\left(1^{\prime \prime}, 20\right)$ au dessus du sol : en 1765, une circonférence de 4 pieds 3 pouces $\left(1^{\mathrm{m}}, 275\right)$; en 1779 , une circonférence de 6 pieds 2 pouces $\left(1^{\mathrm{m}}, 85\right)$, el en 1827, une circonférence de 12 pieds ś pouces $\left(3^{m}, 725\right)$. Je rapporterai, ì ce sujet, des observations que Loudon attribue au second duc John d'Athol.

Le mélèze est le seul des arbres à grandes dimensions que l’on cultive dans cette partie des montagrues d'Ecosse, qui y ait une belle végétation au dela de 900 pieds (270 mètres) d'élévation au dessus du niveau de la mer, et il couserve cette belle végétation jusqu'à 1,600 pieds (480 mètres). Je cite cette circonstance, qui est particulière à cette localité, comme un fait attesté par le duc, sans chercher à en domer la cause; je me contenterai de faire observer que dans d'autres lieux où le climat est aussi rigoureux que dans les montagnes d'Ecosse, on cultive avec succès, à une hauteur de 270 à 300 mètres et plus au dessus du niveau de la mer, des sapins, des pins sylvestres, des chênes et des hêtres, et que le mélère acquiert quelquefois, ainsi qu'on l'a vu, de très-belles dimensions a une beaucoup plus grande hauteur que 480 mètres. Le duc a vait remarqué qu’il vaut mieux planter le mélèze en automne que de le planter au printemps, et yue l'exposition du nord est préférable à l'exposition du midi jusqu'à ce que l'arbre ait atteint 30 ans, mais qu'ensuite elle n'exerce point une influence sensible.

On sait que les lutaies de pins et de sapins qui ont crû à l'état serré étouffent tout sous leur ombrage, et qu'il n'y croît pas même d'herbe, tandis qu'il y a une pâture dans les futaies d'arbres à feuilles caduques qui ont crû ainsi; celle qui se trouve sous les mélèzes est la meilleure. Lorsque ces arbres avaient étouffé les bruyères et les arbustes dans les plantations du duc d'Athol, ees plantes étaient remplacées par une pâture dont le revenu était estimé 8 à 10 shellings ( $10 \mathrm{fr} .08$ a $12 \mathrm{fr} .60$ ) par acre, tandis que le revenu de l'acre de bruyère n'étaiı que de 1 shelling ( $1 \mathrm{fr}$. 26). Mais le principal avantage de ces plantations, c'est qu'elles ont domé naissance à de belles futaies, et que le bois du mélèze s'esı trouvé supérieur en qualité à celui de tous les autres bois cultivés dans ce pays, mème à celui du chêne. $\Lambda$ insi, des poteaux de mélèze et des poteaux de chène ayant été plantés sur les rivages de la Tamise, dans un lieu sujet au flux et au rellux, les premiers ont résisté plus longtemps que les seconds aux alternatives de l'action de l'eau et de l'air. Cette expérience n'est, d'ailleurs, pas d'accord avec celles de llartig sur la durée des bois employés comme poteaux; car cet auteur a trouvé que le chêne, l'acacia, le mélèze, le pin sylvestre, le sapin argenté, le sapin picéa et le pin du lord Weymouth, employés ainsi, avaient la même durée.

Quoi qu'il en soit, le créateur des futaies de Dunkeld et de Blair ne se dissimulait pas qu'il ne pourrait se défaire de ses produits que si ses mélèzes se trouvaient propres à la marine, et ce fut ee qui arriva. On construisit avec les mélèzes les plus âgés, de 1816 a 1820, une frégate de 28 canons, qu'on appela 
l'Athol, où tout jusqu'à la quille, les mâts el les vergues, élait en bois de mèlèze. Cette frégate, qui a été exposée à de rudes épreuves dans différens climats, lut examinée à plusieurs reprises, et l'on a toujours loué la qualité de son bois.

Afin de faire ressortir les grands avantages de la culture du mélèze comparće a celle du chêne, pour obtenir des bois propres à la marine, Loudon fait la compatraison suivante : On doit laisser par acre anglais (40 ares 47 centiares) 300 mélèzes qui se trouveront à 12 pieds $\left(3^{\mathrm{m}}, 60\right)$ les uns des autres; clıque mélèze contiendra en moyenne 50 pieds cubes ( $1^{\mathrm{m}}, 415$ cubes) (le bois d'ouvre à 68 ans, et chaque acre produira par conséquent 15,000 pieds cubes $\left(424^{\mathrm{m}}, 500\right.$ cubes). On ue doit laisser que 40 chênes sur la même étenduc de terrain, parce qu'ils doivent ètre éloignés de 34 pieds $\left(10^{\mathrm{m}}, 20\right)$ les uns des autres; chaque chêne donnera à peu près en moyenne, à 68 ans, 50 pieds cubes, comme chaque mélèze, on 2,000 pieds cubes par acre. Et comme il faut 150,000 pieds cubes de bois d'œuvre puur faire un vaisseau de $\mathbf{7 4}$, il en résulte qu'avee 10 acres seulement de futaic lle mélèz's on fera ce vaisseau, tandis qu'il faudrait 70 acres de futaie de chênes pour le faire en bois de chêne. Toutes les bases de cette comparaison me paraissent erronées: en n'accordant que 12 pieds $\left(3^{\mathrm{m}}, 60\right)$ de distance entre les mélèzes, on n'accorde pas assez; le duc d'A thol a reconnu depuis qu'on devait laisser 15 à 16 pieds (' $\mathbf{1}^{\mathrm{m}}, 50$ à $\left.4^{\mathrm{m}}, 80\right)$ entre ces arbres; en calculant sur 34 pieds $\left(10^{\mathrm{m}}, 20\right)$ pour la distance moyenne entre des chênes âgés de 68 ans, on lenr aceorde plus qu'il ne leur est nécessaire; le bois de chêne n'est d'ailleurs pas assez formé à 68 ans pour ètre employé à la construction des vaisseaux.

Mais si la culture du mélèze, dans les parties montagneuses de l'Ecosse, ne présente point tous les avantages que lui altribue Loudon, d'après le due d'Athol, ellè en présente iucontestablement de très-grands, puisque cet arbre, par suite de l'exemple domné par les ducs d' $\Lambda$ thol, est celui qui est actuellement le plus généralement cultivé dans les parties montagneuses où l'on né peut cultiver a vec succès ni les céréales, ni des arbres à grandes dimensions autres que le mélèze. Non-seulement cet arbre a une très-belle végétation sur les montagnes d'Ecosse, quoiqu'clles soient brumeuses et voisines de la mer, circonstances que Decandolle dit, dans la lettre précédemment citée, contraires à la prospérité du mélèze; nais, ainsi que sur les Alpes suisses, il n'y est pour ainsi dire sujet à aucune maladie.

Il n'en a pas été ainsi le ceux que l'on a cultivés à une moindre élévation, particulièrement dans les plaines; ils n'y sont parvenus souvent qu'à de failıles dimensions quelquefois bien moindres, dans un temps donné, que celles du chêne. Généralement, le mélèze poussait bien pendant les premières années, puis son accroissement se ralentissait tout à coup, et il ne parvenait, en définitive, qu'à de médiocres dimensions; ce que je viens de dire, sujet d'ailleurs à (les exceptions, concerne surtout la culture en grand. Mais ce qui a arrêté la plantation en grand du mélèze, à laquelle l'exemple des ducs d'A thol et d'autres seigneurs écossais avait donné une remarquable impulsion, e'est que des plantations entières de cet arbre ont été altaquées de la pourriture an ermur en 
l'une autre makulie que les sỵlviculteurs anglais appellent blight (brouissure); dans cette dernière maladie, l'écorce de l'arbre est en quelque sorte ulcérée, ce qui résulte de la présence d'un insecte fixé sur cette écorce, qui me parait être un puceron lanigère, d'après ce qu'on en lit. On peut citer des plantations de mélèzes du duc de Portland, dans le Nottinghamshire, et beaucoup d'autres qui ont été clétruites par la pourriture. Il y a peu de situations dans les plaines de l'Angleterre et de l'Eeosse, dit Loudon, 1. IV, p. 2379, où les mélèzes qui ont atteint leur maturité soient entièrement sains au cœur. On trouve dans le Quarterly tournal of agriculture et dans le Gardner's Magazine plusieurs articles relatifs à ces deux maladies, et éétait, ainsi que je l’ai dit, à ce sujet que des rédacteurs du premier de ees journaux avaient écrit à Decandolle.

Un fait singulier qui a été observé en plusieurs cndroits, e’est que dans des plintations de mélèzes exécutées sur des terrains où il y avait auparavant une futaie de pins sylvestres abattus depuis peu, les mélèzes ont été attaqués de la pourriture au cocur dès l'âge de 6 ou 7 ans : je ne sais d'ailleurs si le mème fait a été observé dans toutes les circonstances semblables; car il serait possible que la maladie eùt coïncidé avee la circonstance du remplacement d'une futaie de pins sylvestres par une futaie de mélèzes, sans en avoir été la conséquence.

Je ne trouve rien dans l'Arboretum de Loudon relativement au semis naturel auquel les mélèzes des forêts du due d'Athol doivent donner naissance.

Vill. Amenagement, exploitation et reproduction. - On conclura de ce que j'ai dit, dans l'article précédent, que l'on ne peut exploiter une futaie de mélèzes, sous le climat de Paris, de manière à ce qu'elle se reproduise par le semis naturel; il faut donc éclaircir successivement cette futaie, afin que tous les arbres puissent jouir du soleil et de la lumière, et l'abattre à blanc-étoc quand elle a atteint sa maturité. Si l'on veut conserver en futaic de mélèzes le terrain qu'occupait cette futaie, on y plantera du plant de mélèze en suivant l'une des méthodes que j'ai précédemmenı indiquées. Dans les pays où le mélèze peut se reproduire par le semis naturel, tout ce qui a été dit chap. II, art. VIII, lui est applicable. Cet arbre supporte l'élagage, même lorsqu'il croit isolé; ainsi on peut élaguer les arbres de lisière, mais il faut le faire avec beaucoup de ménagement et ne commencer l'élagage que lorsqu'il a atteint 12 ans. Le mélèze réussit trèsbien en futaie sur taillis de bois feuillus, et, perdant ses feuilles l'hiver, il est celui de tous les arbres résineux conifères à grandes dimensions, que l'on cullive sous le climat de Paris, qui leur cause le moins de dommage.

Le mélèze ne me parait d'aillcurs pouvoir être cultivé avec succès en grand, dans les climats tempérés, pour son produit, que dans des circonstances particulières que je ne puis faire connaître exactement, faute de renseignemens. M. le baron de Berlepseh, direeteur-général dles forêts du royaume de Saxe, a dit, en parlant des forêts de l'Erzgebirge, chaine de montagnes qui sépare la Saxe de la Bohème, dans un discours qu'il prononça au congrès tenu à Altenbourg le I septembre 18'3, discours qui a cté reproduit dans les Amales forestières de 1811: "Le 
- mélèze a été cultivé depuis vingt ans avec beaucoup de zèle, mais surtout dans " les parties qui présentaient peu de chances de succès à l'épicéa. Quoique cette - culture se soit faite sur une très-grande échelle, on s'est cependant vu forcé " de l'abandonner, à cause des faibles résultats qu'elle a produits. ». Je présume, en définitive, que dans les climats tempérés, il y aura bien rarement de l'avantage à cultiver le mélèze en plaine pour son produit.

IX. Qualites et usages du bois; produts divers. - Le pied cube de bois d'un mélèze de 50 ans pèse vert, d'après IIartig (1), 68 livres 13 onces (33 kil. 683 gr.) et sec 36 livres 3 onces (17 kil. 713 gr.); d'après Varennes de Fenille, il pèse sec 52 livres 8 onces (25 kil. $698 \mathrm{gr}$.). Dans mon parc, le pied cube de bois d'un mélèze de 70 ans, abattu le 7 septembre 1843 , pris près de la souche, pesait vert 29 kil. $600 \mathrm{gr}$; ; le 5 septembre 1844, il ne pesait plus que $23 \mathrm{kil} .200 \mathrm{gr}$., et le $\mathbf{1}^{\text {er }}$ mars 1845, étant sec, que 23 kil. 120 gr. J'ai pris le poids du bois du mélèze, lu sapin argenté, du sapin picéa et du pin maritime, sur des cubes de 6 pouces de côté, dont je multipliais le poids par 8; on avait laissé ces cubes, pendant plus d'un an, dans une chambre chaude ou sur une fenêtre exposée au midi ; je n'ai d'ailleurs donné le poids du bois sec qu'après m'être assuré qu'il ne diminuait plus. On voit que la différence entre le poids du bois du mélèze vert et du mélèze sec est beaucoup moins grande que celle que j'ai trouvée entre le poids des bois verts et des bois secs des trois espèces pour lesquelles j’ai donné ce renseignement, et que le poirls du bois de mélèze sec est le plus élevé. J'aurais pu faire la même expérience pour le pin du lord Weymouth el le pin sylvestre; mais il m'aurait fallu abattre des arbres d'allées. Je n'ai qu'un seul pin laricio qui aurait pu me fournir un cube de 6 pouces de côté et l'on conçoit que je n'aie pas voulu l'abạttre.

Le bois du mélèze est d'un blanc terne dans la jeunesse de l'arbre, il esı ensuite blanc veiné de rouge, et enfin il devient d'un rouge tirant sur le brun dans l'intérieur; celte partie rouge est alors entourée d'une zône de bois blanc. Ainsi, sous le climat de Paris, le bois d'un mélèze qui a dépassé 60 ans présente ordinairement ce dernier caractère depuis le sol jusqu'à une certaine hauteur; plus haut il est blanc veiné de rouge, et plus haut encore il est blanc terne. Les mélèzes de 94 ans, dont j'ai parlé page $\mathbf{2 8 4}$, avaient le bois de l'intérieur rouge jusque vers leur cime. La partie rouge du bois est la plus dure, mais la partie blanche esı égallement du bois parfait, car le mélèze, ainsi que les sapins, le pin sylvestre et le pin maritime, n'a point d'aubier; il est même probable que pour le bois de mélèze, ainsi que pour celui des sapins, les menuisiers préféreraient la planche faite avec le bois qui est près de l'écorce à celle qui est faite avec le bois du cour, celte dernière étant plus difficile à travailler et plus sujette à se fendre. Le mélèze de 70 ans que j'avais fait abattre, pour connaître la pesanteur de son bois, n'avait que $0^{\mathrm{m}}, 38$ de diamètre à $0^{\mathrm{m}}, 32 \mathrm{du}$ sol, non compris l'écorce, parce qu'il avait été gêné et dominé daus la lutaie par des sapins; à cette hauteur une

1) Dictionnaive des eaux et forfts, 1. ler, p. 418, art. Bois. 
section du tronc perpendiculaire à son axe faisait voir qu'une gône de bois blanc, de $0^{\mathrm{m}}, 04$, entourait le reste du bois qui était rouge-brun.

'Tous les auteurs qui ont parlí du bois du mélèze s'accordent à le vanter tellement qu'il serait propre en même temps, selon eux, à tous les usages auxquels on emploic le chêne et les bois blanes; j'en ai employé trop peu et depuis trop peu de temps, pour en parler d'après ma propre expérience. On emploie le bois du mélèze à Arkbangel, avec grand succès, pour la construction des vaisseaux; on a employé aussi avec succès, au même usage, le bois des plantations de mélèzes fitites en Écosse pendant le dernier siècle. On vante particulièrement l'usage de ce bois pour tous les travaux où le bois est employé à l'air, dans l'eau ct dans les lieux humides.

Tschudy dit (1) « que le bois du mélèze est d'un grand usage et bien supérieur " à celui du piu et du sapin, en ce qu'il est beaucoup plus dur et qu'il résiste à " l'air et à l'cau. "Kasthofer, dans l'article Mélèze de l'ouvrage précédemment cité, dit " que cet arbre est un des plus utiles employé dans les constructions na"vales et hydrauliques, et que son bois est incorruptible et d'un aussi bon usage " que celui du chêne. "Malesherbes a ajouté ì l'article Mélèze de l'ouvrage de Varennes de Fenille (2), des Observations sur le mélèze, dans lesquelles on trouve le passage suivant: "J'étais, dit-il, dans le Valais en 1778; on me fit voir dans " la vallée du Rhône une maison de paysan construite en mélèze; la date de sa " construction y est inscrite, elle existait depuis 240 ans, exposée à toutes les " injures de l'air, et le bois en était encore si sain et si entier que je ne pouvais "presque y faire entrer la pointe d'un couteau. " I. G. Gand dit pourtant, d'après Bulow, dans le mémoire déjà cité, que dans les Alpes de l'Autriche, le bois du mélèze qui a crù dans les vallées basses et riches ne vaut pas même celui dı sapin picéa, tandis que celui qui a crû dans les lieux plus élevés, sur des terrains calcaires de schiste micacé, peut remplacer le chêne. Kasthofer dit aı contraire, dans l'article que je viens de citer, que l'on a remarqué que le bois dı mélèze des hautes montagnes est moins dur que celui des vallées basses. Dans le lieu que j'habite le pays est plat, le terrain ne contient pas de traces de calcaire et le bois du mélèze est très-dur; je serais donc disposé à croire plutôt Kasthofer que bulow si le climat, le terrain et l'exposition n'apportaient pas quelquefois de telles différences dans la végétation des arbres et dans les qualités de leur bois, que ce qui parait invraisemblable peut pourtant quelquelois être vrai.

On ne peut dire quelle est, sous le climat de Paris, la qualité du bois du mélèze, puisqu'il n'y est guère cultivé que pour ornement et que depuis trop peu de: temps. Les douze mélèzes âgés de 94 ans que mon beau-frèré fit abattre ên janvier 1844, lorsqu'ilsavaient depuis pluśieurs amées atteint leur maturité(Voy.p. 284), étaient sains; j’ai vu et je puis voir chaque jour les bois de charpente qu'on en a tirés. J'ai lait abattre, dans mon parc, six mélèzes qui étaient âgés de 60 à 70

(1) Traile des arbres résineur, p. 16 i.

(2) Mémoire sur l'administration forestière, 1, 11, p. 1 il. 
ans; le tronc de l'un d'eux, que l'on avait déraciné, contenait, tont près du sol, III petit réservoir de térébenthine qui commençait à $0^{\mathrm{m}}, 06$ seulement du cœur de l'arbre, et avait $0^{\mathrm{m}}, 08$ de long $, 0^{\mathrm{m}}, 06$ de large et $0^{\mathrm{m}}, 005$ d'épaisseur; cette térébenthine coula lorsqu'on découpa l'arbre en tronçons (1); un autre mélèze avait un commencement de pourriture au cœur, mais qui n'attaquait encore le tronc qu'au niveau du sol; les quatre autres mélèzes étaient sains. On a vu que la pourriture au coeur attaquait aussi, dans mon parc, des picéas et des sapins argentés. J'ai trouvé que le bois du mélèze était plus dur que celui de ses congénères, que j'ai fait exploiter, et qu'il est plus pesant lorsqu'il est sec; il me paraît de fort bonne qualité, mais ce n'est que depuis huit ans seulement que j'ai sous les yeux de la planche, des solives, des chevrons et des échelles de ce bois, ce qui est insuffisant pour que je puisse l'apprécier. Le bois du mélèze, employé comme bois de chauffage, m'a paru semblable, dans l'usage habituel, à celui du sapin argenté; Kasthofer le trouve un peu meilleur, puisqu'il dit que 16 toises de bôis de mélèze équivalent à 13 toises de bois de hêtre (Voy. p. 105).

On extrait du mélèze une résine qui est connue, dans le commerce, sous le nom de térébenthine de Venise, parce que ce fut d'abord uniquement dans cette ville qu'elle se vendit. J'emprunterai à Duhamel ce qu'il dit de l'extraction de cette substance (2). Les mélèzes dont on extrait la résine doivent être parfaitement sains, ne doivent pas être très-jeunes et ne doivent pas avoir dépassé leur maturité, parce que ceux qui sont trop jeunes ou trop âgés donnent peu de résine et d'une qualité inférieure; on fait cette extraction depuis la fin de mai jusqu'à la fin de septembre, ainsi qu'il suit : on perce les mélèzes à l'exposilion du midi en plusieurs endroits et successivement, en commençant à environ 3 pieds $\left(0^{\mathrm{m}}, 97\right)$ du sol et continuant jusqu'ù 10 à 12 pieds $\left(3^{\mathrm{m}}, 25\right.$ à $\left.3^{\mathrm{m}}, 90\right)$; les trous sont inclinés vers la terre pour faciliter l'écoulement de la résine; on place dans ces trous des chevilles de 15 à 20 pouces $\left(0^{\mathrm{m}}, 41\right.$ i $\left.0^{\mathrm{m}}, 54\right)$ de longueur, percées d'un trou de 6 à 8 lignes $\left(0^{\mathrm{m}}, 013\right.$ à $\left.0^{\mathrm{m}}, 018\right)$ de diamètre et terminées en gouttière.

La résine tombe du bout de celte gouttière dans des auges disposées pour la recevoir; on bouche avec des chevilles les trous qui n'ont point donné de résine ou qui n'en donnent plus et on les rouvre plus tard. Un mélèze sain et vigoureux peut fournir 7 à 8 livres ( $3 \mathrm{kil} .426 \mathrm{gr}$. ì $3 \mathrm{kil} .916 \mathrm{gr}$.) de résine tous les ans, pendant 40 à 50 ans. On passe cette résine dans un tamis de crin, s'il est nécessaire; elle doit être claire, transparente, avoir l'épaisseur d'un sirop bien

(1) Duhamel, qui avait obtenu sur les mẻlèzes des renseignemens de M. Brunet, habitant de Briançon, ville dans le voisinage de laquelle se trouvent beaucoup de forèts de mélèzes, dit dans son Traité des arbres et arbustes, 1. Ier, p. 335, a qu'en coupant l’arbre le plus sain on trouve dans l'intéricur du n bois des dépôts de résine liquide qui ont quelquefois un pouce d'épaisseur, 3 ou 4 pouces de largeur - et autant de hauteur; que dans un tronc de 40 pieds de longueur on trouve quelquefois jusqu'à six n deces principaux réservoirs et quantité de petits, mais que ces dépóts ne se forment que dans le " tronc des gros arbres qui commencent à entrer en retour." Je présume que ce que Duhamel donne comme la régle do't étre l'exception.

(2) Traité des arbres el arbustes, t. ler, p. 331, art. Larix. 


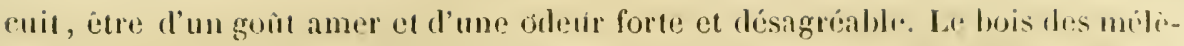
zes, dont on a extrait ainsi de la résine, n'est plus propre qu'au chauffige. La térébenthine, distillée avec de l'eau, donne le prodıit si fréquemmént emploví dans les arts et en médecine sons le nom d'essence de térébenthine.

Il me reste à parler de deux produits pen importans tirés du mélèz: un champignon du genre bolet ou agaric, qui est employé en mérlecine sous le nom d'agaric blane, et que l'on ne trouve que sur le trone des vienx málèes, et une substance appelée manne de Briançon. Je n'ajouterai rien ì ce que je viens de dire du champignon du nélèze, sinon que je ri'en ai point trouvé sur mes mélèzes; je donnerai, au contraire, quelques détails sur la manne de Briançon. Voici ce qu'en dit Duhamel dans l'article que je viens de citer, d'après les renscignemens que lui a vait donnés un labitant de Briançon, et ce qu’ont répété presque tous les atuteurs qui ont parlé de cette substance: "Les mélèzes des Alpes portent, ters " la tin de mai et dans le mois de juin, apiès que les feuilles sont développées n et dans le fort de la sève, de petits girains blancs de la grosseur des semences de. " coriandre, aussi faciles à écraser que des particules de crême foncttée, un péu " gluantés et d'un goût fade comme la manne de Calabre. Les jeunes mélèzes en " sont tout blancs avant qu’ils aient été frappés du solcil, qui dissipe biéntòt tous " les grains qu'ón n'a pas ramissés. Lés pâtres qui se plaisent à sucer ces grains " en sont purrós. C'est là la mame de Briançon, dont les anciens historiens du "Dauphiné ont fait une merveille, et qu'on comnaît sous le nom de manna la"ricea. Quand il s'élève un vent froid, pendant la nuit, et que le ciel est couvert, " on ue trouve point de manne sur les arbres; mais plus la rosée est lurte, plus " les arbres somt chargés de mańne le matin; elle se trouve atissi plus abondante " sur les arbres jeunes et vigoureux; les vieux n'en ont que sur des branchrs "nouvelles qui partent du tronc ou des grosses branclies."

ll y a un auteur qui a parlé de li manne de Briançón de visu; je reproduis textnellement ce qu'il en dit (1) : "La mame est rare à trouver, on ne la rencontre ." même que par gouttes, et je rie doute nullement que la plupart de ce qu'on " nous a débité de ses usages ne soit très-suspect, car il serait difficile d'en ra" masser ure livre. J'äi demandé, sur les lieux, si l'on n’avait jamais appris que " quelqu'ur en eût firit ramasser pour en vendre, et l'on a contirmé unes conjec: "tures disant qu'on avait de la peine à en cueillir une livre, de lempì à autre; "pour satisfaire la curiosité des savans qui la demandaient: On la trouve pat" "gouttes blanches plus ou moins dures, adhérentes aux feuilles et très-ritremeut " aux petits boutons qứ leur servent d'appuri : c'est, à ce que je crois, des hourgeons que transsude cette liquenr mielleuse quri devient concrète par le contact "de l'air et surtout par la clialeur du soleil. Nous avons fait quelques recher" ches, avec M. Guettard, pour tâcher d'éclaircir mos doutes à ce sujet; mais " nous n'arons pu nous satisfaire, quoique nous l'ayons sóuvent rencontrée. "I'ailleurs, on nous a dit que la saison de 1775 bitail moins fertile en manne 
"que bien d'antres : nous en avons tronvé au soleil levant qui était presque. " coulante; d'autres gouttes étaient toutes tombées à terre, et on pouvait les ra" masser sur le gazon parfaitement semblables à celles qui étaient restées sur "l'arbre. Eufin, nous n'avons pas été assez heureux pour trouver la nature sur " le fait et voir sortir la manne de ses couloirs. "J'ai examiné et fail examiner les mélìzes de différens âges que j’ai chez moi, et jusqu’’à ce moment je n’y ai point Irouvé de manne de Briançon.

X. Accidexs, maladies, animaux ntisinles. - Le mélèze, qui supporte quelquefois des froids si rigoureux, ne pourrait éprouver de dommage, sous le climat de Paris, que des gelées tardives; mais elles ne sont, pour ainsi dire, plus à craindre lorsque ses pousses paraissent. Aussi ai-je vu ces gelées nuire, daus mon pare, à nos deux sapins d'Europe, surtout au sapin argenté, et jamais au mélèze. 11 y a des pays, tels que la Bresse (Ain), où les gelées, par suite de eirconstances exceptionnelles, sont quelquefois beaucoup plus tardives que celles dont nous avons à nous plaindre, et alors elles peuvent causer de grands dommages aux mélèzes, dont les pousses sont encore plus tendres que celles des sapins.

Le mélèze souffre moins de la neige, lorsqu'elle tombe avec une grande abondance, et du givre que les autres arbres résineux conifères, parce qu'il ne conserve pas ses fenilles l'hiver.

Les vents peuvent renverser les mélèzes, mais ils ne les brisent, pour aiusi dire, jamais.

Les quadrupèdes ne peuvent muire aux futaies de mélèzes, sous le climat de: Paris, que lorsqu'elles sont jeunes, puisqu'on ne peut les y exploiter en jardinant; les oiseaux ne se perchent point sur la llèche des mélèzes, comme sur celles des sapins et des pins, parce qu'elle est trop mince et trop flexible.

Les lapins broutent fort bien les branches des mélèzes, et j’ai remarqué qu'ils rongent l'écorce des jeunes mélèzes de préférence à celles des jeunes sapins et des jeunes pins.

Je n'ai observé qu'un seul insecte qui soit nuisible au mélèze et je ne l'ai observé que sur de jeunes mélèzes; c'est un puceron lanigère qui se fixe sur les feuilles qu'il suce probablement, et peut-être suce-t-il aussi la sève du bois: les feuilles deviennent alors jaunes, les branches dépérissent et meurent quelquefois; quand cet accident arrive à la tlèche, une branche voisine la remplace bientôt; il est fort rare que cette maladie fasse périr l'arbre, cela arrive pourtant quelquefois. Ratzeburg, page 80 de l'ouvrage déjà cité, n'indique qu'un iısecte particulier au mélìze, le Bostrichus laricis, et il dit qu’il se montre aussi sur les autres conifères. Decandolle dit, dans la lettre précédemment citće, que les mélèzes sont, de tous les arbres des Alpes, ceux qui sont les moins sujets aux maladies et que leurs trones sont remarquablement sains; ils ne sont, dit-il, que bien rarement attaqués par les bostriches, qui sont si redoutables anx sapins et aux pins, mais quelquefois une petie chenille lévore leurs 
leuilles, et il n'en résulte aucun inconvénient, elles repoussent l'année suivante.

En Angleterre, particulièrement dans les plaines, deux maladies, la pourriture au cœur et la rouille, ont attaqué les mélèzes et ont causé de grands ravages, mais ceux qui se trouvaient à plus de $\mathbf{1 8 0}$ mètres au dessus du niveau de la mer n'en ont point été atteints. Je renvoie à ce que j’ai dit précédemment de ces deux maladies page 300 , en parlant des plantations de mélìzes en Angleterre et en Écosse. Il serait à craindre que ces deux maladies ne se déclarassent aussi sous leclimat de Paris, si l'on y faịsait de grandes plantations de mélizes à l'état serré; je n'ai encoré obtenu aucun renseignement à ce sujet. 


\section{CIHAPITRE IX.}

\section{CEDDRE IDU LIBAN, Cedrus Libami(1).}

1. Noms de l'espèce. - Pimus cedrus linné (2). Cedrus Libani Barrelem (3).

Linné ayant compris les pius, les sapins, lés mélèzes el les cèdres, dans un même genre, sous la dénomination de Pinus, devait donner à l'arbre, dont je m’occupe dans ce chapitre, la dénomination de Pinus cedrus; mais je m’élonne que des botanistes, qui ont cru préférable (et je partage leur opinion) de faire plusieurs genres de ces arbres, aient compris le cèdre du Liban, les uns dans le genre mélèze, les autres dans le genre sapin : ainsi Tournefort, Duhamel, Miller, etc., classent le cèdre dans le genre mélèze; Poiret, Loiseleur-Deslongchamps, Lindley, ete. , lans le genre sapin. Je pense comme Barrelier, A. Richard, etc., qu'il est préférable d'en laire un genre à part.

II. Sìve et feulies. - Le cèdre du Liban a deux sèves comme le mélèze; la première commence dans la première quinzaine de mai et se termine dans le. courant de juillet, la seconde part environ quinze jours après que la premiere est arrêtée et finit en septembre.

Les feuilles du cèdre sont raides et d'un vert foncé; elles sont, comme celles dı mélèze, disposées sur le même arbre de deux manières différentes, une à une al par bouquets. Les premières entourent les ponsses de l'année; les secondes soltent de boutons situés sur le bois d'uu an, ou de dards qui sont sur du bois plus îgé et qui ont déjà porté dés feuilles les années précédentes. Loudon dit, 1. W, p. 2403 de son Arboretum, qu'elles tombent tous les deux ans; mais j'ai reconnu que les premières tombent presque toutes ì l'automne, comme celles diss bois feuillus.

(1) Le cèdre du Liban occupait d'abord un article dans le chapitre qui suit : je me suis déeidé à en faire un chapitre à part au moment de mettre sous presse. Voila pourquoi je n'ai point donné de dessins des fcuilles, des fleurs, des cônes et des graines du cèdre du Liban, ainsi que je l'ai fait pour ies arbres auxquels j'ai consacré un chapitre à part; et voilà pourquoi aussi je rie me suis pas conformè entièrement, en parlant de cet arbre, à l'ordre que j'avais prècédemment suivi.

(2) Species plantarum, 3• ridit, t. II, p. 1420.

(3) Planta per Galliam, Hispaniam et Italiam obserratce, p. 122. 
111. Fueuns et cones. - Le cèdre du Liban porte ordinairement des fleurs màles et des tleurs lemelles sur le mème pied; cependant, il resulterait dobservaltions que je rapporterai plus loin, que quelques sujets ne portent que des fleurs miles, d'antres que des lleurs femelles.

les fleurs mâles sont disposées en chatons simples érigés, longs d'environ (1)" (1) sur $0^{\text {"m, }}, 01$ de diamètre à la base, lorsque les fleurs ont alteint leur maturide; res chatons se trouvent sur le dessus des branches et nont de ressemblance,

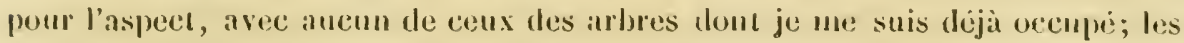
tleurs qui les composent mùrissent en cectobee, sont alors d'un jame pâle et laissent echapprer alondamment une poussiere jantes.

Les lleurs femelles, disposées en chatons simples comme celles des pins, sont aussi érigéés et sont ovoïdes el rougeâtres; elles mûrissent en même tenps que les lleurs mâles, et se transforment en cones peu de temps aptès avoir été fécondées.

Les cònes du cèlre sont ovoüdes et ont de $0^{\mathrm{m}}, 08$ i $0^{\mathrm{m}}, 12$ de long; la description sommaire que j’a faite les cones du sapin argente, page 20, leur est applicable. La graine du cèdre est munic d'une aite, et est de la mêne couleur que celle du sippiu argenté, avee laquelle clle a de la ressemblance pour la forme et pour les dimensions.

Les anteurs qui ge sont vecupés dlu cèdre du Liban, n'étant pas lliccord sur la floritison et sur la fructification de cet arbre, je vais mpporter, à ce sujet, outre les renseiguemens que quelques persommes ont bien voulu me tonner, ceus que j’oi moi-même recueillis; et, en y réunissant mes propres observittions, j'espère éclaircir entierement cette question.

Selon M. Louis Vilmorin, qui a observé avec beancoup de soin la floraison et la fructitication du cèdre du Liban, sous le climat de Paris, les fleurs mâles et les lleurs femelles commencent ordinairement à paratre en mai mais il faut monter sur l'arbre et les examiner de près pour les distinguer. Les fleurs males prennent de: l'accroissentent jusqu'à la lin de septembre ou jusqu'au comnencement d'octobre, époque à laquelle elles se distinguent parlaitement et laissent échipplex une poussière jaune; les fleurs femelles prennent de l'accroissement fendant le même temps, mas cela est moins visible parce qu'elles sont plus petitrs, et elles se transforment en cònes après la fécondation. Ces cones commencent à grossir l'annce suivante, quand part la sève; ils sont d'abord vert-clair, puis ils prennent me teinte violacce ; ils ont acquis an commencement de l'hiver toutes leurs dimensions, et pendant l'hiver ils prement la couleur grise qu'ils conserverunt. L'année suivante, e'est-ì-dire la deuxième année depuis celle ou ils sont nés, ils restent fixés sur l'arbre; ef ce n'est que pendint les mois de fëvrier et de mars de l'année suivante, qui est la troisième depuis celle oì ils sont nés, que les écailles se délachent de l’axe et tombent avec les deux graines qui sont fixées :u bas de chacune d'elles. Ainsi, en supposant que les cones soient formés le

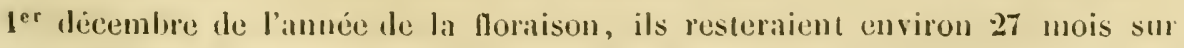
l'arbre jusqua'a ce que tombent les écailles el les graines.

II. Huhamel de Fongerous (arriesr-meven de Buhamel-I)umonceau) at, lans 
le parc de son château de Vrigny, près de Pithiviers (Loiret), cinq cèdres qui ont été plantés par Juhamel-Dumonceau, l'un en 1757, les quaire autres en 1770; il a fait sur la floraison et la fructification de ces cèdres les observations suivantes, qu'il a bien voulu me communiquer : Les fleurs mâles du cèdre se remarquent vers le mois de septembre, et elles atteignent leur maturité et laissent échapper une poussière jaune en octobre, époque à laquelle on distingue aussi les fleurs femelles. L'année suivante les cônes acquièrent à peu près toutes leurs dimensions et ils prennent, pendant l'hiver, la couleur qu'ils conserveront. Au mois de juillet suivant, c'est-à-dire vers le milieu de la seconde année depuis celle où les cônes sont nés, la graine a acquis sa maturité, mais il est très-difficile de l'extraire des cônes. Au mois de juin ou de juillet suivant, c'està-dire vers le milieu de la troisième année depuis celle où les cônes sont nés, les écailles tombent avec les graines et en août il ne reste plus que les axes dẹs cônes fixés sur les branches, comme dans les sapins argentés. Ainsi, les cônes restcraient environ 30 mois sur l'arbre depuis leur naissance jusqu'à ce que tombent les écailles et les graines. Si l'on cueille les cônes peu de temps avant l'époque où doivent tomber les graines, les écailles se détachent de l'axe avec la plus grande facilité; les graines, qui sont molles avant leur maturité, sont fermes alors, presque comme celles du sapin argenté, et elles ont éprouvé un commencement de germination; aussi, en les ouvrant, trouve-t-on l'embryon déjà presque transformé en plantule, et si on les met tout de suite en terre elles lèvent très-promptement. C'est aussi ce qu'il faut faire, car lorsqu'elles ont subi ce commencement de germination elles ne pourraient se conserver jusqu'à l'année suivante. Il lève autour des cèdres de Vrigny beaucoup de plant de semis naturel qui périt étouffé dans la futaie de chène qui entoure les cèdres, écrasé par les promeneurs, ou détruit par d'autres causes; cependant l'on en trouve de 2 et 3 ans que l'on enlève quelquefois pour le mettre en pépinière.

Le 12 août 1844, je fus visiter les cèdres du Liban qui se trouvent dans le beau jardin de M. Guy, à Saint-Germain-en-Laye (Seine-et-Oise), et je vis un grand nombre de fleurs mâles sur plusıeurs de ceux de ces cèdres qui sont isolés; ces fleurs, auxquelles il fallait encore.plusieurs semaines pour atteindre leur maturité, se trouvilent jusque sur les branches les plus basses, où je pus en cueillir; elles étaient f'ermes, coniques, d'un vert pâle, et les plus longues avaient $0^{\mathrm{m}}, 03$ de long; M. Guy me manda qu'elles avaient laissé échapper le pollen dans le courant d'octobre, qu'il était très-abondant et coulcur de soufre. Je ne vis point de fleurs femelles, qui sont bien moins nombreuses; il aurait fillu, pour pouvoir en découvrir, examiner les branches vers la cime, où elles se trouvent ordinairement; mais elles mùrissent nécessairement en même temps que les fleurs mâles, sans quoi elles ne pourraient être fécondées, et elles se transforment peu après en cônes. MI. Guy me dit qu'il faisait cueillir les cônes au printemps de la seconde année après celle où ils sont nés, que la graine était alors fort bonne, et que les marchands ne voulaient pas des cônes cueillis plus tard. Il a remarqué que si les cónes restent sur l'arbre, les écailles et les graines tombent pendant 


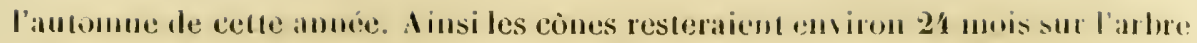
jusqu'au moment où tombent les écailles et les graines.

Les cèdres du jardin de M. Guy sont an nombre de 22, âgés d'environ 70 ans, tous situés dians le voisinage de l'habitation, les uns dans des massits, on its out crù à l'état serré, les autres isolés sur des pelouses; ce sont ces dernicrs qui portent le plus grand nombre de fleurs et de cônes, les preniers ne pouvant en porter qu'al sommet. de remarquai sur quelques-mus des cedres isolés, un grand nombre de cônes de l'année précédente qui avaient déjà atteint à peu près tontes leurs dimensions et qui étaient d'un blane mat; quelquefois ces cónes étaient fixés au dessus de l'arête principale des branches, et tellement rapprochès qu'ils se touchaient presque. L’un des cèdres qui sont isolés, a élé tiré d'un massil qu'on voulait éclaircir, ayant déjà plus d'un mètre de circonférence; cetle transplan tation ne parait pas lui avoir nui, car il est aussi beal que ceux de son voisinage. Les cèdres de M.: Guy donnent abondamment du plant de semis naturel dans les allées, sur les pelouses et dans les plates-bandes; il : périt écrasé sous les pieds, tranché par la faus, ou détruit par le linage, aussi n'en tronve-t-on point de 2 ans. J'en remarquai dans les plates-bandes qui était né depuis quelques mois, et qui était aussi beau que le plant que j’ai obtenu de la graine tombée, cette même année, des cônes du cèdre du Jardindes-Plantes.

I. P'epin, chef de l'École de botanique dı Jardin-des-Plantes de Paris, ayant observé en $\mathbf{1 8 1 4}$ la dissémination des graines du cèdre du Liban de ce jardin, a fait une communication à ce sujet à la Société royale et centrale d'agriculture; on la trouve consignée dans le Bulletiu des séances de cette Société (séance du 20 mars 1811), ainsi qu'il suit: " M. Pepin, membre correspondant pour le département " de la Seine, adresse des graines de cèdre du Liban récoltées sur l’individu "planté en 1735, au Jardin-du-Roi, par Bernard de Jussien, lesquelles ont "germé dans. les cônes encore lixés sur l'arbre, pendant cet hiver, et tombent " à terre depuis la lin de janvier. Cette germination, qui tient saus doute à lat " température douce et humide de l'hiver, a été olsservée, pour la première fois, " cette année. An nombre des graines déjà développées, il en est dont les ti" gelles n’ont pas moins de 4 à 6 centimètres. Plusieurs centaines ramassées en " cet état sur le sol, et semées en février, ont parfititement réussi. "Le semis naturel résultant de la dissémination de ces graines avait domné naissance a "un grand nombre de plants que j'ai visités le 29 avril 1811 ; ils se trouvaient sons la gouttière on près de la gouttière de l'arbre-mòre, oì le ratissage, le piétinage les ouvriers et l'ombrage les ont probablement fait périr, car je n'en ai plus trouvé le 2 ju juin de ectte mème année. Je n’ai point remarqué, et je ne sache pass que personne ait remarqué, que les autres espèces d'arbres résineux dont je une suis occupé daus cet ouvrage, aient donné l'cxemple d’une semblable germination.

M. Renon, inspecteur des forêts de l'Mlgerie, a publié une Notice sur les forits

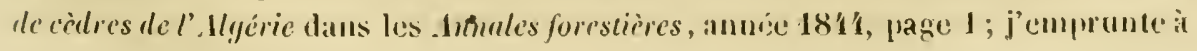


eetle notice le passilge suipant sur les fleurs et sur les cones des deux espèces de cèdres que l'on y a olservies. "L Les fleurs des deux sexes paraissent en septembr: ") et en octobre; au mois de juin suivant, les ovaires femelles présentent déja " l'aspect d'un cône verdâtre long de $0^{\mathrm{m}}, 045$ et d'un diamètre moyen de $0^{\mathrm{m}}, 030$; " ces jeunes cònes sont, pour ainsi dire, encorc à l'état herbacé et ils fléchis" sent sous la moindre pression. Au mois le juillet de l'année suivante, les " cônes ont acquis une consistance ligneuse el renferment des graines à l'útat " parfait de maturité; mais ils ne commencent à se disséminer qu'à l'époque " des pluies d'automne, et il en est même qui subsistent sans s'écailler jusqu’à " la fin de l'hiver. "

Je conclus de ce que je viens de rapporter que les lleurs du cèdre du Lilan mùrissent ordinairement, sous le climat de Paris, dans le courant du mois d'octobre, et je me suis assuré que cet arbre n'en portait point tous les ans; que les cônes restent au maius 21 mois sur l'arbre avant que de laisser tomber leurs écailles et leurs graines; que le moment où tombent les écailles et les graines varie depuis le $2 \mathbf{4}^{\mathrm{e}}$ muis jusqu'au $30^{\mathrm{e}}$, à partir de la naissance des cônes, si les renseignemens qu'on m'a procurés sont exicts; entin, que lorsque les graines ne tombent qu'après l'hiver ou qu'à la fin d'un lịiver dous, elles commeneent à germer dans les cônes mêmes,

Loudon dit, 1. IV, p. 2223 de son Arboretum, que les cônes du cèdre n'atteignent leur maturité qu'an troisième automne, et qu'ou peut les conserver eing on six ans après les avoir cueillis, sans que la graine qu'ils contiennent s'altère. Cette dernière assertion me parait être une erreur, s'il s'agit de cônes qui n'out été cueillis que peu avant la chute des écailles, et que ces écailles ne soient tombées qu'après l’hiver, car alors les graines ont subi un commencement de germination; mais si on les a cueillis quelques mois avant cette époque, elles se conserveront saines dans les cônes pendant un temps plus ou moins long, que je ne puis indiquer, même approximativement. Selon le même auteur, 1. 1N, 1\%. 2104, le cèdre ne commence à porter des tônes que lorsqu'il est âgé de 25 à 30 ans, et la plupart des graines qui se trouvent alors dans ces cônes sont stériles; ce n'est que dans des cônes récoltés sur des cèdres plus âgés que l'on peut trouver des graines fertiles. Il dit que quelques cèdres ne produisent que des fleurs mâles, d'autres que des fleurs femelles, mais que quelques-uns produisent les unes et les autres, et ces remarques ont été faites sur des cèdres àgés de plus de 100 ans. Ainsi, une partie de ces arbres auraient des fleurs diö̈purs: M. Renou a fait la même observation dans les forêts de cèdres de l'Algérice, et l'a consignée dans la notice que j'ai citée plus haut. "Il y a, dit Loudon, t. IV, p. 2404 de son Arbore" tmm, des cèdres à Whitton et Pepperharrow, et dans d'autres lieux, qui, quoi" que âgés de plus de 100 ans et quoique étant d'une croissance vigourcuse, ont " à peine encore porté des fleurs mâles et des fleurs femelles. "

Miller dil (1) que quatre cèdres, qui ont été plantés en 1683, hauts de 3 pieds

I Diclionnaire des jardiniers, 1. \$, p. :3 is, art. Larix cidrus. 
$\left(0^{m,}, \mathfrak{6}\right)$, dans le jadin botanique de Chelsea, et qu'ou croit ètre les premiers qui aient été plantés en Angleterre, "ont prohnit pendant plusieurs années un grand "nombre de lleurs mâles, mais que trois seulement ont donné des cônes qui ne "parviennent à leur maturité que depuis 35 ans; qu'aujourd'hui (en 1766) les " semences qui tombent des cònes, autour de ces arbres, produisent des plantes " en abondance et sans aucun soin."

V. Vilmorin a, dans sa propriété de Verrières, a 12 kilomètres te Paris, un cìdre qui a commence ì donner des fleurs mâles ì 23 ans et des cônes avant 28 ans. J'ai remarqué, dans le pare de Fromont, que des è̀dres âgés d'environ 28 ans portaient des cỏnes. d’ai, chez moi, un cèdre qui a été planté à l'automne le 180.1 par mon père, el qui n'a encore donné ni fleurs ni cônes. M. Gazan en a, à 2' hilomètres de chez moi, qui but été plantés en 1815 et qui n’ont pas encore lructitie : il serait possible que ces arbres portassent moins régulièrement des fleurs et des cônes en France et en Angleterre que dans les pays où ils sont inıligìnes.

IV. Grunes et sems naturel. -- J'ai dit précédemment qu'il levait des plants provenant de semis naturel autour du cèdle du dardin-des-Plantes, autour des cèdres de Vrigny et antour des cèdres du jardin de M. Guy. Une personne de ma connaissance m’a dit avoir remarquué ehez M. Polissard, à Harcigny (Sâone-etLoire), des cèdres qui donnent abondamment du plant de semis naturel et que, parmi ces plants, il y en a qui ont déjà 2 mètres de haut. II. Vilmorin, dans une note du Traité pratique de la culture des pins de Delamarre, page 319, dit qu’il a vu une quantité de jeunes plants s’élever d'eux-mêmes sous les beaux cèdres ilu pare de Bellevue, près Meudon, et qu'un cèdre planté par son père, dans un jardin qu'il possédait à Paris, au faubourg Saint-Antoine, a souvent aussi produit de jeunes plants qui s'étaient semés naturellement dans le massif dont il laisait partic. Il est donc probable que le cèdre pourrait se reproduire en France par le semis naturel, comme dans les pays où il est indigène.

On a vu, par ce qui précède, que je n’ịi pas assez de domnées pour indiquer à quel age le cèdre commence à donner du semis naturel abondant, mais je présume que ce ne doit pas être avant 60 ans. Quant ì l'âge que doivent avoir les cèdres sur lesquels on récolte les cònes pour en extraire la graine, je pense qu’il est prudent, Iorsqu'on le peut, de n'en récolter que sur des cèdres âgés de 60 ans au moins. On a vu que la graine est féconde, dès le printemps de la deuxième année, depuis celle où les cònes ont prịs naissance; c'est alors, et même lorsque les graines proviennent de cônes plus jeunes encore, qu'on les récolte le plus souvent; mais sont-elles parvenues ì l'éṭt parfit de maturité? Je désirerais que l'on fìt à ce sujet des expériences concluantes. Ces expériences ser:aient fort simples, puisqu'elles consisteraient à semer dans le mème terrain des graines extraites de cònes cueillis an printemps de la seconte année, depuis celle ou les comes ont pris natissance, at des graines extraites de connes cueillis sur le mèn arbre, pen avant le moment gin cres cones latissent lomber leurs graines; 
et ensuite, à observer la végétation des plants et des arbres qui proviendraicut de ces semis, pour voir s’ils seraient également beaux et s'ils résisteraient également bien aux intempéries des saisons. Jusqu'à ce que ces expériences aient été faites, il est évidemment préférable de ne cueilllir les cônes dont on veut extraire les graines, que peu de temps avant le moment où les écailles vont se détacher des cônes et tomber avec les graines.

Chez les grainetiers, on ne trouve que des cônes cueillis quelquelois beaucoup! trop tôt; les écailles de ces cỏnes tiennent si fortement à l'axe, qu'on est obligé, pour extraire les graines avec quelque promptitude, de percer d'abord, avec un vilebrequin, le cône d'où on les extrait, à l'endroit où se trouve l'axe. M. L. Deslongchamps conseille (1) de commencer par en retranclier 6 ou 8 lignes $\left(0^{\mathrm{m}}, 013\right.$ ì $\left.0^{\mathrm{m}}, 018\right)$ du bas et autant du haut avec une scie, ces parties des connes ne contenant que des graines avortées; par cette opération préparatoire on rend l'extraction des graines beaucoup plus prompte.

V. Mode de végetation, description, dimensions. - On trouvera chap. XI, art. IX, des détails sur la végétation et l'accroissement du cèdre du Liban, depuis le semis jusqu'au moment de la plantation à demeure; mais je crains d'avoir employé de la graine qui n'avait pas atteint une complète maturité, ce qui fait que je donne avec méfiance les résultats que j'ai ol,tenus. Cet arbre, après avoir dépassé les premières années, a, dans les situations qui lui sont favorables, une magnifique végétation; il surpasse en grosseur, à égalité d’âge, tous les arbres dont je me suis précédemment occupé.

Le cèdre du Liban a un pivot et est très-fortement enraciné, sans quoi il ne pourrait résister aux vents, puisque sa tête s'étale beaucoup quand il croît isolé.

Le trone de cet arbre est droit, mais quand il croit isolé il se partage presque toujours, à plus ou moins de distance du sol, en plusieurs branches, ce qui rísulte souvent de ce que sa flèche, qui est fort nince, a été brisée; ces branches sont ordinairement érigées à l'endroit où elles sortent du tronc, mais lors même que le tronc s'élève à une assez grande hauteur, il décroît promptement de diamètre, parce que l'arbre est garni de branches depuis le sol, comme les sapins, et que dans le nombre il s'en trouve toujours de très-grosses. La flèche de l'arbre est d'abord inclinée, le plus souvent du côté du nord ou de l'est, mais l’année suivante elle se redressc.

Les branches principales s'étalent au loin et sont couvertes, dans leur partic supéricure, d'un épais feuillage; elles ont la forme de palmes, ce qui donne au cèdre du Liban un aspect majestueux tout particulier, qui le fait reconnaitre de loin. L'écorce de cet arbre est d’un gris foncé et plutôt fendillée que rugueuse.

Le cèdre croît très-bien à l'état serré, ainsi que les arlhres dlont je me suis déji

(1) Histoire du cèdre du Liban, 1. $\{9$. 
occupé, son trone file droit et se dépouille de branches; cet arbre change alors complètement d'aspect, de manière à ne pouvoir être reconnu, parce que, indépendamment de la différence qui existe entre les arbres qui croissent à l'état serré et ceux qui croissent isolés, ses feuilles ne sont plus pressées de la même manière sur les branches et sont d'un vert beaucoup moins foncé. Le trone du è̀dre, qui a crù à l'état serré, ne m’a pas paru maintenir sa grosseur mieux que celui du mélèze, du moins d’après ce que j’ai remarquué dans le pare de Fromont et dans le jardin de M. Guy, seuls lieux où j’aie vu en France des cèdres à l'état serré; et en les comparant aux mélèzes à l'état serré qui se trouvent dans mon parc. "Quand les cèdres sont plantés en massif’s, dit Loudon, 1. IV, p. 2125, de * son Arboretum, seuls ou avec d'autres arbres, les branches latérales sont étouf- fées, mais pourtant ils continuent à croître à peu près aussi rapidement que "Ie mélèze et le sapin argenté, quand ces arbres sont traités de mème. Ainsi, en " délinitive, le cèdre n'a peut-être pas plus à soufrrir de la perte de ses branches " latérales qu'aucun autre pin ou sapin. " M. Renou, dans la notice précédemment citée, dit que dans la forêt de cèdres située dans le voisinage de Blidialı, on trouve un mélange de ces arbres depuis l'arbre séculaire jusqu'au jeune plant le l'année; mais qu'un rencontre aussi quelques portions de massifs qui présentent de l'uniformité dans leur composition.

On a inséré dans le $1^{\circ}$ de mai 1844 du Bulletin des séances de la Société royale et centrale d'agriculture, une note relative aux cèdres du mont Ciga, près de Teniat-el-Haâd, adressée par le ministre de la guerre au président de la Société; on y trouve les renseignemens suivans : "Les cèdres qui eroissent sur le Djebel" Ciga sont très-abondans et généralement très-grands; cependant on en trouve " de tous les âges. Le cèdre se reproduit par la graine; cette reproduction est cx" trêmement facile, si l'on en jugge par l'immense quantité de très-jeunes cèdres " Iont la terre est couverte; mais ces jeunes arbres sont détruits par le feu que " les Arabes allument dans la forèt au moment des grandes chaleurs. Dans les " parties de: la montagne que le leu a épargnées, les cèdres de 5 à 6 mètres de " hauteur sont tellement serrés, qu'un homme a de la peine à passer au tran vers. Les cèdres croissent sur le versant nord de la montagne; le terrain qu'ils " occupent forme une rône horizontale de 5 à 600 mètres de largeur sur une lon"gueur de 4 licues; cette zône de terrain est à 400 mètres environ au dessus du " niveau de la mer."

Le cèdre du Liban peut subsister très-longtemps sur les hautes montagnes sans dépérir, puisque voilà près de quatre cents ans qu'on cite quelques cèdres qui sont sur le mont Liban, et ces cèdres, si remarquables par leurs dimensions, ne dépérissent point encore. Il paraît que le cèdre du Liban ne pourrait pas se maintenir aussi longtemps dans nos plaines de l'Europe. Les deux cèdres de Chelsea qui restent des quatre que l’on a vait plantés en 1683, ainsi que je l'ai dit plus laut, sont, dit Loudon, t. IV, j). 2106 de son Arboretum, dont l'édition complèto a paru en 1838, dans un état complet de décatence, ce qui suppose qu’ils avaient atteint leur maturité depuis longtemus; mais ils se trouvent dans un terrain mat- 
gre, sablonneux, mèlé de gravier, reposant à 2 pieıls $\left(0^{\mathrm{m}}, 60\right)$ de la superticie, sur un sous-sol dur et mêlé de rochers. Le même auteur dit 1. I'r , J. 48 du même ouvrage, qu'il y a à Enfield un cèdre qui était en 1821 en état de décadence, et ce cèdre est tout au plus aussi îgé que ceux de Ghelsea. I'armi un grand nombre de cèdres que l'on a plantés en France à dater de 1735, année où lút planté celui du Jardin-des-Plantes, ceux qui occupent des terrains profonds, favorables à la végétation de ces arbres, ne laissent encore apercevoir aucun signe de dépérisscment.

Le cèdre acquiert pendant les premières années, toutes choses égales d'ailleurs, de plus fortes dimensions en circonférence qu'aucume des espèces dont je me suis précédemment occupé; mais je ne crois pas qu'il atteigne à la même hauteur que nos deux sapins d'Europe, ni que ceux des pins dont j'ai déjà parlé qui s'élèvent le plus haut. de me contenterai de quelques citations à l'appui de ce que je viens de dire.

Varemnes de Fenille rapporte (1) que le cèdre du Jardin-des-l'lintes avilit eu 1786 , c'est-ì-dire 52 ans après qu'il avait été planté, 6 pieds 7 ponces $\left(2^{\text {m" }}, 13\right)$ de circonférence à 4 pieds 6 pouces ( $\mathrm{I}^{\mathrm{m}}$, 佔) au dessus du sol. M. L. Deslongehamus dit qu'il a mesuré ce cèdre en 1812 (2) à la même hauteur, et lui a trouvé 8 pieds 8 pouces $\left(2^{\mathrm{m}}, 81\right)$ de circonférence; en 1837 , il l'a mesuré de nouveau et hui a trouvé 10 pieds $\left(3^{m}, 25\right)$. J'ai mesuré ce même arbre le 27 mai 1844 ; il avait à un mètre du sol $3^{\text {m }}, 25$ de circonférence; ainsi il ne prend plus d'accroissement; je n'ai pu prendre cette même dimension au niveau du sol, parce qu'il est entouré d'un banc de pierre; sa hauteur n'est que de $17^{m}, 30$. Je dois d'ailleurs faire ob. server que l'on a chaussé de terre le pied de cet arbre, ce qui est toujour's nuisible, d'où il résulte qu'en le mesurant à un mètre du sol actuel on se trouve à une plus grande hauteur du sol primitil; quant à la hauteur de cet arbre, elle serait plus grande si l'on n'eùt brisé sa tête, il y a environ einquante ans, d'un coup de fusil. La terre dans laquelle il se trouve est maigre et contient beaucoup de plâtras provenant des démolitions de Paris. Son accroissement annuel, en lui donnant 115 ans, avail élé jusqu'en 1841 de $0^{\mathrm{m}}, 009$.

Le cèdre de Vrigny, planté en 1757 par Duhamel-Dumonceau, était par conséquent âgéd'environ 8' ans en 18'11; il a vait à l'automnede cette année un diamètre de $1^{\mathrm{m}}$, , 33 à un mètredu sol, une hauteur de $27^{\mathrm{m}}, 18$, et l'envergure de son branchage, dans sa plus grande largeur, étail de 25 mètres. Il se divise à 4 mètres du sol en plusieurs branches; l'une l'elles continue le trone, ee qui donne à l'arbre un port régulier. L'accroissement amnuel de ce cèdre, calculé sur son diamètrè à un mètre du sol, avait été de (1)",018. Jes quatre autres cèdres plantés aussi à Vrigng par Dubamel-Dumonceau, mais en 1770 , le plus beau a un diamètre de $1^{m}, 07$ à un mètre du sol, $25^{\prime \prime \prime}, 70$ de haut, et sa tige se prolonge druite juscju’à sa cinte; ces arbres sont dans un sable frais et substantiel mèlé de terre de bruyère. Il y a

(1) Mémoire sur l'administration forestière, cle., 1. 11, p. i4s.

2) Histoire du cèdre du Liban, J. 36. 
dans lo potagne de Vrigny un cètre qui a étí semo, en $180 \mathrm{~s}$, avec de la graine du beau civler dont je vieus de parler, et qui avitit par conséquent 37 ans en 1811; il porte depuis plusieurs annes des chatons mâles, mais n'a pas encore porti de connes; il a 15 mètres de haut et un diamètre de (0n, 52; ainsi il a eu, jusqu'en 1814, un aceroissement anumel de $0^{\prime \prime}, 014$ (1).

Jamme Saint-Hilaire a domú daus les Aunales de l'ugriculure française, année 1811 , 1. 201, la cireonférence d’un cèdre du Liban planté en 1743 par DuhamelDumoncean dans sa terre de Denainvilliers, près de Pithiviers (Loiret); cette mesure a été prise a un pied de terre aux époques suivantes : En 1753, il avitit une circonférence de $\left(0^{\mathrm{m}}, 76 ;\right.$; cn 1759 , de $1^{\mathrm{m}}, 86$; on 1786 , de $2^{\mathrm{m}}, 033$; en 1799 , de $2^{m}, 35$; rn 1809, de $2^{m}, 65$; en 1822, de $3^{m}, 14$; en 1831, de $3^{m}, 41$; en 18:35, de :3"', o0. On pent facilement calculer l'aceroissement ammel de ce cè̀lre à ces diflérentes époques, en supposant qu'il avait 6 ou 8 ans lorsqu'on le planta.

Il y a à deux lieues de chez moi, sur la commune de Courteilles, dans un jardin qui appartient à $\mathbf{H}$. A. Richard, professeur à l'Ecole de médecine, lils du célèbre botaniste de ce nom, un cèdre qui était âgé d'environ 51 ans en 1813; je lui tronvai alors $\left(0^{\mathrm{m}}, 80\right.$ de cliamètre et 16 mètres de haut; son tronc est divisé, à $2^{\mathrm{m}}, \mathbf{4 0}$ an dessus du sol, en cinq grosses branches presque verticales à leur origine. L’accroissement annuel de cet arbre avait donc été en 1813 de $0^{\mathrm{m}}, 016$.

Delamarre dit dans la $2^{\circ}$ édit. de son Traité pratique des pius, qui parnt en 18:27, peu de temps avant sa mort, que les trois plus gros cèdres que nous ayons en France sont le cèdre du Jarlin-les-l'lantes, le cèdre de Vrigny et le cèdre de Montigny-Lancoup, près de Provins, planté par les soins de Duhamel chez son ami II. de Trudaine; j’ai donné les dimensions des deux premiers de ces arbres; Delamarre dit que le dernier avait alors 13 pieds 2 pouces $\left(4^{\mathrm{m}}, 27\right)$ de circonférence à 4 pieds 6 ponces $\left(1^{\mathrm{m}}, \mathbf{4 5}\right)$ du sol. M. L. Deslongchamps parle de ce même arbre dans son Mistoire du ciele du Liban, et dit qu'il a fallu quatre persomnes pour embrasser son tronc ì hauteur des bras; on ne peut par conséquent évaluer sa circonférence à moins de 6 mètres; ce cèdre se trouve dans une fort bonne terre.

Le parc de Fromont, à Ris (Seine-et-Oise), qui appartient it M. le chevalier Soulange-Bodin, occupe un cotean exposé au nord-est et s'étend jusqu'au bord de la Seme. Le sol se compose, sur le coteau, d'une bonne terre franche sur un sous-sol de roche calcaire; dans la vallée le sol est profond, mais la terre est sableuse, caillonteuse et fort maigre. Il y it près du château, qui se trouve vers le milieu du coteau, deux cèdres qui ont été plantés en 1813, et dont l'un avait, lorsque je le mesurai, le 31 juillet $1844,2^{\mathrm{m}}, 61$ de circonférence et l'autre $4^{\mathrm{m}}, 86$; le plus gros, qui est fort branchu, ne m’a pas paru avoir plus de 13 mètres de haut; j'évalue la hauteur du second à $1 \breve{5}^{\mathrm{m}}, 50$; d'autres cèdres ont été plantés dix ans après, les uns isolés, les autres dans des massifs. Ceux qui se trouvent dans la partic moyenne du pare, c'est-à-dire dans le terrain le plus fertile et qui

(1) Renseignement communiqui par .11. buhamel de lougeraux. 
sont isolés, avaient $1^{\mathrm{m}}, 50$ à $1^{\mathrm{m}}, \mathbf{7 0}$ de circonférence, et ceux qui ont crû à l'état serré dans la même partie $1^{\mathrm{m}}, 15$ à $1^{\mathrm{m}}, 25$ de circonférence, et jusqu'à environ $14^{\mathrm{m}}, 50$ de haut. Ceux qui se trouvent à la partie la plus élevée du coteau où la roche calcaire est plus rapprochée de la superficie sont à l'état serré; ils a vaient 1 mètre à $1^{\mathrm{m}}, 70$ de circonfërence, et les plus hauts $\mathrm{m}^{\prime}$ ont paru avoir environ $15^{\mathrm{m}}, 50$ de haut. Enfin ceux qui se trouvent dans la vallée dans le mauvais terrain, et qui sont isolés, avaient $1^{\mathrm{m}}, 30$ à $1^{\mathrm{m}}, 45$ de circonférence, et 1 mètre à $1^{\mathrm{m}}, 25$ à l'état serré. Les sapins picéas et les pins sylvestres, qui ont été plantés en même temps que les cèdres, étaient loin d'avoir atteint de telles dimensions en circonférence, et leur hauteur était moindre aussi dans les massifs.

Le jardin de M. Guy, dont j'ai parlé page 310, est situé sur un coteau exposé au sud-est; le sol y a peu de profondeur, le sous-sol est une pierre calcaire impénétrable aux racines; mais, dans quelques parties, on a rapporté des terres de démolition et des plâtras tirés de la ville de Saint-Germain, où l'on bâtit avec le plâtre comme à Paris. Ainsi ces terrains de remblais, sur lesquels ont été plantés les 22 cèdres, sont à peu près de même nature que celui du labyrinche où se trouve le cèdre du Jardin-des-Plantes; et l'on y remarque aussi que le cèdre y réussit assez bien, le pin laricio médiocrement, mais que le sapin argenté, le picéa, le pin sylvestre et le mélèze y viennent rabougris, et que le pin Weymouth n'y vient pas du tout. M. Guy, le père du propriétaire actuel, avait créé son jardin en 1775; les cèdres datent de cette époque ou de quelques années après, et ils doivent avoir au moins $\mathbf{7 0}$ ans. Plusieurs de ces cèdres isolés avaient, lorsque je les mesurai, le 12 août 1844, au delà de 2 mètres de circonférence; le plus gros avait $2^{\mathrm{m}}, 31$; j'évalue leur hauteur à 13 à 16 mètres. Les cèdres qui ont crù à l'état serré sont moins gros, mais plus élevés; ils m’ont paru avoir de 20 à 22 mètres de haut; le plus gros avait $2^{\mathrm{m}}, 06$ de circonférence.

Loudon, à la fin de l'article Cedrus Libani de son Arboretum, i. IV, p. 2426, donne les dimensions de plusieurs cèdres situés dans les parcs de la GrandeBretagne : je vais reproduire ce qu'il dit de ceux dont il donne l'âge par exception, et qui avaient acquis de belles dimensions relativement à leur âge (Voy. p. 38); ainsi on pourra calculer leur accroissement annuel.

A Luscombe, un cèdre planté il y a 30 ans, avait 47 pieds $\left(14^{\mathrm{m}}, 10\right)$ de haut, le tronc 2 pieds 6 pouces $\left(0^{\prime \prime \prime}, 75\right)$ de diamètre. - A Farnham, planté il y a 50 ans, 70 pieds (21 mètres) de haut, son tronc un diamètre de 4 pieds $\left(1^{\mathrm{m}}, 20\right)$. - A Ockham Park, planté il y a 34 ans, 45 pieds $\left(13^{\mathrm{m}}, 50\right)$ de haut, son tronc un diamètre de 2 pieds 6 pouces $\left(0^{\mathrm{m}}, 75\right)$. - A Bowood, planté il y a 50 ans, 60 pieds (18 mètres) de haut, son tronc un diamètre de 3 pieds 6 pouces $\left(1^{n}, 05\right)$. - A Donnington Park, planté il y a 80 ans, 62 pieds $\left(18^{\mathrm{m}}, 60\right)$ de haut, son tronc un diamètre de 8 pieds 6 pouces $\left(2^{\mathrm{m}}, 55\right)$. -- A Ditton Park, planté il y a 90 ans, 80 pieds (24 mètres) de haut, son tronc un diamètre de 5 pieds $\left(1^{\mathrm{m}}, 50\right)$. - A Castle Ashby, âgé de 80 ans, 72 pieds $\left(21^{\mathrm{m}}, 60\right)$ de haut, son tronc un diamètre de 5 pieds $\left(1^{\mathrm{m}}, 50\right) .-\Lambda$ Croome, planté il y a 80 ans, 100 pieds ( 30 mètres) de haut, son tronc un diamètre de 5 pieds $\left(1^{m}\right.$, õo). Le même autcur dit qu'à Whitton le pin maritime, le pin sylves- 
Ire, le sapin argenté el le mélèze, dans lè mẻme sol et dans la mêne situation que le cèdre, niavient pas i heaucoup près un volume de bois aussi considérahe. Je ferai en outre observer qu'il me parait probable qu'une partie des cèdres qui existent en France et en Angleterre, provenus de graines extraites trop tôt des cônes, n'auront point atteint les mêmes dimensions que s'ils fussent provenus de graines parfaitement mûres, et n’auront point été aussi robustes pour résister aux intempéries des saisons.

Pour savoir quelles sont les dimensions les plus fortes auxquelles ces arbres peuvent atteindre, il fiut les examiner dans les lieux oủ ils sont indigènes, et l'alord sur le mont Liban, où se trouvent les cèdres les plus âgés que l'on connaisse. M. L. Deslongchamps dit, dans la brochure précédemment citée, que Corneille Le Bruyn, voyageur hollandais, qui visita ces cèdres en 1682, en mesura un qui avait 57 paumes $\left(12^{\mathrm{m}}, 31\right)$ de circonférence; que Maundrell, vayageur angla is, qui les visita en 1697 , en mesura un auquel il trouva 36 pieds 6 prouces $\left(10^{\mathrm{m}}, 95\right)$ de circonférence; enfin il rapporte une lettre dans laquelle M. le locteur l'ariset, qui viı aussi ces cèdres le 2 août 1829 , dit qu'il n'en mesura aucun, mais qu'ils lui parurent aussi gros que les colonnes du palais de Carnac it Thèbes, qui ont 13 mètres de tour. Dans la forêt de cèdres que M. Bové trouva en se rendant de Tabarieh à Damas, ces arbres avaient, dit-il, de 1 à 5 mètres de circonférence, et leur hauteur dépassait 15 mètres. En Afrique, on a trouvé daus la forêt de cèdres située près de Blidah, des cèdres de 4 et 5 mètres de cirronférence à 1 mètre clu sol. Dans les forêts de l'Ouarenseris, on en a abattu dont le diamètre était tel qu’il a fallu réunir deux lames de scie de 2 mètres de long chacune pour parvenir à les lébiter. Dans la note citée page 315 , il est dil que " le plus grand cèdre qu'on ait vu sur le mont Ciga avait $29^{\mathrm{m}}, 50$ de haut depuis "le pied jusqu'à la naissance des branches formant la tête, et qu’il n’avait qu’un " seul tronc de $1^{\mathrm{m}}, \mathbf{7 0}$ de diamètre au bas et de $0^{\mathrm{m}}, 67$ de diamètre à la partie su"périeure." Les cèdres étant ordinairement plus remarquables par leur grosseur que par leur hauteur, cette hauteur de $29^{\mathrm{m}}, \check{50}$ sans branches, qui suppose au moins $\mathbf{1 0}$ mètres du sol à la cime, me paraît extraordinaire. Il est probable que lorsqu'on connaitra toutes les forêts de l'Algérie et qu'on les aura explorées, on trouvera des cèdres ayant des diamètres plus forts encore.

En France, nos trois plus gros cèdres sont probablement encore celui du château de Montigny, celui de Vrigny et celui du Jardin-des-Plantes, arbres dont j’ai donné plus haut les dimensions.

Lumlon dome dans son Arboretum, 1. IV, p. 2126, les dimensions d'un grand nombre de cèlres qui se trouvent dans les pares et dans les jardins de la GrandeBretagne; je vais reproduire ce qu'il dit de ceux qui avaient les plus fortes dimeusions; il ne donne l'âge que de quelques-uns de ces arbres. Des deux cèdres qui restent encore des quatre que l'on avait plantés dans le jardin botanique de Chelsea, le plus gros a environ 60 pieds (18 mètres) de haut et 5 pieds $\left(1^{\prime \prime}, 50\right)$ de diamètre ì 4 pieds 6 ponces $\left(1^{1 n}, 35\right)$ du sol; les dimensions du seconl il)prochent bancoup de celles-la. On remaregue a Wilton House plusieurs beam 
cèdres plantés depuis 170 ans, et l'un l'eux a 8 pieds 8 pouces $\left(2^{m}, 60\right)$ de diamètre à 1 pied $\left(0^{\mathrm{m}}, 30\right)$ du sol. - Le cèdre de Domnington, qui n’est planté que depuis $80 \mathrm{ans}$, el que j’ai.cité plus haut à cause de la rapidité de sa croissance, avait, à 2 pouces près, le même diamètre. - A Chiswick, il y a un cèdre de 70 pieds (21 mètres) de haut, avec un tronc de 4 pieds 6 pouces $\left(1^{\mathrm{m}}, 35\right.$ ) de diamètre. - Le plus haut cèdre de l'Angleterre paraît être à Strathfieldsaye; il a 108 pieds $\left(32^{\mathrm{m}}, 40\right)$ de haut, avec un tronc de 3 pieds $\left(0^{\mathrm{m}}, 90\right)$ de liamètre. - Le plus haut dans les environs de Londres est ì Claremont; il a 100 pieds ( 30 mètres) de haut, avec un trone de 5 piecls 6 pouces $\left(1^{\mathrm{m}}, 65\right)$ de diamètre. - Le plus beau cèdre de l'Angleterre est probablement, dit Loudon, à Syon; il a 72 pieds $\left(21^{\mathrm{m}}, 60\right)$ de. haut, le diamètre de son tronc à 3 pieds $\left(0^{\mathrm{m}}, 90\right)$ du sol, est de 8 pierls $\left(2^{\mathrm{w1}}, 40\right)$, et celui de l'envergure de son branchage de 117 pieds $\left(35^{\mathrm{m}}, 10\right)$.

Vi. Chimat, exposition, terrain. -- On a cru longtemps qu'on ne trouvait le cèdre du Liban croissant spontanément que sur le mont Liban, proprement dit, à environ 29 kilomètres de Tripoli; ainsi Miller disait, dans la $8^{\mathrm{e}}$ et dernière édition de son Dictionnaire des jardiniers (1768), t. IV, p. 318: "Le cèdre du Liban, cé"lèbre dans la plưs haute antiquité, et qui, ce qui est bien remarquible, ne se " trouve en aucun lieu du monde que sur ces montagnes. "Cependant Pierre Belon, qui voyagea darrs le Lévant vers le milieu du seizième siecle, el qui visita d'abord ces cèlres, en vit ensuite des forêts sur le mont Amanus el sur' le mont Taurus (1). M. Bové, ex-directeur des cultures d'lbralrim-Pacha, àu Caire, penlant un voyage botanique en Syrie, et se rendant de Tabarieh à Damas(2), trouva le $\mathbf{1 1}$ octobre 1832, entre Sakhlélué et le Del-el-Kamar, une forèt de cèdres du Liban couverts alors de fleurs; elle occupait le sommet d'une montagne qui borde la droite de la route. Enfin, depuis l'occupation de l'Algérie par les Français, l'on a trouvé cet arbre dans chacune des trois provinces d'Alger, d'Oran et de Constantine. Il én existe des foréts de plusieurs lieues carrées de superlicie dans les montagnes de l'Ouarenseris, situées dans la province d'Oran, et une magnifique forêt non loin d'Alger, près de Blidah; elle occupe environ 5,000 heetares, et est composée dé cèdres du Liban et de cèdres argentés, espè̀ce on variété dont je dirai quelques mots à la fin de ce chapitre.

Les auteurs, tels que Baudrillart, qui ont dit que le cèdre du Liban se trouvait en Sibérie, sur les monts Altaï, se sont trompés; Pallas n'en parle point daus sa Flora rossica; ils auront été induits en erreur par le nom vulgaire du pin cembro, arbre commun sur les monts Alıai, qui est hedr en russe : le cèdre ne pourrait d'ailleurs supporter les froids de la Sibérie.

Le cèdre du Liban n'a encore été trouvé croissant spontanément que dans des

(1) Les obsertations de plusieurs singularités et choses mémorables troucées en Grice. Asic, Judéc et autres pays étranges. Pierre Belon dit, p. 360 de cet ouvrage : Nous trouvasmes de haults cèdres "(sur le mont Amanus) comme sur le mont Liban; " et, p. 368 : "Nous y trou vasmes de haults cì"Ures (sur le mont Taurus) de mẻme ceulx du mont Liban. "

(2) Ahnales des sciences naturelles, 2e séric, année 1834, 1. Jer, p. 235. 
climats chauds, et il s'y trouvait seulement dans les parties élevécs des montagnes. Ceux du mont liban sont à une hanteur où la neige sćjourne très-longtemps et où il n'existe point d'habitations. La grande forêt de cèdres situéc dans l'Atlas, près de Blidah, est élevée de plus de 1, 100 mètres au dessus du niveau de: la mer. En Europe on a cultivé cet arbre avee succès jusqu'un Écosse, oú Loudon en cite, t. IV, 1). 2127 de son Arboretum, qui avaient depuis 3 jusqu'à 5 piets $\left(0^{\mathrm{m}}, 90\right.$ i $\left.\mathrm{A}^{\mathrm{m}}, 50\right)$ de diamètre. On a réussi à le cultiver en Saxe, puisque, scilon Loudon, il s'en trouve un à Worlitz qui est planté depuis 16 ans, et qui a 25 pieds $\left(7^{\text {"'}}, 50\right)$ de haut; j'ignore si l'on pourrait le cultiver plus au nord avec suecès.

Cet arbre paraît être sensible aux froids rigoureux, et aux alternatives de gelées et dedégels si communes dans les climats tempérés, par exemple en France. Varennes de Fenille, dans l'article Larix orientalis de son Mémoire sur l'udministration forestière, t. 11, p. 447, dit que l'hiver de 1789, qui fut si rigoureux, fit périr la plupart des jeunes cèdres, qu'ils fussent ou non couverts par la neige; que beaucoup de grands cèdres résistèrent, mais qu'ils perdirent leurs feuilles et qu'il en repoussa d'autres. Tous mes cèdres, dont le plus âgé avait été planté en 1804, pertirent ainsi leurs feuilles au printemps de 1810, à la suite d'un mois de février très-doux qui avait mis la végétation en mouvement, et qui fut suivi d'un mois de matrs trìs-rigoureux; elles deviurent brunes at tombèrent : mais un beacoup plus grand nombre de cèdres conservèrent leurs feuilles, aussi bien dans mon voisinage que dans les autres parties centrales de la France; ainsi, par exemple, i deux lieues de che\% moi, le cèdre de Courteilles, dont j'ai déjà parlé, ne souffrit point du tout de cette alternative de température chaude et froide.

Le cèdre du Liban n'est encore cultivé en France que comme arbre d'ornement; il y est commun dans les pares et dans les jardins. Celui qu'on remarque au Jardin-des-Plantes de Paris passe pour être le plus àgé que nous ayons; il fut planté en 1735 par Bernard de Jussieu, qui en avait apporté deux très-petits d'Angleterre; on ne sait oì il planta le second.

Selon Loudon, t. IV, p. 2112 de son Arboretum, la date de l'introduction du cèdre en Angleterre est incertaine. Aiton, dans son ILortus kewensis, dit qu'il y a été introduit en 1683; mais comme ce fut cette année que l'on planta les cèdres de Chelsea, qui avaient déjà 3 pieds $\left(0^{\mathrm{m}}, 90\right)$ de haut, cette introduction est certainement antérieure de quelques années à 1683. Le cèdre est beaucoup plus cultivé en Angleterre qu'en France, néanmoins entièrement aussi comme arbre d'ornement.

Je ne puis indiquer quelle est l'exposition qui convient le mieux au cèdre du Liban; il me paraît réussir à toutes les expositions dans les parties centrales de la France, mais il pourrait en être autrement dans les haules montagnes telles que les Alpes. Les plus beaux cèdres que nous ayons en France sont dans des pays de plaines; il en esı de même en Angleterre.

L.e cèdre du Liban n'est pas difficile sur la qualité du terrain et il paraît pouvoir ètre cultivé dans presque tous les sols; il y en avait, dans l'ancien jardin de Tivoli, à Paris, une douzaine qui avaient une assez. belle végétation, quoique le 
tuf calcaire te se trouvât, en quelques endroits, qu'à $0^{\text {m }}, 32$ de profondeur; il en reste encore six, que l'on va abattre pour bâtir sur leur emplacement. Le cèdre du Jardin-dles-Plantes et les cèdres du jardin de M. Guy se trouvent tlans un terrain tle terres rapportées qui eontient beaucoup de plâtre; il y en a au bois de Boulogne, près de Paris, qui ont une végétation passable dans un terrain fort maigre. Néanmoins, cet arbre ne peut réussir dans des terrains siliceux aussi ınaigres que ceux où l'on peut encore cultiver avec succès le pin sylvestre, le pin laricio et surtout le pin maritime. $\mathbf{~}$. de Larminat avait fait planter 250 cèdres, en 1825, dans la forêt de Fontaineblcau, au lieu dit la Gorge-du-IIoux, dans un terrain fort maigre composé d'un sable blane, recouvert d'une couche de terre de bruyère; cependant des pins sylvestres et des pins maritimes qui y avaient été plantés en même temps que les cèdres y rúussissent. En 1844, il ne restait plus que 13 des 250 cèdres qui avaient été plantés dans la Gorge-du-Houx; 5 de ees arbres n'avaient eu aucun accroissement en hauteur ct étaient restés rabougris; le plus haut des huit autres avait 4 mètres de haut et $0^{\mathrm{m}}, 35$ de circonférence; les pins sylvestres du même temps avaient, dans le même lieu, 11 mètres de haut et 1 mètre de circonférence, les pins maritimes 10 mètres $\mathrm{el} 0^{\mathrm{m}}, 75$. Et c'est bien à l'aridité du terrain qu'il faut attribuer la mauvaise réussite de cette plantation de cèdres, puisque II. de Boisdhyver en ayant fait transplanterquelques-uns dans un terrain de bonne qualité, ils ont repris une belle végétation (1). Le sol qui paraît convenir le mieux au cèdre du Liban est un sable substantiel et profond : e'est dans un sol de cette nature que se trouve le beau cèlre de Vrigny; et dans les environs de Londres, e'est aussi, dit Loudon, dans un sable profond et substantiel, par exemple à Sỵon et à Whitton, qu'il a atteint les plus fortes dimensions.

VII. Culture. - On pense généralement, en France, qu'on ne peut élever le cèdre du Liban avec succès que dans des pots, des terrines ou des caisses que l'on rentre l'hiver. Delamarre dit, page 139 de son Traité pratique, que "les essais " répétés qu'il a finits, en semant rustiquement des graines de cèlre, ne lui ont pas " réussi ; qu'il n'en a obtenu des sujets qu'en semant les graines en pots ou en terri" nes. " Je présume qu'on esı dans l'erreur, puisqu'il lève du plant de semis naturel qui brave la rigueur des hivers et réussirait bien si on le protégeait, afin qu'il ne fùt pas détruit par des accidens. J'ai élevé des cèdres du Liban en pleine terre, ainsi qu'on le verra chap. XI, art. $\mathbf{I X}$; mais j'en ai perdu beaucoup, ce qui tenait peut-être à ce que la graine, que j'avais extraite avec peine des cônes, n'était pas parfaitement mûre. Je recommence cette expérience, ainsi que je le dirai dans le chapitre que je viens de citer.

Je ne sache pas que l'on ait essayé de semer en grand le cèdre du Liban en pleine terre, je présume pourtant qu'on réussirait si l'on employait de la graine parfaitement mûre. Le principal obstacle est la dilficulté que l'on éprouverait ì se procurer dé la graine en suffisante quantité. En effet, celle que l'on extrait 
aree lant de proine dis comes, est ordinairement molle el ne conserverat probablement sa faculté geminative que peu de temps; si l'on veut cueillir les cônes, peu avant le moment où ils laisseront tomber leurs écailles et leurs graines, pour être certin que les graines soient parfaitement mùres, il est dilficile de s'en procurer beaucoup, puisque cette époque est variable; et si d'ailleurs les graines ont éprouvé un commencement de germination, il faut les senter de suite.

L'élagage des arbres résineux qui est nuisible en principe, mais qui est sonvent arantageox quand il est exécuté avec la réserve convenable, parait être ancore plus nuisible an cèdre quaux antres espèces d'arlores résineux dont je me suis déji occupe; du moins Miller et Loudon, fui cite Miller et Boutcher, apportent des faits a l'appui de celte opinion. J'ai éprouvé moi-mème que le lroulage par les lapius, des branches latérales des jeunes cèdres nouvellement plantés, les faisait ordinairement périr, tandis que les pins, les sapins et les mólizes en sont seulcment retardés dans leur accroissement; il ne faut donc élaguer les cèdres qu'avec la plus grande réserve, en commençant vette opération pour les arbres isolés, dès l'âge de $\mathbf{1 2}$ ans, par les branches les plus rapprochées du sol et à raison d'une ou deux branches seulement par an. Lorsque ces arbres croissent ì l'état serré, ils s'élaguent d'eux-mêmes, et l'on peut alors couper les branches du bas de l'arbre qui, étant étiolées, sont destinées ì périr un peu plus lard.

VIII. Qualutes et usages du bơls. - On a cru longtemps, sur la foi des timoignages anciens, que le bois du cèdre était incorruptible et qu'il était l'un des meilleurs qui existassênt pour la marinc, les constructions et la menuiserie. "Le: "bois de cet arbre fameux, dit Miller, est regardé comme incorruptible. "On saiı actuellement quece bois est léger, puisque Varennes de Fenille a trouvéque le pied cube, parfaitement sec, ne pesait que 29 livies (14 kil. $195 \mathrm{gr}$.); je vois pourtant dans Baudrillart (1) que Muschenbrok indique pour le poids du pied cube de bois 42 livres $14011 \mathrm{crs}(20 \mathrm{kil} .979 \mathrm{gr}$.), et Ilassenfratz, 57 livres( $27 \mathrm{kil} .881 \mathrm{gr}$.), dirférences qui résultent probablement de ce que le bois n’avait pas atteint le mème degré de dessiccation. II. Renou dit que te bois de cèdre a de la ressemblinee: arec le bois de l'épicéđ, mais que sa munce est plus foncéc. Dans la note que j’ai citée page 8 , on dit "que le hois de cèdre a la plus grande analogic avec le bois "de sapin, que cependant ce dernier est moins cassant et meilleur pour les cons"tructions. " M. I. Deslongchamps dít, dans la brochure précédemment citéc, qu'il a beaucoup de ressemblance avec le bois de pin, et plus encore avec celui de sapin; que la section du tronc d'un cèdre a plus de ressemblance avec celle du trone d’un sapin argenté qu'avec celle d'aucun autre arbre résineux. "Le " bois de cèdre, dit cet auteur, brùle vite, en pétillant beaucoup, et le feu qu'il " fait dégage bien moins de chaleur que celui du chêne, du clrame ou du hètre; " son charbon esi très-léger el ue produil que pru do chaleur, parce qu'il se

(1) Diefionnaire des saux ef foréfs, 1. ter, p. 53i, arl. Cèdre. 
"convre promptement decendres, comme celui des buis de peuplier ct de saule." Loudon, qui était en position de recueillir des renseignt'mens à ce sujet, puisque le cèdre a été cultivó plus tôt el en beaucoup plus grande quantité en Angleterre qu'en France, lit, t. IV, p. 2417 de son Arboretum, "que le bois de cèdr" " est l'un blanc rougeâtre; qu'il est léger, spongieux, facile à travailler, mais " disposé à se déjeter; qu’il n'est point durable; qu'il ne tient pas bien les clous " et qu'il ne peut être employé qu'en bois de fort échantillon. " Le même auteur dit aussi qu’il a comparé une planche de cèdre avec des planches du pin sylvestre d'Angleterre, et qu'il a trouvé la première inférieure en force aux autres. de ne sais si cet arbre est propre à la marine, ni quel rang il doit occuper comme bois de construction.

IX. Accidens, maladies, axinaux nusibles. - Relativement anx maladies ot aux accidens auxquels est exposé le cèdre du Liban, je ne puis que reproduir. re que dit Loudon 1. IV, p. 2125 de son Arboretum: "Les branches fortes etéten" dues du cèlre peuvent être brisées par le poids dont les accablent quelquefois "d'aboudantes neiges; mais cet arbre est moins sujet à être renversé par les venı̣ı "que les pins, les sapins el les mélèzes, qui n'ont pas, comme lui, de larges et "fortes hranches près du sol. Il n'est pas sujet aux maladies, et il est moins ex" posé à être attaqué par les insectes, d'après ce que nous avons vu et observé, "qu'aucune autre espèce de la tribu des pins et des sapins."

d. Ceine du Liban, variéte argentée. - Deux personnes seulement, je crois, ont parlé du cèdre argenté jusqu'ì ce moment : MI. Renou, dans une Notice sur les forêts de cìdres de l'Algérie, dont j’ai cité quelques passages pagr 312, el V. Durieu de Maison-Neuve, membre de la commission scientifique de l'Algéric. Les observalions de M. Durieu on élé transmises à l'A caadémie des Sciences par M. Bory de Saint-Vincent, dans un mémoire intitulé : Sur les cèdres de l'Atlus et l'emploi de leur bois dans les constructions mauresques d'Alger; el ce mémoire a été inséré dans le Compte-rendu des séances de l'Académie des Sciences, 1. XVIII, n²'1 (10 juin 1841). Loudon parle ì la vérité, dans l'aricle Cedrus Libani, I. IV, p. 2102 de son Arboretum, d'une variété foliis argenteis; mais il dit que les feuilles sont d'une couleur argentée des deux côtés, tandis que celles du cèdre argenté de l'Algéric n'ont cette couleur que d'un seul côté; il ajoute qu'il y en a de beaux sujets à Whitton et à Pains Itill, el qu'il est étonnant que les pépiniéristes n'aient jamais pris la peine de multiplier cette belle variété par le semis ou par la greffe. Ir. Renou pense que le cèdre du Liban et le cèdre argenté forment deux variétés bien caractérisées; M. Durieu dit que la coloration des feuilles en blanc n'est qu'un accident; je rapporterai leurs opinions, et je les ferai suivre de quelques observations.

M. Renou est le premier qui ait parlé du cèdre argenté; il dit, dans la notice que j’ai cilée plus haut, que ces arbres occupent les $7 / 10$ de la forêt de cèdres d'environ 1,680 hectares qui se trouvent dans les environs de Blidah, "t qu'ils y 


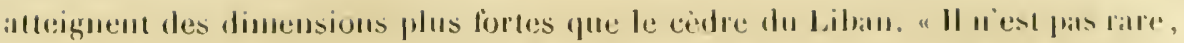
"dit-il, d'en rencontrer qui ont 5 , 6 e et 7 mètres de circunférence à un mètre da "sol, et qui, foin de laisser apercevoir te moindre signe de caducite, semblent " au contraire patreourir les phases de leur phus grand accroissement. " Il. Renou a donné avee sa notice des dessins des lleurs et des cones des denx variétís de cèdres; on voit que leurs heurs et leurs cônes sont parlaitement semblables; anssi n'a-t-il fait de ces organes qu'une seule description, que jai reproduite page 312. Il latit ressortir, ainsi qu’il suit, les dliférences qui existent entre ces deux variélés.

"Les cèdres qui forment le peuplement de celte lorèt présentent deux varié"lés bien caractérisées.

"La première variété semble se rapporter exactement à l'espèce acelimaltée en "France depuis un siècle sous le nom de cedre du Liban, " el M. Renou en liait une description qui me parait justifier cette opinion, mais que je ne reproduirai pas.

"Lat seconde variété diffêre sensiblement de la première : lı:s folioles suml "plus grosses, sans cependant çre plus longues; elles se redressent en se: con"toumant, comme si elles tendaient à converger vers un sommm commun, " " qui donne aux petits faisceaux une forme arrondie. Le caractère le plus trat1"ché de cet arbre, c'est que le dessus des folioles est d'un blanc mall qui prorluit "sur la nuance verte du feuillage un rellet argenté. Les cônes cux-mènes, avant "leur entière maturité, laissent entrevoir à la partie extrême de leurs écalles " cette teinte blanchâtre, qui toutefois est moins apparente que celle des fơlio"les. Le rameau qui supporte les faisceaux de feuilles présente également un re"trécissement assez prononcé à sa partie inféricure; mais il est plus grus que "dans la première variété, et les petites couronnes qui subsistent en saillin "après la chute des folioles sont plus prononcées.

"Les branches s'étendent également en palmes horizontales; mais elles s'in" clinent beaucoup plus vers le sol que celles des cèdres de la première variété. " Cette particularité semble du reste devoir être attribuće à la diflérence de poids " cles folioles, qui, dans le cèdre argenté, sont plus grosses et plus fournies. Les "palmes inféricures tallent beaucoup moins que celles du cèdre vert, et il y at " moins de disproportion entre la longueur des branches à mesure qu'elles par" tent de points plus rapprochés de la cime.

"Son écorce est d'un gris cendré; elle est épaisse, ruguense, et forme des "écailles qui se détachent par parcelles lorsque le sujet a atteint un certain de"grré de vétusté.

"Le bois du cèlre argenté est d'un blane nuancé de jaune; sa contexture est "assez serrée é présente de l’homogénéité; mais il est muins lourd que celui du " eèdre vert.

"Les differences qui existent dans le port, le degré d'élancement el la couleur " du feuillage de ces deux arbres, sont du reste assez apparentes pour permedtre "i un weil un pen eserce de les distinguer l'un de l'autre a de grandes dis-

"tances. 


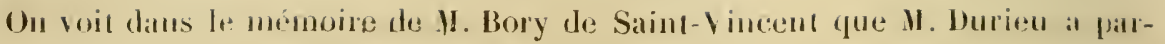
couru la même forêt de cèdres que M. Renou avait parcourue arant lui; que les pâtres allument quelquefois dans ces forêts des incendies qui se propagent souvent au loin; que les montagnards coupent sans choix tout arbre qui se. trouve ì leur proximité et détruisent souvent, pour en obtenir la plus médiocre pièce de charpente, des colosses de végétition respectés par mille tempêtes; que le bois de eèdre était déjà employé à Alger du temps des Tures, sans qu'on se doutât que c'était du bois de cèdre, mais il ne parle pas des qualités de ce bois; qu'il existe dans la forêt de Blidah d'énormes cèdres qui doivent être d'un âge prodigieux; que les cèdres se reproduisent d'eux-mêmes avec la plus grancle facilité, et que M. Durieu vit de toutes parts autour de lui leur germinalion naissante s'élaler sur le sol en pompeuses roseltes du verı le plus suave.

de vais reproduire textuellement ce qui est dit dans ee mémoire pour prouver que le cèdre argenté et le cèdre du Liban ne sout qu'un seul et même cèdre :

" Il est maintenant évident pour M. Durieu qu'il n'existe point deux espèces de " cèdres, comme on l'avilit présumé d'après des renseignemens entièrement " inexacts. On inaginait un cèdre de feuillage obseur comme celui qui fait épu" que vers le sommet du Jardin-du-hoi, et un autre cèdre de fenillage argenté. "On s'était même hậté de publier la figure de l'un et de l'autre. Il sera mainte" nant difficile de considérer, même comme de simples variétés, ces deux pré"tendues espèces. La coloration des cèdres tient à diverses circonstances, el "principalement à l'âge de chacun. En effet, dit notre savant voyageur, j'ai ob" servé une grande quantité d'arbres qui, sur le même trone et sur les mêmes " branches, présentaient les deux teintes fort tranchées avee des nuances inter" médiaires. Quelques pieds cependạt, mais c'étaient les plus grands, consé"quemment les plus vieux, n'oflraient que la couleur argentée d'une manière " lranchante, ce qui leur donnait un aspect tout particulier. Lá caducité se ma"nifesterait donc aussi dans le cèdre par la blancheur. "

Si les observations qui ont été faites par M. Renou sont exactes, il me parait évident qu'il y a deux variétés de cèdres daus la forêt de Blidah, le cèdre du Liban 't le cèdre argenté; et en admettant aussi l'entière exactitude des observations de I. Durieu, elles ne prouvent pas, selon moi, que M. Renou se soit trompé. En rffet, il serait possible que les feuilles du cèdre argenté ne prissent la teinte argentée 'qu'ì un certain âge el que successivement; il n'est d'ailleurs pas possible d'admettre que les feuilles du cèdre du Liban se colorent en blanc quand il vieillit. On n'a ricu remarqué de semblable sur le mont Liban, où se trouvent des cèdres trìsîgés, ni en Angleterre, où il y en a qui sont déjà en état de décrépilude, ni en France, où nous en avons qui approchent de leur maturité, s'ils ne l'ont atteinte. (Yuoi qu'il en soit, on sera bientòt fixé relativement aux cèdres de la forêt de Blidah, en observant ces arbres avec encore plus d'attention, mais surtout en. scmant de la graine de cèdre argenté, pour voir si les cèdres qui en proviendront seront argentés. 


\section{CHAPITRE Y.}

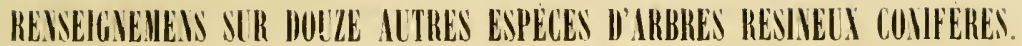

1. Observations phéliminames. -- Je ne me suis point proposé de parler dillo ce chapitre de tous les arbres résineux conilères, à grandes dimensions, cultivables dans les climats tempérés, et en particulier sous le climat de Paris, autres que ceux auxquels je vicus de consacrer un chapitre ì part. Les belles ehosen qu'on dit sur de nouvelles espèces se réalisent quelquefois si peu, que je me suis imposé la loi de ne parler que de celles desquelles je puis dire avec certitude qu'elles sout de pleine terre sous le climat de Paris, non-seulement pour les avoir vu cultiver, mais parce que je les cultive moi-mème. Si l'on excepte le pin d'Autriche et le pin cembro, arbres sur lesquels j’ai pu me procurer des renseignemens plus étendus, je n’ai parté que très-brièvement des autres arbres dont je moccupe dans ee chapitre; et cela devait être, puisque je me proposais unipuement de les faire connaitre comme arbres de pleine terre dans les elinats tempérés, comme arbres à grandes dimensions dans les climats ou ils sont indigènes, et d’engager ì en essayer la culture.

11. P'in d'Autricie, Pimus anstriacu Hoess (1). - On appelle anssi ce pin Pin Nom d’Aurkicne. Les Autrichiens l'appellent Schneraforhe (l'in noir); Arnold, lans son Reise nach Mariazell in Steyermark (Voyage à Mariazell en Styrie), lui donne le nom de P'imus nigra; Host, dans sa Flora anstriacu, 1. II, 1) (628, lui domne le nom de l'inus nigricans, et l'avait d'abord appelé P'ines nigrescens dans le catalogue du jartin botanique de Vienne pour 1822. J'ai préféré le nom de P'iuns austriaca que Iloess lui a donné, parce qu’il rappelle le lieu de l'Europe oì cet itrbre est le plus commun.

On trouve le pin d'Autriche croissant spontanément dans les montagnes de l'Autriche, de la Styrie, de la Carinthie, de la Croatie et du Banat, oì l'on en remarque de très-beaux massifs sur le Damoglet, an dessus des bains d'Hercule; mais on ne le trouve ni dans les Alpes suisses, ni dans les Carpathes. Tenore, qui

(1) Monogrophie der sihwarzfohe , 1. 1. 
l'avait olsservé en Autriche, l'a trouvé aussi sur plusieurs points des montagnes lu royaume de Naples (1). Le pin que les jardiniers de Paris appellent Pinus taurica ut que Lambert appelle I'inus pallasiana (2), deux noms différens donnés au même arbre qui croît dans les montagnes de la Crimée; ce pin me paraît ĉtre le même que le pin d'Autriche, si j'en juge par les descriptions et par les dessins qui se trouvent dans les ouvrages de Lambert et de Ilocss. On remarque pourtant de la différence entre les rameaux portant cônes dont ils ont donné les dessins, et cela devait être, parce que le rameau dessiné par Lambert a été pris sur une branche plus âgée que celle sur laquelle a été pris le rameau dessiné par Iloess; dans tous les pins, le bout des branches des jeunes pins, ou des jeunes branches des pins qui sont dans toute la force de leur végétation, est très-différent du bout des vieilles branches.

J'ai semé en 1837, c'est-à-dire il y a neuf ans, de la graine de pin d'Autriche et de la graine de pin taurique, provenant de la maison Vilmorin-Andrieux, qui les avait tirces directement de l'Autriche et de la Crimée, et j'ai obtenu le même arbre; du moins, jusqu'à co moment, je n'aperçois aucune différence (Voy. chap. Xl, art. X). M. A. Michaux, qui avait semé les mêmes graines, il y a quatre ans, au Vieil-IIarcourt (Eure), propriété que Delamarre a léguée à la Société royale et centrale d'agricnlture, a fait la même remarque; et, en outre, i] trouve les pins qu'il a obtenus semblables à des pins plus anciens qui avaient été semés par Delamarre, sous le nom de pin de Crimée. M. Vilmorin, qui a fait les mèmes semis, a trouvé une légère différence entre les feuilles et les boutons des plants obtenus de ces deux graines : dans quelques années on pourra être fixé à ce sujet.

Le pin que les jardiniers de Paris appellent Pinns caramanica et que nous ne connaissons guère que par quelques sujets provenant des graines apportées de la Caramanie par Olivier (3), en l'an IX (1801), paraît être aussi le même que le pin d'Autriche; il y avait les pins, provenant de ces graines, dans le jardin de Ia Malmaison et dans plusieurs autres jardins des environs de Paris. J'ai vu dans le parc de Fromont, à Ris (Seine-et-Oise), l'un de ces arbres que l'on s'útait procuré dans le jardin de M. Cels; il m'a paru être un pin d'Autriche, autant que l'on peut en juger en comparant la nature avec des descriptions et des dessins. Les jardiniers de Paris ont vendu aussi, pendant quelque temps, un Pin de. Romanie qui n'était autre que le Pinns taurica un Pinus pallasiana, sous un nouveau nom; il est d'ailleurs probable que cet arbre se trouve dans les monts Balkan, situés en Romanie.

(1) Flora napolicana, L. V, p. 266.

(2) A description of the genus Pinus, 1. 1er, 1. 11.

3) Voyage dans l'empire olloman, t. I1, p. s. "Le second pin, dit Olivier, que nous avons trouvé " abondant aux environs de l'Olympe et dans toute l'Asie-Mineure, porte une lige droite et acquicrt n une hauteur et unc grosseur considérables. Ses graines, que j’ai apportées à Paris, ont bien levé au " jardin du citoyen Cels, cultivateur et membre de l'Institut national. " Les pins provenus de ce semis sont reux que les jardinier's de Paris ont appelé P'in de Caramanie, Pinus caramanica, du pays d'où on les avait tires. 
Scton Loudon (1), le pin d'Autriche n'a été introduit en Angleterre quien 18:35, par MI. Lawson; il avait été introduit en France l'année précédente, par la matison Vilmorin-Aulrieux; daus le même temps à peu près elle recevail du directeur du jardin botanique de Nikita, sous le nom de Pinus taurica d'abord, puis sous celuide Pinus pallesiana, des graines de ee pin qui croit sur les montagnes de la Crimé, et que Lambert a décrit (2) sous le nom de P'inns pallasiana. Ainsi, le pin d'Autriche, le pin taurique, le pin de Pallas, le même arlute, selon moi, sous trois noms différens, n'est cultivé que depuis un petit nombre d'années en France et en Angleterre, où l'on cultive depuis beaucoup plus longtemps des pins et des sapins d'Amérique, tous pour l'ornement.

J'emprunterai principalement ce que je vais dire du pin d'Autriche à la Monographie de Iloss, que jai précédemment citée, à son Gemeinfasstiche Anleituny die Bawme und Strunche Oesterreichs ans den Blottern zu crkemen (Guide fitcile servant à reconnaître les arbres et arbrisseaux de l'Autriche par leurs feuilles), et à ma propre expérience, pendant une culture de neuf années en pépinière et en pleine terre.

Li monographie du pin d'Autriche de IIoess est accompagnée de deux planches coloriées sur lesquelles sont représenties, de grandeur naturelle, un rameau qui porte deux cônes, des fleurs mâles, des fleurs femelles, des graines, des plants qui vienuent de lever, et divers délails sur une plus grande échelle; on voil que le rameau a été pris sur un jeune pin, ou sur une jeune branche d'un pin qui était encore dans sa périocle d'accroissement. Hoss cite des botanistes qui ont conlondu le pin d'Autriche avec le pin sylvestre, d'autres avec le pin maritime, d'autres enfin avec le pin laricio, et il fait ressortir les différences qui existent entre ces quitre différentes espèces de pins. Le pin d'Autriche dillëre tellement du pin maritime et du pin sylvestre, qu'on n'a pu les confondre que parce qu'on ne s'était pas tlonné la peine de les comparer; il a, au contraire, avec le pin larieio de nombreux rapports que je lerai remarquer pendant la description sommaire que je vais en faire.

Ce que j’ai dit des boutons du pin laricio s'applique à ceux du pin d'Autriche; ces derniers sont anssi gris-blancs, mais ils sont un peu plus gros que les premiers. Le pin d'Autriche n'a qu'une seule sève qui m’a paru commencer el s'arrèter en même temps que celle du pin laricio; mais les pousses du premier sont III peu plus grosses que celles du second.

Les fenilles du pin d'Autriche sont au nombre de denx dans une gatine; et selon le lieu où se trouve l'arbre, selon l'exposition, le terrain, l'âge, la partie de l'arbre où on les prend, elles ont de 3 à ò pouces autrichiens $\left(0^{\mathrm{m},}, 08 \mathrm{~s}\right.$ ì $\left(0^{m}, 13\right)(3)$; ainsi elles ont à peu près la même longueur que celles dı pin lariciu,

(1) Arboretum et Fruticetum britannicum, t. IN, p. 2206, art. Pinus austriaca.

(2) A description of the genus Pinus, 1. Ier, p. 11.

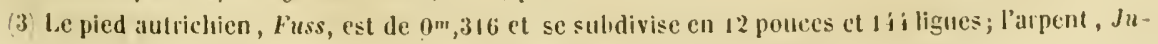
chart, est de 57 ares 55 centiares; la livre, Pfind, est de 530 gramues. 
mais elles sont d'un vert plus loncé, et sont railes et droites dès li jeunesse de l'arbre, au lieu d'être contournées comme celles du piu laricio.

l.es fleurs mâles et les fleurs lemelles sont semblables à celles du pin laricio pour la forme, mais je ne puis dire si elles leur sont semblables pour les dimensions et la couleur, ne les ayant point examinées simultanément sur les deux arbres; les dessins coloriés les mieux exéculés sont insuffisans pour que l'on puisse se permettre de prononcer un tel jugement, parce que les lieurs des pins chingent promptement de couleur, de dimensions et même de forme. Houss dit que le pin d'Autriche heurit plus tard que le pin sylvestre; il en est de même du pin laricio.

Les cônes du pin d'Autriche ont la même couleur que cèux du pin laricio et leurs écailles sont aussi munies d'épines, mais ils sont un peu plus longs, un peu plus minces et un peu plus recourbés vers le bout. Les cônes du pin de Caramanie du parc de Fromont, cet arbre que je crois être le même que le pin d'Autriche, m'ont paru semblables à ceux du dessin de Hoess, et leurs écailles sont munies de très-petites épines comme celles du pin laricio. Les cônes du pin d'Autriche s'ouvrent au bout de 22 à 23 mois après la floraison, comme ceux du pin laricio, pour laisser échapper leurs graines; ce pin porte des cônes tous les ans, et il a tous les cinq ans environ une année d'abondance.

Les graines du pin d'Autriche sont d'un brun clair, dit Hoess, et celles qui sont d'un blanc jaunatre sont stériles; elles conservent pendant plusieurs années leur faculté germinalive. Ces graines ont beaucoup de ressemblance avec celles du pin laricio; néanmoins, ayant fait deux tas de ces graines et les ayant placés à côté l'un de.l'autre, j’ai trouvé que le tas de graines de pin laricio avait une couleur légèrement roussâtre, tandis que celui de graines de pin d'Autriche chait légèrement noirâtre.

L'écorce du trone est noirâtre, plus épaisse que celle des sapins, du mélèze, du pin laricio et du pin sylvestre; elle est recouverte de grandes écailles dans la partie du tronc déponillée de branches qui est près du sol.

Les branches, disposées par étages, sont d’abord érigées dims leur jeunesse, puis elles deviennent horizontales, et enfin elles tombent au dessous du plan lıorizontal qui passerait par leurs points de jonction avec la tige.

Les racines de cet arbre ont la propriété de s’étendre au loin sur les roches calcirires, quelquefois à fleur de terre, et même entièrement à découvert, lorsqu'elles ne peuvent pas s'enfoncer; si elles trouvent une fente, elles y pénètrent avee tant de force qu'elles causent quelquefois des ébonlemens.

Le pin d'Autriche, dans une situation qui lui convienne parfatement, pent acquérir une hauteur de 100 pieds d'Autriche $\left(31^{\mathrm{m}}, 60\right)$, avec un diamètre de 3 à 4 pieds $\left(0^{\text {mt }}, 95\right.$ ì $\left.1^{\text {"n }}, 26\right)$.

Afin de compléter ce que je puis dire pour motiver l'opinion que j’ai émise, que le pin d'Autriche et le pin laricio sont deux espèces différentes, j'ajouterati aux renseignemens qui précèdent les observations suivantus, et j’ai liti moimène celles qui sont relatives anx prenieres annces de ces deux arbres. 
Le pin d'Autriche et le pin latricio sont lont dissemblables dans les premières années : le premier a les lenilles mides, d'un vert loncé et il est chargé de branches près du sol; le second a les feuilles contournées, d'un vert plus clair, est chargé de branches vers la tète è en est déponillé près du sol; cependant, dès yu’ils ont dépassé les premières années, ces arlores ont beanconp de ressembance dans leur aspect. He promenant, en mar's 18:33, dans le jardin lobanique de Berlin, arec M. Link (1) qui en était le directeur, et ayant cru recomnâtre un pin laricio dans un pin gui avait environ á mètres de hatut, je lui témoignai mon b́tonnement de ce yue cet arbre pouvait supporter la pleine terre a celle latitude: "Cen'est point un pin laricio, ne dit-il, e’est un pin d'Autriche. " Je pense effeclivenent que le pin la ricio ne pourrait pas supporter la pleine terre sous le climat de Berlin.

Dans un âge plus avancé, d'après ce que dit Iloess, le pin d'Autriche continue at avoir des feuilles plus droites, phus raides el d'un vert plus foncé que le pin baricio; son écorce est plus épaisse, il est plus chargé de branches, ses branches fendent davantage, son aspect est très-différent; enfin, il contient beaucoup) plus de résine, et son bois est l'une autre couleur. Quesi l’on prétendait que la différence du elimat peut être la cause des dillérences que l'on remarque entre le pin laricio de Corse el le pin d'Auriche, je répondrais que Tenore (2) décrit un pin laricio, qu’il dit ètre le pin laricio de Corse, et un pin noirâtre, 'fu'il dit être le pin d'Autriche, el que ces deux pins se trourent ensemble dans plusieurs parties du royaume de Naples : il comnaissait bien le pin d'Autriche, qu’il avait vu daus plusicurs parties des États autrichiens, et particulièrement dans le jarilin botanique de Vienne, aceompagné de Host, et je présume qu’il comnaissait bien aussi le pin laricio de Corse.

Les opinions sont d'ailleurs partagées; ainsi, parrexemple, M. Franz Antoine, qui a publić à Vienue, en 1810-18'11, un ouvage intitulé Die Coniferen (les conilères), pense que le P'inus laricio, le Pinns pallnsiana (I’in de Crimée ou taurique) "t le l'ims atustriact ue sont que des variélés d'une mème espèce modifiée par des inlluences de climat el de situation.

On conclut, de tableaux donnés par Iloess, que lorsque le pin d'Autriche n'a pats crù en lutaie, sa tige, déduction faite de la cime, des branches el de l'écorce, ‘outient, depuis 80 jus(ju’à 130 ans, un volıme un peu moindre que celle des safins, du méleze el du pin sylvestre; mais un plus fort volume de menu bois, c’esti-dire de celui de la cime el des branches qui a été sćparé de la tige. En lutaie pleine, Hoess ne l’a comparé qu'au pin sylrestre, et il a trouvé que, jusqu'ì 60 ans, le pin d'Autricle contient un plus fort volume de bois que le pin sylvesIre, mais que plus tard c’est fe contraire. Hoess, en clécrivant le pin d'Antriche, fage I le la Monographie précédemment citéc, s’exprime ainsi : "Dis sa jen" nesse et jusqu’’i son àge mùr, cet arbre réunit tout ee qu’il laut pour c̀tre un de

(1) Mink est commu des botanistes par plusicurs savans cicrits.

$\therefore$ Flora nopolitana, 1. V, 1. :666. 
" nos plus beaux arbres résineux conifères. La symétrie de ses parties, son port " imposant, la longueur et l'épaisseur de ses aiguilles, serrées les unes eontre "les autres, sa belle verdure, l’odeur balsamique qu'il répand, la position ré"gulière de ses branches, sa magnifique couronne el ses cônes d'un brun-jau" nâtre, forment un ensemble harmonieux qui frappe par sa régularité. "

Le bois du pin d'Autriche est d'un blanc-jaunâtre vers la circonférence, d'un jaune de rouille vers le cocur; il est, dit Iloess, le plus riche en résine de tous les bois résineux de l'Europe. Cet auteur rapporte que mille tiges de 12 à 14 pouces $\left(0^{\mathrm{m}}, 31\right.$ à $\left.0^{\mathrm{m}}, 36\right)$ de diamètre et de 7 à 8 toises $\left(13^{\mathrm{m}}, 27\right.$ à $\left.15^{\mathrm{m}}, 16\right)$ de haut, exposées la moitié au nord, l'autre moitié au sud, ont donné annuellement 8,267 livres (4,629 kil. 520 gr.) de résine, on 8 livres 27 onces ( 4 kil. 629 gr.) par arbre, et que ce produit est beaucoup plus fort dans les arbres isolés. Le résinage a mis un obstacle à la propagation du pin noir d'Autriche dans les États autrichiens, et en aurait même à la longue causé la destruction, si le gouvernement n'eùt enfin pris des mesures pour régulariser la récolte de la résine; celte opération nuit à l'aceroissement des tiges, mais les pertes que l'on fait ainsi sont plus que compensées par la valeur de la récolte de résine; le bois des arbres qui ont été résinés est d'ailleurs préféré, comme bois d'auvre, et pour la fabrication du gouIron et du charbon, à celui des arbres qui ne l'ont point été. Le bois du pin d’Autriche, plus tenace et plus ferme que celui du pin sylvestre, est employé aux mêmes usages; il est très-estimé pour les constructions dans l'eau, plus même que le bois du mélèze. Les Turcs, dit Olivier, l. II, P. 6 de son Voyage daus l'Empire ottoman, emploient heaucoup le pin de Caramanie (qui parait ètre le même que le pin d'Autriche) à la construction de leurs vaisseaux.

Le pin d'Autriche, (quoiqu'il aime les lieux ouverts et exposés au soleil, croil à toutes les expositions, mais il préfère celle du midi. On en trouve encore de beaux massifs, dit Iloess, à 4,000 pieds (1,224 mètres) au dessus du niveau de la mer; mais alors il n'occupe que les versans sud, sud-est et sud-ouest.

Le pin d'Autriche se contente de toute espèce de sols, pourvu qu'ils ne soient pas trop humides; mais sa croissance et la qualité de son bois varient beaucoup, selon la nature du sol. Les sols calcaires sont ceux où on le trouve le plus souvent et qui semblent le mieux lui convenir; c'est sur ces terrains qu'il prend le plus de qualité, qu'il devient le plus riche en résine, et il y acquiert des dimensions diatant plus belles que le sol a plus de profondeur. Cet arbre croît quelquefois spontanément sur des rochers calcaires à peine couverts d'une couche de terre, où l'on ne trouve aucun autre de ses congénères, soit que les terrains calcaires ne leur conviennent point, soit qu'ils ne puissent croître dims des terrains aussi maigres et sans profondeur. Pour donner une idée de sa ruslicité, Iloess rapporte que sur un terrain des environs de Wiener-Neustadı, qui n'est qu'un mélange de galets et de cailloux calcaires mèlés de très-peu de terre, 1,000 arpens $(2,301$ hectares 20 ares) ont déjà été semés en pin d'Autriche, et que cet arbre y acquiert cepentant une hauteur de 8 i 9 toises $\left(15^{\mathrm{m}}, 17\right.$ il $\left.17^{\mathrm{m}}, 01\right)$ el un diamètre de 10 a 12 junces $\left(0^{\mathrm{m}}, 26\right.$ à $\left.0^{\mathrm{m}}, 31\right)$; les semis sur les ands de galets 
les phus maigres, quoique végétant d'abord misérahloment, finissent par réussir

Le piu d'Autriche se reproduit par le semis maturel aussi facilement que le. pin sylvestre. Un des effets du résinage de ces arbres, quand il a été fait arer molération, est d'augmenter la production des eônes, et les graines sont aussi honnes alors que celles dles arbres qui n’ont point été résinés.

Le pin d'Autriche peut se multiplier par la plantation; mais ce moyen est peu usite en Autriche, et l'on n'emploie ordinairement alors que du plant de $20 u$ 3 ans. Cet arbre m'a paru avoir plus de chevelu que le pin laricio et un pivot - moins prononcé; anssi, en l'élevant ansi que je le prescris chap. XI, art. X, les plantations qu'on en fait ì demeure réussissent parfaitement. Ce que j’ai dit de la création d'une futaie de pins laricio, de son exploitation et de son ammagement, me paraît s'appliquer de tout point an pin d'Autriche; el l'on trouvera (chap. XI, art. X, des renseignemens sur la culture de cel arbre en pépinière el sur sa plantation à demeure.

En Autriche, e'est le semis artilieiel, avec de la graine désailée; qui est le moyen ordinaire pour multiplier le pin d'Autriche; et tous les modes de semis fue l'on emploie avee suceès pour le pin sylvestre, y réussissent égalentent pour le pin d'Autriche. Je rapporterai sommairement ce que Iloess dit de la création des futaies de pins d'Autriche sur cente plaine pierreuse des environs de WienerNenstadt dont je viens de parler, parce que la créalion de ces fulaies el leur deslination présentent des circonstances particulières. On s'est proposé, en créant les futaies sur ces terrains arides qui ne produisaient aucun revenu, de se procurer des leuilles dont on se sert pour litière, ce qui a permis de mettre en culurre des terrains fort maigres de leur voisinage; de se procurer du bois de chauffage, de la résine et du bois d'ouvre; enfin d'améliorer le terrain par le détritus des feuilles, que l'on ne prend ni dans les premières, ni dans les dernières années de la futaie.

La création de ces futaies s'exécute ainsi qu'il suit : on donne deux labours au printemps, et l'on sème successivement de l'avoine, pour ombrager le plant la première année dans ce terrain brûlant, et la graine de pin d'Autriche. Ce semis ne s'exécute que dans la première quinzaine de mai, parce qu’il serait dévasté par les pigeons ramiers si l'on semait plus tôt; on emploie de 20 à 25 livres (11 ì 13 kilog.) de graines par arpent ( 57 ares 55 centiares) pour obtenir un semis épais qui couvre bicn le terrain la seconde annce, et l'on veut que le terrain soit convert la seconde anmée, par la même raison qui a fait semer de l'avoine pour qu'il soit couvert dès la première année. On éclaircit la futaie, pendant les premières ammées, à des époques irrégulières, quand on le juge nécessaire; on éclaircit ensuite à des époques régulières, et l'on commence à ramasser des fenilles dès la quatorzième année, ce qui ne se fait que tous les deux ans au mois d'octobre; on se procure ainsi par arpent, daus les futaies âgées de 14 ì 20 ans, deux ou trois voitures de litière attelées de denx chevaux, et plus tard quatre à cinq voilures: ordinairement on renones à enlever les fenilles au bout l'un certain nombre d'années, pour qu'olles serrent ì l'amélioration du sol. 
Iloss dit que le pin d'Autriche est encore plus robuste que le pin sylvestre, at que, dans ses courses, il n'en a jamais trouvé qui fussent attaqués de pourriture. Les insectes qui peuvent être nuisibles à cet arbre sont ceux qui le sont aussi au pin sylvestre; on ne s'est d'ailleurs jamais plaint, dit Hoess, de leurs ravages dans les montagnes. Cet auteur rapporte, au contraire, que la chenille du pin, Phaléna bombyx pini, parut une fois en si grande quantité dans l'épaisso et jeune futaie qui se trouvait dans la plaine entre Wiener-Neustadt et Neunkirchen, qu'elle mangea toutes les feuilles, mais que les arbres ne périrent poinl; ils se recouvrirent de feuilles l'amnée suivante et se sont bien rétablis.

Le pin d'Autriche peut supporter les climats les plus rigoureux de la France, purisque je l'ai trouvé en pleine terre à Berlin; sa propriété de croître et de se reproduire dans des terrains très-calcaires, tandis que ses congénères refusent dy crô̂tre ou y croissent moins bien que lui, pourrait le rendre très-utile dans les terrains calcaires incultes, par exemple dans les craies de la Champagne, où il réussirait probablement encore mieux que le pin sylvestre, le seul que l'on soit parvenu à y culliver jusqu'ì ce jour.

III. Pin cenbro, Pimas combra Linné (1). - Le pin cembro s'appelle aussi Arole en Suisse et en Savoic, Alviez en Dauphiné, el quelques pépiniéristes lıi a vaient donné le nom de Cèdre de Sibérie, qui ne lui convient sous aucum rapport, puisque cet arbre et le cèdre sont entièrement dissemblables. Les botanist's ont lait trois variétés du pin cembro; mais les caractères botaniques de ces variétés étant les mêmes, je pense, comme pour le pin sylvestre, que ces prétendues variétés ne sont qu'un seul et même arbre, qui présente des caractères différens dans sa végétation par suite des différences de climat, de sol et de température.

On trouve le pin cembro croissant spontanément dans les montagnes de la Suisse, du Dauphiné, du Piémont, du Tyrol, de l'Autriche, de la Hongrie el dans les monts Ourals.

Le pin cembro n'est cultivé en France que comme arbre d'ornement et pas rommunément. Ceux que j’ai che\% moi ne sont plantés que depuis neuf ans; ceux (jui sont au Jardin-des-Plantes de Paris ne me paraissent pas plus âgés que les miens, et le plus âgé que j’aie vu, sous le climat de Paris, n'a qu'environ 32 ans; il appartient à II. Richard, professenr à l'École le médecine, el se trouve darrs un jardin à 8 kilomètres de chez moi, en fort bomne terre; il en existe sans donte de plus âgés encore, mais je ne les ai point trouvés sur mon rhemin, quoique j’aie visité quelques parcs et jardins. J'emprunterai donc en partie ce que je dirai de cet arbre aux différens auteurs qui en ont parlé (2).

Le pin cembro n'a qu'une seule sève, qui m'a paru commencer el se terminer ì peu près en même temps que celle du pin sylvestre.

Les feuilles du pin cembro sont au nombre de cinq dans une gaine: elles ont

(1) Species plantarum, 3e édit., t. 11 , p. 1419.

2) Kasthofer, llmss, Pallas, loerandolle, Loudon, lambert, etc., dont j’ai déjá cité les ouvrages. 
de $0^{m}, 08$ i $0^{m}, 13$ de long comme celles du pin Weymouth; elles sont du même vert que celles de ce pin et marquées comme elles, en dedans, de deux petites raies blanches, mais elles sont plus grosses, plus raides et plus agglomérées; néammoins, les personnes qui ne se sout pas occupées particulièrement des arbres résineux conifères prennent souvent les pins cembro pour des pins Weymonth, pendant la jeunesse de ces arbres.

Les lleurs mâles, semblables pour la forme à celles des pins dont je me suis déjà occupé, paraissent à peu près en même temps que celles du pin laricio; selon Lamber (1), elles sont d'un poirpre vif et plus belles que dans aucune autre espèce de pins: c'est que je n'ai pu constater par moi-môme, quoique le pin cembro dle 32 ans, (qui se, trouve dans mon voisinage, porte des fleurs mâles, n’ayant encore pu l'observer pendant la lloraison. Nais je me suis fait envoyer, a Paris, une lleur mâle de ce pin cueillie de la veille, par mon garde, le 8 juiu 1814; elle avait dépassé sa maturité, avait à peu près les mêmes dimensions que celles de la tleur mâlé du pin Weymoutlu el était alors rouge cinabre. Les lleurs femelles sont d'un bleu-violet et paraissent en même temps que les lleurs mâles.

Les cônes sont ovoïdes, ils ont environ $0^{\mathrm{m}}, 08$ de long et sont d'une couleur bleu-violet, lorsque pendant l'année qui suit leur naissance ils ont atteint toutes leurs dimensions, quoiqu'ils ne soient pas encore mùrs; plus tard, lorsqu'ils sont parvenus à leur maturité, ils prennent une couleur ronge-brun. Je ne puis dire si c'est parce que les écailles s'ouvrent ou parce qu'elles se détachent de l'axe du cône, que les graines tombent, ni au bout de combien de temps elles tombent, ne trouvant nulle part ce renseignement. Kasthofer dit (2) : "L'époque de la llo" raison de l'arole dépend de l'élévation des montagnes sur lesquelles il croì, et " celle de la maturité de ses graines de la température qui y règne; cette récolte: " est done très-casuelle. On n'en compte qu'une en quatre ans, dans l'Oberland "bernois. "On remarquera que si les feuilles du pin cembro ont beaucoup de ressemblance avec colles du pin Weymouth, les cônes du premier sont au contraire fort dissemblables de ceux du second.

Les graines du pin cembro. ont environ $0^{\mathrm{m}}, 013$ de long, sont oblongues et u'ont point d'ailes; clles sont munies d'une enveloppe très-dure, et contiennent une amande blanche agreable à manger, dont on peut extraire une luuile de bonn. qualité et d'un parfum agréable. Gmelin dit (3) que ces amandes sont un puissant spécifique contre le scorbut, et il eite deux capitaines de vaisseaux dont les équipages, atteints de cette maladie, avaient dejal fait de grandes pertes el qui s'en tébarrassèrent en en faisant usage.

Les racines du pin cembro sont vigoureuses et pénètrent profondément dans l. sol, et cela ne saurait être autrement, puisqu'il est celui dles arlıres à grandes di-

(1) A description of the gerius Pimus, 1. la., art. Pinus cembro.

(2) Le Guide dans les fortits, 1. Irt, p. 2'il.

3) Flora silivien, t ler, p. 181. 
mensions qui eroì, à la plus grande hauteur, sur les montagnes de ha Suisse, on il résiste à des vents terribles.

Le tronc du pin cembro est droit, même quand il croît isolé; l'écorce en est verdâtre, lisse et unie dans la jeunesse de l'arbre, elle ressemble alors à celle du pin Weymouth, plus tard elle devient grise et rugueuse. Des branches disposées par étages garnissent le tronc depuis le sol jusqu'à la cime, quand ce pin croît isolé, et il a alors, dans son ensemble, une forme conique comme les sapins et le pin Weymouth; ses branches sont minces et courtes, relativement à la grosseur du tronc.

Le bois du pin cembro est blanchâtre, mais il brunit à l'air; il est léger, tendre, résineux, et répand une odeur agréable qu'il conserve toujours; il est propre à la menuiserie, à la sculpture et aux constructions. "Cet arbre, ainsi que "le bois, dit Kasthofer, t. $1^{\mathrm{er}}$, p. 92 de son Guide dans les forêts, dans l'article De "l'arole, a une durée d'un grand nombre de siècles. " Decandolle parle ainsi qu'il suit du pin cembro, dans le Mémoire déjà cité page 292 : "Le pin cembro est un " des arbres conifères le plus rare de nos Alpes; on ne le rencontre jamais en "forêts, mais on en trouve des pieds épars dans les sommités alpines du Daı"phiné, de la Savoie et du Piémont : son bois est blanc, doux, très-facile à " couper au couteau, aussi bien dans le sens transversal que dans le sens lon" gitudinal : cette nature du bois du pin cembro l'a fait choisir par les habitans " de Chamouny pour une industrie qui leur est propre; c'est avec ce bois qu'ils " fabriquent facilement, et à bon marché, des plans en relief de leurs monta"gnes, onvrages remarquables par la précision géométrique que de simples "paysans savent y apporter."

Le pin cembro croît plus lentement, toutes choses égales d'ailleurs, qu'aucune des espèces d'arbres résineux dont je me suis déjà occupé, surtout lorsqu'il se trouve dans les parties élevées des lıauteś montagnes; mais, dit Kasthofer, I. I, p. 240 de l'ouvrage que je viens de citer, "il ne cesse point de végéter, ì " quelques mutilations qu'il soit exposé. Il s'élève moins que les autres pins, en "proportion de la grosseur de sa tige et de la durée de sa croissance; un trone " de 3 pieds $1 / 2$ de Berne (1) $\left(1^{\mathrm{m}}, 02\right)$ de diamètre, observé sur la Scharmatalp, " n'avait que 60 pieds $\left(17^{\mathrm{m}}, 40\right)$ de longueur, et les plus grands arbres n'excédaient " pas 80 à 90 pieds $\left(23^{\mathrm{m}}, 20\right.$ à $\left.26^{\mathrm{m}}, 10\right)$. " Le mème auteur dit, dans l'article $D e$ l'arole, précédemment cité, "qu'il trouva sur la montagne d'Jtramen, au Grin" delwald, à une hauteur d'environ 6,000 pieds (1,740 mètres), un arole de " 6 pieds $\left(1^{\mathrm{m}}, 74\right)$ de diamètre." Selon Iloess $(2)$, l'arole peut s'élever à 60 pieds d'Autriche $\left(18^{\mathrm{m}}, 96\right)$ et au delà. Pallas dit (3) qu'il attein t rarement 120 pieds anglais (36 mètres) de haut avec un diamètre de 3 pieds $\left(0^{\mathrm{m}}, 90\right)$ à la base. Loudon dit (4)

11. Le pied de Berne est de $0^{\mathrm{m}}, 293$.

(2) Gemeinfassliche Anleitung die Bœume und Strauche Oesterreichs aus den Blceltern zu erkennen, p. 12.

(3) Flora rossica, p. 3.

(i) Arborctum et Fruticetum brilannicum, 1. IV, p. 2277, art. Pinus cembra. 
que le plus grand pin cembro qui soit en Angleterre est celui de Whillon, dont lat plantation remontait, en 1837, it 91 ans, el qui, par conséquent, avait alors près de 100 ans; sa hauteur était de 50 pieds (15 mètrus) et son diamètre d. 1 pied 6 pouces $\left(0^{\mathrm{m}}, 45\right)$. Le pin cembro le plus beau cl le mieux venant, parmi in gramel nombre de ces arbres plantés à Gledhow, près de Leeds, avait, en 1837,45 i i 50 ans après sa plantation, 35 piecls $\left(10^{\mathrm{m}}, 50\right)$ de haut, et 3 pieds 2 pouces ( 1 mètre) de circonférence à 3 pieds $\left(0^{\mathrm{m}}, 90\right)$ au dessus du sol. Le pin cembro qui se trouve dans un jarlin à 8 kilomètres de chez moi, ę qui est âgé d’environ 32 ans, avait, à l'automne de 1811,5 mètres de haut et $0^{\mathrm{m}}, 10$ de circonférence. Je plus haut des miens, qui sont âgés de 12 ans, a $\mathbf{1}^{\mathrm{m}}, 60$.

Le pin cembro est celui de tous les arbres ì grandes dimensions qui peut croître à la plus grandélévation, dans les hautes montagnes, en conservant de belles dimensions. On le trouve, dans les montagnes des Alpes suisses, jusquà 2,000 mètres au dessus du niveau de la mer, quelquefois immédiatement an dessons des neiges éternelles; il y brave les vents, la neige et les frimas, parce (ju'il est fortement enracinć, que ses branches sont courtes et ses rameanx trèstlexibles. Kasthofer rapporle (1) que sur une montagne près le Scarla, dans l'Engadine, il vit des pins cembro isolés à 7,000 pieds $(2,030$ mètres) au dessus clu niveau de la mer, qui s'élevaient avec force et majesté au milieu des pins rampans. Cet arbré peut d'ailleurs prospérer aussi dans des climats beaucoup plus doux, puisqu'on le cultive avec assez de succès en France et en Angleterre. J'en ai remarqué, en 1821 , de petits massifs qui avaient la plus belle végétation dans le pare de M. le marquis de Costa, à deux lieues de Chambéry, sous m climat très-doux oủ l'on cultive la vigne.

Le repeuplement de cet arbre par le semis naturel est lent, parce que ses granimes, étant bonnes à manger, sont recherchées par les hommes et par plusieurs animaux; parce qu'élant lourdes elles tombent au pied de l'arbre, au lieu de se disperser au loin comme celles de ses congénères qui sont légères et munies d'ailes, et parce qu'il ne parvient pas à mûrir ses graines avant sa soixantième année (2). Aussi Kasthofer, après avoir dit, dans l'article que je viens de: citer, "qu’il n'existe point d'arbre forestier en Suisse aussi utile que l'arole, " par l'excellence et l'incorruptibilité de son bois, par la force gu'il a de suppor" ter le froid glacial des montagnes les plus élevées et de braver les ouragans qui " y règnent, "exprime-t-il la crainte qu'il n'ait bientôt disparu de ce pays.

Houss dit, page 12 de l'ouvrage précédemment cité, que le pin cembro prífère un terrain humide et pierreux. Seton Loudon, t. IV, p. 2279 de son Arborelum, "le pin cembro peut croître dans les sols les plus paurres, el dans les " situations les plus élevées et les plus exprosées, où aucum autre pin on sapin " he saurait exister; mais il ne croit rapidement que sur un sol libre, un peu "profond et reposant sur un sous-sol sec."

(1) Voyage dans les petits cantons et dans les Alpes Rhéliennes, p. 201.

(2) I.e Guide dans les forets, 1. 1'r, p. 96, art. De l'Arole. 
Cet arbre peut être propagé par le semiş on par la plantation : ce dernier moyeu réussit très-bien. J'ai voulu l'ilever en pépinière; les graines que je m’étais procurées, et que j’avais semées au printemps de 1837, u’ont pas levé, et je me reproche de n'en avoir pas fait semer de nouveau. Si ces graines avaient levé, le pin cembro aurait eu dans mon chap. XI, ainsi que les antres arbres résineux que j'ai ćlevés en pépinière, un article qui aurait fait connaitre toutes les circonstances de sa végétation, sous le climat de Paris, depuis sa naissance jusqu’à ce moment (1815). Les graines ne lèvent que le second printemps après qu’on les a semées, comme une partie de celles qui ont une écorce très-dure; ainsi il faut les mettre stratifier pendant un an, si l'on veut qu'elles lèvent le printemps même où on les sème. Kasthofer dit, t. $\mathbf{I}^{\text {er }}$, p. 240 de son Guide dans les forồs : "Pour semer l'arole, il faut avoir soin de ne pas ouvrir les cônes à "l'avance, parce que l'amande étant sujelte à rancir, elle perd bientôt la fil" culté de germer. Nise en terre au printemps, elle y reste une année avant h. " pousser, tandis que semée en automne, la plante paraît déjà au printemps sui" vant. "Selon Loudon, les graines semées l'antomne restent deux livers e:t un été en terre avant que de lever, et le jeune plant croit si lentement qu’il atteint rarement, pendant les cing premières années, 1 ou 2 pieds $\left(0^{\mathrm{m}}, 30\right.$ ì $\left.0^{\mathrm{m}}, 60\right)$ dr: haul.

Le pin cembro, à cause de la lenteur de sa croissance, ne pent ètre cultivé en France, sous le elimat de Paris, que comme arbred'ornement; mais dins les louutes montagnes, il peut ètre employé à fixer les terres à des lauteurs où aucun antre arbre à trandes limensions ne peut croître.

Loudon dit, dans l’article de l'Arboretum précédemment cité, qu'en Angleterre il n’est cultivé que comme arlore d’ornement, que le premier de ces arbres qui y a été introduit est celui de Whitton, dont j’ai donné plus haut les limensions, et que c'est Archibald, duc d'Argyll, qui l'y a planté en 1746. "Une: " grande quantité de graine de cet arbre tirée de Suisse, fut, dit-il, semée en "Angleterre vers la fin du demier siècle, et plus de 2,000 des plants obtemus " ainsi furent plantes a Walcolt Hall, résidence de lord Clive; ces plantations " sont toujours en bou état, et plusieurs de ces arbres ont atteint 40 et 50 pieds "(12 et 15 mètres) et produisent des cônes. Plusienrs de ces pius furent aussi "plantes, dans le même temps, a Gledlow, et de là vient le nom de Pin de "Cicellew que l'on donne souvent à cet arbre."

1V. Pin d'Espagne, Pinus hispanica S. E. Cook (1). - Lapeyrouse, naturaliste français, est lo premier qui ait parlé de ce pin, page 14 fo de son Supplément ì l'histoire abrégét' des plante's des Pyrénées, qui parut en 1818. Il trouva ce pin en Esplagne, dans l’Aragon, au midi des Pyrénées, entre la rivière de Cinca et celle d'Esseva, qui rst l'un de ses affluens, et il l'appela Pinus pyrencüca; les

(1) Annals of natural history, 1939, 1. II. P. I63. Article de M S. E. Cook, intitule : On the genera Pinus and Abies with remarks on the cultivation of some specirs (sur les genres $P$ in et Sapin, ivec des remarques sur la eulture de quelques espèces). 
Inabitans lui donnent, dit-il, le nom de Pin nazaron. Lapeyrouse le prit d'abord pour le pin laricio; mais il recomnut plus tard qu'il en différait essentiellement, aussi bien que du pin sylvestre, et qu'il formait une espèce à part; c'est ce dont on ne saurait douter, si la description qu'il en donne est exacte. Ce: pin ne croît pas, selon lui, réuni en massifs, mais çà et là parmi ses congénères. "Le pin des Pyrénées, dit cet auteur, est un très-grand arbre, propre, " lorsqu'il est vicux, à la mâture et aux grandes constructions. Son port est ma" jestueux, il file droit. Son écorce est épaisse et raboteuse, d'un gris-brun, " à gerçures profondes."

M. le capitaine S. E. Cook, naturaliste anglais, qui a vu aussi cet arbre dins les mêmes forêts que Lapeyrouse, dit, dans l'article précédemment cité, que c'est un grand et très-bel arbre; que jusqu'à présent on ne l'a trouvé qu'en Espagne, et qu'il en a observé des forêts depuis la Sierra de Segura (lat. $39^{\circ}$ ) jusqu'au pied des Pyrénées (lat. 4.5\%); qu'il y croit dans les montagnes à une hauteur de 2 à 3,000 pieds ( 6 à 900 mètrès) au dessus du niveau de la mer, et principalement dans celles dont le sol est calcaire; que le pin sylvestre, quand il croit dans les mểmes montagnes, occupe les régions supérieures. Il prétend, ainsi que Lapeyrouse, que cet arbre forme une espèce à part, fait ressortir les différences qui le distinguent du pin laricio, et l'appelle Pinus hispanica, nom que j'ai adopté. M. Cook en a semé au nord de l'Angleterre et il y a bien réussi; ainsi l'on pourrait espérer de le cultiver avec succès, sur toute la partie tempérée du sol de la France.

M. Vilmorin, s'étant procuré des branches et des cônes du pin d'Espagne, cueillis, sur les arbres mêmes, par deux botanistes de sa connaissance, leur tronvi une telle ressemblance avec ceux du pin laricio de Corse, qu'il crut d'abord que: c'était le même arbre; mais en ayant semé des graines, il obtint des plants qui différaient assez de ceux de pin laricio pour le convaincre que c’était une espèce différente. Il compara aussi ces plants avec des plants de pin d'Autriche, de pin taurique et de pin de Caramanie, qu’il élère pour les éludier, et il les trouva dilférens : ces trois derniers pins se ressemblent d'ailleurs assez, dans leurs premières années, dit M. Vilmorin, pour qu'on puisse présumer que e'est le même pin sous des noms différens (Voy. p. 328). J'ai chez moi du plant de pin d'Espagne, provenant de graines authentiques semées en 1844, qui va terminer sa seconde sève au moment où j’imprime ce passage (12 juin 1845); il est fort différent de celui de pin laricio et de pin d'Autriche. J'ajouterai que si la description très-détaillée des caractères botaniques du pin d'Espagne, que nous a donnée Lapeyrouse, est exacte, il diflère du pin laricio par un caractère important; c'est que les écailles de ses cônes ne sont point munies d'épines, du moins il n'en parle pas.

V. Sapin d'Espagne, Ahies hispanica Mihi. - Il existe de vastes forêts dé salpins d’Espagne dans la chaine des montagnes de Rondi, en Espagne, et pourtant il ne nous est comnu que depuis que M. Boissier, qui l'a examiné sur les lieux mèmes, en a fait la deseription dans Ia Bibliohèque de Genève, 1. XIII, ץ. 401. 
année 18:38. Il l'apelle . lbies pinsupo, silpin pinsapo, nom si pen ïphonique que je erois ponvoir me permettre d'y substimer celui rle Sapin d' Espugme, qui rappelle le pays oì on l'a observé d'alord.

11. Boissier dit qu'il a beancoup de ressemblance avec lo sapin argenté, qu' ses cònes sont érigés de mème et perdent aussi leurs écailles dans l'année où ils sont nés; que les axes dès cônes restent ensuite plusieurs années fixés sur les branclıes, comme ceux des cônes du sapin argenté, ee que j’ai vu de mes yeux sur une branche envovée d'Espagne; enfin, qu'il y a aussi deux graines lixées au bas des écailles. Il remarqua quelqurfois jusqu'i huil cònes serrés les uns contre les antres, tandis que dans le sapin argenté les cônes sont ordinairement isolés, quelquefois réun is au nombre de deux, bien rarement au nombre de rrois. Il dit que les feuilles du sapin d'Espagne entourent les branches, landis que dans le sapin argenté, elles ne sont que sur un ou sur denx rangs.

Selon M. Boissier, cet arbre atteint 20 à 25 mètres de hant; mais ce n'est la qu'une évaluation approximative, el les personnes qui n’ont pas l'habitude de ces sortes d'évaluations peuvent commettre ainsi de très-grandes erreurs. Il aurait ćté préférable qu'il se fùt donné la peine de prentre, à 1 mètre au dessus du sol, la eireonlérence des plus grros sapins et la circonférence de ceux qui sont d'une grosseur ordinaire; on en anrait conclu la hauteur a vec une exactitude suffisante, prisque cet arhre offre, dit-il, dans son cnsemble, beancoup de ressemblance avec le sapin argenté, auquel on l'aurait comparé sous ce rapport. M. Boissier n’a commencé à trouver le sapin d'Espagne qu'à 3,500 pieds $\left(1,136^{\mathrm{m}}, 93\right)$ au dessus du niveau de la mer; il est donc probable qu'une certaine élévation on l'air vif a agité des montagnes lui est nécessaire, à cente latitude, pour qu'il aequière les plus belles dimensions auxquelles il puisse parvenir, el il est incerlain qu'il parvienne aux mêmes dimensions sous le climal de Paris.

I. Vilmorin me donna, le 7 mars 1811 , quatre sapins d'Espagne, âgés de 3 ans, provenant de graines que hui avait envoyées $N$. Buissier; ils ont trìs-bien repris. Au printemps de 1843 , des gelées tardives, survenues en mai, détruisirent ume partie de leurs pousses et leur furent aussi nuisibles qu'aux sapins argentés; à l’automme de 1813 , celui qui avait le moins soulfert a vait $0^{\text {m }}, 30$ de lıaul; à l'automne de 1814 , il avait $0^{\mathrm{m}}, 36$.

Cet arbre n’a qu'une seule sève, qui commenee el finit à peu près en même: temps que celle du sapin argenté. Ses feuilles paraissent, comme celles des sapins, en même temps que les pousses sur lesquelles elles sont fixées; elles sont très-raides, linéaires, légèrement aplaties, terminées en pointe, d'un vurt noir par dessus et blanchâtres par dessous, parce qu'il s'y trouve deux raies blanches, comme sous celles du sapin argenté; elles sont longues de $0^{\mathrm{m}}, 016$ à $0^{\mathrm{m}}, 022$ et sont dispersées une à une tout autour des pousses.

Si je compare les jeunes sapins l'Espagne, que j’élève actuellement, à de jeunes sapins argentés du même âge, je trouve ces jeunes plants fort différens par leur aspect, par la forme de leurs fenilles, par la manière dont elles sont tixées sur le bois, el surtout par la couleur très-lifférente qu'out d'aborl les 
feuilles des ponssen dans les deux espèces : dans le sapin d'lisplague, efles sonl d'un vertsale; dans le saphu argenté, d'un vert chair fort gai ; ces fenilles prennent ensuite une coulenr d'un vert foncé dans les denx espèces, mais tirant sur te noir dans le sapin d'Espagne et fort différent encore du vert des lenilles du sapin argenté. Le sapin d'sispagne el le sapin argenté sont tellentent dissemblables dans leurs premières années, que je dois présumer quece sont deux espèces diflérentes.

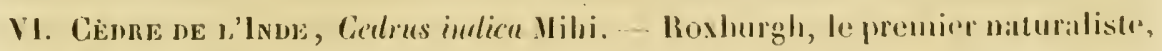
je crois, qui ait observé le cèdre de l'lnde, lui dome le nom de Ciedrus devdarn (1); je me suis pernis de lui domer le nom de Cidre de l'lude, qui rappelle le pays ou il a été olsservé d’ahord el vin il croit spontancment. Les ludiens l'alppellent Inevedaroo on Develer, dit Roxburgh, et ils le considerent eomme un arbre sacré. Le cèle de l'lude n'est guère commu que par é qu'en disent lambert el Loudon, d'après les botanistes el les voyageurs qui ont observe cel arbre dints I'Inde; cest de ces auteurs que ceux qui en ont parlé ont emprunté ee qu'ils en discent, el c'est ce que je lerai aussi.

Le cedre de l'Inde croit spontanément an nord de l'lnde, dins le Nepaul a dims les montannes indo-lintares, ou l'on en trouve quelquefois qui croissent jusqu'à 3,600 mòtres au dessus du uiveau de la mer. Il a hes mèmes caraclères lwalaniques que le cèdre du Liban, mais ses cones, ses fleurs el ses fenille's en diffèrent "u peu par la couleur; on a remarqué aussi que ses cònes sont un pen plus gros el ses feuilles un peu plus larges. Il se distingue d'ailleurs du ceitre du Liban an premier aspect, parce que ses peusses sont d'abord pendantes comme celles du saule pleureur, mais elles se redressent il'automne el au printemps suivant; celte disposition des pousses el la forme pyramidale de l'arbre, dams sil jeunesse, lui doment alors l'aspect te plus gracieux. Cet arbe acquiert, dans l'lnde, de mat-

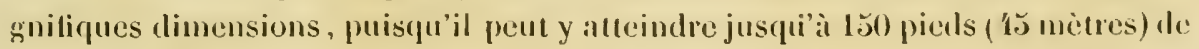
haut avec une circonférence de, 30 pieds (9 mètres). Son bois est bien diflérent de celui du cèdre du liban; il est très-complact, très-résincux, répand un p:urfum fort agréable, et parait posséder les qualités que les anciens altribuaicnt au bois du cèdre du Liban, el que nous ne lui trouvons plus; il prend un si beau poli yu'un plateau de 4 pieds $\left(4^{\mathrm{m}}, 20\right)$ de diamère, envoyé à Lambert par Wallich, paraissait être un morceau d'agate.

Le bois du cèdre de l'Inde est employé à tonte espèce d'usages et il est d'une grande durée, qu'on l'emploie à l'abri, exposé à l'air ou dans l'eau. On en a trouvé de parfaitement sain dans des charpentes de temples indiens qui n'avaient pas moins de 200 ans. Le docteur Lindley dit que Mooreroft lui envoya un morean de ce bois, provenant du pont de Zein-ool-Kuddul à Ladakh, où il itvait éte exposé ì l'eau pendant environ 100 ans; Loudon qui cile ce lait, 1. IV, p. 2131 de son Arboretrm, ne dit pas dims quel état élait ce hois. Le mène anteur rap-

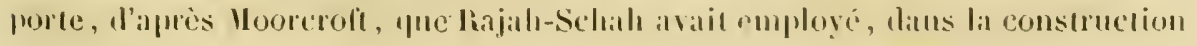


d'une maison, du bois de cèdre de l'Inde encore très-sain, quoique provenant de la démolition d'un édilice bâti 225 ans auparavant par l'empereur Akbar.

Le cèdre de l'Inde, selon Loudon, n’a été introduit dans la Grande-Bretagne qu'en 1822; il y a crû parfaitement en pleine terre jusqu'au nord de l'Écosse, et il a été trouvé plus robuste que le cèdre du Liban. Loudon cite plusieurs de ces arbres qui se trouvent dans les parcs et jardins de la Grande-Bretagne; le plus âgé, en 1837, se trouvait dans le jardin de la Société d'horticulture, avait 7 ans de plantation et était haut de 8 pieds $\left(2^{n}, 40\right)$. Il y a au Jardin-des-P'lantes de Paris deux ou trois de ces arbres; le plus haut m'a paru avoir (cn 181 1' de 3 à 4 mètres de haut. J'en ai, che\% moi, deux qui ont élé greffés en 18 '12 sur cèdre du Liban; le plus haut a un mètre; ils ne paraissent souffrir ni des hivers rigoureux, ni des gelées tardives. Selon Loudon, la culture en pépinière dı cèdre de l'Inde, le sol et l'exposition qui lui conviennent, sont les mêmes que pour le cèdre dı Liban. Chaque plant de cet arbre se vendait encore $50 \mathrm{fr}$. dans les pépinières de I.ondrus, en 1833.

VII. P’ı du Népau, Pimns nepalensis Mihi. - Wallich, le premier naturaliste, je crois, qui ait observé le pin du Népaul, l'appelle P'ims excelsa (1); ce $110 m$ pourrait convenir à plusieurs pins aussi bien qu’à celui-là ; je me suis permis de lui domer le nom de Pin dı Népaul, qui rappelle le pays où il a été observéd’abord et oủ il se irouve le plus communément. Les luabitans de l’Indoustan l'appellent Racsucla (roi des arbres), et les voyageurs $P$ in pleureur, à cause de la disposition de ses feuilles, dont il sera question plus loin. Ainsi que pour le cèdre de l'Inde, et par les mêmes raisons, j'umprunte à Loudon et à Lambert ce que je vais dire du pin du Népaul.

Le pin du Népaul croit spontanément dans plusieurs parties du nord de l'Inde, principalement dans le Boutan et dans le Népaul. Loudon et Lambert déerivent avec détail ses caractères botaniques; mais mon but n'étant que de fixer, sur cet arbre, l'attention des personnes qui s'uccupent de plantations, je me coutenterai de dire, comme l'ayant observé moi-même, que ses feuilles sont réunies, au nombre de cinq, dans une gaine et que la description que jai faite des feuilles du pin Weymouth leur est applicable, sauf les différences suivantes: les feuilles du pin du Népaul sont plus longues, plus larges, d'un vert encore moins foncé que celles du pin Weymoutl, et leurs raies blanches sont plus larges; ces feuilles sont ployécs à une petite distance de leurs gaînes, de manière à être pendantes, et le pin du Népaul est plus_clıargé de feuilles que le pin Wey-mouth. Ia disposition de ses feuilles justifie le nom de pin pleureur, et lui donne un aspect bizarre et tout particulier qui n'est pas sans agrément.

Lambert, dans l'ouvrage précédemment cité, dit que ce pin ressemble tellement au pin Weymouth, qu'il est difficile de l'en distinguer, et Loudon reproduit (2) celte asscrtion; cela me semble d'autant plus extraordinaire, que la des-

(1) Plante asiatica rariores, 1. $111, \mathrm{p} 1$.

2) Arboretum ef Fruticetum britannicum, 1. 1V, p. 2287, arı. Pinus exfelsa. 
cripliun quen font ces anterurs, aussi bien que les dessins qu'ils domment d'une branche portant des cónes, nous les montrent comme fort diflérens. J'ajouterai, d'après ce que j’ai observé moi-même, que ces deux arbres, dans leur jeunesse, sont tellement différens, qu'il n'est pas possible de les prentre l'un pour l'autse: il su hìrait de la disposition particulière des feuilles du piu du Népanl pour qu'il fùt impossible de le conlondre avec un autre pin.

Le pin du Népaul, dit Loudon, est commun daus le llant-Népaul et diuns le Buntan; il ajoute que, daus ce dernier pays, son bois d'ocuve est préféré par les labbitans à celui de tous les autres pins. Voilà un magnaitique élogre; mais celui que le même auteur a fait du bois du cèdre de l'lude le surpasse encure. II laut se tenir en girde contre de tels éloges el allendre un plus ample informé; if litut surtout attendre que nous ayons, sous le climat de Paris, des pins du Népaul de 60 ans au moins, pour savuir à quelles dimensions il y parviendra ef quelles y seront les qualités de son bois.

Loudon dit que ce pin a été introduit en Angleterre par le docteur Wallich, vers 1827 , et que sa croissance, sous le climat de Londres, est presque la meme que celle du pin du lord Weymouth; il rapporte qu’un pin du Népaul, plantedepuis 8 ans dins le jardin de la Socicté d'horticulture, avait, en 18:37, 12 pieds $\left(3^{n},(i)\right)$ de haut. Il y a au Jardin-des-Plantes de Pantis, et en pleine terre, un pin du Népaul qui a vait environ 2 mètres de haut à l'autonme de 1811; j’en al cintl chez moi, trois provenant de semis, qui sont âgés de 3 ans, et deux qui ont été greflés en 1813 sur pin Weymouth; ils n'ont pas souffert des hivers, quoigrivn n'en ait pris d'autre soin que de leur metre une converture de feuilles. Je présume que la culture de cet arbre, en pépinière, est la mème que celle du piu Weymouth, et je ne le crois pas plus délicat. Loudon dit, dans son Lrborctum. qui a paru en 1838, que les plants de cet arbre étant encore rares, dims les pépinières de Londres, coùtent $50 \mathrm{fr}$. chacun.

VIII. P's doux, l'inus mitis A. Michaux (1). - J'ignore s'il existe en France des pins doux, mais, $s^{\prime} i l$ y $\in n$ a, ils ne sont pas communs, call je n'en connais point d’autres que ceux que j’ai élevés moi-mème, et ils n'ont encore que huit ans, puisque je les ai semés en 1837. Je puiserai ce que je vais dire de cel arbre dans l'ouvrage de M. A. Michaux, que je viens de citer; el ayant élevé des prins doux en pépinière, je renverrai, pour ce qui concerne leur culture, leur végélitlion e- leur accroissement, depuis leur semis jusqu’à leur plantation à deneure, e jusqu’à l’âge de 9 ans, à ce que j'en dirai chap. XI, art. XI.

Le pin doux est un arbre de l'Amérique septentrionale, répandu dans les forèts de ce contiuent sur une très-grande étendue; il entre dans la composition des forêts en dilférentes proportions, qui varient selon la nature du sol; moins: le sol est bon, plus le pin doux abonde. I. Michaux l’a tromś jusque dians les Éats de Massachussets et de Connerdieut, qui oreupent le nord des Etilt:-

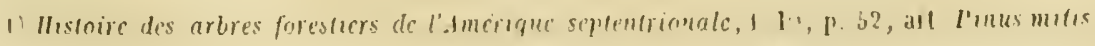


Unis; ainsi, sous le rapport du climat, on peut le cultiver dans le nord de lit France.

Cet arbre présente un aspect particulier, lorsqu'il est parvenu à son entier développement; il le doit à la disposition de ses branches, qui s'éloignent d'autant moins les unes des autres qu'elles sont plus élevées, et qui, se reployant sur cllesmêmes, lui forment un sommet pyramidal très-régulier. Le pin doux dépasse quelquefois 20 mètres en hauteur avee une circonférence de $1^{\mathrm{m}}, 80$ à 2 mètres. Ses feuilles, longues de $0^{\mathrm{m}}, 012 \mathrm{a} 0^{\mathrm{m}}, 015$, d'un vert sombre, sont réunies deux ì deux dans une gaine; souvent elfes sont au nombre de trois, dans les pousses qui se trouvent sur de jeunes branches, ou pendant les premières années de l'arbre; et l'on verra, chap. XI, art. Xl, que les pins doux que j'ai élevés el qui ont actuellement 9 ans, ont eneore trois feuilles dans chaque gâne. Les pousses de cet arbre ont une teinte violette; lui et le Pinns inops (Pin paurre) sont les seuls arbres résineux conifères, observés par M. A. Michaux, qui présentent ce caractère. Les cônes du pin doux ont une forme ovale et ne dépassent point $0^{\mathrm{m}}, 02$ ì $0^{\mathrm{m}}, 03$ cle long dans les vieux arbres; leurs écailles sont armées de pointes fines.

Lorsque M. Michaux parcourut l'A mérique septentrionale, au commencement du $X 1 \mathrm{X}^{\mathrm{e}}$ siècle, le pin doux était si abondant dans les Élats-Unis, qu'une partic des maisons, dans les États du centre, étaient encore construites avec ce bois; les coustructions navales en consommaient aussi une très-grande quantité. Les planches et les madriers de ce bois étaient alors l'objot d'un commerce d'exportation très-considérable, on les payait plus cher que ceux du pin du ford Weymouth. "D'après les différens a vantages que présente son bois, dit cet auteur, " il est incontestablement, après le Pinus rubra (Pin rouge), l'espèce la plus inté" ressante à eultiver dans le milieu et dans le nord de l'Europe. "London dit, I. IV, p. 2196 de l'Arboretum, que l'époque de l'introduction du pin doux dans la Grande-Brelagne est incertaine; il aurait été plus exact s’il eût dil qu’il ignore si ce pin y existe. En effet, il ne cite qu'une seule plantation tont les arbres répondent, quoique imparfaitement dit-il, à la description de II. Michaux; cette plantation se trouve à Dropmore; on donne le nom de Pinus variabilis aux arbres qui la composent.

IX. PIn rouge, Pinus mbra A. Michaux (1). - J'emprunterai ce que je dirai du pin rouge à l'ouvrage de M. A. Michaux, que je viens de ciler. Le nom de Pin ronge, en anglais Red piue, est celui que les habitans des États-Unis el clu Canada donnent ordinairement à cet arbre de l'Amérique septentrionale; et ce nom exprime un de ses caractères extérieurs, qui est d’a voir une écorce très-rouge, ce qui ne se remarque sur aucun de ses congénères des pays où il se trouve. Tout se réunit done pour fiaire prélérer le nom de P'inus rubra à celui de l'inus resinosa qu'Aiton a donné à ce pin, el qui a été adopté par Lambert el par Lon-

(1) Histoire des arbres forestiers de l'Amérique seplentrionale, t. Ier, p. is, art. P'inus rubro. 
don; on peut ajouter que le pin ronge n'est pas le plus résineux des pins de l'Amérique sephentrionale, ét qu'on l'en extrat mème point de résine : ce der-

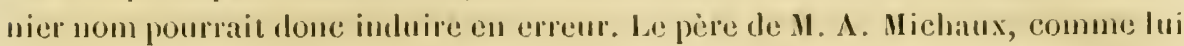
naturaliste et célèbre voyageur, l’a pas trouvé cet arbre plus au nort que le lau Sant-dean en Canatat, silué par $48^{\prime \prime}$ de latilude; ed .I. A. Michaux ne l'a pats

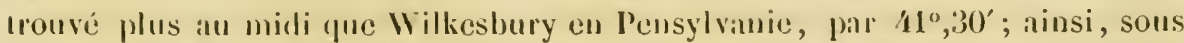
le rapport du climat, on pourra le cultiver jusque daus te norl de l'Europe. Cet arbre ne forme point d'immenses lorèts comme plusieurs des arbres indigènes des mèmes pays que hui ; il couvre seulement de petits espaces de quelques centaines d'arpens, seul ou mèlé avee le pin Weymouth, et il croit habitucllement daus des terres arides et sablonneuses.

Le pin ronge acquiert une hauteur de 22 a 25 mètres avec un diamètre de (1)" liers de sa hauteur; aussi lournit-il des planches de 12 i 13 metres ('10 pieds) de long sans ancun noud. Le bois de cet arlore est lort estimé el est employé pour la marine; M. A. Michaux eite un vaisseau de gutere construit ì Quebec, le

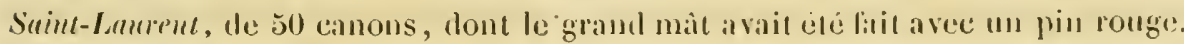
Cet anteur contredit done formellement l'opinion de Lambert, qui dit, daus l'artide qu’il a consacré à ce pin, sous le nom de Pinus resinosu, que son bois est de mam atise qualite: l'opintion du naluraliste voyageur qui a visite les forèts, les ateliers et les chantiers de l'Amérique septentrionale, me parait avoir plus de poids, à eé égard, que celle du botaniste renfermé habiluellement dans son cabinet.

Les feuilles du pin rouge sont d'un vert sombre, fongues de $0^{m}, 13$ ì $1^{\text {"I }}, 16$, et sont réunies deux à deux dans une garine; elles sont rassemblées en parjuets a l'extrémité des branches comme dans le pin maritime. Les fleurs fentelles du pin rouge sont blentitres dans les premiers mois de leur applatition, el ses cones, qui sont dépourvus d'épines, ont environ $0^{\mathrm{m}}, 03$ de longueur; ils sont arrondis à leur base el se terminent promptement en pointe. (Guelques botanistes ont pretemlu que le pin ronge était le même que notre pin lanicio; e’est évidenument une erreur, puisque le pin laricio n’a pas l'écorce rouge el que ses cones sont munis de petites épines. Loudon dit, 1. IN, p. 2212 de son trborehm, que le pin rouge a été introduit en Angleterre en 1755 par Ilugh, duc de Northumberland, e' il cite plusieurs lieux ou Lambert en avait vu des plantitions en 1801) mais il ajonte que les arlores de ces plantations sont tous morts ou qu'ils ont ćlé alattus, car on ne les y trouve plus. Voici ce que eet anteur rapporte d'une plantalion de ces arbres. Vers la lin du demier sièce, $\mathbf{1 1}$. Louldiges élevèrent anviron 100 plants de pin ronge provenant de graines quils avaient tirées de Plibialelphice, et la prespue tolalité de ees pins lurent plantés par le marquis de Blandford (actuellement duc de Marlborongh) a White Knighlss, oi la plupart d'entre

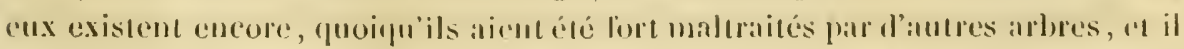

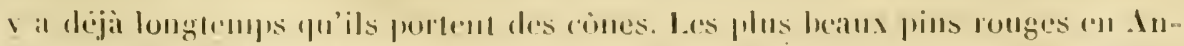

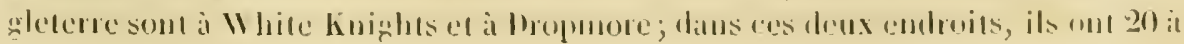


25 pieds $\left(6\right.$ mètres a $\left.7^{\text {"I }}, 50\right)$ de haut, el produisent ordinairement des cònes luus les deux ans. loudon ne donne pas l'âge de ces arbres, probablement parce ujue: ce sont ceux qu'avaient élevés $M . .1$. Loddiges; s'il en est ainsi, ils auraient eu an moins 38 ans en 18:38, époque à laquelle a paru l'ouvrage de Loudon, et leur accroissement aurait été faible, comparé a cẹlui de plusieurs de leurs congénères dans le même climat.

Je sais qu'il y a de très-jeunes pins rouges anx Barres, terre de M. Vilmorin, près de Nogent-sur-Vernisson (Loiret), el à Cheverny, terre de 11 . Ie marquis de: Vibraye, à 12 kilomètres au midli de Blois (Loir-et-Cher); je n'en commais point ailleurs en France. Cet arbre est le seul des arbres dont je parle dans ce chapitre que je n'aie pas chez moi en pleine terre; je ne l'ai pas tronvé chez nos pépiniéristes, et je ne l'ai point fait venir de Londres : les licux tris-fruids oil on le tronve dans quelques parties de l'Amérique septentriunale ne permetlent pas do: douter qu'il ne soit de pleine lerre, même dans le nord de la France.

X. Pan de Lanaert, Pims lambertiana Douglas (1). - Le pin de Limbert n'est encore, pour ainsi dire, connu en lurope que par ce qu'en a dit Douglas, naluraliste anglais, qui l'a olsservé dans la Nouvelle-Albion; ce que je viris en dire sera done emprunté à London, qui en a parlé d’après ce naturalisle. Donglas observa ce pin vers $43^{\circ}$ de latitude, à environ 100 milles ( 160 kilom.) de: l'Océan, ou il occupait une vaste élendue de payss; il le rencontra ensuite an dela d'une: chaine de montagnes fui se terminent an cap Orford. Il s'y trouvait sur des silbles purs qu'on aurail crus incapables de jrorluire ancun végétal, el non co massifs, comme les autres pins de l'Amérique; mais dispersé ça el lá, ansi đue le pin rouge, avec lequel il est quelquefuis mêlé. C'est sur ces sables arides qu'il parvenait à ses plus grandes dimensions; il y atteignait ordinairement I50 i 200 piecls anglais (45 à 60 mètres) de haut, et 20 à 60 pieds ( 6 à 18 mètres) de circonférence. Un de ces arbres, qui avail élé renversé par les vents, était lonğ de 215 pieds $\left(61^{m}, 5\right)$; sa rireonférence, à 3 pieds $\left(0^{m}, 90\right)$ dı sol, était de ja pieds 9 ponces $\left(17^{m}, 58\right)$, ce à 133 pieds $\left(40^{m}, 20\right)$, de 17 pieds 5 pouces $\left(5^{m}, 37\right)$.

Le trone du pin Lambert, qui ordinairement n'est pas droit, est déponillé de branches jusqu'aux deux tiers environ de sa hauteur. Son écorce, plus unic que ses grandes dimensions ne sembleraient le comporter, est d'une couleur brunclair du côté du midi et blanchâtre du côté du nord. Ses branches sont pendantes et son aspect est pyramidal, comme.cehui des sapins. Ses feuilles, contenmes au nombre ile cinq elans une, gaine, som longues de 4 à 5 pouces $\left(0^{\mathrm{m}}, 10\right.$ a $\left.0^{\mathrm{m}}, 13\right)$, d'un vert brillant, mais pis lustrées, el clles sont rudes an toncher. J'ai remarqué qu'elles avaient intérienrement denx raies blanches comme les leuiles du pin Wcymoulh, mais beancoup moins apparentes. Ses cônes sont placés aux extrémités des branches; ils sont errigés la première année et pendaus la seronde annéc; ils ont d'albord une lorme conique, et devicmont ansuite oblongs

1. Arberctum et linflectum brtannicum, 1. 11. 1'. 228s, äl. Pinus lambertana. 
et légèrement courbes; ils ont environ 11 pouces $\left(0^{m}, 275\right)$ de circonférence dans l'endroit du plus fort diametre, et 12 à 16 pouces $\left(0^{\mathrm{m}}, 30\right.$ a $\left.0^{\mathrm{m}}, 41\right)$ de long; ils atteignent leur maturiti au bout de deux ans. J'en ai mesure un dans le calbinet d'histoire naturelle de M. le baron Benjamin Delessert; il a $0^{\mathrm{m}}, 32$ de long. Les graines sont longues de 8 lignes $\left(0^{\mathrm{m}}, 016\right)$ et larges de 4 lignes $\left(0^{\mathrm{m}}, 008\right)$; lrur amande a un goît lort agréable; les ailes dont elles sont munies sont cuviron deux fois plus longues (pue les graines. Le bois du pin de Jambert est blane, teudre et léger.

Loudon dit que cet arbre ne lui paraît pas être plus délicat que le pin du lord Weymouth, et que le plus grand plant de cette espèce qu'il connaisse a éte semé en 1829 dans le jarlin de M. William Wells, à Redleaf; il avait, dit-il, I0 pieds 2 pouces $\left(3^{\mathrm{m}}, 05\right)$ de laut, probablement en 1838, lorsque Loudon publia son ouvrage.

Je n’ai vu de pins Lambert en France que dans la pépinière de $\mathbf{M}$. Cels et dans le parc de Fromont, où ils étaient fort jeunes, et provenaient de greffes en placage laites sur pin Weymouth; je me suis procuré denx de ces pins, qui n’ont encore (1815) que trois ans de greffi; ils ont très-bien passé en pleine terre l'hiver de 181'1-1815, dont le commencement et la fin ont été rigouruxx, sans qu'on en ait pris d'autre soin que de leur mettre une couverture de feuilles.

XI. Pin de Sabine, Pinus sabiniana Douglas (1). - Le pin de Sabine a été observé par Dunglas, pour la première fois, en 1826; ce qu'en dit Loudon est extrait des lettres de ce naturaliste, et j'emprunte à Loudon ce que je vais en dire. Le nom que Douglas a domné à ce pin est celui de M. Sabine, son ami. Les plus beaux arbres de cette espèce de pin croissent en Amérique sous $40^{\circ}$ de latitude, sur le versant ouest des Cordillières de la Nonvelle-Albion, à une hauteur considérable an dessus du niveau de la mer, et à 1,600 pieds ( 180 mètres) au dessous des neiges éternelles, dans des terres de dépôt. Plus au midi, sous $31^{\circ}$ de latitude, on trouve ces arbres sur le sommet de montagnes moins hautes situées au borl de la mer; ils y jouissent d’une température plus élevée et plus rígulière; ils y occupent des terrains schisteux et graveleux, et n'y parvienment qu' i de faibles dimensions.

Le pin de Sabine est droit, a unc forme pyramidale, et est garni de branches du sol à la cime, quand il croît isolé on qu'il n'est pas trop serré; il peut, dans les siluations favorables, atteindre de 110 i 140 pieds (33 it 42 mètres) de haut, a vec une circonférence de 3 à 12 pieds $\left(0^{\prime \prime \prime}, 90\right.$ i $\left.3^{\text {m" }}, 600\right)$. Ses lenilles, contenues an nombre de trois dans une gâne, sont droites, longues de 11 à 12 pouces $\left(0^{\mathrm{m}}, 27\right.$ כ it $\left.0^{\mathrm{m}}, 30\right)$, et d'un vert glauque. Ses cones sont agglomérés au nombre de trois à neuf antour des branches; ils atteignent leur maturite au mois de novembre de l'ammée qui suit celle où its sont mes, et ont alors de 9 à 11 pouces $\left(0^{m}, 2.25\right.$ à $\left(0^{\mathrm{m}}, 275\right)$ de long; leurs écailles sont armées d'une prointe recourbée très-lorte et 
très-aiguë. Les graines, longues de 1 pouce $\left(0^{\mathrm{m}}, 025\right)$, légèrement ublongues, plus minces à l’un des bouts, munies d’ailes moitié plus courtes que la graine, contienment une amande d'un goùt agréable. London dit que des graines envoyées par Douglas en 1832 furent semées cette annéc même dans le jardin de la Société d'horticulture, et que l'un des plants provenant de ce semis avait, en 1837, 4 pieds 6 pouces $\left(1^{\mathrm{m}}, 3 \mathrm{\partial}\right)$ de haut; un autre plant à Dropmore avait, li même annéu, š pieds 6 pouces $\left(1^{\mathrm{m}}, 65\right)$ de lıat. Celte espèce, dit Loudon, parait ètre aussi robuste que le pinuster (pin maritime).

Il y a en pleine terre, an Jardin-des-Plantes de Paris, un pin de Sabine yui avait environ 2 mètres de haut à l'automne de 181' ; j'en ai chez moi deux qui ont été greffés en 1843 sur pin Weymouth; ils ont très-bien passé les hivers en pleine terre, sans qu'on en ait pris d'autre soin que de leur mettre une couverture de leuilles.

XII. Pin de Coulter, Pims Conlteri D). Don (1). - Le pin de Coulter a élé ubservé pour la première fois par le docteur Coulter, on ne dit pas en quelle année. Peu de temps après, en 1832, Douglas euvoya en Anghterre des graines et des cònes que: Loudon prétendait appartenir au pin de Coulter, landis qute Lindley prétendait qu'ils appartenaient à une variété du P'imns sabiniona ou à une autre espèce qu'il a appelée Pims macrocarpa. Ainsi, selon Loudon, te P'inns macrocarpa de Lindley ne serait autre que le P'imus Conleri de: D. Don. (Wnoi qu’il en soit, il nous arrive d'Angleterre, sous l'un el l'autre noms, des plants qu'il est difticile de distinguer les uns des antres, et qui sont de pleine terre sous le climat de Paris; d'autre part, il y a un arbre à grandes dimensions, daus l'Amérigue septentrionale, que Loudon dit être ce pin de Coulter; je vais done emprunter ì cet anteur ce qu'il en dit, n'ayant d'autre but que d'éveiller l'altention des persommes qui s'occupent de plantations.

Le docteur Coulter trouva le pin auguel on a donné son nom dans la Californie, sur la montagne de Sinnte-Lucie, près de la mission de Saint-Antoine, sous $36^{\circ}$ de lattitude et à une hauteur de 3 à 4,000 pieds (900 à 1,200 mètres) au dessus du niveau de la mer; il y élait mèlé avec le pin de Lambert. Le pin de Coulter est un arbre à grandes dimensions, qui croît rapidement et qui s'élève a une hauteur de 80 à 100 pieds (24 à 30 mètres). Son écorce est brune. Ses branches, lortes et étendues, occupent liı eime de l'arbre. Ses pousses ont ure teinte violelte, comme celles du pin doux. Ses feuilles, contenues aur nombre de trois dans une ganne, de la mème couleur que celles du pin de Sabine, sont plus grosses que les feuilles d'aucun autre pin et sont longues de plus de 9 pouces (1)"m,2-25). Ses cònes sont isolés; ils sont oblongs et ont quelquefois plus de l pied $\left(0^{\mathrm{m}}, 3(1)\right)$ de long, avee un diamètre de 6 pouces $\left(0^{\mathrm{m}}, 15\right)$. Ses graines sont elliptiqu's, longues de 6 lignes $\left(0^{m}, 0125\right)$, et elles sont munies d'une aile qui a 6 lignes (1)"', (1675) de long. Le pin de Coulter et le pin de Sabine se ressemblent beaucoup

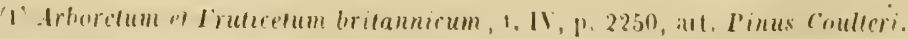




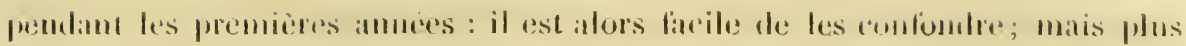

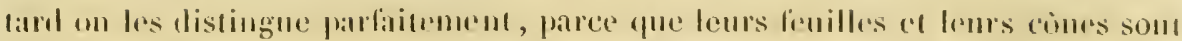
fort dillérens.

Jemprunte i Louton, 1. W, p. 22.s de son trboretum, une comparaison du pin de Coulter et du pin de Sabine: "Douglas envoya, dit-il, des cones de pin "de Coulter en 1832, ef des plants furent élevés de leurs graines l’amén sui"vante; l'un de ceux du jardin de la Société d’horticulture avait, en 1837, 7 pieds " (2"m, 10) de haut. Dans son ensemble, le pin de Coulter ressimble au pin de Sil" hine, mais on peut ficilement l'en distinguer par le caractère de raileur de son "fenilage. Ces deux arbres ont les boutons de la même forme et de la mêne "couleur; les fenilles de la même; couleur glauque à toutes les époques de leur " accroissement; les jeunes pousses d'un violel glanque comme celles du Pinus "inops er du Pinns mitis, et tons les deux conservent leurs feuilles jusqu'à l'été " de la troisième année. La conleur el la forme des graines dans les deux arbres " sout exactement les mênes; mais celui des deux qui porte les plus gros cônes "a Ies plus petires graines. 11 nous semble que ces arbres sont seulement des " variétés d'une même espèce; mais, s’il en est ainsi, ces variétés sont anssi dis" tinctes que quelque espèce que ce soit. Ces arlores sont d'une grande beauté, " el ce qui ajoute beaucoup à leur valeur, éest qưils paraissent être très-ro"bustes. "

Il y a en pleine terre, an Jardin-des-Plantes de Paris, un pin de Coulter qui avait environ 2 mètres de haut à l'automne de 184. J'en a chez moi deux qui ont été grelfés en 48 't' sur pin Weymouth, et qui ont bien résisté à l'hiver do ISt1-1815, protégés senlement par une converture de feuilles.

1III. Cypnès mstrque, Cupressus disticha Linné (1).-- On appelle aussi cen arbre Crpres de l'A métheve el Crplies de La Lousuan, du nom des pays où il est indigine, et Crpres cinuve, paree qu'il ne conserve pas ses feuilles l'hiver. Jemprunterai principalement ce que je dirai du cyprès distique, qui n'est encore cultivé en France que comme arbre d'omement, à M. A. Nichaux (2), qui l'a observé sur les lieux mêmes où il est inligène, et à Loudon (3).

Le cyprès distique est très-lacile à recommattre par ses feuilles, qui sont composées de folioles semblables, pour la forme, à celles des sapins, mais beancoup, plus minces; ces folioles sont rangées de chaque côté d'une nervure commmme ot silnées sensiblement dans le même plan. Les feuilles du cyprès distịne sont du vert le plus tendre, et, à l'automue, elles deviemnent rouge-brique avant d. tomber. Cet arbre porte des lleurs mâles et des fleurs femclles disposíes en chatons. Ses cönes, qui ont environ $0^{\mathrm{m}}, 02 \mathrm{~T}$ de diamètre, sont durs, presufue ronds, et leur surface, d’un brun rougeâtre, est rabotense.

\footnotetext{
1) Species plantarum, ze édit., p. 1 122.

2) Histoire des arbres forestions de l'amérique septentrionale , 1. III, p. 5, art. Cupressus disticha

3' Arboretum ef Fruticetum britannicum, 1. 11. p. 2isı, illt Tarodium distichum.
} 
Le cyprès distique est indigène des provinees méridionales des Élats-Unis, et il ne dépasse guère $38^{\circ}$ de latitude; on l'y trouve dans d'immenses marais, où il occupe quelquefois des milliers d'hectares, et sur les bords de quelques rivières; dans ces deux situations, son tronc est couvert d'eau pendant plusieurs mois, quelquefois jusqu'à la hauteur de 3 mètres à $3^{m}, 25$ au dessus de ses racines. Cet arbre aime les marais les plus prólonds, les plus sombres, les plus inaccessibles et les plus inondés; cette situation au milieu des eatux, dans des terrains tourbeux ou sablonneux, est celle qui lui convient le mieux; sa végétation est beaucoup moindre dans les marais à base d'argile.

Dans les situations qui lui sont le plus farorables, "il acquiert, dit M. Mi" chaux, 40 mètres d'élévation sur 8, 10 et 12 mètres de circonférence au dessus " de sa base conique, dont la grosseur à la surface du sol est toujours trois à " quatre fois plus considérable que celle du corps de l'arbre. C'est ce qui fait que " les nègres chargés d'abattre ees cyprès sont obligés d'élever des échafaudages " au dessus de terre pour les couper à l'endroit oì le tronc commence à prendre " une grosseur uniforme. Celte partie inférieure du tronc, ordinairement creuse " dans les trois quarts de son volume, n’a pas une forme pyramidale aussi régu" lière que celle du Nissa grandidentata; elle en diffère surtout en ce qu'elle pré" sente à sa surface de larges sillons longitudinaux, dont les parties saillantes " sont inlérieurement comme autant de crampons destinés à fixer cet arbre dans " le terrain qui a peu de consistance. De la surface des racines des plus gros ar"bres, et surtout de ceux qui sont le plus exposés aux inondations, maissent des " espèces d'exostoses olı de protubérances coniques qui ont jusqu'à $1^{\mathrm{m}}, 30$ ì $1^{\mathrm{m}}, 60$ " de hauteur, mais communément $0^{\mathrm{m}}, \mathbf{4 0}$ à $0^{\mathrm{m}}, 60$. Ces excroissances, toujours " creuses à l'intérieur, et dont le sommet est lisse, sont couvertes d'ume écorce "rousse comme celle des racines, auxquelles elles ressemblent encore par leur "texture ligneuse, qui est très-tendre."

M. Michaux dit, en parlant des qualités du bois du cyprès distique, qu'il est d'une teinte rougeâtre lorsqu'il a été exposé quelque temps à la lumière; qu'il est moins résineux que celui des pins; qu'il est doué d'un grand degré de force el d'élasticité; qu'il résiste très-longtemps aux alternatives de la chaleur et de l'humidité; qu'on en fait les meilleurs conduits souterrains pour les eaux; il dit que les maisons de la Nouvelle-Orléans en sont presque toutes construites, et qu'on l'emploie aux constructions de la marine; enfin que l'on construil avec le tronc de cet arbre des canots ou pirogues, d'une scule pièce, qui ont plus de 10 mètres de longueur sur 2 mètres de largeur.

Malesherbes rapporte dans un mémoire sur le cyprès distique, inséré par larennes de Fenille dans ses Mémoires sur l'udministrution forestičre (17)-2), 1. II, p. 160 , que sur l'habitation de la Boule-Ronge, à 26 lienes de la Nouvelle-Orléans, on remarquait l'un de ces arbres qui, avec une hauteur extraordinaire, a vait 12 brasses de tour. I.e cyprès distique est l'un des arbres exotiques que l'on cultive depuis le plus longtemps en France, puisque Malesherbes dit, dans le mémoire que ju viens de citer, que ses cyprès ont fructifié, mais n'ont pas donné 


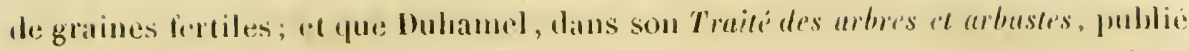
(n 1755, dit que cet arbre est encore très-rane en France : on l'y culdivat done dóji depuis plusieurs années il y a 89 ins.

la Louisiane, on le eyprès distique est le plus commun et acquiert les plus lwelles dimensions, étant mo pays chaud, on pouvait eraindre qu’il ne résistât fas anx froids du nord de la France; mais il y a très-bien résisté, puisque Mitlesherbes nous apprend qu'il n'a point sonfiert des hivers si rigomrenx de 1766 at de 178\%. 1. mème auteur rapporte qu'ayant cultivé cet arbe dans des torraius sees, il y a perri, et que daus une bonne terre de jardio il il en une végétittion chétive, tandis qu'il a très-bien réussi dans de manvaise tourbe el daus des sables très-lıumides. Il serait d'ailleurs possible que cet arlore, quoique riosistant aux hivers du nord de la France, ne pùt y alteindre les magnitiques dimensions qui le font remarquer dans les marais et sur les bords de quelques rivières des provinces méridionales des litats-Unis, que même il n'y atteignit ordinairement que de médiocres dimensions.

I'ai vu dans les environs de Paris quelques eyprès distiques, el je n'en ai pirs trouvé dont les dinususions fussent remarquables; ma ınauvaise santé, encors: plus que mes ocenpations, est cause que je n'en ai pas examine un plus grand nombre. Cenx que j’a chez moi ont environ 14 ans. Il y en a six dans le pare de: Conclé, à 3 kilomètres de clıc\% moi, sur le bord de la rivière d'lton; ils ont été plantís en 1814. Le tronc du plus beau de ces arbres avait, a l'autonne de 1841, une circonférence de $\mathbf{1}^{\prime \prime}, 20$, et l'arbre avait environ 8 mètres de haut.

Un remarque autour de l'étang du pare de Trianon, au bord de l'eau, onze cyprès distiques qui sont âgés de plus de 60 ans, s’ils datent de la création du parce, el qui ont des dimensions bien moindres que les antres arbres résinenx conifères de ce parc, du mème âge. Le plus haut de ces cyprès, qui est en mêmr temps le plus gros, avait, à l'automne de 1814, environ 12 mètres de lant et I", 31 de circonférence; le plus petit, non compris celui dunt la tête est écrasée, avait environ $6^{\mathrm{m}}$,50 de haut et $0^{\mathrm{m}}$, 68 de circonférence.

Bose, qui avait vu le cyprès distique dans la Louisiane, dit, dans son article Cypress distique lu Dictionnaire raisonué ét uniecersel d'agriculture, que la plus grande plintation fu'il comnaisse aux environs de Paris est it Rambouillet, et qu'on nu: pouvait trouver une localité qui leur fùt plus favorable. " Fih bien! ajoute-t-il, " au lieu de les planter au milieu du marais, dians des llaques d'eau, on les a plat" cés sur la berge d’un fossé creusé pour l'écoulement de ces eaux. Aussi quelle " misérable régétation ils amoneent, tandis qu'un pied qui a été mis, sans doute " par hasard, dans un fond, a près d'un pied de diamètre et 30 à 40 pieds d'élé"Vation. Tous ces arbres doivent avoir aujourd'hui (1821) 36 ans environ." M. Michaux émet uneopinion que je vais reproduire relativementaux parties de? I'Europe où le cyprès distique pourra être cultivé comme arbre utile. "Je suis "prersuadé, dit-il, que la culture du Cupressus disticha, comme arbre utile, no

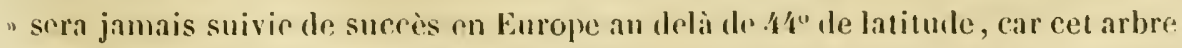
" a autant besoin de chaleur gur d'humidite pour vigéter ave vigueur; e'est ce 


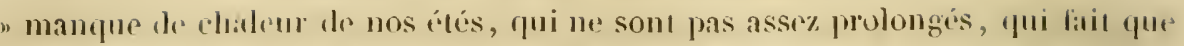
"beancoup de reprès chauves plantés près de Paris, lepuis plus de 25 ans, me " complètent pas la maturité de leurs fruits, quoiqu'ils fleurissent tous les ans; " e'est à cette même cause qu'on doit attribuer la lenteur de lenr régétation; car " la plupart ont moins de 6 à 8 mètres d'élévation. Les plus gros Cupressus disti" cha que nous possédons se trouvent à 100 kilomètres de Paris, dans les an" ciens domaines de M. Duhamel : plantés il y a plus de 40 ans et placés dans la " situation la plus favorable à leur végétation, ils se sont élevés à $12^{\mathrm{m}}, 80 \mathrm{sur}$ " $0^{\mathrm{m}}, 32$ de diamètre, et cependant leurs graines viennent très-rarement à ma" turité. Un propriétaire, dans les landes de Bordeaux, a obtenu un succès très" marqué dans la culture du Capressus disticha; des graines que je lui enroyai, " en 1803, de la Caroline méridionale, il a élevé cinquante individus qui, dans "le cours de ces huit dernières années, ont déjà atteint 6 à 10 mètres de hant. "Ce fait vient à l'appui de l'opinion où je suis que cet arbre ue réussira jamais " bien en France que dans nos départemens méridionaux, et notamment dans " les royaumes d'Italic et de Naples, partout où il se trouve des marais non cul" Livés. "J'avais d'abord adopté l'opinion de M. Michaụx, et je ne devais point parler du cyprès distique, puisque cet arbre ne pourait atteindre que de midiocres dimensions sous le climat de Paris; mais .I. Bernard, pharmacien it Malesherbes (Loiret), m'a envoyé, en octobre 1814, un renseignement que je vais reproduire, qui prouve qu'il en est autrement lorsque cet arbre croît daus une situation de tout point favorable, ce qu'il est d'ailleurs rare de rencontrer.

Malesherbes avait établi une pépinière de cyprès distiques au fond d'une vallée, à 2 kilomètres de la petite ville de Malesherbes, dans un terrain exposé au sud-est, tout à la fois tourbeux et marécageux, et dans lequel on troure l'eau it $0^{\mathrm{m}}, 32$ au dessous de la superlicie du sol. Ces arbres, semés d’abord sous châssis, y avaient élé repiqués en pépinière en $\mathbf{1 7 8 4}$, et furent pris ensuite pour être plantés à demeure; mais il en resta dix-neuf, les plus petits probablement, sur une étendue de 26 centiares, et ils y sont encore : le propriétaire de ces débris le plantations est le comte de Châteaubriand, neveu du grand écrivain, arrièrepetit-fils de Malesherbes. Voici quelles sont aujourd'hui les dimensions de cors arbres, qui ont dépassé 60 ans. Le plus gros a 2"m,30 de circonférence à 1 mètre au dessus du sol, el le moins gros a $0^{\mathrm{m}}, 80$; deux out 2 mètres; neuf ont $1^{\mathrm{m}}, 50$ ì $1^{\mathrm{m}}, 90$; sept ont $0^{\mathrm{m}}, 90$ à $1^{\mathrm{m}}, 21$ : on leur donne une hateur d'environ 24 à 27 mèIres; mais je suis disposé à croire que cette évaluation est trop élevée.

Quoique ces cyprès distiques aient pris en partie leur nourriture dans la terre et dans l'espace qui environne les 26 centiares sur lesquels ils se tronvent, leur régétation n'en aurait pas moins été extraorlinaire, lors même que leur hauteur serait moindre que celle qu'on leur attribue, el cette petite ítendue de terrain aurait produit un revenu prodigicus. Supposons en effet que le trone de ces arbres, qui est toujours beaucoup plus gros près du sol, n’ait plus, en en retranchant 1 mètre à partir du sol, que le décroissement ordinaire du trone dus sapins argentés, "y qur leur hauteur soit de 16 à 20 mètres seuloment; je trourr, 
en évaluant le bois au même prix que celui du sapin dans le lieu que j'habitc, que ce bois converti en pontres, planches, solives et chevrons, vaudrait environ $3 \breve{50} \mathrm{fr}$, vendu à un marchand : ainsi le cyprès distique, s'il pouvait avoir une telle végétation en croissant à l'état serré sur une plus grande surface, clonnerait, par hectare, un revenu de 134,615 fr. 38c., ce qui serait merveilleux. Mais si le tronc de ces arbres ne maintient pas sa grosseur comme celui des sapins, ce qui est probable; s'ils n'ont pas de 16 à 21 mètres de hatuteur, ce qui est possible, mon évaluation serait fort exagérée. M. Bernard m’a envoyé des cônes de ces arbres en décembre 1814, et je me suis procuré dans ce même mois des cônes des cyprès distiques du parc de Trianon; ces graines n'avaient pas complété leur maturité, car elles ne contenaient qu'un liquide résineux.

Miller, dans l'édition de son Dictionnaire de $\mathbf{1 7 3 1}$, citait un cyprès distique à Winbledon, dans le Surreyshire, qui produisait abondamment, depuis plusieurs années, des graines qui mûrissaient aussi bien et étaient aussi bonnes que celles d'Amérique, quand la saison était favorable. Loudon dit, page 2485 de l'ouvrage précédemment cité, que cet arbre parait avoir élé introduit en Angleterre avant 1640 , sans apporter de preuves à l'appui de cette assertion; il donne les dimensions de plusieurs cyprès distiques répandus dans les pares et jarlins de la Grande-Bretagne. Je vais reproduire quelques-unes de ces dimensions.

A Whitton, dans le voisinage de Londres, un cyprès avait : diamètre du tronc, à 2 pieds $\left(0^{\mathrm{m}}, 60\right)$ du sol, 5 pieds $\left(1^{\mathrm{m}}, 50\right)$; hauteur, 81 pieds $\left(24^{\mathrm{m}}, 30\right)$..Un cyprès distique à Port Elliot, plante depuis 80 ans, avait : diamètre du tronc, 3 pieds $\left(0^{\mathrm{m}}, 90\right)$; hauteur, 50 pieds (15 mètres). - Un cyprès, planté il y a 35 ans à Saint Anns Ilills, avait : diamètre du tronc, 2 pieds $\left(0^{\mathrm{m}}, 60\right)$; hauteur, 45 pieds $\left(13^{\mathrm{m}}, 50\right)$. - A Ditton Park, un cyprès âgé de 90 ans avait : diamètre dı tronc, 3 pieds 6 pouces $\left(4^{\mathrm{m}}, 05\right)$; hauteur, 80 pieds ( 24 mètres). - Un cyprès,

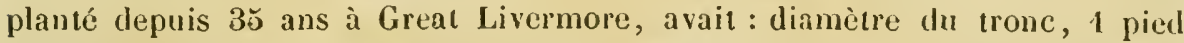
2 pouces $\left(0^{\mathrm{m}}, 35\right)$; hauteur, 37 pieds $\left(11^{\mathrm{m}}, 10\right)$. - Un cyprès, planté depuis 60 ans à Croome, avait : diamètre du tronc, 2 pieds $\left(0^{\mathrm{m}}, 60\right)$; hauteur, 55 pieds $\left(16^{\mathrm{m}}, 50\right)$.

Le même auteur dit qu'il y a en Prusse, à Sans-Souci, près de Potsdåm, un cyprès distique âgé de 40 à 50 ans, et qui avait : diamètre du tronc, 1 pied $\left(0^{\mathrm{m}}, 30\right)$; hauteur, 20 pieds (6 mètres). - En Autriche, à Brück, sur la Leytha, près de Viemne, un cyprès, planté depuis 30 ans, qui avait : diamètre dụ tronc, 1 pied 6 pouces $\left(0^{\mathrm{m}}, 45\right)$; hauteur, 36 pieds $\left(10^{\mathrm{m}}, 80\right)$. -- En Lombardie, à Monza, un cyprès, planté depuis 20 ans, qui avait : diamètre du tronc, 4 pieds 2 pouces $\left(1^{\mathrm{m}}, 25\right)$; hauteur, 62 pieds $\left(18^{\mathrm{m}}, 60\right)$. - En Amérique, à Plıiladelphie, dans le jardin botanique de Bartram, un cyprès qui avait : diamètre du tronc, 28 pieds 6 pouces $\left(8^{m}, 55\right)$ au dessus du collet; hauteur, 120 pieds (36 mètres). Les cyprès distiques suffisamment âgés portent, en Angleterre et en France, des lleurs mâles et des cônes; mais j’ignore si en France, sous le climat de Paris, leurs graines parviennent à la maturité. Il est indubitable qu'elles y parviendront facilement dans les parties méridionales de la France, si, ainsi que te dit Miller, elles mûrissent quelqurefois en Angreterre. 


\section{CIIAPITRE XI.}

\section{PÉPINIERE ET PLANTATION A DEMEURL.}

I. Observations préliminalres et trayaux preparatolres. - Je vais moccuper dans ce chapitre de la culture en pépinière de dix des espèces d'arbres résineux conifères dont j'ai précédemment parlé, et de la plantation à demeure des plants obtenus ainsi; ces dix espèces sont les huit espèces à chacune desquelles j'ai consacré un chapitre, et en outre le pin d'Autriche et le pin doux.

Le semis artificiel à demeure échoue toujours dans certaines circonstances (Voy. p. 11), et il réussit très-difficilement sous le climat de Paris, ainsi qu'on l'a vu, pour quelques-unes des espèces dont je me suis occupé. Il y a donc nécessité absolue, dans quelques cas, d'employer la plantation à demeure pour créer des bois d'arbres résineux conifères; il y a un avantage qui équivaut presque à une nécessité dans d'autres cas, et cela est nécessaire dans plusieurs circonstances, même pour les espèces dont le semis artificiel à demeure réussit très-bien. Ainsi, par exemple, cela serait nécessaire pour former des allées, pour créer des bosquets, pour se procurer le plus promptement qu'il est possible un bois d'arbres résineux; car, presque toujours, c'est en employant la plantation que l'on y parvient : il peut arriver aussi que l'on veuille défricher un bois feuillu, après unc coupe qui ne devra être exécutée que dans quelques annćes, pour le remplacer par un bois résineux; et alors, pour gagner du temps, on fait d'avance une pépinière les espèces que l'on veut substituer à ce bois feuillu.

Je ne craindrai pas de répéter ici ce que j’ai déjà dit, qu'un propriétaire qui aurait dans ses bois du plant de semis naturel, ainsi que j'en ai dans les miens, ou qui aurait du plant provenant de semis artificiel à demeure, ne devrait pas, par cette raison, se dispenser d'élever du plant de pépinière, s'il estdans l'intention de faire des plantations. En effet, le plant de pépinière présente de très-grands avantages, parce que l'extraction en est plus facile; parce que ses racines étant bien garnies de chevelu, il reprend beaucoup mieux, el que les pertes, et par conséquent les remplacemens, sont alors beaucoup moindres; enfin parce que ses racines n'ayant pas été mutilées, ainsi que cela arrive ordinairement quand on emploie du plant de semis naturel, il donne généralement naissance à des arbres plus beaux. 
Toutes les personnes qui s'occupent de plantations savent d'ailleurs actuellement que les plantations de sapin argenté, de sapin piéa, de pin sylvestre, de pin laricio, de pin du lord Weymouth, de mélèze et même de pin maritime, exécutées aveć du plant de pépinière planté à l’àge et avec les soins convenables, réussissent très-bien. J'ai tronvé qu'il en était de même de celles de pin d'Autriche et de pin doux; le cèdre du Liban m’a parn plus délieat. Je ne prétends pas que l'on réussira également bien, dans l'éducation et la plantation à demeure de ces arbres, en les traitant tous de la même manière; il faut que l'on donne à chacun d'eux les soins qu'il réclame elque je vais indiquer, selon que je l'ai pratiqué : je n'aflirme d'ailleurs point que ce soit ce que l'on peut faire de mieux, mais seulement que j’ai obtenu des résultats satisfaisans.

Je ne m'occuperai point de la culture en pots, qui est coûteuse, qui exige des soins continuels, et qui n'est applicable qu'à de petites ou à de médiocres quantités de plants; on réussit d'ailleurs mieux, pour les arbres résineux à grandes dimensions dont je m’occupe, avec du plant de pépinière bien garni de chevelu, qu'avec du plant élevé en pots, dans ce sens que le premier ne boule que pendant un an, tandis que le second, dont les racines élaient entassées dans les pots, boude pendant plusieurs années.

Ces arbres ne sont pas aussi délicats que tant d'auteurs l'ont dit, et ils peuvent reprendre très-facilement, quoique l'on ait eassé ou coupé quelques-unes de leurs racines; s'il en était autrement, on ne pourrait laire réussir un seul arbre de pépinière, car à la distance à laquelle on les place dans la pépinière, il y a impossibilité de les lever sans couper ou casser le bout de quelques racines; mais si le plant n'a point de pivot et est bien garni de chevelu, cette légère mutilation ne l'empèche point de reprendre. Ce qui est encore plus nuisible au plant de ees arbres qu'à celui des arbres feuillus, c'est de laisser leurs racines exposées au hâle, au soleil ou à la gelée; il faut les planter le plus promptement possible après qu'on les a arrachés, et, si l'on ne le peut, il faut les mettre en jauge; si le retard dans la plantation ne doit être que de quelques lıeures, on se contente de les couvrir soigneusement. S'ils dọivent être expédiés plus ou moins loin, il faut les emballer aussitôt qu'ils sont arrachés et les entourer suffisamment de mousse et.de paille. Je citerai quelques faits pour prouver que des arbres résineux peuvent bien reprendre, quoique leurs racines aient été mutilées.

J'ai planté un picéa, un pin sylvestre et un mélèze, qui provenaient originairement de pépinière : les deux premiers avaient 7 mètres de hant, le troisième 8 mètres, et plusieurs de leurs racines avaient été coupées à la pioche; ils ont bien repris, mais ils ont boudé pendant six ou huit ans, et je donte qu'ils deviennent jamais de beaux arbres. J'ai planté des sapins argentés de pépinière qui avaient tous un pivot, parce qu'on ne les avait pas repiqués et qu'ils n'avaient éti transplantés qu'une fois; ils étaient d'ailleurs hien garnis de chevelu; on leur a coupé le pivot en les arrachant, et ils n'en ont pas moins bien repris. Mon père ne remplaçait les sapins, dans les allées de son parc, qu'arec du plant de semis naturel qui n'avait pas de phevelu, el dont on mutilail les racines on l'arrachant, 
cependant il en reprenait quelques-uns. J'ai planté un cèdre de pépinière, quoiqu'il eùt perdu l'une de ses deux racines principales, qui éelata près du collet; lat flèche périt, l'arbre bouda pendant quatre ans, puis trois branches formèrent des flèches; cet arbre a actuellement une belle végétation. Il n'est d'ailleurśs pas frudeut de planter des arbres résineux auxquels on a coupé ou brisé le pivot, ou des racines principales, parce qu'ils sont sujets à la pourriture au coeur, malalie: qui commence par les racines.

Les auteurs qui ont parlé de la plantation des arbres résineux conifères disent depuis longtemps, en se répétant les uns les autres, qu'on ne doit les planter qu'au printomps, au moment ou peu de temps avant le moment où ils entrent en sève. Je préteuds, au contraire, d’après une longue expérience, que, pour presque tous les arbres dont je moccupe dans ce chapitre, il est préférable de planter l'automne, du moins sous le climat de Paris où j’a fait mes plantations. On y trouve d'ailleurs cet avantage incontestable que leurs racines sont alors beatucoup moins expasées à l'action du hâle et du soleil, à laquelle elles sont si sensibles; aussi quelques-uns d'entre eux, lorsqu'on les a plantés l'automne, avec les précautions que j'indiquerai, poussent-ils au printemps suivant presque aussi bien que s'ils fussent restés dlans la pépinière; ils boudent toujours, au contraire, pendant un an au moins, lorsqu'ils ont été plantés au printemps. Ia plantation d'automne a pourtant l'inconvénient d'exposer les racines, dans une terre nouvellement remuće, aux alternatives de gelée et de dégel, communes sous le climat de Paris, ce qui est nuisible au plant de quelques espèces; et pour celles de ces espèces dont le plant est chargé de branches vers la tête, de les exposer, après la plantation, à être ébranlées par les vents qui sont plus violens l'automne et l'hịver que pendant le reste de l'année : je donnerai, sur chacune des espèces dont je vais m'occuper, tous les renseignemens qu'on peut désirer à ce sujet.

Le plus ou le moins de rapidité d'aceroissement des arbres, dans leurs premières années, étant une des causes qui délerminent le nombre de transplantations qu'on leur fait subir et l'âge auquel on les plante à demeure, je vais indiquer quel était l'ordre de ċet accroissement, dans la localité que j'habite, pour le plant des arbres dont je vais m'occuper. Le mélèze, le pin maritime et le pin doux étaient ceux qui avaient l'accroissement le plus rapide; le pin sylvestre et le sapin picéa suivaient, le pin du lord Weymouth venait ensuite, puis le pin laricio, le pin noir d'Antriche et le cèdre du Liban, enfin le sapin argenté. II pourrait y avoir quelques changemens dans cette marche de la végétation dans une autre localité, d'autant plus que mon terrain, qui est silico-argileux; ne contient point de calcaire; mais pas ordinairement, je crois, dans une terre préparée, ainsi que je vais le dire, en ce qui concerne les huit espèces dont je me suis occupé spécialement. Néammoins, je me permettrai d'exprimer un doute relativement au cèdre du Liban, ayant la crainte d'avoir employé de la graine. qui n'était pas cutièrement mûre.

La terre qui convient pour l'ŕtablissement d'une pépinière des arbres rési- 
menx dent je miocrupe, en ce qui comerne le repingage el la llausplantation, est une terre lianche, légère, ficilement pénétrable aux racines, reposant sur uII sous-sol qui laisse passer l'eau. Il est utile d'y ajouter de la lerre de bruyère pour les pius sylvestres, les pins maritimes, les pins laricio, les pius doux ef less fins d'Autriche; cela ne me paraitrait utile pour les antres espèces que si li terre nétait pas parlaitement meuble, car il faut d'abord que la terre soit mellhe, c'est unc condition de réussite que rien ne peut suppléer. Des pépinières des cinq espèces de pins que je viens de nommer peuvent aussi s'établir, avere un entier succès, dans une terre siliceuse ou sablonneuse suffisamment substanliclle; il laut d'ailleurs toujours que le sous-sol la isse facilement passer l'eau. La terre dans laquelle on exécute le semis doit ètre encore plus meuble, pour que les racines du jeune plant puissent facilement s'y étendre; on la préparera avec de la terre franche, de la terre de bruyère el du terreau, neltoyés, bien mêlés el réunis dins les proportions nécessaires. J'indiquerai les précaulions a prendre pour le semis daus les articles consacrés aux diverses espèces d'arbres dont je vais parler, carr ces précautions ne sont pas toujours les mêmes.

L'exposition qui me parait préférable est le nord pour le sapin argenté, le: sapin picéa, le pin sylvestre, le pin du lord Weymouth, le pin loux, Ie mélèze, le pin d'Autriche et le cètre dlu Liban; le pin maritime el le pin laricio élant indigènes du midi de l'Europe, devraient, sous un climat qui se rapproche du nord, préférer l'exposition du midi et du couchant : presque tous ces arbres prospérerout d'ailleurs en pépinière, à toutes les expositions, si on leur donuc les soins convenables. Au uord, on a l'avantage que les alternatives de gelée el de dégel de la terre sont moins rapides et même moins fréqututes.

Après avoir choisi et préparé un terain convenable, il faut se procurer de bonme graine, ce qui n'est pas toujours facile; on coupera done plusieurs graines en denx pour voir si elles contiennent une amande, aninsi que cela tloit êtro, on examinera si elles ont le poids, l'odeur et surtout la couleur qu'elles doivent avoir. Mais comme il peut arriver que le germe (l'mbryon) ait péri sans que cela soit apparent, ainsi qu'il arrive, par exemple, lorsque les graincs ont éprouvé une fermentalion ou une chaleur trop vive, le plus certain est d'éprouver cette graine en petit sous une bâche on dans une serre, oì elle lève plus vitı. Quand on dispose d'une serre chanffée, on peut l'éprouver l'hiver, et on le peut même dans une chambre tenue à une température convenable; on sème daus des pots et l'on arrose avec de l'eau tenue à la température de cette chambre; jai lait cette éprenve dans ma chambere, pendant l'hiver de 1812-1813, sur de lit graine fle pin sylvestre et de pin maritime, et elle a réussi : cette éprenve ast d'ailleurs incertaine, puisqu'elle dépend de la température que l'on entretient dans une chambre, température qui est ordinairement très-variable. J'ai aussı essayé de faire germer des graines entre deux morceaux de flanelle que j’arrosalis rous les jours, le pin sylvestre seul germa.

de dis, pour ne pas le répéter dans chacun des articles qui vont suirre, que l'on doil toujours employer', antant quion le peut, he lat graine qui a muri dans 
l'annéc mêne où on lá sème; elle présente moins de déchet que de la graine plus vieille, lève mieux ut donne naissance à des plants plus robustes qui deviennent probablement des arbres plus beaux. Cela est surtout indispensable pour la graine du sapin argenté, dont la plus grande partie ne lève plus la seconde année; quant aux autres graines, on a vu, dans les chapitres consacrés aux arbres qui les produisent, qu'il y en a une partie qui conservent leur faculté germinative pendant trois ans au moins, si l'on en prend le soin convenable.

Le terrain destiné à la pépinière sera disposé et distribué, ainsi qu'il suit : on y lera des planches pour le semis, des planches pour le repiquage, des planches pour la première transplantation, si l'on eultive des espèces qu'il faille transplanter deux fois, et des quartiers dans lesquels on transplante le plant qui doit y rester jusqu'à ce qu'on l'enlève pour le planter à demeure. La terre de ces planches et de ces quartiers sera telle que je l'ai indiquée, et on leur donnera le nombre de façons nécessaires aux époques convenables avec une fourche à bêcher qui a trois dents plates (Pl. VII, fig. 3 el 4', et sert tout à la fois à bêcher les tcrres légères et les terres mcubles, el à arracher les arbres de pépinière de petite dimension, pour la transplantation : cet instrument est le seul dont on devrait se servir pour bêcher autour des racines des arbres, par exemple dans les plates-bandes des espaliers, et il est inconnu dans la plus grande partic de la France. On doil d'ailleurs toujours semer el transplanter à part chacune des espèces dont je vais m’occuper, à cause de la différence qui existe dans la rapidité de leur aceroissement.

Les planches pour le semis auront $\mathbf{L}^{\mathrm{m}}, \mathbf{4 0}$ de large et une longueur dépendant de la quantité de plant que l'on veut élever; elles ue doivent jamais ètre plus larges, afin que l'on puisse les désherber facilement. Les planches sur lesquelles on repiquera le plant (et le plant de toutes les espèces dont je moccupe dans ce chapitre (loit être repiqué dans la première année) auront la même dimension. Lorsque l'on aura plusieurs planches destinées au semis et au repiquage, ce qui est le cas ordinaire, elles seront séparées par des sentiers qui auront au moins $0^{\mathrm{m}}, \mathbf{2 \tau}$ de large; cette largeur est deux fois celle d'un sabot; les jardiniers forment ces sentiers en les piétinant : en ne donnant pas aux planches plus de $1^{\mathrm{m}}, 40$ de large, on peut, ainsi que je viens de le dire, désherber le plant, et l'on pent aussi, encore plus facilement, biner le plant repiqué avec une petite binette représentée Pl. Vll, fig. 1 et 2 , en se plaçant tantôt d'un eôté de la planche, tantôt de l'autre côté.

Les planches destinces à la première transplantation du plant que l'on transplante deux fois, auront $1^{\mathrm{m}}, 52$ de large et seront plus ou moins longues, selon le besoin; s'il y en a plusieurs, elles seront séparées par des sentiers de $0^{\mathrm{m}}, 65$ de large.

Les quartiers dans lesquels on transplante le plant, qui doit y rester jusqu'à ce qu'on l'enlève pour le planter à demeure, seront rectangulaires, atutant qu'il sera possible, auront 30 mètres de large et une longueur dépendante des besoins ou de la disposition du terrain; ils serout séparés par des allées de $1^{\mathrm{m}}, 30$ de large. 
On leral, s’il est nécessatre, le long de la pépinière, on dans l’interienr de la pepinière, un chemin pour charettes, ou pour une petitu voiture à un cheval on it âne; l'importance de la pépinière et le besoin des localitís détcrmineront ce qu'il "st nécessaire de laire à cet égard: il est évident, par exemple, que si une pépinière est longue el peu large, et qu'elle soit hordée, daus toụte sal longueur, par un chemin de voilures, il ne seria pas nécessaire d’en avoir un dans la pépinière.

Les quadrupèdes domestiques et les quadrupèdes sauvages ne doivent point eauser de dommages dans les pépinières, parce qu'ou doit avoir le soin d'entonrè ces pépinières d'une clôture s'il est nécessaire. Les petits oiseaux peurent être très-muisibles aux semis, en arrachant les graines à mesurequ'elles lèvem, ot je l'ai éprouvé. Ce sont les insectes qui peuvent causer les plus grands dommages daus les pépinières, quoique rarentent, si j'en juge d'alı'ès ma propre expérience, car voilà neuf ans que j’entretiens une pépinière des arbres dont je parle dans ce chapitre, depuis le semis jusqu’à la plantation à demeure, et ju n’ai point encore eu a m'en plaindre d'une manière notalble.

La larve du hanneton, vulgairement le man ou ver blanc, est celui de lous ces insectes qui cause le plus fréquenment des raviges dans les pépinières, ral mangeant les racines du plaut; mais si l'on repique el que l'on transplante l'antomme, el que l'on mette une converture sur le terain, conme je l'indiquerai plus loin ( ce qui est lort utile d'ailleurs), on se préservera des mans, la lémelle du hammeton ne pouvant déposer ses aul's dans une terre sur laquelle il y a une couverture.

Lal courtillière pent catuser les dégâts dans les planches de semis par les nomhreuses galeries qu'elle fait tout près de la surface de la terre. L'on a vu qu’il y a un puceron du sapin argenté, un puceron du pin du lord Weymouth et un puceron du mélèze; je présume que les autres espèces dout je moecupe ont aussi chacune leur puceron; ces insectes doivent être surtout muisibles an plant de pépinière; heureusement ils ne paraissent pás communs.

Les bostriches que j’ai remarqués sur de jemes pins sylvestres provenant de semis à demeure, et mangeant à mème les pousses de ces pins pendant yu'elles etaient encore herbacées, causeraient les mêmes ravages sur les plants de pins sylvestres daus les pépinières; j’ignore s'il y a, pour les antres espèces, des insectes vccasionnant des ravages semblables.

La chenille que j’ai trouvée mangeant les leuilles des pousses des jeunes picéas de mon parc (Voy. p. 141), causerait de semblables dégâts sur les plants de picéas dans les pépinières.

Rat\%elurg, en parlant des inscetes destructeurs de cultures d'arbres à aiguilles (1), cite d'abord le hanneton, dont la larve, dit-il, est le plus terrible des destructeurs de ces cultures; puis deux espèces de charangons, trois de hostriches et quatre de papillons. Une partie de ces insectes attaque les jeunes pins sylvestres, l'autre les jeunes picéas, soit parce que l'iusecte parlait perce l'écorce, soit parer. que les larves so tracrut des galeries dians le liber, mangent les jeunes puusses,

(1) Les hylophthiris ef leurs enuemis, 11, 35 et suivantes. 
ou percent les feuilles d'un grand nombre de trous. M. Vétillart, dans son mémoire sur la culture du pin maritime, précédemment cité, indique l'IIylesimus piniperda Fabricius, qui attaque les pins maritimes de 4 à 10 ans en mangeant la moelle des pousses et cause quelquefois de très-grands ravages dans les jeunes plantations; il parle aussi d'un autre insecte qui exerce de grands ravages dans les pépinières sur les arlhres verts, partieulièrement sur les pins du lord Weymouth, en les perçant d'une infinité de petits trous. Il cite, dans son voisinage, la pépinière d'un jardinier-décorateur dont tous les plants ont été létruits par cet insecte, qu'il ne nommé d'ailleurs point. ll est gênant pour les pratieiens que MI. les entomologues aient donné aux mêmes insectes des noms différens; ainsi eclui que M. Vétillart nomme IIylesimus pimiperda Fabricius, est appelé aussi Dermestes pinit:erda Linné, Scolytus piniperda Latreille, Ips piniperda Jaron de Geer, Bostrichus piniperda Paykull, ete.

Pendant les années qui suiveut la plantation à lemeure du plant élevé en pépinièrc, la larve du hanneton et un animal rongeur, le lapin, penvent eauser de grands ravages dans les nouvelles plantations. Le hanneton, voyant la terre nouvellement remuée autour des plants, peut y venir pondre, et ses larves les feraient périr frar la suite; j'en ai vu des exemples. Je pense donc que si dans l'endroit où l'on a fait une plantation, il se trouve, autour de cette plantation ou auprès, un bois feuillu couvert de hamnetons, qui semblent y être fixés jusqu'au moment de la ponte, il est prudent de mettre une converture sur la terre nonvellement remuée qui entoure les plants.

Lorsque les lapins seront nombreux dans les bois où l'on fera des plantations d'arbres résineux, il sera indispensable de n'employer que du plant ayant au moins un mètre de lıant, pour qu'ils ne puissent en atteindre la tête; car sans cela ils pourraient lui couper la flèche aussi bien que des branches, dans l'année qui suit la plantation : cela est particulièrement à eraindre pour les espèces qu'ils paraissent se plaire à brouter. Lorsque le plant est trop haut pour qu'ils puissent en atteindre la tête, ils ne se contentent point de couper les branches, ils rongent quelquefois le trone, ainsi que je l'ai surtont remarqué sur des nnélèzes, sur des pins sylvestres et sur des pins doux. J'en parlerai d'ailleurs par expérience; ils ont attaqué ainsi, dans mon pare, ordinairement pendant les mois qui suivent la plantation, des sapins, des pins, des mélèzes, mais surtout des pins doux et des sapins picćas, et ils m'ont forcé à n'employer que du plant assez élevé pour qu'ils ne pussent en atteindre la tête : ils attaquent beaucoup moins les plants des mêmes espèces provenant de semis naturel; je ne puis expliquer cet instinct qui les porte à détruire ee qui est l'ouvrage de l'homme. Aussitôt que les traces de la plantation sont effacées, c'est-ì-dire au bout d'un an ou deux, ils ne touchent guère plus à ce plant qu’à eelui qui provient de semis naturel; aussi m'est-il arrivé quelqquefois de ne pas faire biner dı plant l'année d'après sa plantation, selon mon usage, dans la crainte d'attirer de nouveau les lapins.

Les plantations faites le printemps sont un peu moins exposées aux dégâts des lapins que celles de l'autonme, parce que c'est l'hiver, et par la neige, que: 
ces animaux causent le plus de dommages. J'ai réussi en partie à les éloigner des arbres que je voulais protéger, en en faisant enduire le tronc avec de la bouse de vache, mais ils reviennent lorsque l'odeur est dissipée; il est très-ıtile aussi de couvrir le pied de l'arbre, nouvellement planté, d'une couche de feuilles qui efface les traces de la plantation.

II. Sapiv argente, Abies argentea. - Je vais commencer par m'occuper du sapin argenté, et ce que j'en dirai s'appliquera aux autres espèces, en ee qui concerne le repiquage, la transplantation et la plantation à demeure. Je n'ai rien à ajouter à ce que j'ai dit, dans les observations préliminaires, du choix et de.Ia préparation de la terre, non plus que des dimensions à donner aux planches et aux quartiers, pour le semis, le repiquage et la transplantation.

Si l'on imitait la nature, on sèmerait la graine l'automne, mais on aurait à redouter les gelées tardives du printemps suivant; ces grraines pourraient être mangées par des animaux ou par des insectes, et le plant ne se trouverait d'ailleurs point dans la même situation, sous le rapport des abris, que dans les sapinières. On évite ces inconvéniens en semant au printemps, et l'expérience a prouvé que cela est préférable. J'ai dit que l'exposition du nord me semblait la meilleure, et il sera très-avantageux que le terrain sur lequel s'exécutera le scmis soit à miombre. Une excellente situation serait une clairière de futaie à mi-ombre, et dont le terrain conviendrait au sapin argenté. Cette situation serait favorable aussi, aux semis de sapins picéas et de mélèzes, si le terrain leur convenait d'ailleurs. Quand on a de la sciure de bois, on en courre la graine après avoir semé, ce qui empêche l'envahissement de l'herbe. Au bout d'un, deux ou trois ans, on repique ou l'on transplante le plant dans une pépinièrc. J'ai vu exécuter ainsi, dans la sapinière de Raveton, des semis de sapin argenté qui avaient très-bien réussi.

Dans ma pépinière, j’ai fait exécuter les semis de sapins argentés à l'exposition du nord près d'un mur; une partie du semis était à l'ombre, une autre partic à mi-ombre; j’ai bien réussi. Avec de la terre bien préparée et les soins convenables, en arrosages et bassinages, on réussira même en terrain découvert, quoique moins bien.

On sèmera ì la lin de mars ou dans les premiers jours d'avril, sur des planches préparées, ainsi que je l'ai dit page 358, et l'on sèmera très-épais, de manière à ce que lés graines se touchent presque, parce qu'une partic de la graine du sapin argenté est toujours mauvaise. J'ai toujours fait semer à la volée, mais on peut aussi semer en lignes, et il serait suffisant, je crois, de mettre $0^{\mathrm{m}}, 08$ de distance entre les lignes; le semis à la volée occupe moins de ferrain, le semis en lignes est plus facile à netluyer et à lever pour le repiquage. On enterrera les graines légèrement a vec le râteau, ou en les courrant avec $0^{\mathrm{m}}, 002$ à $0^{\mathrm{m}}, 003$ (environ une ligne) de terre de bruyère : chez moi on a fini par les couvrir avec du terreau pris sous les sapins; on plombe ensuite la planche où l'on a semé, avec le rlos d'une pelle en lei on avec me batte. La graine leve au bout de cing a sept 
semaines environ, selon que la température a été plus ou moins favorable; si l'on avait semé plus tard, elle aurait mis un peu moins de temps à lever. Si l'ou avait semé l'automne, aussitòt après avoir recueilli les graines, elles auraient levé du 15 mars au $\mathbf{1 5}$ avril, et le plant se serait trouvé exposé à être détruit pilr les gelées lardives du printemps. Il ne faut pas semer plus tard que le $\mathbf{1}^{\text {er }}$ mai, parce qu'il faut que le plant soit robuste pour n'éprouver aucun dommage, par suite du repiquage qu'il doit subir l'automne même de l'année où on l'a semé.

On arrose le terrain où l'on ai semé, quand il est nécessaire, jusqu'à ce que le plant soit levé; mais aussitôt que le plant est débarrassé de l'enveloppe de la garaine qu'il porte au bout de sa tige lorsqu'il lève, on ne l'arrose plus que lorsyu'on le juge absolument nécessaire, ce qui se distingue facilement; on le tieut net, en arrachant les herbes ì la main. Après le $\mathbf{1 5}$ octobre, époque à laquelle le jeune plant aura acquis tout le développement qu'il piendra pendant la première ammée, on s'occupera do le repiquer pour le desserrer et lui faire former. du chevelu; cette opération peut s'exécuter dęuuis le 15 octobre jusqu'au moment où la sève se met en mouvement l'amée suivante; mais il est préférable dé l'exécuter avant le $\mathbf{1}^{\text {er }}$ décembre : on ne le peut d'ailleurs pendant qu'il gèle et pendant qu'il plent, et l'on doit éviter les journćes de hâle et de soleil ardent; un temps gris et mou, en terme de jardinier, est le meilleur : je rappellerai que les planches sur lesquelles s'exícute le repiquage, ont la même dimension que celles sur lesquelles on a semé.

On lève le plant en le soulevant de la main droite, et de deux côtés successivement s'ille faut, a vecle lève-plant, petit instrument que j'ai lait faire pour cet usage (PI. VIf, fig. 5 et 6); il a la forme d'une dent de la fourche à bêcher. Dans les même temps qu'on soulève le plant de la main droite, on le tire peu à peu de la main gauche, et l'on parvient ainsi à le lever avec toutes ses racines, qui ont déjà plusicurs ponces de long; on met de côté le plant chétif ou de mauvaise apparence pour le repiquer à part. On peut aussi, lorsque le plant est robuste, employer la petite fourche à deux dents (Pl. VIl, fig. T et 8) qui sert pour la première transplantation, ou enfin la fourche à bêcher. Si l'on a vait semé le plant en ligne, on pourrait toujours le lever avec la petite fourche à deux dents, dont je viens de parler, ct même avec la fourche à bêcher.

Le plant de rehut sera placé dans des lignes tracées au cordeau, distantes les unes des autres de $0^{\mathrm{m}}, \mathbf{1 1}$, et il sera mis à $0^{\mathrm{m}}, \mathbf{1 1}$ de distance dans les lignes ; ceux qui périront feront place aux autres. Le bon plant sera placé dans des lignes distantes les unes des autres de $0^{\mathrm{m}}, 16$, et il sera mis à $0^{\mathrm{m}}, 14$ dans les lignès. Pour repiquer le plant on se sert d'un plantoir de la grosseur de ceux avec lesquels on plante les choux, mais beaucoup moins pointu, afin qu'il ne puisse rester de vide au fond du trou; l'ouvrier fait un trou suffisamment grand avec le plantoir, y place le plant, en ployant le bout des racines, s’il est nécessaire, et le remplit de terre avec le plantoir ou avec la main, ce qui vant encore mieux. Ce: mode de repiqquage pourrait avoir des inconvéniens dans une terre argileuse qui se collerait par la pression du plantoir; mais lans une terre convenable a la 
eulture des arbres résineux en pépinière, lorsqu'il aura été bien exécuté, on ne remarquera pas de différence entre la végétation des plants qui ont été repiqués et la végétittion des plants qui seraient restés en place. J'ai supposé qu'on repiquait tout de suite le plant qu'on lève; si, au contraire, on trausportait ee plant assez loin pour qu'il lùt plusieurs heures sans être mis en terte, on le disposerait par rangs dans un panier; et s'il faisait du hâte on du soleil, on placerait au fond de ce panier, et par dessus le plaut, de la monsse ou de la paille humide. Mais il est on ne pent plus utile qu'il soit arraché et repiqué le même jour; on ne doit point le mettre en paquets, il faut le poser légèrement dans un panier sans le serrer.

Sur une planche rectangulaire qui avait $4^{m}, 40$ de large et $2^{m}, 50$ de long, j'ai obteuu, par suite d'un semis exécuté comme je viens de l'indiquer, 880 plants qui, repiqués à la distance que j’ai prescrite, ont occupé une planche de la mème largeur et de $14^{\mathrm{m}}, 08$ de long. Le plant de sapin argenté reste dans cette position pemlant deux ans, e'est-ì-dire jusqu'à ce qu’il ait pris trois sèves, puisqu'on a vu page 17 qu'il n'a qu'une sève par an. Les soins qu'on lui donne consistent à le bincr aussi souvent que cela est nécessaire avec une petite binette representée Pl. VII, fig. 1 et 2 , et i l'arroser quand il en a absolument lesuin.

Le jeıne plant ayant pris trois sèves et étant, par conséquent, tans sa troisièmc année, on le transplantera une première fois pendant le temps qui se trouve entre le 15 octobre et le moment où partira la quatrième sève; on se conformera, pour le chois des jours pendaut lesquels s'exécutera ce travail, à ce que j'ai dit en parlant du repiquage. Les planches sur lesquelles on mettra ce plant anront I' " $^{2} 2$ de large et seront plus ou moins longues, selon le besoin et l'étendue du terrain dont on disposera; elles seront façonnées avec autant de soin que celles desquelles on l'a tiré; les senticrs entre les planches auront $0^{\mathrm{m}}, 65$ de large, parce que les branches en occuperont une partic. On placera sur ces planches huit rangées de plant à $0^{\mathrm{m}}, 22$ les unes des autres; ainsi la première et la lunilième rangée se trouveront sur les lignes qui terminent les planches dans le sens de leur longueur; le plant sera mis à la même distance dans les lignes, ou à $0^{\mathrm{m}}, \mathbf{2 4}$ 't même $0^{\text {m }}, 27$, selon sa force.

On lève le plant avec une petite fourche à deux dents (Pl. VII, fig. 7 et 8), que j’ai fait faire pour cet usage, et qui se manie d'une seule main; à défant de fourche à deux dents, on emploie la fourche-bêche à trois dents (Pl. VI], fig. 3 r (4). Si l'on ne met pas le plant en terre aussitôt après qu'il a été levé, ou prend, pour sa conservation, les précantions que j’ai prescrites en parlant dı repiquage.

Pour planter le plant, un ouvrier commence par faire, avec la fourche-bèche, la rigole dans laquelle on plantera la quatrième rangée, en plaçant la terre sur te hord du côté où se mettra l'ouvrier plantenr'; puis, pendant que ce dernier plantera dans ectte rigole, le premier fera celle de la cinquième raugée, en mellant la trrre du côté opposé, et ilinsi de suite. Un voit qu'on ne fait les rigoles que sue- 
cessivement, en commęçant par celles du milieu de la planche et à mesure que celles qui précèdent ont été plantées; on leur lonne la largeur et la profondeur nécessaires pour que l'on puisse y placer facilement les racines du plant. Il laut, pour faire les rigoles de la quatrième et de la cinquième rangée, et pour les planter, mettre les pieds sur la planche; les denx ouvriers qui exécutent ce travail emploieront done chacun une planche de bois, s'ils jugent que le piétinage soit nuisible. L'ouvrier planteur doit planter à la main, tout autre moyen étant plus long et moins parfait; lorsqu'un plant a un pivot, il en ploie le bout, qu'il place horizontalement. L'ouvrier qui fait les rigoles achève, immédiatement après qu'une rigole vient d'être plantée, de la remplir et d'en ajuster la terre avant que d'en commencer une autre. Il l'aut trois ouvriers pour exécuter $\cdots$ travail promptement : un qui lève le plant, un qui fait les rigoles, un qui plante.

Les soins à donner à cette plantation sont d'y mettre, aussitôt après qu'elle vient d'être exécutée, une couverture de chaume, de balles de blé ou de toute autre matière qui soit propre à cet usage; de la biner quand il sera utile avec une pelite binette, telle que celle qui est représentée PI. VII, fig. 1 et 2, mais ayant un tranchant d'un tiers plus long, et de l'arroser si on le juge absolument nécessaire. On pourrait planter ce jeune plant de trois ans à demeure, et il réussirait très-bien s'il n'était étouffé par des herbes on des arbustes, et si la sécheresse ou un ombrage trop épais ne le faisait pas périr, ce qui peut arriver plus ou moins à toute espèce de plant; quand on plante du plant plus àgé, il souflie moins des plantes et des arbustes.

Le plant de sapin argenté restedans cette position pendant dieux ans, e'est-àdire jusqu'à ce qu'il ait pris cinq sèves; on pourait dès lors le planter à demeure et il n’en réussirait que mieux, mais les pépiniéristes ne trouveraient pas à le vendre, parce qu’il est encore trop petit; il est d'ailleurs souvent nécessaire d'avoir du plant plus haut. On transplantera done de nouveau ce plant de cint ans à la même époque de l'année que j’ai indiquée pour la première transplantation, mais dans des quartiers disposés ainsi que je l'ai prescrit page $35 \dot{8}$; on se conformera, pour le choix des jours pendant lesquels on transplantera, à ce que j'ai dit précédemment, et en outre on choisira un temps calme ou du moins peu agité.

La plantation se fera en lignes distantes de $0^{\mathrm{m}}, 65$ les unes des autres; on conservera entre les plants la même distance au plus dans les lignes, et ils seront disposés en quinconce; on pourrait aussi ne les mettre qu’à $0^{\mathrm{m}}$, ว́4 ou même qu'à $0^{\mathrm{m}}, \mathbf{4 9}$ dans les lignes, mais alors quand on les lève pour planter à demeure, on brise beaucoup de racines; néanmoins on réussit aussi, quoique moins bien, en prenant les précautions que j'indiquerai. Il ne faut d'ailleurs jamais dimi-nuer la distance entre les lignes, qui est absolument nécessaire au développement des racines et qui dispense de créer des sentiers, puisqu'on peut alors passer partout dans la pépinière; il ne faut pas non plus mettre plus de $0^{\mathrm{m}}, 65$ entre les plants, paree que les racines prendraient trop d'estension. 
at qui rentrat la phantation it demeure plus dilficile el plus coùteuse ì bien execuler.

On ne mettra ensemble, dansectte dernière transplantation, que des plants lu mème âge, et ayant la même apparence, sous le rapport de la vigueur de la végétation. Ainsi, si l'on a sur tes terrains différens du plant de qualité différenté, quoique dı même âge, on ne le mêlera point; chaque qualité de plant sera plantée dans un quartier i part; on ne mèleritit pas non plus les espèces, si l'on en cultivait plusieurs à la fois. Cette attention est fort importante, parce qu'il en résultera que le plant de chaque espèce, de mème âge et de mème vigueur, occupant un quartier ì part, le plant de chaque quartier se trouvera prèt à ètre plinté ì demenre, en totalité, la même aimée; et qu'alors on pourra en débarrrasser le terrain en le levant en plein successivement.

La seconde transplantation s'exécute ainsi qu'il suit : on lève le plant avec la fourche-bèche, en le soulevant de deux còtés avant que de l'enlever, de manière it conserver toutes les racines, et une petite molte de terre au dessous du collet, lor'sque cela est possible. Dans le même temps, des trous sont préparés sur des lignes tracées au cordeau, aux distances que j’ai indiquées, el on les fait tels qu’ils puissemt bien contenir les racines. Une profondeur de $0^{\mathrm{m}}, 27$, rédnite à $0^{\mathrm{m}}, 22$ par l'ouvrier planteur qui y fait tomber un peu de terre, avant que de placer - le plint, est ordinairement suffisante; on ploie horizontalement le pivot, s'il y en it un, el circulairement les racines qui dépassẹaient cette profondeur; on convre légèrement les racines de terre bien meuble avec la main, puis on achève de remplir le trou avec la binette, ou mieux avec la main: on ne foule point la terre sur les racines, et elle duit dépasser un peu le collet, mais lorsqu'elle a éprouvé tout son tassement, et après le premier binage, le collet de: l'arbre doit se trouver au niveau du terrain, tel qu'il était sur la planche de premiere transplantation où on l'a pris.

Il faut quatre ouvriers pour exécuter ce travail promptement : un qui fait les trous, un qui lève le plant, un qui lé porte près des trous, en motte atutant que possible, el un qui le plante. Il est évident qu'un seul onvrier pent faire cette besogne, puisqu'il peut faire d'abord les trous, arracher ensuite le plant, lo transporter et enfin le meltre en terre; mais il est évident aussi que deux feront mirux qu'un, trois mieux que deux, et quatre le mieux qu'il est possible, parce qu'alors le plant sera moins longtemps hors de terre. Si l'on transporte le plant asse\% loin pour c̀tre contraint d'employer une voiture, on se servira d'un tombereatu, ou d'une petite voiture à ridelles, fermée devant et derrière, qu'on garnira de paillassons sur. les côtés. Le plint sera placé par rangées, et verticalement, si l'on n'en met qu'un seul rang; il sera incliné à 45 degrés environ, si l'on veut mettre plusieurs rangs les uns sur les autres; le tout sera reconvert légèrement de paille mouillée, s’il fait du soleil ou du hàle. Je ne parlerai point de l'emballage du plant pour expédier au loin, écrivan pour les propriétaires et non pour les pépiniéristes.

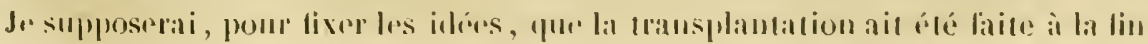


d'octobre; on unettra sur le quartier clans lequel on aura transplanté le plant une couverture de feuilles ou de chaume, ou de toute autre matière légère. Dans le courant du mois d'aviil ou de mars de l'année suivante, par un temps de hâle, il sera donné un binage avec une pioche légère dont je ne crois pas nécessaire de lonner le dessin, parce qu'elle est employée partout, je crois; et l'on aura soin de chausser ou de déchausser le pied des arbres, selon qu'il sera nécessaire. Pendant le cours de l'année, on donnera un ou deux autres binages avec une ratissoire à pousser (Pl. VIl, fig. 9 et 10) qui est excellente pour ce travail, et dont je n'ai pourtant vu les dessins nulle part. On continuera, pendant les années suivantes, à entretenir une couverture sur le plant, mais plus épaisse, et l'on pourra employer à cet usage du jonc marin, du gènêt, de la bruyère, des élagages de haies, et aussi des feuilles, de la paille de rebut et dı chaume : les joncs marins sont peut-être alors ce qu'il y a de mieux.

Ces couvertures protégeni les racines, pendant le premier hiver qui suit lil transplantation, contre l'influence des gelées et des alternatives de gelée et de dégel; elles étouffent l'herbe, elles farorisent l'extension des racines près de lit surlace du sol, ce qui fait qu'elles pénètrent moins profondément dans la terre; elles procurent au plant, en pourrissant, un engrais qui lui est très-profitable; enfin, elles empêchent le hanneton de venir déposer ses œufs sur ce terrain, et l’on évite ainsi que le plant puisse être détruit par la larve de cet insecte : mon jarlin et mes pépinières se trouvent dans le même enclos; j’ai eu plusieurs fois les vers blancs dans mon jarlin, jamais dans mes pépinières, ce que j'attribue aux couvertures.

Après la première façon donnée à la pioche, on ne se sert plus, pour biner le plant, que de la ratissoire à pousser dont je viens de parler; ce binage n'est que superficiel, el c'est ce qu'il faut, les racines se trouvant à fleur de terre; cet instrument passe d'ailleurs sous les couvertures les plus rudes, telles, par exemple, que celles de joncs marins. Aussitôt que les branches des sapins se sont jointes et que ces jeunes arbres couvrent tout le terrain, il n'y a plus besoin de couvertures.

Il arrive quelquefois que les jeunes sapins ont deux flèches; on tord la moins belle et on la reploie de manière à lui renverser la tête; l'autre flèche s'empare alors de la sève; on peut aussi se contenter d'arracher les boutons qui se trouvent au bout de la flèche dont on veut arrèter l'accroissement, mais il est préférable de la tordre. De 8 à 9 ans le plant aura acquis les dimensions qui le rendent propre soit à être planté à demeure, pour le renouvellement d'une futaic dont on a fait une coupe rase, soit à former des massifs ${ }_{2}$ des allées et des bosquets, soit enfin à ètre vendu.

On pourrait, sans doute, se dispenser de faire deux transplantations, et alors, ayant repiqué moins serré, on ne transplanterait le plant qu'après la quatrième sève; on le mettrait dans des lignes distantes entre elles de $0^{\text {m }}, 65$, et à $0^{\text {th. }} 54$ ou mème à $0^{\mathrm{m}}, 49$ seulement dans les lignes, en ayant soin de mettre une couverture sur le terrain dès l'année même de la transplantation. Mais pendant 
les quatre on cinq années qui s'écouleratent depuis cette transplantation jusqu’à la plantation à demeure, la racine du plant aturait formé un pirol assez longo pour gue l'on fùt presque toujours ol)ligé de le couper en arrachant le plant; cette rirconstance, quoique nuisible, ne l'empêcherait d'ailleurs pas de réussir parlaitement, ainsi que je l'ai ćprouvé, parce qu'il serait bien garni de chevelu : en définitive, les deux transplantations me paraissent préférables.

Je viens de décrire les travaux à exécuter pour obtenir du plant bien préparé pour la plantation à demeure, en commençant par le semis; le proprićaire d'une sapinière peut aussi se procurer du plant semblable, en prenant d'abord te jeune plant dans sa sapinière. Il y fera lever en motte du plant de semis naturel de 2 ì 5 ans, pris dans les allées, dans les clairières, ou dans les bordures de sa sapinière; ce plant sera classé par âge, selon l'apparence, et repiqué on transplanté sur des planches préparées, ainsi qu'il a été dit précédemment. Il mourra quelques-uns de ces plants, et ils bouderont plus ou moins longtemps; mais, en définitive, la plupart reprendront, si on leur donne les soins convenables en binages, en arrosages et surtout en couvertures, qui sont on ne peut plus utiles avec du plant tirć d'une situation à l'ombre ou à mi-ombre, pour le mettre dans une situation découverte : du plant de semis naturel traité ainsi formera du chevelu, il acquerra une belle végétation, et il prentra une forme régulière. On se procurera, par ce moyen, du plant entièrement sembiable à celui qu'on obtient par la culture artificielle complète, mais moins promptement: j'cn parte par expérience, ayant eu dans ma pépinière de beaux quartiers de sapins argenlés élevés ainsi.

Avant de décrire la plantation à demeure, je vais donner quelques détails succincts, relativement au mode de végétation et à l'accroissement successif du sapin argenté, pendant les huit ou neuf années qui la précèdent.

Le sapin argenté, semé à la fin de mars ou dans les premiers jours d'a vril, lève, ainsi que je l'ai dit au commencement de cet article, au bout de cinq à sept semaines : de la graine que je semai le 15 mars 1841 ne commença à lever que le 16 mai ; de la graine que je semai le 29 mars 1842 commença à lever le 18 mai; de la graine que je semai le 14 mars 1843 commença à lever le 22 avril. Le sapin argenté lève ayant au bout d'une petite tige la coque de sa graine, qui tombe bientôt et laisse voir dix feuilles séminales en aiguilles tixées au bout de cetle tige, en forme d'étoiles; la moitić de ces feuilles sont un peu plus grandes que les au. tres avec lesquelles elles alternent : le plant qui n’a qu'une seule sève borne lì son accroissement la première amnéc de sa missance, et sa tige atteint seulement $0^{\mathrm{m}}, 02$ à $0^{\mathrm{m}}, 04$ de haut. An bout de cetle tige se trouve le bouton duquel partira la flèclıe l'annće suivante.

La seconde année, un bouquet de nouvelles leuilles parait au centre des feuilles séminales, pendant la dernière quinzaine d'avril ou pendant la première de mai, selon les localités et la température qui a régné; et enfin part la flèrhe, qui est gamie de petites feuilles dans son pourtour, et mème quelquelois d'une petite branche. La flèche el les auldes pousse's out terminé leur croissancer eal 
longueur an bout de six à neuf semaines environ, selon la température qui a régné, et la sève reste dès lors inactive jusqu'au retour de la sève de l'année suivante; mais ensuite les pousses grossissent encore un peu, et deviennent ligneuses d'herbacées qu'elles étaient; la tige du jeune sapin a alors $0^{\mathrm{m}}, 06$ à $0^{\mathrm{m}}, 10$ de haut. La troisième année, le tronc du sapin se couvre de plusieurs petites branches, ou plus exactement de plusieurs ramilles, car les branches ne paraissent que plus tard, et il atteint une hauteur de $0^{\mathrm{m}}, 09$ à $0^{\mathrm{m}}, \mathbf{1 6}$. La quatrième année, il atteint une hauteur de $0^{\mathrm{m}}, 12$ a $0^{\mathrm{m}}, 21$; la cinquième année, une hauteur de $0^{\mathrm{m}}, 25$ à $0^{\mathrm{m}}, 36$. Je ferai d'ailleurs observer que si le repiquage ne retarde point la végétation du sapin argenté, chaque transplantation la retarde, quel que soit le soin avec lequel on l'exécute.

On voit que, pendant les quatre ou cinq premières années, la végétation du sapin argenté est fort lente; la flèche se maintient dans une ligne verticale; mais le jeune sapin, considéré dans son ensemble, présente peu de régularité. Après qu'il a dépassé cet âge, sa végétation devient plus active, et il prend peu à peu la forme d'un cône surmonté d'une flèche située dans le prolongement du tronc; néanmoins, de 8 à 9 ans, âge auquel on peut le planter à demeure, il n'a ordinairement qu'environ 1 mètre à $1^{\mathrm{m}}, 50$ de haut. J'ai donné, pages 1T-21, une description de la marche de la végétation dans les sapins argentés adultes, en ce qui concerne leur sève, leurs boutons, leurs feuilles, leurs fleur's et leurs cônes; et, pages 29-42, j'ai parlé de leurs racines, de leur tronc, de leurs branches, de leur accroissement annuel et des dimensions auxquelles ils parviennent.

Au moyen des précautions que j’ai précéclemment indiquées, tout le plant que l'on va planter à demreure aura à peu près les mêmes dimensions, et l'on pourra le lever en plein successivement, ce qu'il faut toujours faire lorsque cela est possible; on débarrasse ainsi peu à peu le terrain, dont on peut dès lors disposer pour une antre culture, et l'on a plus de facilité pour arracher le plant. Lorsqu'au contraire on arrache les plants, en choisissant çà et là les plus beaux, il en résulte, si l'on ne remplace point, que l'on perd du terrain et que les racines du plant qui reste encore prennent trop d'extension; et si l'on remplace avec du plant plus jeune, que ce plant vient mal, parce qu'il se trouve opprimé, sous terre et hors terre, par des voisins plus âgés que hui. En détinitive, on ne doit pas hésiter, après avoir commis la faute d'arracher du plant çà et là pour le planter à demeure, à arracher avec le plus grand soin des lignes entières de ce qui reste de ce plant pour le replanter où l'on a fait des vides, ạlin que le terrain se troure occupé. On espacera seulement un peu plus ce plant : ainsi on pourra n'en mettre que deux ou trois où il y en avait trois ou quatre; on se procurera en outre, ainsi, l'avantage de rendre une partie du terrain libre.

Les plantations de sapin argenté réussissent très-bien lorsque le plant a été élevé ainsi que je viens de l'indiquer; il a beaucoup de chevelu, plus peut-être qu'aucune des dix espèces dont je vais m'occuper dans ce chapitre, à l'exception du picéa. Le moment le plus favorable pour le planter est l'automne, et j'en parle d'après mon expérience; mais on peut le planter avec succìs pendant 
tout l'hiver, lorsque les geclées ou les pluies ue s'y opposent point, et au printemps jusqu'au moment où part la sève: planté l'automne, ainsi que je vais l’indiquer, il pousser'a presque comme s'il n'eùt pas quitté lá pépinière; planté au printemps, ainsi qu'il est prescrit par tous les auteurs, il bouderiı pendant. in an.

Lorsque l'on voudra planter à demeure les sapins argentés de lat pépinière, on commencera vers le 1 ó octobre, et l'on pourra continuer jusqu'à l'époque où la sève de ces arbres commence à se inettre en mouvement, mais le plus tôt apıès le 15 octobre sera le mieux. A ce que j'ai dit précédemment du choix des journées pendant lesquelles on plantera, il faut ajouter qu'il est très-important de planter par un temps calme, afin que la terre ait au moins quelques heures, sinon quelques jours, pour se rasseoir et affermir le plant. Quand on plante par un grand vent, les plants se trouvent tout de suite ébranlés, ce qui leur est trèsnuisible; tandis que si l'on plante par un temps calme et qu'il s'écoule quelques jours ainsi, la terre se tasse peu à peu, surtout s'il fait de petites pluies, et la nouvelle plantation peut résister aux premiers vents qui surviennent. Le sapin argenté étant d'ailleurs plus chargé de branches et de feuilles vers le sol que vers la cime, est l'un des arbres qui, parmi ceux dont je m'occupe dans ce chinpitre, ont le moins à souffrir de l'action des vents.

On peut faire les trous d'avance tant que l'on n'est pas encore entré dans la saison des pluies; on y trouve l'avantage que la terre se mûrit, et cela est particulièrement utile dans les terres fortes, surtout si ce sont de celles qui se délitent à l'air; mais lorsque la saison des pluies est arrivée, si l'on faisait les trous d'avance, ils pourraient se remplir d'eau; la terre qu'on en a tirée pourrait être trempée de manière à former un mortier; la plantation deviendrait impraticalıle, ou, si l'on plantait, ce serait on ne peut plus mal, dans l'eau et dans la boue. Lors donc que la saison des pluies sera arrivée, on ne fera plus les trous qu'au moment de planter; c'est ce que j’ai toujours pratiqué, et je n'ai jamais remarqué qu'il en résultât le moindré inconvénient.

11 est suffisant de faire cles trous carrés de 1 mètre de côté et de $0^{\mathrm{m}}, 50$ de profondeur, pour planter à demeure le plant de la pépinière; néanmoins, si on leur donne $\mathbf{1}^{\mathrm{m}}, \mathbf{1 4}$ de côté, ce sera encore mieux. On doit faire trois lots de la terre que l'on tire dı trou, en ayant soin de la débarrasser des trop grosses pierres : le premier, de celle que l'on tire de la partie supérieure du trou, qui est ordinair'ment la meilleure; le second, de celle que l'on tire ensuite; le troisic̀me, de celle que l'on tire la demière, qui est ordinairement la plus mauvaise, et l'on doit piocher la terre du fond du trou pour que les racines de l'arbre que l'on va planter puissent facilement la pénétrer. Les trous étant faits et le temps étant favorable ou à peu près, si l'on est décidé à planter, on s'occupera d'arracher les sapins dans la pépinière avec soin et promptitude; car moins les racines auront été de temps hors le terre, mieux la plantation réussira; on doit donc, si on le peut, combiner cette operation de manière à n'arracher chaque jour que ce qu'on pourra plantrr : éest ainsi que j’ai toujours fait. 
Pour arracher un plant, on commence par donner des coups de pioche tout autour, entre ce plant et les plants voisins, avec le côté pointu d'une grande proche à pic (II. VII, fig. 11 et 12)(1), de manière à détacher ses racines latérales; puis deux ouvriers soulèvent l'arbre, l'un a vec une grande fourche à deux dents (1). VII, fig. 13 et 14), l'autre a vec une fourche-bêche, tandis qu'un troisième le tire en le prenant par le tronc, près du collet. L'on peut aussi se servir de la grande pioche pour soulever le plant; on l'enfonce avec furce jusque sous les racines par le côté du tranchant, et l'on fait une pesée en appuyant avec le pied droit sur le bout de l'autre côté; lorsqu'il n'y a que deux ouvriers employés it l'arrachage, l'emploi de la grande pioche est plus commode el plus expéditif.

Il est impossible, dans cette opération, de ne pas briser quelques racines; mais ce plant n'ayant pas de pivot, ayant beaucoup de chevelu, et peu ou point de grosses racines, on ne pourra en briser qu'un très-petit nombre, et que vers les extrémités seulement; si pourtant, par exception, il se trouvait quelque racine un peu forte qui s'étendit an loin, on la tirerait à la main. En détinitive, on obtiendra ainsi le plant avec tout son chevelu, aree une bonne motte de terre autour du collet et sans avoir brisé de racines de manière à nuire à sa reprise. La conservation d'une motte de terre autour du collet est utile, mais n'est point indispensable, et l'on ne peut laisser de la terre autour des racines du plant lorsqu'on l'expédie au Join.

Le plaut se transporte de la pépinière an lieu oì l'on doit le planter, dans un tombereau ou dans une charrette disposée ainsi que je l'ai dit précédemment; l'on ne doit en metre qu'un seul rang, que l'on dispose verticalement la flèche en l'air. Lorsque l'on veut transporter une plus grande quantité de plant ì la fois, on emploie une voiture dite guimbarde (2), qui sert ordinairement à rentrer les récoltes, el à laquelle on met des paillassons ou de la paille le long des ridelles, qu'on prolonge avec les gaules jusqu'aux cornes qui ferment la voiture. Pour charger celte voiture, on place une rangée de plants inclinés à environ 4̌ degrés, les racines appuyées contre le fond de la voiture; clle se troure ainsi remplie jusqu’a la lıuteur des ridelles qui dépassent les roues; puis on place successivement sur ce premier rang plusieurs langées de plant horizontalement, les racines se joignant au centre de la voilur', les lleches en dehors; on tinit par recouvrir de paille longue el par fixer le tout au moyen d'une liure, ainsi qu'on le fait pour un chargement de foin ou de b]é. J'ai placé ainsi sur une guimharde s00 plants de pin sylvestre, de 1 mètre à $4^{\mathrm{m}}, 50$ de haut, qui avaient encore conservé de la terre autour de leurs racines près dı collet; cela faisait la charge de trois chevaux; peut-être n'aurait-on pu placer un aussi grand nombre de plants de sapin argenté sous un même volume, parce que les branches sont plus raides et s'écartent plus du tronc.

$\mathrm{Si}$, par une cause quelconque, on ne plante pas tout de suite le plant qui est

1) Cette grande pioche est emploỵe aussi à détoncer les terres dificiles et aux défjechemens.

2) Cours de cullure el de naluralisation des régétaux. Allas . pl. 22 , fig. 4 . 
chargé sur une voiture, ainsi que je viens de le dire, il pourra rester une couplo de jours sur la voiture, s'il ne gèle point et qu'on la mette à l'abri; on pourrait aussi le déposer pendant quelques jours sous un hangar, en ayant soin de bien le couvrir de paille humide, s'il fait du hâle. Si, an contraire, on doit tarder plus longtemps pour le planter, on le placera dins une tranchée préparée d'avance en terre meub]c, ayant au moins 1 mètre de large et $0^{\mathrm{m}}, 50$ de profondeur; il y sera placé incliné par rapport à l'un des côtés de la tranchée sur lequel s'appuiera le tronc du plant, les racines se joignant, et l'on courrira ces racines de terre : c'est ce que les pépiniéristes appellent meltre du plant en jange.

Le plant ćtant rendu sur le terrain où on veut le planter, on pourra le prendre suecessivement dans le tombereau ou la petite roiture; mais si l'on veut le décharger tout de suite, on en fera plusieurs lots rapprochés des trous et l'on couvrira ses racines. Lal plantation de chaque plant s'exécutera ainsi qu'il suit : on mettra d'abord au fond du trou la terre du premier lot, qui est celle que l'on aura tirée de la partie supérieure du sol, et s'il s'y trouve des gazons, des mottes de joncs marins, de genêts, de bruyères, on les retournera è on les piétinera; on ajoutera ensuite assez de terre pour que le collet du plant, quand on le mettra dans le trou, se trouve à la hauteur du sol, absolument comme il ètait dans la pépinière. Si la terre la plus meuble se trouvait être parmi celle qui a été tirée de la partie supérieure du trou, on la réserverait néanmoins pour être mise sur les racines, car c'est là le soin le plus important.

Je suis dans l'habitude de faire attacher un brin de paille aux plants du côté du midi, avant de les faire arracher, afin de pouvoir les orienter quand on les plante; mais je n'oriente le plant qu'autant que je puis en même temps bien disposer les racines. Hartig (1) prescrit d'orienter les plants; Duhamel (2) pense que celia est sans importance; je pense, comme Duhamel, qu'il est pen important d'orienter le plant de pépinière, mais je crois utile d'orienter lorsque l'on plante des arbres beaucoup plus âgés, ce qui est un cas exceptionnel.

Le plant étant placé ainsi que je l'ai dit, on étalera les racines et l'on ploiera le long des còtés du trou celles qui seraient trop longues; puis on convrima d'abord les racines arec de la terre bien émiée en soulevant et rabaissant trèsdoucement la tige, s’il est nécessaire, pour faire pénétrer cette terre entre les racines; on achèvera de remplir le trou avec ce qui restera du second lot de terre et avec celle du troisième lot. Aiusi, ordinairement la terre sera replacée dans les trous, dans un ordre opposé à celui dans lequel on l'avait tirée. On ne foulera point la terre que l'on met sur les racines, mais, quand la plantation sera terminée, on appuiera légèrement avec le pied autour du collet du plant. J'ai dit que le collet devait se trouver à la hauteur du sol; il en résultera, puisque les terres remuées occupent plus de place que les terres vierges, que le plant se trouvera d’abord un peu plus enterré qu'il ne l'était dans la pépinière, ce qui

1) Baudrillat!, d'après llartig, Dictionnaire des eaux ct forêts, I. II, p Air.3.

(2) Des semis et plantalinus des arbres ef de leur culture, p. 205. 
est micessaire pour yu’il te soil absolument de mêne, lorstun les terres se seront tassées.

Dans ce que je viens de prescrire pour exécuter la plantation à demeure, j’al supposé que la terre que l'on tire de la superficie du sol était la meilleure, ct celle que l'on tire du fond des trous la plus mauvise. S'il en ćtait autrement, on réserverait la terre la plus meuble pour ètre dispersée sur les racines quanul le plant est placé; on mettrait ensuite la meilleure terre au fond du tron et la plus mauvaise par dessus.

Il fant quatre ou cinq onvriers pour planter bien et promptement : jesupposeque l'on ait d'avance mis au fond des trons les gazons ou mottes de bruyeres, de joncs marins on autres plantes; un ouvrier placera le plant, un second disposera ses racines, un troisième jettera les premières pelletées de trrre; puis, aidé de celui qui a placé les racines, il continuera à jeter de la terre dans le trou jusqu'à ce que co plant soit bien fixé provisoirement, et ils passeront anssitôt à un atutre trou, oì ils fixeront provisoirement un autre plant de la même manière; dans le mêmr temps, un ou deux antres ouvriers achèveront de remplir les trous sans jamais fouler la terre avec le pied. Lorsque tous les plants sieront fixés provisoirement, tous les ouvriers réunis achèveront de remplir les trous; des plants frxés ainsi peuvent d'ailleurs, par un temps calme, attendre sans inconvénient jusqu'au lendemain, que l'on achìve de remplir les trous.

Cinq onvriers, conduits ainsi que je viens de l'indiquer, peuvent arracher et planter 100 plants en $u n$ jour, et en planter 120 s'ils ne les arrachent point: c'ust la manière d'exécuter la plantation tout à la fois le mieux et le plus vite : deux ouvriers et même trois emploieraient un plus grand nombre de journées pour en planter autant et anssi bien. Si une pluje, de la neige ou un" gelće contraignaient à suspendre la plantation, on mettrait le plant en jauge, avec le plus grand soin, dans de la terre meuble sur une seule ligne. Si ía saison était avancéce et qu'on craignit de fortes gelées, on mettrait sur la terre qui courre les racines unc couverture de genêts, de joncs marins ou de branchages.

Il me paraît utilc, pour toutes les espèces de plantations, de mettre avant les gelées, sur la terre qui couvre les racines, une couverture de feuilles, de jones marins, de genêts ou de toutes autres matières; c'est d'ailleurs une précaution coùteuse et que, par cette raison, on prend rarement. Ces couvertures empèchent la gelée de pénétrer aussi profondément dans les trous; clles empèchent l'herbe de croitre; s'opposent à ce que le hanneton vienne pondre au pied des arbres, daus la terre nouvellement remuée, et sont un engrais pour ces jeunes arbres.

Immédiatement après les premiers vents qui se seront élevés depuis que l'on aura terminé la plantation, un ouvrier intelligent, muni d'une pioche, fera la visite des plantations pour redresser et rechausser les plants qui auraient été ibranlés par les vents, on qui se scraient inclinés par suile d'un tassement inégall des terres; on recommencera cette visite des plantations quand on présu- 
mera qu'elle sera nécessaire, e’est-à-dire après les grands vents, les grandes pluies et les degels.

Au printemps qui suivra la plantanion, et par un temps de lâle, on donnera un binage à tous les plants, en ayant soin de déchausser le collet jusqu'an niveau du sol environnant, alin qu’il ne se trouve pas polus enterré qu'il ne l'était dans la pépinière; il en résultera une légère pente des còtés du tron vers le collet, parec que la terre ne sera pas encore entièrement tassée, et cela est avalllageux pour la conservation de l'humidité dans la terre qui enveloppe les racines. Si l'on peut faire faire un second binage, cela sera toujours utile, car la propriété des binages est de conserver à la terre sa fraicheur. La deuxiente année après la plantation, je ne fais plus biner, mais il serait mieux de le faire encore. Ce sont mes ouvriers à l'année qui me font ces binages à la journée, ainsi je ne puis dire exactement combien un ouvrier à l'entreprise pourrait biner d'arbres plantés dans des trous d'un mètre de côté; je présume qu'il pourratit en hiner de 90 ì 100.

11 arrive tous les quinze ou vingt ans des années extraordinairement sèches pendant lesquelles les binages deviendraient insuffisans; ce sont des cireonst:mces exceptionnelles : il fiut alors arroser, et si on ne le peut, une partie des plants meurent, malgré tout le soin a vec lequel on avait plante et malgré les biuages. Je dois ajonter que lorsqu'on a commencé à arroser on doit continter tant qu’il est nécessaire, silns quoi cela pourrait être plus nuisible qu'utile à la plantation.

Lorsque l'on plante des sapins argentés et en général des arbres résineux conifères, on ne doit toucher avec la serpette ni aux racines, ni anx branches; el j’aurais probablement oublié de le dire, croyant que cela élait su généralement, si je n'eusse vu des planteurs qui rufraichissuicut les racines des plants de ces arbres et qui coupaient et raccourcissaient quelques-mnes de leurs branches. Il est surtout fort unisible de couper de grosses racines aux arbres résineux que l'on plante, et e'est ce qui n'arrive jamais quand on plante du plant de pépinière élevé, ainsi que je l’ai preserit, parce qu’il n’a ni pivot ni grosses racines; mais on eoupe ordinairement des racines, et presque toujours le pivot, aux plants de sappins, hatuts seulement de 1 mère, que l'on prent dans une sapinière pour les planter; of pourtant il en reprend quelques-uns qui deviennent de beaux arlures, malgré la mutilation de leurs racines. J'ai vu mon père laire planter ainsi, pendant plus de trente ans, du plant de sapin argentè et de sapin picéa provenaut de semis naturel que l'on prenait dans sa sapinière; et j’ai, dans mon pare, une très-belle allée de sapins argentés, dans laquelle une partie des arbres ont 2 mètres de circonférence, qui a été plantée en 1786-1787 avee du plant de semis naturel de plus de 1 mètre de haut, tiré de la sapinière. Mais le plant que mon, père plantait ainsi boudait longtemps, le plus garand nombre périssait et il n'y en avali peut-ètre pats un sur dix qui réussit tout-à-lait bien; quant à l'allée plantée en L7\$6, on prit les plus grantes précautions pour arracher et planter le plant, onl l'arrusil pendant deux chés, ce pourtant il fallut con remplaced plusieurs. 
Si l'on plantait à demeure du plant de 3 ans, il suffirait que les trous dans lesquels on le mettrait eussent $0^{\mathrm{m}}, 27$ ì $0^{\mathrm{m}}, 32$ de côté et $0^{\mathrm{m}}, 22$ de profondeur; si l'on plantait du plant de 5 ans, ils devraient avoir $0^{\mathrm{m}}, 50$ de côté el $0^{\mathrm{m}}, 25$ de profondeur. Dans la localité que j'ıabite, où la terre est silico-argileuse et ordinairement mêlée de petits cailloux, un ouvrier peut faire cinq trous de $0^{\text {m }}$, כo de côté ut $0^{\text {m }}, 25$ de profondeur, ou dix de $0^{\mathrm{m}}, 32$ de côté el $0^{\mathrm{m}}, 22$ de profondeur, pendant qu'il en ferait un de $1^{\mathrm{m}}, 14$ de côté et de $0^{\mathrm{m}}, 50$ de profondeur; chacun de ees deruiers trous coûterait 15 centimes.

Ce que jè viens de prescrire pour élever du plant de sapin argenté, et surtout pour le planter à demeure, s'applique, sauf quelques légères modifications que j’indiquerai, aux autres espèces d'arbres dont je vais parler dans ce chapitre. Il n'y a d'ailleurs point de plant, parmi les espèces que j'ai cultivées en pépinière, lont la plantation réussisse micux que celle du sapin argenté. Pour donner une idée des résultats qu'on peut obtenir en se conlormant à ce qui vient d'être prescrit, je citerai les plantations que je fis exécuter pendant l'automne el l'hiver le l'année 1812-1843, et je ferai connaître l'état dans lequel elles se trouvaient i l'automne de 1843 ; les plants dont je me servis avaient été élevés dans ma pépinière, depuis le semis jusqu'à la plantation à demeure.

Je fis planter 300 sapins picéas, hauts de 1 mètre à $1^{\text {"m}}, 50$, dans les allíes de mon parc; à l'automne de 1843 , ils étaient tous en bon état. Je lis planter 51 pius d'Autriche el 6 pins doux ayant un peu moins de 1 mètre de haut daus l'allée l'un bois attenant à mon parc; à l'automne de 1813, il était mort un pin d'Autriche; le reste était en bon état. Je fis planter 79 sapins argentés, pins sylvestres, pins du lord Weymouth, pins laricio et mélèzes, hauts de 1 à 2 mètres, dans une clairière d'un bois feuillu garnic en partie d'épines, de genêts et de joncs marins; à l'automne de 1843 , ils étaient tous en bon état. Je fis planter à 2 mètres de distance, en quinconce, sur un défriché d'épines attenant à un bois, 75 sapins argentés de pépinière hauts de moins de 1 mètre, provenant originairement de plant de semis naturel; on planta, entre ces sapins, de très-petits sapins de semis naturel, levés en motte dans les allées de mon parc; à l'autumne le 1813 , il était mort un sapin de pépinière, et un sixième seulement de ceux de semis naturel; les autres étaient en bon état: les sapins de semis naturel avaient pourtant été pris à l'ombre ou à mi-ombre, pour être mis à découvert, et ils avaient beaucoup souffert des gelées tardives du mois de mai 1813.

J'avais commencé, à l'automne de $\mathbf{1 8 4 1}$, une plantation dans des joncs marins mêlés de bruyères en quelques endroits, et situés au milieu du coteau qui borde l'Iton, non loin de mon habitation; on y planta alors des pins du lord Weymouth, des pins doux, des pins sylvestres et des mélèzes. A l'automne de 1812, j’y fis planter 252 sapins picéas, 10 sapins argentés, 10 mélèzes, 8 cèdres du Liban, 15 pins du lord Weymouth et 217 pins laricio; les sapins picéas et les mélèzes avaient une hauteur de 1 mètre à $1^{\mathrm{m}}, 50$; les plants des autres espèces avaient au plus 1 mètre de lıut; à l'automne de 1813, il était mort deux picéas; tout le reste de la plantation était en bon état. Il laut remarquer qu'alrès que l'on 
eut lait celte plantation; il s'éleva des vents d'une telle violence que plusleurs sapins furent renversés diaus mon parce; il lallut redresser les plantallons jusqu’à trois lois, dans les endroits oủ elles n'étaient pas abritées, par exemple sur le cotean de la vallée de l'Iton qui est exposé à l'onest; la couverture en joncs marins que j’avais fait mettre autour des eères fut emportée plusieurs tois. lleureusement l'hiver lut doux, cireonstance très-favorable pour les plantations d'automne sous le climat de l'aris, patre que les hivers rigouteux y sont toujours accompangnés d'alternatives de gelées et de dégels, ce qui est très-nuisilıle à ces plantations.

Les terres dains lesquelles j'avais fait exécuter les plantations dont je viens de pirler étrient toutes silico-argileuses, plus ou moins substantielles, plus ou moins maigres, mais elles ne contenaient aucune trace de caleaire; chaque espèce avait été placée dans le terrain qui me paraissait le mieux lui convenir. de lois avouer d'ailleurs que je n'ai pas toujours aussi bien réussi, par exemple en 1813-181\%.

III. Sipin picka, Ibies picéa. - Le choix el la préparation du terrain pour le semis, le choix de la graine, l'époque du semis, les précautions à prendre pour le repiquage, pour la transplantation et pour la plantation à demeure, la salison pendant laquelle s'exécute cette plantation, seront tels que je l'ai indiqué dims l'art. I et daus l'art. II.

On sèmera épais, mais beaucoup moins que pour le sapin argenté, parce que parmi les graines du sapin picéa il s'en trouve moins de mauvaises que parmi celles du sapin argenté. Le plant se repique pendant l'automne de l'année où il a été semé, dans des lignes distantes de $0^{\mathrm{m}}, 20$ les unes des autres, et on le anet à $0^{\mathrm{m}}, \mathbf{2 0}$ de distance dans les lignes. Le plant de rebut se mettra dans des lignes distantes les unes des autres de $0^{\mathrm{m}}, \mathbf{1 6}$, et il sera espacé de $0^{\mathrm{m}}, \mathbf{1 6}$ dans les lignes.

Le sapin picéa ayant pris trois sèves et étant par conséquent dans sa troisième année, puisque ce sapin n’a qu’une seule sève par an, on le transplantera dans des quartiers disposés ainsi que je l'ai prescrit page 358; on le mettra par lignes distantes les unes des autres de $0^{\mathrm{m}}, 65$, et à $0^{\mathrm{m}}, 65$ de distance au plus dans les lignes, en ayant soin de disposer les plants en quinconce. On traite le plant pour les binages, et le terrain pour les couvertures, absolument de la même manière que je l'ai preserit à l'article du sapin argenté, en parlant de la deuxième transplantation. Lorsqu'un plant a deux llèches, on tord celle qui est la moins belle. On peut aussi planter le jeune plant de trois ans à demeure et il réussira parlaitement bien; j'en ai planté qui avait cet âge, auquel les lapjins ont coupé la tète et mangé toutes les feuilles, et qui a pourtant repris.

Pendant la sixième année qui suivra le semis, après que la sisième sève sera terminée, presque tous les plants auront dépassé 1 mètre de haut et serout propres ¿l être plantés à demeure ou à être vendus; après la septième sève, tout le quattier sera propre à être planté ou vendu, ét c'est c'e qu'sl laudra linire pendant ceute seplième amnée, car il y aurail beaucoup de désavantage à attende. Si l'on prend 
'juelques picéas dès la sixième année, on ne les remplacera pas; les plants de trois ans qu'on mettrait à leur place dépériraient, étant opprimés par ceux qui occupent déjà le terrain par leurs racines et par leurs branches. On prend pour bien äracher le plant, pour le bien planter et pour le soigner après la plantation, les mêmes précantions que j’ai indiquées pour le plant du sapin argenté. On peut le planter l'automne, l'hiver et le printemps jusqu'au moment où part Ja sève, mais il est préférable de le planter l'automne.

J'ai fait les olsservations suivantes relativement au mode de végétation et à l’aceroissement du sapin picéa pendant les sept années qui précèdent sa planlation à demeure. Le sapin picéa, semé à la fin de mars ou daus les premiers jours d'avril, lève au bout de cinq à six semaines; il lève ayant au bout d'une petite tige la coque de sa graine, qui tombe bientôt et laisse voir un bouquet de feuilles séminales en aiguilles tixées au bout de cette tige; puis la petite tige du picéa se garnit de feuilles dans son pourtour, sur les deux tiers de sa hauteur, à partir du sommet. Le plant qui n'a qu'une sève (Voy. p. 118) borne lì son accroissement la première année de sa naissance, et sa tige atteint seulement $0^{\mathrm{m}}, 024$ ì $0^{\mathrm{m}}, 045$ de haut; au bout de celle tige se trouve le bouton ducuel partiriı la flèche l'année suivante.

La seconde annće, dans le courant de mai, un peu plus tôt ou un peu plus tard, selon les localités et la température qui a régné, on voit partir la flèche, qui est gamie de petites feuilles dans son pourtour, et une ou plusieurs petites Iranches. La flèche et les autres pousses ont terminé leur croissance en longueur au bout de six à neuf semaines environ, selon la température qui a régné; milis ensuite ces pousses grossissent encore un peu et deviennent ligneuses, d'herbacées qu'elles étaient. La tige du jeune sapin picéa a alors 0,11 à 0,25 de haut; les boutons du bout de la flèche et du bout des pousses, desquels partitiront les pousses de l'année suivante, sont alors parfaitement formés. La troisième année, le tronc du picéa se couvre d'un plus grand nombre de petites branches ou plus exactement de ramilles, car les branches ne paraissent que plus tard, et il atteint une hauteur de $0^{\mathrm{m}}, 24$ à $0^{\mathrm{m}}, 5$ 's.

A partir de eette troisième année, le sapin picéa se couvre d'un grand nombre de ramilles, et il prend la forme d'un épais buisson conique, surmonté d'une llèche située dans le prolongement du tronc. Après la sixième ou la septième sève, lorsque le plant a par conséquent 6 ou 7 ans, âge auquel on peut le planter à demeure, il a ordinairement environ $1^{\mathrm{m}}$,, 50 de haut. J'ai donné, pages 118-122 et 125-127, une description de la marche et des effets de la végétation dans les sapins picéas adultes.

Le plant de sapin picéa réussit aussi bien, quand on le plante à demeure, que celui de sapin argenté; excepté sur les terrains couverts de joncs marins, de: bruyères ou d'autres plantes semblables, dont les racines nuisent d'abord à celles du picéa, qui sont traçantes; dans cette situation, le plant de picéa boude pendant plusieurs années avant de se déeider, et il en périt même quelquefois. On peut planter des picé:ıs déjà grands, en prenant beaucoup de précautions, et 
réussir lorsqu'ils viennent originairement de pépinière; j'en ai planté ainsi qui avaient so mètres de haut.

J'avais planté pendant l'automne de 1836 , daus mon pare, des sapins picéas de pépinière qui étaient alors lıants de $1^{\mathrm{m}}, \mathbf{4 6}$ environ; ces picéas remplaçaient, dans une allée, de grands sapins argentés que l'on avait déracinés; le terrain où on les avait mis paraissait leur convenir; l’allée où ils se trouvaient étant large, ils a vaient sulfisamment de lumière et de soleil. Je mesurai la hanteur de ces picéas, à l'automme de 1842 , el l'un d'eux avait $5^{m}, 20$ de hatut, les autres un peu moins; mais tous avaient poussé de plus de $0^{\text {m, }}$, 19 par chaque année, l'une dans l'autre. Si le terrain où se trouvaient ces picéas eût été entièrement défoncé, leur accroissement eût été encore plus rapide; je n'ai pas d’ailleurs toujours aussi bien réussi.

IV. Pin sylvestre, Pinus syllestris. - Le choix et la préparation du terrain pour le semis, le choix de la graine, l'époque du semis, les précautions à prendre pour le repiquage, pour la transplantation el pour la plantation à demeure, la saison pendant laquelle s'exécute cette plantation, seront tels que je l'ai indiqué dans l'article I el dans l'article 11.

On sèmera épais, mais beaucoup moins que pour le sapin argenté et moins aussi que pour le sapin picéa; parce que la graine de pin sylvestre, lorsqu’elle est bien récoltéc, sur des arbres assez âgés, contient moins de manvaise graine que celle de ces sapins, et que le plant de ce pin occupe la première année plus de place que le plant des sapins.

Le plant se repiquera pendant l'automne de l’amnée où il a élé semé, dans des lignes distantes de $0^{m}, 22$ les unes des autres et à $0^{\mathrm{m}}, 22$ de distance dans les lignes. Le plant de rebut se mettra dans des lignes distantes les unes des autres de $0^{\mathrm{m}}, \mathbf{1 6}$, et il sera espacé de $0^{\mathrm{m}}, 16$ dans les lignes. Le plant de pin sylvestre ayant pris trois sèves, et étant par conséquent dans sa troisième année, puisque ce pin n’a qu'une sève par an, on le transplantera dans des quartiers disposés ainsi que je l'ai prescrit page 358 ; on le mettra par lignes distantes de $0^{\mathrm{m}}, 65$ les unes des au-

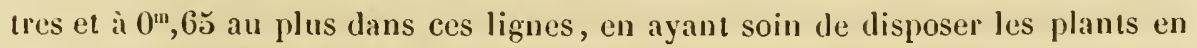
quinconce. Lorsqu'un plant a deux flèches, on tord celle qui est la moins belle ou on lui arrache ses boutons terminaux. On traite le plant pour les binages, et le terrain pour les couvertures, absolument de la mème manière que je l'ai dit en parlant de la création d'une pépinière de sapins argentés. On peut planter à demeure le plant de $t r$ is ans, et il réussira mieux que quand il sera plus âgé; mais il est souvent nécessaire d'avoir du plant plus haut.

P'endant la cinquième année qui suivra le semis, après que la cinquième sève sera terminéc, les plants auront ordinairement dépassé 1 mètre, et seront propres à être plantés à dlemeure ou à ètre vendus. Si l'on jugeait avantageux ou s’il élait nécessaire d'attendre jusqu'i la sixième année pour planter ou pour vendre ce plant, on le punrail; mais il y aurait beancoup de désavantage i attendre plus longtemps. Si lon me prenatit que quelpues pins sylvestres pen- 
dant la cinquième année, on ne les remplacerait pas, parce que les plants de trois ans qu'on mettrait à leur place dépériraient, étant opprimés par ceux qui occupent déjà le terrain par leurs racines et par leurs branches. On plante le pin sylvestre aux mêmes époques que le sapin argenté, et l'on prent pour le bien arracher, pour le bien planter et pour le soigner après la plantation, les mêmes précautions que j’ai indiquées pour le plant de sapin argenté.

J'ai fait les observations suivantes relativement au mode de végétation et à l'accroissement du pin sylvestre, pendant les six années qui précèdent sa plantation à demeure. Le pin sylvestre, semé à la fin de mars ou dans les premiers jours d'arril, lève au bout de quatre à six semaines, ayant au hout l'une petite lige la coque de sa graine qui tombe bientôt et laisse voir un bouquet de feuilles séminales en aiguilles fixées au bout de cette tige; puis cett: petite tige se garnit de feuilles, dans son pourtour, et quelquefois d'une ou deux petites branches sur la moitié environ de la tige, à partir du sommet; les leuilles qui paraissent cette première année, après les feuilles séminales (les feuilles mimordiu'es), sont solitaires. Le plant borne là son accroissement la première annéc de sa naissance, et sa tige atteint seulement $0^{\text {m }}, 025$ à $0^{\text {mo }}, 060$ de hant; les feuilles qui sont au bout de cette tige ont à peu près, dans leur ensemble, la forme d'un cône renversé, et au milieu l'on distingue le bouton duquel partira la flèche l'annece suivante.

La secondeannée, vers la fin du mois de mars, on voit partir la fleche qui est d'abord garnie de bourgeons à feuilles, puis de feuilles daus tout son pourtour, 't ilussi quelques petites branches qui ne sont, à proprement parler, que des ramilles; les feuilles sont contenues, au nombre de deux, dans une gaine, et elles seront toujours ainsi dans les annees suivantes. La llèche et les autres pousses ont terminé leur croissance en longueur au bout de deux à trois mois environ, selon la température qui a régné; mais ensuite ces pousses grossissent encore un peu et deviennent ligneuses, d'herbacées qu'elles étaient. La tige du jeune pin sylvestre, lorsque la croissance de la flèche est terninée, a une hauteur de $0^{\text {mn }}, 09$ ¿ $0^{\mathrm{m}}, 20$; les boutons du bout de la flèche et du bout des pousses, desquels partiront les pousses de l'année suivante, sont alors parfaitement formés.

La troisième année, un étage de branches bien déterminé commence à sc montrer, ce qui résulte de ce qu'il ne pousse point de ramilles sur le trone du pin sylvestre comme il en pousse sur celui des jeunes sapins; et si l'on ne laisse pas entre les plants plus d'espace que je l'ai prescrit, ils poussent en hauteur, tandis que s'ils croissaient isolés ou qu'ils fussent trop éloignés les uns des autres, ils seraient sujets à devenir branchus; le plant atteint cette troisième annće une hauteur de $0^{\mathrm{m}}, 30$ à $0^{\mathrm{m}}, 5$ s̆. A quatre ans, le plant de pin sylvestre a de $1)^{\mathrm{m}}, 60$ à $0^{\mathrm{m}}, 90$, el à l'automne de la cinquième année, âge auquel les pépiniéristes sont dans l'usage de le venclre, il a ordinairement une hauteur de 1 mètre à $1^{\mathrm{m}}$, 50. d'ai donné, pages 1 13-1/50 el 151, une description de la marche et des effets de lit végétation dans les pins sylvestres adultes.

Le plant de pin svlvestre, élevé aninsi que je viens de le prescrire, esı bien 
garni de chevelı, moins pourtant que celıi des sapins; il est plus sujet qu'eux à être ébranlé par les vents, ayant beaucoup moins fa forme pyramidale é étant mème souvent chargé de branches vers sal cime; quelquefois il pousse bien dès l'année où on le plante, le plus souvent il boude et ne pousse bien que l'année suivante. On peut en planter de très-grands, en prenant beaucoup de précautions, lorsqu’ils viennent originairement de pépinière et réussir; j’en ai planté ainsi qui avaient 5 mètres de haut. Le plant de semis naturel de pin sylvestre u’a paru être celui des lıuit espèces lont je moccupe particulièrement dans ce Traité qui reprend le mieux; en le prenant âgé de 1 à 3 ans, on peut en former des pépinières.

J'avais fait planter, pendant l'automne de 1836 , a l'entrée de mon parce, au commencement de la futaie, deux petits massifs de différentes espèces d'arbres résineux, en remplacement de grands sapins que j'avais fait abattre; il se trouvait, parmi ces arbres, des pins sylvestres de pépinière hauts de $1^{\text {mo }}, 46$ environ; je les ái mesurés pendant l'automne de 1812 , et l'un d'eux avait $4^{\mathrm{m}}, 8 \mathbf{7}$ de haut: la végétation de ces pins aurait été encore plus rapide, si le terrain oì ils se trouvaient eùt été complètement déloncé; néanmoins, je n’ai pas toujours ubtenu l'aussi beaux résultats.

V. Pın mantrue, Pinus maritima. - Le choix et la préparation du terrain pour le semis, le choix de la graine, l'époque du semis, les précautions à prendre pour le repiquage, pour la transplantation et pour la plantation à demeure, seront tels que je l'ai indiqué dins l'art. I et dans l'art. 11.

On sèmera dans les premiers jours d'avril et l'on sèmera épais, beaucoup moins pourtant que pour le sapin argenté, la graine du pin maritime étant presque toute bonne, quand elle a été bien récoltée sur des arbres assez âgés, et le plant le pin maritime occupant beacoup plus de place, la première annéce, que celui de sapin argenté.

On peut repiquer le plant pendant l'automne de l'année où il a élé semé; mais il faudra alor's, sous le climat de Paris, exécuter ce travail de bonne heure, pour que le terrain ait le temps de se bien rasseoir, et mettre une couverture de balle de blé, par exemple; car ce plant craint la gelée et les alternatives de gelées et de dégels. Il arrive même quelquefois que la tige du plant gèle en totalité ou en partie, sout qu'on le laisse en place, soil qu'on le repique; mais, dans le premicr cas, la racine reste ordinairement saine et il en part un jet vigoureux au printemps suivanl; si l'on transplante au printemps, en mars ou en avril, ce qui est, je crois, préférable, il est utile, mais il n'est pas indispensable de mettre une couverture. On repiquera ce plant dans des lignes distantes de $0^{\mathrm{m}}, 22$ les unes des autres, et il sera à $0^{\mathrm{m}}, 22$ de distance dans les lignes. Le plant de rebut se mettra dans des lignes distantes les unes des autres de $0^{\mathrm{m}}, 10^{i}$ et à $0^{\mathrm{m}}, 16$ dans les lignes.

Le pin maritime ayant pris deux sèves, et élant par conséquent dius sal se-

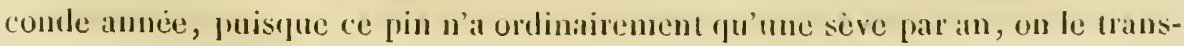


plantera dans des quartiers disposés, ainsi que je l’ai preserit diuns l'art. 1. Un le mettra par lignes distantes de $0^{\mathrm{m}}, 6$ bes unes des autres, et à $0^{\mathrm{m}}$, ŏ4 dans les lignes, en ayant soin de disposer les plants en quinconce. Cette transplantation pourra se faire l'automne; en mettant une bonne couverture, ou au printemps. On traite le plant pour les binages, et le terrain pour les couvertures, absolument de la même manière que je l'ai dit en parlant de la création d'une pépinière de sapins argentés. Je prescris de transplanter le pin maritime dès l'année qui suit celle où on l'a repiqué, parce que si l'on attend à la troisième année, ainsi que je le faisais d'abord, le plant a déjà un pivot très-fort et long quelquefois de $0^{\mathrm{m}}, 50$, d'où il résulte qu'il reprend difficilement. On peut planter à demeure le plant de deux ans, et il réussira.mieux que quand il sera plus âgé; mais il est souvent nécessaire d'avoir du plant plus haut.

Pendant la quatrième aunée qui suivra le semis, après que la quatrième sève sera terminée, presque tous les plants auront alteint ou dépassé 1 mètre, et ils seront propres à être plantés à demeure ou vendus. Il serait très-désavantageux d'attendre qu'ils fussent plus âgés pour les planter, parce que le plant de ce pin élevé en pépinière étant dépouillé de branches près du sol, tandis que sa tête en est chargée, est fort exposé à ètre ébranlé par les vents. On prend absolument les mêmes précautions pour bien arracher le plant de pin maritime, pour le bien planter et pour le soigner après la plantation, que celles que j'ai indiquées pour le plant du sapin argenté. Je n'oserais me prononcer relativement à l'époque ou il est préférable de le planter à demeure; le printemps me paraît plus sùr, le's fortes gelées sont alors passées et une partie des plus grands vents aussi : si on le plante l'automne, il est prudent de mettre une couverture, et cela est utile aussi mème lorsqu'on le plante au printemps; il finut d'ailleurs le redresser chrique fois qu'il a été ébranlé par les vents.

J'ai fait les observations suivantes relativement au mode de végélation et à l'accroissement successif du pin maritime pendant les quatre années qui précèdent sa plantation à demeure. Le pin maritime, semé dans les premiers jours l'avril, lève au bout de cinq à sept senıines, ayant au bout d'une petite lige la coque de sa graine, qui tombe bientôt ct laisse voir un bouquet de feuilles séminales en aiguilles fixées au bout de cette tige; puis celte petite tige se garnit de feuilles dans son pourtour et d'une à trois petites branches dispersées sur Ies quatre cinquièmes environ de la tige, à partir du sommel; les feuilles de celte première année qui paraissent après les leuilles séminales (les feuilles primordiales) sont solitaires. Le plant borne là son accroissement la première année de sa naissance; sa tige a $0^{\mathrm{m}}, 06$ à $0^{\mathrm{m}}, \mathbf{1 1}$ de haut; le bouquet de feuilles qui est au hout de cette lige est terminé en forme de pinceau, et au milieu se trouve le houton duquel partira la flèche l'année suivante.

La seconde année, vers la fin de mars, on roit partir la flèche, qui est d'abord garnic de boutons à feuilles, puis de feuilles, dans tout son pourtour, et aussi quelques petites branches, qui ne sont à proprement parler que des ramilles; les feuilles somt alors contenues an nombre de deux dius une gaine, et elles se- 
ront tonjours ainsi dans les années suivantes. La lhèche ol les aulres pousses out terminé lenr croissance en longueur au bout de deux à trois mois environ, selon la tempéraure qui a régué, et la sève reste dès lors inaclive jusqu'au retour de: la sève de l'année suivante; mais ensuite ces pousses grossissent encore un peu, et deviemment ligneuses, d'herbacées qu'elles étaient. La tige du jeune pin maritime, lorsque la croissance de la flèche est terminéc, a $0^{\mathrm{m}}, 25$ ì $0^{\mathrm{m}}$, 45 de haut; les boutons dı hout de la flèche et du bout des pousses desquels partiront les pousses de l'année suivante sont alors parfaitement formés.

La troisième ammée, un étage de branches bien déterminé commence à se montrer, ce qui résulte de ce qu’il ne pousse point de ramilles sur le tronc; et si on ne laisse pas entre les plants plus de distance que je ne l'ai prescrit, ils poussent en hauteur, tandis que s'ils croissaient isolés ou trop éloignés les uns des autres, ils seraient sujets à devenir branchus et même crochus; le plant alteint cette troisième annéc une hauteur de $0^{\mathrm{m}}, 46$ à $0^{\mathrm{m}}, 60$, et il atteignait jusqu'à 1 mètre lorsqu'au lieu de transplanter la deuxième année je ne transplantais que la troisième. $\Lambda$ partir de cette troisième amée, le plant de pin maritime se charge de branches vers le haut de sa tige et il pousse avec rapidité; mais la uransplantation lui occasionne du retard, ainsi que je viens de le dire; néanmoins, à 4 ans, âge auquel on devra le planter à demeure, il aura généralemeuı plus de 1 mètre de haut. J'ai clonné, pages 201-20. et 207, une description de: la marche et des effets de la végétation dans les pins maritimes adultes.

Le plant de pin maritime, élevé ainsi que je viens de le prescrire, est suliisamment garni de chevelu, un peu moins pourtant que le pin sylvestre; il est fort sujet à ètre ébranlé par les vents, ayant la tête chargée de branches; aussi serait-il préférable de le planter à demeure à deux ou trois ans; il boude l'anni.s oì on le plante, mais il pousse très-bien l'année suivante; son plant de semis naturel reprend moins facilement que celui de pin sylvestre; on peut pourtant en former des pépinières avec du plant d'un ou deux ans : je l'ai essayé, et cela m’a bien réussi.

VI. Pin laricio, Pimus laricio. -- Le choix et la préparation du terrain pour lo semis, le choix de la graine, l'époque du semis, les précautions à prendro pour le repiquage, pour la transplantation et pour la plantation à demeure, seront tels que je l'ai indiqué dans l'art. I et dans l’art. 11. On sèmera épais, mais beaucoup moins que pour le sapin argenté, la graine étant presque tonte bonne quand elle a été bien récoltée sur des arbres assez âgés; on peut semer anssi épais que pour le pin sylvestre, quoiqu'il y ait encore moins de décher lans la graine, parce que le plant de pin laricio occupe la première anmí. moins de place que celui de pin sylvestre.

Le plant se repique pendant l'automne de l'année oì il a été semé, dans dess lignes distantes de $0^{\mathrm{m}}, \mathbf{1 6}$ les unes des autres et à $0^{\mathrm{m}}, \mathbf{1 6}$ dans les lignes; le plant de rebut se metura daus des lignes distantes les unes des autres de $0^{\mathrm{m}}, 1 / 4$ ot i $0^{\mathrm{m}}, 1$, dans les lignes. Le plant ayant pris trois sives, e cetant par consćcuent dans sal 
troisième amnée, puisque ce pin n'a qu'une sève par an, on le transplantera une première fois pendant le temps qui se trouve entre le 15 octobre et le moment où partira la quatrième sève. On le mettra sur des planches de $1^{\mathrm{m}}, 52$ de large, par lignes distantes entre elles de $0^{\mathrm{m}}, 24$ et ì $0^{\mathrm{m}}, 24$ de distance dans les lignes; ainsi il y en aura sept par chaque planche, dont une au milieu; les planches seront séparées par des sentiers le $0^{\mathrm{m}}, 6 \mathrm{a}$ de large; on mettra une couverture sur le terrain aussitôt après la plantation. On peut planter ce jeune plant à demeure, ainsi que je l'ai dit de celui des sapins de même âge, mais il ne supporte pas l'ombrage comme eux.

Lorsque le plant sera resté pendant deux sèves dans cette position, on le transplantera de nouveau dans des quartiers disposés ainsi que je l'ai prescrit dans l'art. 1; on le meltra par lignes distantes les unes des autres de $0^{\mathrm{m}}, 65$, et à $0^{\text {in }}, 6 \check{\text { s }}$ ou seulement à $0^{\mathrm{m}}, 5 \mathbf{4}$ de distance dans les lignes, en ayant soin de disposer les plants en quinconce. Lorsqu'un plant a deux flèclses, on torl celle qui est la moins belle ou on lui arrache ses boutons terminaux. On traite le plant pour les binages, et le terrain, pour les couvertures, absolument de la même manière qu'il a été dit à l'art. II de celui du sapin argenté. On peut planter à demeure le plant de 5 ans, et il réussira mieux que quand il sera plus âgé; mais les pépiniéristes ne trouveraient pas à le vendre, parce qu'il serait trop petit.

Après la septième sève, e'est-ì-dire au bout de sept ans après le semis, le plant est propre à être vendu ou planté à demeure; il est garni le chevelu à pen près comme le plant de pin maritime, moins par conséquent que celui de pin sylvestre, et il est encore plus exposé que ce pin, et presque autant que le pin maritime à être ébranlé par les vents, parce que sa tête est alors chargée de branches; par celte raison, lorsqu'on n'élève pas ce pin pour le ventre, je trouve préférable de le planter à lemeure à 5 ou 6 ans, et l'on ne firil alor's qu'une transplantation; si on le garde jusqu'à 7 ans et plus en pépinière, deux Iransplanlations me paraissent nécessaires pour faire prendre du clovelu à ses racines.

J'ai presque toujours planté le pin laricio à demeure pendant l'automne, et j’ai bien réussi; néanmoins, il en est mort quelques-uns, et je n'oserais me prononcer relativement à l'époque à laquelle il serait préférable de le planter; je pencherais pour Ia plantation d'automne en mettant une couverture, précantion que je n'ai pourtant prise que bien rarement. Le pin laricio boude ordinairement l'année où on le plante à demeure; néanmoins, je l'ai vu quelquefois bien pousser dès cette première annéc.

J'ai essayé de former des pépinières avec du plant de 3 ans pris dlans un semis à demeure sur labour et dans un semis en potets; je n'ai pas réussi, puisqu'il n'en reprit peut-être pas deux sur cent, et je présume qu'il en sera presque toujours ainsi, parce que le plant de ce pin provenant de semis à demeure n'a ordinairpmont, ainsi que le plant de semis naturel, qu'une seule racine, semblable à calle d'une carotte sauvage, et pour ainsi dire point de chevelu. Si le plant n'en̂t eu que 1 ou 2 ans et eût été tiré d’un terrain sablonneux où il aurait pu former 
du chevelu, jaurais probablement réussi, ear il aurait été presque semblable à du plant de pépinière.

J'ai recueilli les renseignemens suivans sur le mode de végétation et d'accroissement du pin laricio pendant les sept années de sa eulture en pépinière. Le pin laricio, semé dans les premiers jours d'avril, lève au bout de quatre à six semaines. Le bout de sa tige est garni de fenilles séminales au milieu desquelles se rrouve le bouton qui domnra naissance à la flèche de l'année suivante, et sur cette tige on remarque des feuilles primordiales solitaires et quelquefois une trèspetite branche; la tige atteint cette première année $0^{\mathrm{m}}, 03$ ì $0^{\mathrm{m}}, 0$ s. La seconde année, elle atteint $0^{\mathrm{m}}, 05$ à $0^{\mathrm{m}}, 06$, et sur quclques-unes des tiges on remarque une on leux très-petites branches et quelques feuilles, au nombre de deux dans une gaîne, telles qu'elles seront toujours par la suite; ces feuilles sont contournées, ce qui fait distinguer facilement le plant du pin laricio cle celui dı pin sylvestre et de celui du pin maritime. Li troisième année, le plant a $0^{\mathrm{m}}, 11$ à $0^{\mathrm{m}}, 20$ de haut. La quatrième année, il a $0^{\mathrm{m}}, 25$ à $0^{\mathrm{mn}}, 40$. A dater de cette époque, la végétation du pin laricio devient beaucoup plus active, et ì sept ans, lorsqu'on le plante ì demeure, il a ordinairement dépassé $1^{\mathrm{m}}, 30$, quoiqu’il ait été retardé jar les deux transplantations qu'on lui a fait subir. Les branches des deux ou trois demières années sont en forme de candélabre, ot beaucoup plus longues que celles des premières années, ce qui fait que te plant 'st chargé de branches du côté de la tête. J'ai donné, pages 216-218 et 25 , une deseription de la marche el des effets de la régétation dans les pins laricio adultes.

Il y a deux allées de pins laricio dans mon pare; dans l'une ils alternent avec des hêtres et des sapins picéas, dans l'autre ils alternent avee des mélèzes; ces allées sont bordées de bois taillis. Les pins laricio qu'on y a plantés avaient étí semés en pépinière en 1828, avec de la graine que j’avais obtenue du ministre dr: l’intérieur, et ils ont été plantés ì demeure en 1831; l'un de ces pins avait atteint 7 mètres de haut en 1812, mais c'est un eas exceptionnel; un grand nombro avaient 5 à 6 mètres de haut, d’autres un peu moins de 5 mètres; s'ils avaient un mètre de haut lorsqu'on les a plantés, on peut évaluer à plus de $0^{\mathrm{m}}, 40$ leur accroissement moyen annuel on hauteur, do 1834 ì 1812 inclusirement.

VII. Pin du lond Wermouri, Pinus strobus. - On élèvera le pin du lord Weymouth absolument de la même manière que le pin laricio; erpendant, sa végétation élant un peu plus prompte, pendant les premières ammées, que celle de ce pin et un peu moins que celle dı pin sylvestre, et ses racines étant aussi bien garnies de cheveln que celles de ce dernier pin, on peut aussi l'élever comme le pin sylvestre : si l'on jugeait alors que le plant fùt trop petit, après la troisième sève, pour exécuter la transplantation, on ne l'exćcuterait qu'après la quatrième sève, et l'on a vu, page 262, que le pin du lorl n'a fu'une sève par an. J'ajouterai les olservations suivantes à ce qur jai dit do la création d’une pépinière de pin laricio el de pin sylrestre. 
On doit semer la graine de pin du lord Weymouth plus éparis que celle du pin laricio, parce que ses graines sont un peu plus grosses et qu'elles présentent ordinairement plus de déchet. Je ne sais si une partie des graines conservent leur faculté germinative pendant trois ans, comme celles du pin laricio, n’ayant fait aucune expérience à ce sujet; quoi qu'il en soit, il sera toujours très-avantageux de semer de la graine nouvellement récoltée qui est toujours la meilleure et présente moins de déchet que la graine suramnée.

Le plant du pin dı lord est aussi bien garni de chevelu que le plant du piı sylvestre et par conséquent un peu mieux que celui du pin laricio. Planté l'aıtomne, il reprend parfaitement saus couverture, quoiqu'il soil toujours utile, sous le climat de Paris, de mettre une couverture au pied des arbres que l'on plante l'automne à cause des altermatives de gelée et de dégel: je les ai toujours plantés sans couverture, presque toujours l'automne, et je crois que c'est l’époque la plus favorable; cet arlure ayant la forme pyramidale, ainsi que les sapins, ne souffre pas autant que les trois pins dont je viens de parler de l'ébranlement causé par les vents. Le plant boude la première année, mais pousse trèsbien l'amnée suivante.

J'ai recueilli les renseignemens suivans sur le mode de végétation et d'accroissement du pin du lord Weymouth pendant les sept années de sa culture en pépinière. La graine du pin du lord Weymouth, semée dans les premiers jours d'avril, lève au bout de quatre à six semaines; le plant est composé, lorsque la pousse du. la première année est terminée, d'une lige haute de $0^{\mathrm{m}}, 04$ à $0^{\mathrm{m}}, 07$ terminée par un bouquet de feuilles séminales en aiguilles, et au milieu se trouve le bouton duquel partira la flèche l'année suivante; l'on remarque sur cette tige des feuilles primordiales solitaires et une ou plusieurs pelites branches. La seconde année, le plant a de $0^{\mathrm{m}}, 08$ a $0^{\mathrm{m}}, 11$ de haut; sa tige est garnie de plusieurs très-petites branches, et, indépendamment de ce qu'il conserve des leuilles primordiales, il porte déjà quelqu's feuilles, au nombre de cinq dans une gaine, telles qu'elles seront toujours par la suite. A trois ans, le plant a $0^{\mathrm{m}}, 12$ à $0^{\mathrm{m}}, 23$ de haut. A quatre ans, il a $0^{\mathrm{m}}, 25 \mathrm{à} 0^{\mathrm{m}}, 40$. A sept ans, lors de la plantation à demeure, il dépasse $1^{\mathrm{m}}, 30$ de haut. J'ai donné, pages 262-265 et 267 , une description de la marche et des effets de la vigétation dans les pins du lord Weymouth adultes.

J'ai planté en 1837, dans les deux petits massifs dont j'ai parlé page 379, des pins du lord Weymouth qui avaient $1^{\mathrm{m}}, 46$ environ de haut, et à l'automme de 1812 , l'un d'eux avait $4^{\mathrm{m}}, 87$ de haut; leur végétation aurait été encore plus rapide si le terrain avait été entièrement défoncé. Ils me paraissent pousser aussi promptement que le pin sylvestre, pendant les années qui suirent la plantation à demeure. On peut planter des pins dı lord, très-grands, arec succès, en prenant beaucoup de précautions, quand ils proviennent originairement de pépinière; j'en ai planté ainsi qui avaient $4^{\mathrm{m}}, 70$ de haut, et j'ai réussi.

VII. Matize d'Europe, Larix europera. - Le semis du inélèze exige des précautions particulières, parce que le plant de cet arbre est très-délicat pendaurt 
les cinq premiers mois qui suivent sa naissance; et l'on a vu, pages 282 et 2!) que le semis nạturel et le semis à demeure du mélèze ne peuvent réussir, sous le climat de Paris, que dans des circonstances exceptionnelles. Si l'on ne pre. nait pas d'autres précautions pour ce semis que celles que j’ai indiquées pour celui des sapins et des pins, la totalité ou une grande partie du plant périrait, soit par suite de l'action du soleil, soit par suite de l'humidité : dans le premier cas, le plant se dessèche an collet, il se renverse et meurt; dans le second cas, il périt par la pourriture de ses racines. On trouvera des détails très-étendus, à ce sujet, dans une bonne Monographie du mélèze de M. Evon, déjà citéc page 291; on en trouvera aussi dans un ouvrage du baron de Tschudy (1).

Il faut, pour faire réussir avec certitude et complètement un semis de mélèze, que le sous-sol laisse parfaitement passer l'eau et que la terre soit ombragée quoique éclairée, ou qu'elle ne reçoive que très-pen les rayons du soleil. On atteindra ce résultat, si le sous-sol ne laisse pas parfaitement passer l'eau, en faisant une fosse, au fond de laquelle on mettra un lit de branches ou de pierres el qu'on couvrira de $0^{\mathrm{m}}, 20$ à $0^{\mathrm{m}}, 2$ š de terre, préparće ainsi que je l'ai dit page 357 ; on peut anssi mettre dans des caisses, percées au fond de trous couverts de tuilots, un lit de petites pierres, et par dessus $0^{\mathrm{m}}, \mathbf{2 0}$ de terre préparée ainsi que je viens de le dire. On couvre cette conche froide, depuis dix heures du matin jusqu'à cinq heures dı soir, d'une toile fixée à quatre pieux; cette toile sert aussi à garantir le semis des grandes pluies : on ne la met point quand le temps est couvert. On peut se contenter de mettre une fosse, préparée ainsi que je viens de le dire, à l'ombre d'une maison on d'un mur' mais si le temps est trop pluvieus, on ne réussit pas ou l'on réussit ınal; on peut aussi la placer dans des clairières de futaies ou de grands taillis, ou à l'abri de haies suffisamment élevées. On peut enfin la mettre en terrain découvert, en l'abritant avec des branches d'arbres ou de genêts piquées dans la terre, ou avec une très-légère couverture de jones marins; ce dernier moyen préserve, en outre, le semis du ravage qu'y font souvent les oiseaux au moment où lève le plant.

Le terrain destiné au semis étant donc préparé et disposé ainsi que je viens de le dire, on sèmera, à la fin de mars, épais, parce qu'une partie de la graine est toujours mauvaise et que le plant pent rester très-serré, puisqu'il sera repiqué dans l'année où il a levé; on cuuvre de $0^{\mathrm{m}}, 002$ à $0^{\mathrm{m}}, 003$ (environ une ligne) de terreau, et l'on plombe le terrain avec le dos d'une pelle on avec une batte; on donne les soins nécessaires en bassinage et en arrosage. Quand le plant a dépassé six mois, il est aussi robuste que celui du pin sylvestre. On repiquera ce plant, après le 20 octobre, dans des lignes distantes de $0^{\mathrm{m}}, 27$ les unes des autres, et à $\left.0^{\mathrm{m}}, 2\right\rceil$ de distance entre les lignes; le plant de rebut se mettra à part, à $0^{\mathrm{m}}, 21$ senlement. Le repiquage peut s'exécuter depuis le $\mathbf{1 5}$ d'octobre jusqu’à la fin de mars; il est utile de mettre une couverture. On transplantera le plant deux ans après le repiquage, c'est-i-dire après que la seconde sève de la troi-

(1) Traité des arbres résineux conifères, p. 68 et 175. 
sième année sera terminée, dans des quartiers disposés ainsi que je l'ai dit page 358; on le meltra par lignes distantes de $0^{m}, 65$ les unes des autres, et à $0^{\mathrm{m}}, 65$ an plus dans ces lignes, en ayant soin de disposer les plants en quinconce. Lorsque le plant aura atteint 5 ans, à partir du semis, on le plantera à demeure. On se conformera d'ailleurs, relativement aux travaux qui suivent le semis, it ce que j'ai prescrit dans les articles I et II de ce chapitre. Le plant de mélèze est aussi bien garni de chevelu que le plant de pin sylvestre, et ayant la forme pyramidale, il n'est pas plus exposé que les sapins à être ébranlé par les vents.

J'ai presque toujours planté le mélèze à demeure l'automne, mais j'ai, dans mon voisinage, un amateur d'arbres verts qui l'a toujours planté le printemps et qui a bien réussi. On a vu, page 299 , que le duc d' $\mathbf{\Lambda}$ thol trouve préférable de planter l'automne, et je le préfère aussi, sous le climat de Paris; mais à cause des alternatives de gelées et de dégels, il sera toujours utile de mettre une couverture. Le plant de mélèze ne reprend pas tout-à-fait aussi facilement que celui des sapins et du pin sylvestre; il boude la première année et pousse ensuite très-bien.

J'ai recueilli les renseignemens suivans sur le mode de végétation el d'accroissement du mélèze, pendant les cinq années qui précèdent sa plantation à demeure. Le mélèze, semé à la fin de mars ou dans les premiers jours d'avril, lève au bout de trois à cinq semaines, ayant au bout d'une petite tige la coque de si graine, qui tombe bientôt et laisse voir un bouquet de feuilles séminales en aiguilles, fixées au bout de cette tige; puis cette petite tige prend un peu d'accroissement, se couvre de feuilles solitaires, d'une à trois petites branches, et atteint nne hauteur de $0^{\mathrm{m}}, 07$ à $0^{\mathrm{m}}, 11$. La seconde année, le tronc du mélèze se couvre de quelques nouvelles petites brauches; il ne porte encore que des feuilles solitaires et il parvient à une hauteur de $0^{\mathrm{m}}, 30$ à $0^{\mathrm{m}}, 55$. A l'automne, on remarque déjà sur le bois les boutons desquels sortiront des bouquets de feuilles l'amnée suivante. La troisième année, le nombre des petites branches ou ramilles du mélèze augmente beaucoup, et il prend la forme pyramidale qu'il conserve 10ujours, lorsqu'il croît isolé; il commence à avoir en mème temps des bouquets de feuilles qui paraissent d'abord, el des feuilles solitaires qui se trouvent sur les pousses; il parvient à une hauteur de $0^{\mathrm{m}}, 80$ à $1^{\mathrm{m}}, 50$. La transplantation à l'âge de 3 ans arrête ce rapide accroissement, et pourtant la cinquième annće, lorsqu'on le plante à demeure, il a $1^{\text {'" }}, 50$ à 2 mètres de haut.

Le mélèze est celui de tous les arbres dont je m'occupe dans ce chapitre qui a la croissance la plus rapide en hauteur pendant les premières annécs; j’ai eu, dans ma pépinière, un mélèze que j'avais conservé, pour le planter plus grand, et qui poussa de $\mathbf{1}^{\mathrm{m}}, \mathbf{4 0}$ pendant la sixième annće, à partir de celle où il avait été semé.

Il y a, dans mon pare, une allée de mélèzes qui a été plantée en 1786-1787, et dont les arbres mont donné du semis naturel dans des circonstances que j’ai indiquées page 282; on peut faire une pépinière avec ee semis naturel en le levant à un on deux ans. Il y a, dans le même parc, une autre allée de mélèzes qui a 
été plantée en 1832-1833, et dans laquelle les mélèzes alternent avec lespins laricio; cette allée traverse un bois taillis et une pinière; le terrain, dans la partie oì se trouve la pinière, est de mauvaise qualité, on n'y tronvait autrefois que de la bruyère et des chênes rabougris. L'un des mélèzes de cette alléc, que j’ai mesuré pendant l'automne de 1812 , avait $6^{\mathrm{m}}, 80$ de haut; mais il y en avait de moitié plus petits dans le mauvais terrain. On peut transplanter avec succès des mélèzes très-grands, quand ils proviennent originairement de pépinière, en ap)portant beaucoup de soin à la plantation. J'en ai planté un qui avait $8^{\mathrm{m}}, 50$ de haut, et j'ai réussi, mais il a boudé pendant sept ans; il y aurait eu de l'avantage à planter un bon plant de pépinière avec beaucoup de soin, car il est à craindre que des arbres aussi grands, ayant été nécessairement mutilés dans leurs racines, n'acquièrent jamais de belles dimensions.

IX. Cèdre du Liban, Cedrus Libani. - Je ne me suis proposé, en élevant quelques cèdres du Liban en pépinière, que d'éprouver s'il était vrai que l'éducation de cet arbre demandât tous les soins qui sont prescrits par les auteurs qui en ont parlé; mais j'ai commis la faute d'extraire les graines que j'ai employées de cônes provenant d'un cèdrè qui n'avait que 45 ans, et de ne pas m'assurer si ces cônes étaient restés sur l'arbre Je temps nécessaire pour que la graine qu'ils contenaient fût parfaitement mûre.

En 1837, je me procurai deux cônes de ce cèdre, âgé alors de $\mathbf{1 5}$ ans, qui se trouve à 8 kilomètres de chez moi, et dont j'ai parlé dans le chapitre précédent; ces cônes avaient la couleur de la maturité; l'un d'eux contenait 170 graines et l'autre 180.

Je fis semer la plupart de ces graines, le 29 marș 1837, sur une planche de jardin située à mi-ombre, après l'avoir préparée avec de la terre de bruyère; j'en fis serner aussi quelques-unes sur une plate-bande de jardin, qui n'avait reçu aucune préparation. Il ne leva qu'une petite partie de ces graines sur la première planche; mais, quoiqu'on ne traitât pas le plant avec plus de précalıtion que celui des espèces dont j'ai précédemmient parlé, il réussit bien; il leva quatre ou cinq des graines que j’avais semées sur la plate-bande. On ne prit d'autres soins de ces derniers plants que de les débarrasser des herbes qui les entouraient; au bout de trois ans il n'en restait que deux, mais en aussi bon état que ceux qui étaient sur la planche : le rigoureux hiver de 1837-1838 ne fit périr que quelques-uns de ces plants de cèdre.

Pendant l'automne de 1839, on transplanta tout ce plant, que je n'avais point fait repiquer à l'automue de 1837, parce qu'il avait levé trop clair, en quoi j'a vais eu tort. Cette transplantation fut exécutée ainsi que je l'ai dit page 363 ; mais on ne mit sur le plant repiqué qu'une couverture trop faible, il y avait même un enılroit où il n'y en avait pour ainsi dire point. Le plant passa très-bien l'hiver et le mois de février encore mieux, parce que ce mois fut remarquablement doux; malheureusement, à ce temps si doux, qui avait mis la sève en mouvement, succéda un mois de mars tris-rude; le thermomètre centigrade descen- 
dait toutes les muits de 6 à 7 degrés au dessous de zéro, tamdis que pendant le jour un soleil ardent réchauffait l'atmosphère. Ces alternatives de gelées et de dégels furent funestes aux jeunes cèdres : leurs fenilles, qui sont ordinairement persistantes, devinrent brunes et tombèrent ensuite toutes; il n'en périt pourtant que quelques-uns, el seulement parmi ceux qui n'avaicnt point de couverture, les autres ne furent que retardés dans leur végétation.

La chute de leurs feuilles ne peut d'ailleurs être attribuée à ce qu'ils avaient été transplantés l'automne précédent, car j’avais des cèdres âgés de 8 à 11 ans, ransplantés depuis trois ans, et un cèdre de 40 ans, qui perdirent aussi leurs feuilles; je craignis même de perdre le cèdre de 40 ans; heureusement il se recourrit de feuilles et s'est bien rétabli. Le cèdre duquel j'avais tiré mes graines, plus âgé et d’une végétation plus vigoureuse que le mien, n’éprouva aucune atteinte de ce bouleversement dans la marche de la température. A l'automne de 1812, il ne me restait plus que 30 des cèdres semés au printemps de 1837, et le plus haut n'avait que $0^{\mathrm{m}}, 65$ ( 2 pieds); mais on a vu que leur végétation avait été retardée par des alternatives de temps doux ef rigoureux, et que j’ignore si les graines que j’avais employées étaient dans un état parfait de maturité. Je plantai une partie de ces cèdres à demeure pendant l'automne de 1812, unè autre partie au printemps de 1843; on leur mit une épaisse couverture de joncs marins, la plantation réussit: j’ai planté le reste au printemps de 1844, et ils ont péri:

J'ai éprouvé plus de pertes dans les plinntations de cèdres, qu'elles aient été exécutées à l'automne ou au printemps, que dans celles des autres arbres dont je parle dans ce chapitre; et ils ont quelquefois boudé plusicurs années, avant que de reprendre la belle végétation qu’ils avaient quand on les tirait de la pépinière : je me suis d'ailleurs trop peu occupé de la culture du cèdre pour pouvoir donner mes observations comme une règle, et je suis dans le dout relatirement à l'époque à laquelle on doit planter cet arbre à demeure; néanmoins, j'ai mieux réussi l'automne, mais j'ai toujours eu le soin de faire mettre une couverture.

On peut conclure de mon essai pour élever le cèdre en pépinière, en pleine terre, sans prendre plus de précautions que pour les sapius et les pins dont j'ai précédemment parlé, et de ce que cet arbre se reproduit par le semis naturel, sous le climat de Paris (Voy. p. 310-313), qu'il est de pleine terre en France, même dans ses premières années. Je répète d'ailleurs cet essai avec huit plants que m’a donnés II. Neuman, chef des serres au Jardin-des-Plantes de Paris, et qui proviennent de la graine tombée des cônes du cèdre du Jardin-des-Plantes en février 1844 (Voy. p. 311); il avait pris du plant de semis naturel sous la gouttière de l'arbre et l'avait mis en pot. J'ai tiré ces plants du pot dans lequel ils étaient, pour les repiquer en pleine terre à l'automne de 1841; ils ont très-bien supporté l'hiver de 1841-1815, dont le commencement et la fin ont pourtant été rigoureux, quoique l'on n'ait pris d'autres précautions que de mettre sur celte petite plantation une converturc de balle de blé. 
X. Pin b'Autracue, Pinus unstriucu. - Se me suis procuré la sraine de pin d'Autriche dans la maison Vilmorin-Andrieux, qui la tirait directement de l'Autriche, et je l'ai semée au printemps de 1837; ainsi les arbres provenus de ce semis ne portent pas encore de cônes. J’a comparé les plants que miont donués ees graines avec des plants obtenus par M. Ie marquis te Vibraye, dins sa terre de Cheverny (Loir-et-Cher), de graines qu'il avait rapportées d'Autriche: M. de, Vibraye m’a donné quelques-uns de ses plants, que j’ai placés à côté des miens; ils me paraissent entièrement semblables.

J'ai traité le plant de pin d'Autriche absolument comme le plant de pin laricio, parce qu'il m’a semblé que son accroissenent était à peu près le même, pentant les prenières amnées, et je l'ai planté à demeure pendint l'autonme de 18'2, en allée et en massif; je lui ai trouvé autant de chevelu qu'au plant du pin sylvestre, un peu plus, par conséquent, qu'à celui du pin laricio. J'arais alussi semé, sous le nom de graine de pin tunriyne, de la graine que je m'étais procurée également dans la maison Vilmorin-Andrieux, qui l'avait lirée directement de la Crimée; le plant qui en est provenu m’a paru absolument semblable à celui de pin d'Auriche (Voy. p. 328) : j'ai d'ailleurs séparé ces deux sortes de plants lorsque je les ai plantés à demeure, afin que l'on puisse voir si, par la suite, il ne se montrera pas entre eux quelque différence. Les pins l'Autriche que j’ai semés en pépinière en $\mathbf{1} \$ 37$, et que j’ai depuis plantés à demeure, avaient, en moyenne, à l'automne de $1811,1^{\mathrm{m}}, 20$ de haut, et le plus haut avait $1^{\text {mn }}, 90$. A 1 jourd'hui ( 28 juin 1845), au moment où j'imprime cet article, ils ont en moyenne $1^{\text {'" }}, \bar{\jmath} 5$, et le plus haut a $2^{\mathrm{m}}, 43$.

XI. PIn doux, Pinies micis. - Je me suis procuré la graine de ce pin daus lil maison Vilmorin-Audrieux, sur l'indication de M. A. Hichaux, qui m'assura qu'elle était authentique, ćtant arrivée dans ses cònes, qu’il avait reconmus pour ètre bien ceux du pin doux. J'ai semé cette graine en 1837, sur une planche préparéc avec de la terre de bruyère, et elle a très-bien levé. La végétation du plant de pin donx ayant été aussi active, pendant les premières années, que eclle du plant de pin maritime, et ce plant ayant la tête chargée de branches comme celui de pin maritime, je pense qu'on devait le traiter de même; mais ignorant quelte serait la marehe de sa végétation, je l'ai traité comme le pin sylrestre.

Il m’arriva, d’ailleurs, en élevant ce plant el ne prenant d'autres précautions que celles que j’ai précédemment indiquées, que je fus sur le point de le perdre. Après que le plant eut été transplanté dans le quartier où il devait rester jusqu'à ce qu'on le plantât à demeure, il commença à dépérir; ses feuilles devinrent jaunes, sa végétation se ralentit d'abord, et s'arrêta ensuite presque entièrement; des pins doux du même semis que j'atvais fait planter en même temps, à mi-ombre dans un bosquet et dans ma sapinière, avaient, au contraire, la plus belle végétation. Je présmma que le pin doux dentandait ì ètre ilevé à mi-ombre, dans sil junnesse, jusqu'ì un igge julus avancé que celui anquel il 
avait été mis à $0^{\mathrm{m}}, 65$ (2 pieds) de distance en tout sens, dans un quártier entièrement découvert; je transplantai dunc de nouveau quelques-uns de ces plants malades dans d'autres parties de ma pépinière, où ils étaient ombragés par des plants plus âgés, et j'en plantai encore à demeure à mi-ombre daus mon parc; tous reprirent une belle végétation.

Par suite de ce résultat, je fis planter en 18/1-1842 le reste de ces plants malades, qui périssaient successivement, au nombre de 200 environ, dans un bois taillis de mauvaise qualité voisin de ma pinière, et ils se seraient très-bien rétablis, car ils reprirent au bout de peu de temps une belle couleur; mais malheureusement il y avait dans le voisinage un terrier de lapins bien habité, et ces animaux, en les broutant et en en coupant le tronc quand ils ne pouvaient atteindre la tête, les auraient tous fait périr, si je n'eusse imaginé de leur mettre une couverture de fenilles et de les faire enduire de bouse de vache, ce qui parut les écarter. Pendant que les lapins dévastaient ainsi cette plantation, je remarquai que les pins doux dont le tronc avait été coupé repoussaient du pied comme le bois feuillu; j'en coupai plusieurs rez terre en 1813 , lorsque la première sève était déjà avancée, et il partit des jets de bonne apparence. Si le pin doux repoussait de souche comme les bois feuillus, on pourrait le cultiver en taillis; mais c'est ce que je n'oserais affirmer, puisque cette propriété de se reproduire par des rejets, propriété que je n’ai observée que sur de très-jeunes pins doux, pourrait bien ne plus exister pour des pins plus âgés.

Ainsi, pour élever avec succès le pin doux, il faut que le semis soit fait à l'ombre ou à mi-ombre, et que les plants, jusqu'au moment de la plantation à lemeure, soient aussi élevés à mi-ombre; on peut, par exemple, si l'on a dans une pépinière des plants d'arbres feuillus de haute tige, lés mettre au nord de ces arbres. Je présume qu'en en conservant le plant en pépinière à mi-ombre jusqu'à sa cinquième année, il pourrait ensuite être placé sur un terrain entièrement découvert; j'en ai planté en 1811-1812, c'est-ì-dire cinq ans après le semis, sur un petit coteau découvert situé au nord et couvert de joncs marins, et ils ont assez bien repris; ces plants avaient d'ailleurs souffert dans la pépinière, ainsi que je l'ai dit : peut-être l'ombrage des joncs marins leur a-l-il été fivorable. L'un des pins doux que j'avais plantés d'abord dans mon parc avait, à l'automne de 1812, c'est-ì-dire six ans après le semis, $1^{\mathrm{m}}, 90$ de haut, et $3^{\mathrm{m}}, 50$ à l'automne de 1811 .

Je terminerai cet article par exprimer un doute relativement à l'arbre que j'ai cultivé sous le nom de Pin doux. Je crains, quoique M. A. Michaux ait cru reconnaître les cônes desquels ont été tirés les graines que j'ai employées, qu’il ne se soit trompé, car les pins que j’ai cultivés ont tous, jusqu'aujourd'hui (1845), leurs leuilles contenues au nombre de trois dans une gaine, et M. Michaux dit (1) qu'elles sont réunies dieux à deux dans une même gaine; qu'on en remarque souvent trois dans les pousses de l'année, mais sur les très-jemes branches seu-

(1) Histoire des arbres forestiers de l'Amérique septentrionale, 1. 1, 1. 5i. 
lement (et par consequent sur le plant); entin qu'elles sont d'un vert sombre, tandis que jusqu'i présent, celles du pin que j’ai cultivé sont d'un vert clair. Les jeunes pousses sont d'ailleurs violettes, caractère que M. Michaux dit être particulier à ce pin et au P'inus inops; mais l'arbre a teux sèves, ce que M. Michaux ue dit pas du pin doux. Quoi qu'il en soit, si ce pin n'est pas le pin doux, el que sal végétation se soutienne telle qu'elle s'est montrée jusqu'à ce jour, ce sera un fort beau pin. J'ai donné cent des plants de ce pin à la Société royale et centrale d'agriculture, pour ses bois du Vicil-Harcourt, et j'en ai domné à quelques personnes de mon voisinage. 


\section{CHAPITRE XII.}

\section{OBSERVATIOIS, FAITS ET REISEIGNEIEIS DIVERS.}

I. Alternance des bols sur le sol. - L'utilité de l'alternance, dans la culture des végétaux herbacés nécessaires aux besoins des hommes, est aujourd'lui presque généralement reconmue, et exerce une grande influence sur li direction donnée aux cultures; il n'en est pas encore ainsi relativement aux bois.

Une partie des hommes qui ont médité sur la culture des bois croient à l'utilité de l'alternance; quelques-uns restent dans le doute, d'autres ne croient pas à cette utilité. On est également divisé, relativement à la marche que suit la nature; les uns pensent qu'elle fait alterner les essences, les autres que cette loi n'existe point. Ceux qui admettent la loi d'alternance, comme ceux qui la repoussent, s'appuient sur des faits d'expérience : les premiers citent des mutations d'essences de bois opérées par la nature, et ils disent que les parties de forêts qui présentent des caractères incontestables de décadence sont ordinairement composées d'une seule essence, et que les futaies mélangées produisent, sauf quelques exceptions, plus de bois que celles d'une seule essence; les seconds citent des forêts composées d'une seule essence depuis un temps immémorial et qui sont toujours belles, et ils ajoutent, comme une raison sans réplique, qu'il n’est pas possible d'expliquer l'al ternance spontanée des essences. Je me range pourtant parmi les personnes qui croient à la loi d'alternance, et je vais citer, à l'appui de mon opinion, quelques faits qui m'ont paru dignes de remarque : je n'ai d'ailleurs point la prétention d'en domer l'explication; il y a bien d'autres mystères que l'intelligence humaine n'a encore pu parvenir et ne parviendra jamais à dévoiler.

On cite dans l'A mérique septentrionale des terres nouvellement défrichées sur lesquelles le blé, qui est une plante annuelle, est revenu plus de vingt-cinq fois de suite, avant que la terre parût lassée de le produire. Si la terre pouvait ainsi porter, sans se lasser, plusieur's générations des essences de bois qui occupent le terrain pendant plus d'un siècle, on conçoit combien il deviendrait difficile l'observer la loi d'alternance opérée par la nature : cette loi pourrait d'ailleurs 
présenter des exceptions pour quelques espèces de bois, conme on prétend qu'elle en présente pour quelques végétaux herbacés; mais l'alternance effectuée par la nature, dans beaucoup de cas, paraît être un fait incontestable.

Les espèces d'arbres résineux dont je me suis occupé dans ee Traité semblent, pour la plupart, moins soumises à cette loi que les arbres feuillus; néanmoins, on peut citer un grand nombre d'exemples de l'alternance de ces bois avec des bois feuillus, par exemple, du sapin argenté avec le hêtre, dans les pays de montagnes : telle forêt de hêtres était autrefois une forêt de sapins, et réciproquement. Lorsque l'on coupe une futaie qui avait, pour ainsi dire, éteint toute végétation par son ombrage, il naît sur le terrain qu'elle occupait, après que par cette exploitation on lui a rendu l'influence du soleil et de la lumière, une très-grande quantité de plantes parmi lesquelles il s'en trouve qui sont rares dans les environs, et d'autres qui n'existent point dans le pays; le bois qui remplace celui que l'on a coupé est souvent d'une autre essence.

Ce changement d'essence de bois s'opère souvent beaucoup plus promptement encore : ainsi, dans le pays que j'habite, pour laire un bois on plante ordinairement du bouleau, que l'on recèpe à quatre ou cinq ans, et on l'exploite ensuite tous les neuf ans. Dès la troisième ou quatrième exploitation, on commence à y apercevor du ehène, et au delà de cent ans le chêne a ordinairement remplacé presque entièrement le bouleau. L'explication qu'on donne de ce phénomène, dans le pays, est que ce sont les oiseaux, particulièrement les geais, qui ont apporté les glands; je conviens, sans embarras, que cette explication ne me satisfait point.

Au Brésil, dans la province des Mines (1), les habitans brùlent les parties de forêts vierges qu'ils veulent mettre en culture, font deux récoltes et laissent reposer la terre; elle se couvre aussitót d'arbustes qui n'existaient point dans la partie de forêt vierge que l'on vient de détruire : au bout de cinc ou six ans on brùle ces taillis d'arbustes, on sème dans leurs cendres et on laisse ensuite reposer la terre, qui se recouvre de nouveau d'arbustes d'une autre espèce encore. Dans d'autres parties de cette même province, après avoir fait un très-petit nombre de récoltes sur un terrain, on y voit naitre une grande fougère qui s'en empare entièrement; cette fougère est bientôt détruite par une graminće visqueuse, appeléc Capin gordura, qui n'a paru dans ce pays que depuis environ soixante ans; entin, si le terrain est de bonne qualité, on y voit paraître, au bout d'un certain temps, des arbres el des arbustes qui finissent par s'en emparer et par détruire entiùrement le Capin gordura. Comment expliquer ees apparitions spontanées de plantes, d'arbustes et d'arbres? Je sais qu'on parvient à tout expliquer; mais les explications qu'on m'a données, jusqu'à ce moment, ne m'ont pas satisfait.

Relativement à des apparitions de végétaux, dont on ne peut donner aucune explication satisfaisante, selon moi, je dirai que lorsqu'on crée un étang dans un

(1) Voyages dans les provinces de kio de Janciro el Minas Geraes, 1. 1, p. 194 et 201. 
lieu où il n'y en avait jamais eu, au milieu d'un désert, par exemple, on voit bientòt croître daus ses eaux et sur ses rives des plantes aquatiques dont les pareilles n'existent souvent qu'à de très-gुrandes distances; et réciproquement, si l'on dessèche l'étang, les plantes aquatiques périssent, el il paraît d'autres plantes qui souvent n'existent pas même dans le pays. Je rapporterai, à ce sujet, un lait qui se trouve consigné dans les Mémoires de la Société royale ê centrale l'agriculture, année 1812, page 138, dans un article de M. Masson, sur les étangs de l'Indre (Meurthe), qui produisent successivement du poisson et des récoltes. Pendant l'année où l'on met à sec l'un de ces étangs pour en livrer le sol à la culture, un lot de terre d'environ 200 liectares reste en prairies; "le niveau, " dit M. Masson, en est aussi régulier que celui d'une table de billard, il est pen" dant trente-deux mois sous 4 mètres d'eau, il ne produit pas de plantes aqua" tiques; au moment où il est découvert it n’y existe pas la plus légère trace de "végétation : mais à peine a-t-il été frappé des rayons du soleil, qu’il y naît un "tapis de trèfle blanc tellement riche, tellement régulier, que je défie le plus "habile agriculteur, placé sur le meilleur champ de France, d'en créer un pa"reil. Je cite le fiat, dit M. Masson, mais je ne cherche point à l'expliquer."

Si l'on admet que l'alternance des bois sur le sol soit une loi de la nature, du moins pour le plus grand nombre des essences forestières, on en tirera la conséquence que, toutes choses égales d'ailleurs, il y a avantage à mêler les bois selon l'inclication de la nature. Mais souvent, au contraire, on a intérêt à favoriser une seule essence, tant qu'elle a une belle végétation, à cause de son prix élevé, par exemple.

11. Greffe herbacée. - On ne peut se dispenser de parler, dans un Traité des arbres résineux conifères, de la greffe herbacée due au baron de Tschudy, fils de celui qui a publié, sur les arbres résineux conifères, un ouvrage que j’ai précédemment cité; il commença à la mettre en usage en 1815, et il l'a décrite dans une brochure intitulée Essai sur la greffe de l'herbe, des plantes et des arbres, qui fut publiée à Metz en 1819. La greffe herbacée a été décrite en outre par Delamarre, dans son Traité pratique de la cullure des pins, page $2 \pi$, d'après ce qui se pratiquait alors dans li forèt de Fontainebleau; par M. Soulange-Bodin, dans le $\mathbf{n}^{\circ}$ de juin 1839 des Annales de l'Institut horticole de Fromont, d'après ce qui se pratique à Fromont, et par M. de Boisdhyver, dans les Annales forestières d'avril 1843, d'après ce qu'il fait pratiquer dans la forêt de Fontainebleau. Cette greffe est devenue usuelle en horticulture et même en silviculture, depuis qu'elle a été employée sur une grande échelle dans cette forêt; son utilité est incontestable surtout en ce qui concerne les arbres résineux conifères qui ont une flèche (sont umitiges), et particulièrement les pins, car ce sont les arbres que l'on greffe ainsi le plus facilement et avec le plus de succès. Elle sert à faire produire à certains sols des espèces qu'on ne pourrait y obtenir franches de pied; elle peut faciliter l'acclimatation d'espèces nouvelles; elle rend plus prompte et plus lacile la propagation d'espèces peu réfandues, moins encore en donnant la facilité de les obtenir par le grrefiage, 
qu'en procurant des porte-graines plusieurs années avant l'époque où l'on en aurait obtenu par le semis.

Le pin sylvestre a été trouvé le plus propre à recevoir la greffe des pins à deux leuilles; l'emploi du pin maritime (qu'on se procure si facilement par le semis) pour sujet, n'a pass donné de bons résultats; selon M. de Boisdhyver, le pin rigide, Pinus rigida, pin à trois feuilles, réussit aussi sur le pin sylvestre, quoique moins bien que les pins à deux feuilles. Le pin cembro peut se greffer, avec un entier sucè̀s, sur le pin Weymouth, qui est à cinç fenilles comme lui, et il croît alors beaucoup plus vite que lorsqu'il est franc de pied. Mais ce qu'on n'aurait pas présumé, le pin cembro se greffe avec succès sur le pin sylvestre, ainsi que le prouvent plusieurs greffes âgées déjì de 8 ans (1814) que M. de Boisdhyver a fait exécuter dans la forêt de Fontainebleau. Les mélèzes peuvent se greffer les uns sur les autres. Le cèdre du Liban réussit difficilement sur le mélèze; le cèdre de l'Inde réussit bien sur le cèdre du Liban. Le sapin baunier de Gilead, Abies bulsamea, réussit sur le sapin argenté; les sapinettes d'Amérique se greffent les unes sur les autres, et l'on parvient quelquefois à les greffer sur le picéa.

Je vais décrire la grefte herbacée d'après ce qui se pratique dans la forêl de Fontainebleau, où elle a été employée particulièrement pour greffer le pin larieio sur le pin sylvestre, et d'après ee que j’ai pratiqué moi-même.

On a commencé à employer la greffe herbacée, dans la forêt de Fontaincbleau, en 1822, par les ordres de II. le baron de Larminat, qui était alors conservateur de cette forêt; M. de Boisdhyver, qui lui a succédé, a suivi cette impulsion. Les gardes de la forêt de Fontainebleau, dit-il dans l’article des Annales forestières que j'ai cité, greffent annucllement de 8 à 10,000 pins sylvestres; et il y avait en 1814, daus cette forêt, 120,000 pins laricio greffés sur pins sylvestres, indépendamment dles greffes de quelques autres espèces encore rares. Les premiers pins sylvestres de cette lorêt greffés en pins laricio avaient en 1843, e'est-à-rlire au bout de 21 ans de greffe, jusqu'à $0^{\mathrm{m}}, 70$ de circonférence à 1 mètre du sol, el 12 mètres cle haut; en moyenne $0^{\mathrm{m}}, 60$ de circonférence et 10 mètres de haut; on ne voyait pour ainsi dire jamais de bourrelet au point de jonction de la greffe avec le sujet. Ainsi la forêt de Fontainebleau fournira des graines de pin laricio environ huit ans plus tôt que si l'on eùt semé au lieu de greffer, $e c$ qui sera fort utile. Je pense d'ailleurs qu'il ne serait pas prudent de greffer un plus grand nombre de pins sylvestres en pins laricio avant de savoir si les arbres que l'on obtiendra par la greffe seront aussi benux que ceux que l'on obtient si fitcilement et avec tant de suecès, ainsi qu'on l'a vu chapitre VI, par le semis et par la plantation; et si le tronc ne sera pas sujet à se disjoindre au point de jonction de la greffe et du sujet quand on l'emploiera comme bois d'œuvre.

La greffe herbacée des pins peut être exéentée par une personne seule; mais il est préférable qu'elle soil exécutée par deux personnes, parce que l'opération est plus tôt terminée, ce qui est avantageux, les pousses herbacíes sur lesquelles on opère étant très-délicates. Il esı à désirer aussi, Jorsque l’on opère en grand, que l'on ne arefle que des arbres ansez peu élevés pur qu’il ne soit pas nécessaire de 
monter sur une chaise ou sur une échelle double, ce qui rend l'opération plus longue : d'ailleurs, plus la greffe s'exécute loin du sol, plus le trone conserve de bois du sujet, ce qui peut avoir des inconvéniens. Chacun des deux ouvriers doit être muni d'un greffoir bien tranchant, el l'un d'eux doit en outre être porteur d'une petite pierre, moins encore pour repasser les greffoirs que pour les débarrasser de la résine qui s'y attache très-promptement et les empêche de couper. Je parlerai d'abord de la grefle des pins.

Le moment d'exécuter la greffe herbacée des pins est celui où les feuilles du bas de la flèche ont presque pris leur distance, et où les pousses n'étant pas encore ligneuses peuvent se casser net à la main; trop tôt, elles ne cassent pas uet, parce qu'elles sont trop molles; trop tard, elles ne cassent plus, parce qu'elles sont devenues ligneuses; il y a done un moment à saisir dont on ne peut acquérir la connaissance que par l'habitude, mais c'est une habitude qui s'acquiert très-promptement. Le greffage des pins, dans la forêt de Fontainebleau, commence, selon que la saison a été avancée ou retardée, du 15 au 25 mai, et demeure praticable pendant douze à quinze jours. Les greffes que l'on fait les premières doivent être plus rapprochées de la base de la flèche que celles que l'on fait à une époque plus avancée, parce que c'est cette partie de la flèche qui devient ligneuse la première. Il va sans dire que les arbres les plus vigoureux et qui ont de belles pousses sont ceux sur lesquels on a le plus de chances de réussir, et que plus les pousses sont petites, plus la greffe est difficile à exécuter, parce qu'on est exposé à les endommager pendant l'opération. Les greffes doivent être, autant que possible, de la grosseur de la llèche sur laquelle on les place et jamais plus grosses; si elles étaient plus grosses, il en résulterait un bourrelet qui occasionnerait par la suite leur mort. Elles se cueillent à l'extrémité des branches des arbres dont on veut reproduire les espèces, et l'on doit s'en servir le plus tôt que l'on peut après les avoir cueillies; cependant elles peuvent être conservées pendant quarante-huit heures dans de la mousse ou de l'herbe humide, et c'est ainsi qu'on doit les placer quand on ne les emploie pas tout de suite. ll ne me reste plus qu'à décrire l'opération, et je le ferai pour le greffage du pin laricio sur le pin sylvestre; je domne en outre, ci-joint, un dessin de celte greffe de grandeur naturelle, exécuté avec soin d'après nature; car le plus mauvais dessin est souvent plus utile que la meilleure description.

Un sujet ayant été choisi, par exemple un pin sylvestre, pour y poser unc greffe de pin laricio, on cassera la flèche, ou on la coupera avec un grefloir bien tranchant, à plus ou moins de clistance de sa base, selon que la sève sera plus ou moins avancée. 11 est préférable de couper; mais alors le greffoir se salit plus vite de résine; on cassera donc, et si la cassure n'est pas sensiblement perpendiculaire à l'axe de la flèche, on la dressera avec le greffoir. Les feuilles qui entourent les pousses n'ont encore atteint alors qu'une petite partie de leur Jongueur; on les coupera soignẹsement avec le greffoir dans la partie que derra occuper la greffe, en en réservant pourtant quelques-unes près de l'endroit où l'on al eassé la flèehe, pour servir à altirer la sève. On romjera ensuite à 
la main les pousses de la courome qui se trouve à la base de la fleche, pour

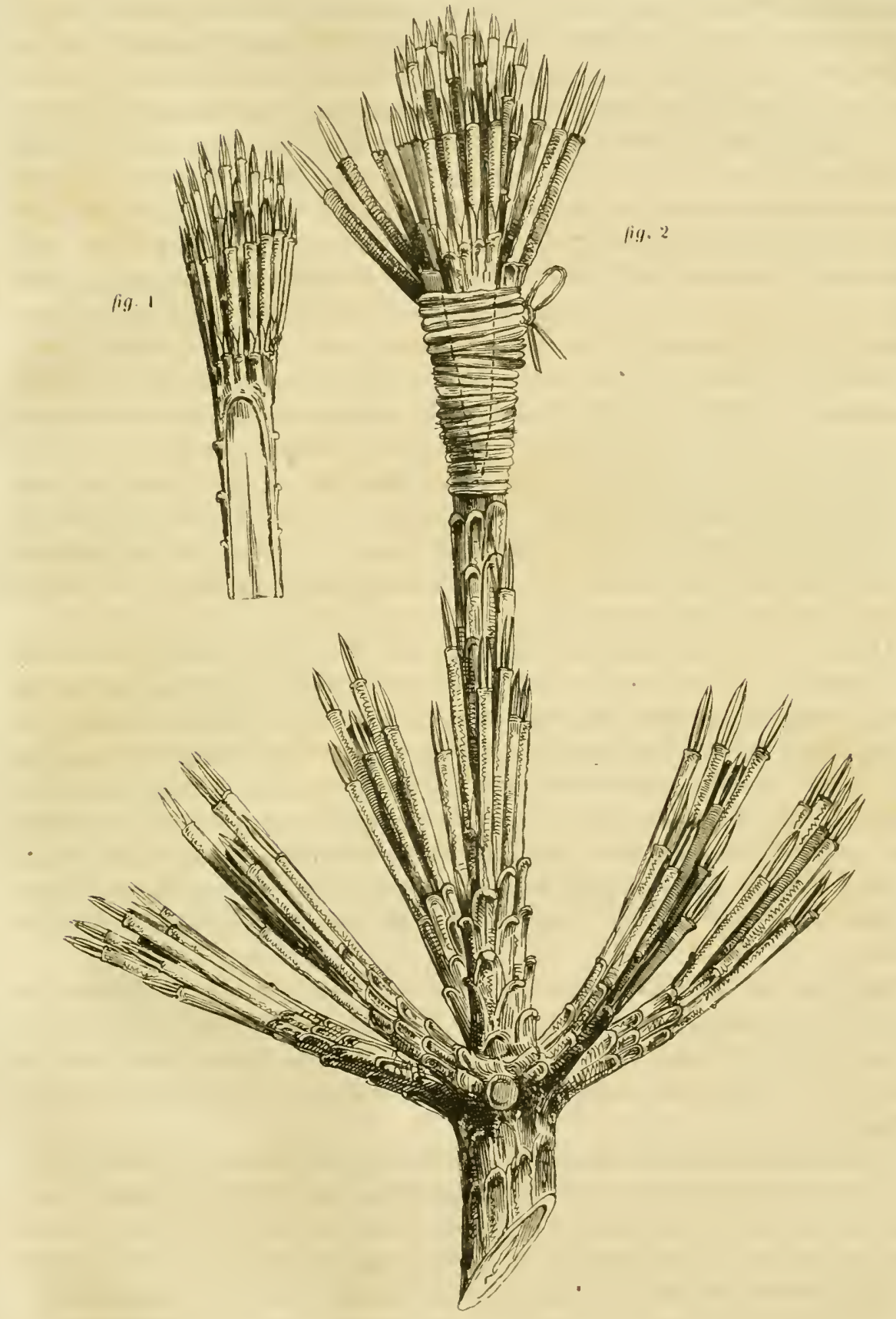

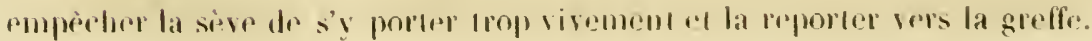


Les feuilles ayantélé coupées sur la flèche comme il vient d'être dit, dans la partie qui doit être fendue, on taillera la greffe en forme de coin, en évitant d'appliquer les doigts sur les plans qui forment le coin, de manière qu'elle ait au plus, lorsque l'opération sera terminée, $0^{\mathrm{m}}, 06$ de long $(f g .1)$. Dans le même tems, s'il y a deux greffeurs, et immédiatement après, s'il n'y en a qu'un, on fendra la flèche par le milieu, un peu plus profondément que ne l'exigerait en apparence la greffe, et l'on placera tout de suite celte greffe dans la fente qu'on vient de faire de manièrc qu'elle porte bien au fond; les deux parties de la flèche entre lesquelles elle se trouve placée devront dépasser un peu les plants qui forment les faces du coin. Enfin on fixera la greffe avec de la laine, dı jonc ou une lanière d'écorce, ainsi que cela se pratique pour la greffe en écusson, en commençant par le haut de la fente; mais on ne fera point passer la ligature sur les feuilles qui servent de tiresève. La fig. 2 représente la tête du pin lorsque l'opération est terminée.

Lorsqu'on greffe des espèces d'une reprise difficile, parce qu'elles ne se trouvent point en suffisante analogie avec le sujet, on enveloppe la greffe d'un cornet de papier attaché par le bas avec de la laine ou une ficclle, et l'on ne retire ce cornet de papier qu'au bout de dix à quinze jours. On ne prend point cette précaution dans la forêt de Fontainebleau pour la greffe du pin laricio sur le pin sylvestre; cependant je crois prudent de la prendre, si l'on ne fait que quelques greffes que l'on tient absolument à faire réussir, mais on peut alor's retirer les cornets au bout de trois oll quatre jours.

Quatre à cinq semaines après l'opération, la suture de la greffe avec le sujet est ordinairement complète, et il faut retirer la ligature qui les unissait et qui par sa compression nuirait à la végétation; si la suture n'était pas complète, on remettrait la ligature pour la retirer un peu plus tard. On coupera all commencement de l'automne, dans le sens de la tige, les deux portions supérieures de la partie fendue de la flèche qui débordent la greffe; on supprime ainsi les feuilles qui ont servi à attirer la sève et qui deviendraient nuisibles pendant la sève de l'année suivante; cela s'appelle parer la greffe. La greffe posée sur un pin pousse à peine la première annéc, mais elle pousse très-vivement dès la seconte année.

Selon M. Soulange-Bodin, un bon ouvrier greffeur, aidé par un homme qui prépare les greffes, peut greffer dans une pépinière jusqu’à 250 sujets par jour, y compris le placement d'un cornet de papier autour de chaque greffe; dans un bois, où les sujets sont plus éloignés les uns des autres, il n'en grefferait pas autant.

Le nombre des réussites des greffes herbacées de pin laricio sur pin sylvestre, exécutées en grand dans la forêt de Fontainebleau par différentes mains, a été environ des trois cinquièmes, et ce nombre aurait sans donte été plus grand si l'on eût mis des cornets de papier; je présume que la greffe du pin cembro sur le pin du lord Weymouth, exécutée en grand, aurait au moins le même succès.

Relativement à la greffe des mélèzes, des cèdres et des sapins, Tschudy s'exprime ainsi qu'il suit, page 39 de sa brochure : "L'herbe centrale (la flèche) des 
" mélezes (1) et des sapins nous présente des petites feuilles; lans l'aisselle d'ume. " ou de plusieurs feuilles réside un bouton; ces funilles sont nourrices spéciales " du bouton, et les feuilles qui n'ont pas de gemmes sont nourrices auxiliaires. "Dès qu'on coupe l'herbe centrale d'un de ces arbres au dessus d'un houton, on " transporte le foyer de vitalité sur ce bouton. C'est done en opposition d'un bou"ton, el à la hauteur d'un bouton que je greffe la tige verte tronquée des mélèzes " et des sapins avec un scion formé d'un faisceau d'herbes terminales."

Ainsi, pour exécuter la greffe herbacéc sur un mélèze ou sur un sapin, on attendra que les feuilles inférieures de la flèche aient pris leur distance, ce qui arrive lorsqu'elles ont parcouru les deux tiers environ de leur développement; puis on coupera celte flèche à l'endroit où les feuilles, pressées l'une contre l'autre, accusent un retard dans l'action du prolongement, et immédiatement au dessus de l'un de ces boutons qui se trouvent sur la llèche. On ôtera ensuitc les feuilles de cette flèche dans la partie que devra occuper la greffe, en réservant le bouton el quelques feuilles pour servir à attirer la sève; enfin on posera une greffe, cueillie à l'extrémité des branches de l'arbre dont on veut reproduire l'espèce, en se conformant à ce que j'ai prescrit précédemment pour la greffe des pins. On parera la greffe au commencement de l'automne, d'oì il résultera la suppression du bouton et des feuilles qui avaient été conservés pour tire-sève, et qui ne seraient que nuisibles pendant la sève de l'année suivante; on supprimera par la même raison les boutons qui se trouveraient sur la flèche.

111. Dendromìties. - Il peut être utile de mesurer la hauteur des arbres sur pied dans des circonstances exceptionnelles, comme, par exemple, pour savoir approximativement quelle est la hauteur moyenne des arbres d'un canton de futaie, ce que l'on sait en en mesurant quelques-ıns; car des arbros du même âge, situés à la même exposition, qui ont crû également serrés et dans la même nature de terre, auront à peu près la même hauteur. J'ai fait construire un instrument fort simple (un dendromc̀tre) destiné à cet usage (PI. VI, fig. 8); c'est un triangle rectangle isocèle, c'est-à-dire qui a deux côtis égaux; cet instrument se fixe sur un pied que l'on liche en terre. Des deux côtés égaux, l'un B C est placé verticalement au moyen du fil à-plomb, et alors l'autre A B se trouve placé horizontalement. Parallèlement au côté A B se trouve une rainure que l'on dirige vers la tige de l'arbre, et sur le milieu du côté A $\mathrm{C}$ une autre rainure par laquelle on vise le sommet de l'arbre, en avançant ou en reculant le pied de l'instrument, le haussant ou le baissant selon qu'il est nécessaire; lorsque celte rainure est dans la direction du sommet de l'arbre, l'autre rainure se trouve dans la direction du milieu de sa tige, si elle est verticale. La hauteur de l'arbre est alors égale à la ligne horizontale comprise entre le point A et le milieu de l'arbre, augmentée de la hauteur depuis le pied de l'arbre jusqu'ì cette ligne. On ne peut fitire usage de cet instrument que par un temps calme. Celui dont je me suis 
servi d'abord avait été fait par un menuisier de campagne, et il élait entièrement en bois; il ne pouvait ni se hausser ni se baisser, ce qui est indifférent pour l'exactitude, mais est un peu plus gênant.

J'ai fait construire un autre dendromètre, plus compliqué, mais plus commode (Pl. VI, fig. 9 et 10). Les hauteurs y sont indiquées sur un arc de cercle que parcourt l'alidade lorsqu'on vise le sommet des arbres dont on veut mesurer la hauteur; elles ont été calculées pour une base déterminée, c’est-ä-dire pour sc placer toujours à une même distance de l'axe de l'arbre. Il y a sur cet instrument trois dendromètres, et par conséquent trois arcs de cercle concentriques qui correspondent chacun à une base différente, parce que de la même distance on ne pourrait pas toujours voir la cime des arbres de différentes hauteurs. Ainsi, par exemple, si l'on sc plaçait à 15 mètres d'un arbre de 40 mètres de haut, on ne verrait probablement pas sa cime de ce point, parce qu'elle serait cachée par ses branches. On a inscrit sur l'arc de cercle qui a le plus grand diamètre les hauteurs correspondantes à une base de 2 ŏ mètres; sur le second arc de cercle celles qui correspondent à une base de 20 mètres, et sur le troisième, qui a le plus petit diamètre, celles qui correspondent à une base de 15 mètres.

Supposons, par exemple, que l'on veuille mesurer un arbre de plus de 30 mètres de haut, on placera le dendromètre $(f i g .9)$ à 25 mètres de l'axe de cet arbre; on mettra le plan de l'instrument dans le plan de l'axe de l'arbre; on fixera le fil à-plomb devant la ligne A $\mathrm{C}$, et la ligne A B se trouvera alors horizontale; on dirigera ensuite l'alidade AD sur la cime de l'arbre, puis dans la dircetion de la ligne A B, qui doit alors passer par l'axe de l'arbre, si cet arbre est vertical. La hauteur de l'arbre sera égale à la hauteur marquée sur l'arc de cercle, au point où l'alidade le coupait quand on a visé la cime de l'arbre, plus à la hauteur depuis le pied de l'arbre jusqu'à la ligne horizontale A B, qui passe par l'axe de l'arbre ou à peu près. Cet instrument peut servir aussi à mesurer la hauteur d'un clocher'; toutes les hauteurs enfin qui ne dépassent pas celles qui ont été calculées sur les cercles, lorsqu'on peut se placer à 15 mètres, à 20 mètres ou à 25 mètres du point où la verticale abaisséc de leur sommet vient toucher le sol.

Pour marquer les divisions sur les ares de cercle, j'ai, sur une feuille de papier et d'un même centre, tracé ces cercles de la grandeur qu'ils devaient avoir sur l'instrument; et prenant l'échelle de $0^{\mathrm{m}}, 01$ pour 1 mètre, j’ai élevé sur une ligne horizontale, à $0^{\mathrm{m}}, 15$, à $0^{\mathrm{m}}, 20$ et à $0^{\mathrm{m}}, 25$ du point pris pour centre des cercles, des perpendiculaires hautes de $0^{\mathrm{m}}, 50$. La première verticale m'a servi à la détermination des points du plus petit cercle correspondans à des hauteurs de 50 mètres et au dessous; la deuxième à la même détermination sur le cercle suivant; enfin la troisième à la détermination des mêmes points sur le plus grand cercle. J'ai inscrit sur le plus petit cercle les hauteurs correspondantes à la plus petite base; j'aurais pu les mettre sur l'un des deux autres cercles, en le faisant correspondre à la base de $0^{\mathrm{m}}, 15$, et réciproquement.

J'indiquerai l'opération pour l'un des cercles senlement, le plus grand par 
exemple, puisqu'elle est la mème pour chacun des deux autres. J'ai divisé la verticale de $0^{\mathrm{m}}, 50$, située à $0^{\mathrm{m}}, 25$ du centre du cercle de l'instrument, en parlies égales de $0^{\mathrm{m}}, 01$ à partir du sommel; ces divisions correspondaient à celles de 1 mètre que j’aurais faites sur une verticale de 50 mètres de haut, silnée à 25 mètres du centre dı cercle de l'instrument; c'est-à-dire, par exemple, que la ligne tirée du centre par le point situé à $0^{\mathrm{m}}, 10 \mathrm{sur}$ la verticale de $0^{\mathrm{m}}$, â0, étant prolongée, passerait par le point silué à 40 mètres sur la verticale de 50 mètres, et ainsi de suite; on voit que ce tracé est fort simple. On u'obtient ainsi la hauteur tles arbres qu'à 1 metre près, ce qui m’a paru suffisant pour les grands arbres; on pent d'ailleurs tenir compte à peu près de la situation de l'alitlade, lorsqu'elle ne tombe pas exactement sur une division. Mon but, en ne metlant pas un plus grand nombre de divisions, a été de rendre l'usage de cet instrument (1) tellement facile que tout homme qui sait lire les chiffres puisse s'en servir. En preuant une base dix fois plus grande, on pourrait mesurer des hauteurs de 500 mètres, puisque chaque division représenterait une longueur décuple.

Le même instrument peut servir à mesurer des distances dans le plan des cercles qui y sont tracés, el j'ai fait disposer le mien de manière à ce qu'il puisse se placer horizontalement ou sous un angle quelconque, comme on le voit Pl. VI, fig. 10. Mais les distances à mesurer pouvant être plus longues que ä) mètres, il faudrait alors, au licu d'une base de 15, 20 ou 25 mètres, prendre une base de 150,200 ou 250 mètres, afin de pouvoir mesurer des distances de 500 mètres sur une perpendiculaire élevée à l'extrémité de cette base. On pourrait alors, a vec cet instrument, mesurer la largeur des rivières, ce qui peut être utile à la guerre.

Ce dendromètre doit être placé sur un pied à trois branches, tels que ceux dont on se sert pour les niveaux d'eau.

IV. Visite aux bois résineux du Vieil-Harcourt. - J'ai visité les bois résineux du Vieil-Harcourt, provenant des semis de Delamarre, auteur d'un Traité pratique des pins à grandes dimensions, et l'un ouvrage intitulé Iristorique de la création d'une richesse millionnaire par la culture des pins; ces bois, auxquels il attribuait dans l'avenir une valeur prodigieusement exagérée, font partic de la propriété qu'il a léguée à la Sociétć royale el centrale d’agriculture. Je les ai visités le $\mathbf{1 5}$ juin $\mathbf{1 8 3 8}$, dans le moment où les arbres, ornés de leurs fenilles et de leurs pousses nouvelles, avaient revêtu tonte leur parure. M. A. Michaux, administrateur de cette propriété pour la Société, m’avait engagé à faire cette visite el eut l'obligeance de m'accompagner.

Je n'ai trouvé an Vieil-Harcourt que des bois de pins maritimes, de pins sylvestres et de ces deux espèces mélangées; le pin maritime y domine de manière

(1) J'ai fait exécuter cet instrument, en buis et cuivre, par II. Barbier, qui me l'a filit payer $150 \mathrm{f}$; : M. Barbier m'a dit qu'il pourrait, actuellement que la plaque de division est faite, ic donner pour $120 \mathrm{fr}$; ; il demeure chaussée de Ménilmontant, n81, à Kelleville, banlieue de Paris. 
it occuper les dix-manf' vingtièmes dn terrain ; il n’existo d'autres arbres résineux sur cette propriété que par échantillons. Ces pinières, dont les plus âgées ont élé senées en 1812, sont entièrement semblables à celles de la même espèce qui occupent de si grandes étendues de terrain dinns les provinces du Maine et de l'Orléanais; il y a d'ailleurs cette différence entre ces dernières plantations el celles rle Delamarre, qu'elles occupent des terrains mauvais ou très-médiocres, généralement impropres à la culture des céréales et même à la production des hois fenillus, tandis qu'il y a très-peu des terrains où Delamarre a semé des pins maritimes ef des pins sylvestres qui soient dans ce cas. Au contraire, sur la plus grande partic de ces terrains, les bois feuillus, qu'il n'est pas parvenu à clétruire, prospéraient, et ils étaient, selon moi, d'un meilleur rapport que les pins maritimes qu'il y a substitués. Aussi à mesure que l'on éclaircit les pins, ces hois reprennent-ils possession du terrain dont il était parvenu en partie à les expulser.

V. Sur ce qle dit M. Ratzeburg ifes insectes vulsibles aux arbres résineux. - .1. le comte de Corberon a donné la traduction d'un ouvage de M. le docteur Ratzeburg, qui est un abrégé d'un plus grand ouvrage du même auteur, en 3 vol. in- $4^{\circ}$; cette traduction est intitulée: Les hylophthires et leurs enmemis, ou Description et iconographie des insectes les phus muisibles aux forets, ainsi que des autres animaux causant des dégüts dans les bois, avec une méthorle pour apprendre ì les détruire et à ménager cenx qui leur font la guerre, 1 rol. in-8", Paris, 1812. Le titre allemand de cet ahrégé est : Die Waldverderber und ihre Feinde, oder, etc., littéralement : Les gâte-forêts el leurs ememis, on, ctc.; le traducteur a done rendu le mot Walverderber par le mot hylophthires, tiré du grec. Mes observations, qui ne seront relatives qu'à ce que l'auteur dit des insectes nuisibles aux arbres résineux conifères, sont aussi bien applicables au grant ouvrage qu’à l'abrégé.

L'auteur a observé particulièrement les insectes nuisibles au sapin picéa et au pin sylvestre, les deux arlores résineux conifères les plus répandus dans les forêts de la Prusse; il ne s'est point occupé, sous ce rapport, du piu maritime, qui ne peut être cullivé en Prusse, ni du pin Weymouth, qui y est pourtant cultivé; il ne parle du mélèze que pour dire qu'il est attaqué par um bostriche qui se montre aussi sur les autres conifères; relativement au sapin argenté, à l'exception d'un bostriche auquel il consacre quelques lignes, il se contente de dire que les insectes nuisibles au sapin picéa le sont aussi an sapin argenté. 11 n'a point parlé des pucerons, quoique les arbres dont il s'est occupé soient indubitablement sujets à l'attaque de ces insectes, en Prusse comme ailleurs, surtout dans leur jeunesse; il n'a rien dit non plus de ces chenilles qui ont causé de si grands ravages dans ma sapinière, et dont j'ai parlé en détail pages 112-115; il fail d'ailleurs comnaitre avec heaucoup de soin l'histoire naturelle, les mocurs et les habitudes de vie des insectes dont il s'est occupí, et il les met sous les yeux de ses lecteurs, an moyen de planches coloriées.

(Quant aux moyens preservatifs el aux moyens dedestruction qu'il prescrit, jo 
dois avouer que je ne parlage pas sa contiance dans leur efficaciti, surtout lorsque les insectes se sont multipliés extraordinairement. Tels sont, par exemple, la cueillette des oenis de chenilles, la destruction des placards de jeunes chenillettes, la collecte des chenilles, des chrysalides et des papillons pendant l'été; les petits fossés pour isoler les quirtiers infestés, car si l'on arrête ainsi les chenilles, on n’arêtcra pas les papillons qui en proviendront : en supposant d'ailleurs que l'on obtienne ainsi des résultats marquans, il fitut savoir si les avantages compenseront la dépense. J'ai encore moins de confiance dans les lagots d'appât, les écorces d'appât, les bùches d'appât, les fosses d’appât et les arbres l'appât, comme moyens de destruction des charançons et des bostriches. Il peut d'ailleurs être très-difficile, à en juger par les propres paroles de l'auteur, de déeider dans quelles circonstances l'emploi de ces moyens, et surtout du dernier, qui serait si dispendieux, serait utile ou nuisible : en effet, " les arbres d'appât, " dit-il, ne doivent être mis en usage que lorsque les insectes se montrent en " nombre assez grand pour pouvoir donner de l’inquiétude. Dans le cas con" traire, ee moyen ne servirait qu’à les attirer, et, par conséquent, à protéger les " couvains, qui sans cela n'auraient pas paru. "

Enfin, je ne partage point du tout l'opinion de l'auteur relativement à l'utilité des oiseaux pour la destrnction des insectes nuisil)les aux forêts; l'invasion des insectes, lorsqu'elle devient redoutable, paraît être indépendante du nombre de ces oiseaux, et ce que ces oiseaux mangent d'insectes est tout-à-fait insignifiant comparé à la quantité innombrable qui en paraît alors. Ils mangent d'ailleurs encore plus de mouches et par conséquent d'ichneumons que de chenilles, de papillons et de bostriches, et les ichneumons sont les plus elficaces destructeurs de ees insectes; ainsi il est probable que les oiseanx sont plutòt utiles que nuisibles à la propagation des chenilles. Je crois donc qu'il n’est point nécessaire, ainsi que le désirerait II. Ratzeburg, de défendre la chasse au lacet et de punir sévèrement les oiseleurs qui, par une sordide et ignare spéculation, tendent des lacs mux oisenux mopices. Je persévère surtout à croire muisibles la pie et la: pic-vert, qu’il classe parmi les oiseaux utiles; la pie, parce qu'elle brise ou endommage la flèche des arbres verts, en se perchant sur cette flèche; le pic-vert, paree qu'il perce les arbres, ee qui les endommage et les fait quelquefois pourrir.

VI. Sur da plantatiox a deneule des armes feullus. - Je rais me permettre de consigner à la fin de ce chapitre quelques observations qui ne seront pent-être pas sans intérêt, mais qui n’ont de rapport avec le sujet que i’ai traité que parce que j’ai imité, pour la plantation des arbres feuillus, ce que j’avais pratiqué pour. la plantation des arbres résineux conifères. On a vu que l'on plante les arbres résincux coniferes sans leur couper ni branches ni racines; qu'ils boudent ordinairement pendant un an, el que l'annéc suivante, s’ils ont été plantés avee soin el dans un terrain qui leur convienne, la régétalion reprend son cours comme avant la plantation. J’ai essayé de planter ainsi des arbros feuillus de haute tige, sans leur refranchor une seule branche, loin 
de: leur couper la tête, et je m’en suis bien tronvé; si, par exception, la tète de quelques-nns de ces arbres s'atrophic, e'est alors seulement que je la leur coupe pour obtenil un autre jet. J'ai planté ainsi des ormes, des platanes, des érables, les acacias, des tulipiers de Virginie, des marronniers, des noyers, des ponmiers, des poiriers, des pêchers, des pruniers, etc.; les peupliers ne se plantent pas autrement. Je sais que n'y ent-il que l'avantage de diminuer l'action des vents, en coupant des branches de la tête et même la tête, c'en serait déjà un fort grand, dans beaucoup d'expositions; mais je ne me propose que de constater un fait, el ce fait acquiert beaucoup d'importance relativement aux arbres fruitiers, surtout pour les espèces qui ne portent du fruit que sur du bois de trois ans.

On peut transplanter les arbres fruitiers de plein vent avec toutes leurs branches tant qu'ils ne sont pas trop âgés el qu'on les arrache avec le plus grant soin; cependant je crois utile de prendre un terme moyen, qui est de couper quelques petites branches, pour diminuer l'action des vents. Quant aux arbres fruitiers de jardin en espalier, en contre-espalier ou en quenouille, on peut et l'on doit les planter a vec toutes leur's branches; cette plantation réussira toujours lorsqu'ils ne seront pas trop âgés, si elle se liait en bonne saison et qu'un l'exícute avec soin, ainsi que je le dirai plus loin ; elle réussit même souvent avec des arbres converts de feuilles; si quelques branches souffrent de cette transplantation, ce qui s'aperçoit an printemps suivant, on les supprime.

Lorsque je devins propriétaire lu château que j'habite, je trouvai, dans le jardin, quelques espèces d'arbres de contre-espalier qui fleurissaient quelquefois et pourtant ne donnaient, pour ainsi dire, jamais de fruits; j'attribuai cette circonstance à la situation du jardiı dans lequel ils se trouvaient, dans la vallée de l'Iton; car il en arrivait de méme à d'autres arbres fruitiers des jardins dı voisinage situés dans la même vallée: je transplantai les plus jeunes de ces arbres, qui avaient de 20 il 10 ans, dans un autre jardin sur le plateau qui borde la vallée, sans leur couper ni branches ni racines; deux ans après ils donnaient du fruit. Lorsqu'un arbre ne donne point de fruit, quoi qu'on ait fait pour le meltre à fruit, on doit le transplanter; c'est le remèle le plus sûr, si l'arbre est sain el assez jeune. Il faut toujours alors couvrir de fumier pailleux de cheval ou de mouton, la terre du pied de l'arbre qui a été remuée, el cela doit se faire même pour le plant de pépinière que l'on plante à demeure; on garantit ainsi ses plantations des dommages que leur causent les alternatives de gelées el de légels, et les sécheresses : on lève la couverture pour donner les façons, et on la replace après; on arrose s'il est nécessairc.

Je rapporterai, à l'appui de ce que je viers de dire, la manière donı j’ai dirigé et conduit un espalier où tout était neuf, arbres, mur en brique, treillage. J'achetai, pendant l'automme de $\mathbf{1 8 3 6}$, de belles quenouilles choisies, pour la plupart, parmi les espèces nouvelles encore peu répandues el reconnues bonnes; on les arracha et on les emballa dans l'après-milli qui précéda leur départ, eı le lendemain matin on les plantait à $2^{\mathrm{m}}, 33$ les unes des autres, avec le plus grand soin; on mit, alu pied re chaque arbre, une couverture de fumier 
pailleux de cheval. Mon jordinier aturait bien désiré les rabaltre pour refure ses arbres, ce qui n'aurait eu d'autre effel que de retarder leur fructilication de six ans au unoins el d'en faire périr queltues-uns; mais je ne laissai toucher ni aux racines, ni aux branches, excepté an très-petit nombre de racines qui pouvaient ètre déchirées à leur extrémité; el l’on supprima quelques branches qui se trouvaient du còté où l'arbre devait s'appuyer contre le unur, lorsqu'il ne fut pas nécessiare de les ployer pour les palisser. Je ne lis planter ces arbres qu'a $2^{m}, 33$ de distance les uns des antres, dans l'intention d'en prendre un sur deux, pour les placer ailleurs, lorsqu'ils commenceraient à être gènés.

Le mur contre lequel je plaçai d'abord mes arbres étail à l'exposition du couchant el convert d'un treillage en bois scié, varlopé et peint; mais ailleurs je me suis contenté de fils de fer disposés dans le sens vertical seulement, et placés a la distance de $0^{\mathrm{m}}, 27$ les uns des autres, excepté ceux qui se trouvent imuréliatement de chaque côté du trone de l'arbre, lesquels sont éloignés entre eux de (0"',65 : ce genre de treillage est aussi bon que celui de bois seié el peint, coùte beaucoup moins et dure beaucoup plus longtemps.

Lannée même qui suivit la plantation de mes arbres, cenx qui avaient des boutous portèrent des lleurs el quelques-uns des fruits; les amnées suivantes, tous eurent une belle végétation et la plupart portèrent des fruits. J'adoptai, four ces arbres, la taille en palmetle. On tailla court le jet qui prolonge le tronc, parce que ce jet élant vertical, est disposé à s'emporter, et alin de reporter la sève dans les autres branches, qui sont maintenues horizontalement; on tailla plus long les arbres qui avaient la végétation la plus aclive, et surtout on leur laissa les brindilles, qui deviennent souvent des branches à fruit (1) dans la jeunesse de l'arbre, surtout dans quelques espèces. Pendant l'automuc de 1810 , je transplantai un poirier de virgouleuse qui avait poussé avec une telle vigueur qu'il avait déjà atteint le sommet du mur, quoiqu'il eùt acquis en largeur un très-beau développement, et qui ne donnait qu'une ou deux poires par an; je le plagai au nord, exposition qui convient à cette espèce; cn 1811 , iln'eut encore que deux ou trois poires; mais en 1812, il donna une belle récolte.

Pendant l'automne de 1841 , je dédoublai mon espalier du mur en brique; j'en retirai les arbres qui portaient des numéros pairs et je les plantai à $\mathbf{4}^{\mathrm{m}}, 66$ les uns des autres, sans leur couper ni une racine, ni une branche; dans le même temps je fis permuter sur cet espalier un poirier de Sieule avec un poirier de beurré d'A rembert, deux arbres d'une magnilique apparence, mais qui ne donnaient pas encore de fruit, quoique d'autres arbres de moindre apparence, de la mène espèce et plantés en même temps en domnassent déjà. Voici les précautions que l'on prit pour exécuter ces plantations : on fit des trous suffisamment gramels,

(1) Les auteurs nous parlent de trois espèces de branches à fruit; je n'en vois que d'une cspere', mais elles sont plus ou moins longues. Les jardinicrs ignorans, qui sont si communs, coupent toutes les branches à fruit qui ne sont pas courtes et trapues; ils ne laisseraient pas venir de furils sur le hon-c'lurétien d'éte, qui n'en a quère que de longues. 
on en piocha le fond, et dans chaque trou l'on remit de la terre, près du mur, pour former une petite butte destinée à supporter l'arbre qu'on devait y placer. Lorsqu'on avait arraché l'un cle ces arbres avec les soins nécessaires pour qu'il conservât toutes ses racines et tout son chevelu, on le plaçait de manière à ce qu'il eùt le collet absolument dans la même situation, par rapport au sol, que dans l'endroit d'où on l'avait tiré; on étalait ses racines el l'on en formait deux élages, lorsqu'on le jugeait utile : sur le premier étage on mettait de la terre substantielle et très-meuble, puis on plaçait le second étage de racines, que l'on couvrait de même, et l'on remplissait le trou de terre sans la fouler; enfin, on couvrait le pied de l'arbre d'une couche de fumier pailleux de cheval, et on le fixait provisoirement au treillage avee quatre liens d'osier. Au printemps suivant, on façonnait la terre et l'on dégageait le collet, s'il était couvert de terre; on le chaussait dans le cas contraire ; après cette façon, on remettait soigneusement la couverture de fumier.

En 1842, une partie des arlores que l'on avait transplantés pendant l'automne de $\mathbf{1 8 1 1}$ donnèrent du fruit, mais moins beau que si on ne les eût pas déplacés; le poirier d'Arembert et le poirier de Sicule, qui n'avaient pas de boutons à fruit et n'auraient probablement point encore eu de fruit si je ne les eusse déplacés, formèrent des boutons à fruit pendant l'hiver et eurent du fruit. En 1813, tous ces arbres donnèrent d'aussi beaux fruits que ceux que l'on n'avail pas déplacés. Je ne me suis point encore aperçu des inconvéniens qui résultent, dit-on, de la taille en palmette, j'en suis fort content jusqu'à ce moment; mon espalier couvre bien le mur, il est beau et productif. 


\section{CIIAPITRE XIII.}

RESUIIE.

Dins le chapitre premier, j’ai fait sentir quels avantages la culture des arbres résineux con ifères à gramles dimeusions, de pleine terre dans les climats tempérés, feut offrit en France. J’ai indiqué ceux de ces arbres qui y sont cultivés en assez. grande quantite el dejuis assez longtemps pour que l'on puisse en parler avec détail; el ceux yui étant à grandes dimensions daus les pays où ils sont indigènes, sont de pleine terre sous le elimat de Paris, mais dont on ne peut parler que sommairement, parce qu'ils n'y sont cultivés que depuis très-peu de temps. J'ai fait ressortir, par plusieurs exemples, la confusion qui règne dans la nomenclature et la synonymie des pins. J'ai décrit les caractères généraux des gentes auxquels appartiennent les espèces dont je me suis occupé dans ce Traité. J'ai fait quelques olsservations également applicables à toutes ces espèces, ou qu’il étaiı nécessaire de réunir en faiseèu; ainsi, j’ai examiné quelle esı l'inltuence de la latitude et de l'altitude sur leur végétation, quels sont leurs moyens de reproduction, el si l'on doit, quand on les abat, avoir égard aux ploases de la lunc, etc. J'ai prouvé, par quelques exemples, que des hommes, très-savaus d'ailleurs, peuvent commeltre de très-graves erreurs lorsqu'ils parlent des arbres à grandes dimensions, sans les avoir bien examinés de leurs yeux, dans les diverses phases de leur végétation.

J'ai consacré chacun des chapitres $11, \mathrm{ll}, \mathrm{IV}, \mathrm{V}, \mathrm{VI}, \mathrm{VIl}$, Vlll et IX à une espèce d'arbres résineux conifères dins l'ordre on je vais les nommer : le sapin argenté, le sapin picéa, le pin sylvestre, le pin maritime, le pin laricio, le pin du lord Weymouth, le mélèze el le cèdre du Liban.

Le sapin argenté est celui de ces huit éspèces l'arbres dont on peut obtenir le revenu le plus élevé, sous le climat de l’aris, sur une surface donnée, paree que e'est celui qui peut y produire la plus grande quantité de bois propre ì différens services; il y aurait plutôt à ajouter qu'ì retrancher, sous ce rapport, à ce que j'ai dit des sapinières. Mais tous les terrains dans lesquels ce sapin peut prospérer citant propres à la culture des céréales, on conçoit qu'on ne veuille pas léwèrement se priver d'un revenu ammut, dans l'espérance d'un revenu à venir 
plus élevé dont on ne doit peut-ètre jamais jouir. Heureusement le sapin argrenté a la propriété de résister à l'ombrage des taillis de bois feuillus; on peut donc créer une sapinière dans un de ces taillis, sans perdre beaucoup de son revenu, jusqu'au moment où l'on sera amplement dédommagé par le produit qu'on tirera de la sapinière. Les terres sur lesquelles le revenu qu'on peut tirer d'une sapinière dépasse le plus celui qu'on en tirerait en les cultivant en céréales, sont les terres argileuses propres à la culture du sapin argenté, ef dont la culture en céréales est dispendieuse.

Le bois de sapin argenté dure assez longtemps dehors et très-longtemps à couvert; il est très-facile à travailler; il est propre à un grand nombre d'usages; il a le mérite le fournir des pièces des plus fortes dimensions, parfaitement droites et qui ne se tourmentent point. On obtient du sapin argenté un produit connu, dans le commerce, sous le nom de térébenthine de Strasbonrg; l'extraction en est si difficile, que le gouvernement l'autorise, dans ses forêts, sans en tirer aucun bénéfice.

Les semis de sapin argenté ne réussissent pas en terrain découvert, pårce que le plant a besoin d'ombrage pendant les premières années; ainsi l'on échoue si l’on sìme la graine de cet arbre sur une terre découverte, préparée par des labours; on réussit au contraire, si on la sème dans des clairières des bois qui ne soient ni trop, ni trop peu ombragées. Les plantations avec du plant élevé en pépinière, ainsi que je l'ai indiqué, réussissent très-bien. On peut les exécuter depuis le mois d'octobre jusqu'au moment où part la sève l'année suivante; les plantalions d'automne sont préférables à celles du printemps, et il est toujours utile de mettre sur ces plantations une couverture de feuilles ou d'autres matières; mais on peut fort bien s'en dispenser, et c'est ce que l'on fit it quand on plante en grand ou que l'on n'a pas sous la main des matériaux pour couverture.

J'ai décrit avec beaucoup de soin, dans le chapitre II, tout ce qui est relatif à l'aménagement, à l'exploitation et à la reprorluction des futaies de sapin argenté. Aussi, dans les chapitres suivans, consacrés chacun à une espèce, n'ai-je plus, sur ces matières, qu'à renvoyer à ce qui leur est applicable dians le chapitre II, sauf quelquefois à indiquer quelques légères modifications.

Il y a cinq modes d'exploitation, que je vais rappeler en peu de mots :

$1^{\circ}$ En jardinant, et il faut alors par des éclaircissages, par des élagages, par des nettoyages et en abattant les arbres les plus âgés, favoriser le repeuplement par le semis nalurel, de manière à maintenir la sapinière bien vivante et meublée d'arbres de différens àges.

$2^{\circ}$ Par coupes rases, et il fautalors, par des éclaircissages successifs, ne conserver dans la sapinière qu'un certain nombre d'arbres convenablement espacés, et ayant tous à peu près la même hauteur. Lorsque le moment de l'exploitation est arrivé, on coupe la sapinière à blanc-étoc et on ne la repeuple que par la plantation, avec du plant de pépinière élevé d’avance, puisqu'on ne peut employer le semis, qui ne réussit pas sans ombrage sous le climat de Paris.

$33^{\circ}$ Par conpes rases par bandes étroiles: pour ce mode d'exploitalion, la sapi- 
nière ayant élé préparée par des éclaircissages successifs, ainsi que je viens de le dire, lorsque le moment de l'exploiter est arrivé, on la divise en bandes de 30 mètres de large environ que l'on numérote; on coupe à blanc-étoc, les bandes impaires par exemple, dans une année d'abondance de cônes, après la chute des graines; si le plaut de semis naturel n'a pas été assez abondant, on achève le repeuplement au moyen de la plantation ou du semis en potets. Quelques années ạprès avoir coupé les bandes impaires, on coupe les bandes paires, également à blanc-étoc.

$4^{\circ}$ I'ar éclaircies : pour ce mode d'exploitation, la sapinière ayant été préparée par des éclaircissages successifs, ainsi que je l'ai dit, lorsque le moment de l'exploiter est arrivé, on la coupe à blanc-étoc, en trois fois, pour obtenir le repeuplement par le semis naturel. La première coupe, que l'on appelle coupe d'ensemencement, sera exécutée dans une année d'abondance de cônes, après la chute des graines; la seconde, que l'on appelle coupe claire, sera exécutéc quelques années après, lorsque le plant aura environ $0^{\mathrm{m}}, 32$ de haut, et la troisième, qu'on appelle coupe défnitive, quelques années après la seconde. Si le plant de semis naturel n'élait pas assez abondant, on y suppléerait par la plantation ou par le semis en potets.

50 Por la méthode mixte, qui consiste à maintenir la sapinière bien meublée de sapins de différens âges, comme dans l'exploitation en jardinant, et à faire tous les 25 ì 35 ans une coupe rase de tous les sapins qui ont plus de $0^{\mathrm{m}}, 5 \mathrm{f}$ de circonférence à $1^{\mathrm{m}}, 30$ au dessus du sol.

On peut employer partout le premier, le second et le cinquième mode d'exploitation avec certitude de réussir; mais il n'en est pas ainsi de l'exploitation par coupes rases par bandes étroites, ni de l'exploitation par éclaircies. L'administration forestière française commence à faire l'essai de ces deux derniers modes d'exploitation, qui n'avaient encore été employés qu'en Allemagne, depuis un petit nombre d'années et en quelques lieux seulement. Il est donc exact de dire qu'ils sont encore à l'état d'essai, particulièrement l'exploitation par éclaircies; et jusqu'à ce jour, quand on les a employés, le repeuplement par le semis naturel, but qu'on se propose d'atteindre, a toujours été incertain. On sait d'ailleurs déjà, par expérience, que ces deux modes d'exploitation sont impraticables, surlout le second, dans plusieurs parties des montagnes et sur quelques plateaux ćlevés; soit parce que les vents y renversent la futaie après la coupe d'ensemencement ou après la coupe claire, soit parce qu'on ne peut ainsi y obtenir de repeuplement par le semis naturel.

Le sapin argenté supporte l'élagage, et cette opération peut quelquefois être utile, mais elle doit ètre exécutée avec les précantions que j’ai indiquées.

Sous le climat de Paris, le sapin picéa ne supporte pas tont-ì-fait aussi bien l'ombrage que le sapin argenté; il ne peut pas croitte aussi serré, il n'a pas un accroissement aussi rapide, son trone ne maintient pas aussi bien sa grosseur, i] ne se reproduit pas aussi ficilement par le semis naturel; enfin, je présume 'jue son bois, qui est propre aux mêmes usages, ne valut pas, sous ce elimat, 
celui du sapin argenté. Linsi il lui est inférieur sous plusicurs rapports, el une sapinière ele sapins picéas n'y présenterait pas, toutes clıoses égales d’ailleurs, les mêmes avantages qu’une sapinière de sapins argentés. Cette infériorité résulte sans doute de ce que le sapin argenté est indigène, tandis que l'autre ne l'est pas. On extrait facilement du sapin picéa de la résine dont on fait la poix de Bourgogne; on peut ainsi tirer parti de cet arbre dans les localités où il ne serait pas possible de l'exploiter, à cause de la difficulté des lieux, et dans celles où lẹ bois serait sans valeur.

Ce que j'ai dit des semis et des plautations de sapin argenté est applicable au sapin picéa. Cet arbre est moins difficile sur le terrain que le sapin argenté; mais on ne pourrait pourtant le cultiver avec sucè̀s sur des terres siliceuses très-maigres, où l'on peut encore cultiver plusicurs espèces de pins, ni sur les terres trop calcaires. J'en ai vu qui avaient une végétation passable sur un sol où le-sapin argenté restait rabougri. Cet arbre supporte plus difficilement l'élagage que le sapin argenté; ainsi, quand on veut l'élaguer, il ne faut lui couper qu'une demi-couronne au plus chaque annéc. Ce que j'ai dit de l'aménagement, de l'exploitation et de la reproduction des futaies de sapins argentés s'applique presque de tout point à celles de sapins picéas.

Le pin sylvestre, le piu maritime et de pin laricio présentent le très-grand avantage de pouvoir être cultivés sur des terrains siliceux si maigres, qu'on n'y peut cultiver avec succès ni céréales, ni bois feullu. Le semis arlificiel en grand de ces trois espèces de conifères réussit facilement et n'a pas besoin d'ombrage, ainsi il peut être exécuté sur un terrain préparé par des labours ou dans des potets.

Le pin sylvestre ne peut ètre cultivé sur des sables aussi arides que ceux sur lesquels on peut encore cultiver le pin maritime, mais il acquiert de plus belles dimensions que lui sous le climat de Paris. Son bois, d'excellente qualité, et supérieur à celui des sapins dont je viens de parler, est, dit-on, propre à tous les usages auxquels on emploie le clıene, et il est le meilleur que l'on comnaisse pour la mâture. Le pin sylvestre est, jusqu'à ce moment, le senl des arbres résineux conifères que l'on soit parvenu à cultiver sur les terrains crayeux de la Champagne, et lorsque la terre a été recouverte par une couche de terreau provenant du détritus de ses feuilles, il s'y reproduit par le semis naturel; il est anssi le seul de ces arbres que l'on ait exploité en taillis pour en obtenir du bois de chauffige on de la litière. Il serait possible que d'autres de ses congénères pussent être exploités de la même manière, mais il n'est pas venu à ma conıaissance que l'expérience en ait été faite.

Les semis de pin sylvestre réussissent bien en terrain découvert, et par conséquent sur des terrains préparés par des labours; mais pourtant moins bien que ceux de pin maritime et que ceux de pin laricio; les plantations de cet arbre réussissent au contraire mieux que celles de ces deux derniers pins. Les plantations d'automue sont préfésables à celles du printemps; il est utile de leur mettre une remverture, mais on ne peut prendre cette préeaution quand on late de grandes 
Ilantations; je ne l'ai jamais litit, et j’ai bien réussi. Le pin sylvestre est, je crois, celıi des arbres dont je ne suis oceupé, qui supporte le mieux l'élagage, ce qui n'empêche pas qu’il ne faille exécuter cette opération avec beaucoup de ménagement, comme pour tous les arbres résineux.

Le meilleur mode d'aménagement, d'exploitation et de reproduction pour les futaies de pins sylvestres, est de les éclaircir successivement, afin d'obtenir un massif où tous les arbres, convenablement espacés, soient à peu près de la même hauteur. On fait une coupe rase de la pinière, quand le moment de l'exploitation est arrivé, et l'on repeuple l'emplacement oụ elle se trouvait par le semis sur labour ou par le semis en potets. On peut aussi repeupler une lutaie de pins sylvestres qu'on vient d'exploiter, ainsi que je viens de le lire, au moyen de la plantation, le plant de pépinière de cette essence reprenant trèsfacilement.

Le pin maritime peut être cultivé sur des sables quartzeux si arides, qu'il n’y peut végéler aucune autre plante utile indigène, ligneuse ou herbacée; on peut ainsi tirer un revenu important de terrains qui n'en produisaient aucun. Le bois de cet arbre est d'ailleurs de médiocre qualité, à moins qu'il n'ait été genmé. Le gemmage, qui ne se pratique encore que dans le Midi, nuit à la végétation; mais on est dédommagé par la récolte de résine, et parce que le bois qui a été gemmé est beaucoup meilleur pour les constructions que celui qui ne l'a pas été.

Les semis de pin maritime sont ceux qui réussissent le mieux; ils ne manquent jamais quand ils ont été exécutés, ainsi que je l'ai indiqué, avec de bonne graine, sur un terrain convenable. Les plantations de cet arbre sont, all contraire, celles qui reprennent le plus difficilement, à moins que le plant ne soit encore herbacé, parce que ce plant a peu de chevelu et que sa tête est chargée de branches; néammoins, si l'on se conforme, pour élever le plant en pépinière et pour sa plantation, à ce que j’ai prescrit, chap. Xl, art. V, on réussira presque toujours. Les plantations d'automne avec une couverture sont préférables à celles du printemps; sans couverture, je préférerais planter au printemps. Ce (fue je viens de dire du meilleur mode d'aménagement, d'exploitation et de reproduction pour les futaies de pins sylvestres, s'applique aux futaies de pins maritimes; mais avec cette différence qu'on ne doit employer, pour repeupler ces dernières futaies, que le semis, qui réussit très-facilement, et non Ia planlation, par les raisons que je viens de donner.

Le pin laricio peut être cultivé sur tous les terrains siliceux où l'on peut eulliver le pin sylvestre; il réussit aussi dans les terrains calcaires, tandis que le pin maritime n'y réussit jamais ; il ne pourrait pourtant étre cultivé avec succès daus les craies, comme peut l'être le pin sylvestre. Le tronc de cet arbre sc maintient droit, même lorsqu'il croit isolé. On ne peut dire encore de quelle qualité sera son bois sous le elimat de Paris; en Corse, on l'emploie ì la menuiserie et comme hois d'ouvre; le gouvernement s'en sert, à Toulon, pour les ronstuctions de la marinc. Les semis de pin laricio mont pariu rénssir mieux 
que ceux de pin sylvestre, moins bien que ceux de pin maritime; les plantations de cet arbre reprennent un peu moins bien que celles de pin sylvestre, mieux que eelles de pin maritime. Le plant de pin laricio, comme celui de pin maritime, a peu de elıvelu et est chargé de branches vers la tête; néanmoins, élevé en pépinière et planté à demeure, quand il n’a pas plus d'un mètre de haut, ainsi que je l'ai prescrit, il reprend très-bien. Les plantations d'automne sont préférables à celles du printemps; il est utile de leur mettre une couverture, mais on peut s'en dispenser. Ce que j'ai dit du meilleur mode d'aménagement, d'exploitation et de reproduction du pin sylvestre s'applique, je crois, au pin laricio.

Le pin du lord Weymouth, qui nous a été apporté d'Amërique, exige un terrain plus substantiel que les pins dont je vieus de parler. Je l'ai d'ailleurs vu réussir lans une terre silico-argileuse qui était pleine d'eau l'hiver, très-sèche l'étć et pour ainsi dire impropre, par cette raison, à la culture des céréales. Cet arbre a une belle végétation, sous le cliniat de Paris, du moins jusqu’à 60 ans; il ne me parait paș probable qu'il y parvienne jamais aux magniliques dimensions qui le font remarquer en Amérique. Je présume que le semis en grand du pin Weymouth n'a pas besoin d'ombrage, et qu'il réussirait sur des terres préparées par des labours aussi bien que celui de pin sylvestre, de pin maritime et de pin laricio, si l'on employait de bonne graine. J'ai essayé une seule fois de le semer ainsi, et je n’ai obtenu qu'un médioere succès, parce que le terrain ne se trouva pas garni, mais peut-être la graine élait-elle de mauvaisc qualité; je ne trouve le récit d'aueun essai de ce genre, dans les auteurs qui ont parlé du pin Weymouth. Les plantations de pin Weymouth, élevées en pépinière avec le soin convenable, m’ont paru réussir presque aussi bien que celles de pin sylvestre, mieux que celles de pin laricio el de pin maritime. Les plantations d'automne sont préférables à celles du printemps. Je ne puis dire quelle est la qualité du bois de pin Weymouth, sous le elimat de Paris, parce qu'on n'y cultive eet arbre que pour l'ornement et que depuis trop peu de temps. En Amérique, ce bois est cmployé en énorme quantité à la menuisęrie, comme bois d'œuvre, et aux constructions de la marine; il est inférieur en qualité à celui de pin sylvestre et de plusieurs de ses congénères de l'Amérique.

Le mélèze est celui des arbres que je viens de passer en revue, qui a, sous le climat de Paris, l'aceroissement le plus prompt en lıateur, pendant les premières années qui suivent sa naissance, et cet aceroissement, s'il n'est pas longtemps aussi rapide, se maintient pourtant assez bien jusqu'à ce qu'il ait atteint 25 à 30 ans, mais alors il se ralentit beancoup. Je ne pense pas que cet arbro puisse jamais parvenir, sous le climat de Paris, aux dimensions qu'il atteint dans les pays où il est indigène; il est d'ailleurs à eraindre qu'il n'y soit sujet à la pourriture au cour et à la brouissure, maladies dont la première surtout a fait périr, en Angleterre, de nombreuses et vastes plantations de eet arbre qui avaient été faites dans des pays de plaines; car celles qui se trouvaient à une certaine hauteur, sur les montagnes de l'Eeosse, n'out, pour ansi dire, point 
en ì en souffrir. On ne peut ètre éclairé à ee sujut par l'expérience, puisqu’il n'existe point de gramles plantations de cet arbre dans les plaines centrales de la France. En définitive, je présume que la culture en grand du mélèze, qui a été fort prônée, ne procurera pas les avantages que l'on s'en promettait.

Il est fort clillicile, sous le climat de Paris, de faire réussir un semis de mélèze exécuté en grand, parce que le plant est très-délicat pendant les quatre ou cinq premiers mois; il hui faut tout à la fois de l'ombrage et un terrain très-perméible à l'ean; passé ces premiers mois, il n'y a pas de plant plus robuste. Ainsi, sons le climat de Paris, les semis de mélèze ne penvent réussir sur un terrain découvert qui aurait été préparé par des labours, et ils ne réussissent même dans les potets convenablement ombragés, que dans des circonstances particulières. Les plantations de cet arbre reprennent au contraire très-bien, et e’est le moyen de propagation qui a été généralement employé en France et en Angleterre. Lá plantation d'automne est préférable à celle du printemps, el une. couverture est utile, parce que les plants nouvellement plantés sont sensibles aux alternatives de gelées et de dégels, si fréquentes sous le climat de Paris; néammoins, j’en ai rarement fait usage.

Ce que j’ai dit du meilleur mode d'aménagement, d'exploitation el de reproluction pour les futaies de pins sylvestres, s’applique aux futaies de mélèzes; m!ais avec cette différence qu'on ne doit les repeupler qu'au moyen de la plantation, à cause de la difficulté de faire réussir les semis. Ie mélèze n'est pas délicat sur le terrain, cependaut il ne vient point dans les terres marécageuses et il réussit mal, dit Decandolle, dans les terrains extrêmes, c'est-à-dire qui seraient trop argileux, trop siliceux ou trop calcaires. On ne peut dire avec certitude quelle est, sous le climat de Paris, la qualité du boìs du mélèze, tant vanté par tous les auteurs qui en ont parlé, puisque cet arbre n'y est guère cultivé que pour l'ornement et que depuis trop peu de temps. J'ai trouvé son bois plus dur que celui de ses congénères que j’ai fait exploiter, et plus pesant lorsqu'il est sec; il m’a paru d'ailleurs de très-bonne qualité.

On a cru longtemps que le cèdre du Liltan ne eroissait spontanément que sur le mont Liban; mais, en 1588, Belon le vit sur le mont Taurus, et dernièrement on l'a observé sur plusieurs parties de l'Atlas. Cet arbre n'est encore cultivé, en France, que comme arbre d'ornement, et l'on n'en fait point de semis sur place, on ne le multiplie que par la plantition. En supposant même que le semis en grand, sur un terrain découvert préparé par des labours, pût réussir, ce procédé devientrait for conteux, à cause de la difficulté d'extraire la graine des eônes que l'on trouve chez les grainctiers. Si l'on at tend pour cueillir des cônes que les écailles soient sur le point de sédétacher de l'axe, les graines ont souvent alors commencé à germer, et par conséquent elles ne sont pas susceptibles d'ètre gardées, il faut qu'elles soient semées $10 u l$ de suite; mais le moment où les écailles tombent, sous le climat de Paris, paraît être variable, dans des limites de plusieurs mois, an lieu d'ètre variable dans des limites de quelques jours seulement comme pour le sapin argenté; il est donc difficile de saisir ea 
moment, qui peut d'ailleurs arriver dans une saison défavoralıle pour le semis artificiel.

Les plantations de cèdre m'ont paru réussir moins bien que celles des autres arlores dont je viens de parler, et les plants boudent souvent pendant plusieurs années avant que de reprendre une belle végétation; cela pourrait tenir à des circonstances particulières à la localité que j'habite, ou résulter de la qualité inféricure des plants que j'aurais employés. Malheureusement, lorsque l'on fait des expériences sur la culture de cet arbre avec de la graine extraite de cones achetés chez les graineticrs, on est toujours dans la crainte d'avoir employé de la graine qui n'avait pas atteint une complète maturité el qui a pu domer naissance à des plants chétifs et maladifs. Je crois la plantation d'automne préférable à celle du printemps, mais avec une couverture. L'accroissement des jeunes plants, quand ils ont pris leur essor, est très-rapide, non-seulement en hauteur, mais surtout en grosseur, et ils se maintiennent ainsi pendant une soixantaine d'années. Le cèdre n'est pas difficile sur le terrain; ce que j’ai dit du mélìze à ce sujet, me paraît lui être applicable; je n'ai pas encore assez de dounćes pour m'n exprimer arec certitude.

L'aspect du cèdre du Liban, lorsqu'il est isolé, est fort remarquable; son tronc est souvent garni de branches jusque près du sol, et souvent aussi il se divise, ì peu de distance du sol, en plusicurs grosses branches qui s'étalent au loin en forme de palmes; ce même arbre est méconnaissable lorsqu’il croit à l'état serré; son tronc file droit, il n'a plus que de petiles branches comme le mélèze. Je ne puis d'ailleurs parler des futaies de cèdres, sous le climat de Paris, puisque cet arbre n'y est cultivé qu'en petite quantité et que pour l'ornement. Le cèdre acquiert de plus fortes dimensions en circonférence qu'aucune des espères dont je viens de parler, mais je ne crois pas qu'il parvienne à la même hauteur que nos sapins d'Europe. On sait actuellement que le bois de cidre, que l'on avait cru longtemps incorruptible et le meilleur de tous les bois, est fort inférieur à celui de plusieurs de ses congénères pour la menuiserie, et l'on n'est point encore fixé sur son mérite comme bois de construction.

J'ai parlé sommairement, dans le chapitre $\mathrm{X}$, de douzc espèces d'arbres résineux conifères cultivables dans les climats tempérés et en particulier sous le climat de Pařs; j’en ai parlé avec certitude, sous ce dernier rapport, puisque je les ai tous chez moi, à l'exception du pin rouge, qui supporte dans l'A mérique septentrionale des froids plus rigoureux que ceux du climat de Paris. Ces arbres sont d'ailleurs tous cultivés en Angleterre depuis plus longtemps qu'en France, à l'exception du pin d'Autriche qui u'a été introduit que depuis peu d’années dans ces deux pays; et l'on sait que les arbres qui supportent le climat de l'Angleterre peuvent aussi supporter le climat de Paris. Mon Jut, en parlant d'une manière aussi incomplète, faute de pouvoir le faire autrement, de la plupart des arbres compris dans ce chapitre, a été d’engager à les cultiver assezen grand pour savoir quelles seront leurs dimensions et quel partion poura en tirer. Ces douze respèces sont: le pin d'Autriche, le pin cembro, le pin l'Espagne, le 


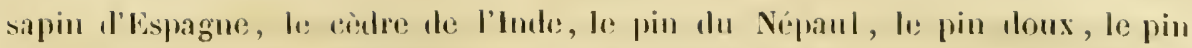
rouge, le pin de Lambert, lo pin de Sabine, le piu de Coulter et le cyprès ilistique.

Le piu d'Autriche, si j'en juge d'après ma propre expérience, paraît devoir réussir aussi bien que le pin laricio sous le climat de Paris; sa culture ne présente pas plus de difficultés, et il u'est pas plus difficile sur le terrain; il est d'ailleurs présumalole qu'il pourra être cultivé avec encore plus de succès que le pin sylvestre sur des terres excessivement calcaires, telles que les craies de la Champagne, puisque éest le seul arbre résineux que l'on trouve en Autriche sur certains coteaux très-calcaires, quoiqu'il y ait souvent des pins sylvestres dans le voisinage. Ilocss, dans sa Monographie de cet arbre, vante beaucoup la qualité de son bois, qu'il dit être plus tenace et plus ferme que cehui du pin sylvestre, el encore plus estimé que celui du mélèze pour les constructions dans l'eau; il est, selon cet auteur, le plus riche en résine de tous les arbres résineux de l'Enrope; et l'extraction de la résine de cet arbre en aurait amené la destruction en Autriche, si le gouvernement n'eut interposé son autorité pour le prolíger contre l’avidité des propriétaires.

Le pin cembro a un accroissement si lent sous le climat de Paris, qu'il ne peut y être cultivé que comme arbre d'ornement.

Nous ne savons encore rien du pin d'Espagne ni du sapin d'Espagne, sinon que ce sont des arbres à grandes dimensions en Espagne.

Nous savons que le cèdre de l'Inde est on ne peut plus gracieux pendant ses premières années. Les voyageurs dont Lambert et Loudon ont reproduit les récits font un éloge prodigieux de son hois; nous apprendrons peut-être, par la suite, qu'il ne vaut pas mieux que celui du cèdre du Liban. Ces réflexions s'appliquent au pin du Népaul, que les habitans de ce pays appellent Raesuela (roi les arbres), et dont ils préfèrent, dit-on, le bois d'ocuvre ì celui de tous les autres arbres.

Je ne vois rien à dire du pin doux ni du pin rouge, sinon que M. A. Michaux en conseille la culture, à cause des qualités de leur bois, et parce qu'ils ne sont pas difficiles sur le terrain.

Nous ne connaissons encore le pin de Lambert, le pin de Coulter et le pin dr. Sabine que par ce qu'en a dit Douglas, voyageur et naturaliste anglais; les deux premiers, qu'on rencontre souvent mêlés ensemble, ont le mérite de pouvoir croître sur des sables purs qu'on croirait incapables de supporter aucune végétation; le troisième avait été olsservé sur un sol schisteux et graveleux.

Quoique le cyprès distique ait bien supporté le climal des provinces septentrionales de la France, il est évident que celui des provinces méridionales lıi convient mieux; mais il paraît que cet arbre ne peut obtenir un accroissement tel qu'il soil avmtagenx de le cultiver pour son produit, que sur des terrains tout à la fois tourbeux el marécageux; je ne sache pas que l'on en ail essayé la culture en gramel, daus des marais, sur aucun point de la France.

La cullurr des arbres réwineux coniferes lw pleine lorr, à grandes dimensions, 
a pris beancoup d'extension en France depuis une quinzaine l'années; les personnes qui se livreront par la suite à l'étude de cette culture, ainși que je l'ai fait, trouveront donc pour les guider des faits d'expérience qui m'ont manqué. Ainsi, par exemple, il est probable que parmi les propriétaires qui ont créé des futaies de pins sylvestres sur les terres crayeuses de la Champagne, il s'en trouve qui y ont essayé le pin laricio et même le pin d'Autriche, mais cela n'esı́ pas venu à ma connaissance. Il y en a sans doute aussi qui ont planté de ces arbres exotiques dont j'ai parlé dans le chapitre $X$, depuis plus longtemps et en plus grande quantité que moi; car, à l'exception du pin doux, je ne les ai cultivés que par échantillons, si je puis m'exprimer ainsi, pour savoir s'ils étaient de pleine terre et pour les observer pendant leurs premières années, laissant à mon fils le soin de les observer plus tard.

Je citerai à cette occasion les plantations d'arbres résineux conifères, indigènes et exotiques, de pleine terre, que M. le marquis de Vibraye a fait exécuter sur une étendue de plusieurs centaines d'hectares dans sa terre de Cheverny, en Sologne (Loir-et-Cher), à 12 kilomètres de Blois, sur la rive gauche de la Loire. On y trouve de jeunes fulaies des espèces les plus répandues en France, mêlées ou réunies par espèces; et l'on y trouve aussi, mais en moindre quantité, la collection de toutes les espèces, peu répandues ou rares encore, qui peuvent ctre cultivées en pleine terre sous le climat de Cheverny. Je citerai par exemple l'araucarier imbriqué, Araucaria imbricata Pavon, dont je n'ai pas cru devoir parler, parce qu'on prétend qu'il n'est pas de pleine terre sous le climat le Paris, et dont j'essaie actuellement la culture en pleine terre chez moi ; cet arbre a trèsbien supporté la pleine terre jusqu'à ce jour (1845) à Cheverny, et cela ne doit point étonner, puisqu'il la supporte en Angleterre, où le climat est plus rigoureux.

Dans le chapitre $\mathbf{X I}$, j'ai parlé avec détail de la culture des arbres résineux conifères en pépinière et de leur plantation à demeure, d'après ce que j'ai pratiqué chez moi; cette culture ne présente pas plus de difficul tés que celle des arbres feuillus, et la plantation à demeure des premiers réussit aussi facilement que celle des seconds quand le plant est bien garni de chevelu, ce qui arrive toujours lorsqu'on l'a élevé ainsi que je l'ai prescrit. On brise nécessairement quelques petites racines en arrachant le plant, mais cela ne cause pas un dommage sensible; le soin le plus important à prendre pour la réussite de la plantation des arbres résineux conifères, est que les racines ne soient point exposées au hâle, au soleil, ou à la gelée. Les arbres dont j’ai décrit particulièrement la culture en pépinière sont le sapin argenté, le sapin picéa, le pin sylvestre, le pin maritime, le pin laricio, le pin du lord Weymouth, le mélèze, le cèdre du Liban, le pin d'Autriche et le pin doux; j'ai donné en outre des détails sur la végétation et sur l'accroissement du plant des sept premières de ces espèces, depuis le semis jusqu'au moment de la plantation à demeure.

Il est digne de remarque qu'en France, sous le climat de Paris proprement dit, on plante moins communément le sapin argenté que le sapin picéa, le pin 
sylvestre, le mélèn, le pin $1 \mathrm{l}$ eymouth, le pin larieio et mène le cèdredu Liban; je ne parle pas du pin maritime, que l'on obtient si facilement et si vite par le semis à demeure. Cependant le sapin argenté est le seul de ces arbres qui soit indigène de ce climat; il est celui dont la culture peut y donner le revenu le plus élevé, et qui probablement peut y parvenir aux plus belles dimensions; e'est un arbre magnilique, propre tout à la fois ì former tes allées et à oruer des parcs; son plant reprend très-facilenent. La cause du peu d'extension que l'on donne à la culture de cet arbre, malgré les avantages qu'elle présente, est fort simple : le sapin argenté est, de tous les arbres que je viens de nommer, celui qui a la végétation la plus lente pendant les premières années, et les pépiniéristes ont, par cette raison, moins d'intérêt à en élever.

J'ai réuni dans le chapitre XII cinq articles sur différens sujets. Dans le premier, j'ai examiné la question de l'alternance des bois, sur laquelle on n'est pas encore fixé; dans le second, j’ai décrit en détail la greffe herbacée, applicable en grand à la transformation de certaines espèces d'arbres résineux en d'autres espèces; j’ai parlé dans le troisième des arbres résineux plantés au Vieil-Ilarcourt par Delamarre; le quatrième est consacré à la description de deux dendromètres; le cinquième est étranger au sujet que je traite dans cet ourrage, j’ai pourtant cru pouvoir l'y intercaler et voici pourquoi : il est relatif à la plantation à demeure des arbres feuillus, opération que j’ai été conduit à modifier en imitant ce que j’ai pratiqué pour les arbres résineux conifères; j'espère qu'on reconnaîtra à cet article quelque utilité, parțiculièrement en ce qui concerne les arbres fruitiers.

Enfin, dans ce chapitre XIII et dernier, je me suis proposé, non pas de faire un résumé brillant, mais un résumé utile. 



\title{
TITRES DES OUVRAGES CITES DANS CE TRAITE.
}

\author{
Prom ordue de date de publication.
}

PrINI secundi Historice naturalis libri XXXVII quos interprelatione et ug(is illustravit Johannes Harduinus e societate Jesu. Parisiis 1741 ( 2 vol. in-folio).

BELLov Cenomani De arboribus coniferis, resiniferis, aliis quoquc nomullis sempiternd fronde tirentibus cum earumdem iconibus ad vivum expressis, etc. Parisiis 1553 (broch. in- $4^{\circ}$ ).

Les observations de plusieurs singularités el choses mémorables trouvées en Grèce, Asie, Judée, Egypte, Arabic et autres pays estranges, en 3 liv.; par Prerhe Belox, du Mans, 1 vol. in-40. Paris, 1588 .

Maturou Senensis medici Commentarii in sex libros Pedacii Dioscoridis Anazarbei de medica materia, etc. Venetiis $\mathbf{1 5 6 5}$ (in-fol.).

DODONAI Mechliniensis medici Cæsarei Stirpium historice pemptades sex sive libri $X X X$. Antverpix 1583 (in-fol.).

CrusIr Atrebatis, impp. cæss. augg. Maximiliani II, Rudolphi II aulæ quondam familiaris, Rariorum aliquot stirpium per Pannoniam, Austriam el vicinas quasdam provincias, observatarum historia, quatuor libris expressa. Antverpiæ 1583 (in-8).

CıUSII Atrebatis, etc. Rariorum plantarum historia. Antverpiæ 1601 (in-fol.).

Eicones plantarum seu stirpium, arborum nempe, fruticum, lignorum, radicum omnis generis, tam inquilinorum quam exoticorum, qua partim Germania sponte produxit, partim ab exteris reyionibus allata in Germania plantantur. Francofurti ad Mœnum, 1590 (in-40 oblong).- L'auteur ne se nomme point; mais on trouve, tome $\mathrm{V}$ du eatalogue de Banks, que cet ouvrage est de TABER Monta avs, médecin de l'électeur.

Historia plantarum universalis, nova et absolutissima cum consensu et dissensu circa eas, auctoribus Joh. Baunixo, ill, cels. wirt. archiatro et J.H. Chercero philosopho et medic. doct. Basiliensibus, quam recensuit et auxit dominus CHABREUs med. doct. Genevensis, etc. Ebroduni 1610 ( 3 vol. gr. in-fol.).

Caspari Baunivi, viri clarissimi, Pinax Theatri botanici, sive index in Theophrasti, Dioscoridis, Plinii eibotanicorum qui a saculo scripserunt opera. Basiliæ 1671 (in-4º).

Plante per Galliam, Hispaniam et Ilaliam observate iconibus ceneis exhibitce à R. P. J. BA RREI. E ERo Parisino in sacrâ theologiâ magistro, etc. Opus posthumum accurante A. de JussıE Lugdunæo. Parisiis 1714 (in-fol. avec 1,325 fig.).

Histoire des plantes qui naissent aux environs d'Aix el dans plusieurs autrcs endroits de la Prorence; par GARIDEL. In-fol. Aix, 1723.

Flora sibirira, sive historia plantarum Sibiria, auctore D. GuExin, Petropoli 1747. (4 vol. int $-\{0$ ! 
Traite des arbres et arbustes qui se cultivent on France en pleine terre; par DU HAMEL-1)LMU. CEAC. 2 vol, in-10. Palris, 1755.

Des semis et plantations des arbres et de leur culture, ou, etc.; par DiHanel-DuMoNCEav. 1 vol, in-40. Paris, 1 i G0.

De l'explnitation des bois, ou, etc.; par Denaye-Dumovenac. In-40 en deux parties. Paris, 1 iıł.

Flora espanola, o Historia de las plantas que secrion en Espana (Flore espagnole, ou Histoir des plantes qui croissent en Espagne), su autor J.QUER, cirugiano, etc. Madrid, 1762-1784. (6 vol. in $-4^{n}$. (Pas traduil.)

LIXXEI equitis aur. de Stella polari, etc. Species plantarum, exhibcrtes plantas rite cognitas ad ycnera relatas, cum differentiis specificis, nominibus trivialibus synonymis selectis, locis natalibus, secundum systema sexuale digestas. Editio lertia. Vindobonæ $1764 .\left(2 \mathrm{vol}\right.$. in-8 $\left.{ }^{\circ}\right)$.

Traité des arbres résineux conifères, extrait et traduit de l'anglais de Miller, avec des notes, obserrations et expériences; par le baron de Tscucoy. In-80. Metz, 1768.

Dictionnaire raisonné et universel d'histoire naturelle; par VA wONT DE BONARE. 6 Vol. in-i०. Paris, 1775.

Mémoires sur les travaux qui ont rapport à l'exploitation de la mature dans les Pyrénées; pall LEROY, ingérieur des ports el arsenaux de la marine. I vol. in-40. Londres, 1776, el Paris.

Flore francaise, ou Description, etc.; par le chevalier de LAмa K. 3 vol. in-8. Paris, 1778.

Encyclopédie méthodique ou par ordre de matières; par une société de çens de lettres. - Botanique, par LA MARK et Poiret. 8 vol. in- $4^{\circ}$, dont les quatre premiers pas LAMARK, et les qualre derniers par Poinet. Paris, 1783-1808.

Cours complet d'agriculture thérique, pratique, économigue et de médecine rurale et vitérinaire, suivi d'une méthode pour étudier l'agriculture par principes, ou Dictionnaire umicersel llagriculture; par une société d'agriculteurs, et rédigé par l'abbé Ruzı E 10 vol. in-40. Paris, 1781-1\$00. Les 2 derniers vol. ont été publiès en 1796 et 1800 par une société de savans el d'agriculteurs, qui ont publié aussi 2 vol. de complément en 1805 .

Instruction sur les bois de marine el autres; par TEr.tis D'ACOSTA, grand maître des eaux-etforèts de France. In-8․ Paris, 1782, avee deux supplémens en 1is \$-1786.

Plan d'une nouvelle administration pour les forêts de France; par TELL L̇ D'ACOST A. 1 vol. in- $8^{\circ}$. Paris, 1791.

Flora rossica seu stirpium imperii rossici, per Europam et Asiam indigenarum descriptiones $\mathrm{cl}$ icones; edidit P. S. PALLAS. In-fol., 1784-1786.

Mémoires d'agriculture, d'économie rurale et domestique; publiés par la SocrétÉ D'AGRICULTURE DE PARIS. 25 vol. in-8०. Paris, 1785-1791.

Reise nach Mariazell in Steyermark (Voyage à Mariazell dans la Styrie); par ARNoLD. Broch. in-4․ Vienne, 1785 .

Dictionnaire des jardiniers; traduit de l'anglais de P. MILLER, sur la se édition, par L. M. de

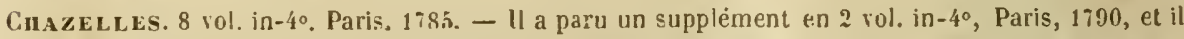
y a une édition en 8 vol, in- $8^{\circ}$, Bruxelles, 1785 . - Loudon eite une édition de l'ourrage de Miller de 1731 , qui est, je crois, la première.

IIistoire des plantes du Dauphiné, contenant, etc.; par VilLa Rs. 3 vol. in-8º. Grenoble, 1786.

Ilortus Kencensis, or a Catalogue of the plants cultivated in the royalbotanic Garden at Kenc. (Joidin de $K e w$, ou Calalogue des plantes cultivées dans le jardin botanique du rni à $K$ ew); par W. A1 Tox. 1 re édit., 3 vol. in-8॰. Londres, 1 789. (Pas traduit.)

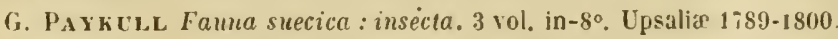

Mémoire sur l'administration forestière et sur les qualités individuelles des bois indigénes ou qu sont acclimatés en France; par P. C. VAR Exxes De FexilLe. 2 vol. in-8․ Boul'z, 1792.

Flore peruvianre el chilensis prodomus; par don Hipolito Rriz et don José Pavax. 5 vol. ill-ful. dont $i$ de planches. Madrid, $179 \mathrm{i}$. 


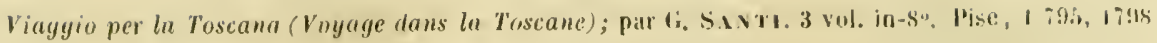
1806 .

Annales de l'agriculure fruncaise, journal nemsuel. Paris, 1795-184.

flora pisana (Flore de l'ise); par G. SAv1. 2 vol. in-So. l'ise, 1798.

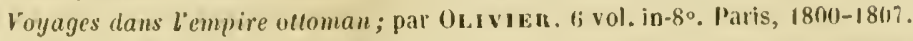

Vouveau Duhamel, on Traite des arbres et arbustes que lion cultire en France. (cumpilaliun de.

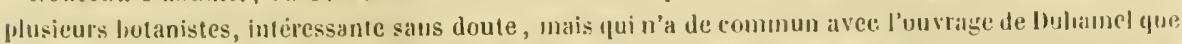

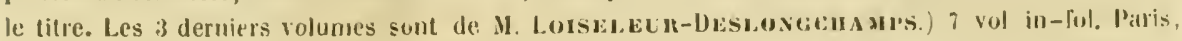
$1800-1819$.

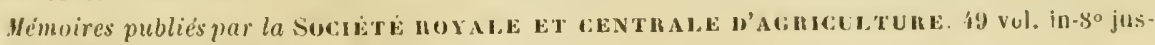
qu'en 1812. Paris, 1800-1812.

Felicis Avellar lBnetwi Flora lusitanica seu planlarm que in Lnsilanid rel spente crescunt, vel frequentius coluntur, ex florum presertim sexubus systematice distributarum synopsis. 2 vol. in-8\%. Olissipone 1804.

Anveisung zur Holzzucht für Foerster (Instruction sur la culture du bois, a l'usage des forestiers); lraduit de l'allemand de G. L. IIARTig, aves: l'allemand en regard, par Ba UUILLA K T. In-12. Pilris, 1805 .

Lchrbuch für Faprster und die es uerden wollen (Instruction pour les forestiers et ceux qui veulent le devenir); par (8. L. II A TIG, grand maitre des forè!s de Prusse. 7e édit., 3 vol. in- $8^{\circ}$. Stultgaru, 1808-1820. (Pas I raduit.)

Flore francaise, ou Hescription succincte de toutes les plantes qui croissent naturellement en

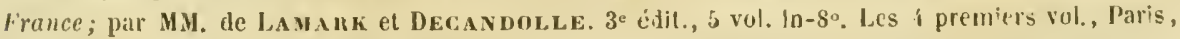
an XI (1805); le 5 e vol., Paris, 1815.

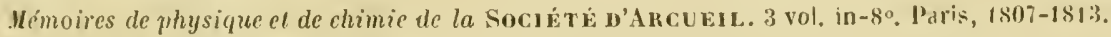

Nouveau Manuel forestier; traduit de l'allemand de BumgsDors, grand-matre des forèts de Prusse, par Baulurillalit, sur la $4^{e}$ édit. 2 vol. in-8\%. Paris, 1508.

IIstoire des arbres et arbrisseaux qui peuvent étre cultivés en plcine terre sur le sol de la france; par Desfoxtanes. 2 vul. in-So. Paris, 1909.

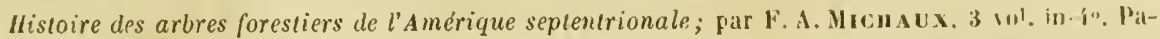
ris, $1810-1813$.

Pratique des defrichemens; par L. F. II., marquis de Turni1.L. Paris, 1811.

Flora napolitana, ossia descrizione delle plante indigene del regno di Napoli (Elore napulitaine, ou Description des plantes indigènes du royaume de Naples); par M. TExun k. 5 vol. in-fol., avee un atlas. Naples, 1811-1836.

Essai sur la géographie physique el botanique du royaume de Naples; pat M. TENunE. In-So. Naples, imprimerie française; 1827.

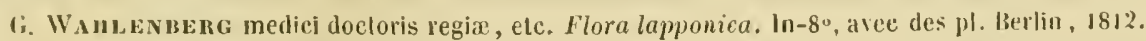

Dissertation sur la cultare des pins; traduit de l'italien de L. Fumsas r, abbe de lallumbeuse, par wis deres FinUhinges. Broch. in-8*. Paris, 1813.

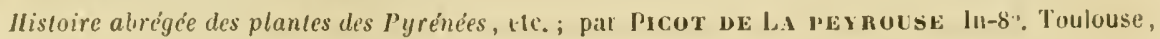
1813.

supplément i l'histoire abrèéc des plantes des Pyrénces; pall le baron PICOT DE LA PEY HULSL. In-so. Toulouse, 1818.

Dictimmaire des sciences nalurelles, suivi d’une biographie des plus célèbres naturalistes; palt

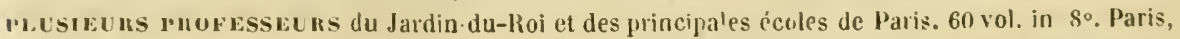
$1813-1830$.

Mémoires du Muséum d'histoire naturelle; par ess phoresseurs de ect établisspnent. 20 vol. in-1\%. Paris, 1815-1832.

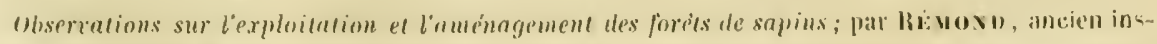

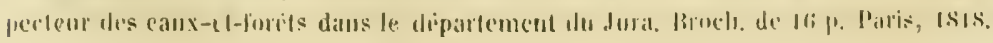


Essai sur la greffe de l'herbe des plantes et des arbres; par le baron de Tscuudy (fils de l'auteur du Trailé des arbres résineux). Broch. in- $8^{\circ}$. Metz, 1819.

Traité des forêts d'arbres résineux et des terrains adjacens sur les montagnes de la France; par DRALET, inspecteur principal des forêts du Midi. In-12. Toulouse, 1820.

Traité du hêtre et de son aménagement comparé à celui du chêne et des arbres résineux; par DRALET, conservateur des forêts du 12e arrondissement. In-12. Toulouse, 1824.

Anweisung zur Forst-Einrichtung und Abschcetzung (Instruction sur l'aménagement et l'estimation des forêts); par Coтt TA. In-8. Dresde, 1820. (Pas traduit.)

Traité de culture forestière; traduit de l'allemand de H. СоттA, conseiller supérieur des forèts du royaume de Saxe, sur la $5^{\circ}$ édit., par G. GaND. In-8º Paris, 1836.

Principes fondamentaux de la science forestière; traduit de l'allemand de H. CotT A sur la 2e édit, par J. Nouguier. In-8॰. Paris, 1841.

Dictionnaire raisonné et universel d'agriculture; par LES MEMBRES de la Société d'agriculture de l'Institut de France, etc. 16 vol. in $8^{\circ}$, nouv, édit. Paris, 1821.

Dictionnaire classique d'histoire naturelle; par MM. AUborN, Isid. Bourdon, etc. 16 vol. in-8º. Paris, 1822-1830.

Dictionnaire général, raisonné et historique des eaux et forêts; par BAUDRILLART. 5 livraisons formant 2 vol. in-4․ Paris, 1823-1825.

Mémoire sur les conifères et les cycadées; par L. C. RichaRd. In-4․ Paris, 1826.

N. T. Host Cæs. reg. archiatri Flora austriaca. Viennæ 1827 1831. (2 vol. in-8 ${ }^{\circ}$ )

Cours de culture et de naturalisation des végétaux; par A. Thouıs. 3 vol. in-8॰, avec un atlas. Paris, 1827.

De la préférence à accorder en Sologne, et dans les sols d'alluvion quartzeuse, à la culture du pin maritime sur celle des pins d'Ecosse et laricio; par le baron de MoroguEs. Broch. in-8\%. Orléans, 1827. (Extrait du t. VIII des Anriales de la Société des sciences, belles-lettres et arts d'Orléans.)

Historique de la création d'une richcsse millionnaire par la culture des pins; par L. G. DELAMARRE. In-8`. Paris, 1827.

Traité pratique de la culture des pins à grandes dimensions; par L. G. DELAMARRE, 3e édit., avec des dotes de MM. A. Michaux et Vicmoris. In-8०. Paris, 1831.

Botanographie belgique, ou Flore du nord de la France et de la Belgique proprement dite; par $\mathbf{F}$.

J. LESTIBOU TOIs. 2 vol. in-8०. Paris, 1827.

Planta Banatus rariores iconibus et descriptionibus illustrata; auctore A. RoECHEL. Pestini, 1828.

The Quarterly Journal of agriculture, and the prize essays and transactions of the Highland Society of Scotland (Journal trimestriel d'agriculture, et essais couronnés et transactions de la Société des Highlands d'Ecosse). Londres et Edimbourg, 1828-1845.

$A$ description of the genus Pinus, illustrated with figures (Description du genre Pin, ornée de figures). A. B. LAMBERT, 2 édit., 2 vol. gr. in-fol. Londres, 1828. - Il a été publié un tome III de cet ouvrage en 1837 .

Voyage dans les petits cantons et dans les Alpes Rhétiennes; traduit de l'allemand, de C. KASThofer, par Fazy-CAzAL. In-8*. Genève et Paris, 1828.

Le Guide dans les forêts; par C. KASTHOFER, haut-forestier ì Unterseen. 2 vol. in- $8^{\circ}$. Vevay, 1830 .

Annales de l'institut horticole de Fromont, Journal mensuel. Paris, 1829-1834.

Naturhistorische Skizze von Lithauen, Wolhynien und Podvlien, etc. (Esquisse de l'histoire naturelle de la Lithuanie, de la Volhynie et de la Podolie); par E. Eicinvald, professeur à l'Académie de Pétershourg. In $-4^{\circ}$ avec pl. Wilna, 1830.

Voyage dans les provinces de Rio de Janeiro et de Minas Geraes; par A. de SAINT-HILAIRE. 2 vol. in-8 ${ }^{\circ}$. Paris, 1830.

Plante asiatica rariores, or Descriptions and figures of a select number of unpublished East-Indian plants (Plantes rares de l'Asie, ou Descriptions ct figures d'un nombre choisi de plantes des Indes. 
TITES HES OUNAGES CITES DANS EL TMITL.

Orientales qui n'ont pas encore ćté décrites); par N. WA LLICn. 3 vol. gr. in-fol. Londres, 18301832.

Gemeinfassliche Anlcitung die Baume und Strauche OEsterreichs aus den Blceltern zu erkennen (Guide facile servant à reconnaitre les arbres et arbrisseaux de l'Autriche par leurs feuilles); par F. HoEsS. In-16. Vienne, 1830 .

Monographie der Schwarzfohre (Pinus austrlaca) in botanischer und forstlicher Beziehung (Monographie du Pin noir (Pinus austriaea) sous les rapports bolaniqucs et forestiers); par F. Hoess. Broch. in-fol. Vienne, 1831.

Report on the Athol system (Rapport sur le systėme d'Athol, relatif à la manière de planter et d'èlever les mélèzes); par W. SHicLLS. Broch. in-8॰. Edimbourg et L.ondres, 1831.

Flora indica, or Description of the indian plants (Flore indienne, ou Description des plantes de l'Inde); par Roxвurgir. 3 vol. in-8º. Serampore, 1832.

Traité de la culture des forêts; par M. Nornot. In- $8^{\circ}$. Paris et Dijon, 1832.

Mémoire sur l'amenagement et le mode d'exploilation des bois de pin dans les environs du P'uy; par

J. M. Berthand de Doue. Au Puy, 1833. (Cette brochure est extraite des Annales de la Suciété d'agriculture, sciences et arts du Puy, pour 1832-1833.)

Annales des sciences naturelles, Journal mensuel, $2^{e}$ série; par MM. Broxgniart, Guillemix

et Decarsne. l'aris, 1834-1844.

Observations pratiques sur la culture du pin maritime dans le département de la Sarthe; par

M. Vétillant. - Mémoire qui a ètè inséré dans les Mémoires de l'année 1835 de la Société royale et centrale d'agriculture. - Il a été tiré à part, ft forme une broch. in-8 $8^{\circ}$ qui ne s'rst p's vendue.

Cours complet d'agriculture pratique; traduit de l'allemand de BURger. PFell, Rohlives et

RufFiny, par M. Noinot. In-4º. Paris et Dijon, 1836.

Maison rustique du XIX' siècle. Encyclopédie d'agriculture pratique; par une réunion d'agrono-

mes et de praticiens, sous la direction de M. Malepeyne ainé. 4 vol. gr. in-8 ${ }^{\circ}$. Paris, 1836.

Cours élémentairc de culture des bois; par MM. Lonentz et Panade. $2^{2}$ édit. in- $8^{\circ}$. Paris et

Naney, 1836.

IIistoire du cèdre du Liban; par M. LoISELEUR-DEslongCHAMPS. Broch. in $8^{\circ}$. Paris, 1837.

Quclques considérations sur les pins et sur les arbres forestiers en général; par M. LOISELEUB-

Deslongchaups. Broch. in-8॰. Paris, 1843.

Monographie de la famille des caniferes; par M. JACQUES. Broch. in- $8^{\circ}$. Paris, 1837.

Journal d'agriculture pratique, Journal mensuel. Paris, 1837-1845.

Nouvelle Flore du Péloponèse el des Cyclades; par ChaURART et Bony DE SAINT-Vincent. In-fol. Paris, 1838.

Annals of natural history (Annales d'histoire naturelle), Journal mensuel. Londres, 1839-1845.

Arboretum et Fruticetum britannicum; or the trees and shrubs of Britain native and foreign, hardy and half-hardy, pictorially and botanically delineated, and scientifically and popularly described; with their propagation, culture, management, and uses in the arts, in useful and ornamental plantations, and in landscape-gardening; preceded by a historical and geographical outline of the trees and shrubs of temperate climates throughout the warld. (Les arbres et arbrisseaux de la GrandeBretagne, ou, etc ); par J. C. Loudow. 8 vol. in-80, dont 4 de planches. Londres, 1838.

Mémoire sur l'allernance des essences forestières; par G. Gaxd. Broch. in-8 $8^{\circ}$ de 39 pages. (Prèsentè à l'Académie des seiences.) Paris, 1840.

Essai sur les stations et habitations des conifères en Europe; par G. GAND. Broch. in-4․ (Mémoire présentẻ à la Sociẻtė du Muséum de Strasbourg.) Strasbourg, 1840.

Traitè général de statistique, culture et exploitation des bois; par J. B. Thomas. 2 vol. in-8. Paris, 1840.

Notice sur le mélèze et les avantages de sa culture; par Koevig. Broch. in-8०. Colmar, 1810.

Die Coniferen (les Conifères); par Fnavz-AvtorvE. In-ful, Vienne, 18i0-18il.

Agriculture de l'ouest de la France, Journal trimestriel; par J. RiEFFE. Paris el Nantes, 18 í$1 \times 15$. 
Vérilés sur les landes de Gascogne et sur la culture forestière des pins; par un paysan des Landes (M. Dallier). Broch. in-8॰. Paris, 1841.

Note sur quelques travaux agricoles exécutés sur la terre de Dampierre; par M. de BËHGUE. Broch. in-8०. Paris, 1841.

Annales forestières, Journal mensuel. Broch. in-8 ${ }^{\circ}$. Paris, 1842-1845.

Les Hylophthires et leurs ennemis, ou Description et iconographie des insectes les plus nuisibles aux forêts, ainsi quc des autres animaux causant des dégats dans les bois; avec une méthode pour apprendre à les détruire et à ménager ceux qui leur font la guerre; traduit de l'allemand de J. F. R. T zeBURg, par le comte de Corberox. In-8. Paris, 1842.

Recherches sur la croissance du pin sylvestre dans le nord de l'Europe; par A. BRAVAIS et CH. Martins. (Mémoire inséré dans le tome $\mathbf{V}$ des Mémoires de l'académie royale de Bruxelles.) Bruxelles, 1843.

De la plantation du mélèze, d’après les obscrvations faites en Ecosse; par G. L. H. (LAINGMEASON). Broch. in-8० (sans date). 


\section{PLANGHES.}

\section{NUTE}

RELATIV IUX DESSINS QUU SE TROUVENT SUR LES PLANCHES I, 11, 111, IV ET I.

Les rameaux, les leuilles, les fleurs, les cônes et les graines qui sont représentés planches I, II, III et IV sont de grandeur naturelle; la position des rameanx esi celle qu'ils avaient par rapport au trone, que je suppose être verlieal; mais ces rameaux ayant été pris sur des arbres d'àges différens, où ils ne se trouvaient pas toujours dans la même situation, il est nécessaire que j’entre dans quelques détails à ce sujet, parce quue la forme et la disposition des branches diffèrent selon leur âge, et, par conséquent, selon qu'elles sont plus ou moins éloignées du sommel de l'arbre.

Les rameaux de sapin argenté ont été pris vers la cime, sur un arbre de 60 ans; ceux de sapin picéa sur un arbre du même âge el aussi vers la cime. Les rameaux de pin sylvestre ont été pris sur un arbre de 40 ans, vers le bas de l'arbre; ceux de pin maritime sur un arbre de 40 ans, vers le sommet. Les rameaux de pin larieio ont été pris sur un arlıre de 37 ans, vers la cime; ecux de pin du lord Weymouth sur un arbre de 40 ans, vers la cime; ceux de mélèze sur un arbre de 40 ans, vers le bas de l'arlore.

Les rameaux portant des ehatons mâles ont été dessinés au moment où les fleurs atteignent leur maturité, à l'exception du rameau de mélèze, qui a été dessiné lorsque la fleur mâle avait dépassé sa maturité, paree que j’ai voulu qu’on y vit des bouquets de feuilles naissantes. Les rameaux portant des cônes ontété dessinés peu arant que ces cônes ne s'ouvrissent, à l'exception du rameau de mélèze, qui a été dlessinć un peu avant que les feuilles ne tombassent, parce que f'ai voulu gụ? l'on y vît el les feuilles disposées en bouquets, e relles qui sont placés une a une autom des pousses de l'année.

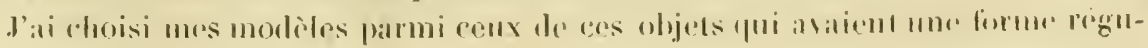


lière et les dimensions ordinaires, et j'ai eu l'attention que les chatons mâles, les cônes et quelques-unes des feuilles lussent vus dans toute leur longueur. II ne m'a pas paru utile aux praticiens que je donnasse les dessins des fleurs femelles, qui se transforment bientôt en cônes. Les chatons mâles des pins étant placés autour et au bas des jeunes pousses, il y a ordinairement d'autres pousses au bas de celles sur lesquelles ils se trouvent, mais quelquefois aussi il n'y en a point; on a choisi les rameaux dont on a donné les dessins parmi ceux qui n'ont qu'une pousse autour de laquelle se trouvent les chatons mâles, afin qu'on distinguât mieux ces chatons. Je me suis contenté de donner, dans le texte, le maximum et le minimum habituel de la longueur des cônes, les autres dimensions, ainsi que la forme, étant suffisamment indiquées par les dessins.

Indépendamment des dessins de grandeur naturelle dont je viens de parler, j'ai donné sur la planche $\mathbf{V}$, à moitié de grandeur naturelle, des dessins d'un rameau de sapin argenté, portant des axes de cônes, et des dessins de rameaux de pin sylvestre, de pin maritime, de pin laricio et de pin Weymouth, portant des cônes de deux années consécutives; ces rameaux ont été pris vers la cime des mêmes arbres sur lesquels on a pris les modèles des dessins de grandeur naturelle. Il n'y a d'ailleurs qu'un petit nombre de rameanx qui portent ainsi des cônes de deux années consécutives, puisqu'il y a des années où les pins ne portent pas de cônes ou n'en portent qu'un petit nombre. A côté de chaque rameau est un cône ouvert, tels qu'ils sont après que les graines sont tombées. On trouvera, dans les chapitres consacrés à chacun des arbres dont on a dessiné des rameaux, tous les renseignemens nécessaires pour se rendre compte des dessins; et les dessins serviront à l'intelligence de ce qui a été dit des feuilles, des fleurs, des cônes et des graines dans ces chapitres.

Je ferai observer que sur la figure 4, 'qui représente un rameau de pin maritime, on voit des pousses entre l'étage de cônes mûrs et celui de cônes plus petits qui sont au bout du rameau, tandis qu'ordinairement il n'y a de pousses, ainsi que je l'ai dit, qu'au bas des jets terminaux; le dessin représente donc ce qui n'existe que sur les rameaux qui ont eu deux sèves l'année précédente, ce qui est un cas exceptionnel, du moins sous le climat de Paris. Ainsi j'aurais dú éviter de douner le dessin d'un tel rameau, et je l'aurais remplacé si ce n'est que je ne me suis aperçu de cette laute qu':uu moment de publier l'ouvrage. 
LEGENDE DES PLANCHES 1, 11 , III, IV E'T V,

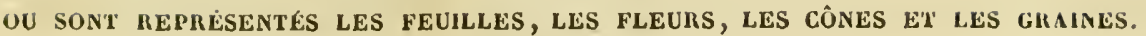

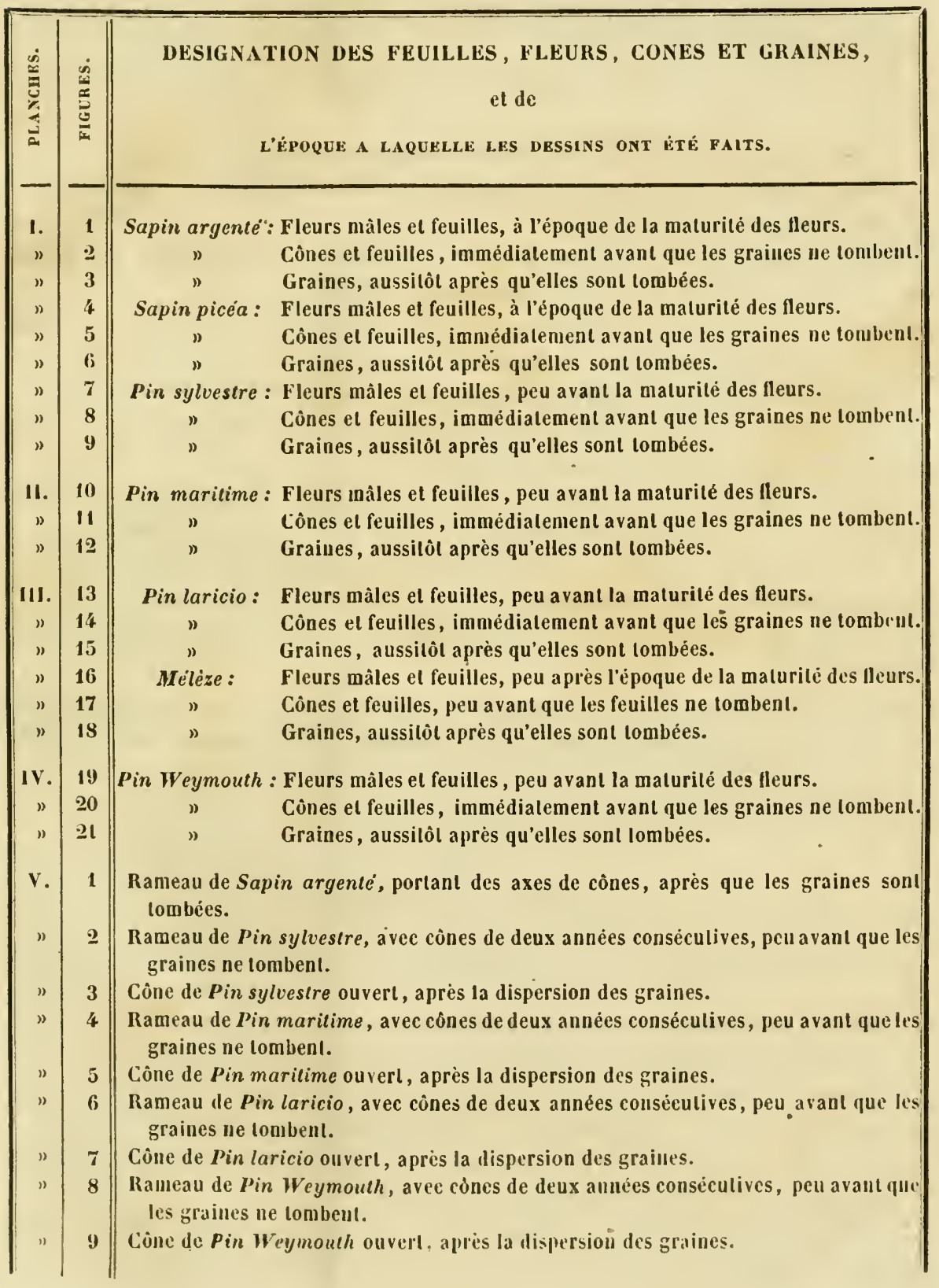




\section{EGENIEE IUE LA PLANCHE W.}

OU SONT REPRESENTES DES OUTILS ET DES INSTRUMENS EMPLOIES POUR L'EXPLUITATION DES FUTAIES.

Serpe ì élaguer : Projection sur un plan horizontal, fiy. 1. - Le manche a ()$^{\text {tu, }}, 30$ de long.

Vue de la serpe sur louvrier, quand il la porte pour monter dans les arbres, fig. 2.

Crochet ì porter la serpe: Projection sur un plan horizontal, fig. 3.

Ciseau ì élagner: Projection sur un plan horizontal, fiy. 4. -- Le manche a $2^{n}, 30$ de iong jusqu'à la douille.

Cognée de bücheron des environs de Paris : Projection sur un plan horizontal, fig. 5. - - Le manche a $0^{\text {m' }}, 7 \cdot 2$ de Iong jusqu'à la douille.

Cognée de bîcheron des sapinières de Laigle : Projection sur un plan vertical, fig. 6. - Le manche a ( $)^{\mathrm{m}}, 70$ de long júsqu'à la douille.

Echelle pour l'abattaye: Projection sur un plan vertical, fig. 7 .

Dendromètre: I'rojection sur un plan vertical, fig. 8. - Le pied a $1^{\mathrm{m}}, 50$, y compris la pointe en fer que l'on enfonce $\epsilon$ terre.

Autre dendromètre : Projection sur un plan vertical, lorsque le dendromètre est placé dans un plan vertical parallèle au plan sur lequel on le projette, fig. 9. - Projection sur un plan vertical lorsque le dendromètre est placé daus un plan horizontal, fig. 10. - Le pied a $1^{\mathrm{m}}, 50$, y compris la pointe en fer; mais il est bien préférable d'employer le pied à trois branches dont on se sert pour les niveaux d'eau.

Nota. Les dessins des dendromètres et de l'échelle ont été exécutés au sixième de la grandeur de l'objet; ceux du crochet à porter la serpe à moitié; ceux des aulres instrumens au quart.

\section{LEGENIDE DE LA PLANCHE VII,}

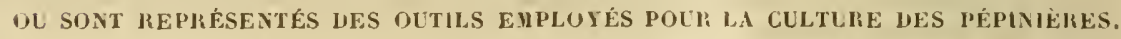

Binetle: Projection sur un plan horizontal, fig. 1 ; coupe suivant A B, fig. 2.2. - Le manche a $0^{\mathrm{m}}, \mathbf{1 9}$ de long jusqu'à la donille; le tranchant a $0^{\mathrm{m}}, 05{ }^{\prime}$.

Fourche à bècher à trois dents: Projection sur un plan horizontal, fig. 3; coupe suivant A B', fig. 4. -- Le manche a 1 mètre de long jusqu'à la donille.

Lìre-plamt : Projection sur un plan horizontal, fig. 5; coupe suivant A B, fị. 1 . - Le manche a $0^{\mathrm{m}}, 19$ de long jusquà la douille.

- Pretite fourche ì deux dents : Projection sur un pl:m horizontal, fig. 7 ; roupw?

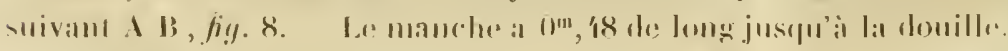


Rutissoire il ponsser : Projection sur un plan horizonlal, fiy. 9; coupe suivant A B, fiy. 10. - Le manche a $1^{\text {"I }}, 20$ de long jusqu'à la douille; le tranchant a ()$^{\mathrm{m} \prime}, 16$.

Grande pioche ì pic: Projection sur un plan horizontal, fig. 11 ; coupe suivant A B, fig. 12. - Le manche al $0^{\mathrm{m}}, 92$ de long à partir de l'oeil.

Crande fourche ì deux dents : Projection sur un plan horizontal, fig. 13; conpe suivant $\Lambda$ B , fig. 14. - I.e manche a $0^{m}, 81$ de long jusqu'à la douille.

Nora Tous res dessins ont été exécutés exactement au quart de la grandeur des outils.

\section{ERRATA}

Page 4, ligne i. Au lieu de: sur quinze espèces... lisez : sur douze espèces.

Page 4, ligne 9. Au lieu de: ces quinze espèces... lisez : ees douze espèces.

Et dans la nomenclature qui suit on supprimera le PIN Taunique, le PiN DE Pallas et le Pinde Garamanie, puisque jen'ai parlé de ces trois pins, daris le chapitre X, que dans l'article du PiN D'Autricie, uniquement pour dire qu'ils me paraissent ètre les mèmes que ce pin.

Page 8, ligne 17. Au lieu de: de feuilles.... lisez: de fruits.

Page 10, ligne 13. Au lieu de: sont toujours munies.... lisez: dans presque tous ces arbres, sont munies.

Pigge 93, dernière ligne. Au lieu de : au commencement de... lisez : à la fin de. 

II. 1

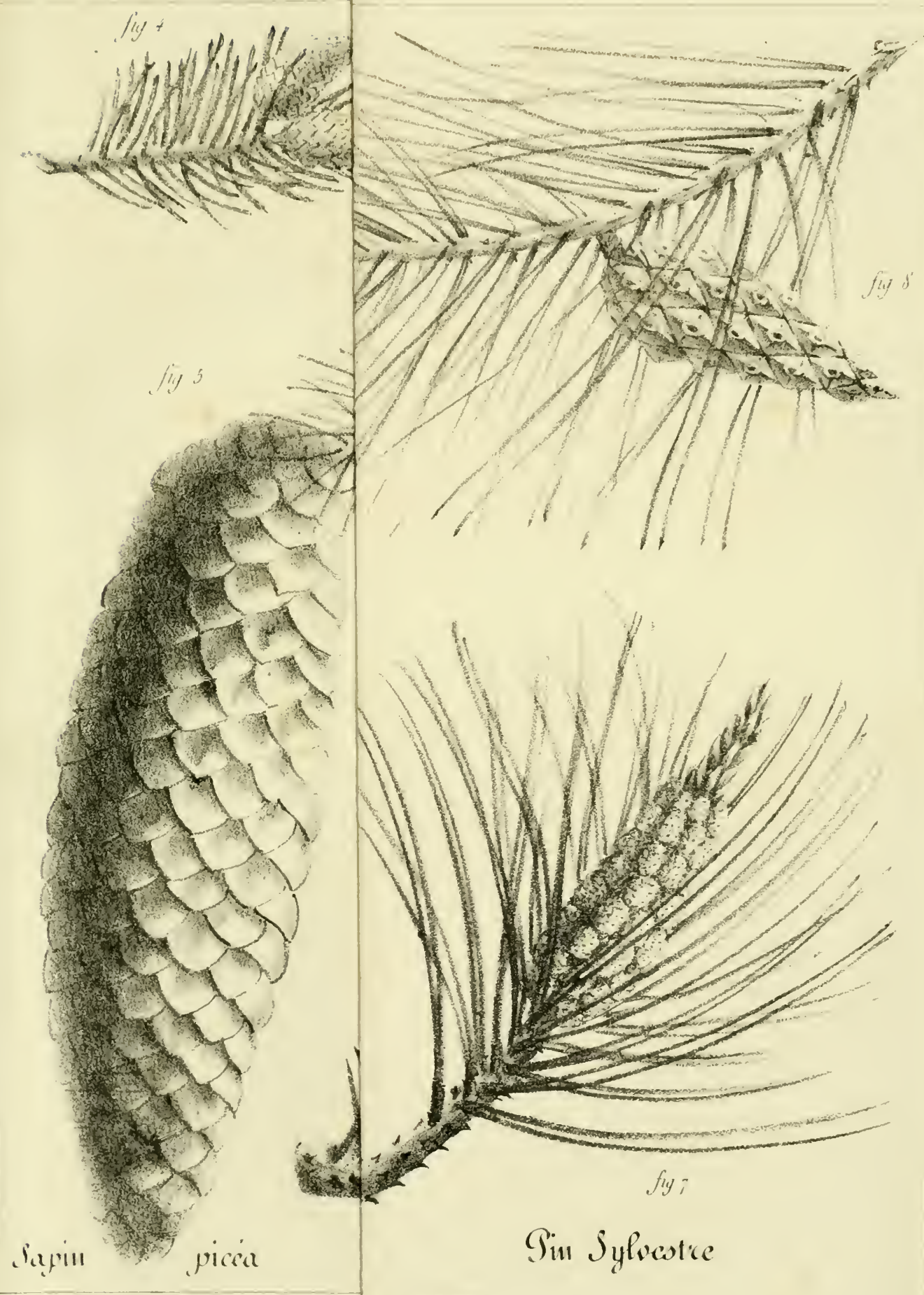




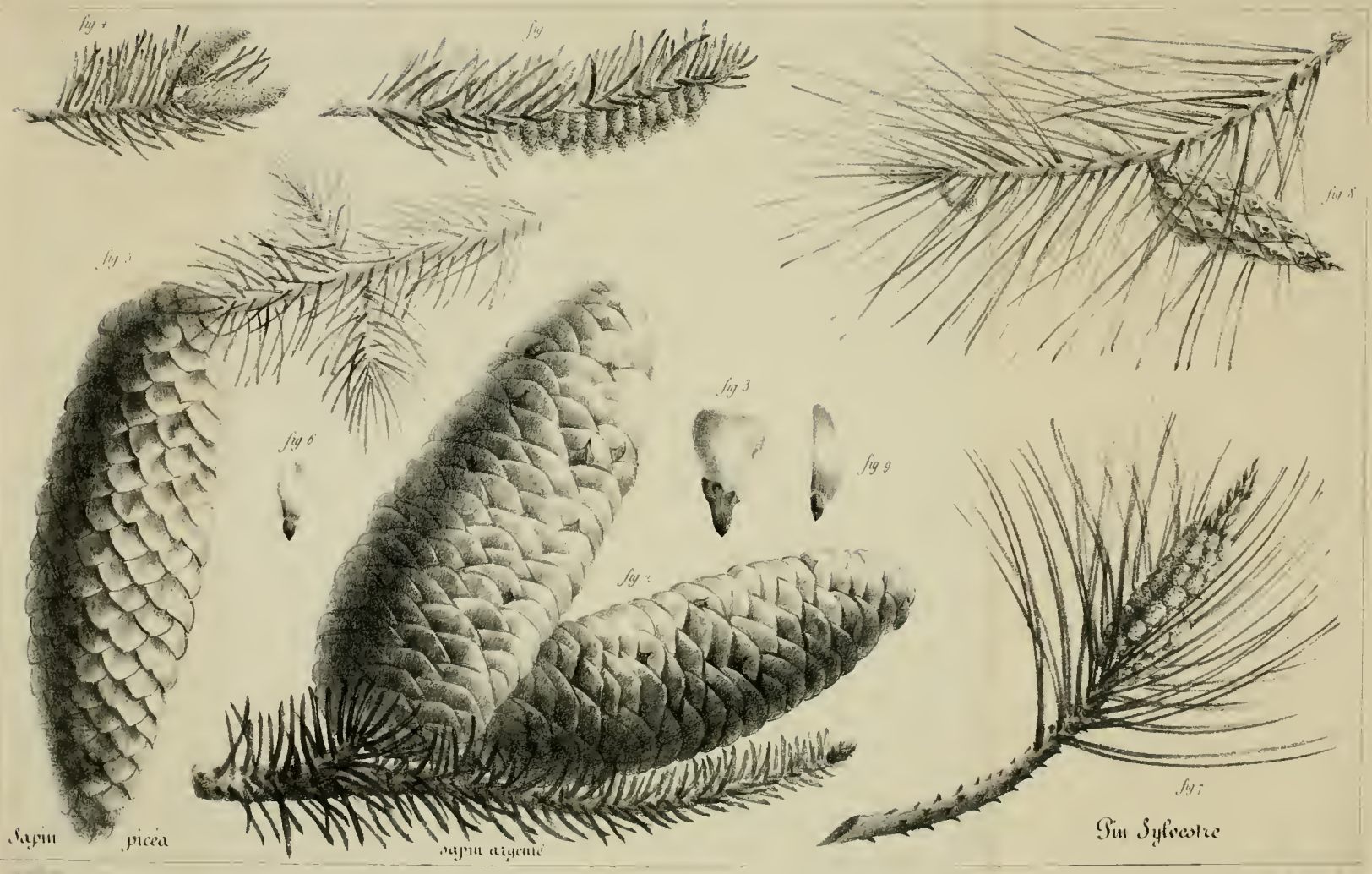


l'!. II.

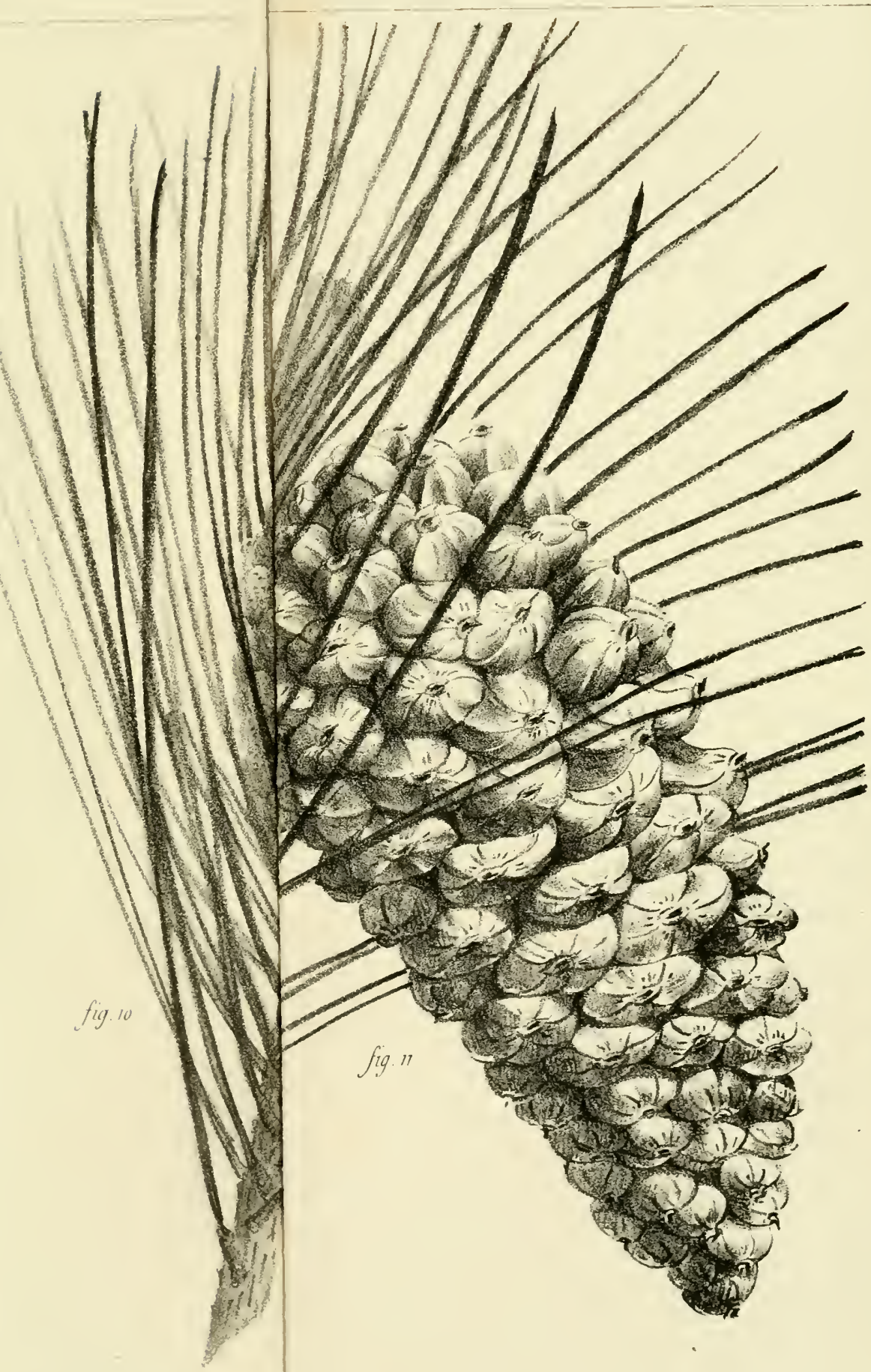



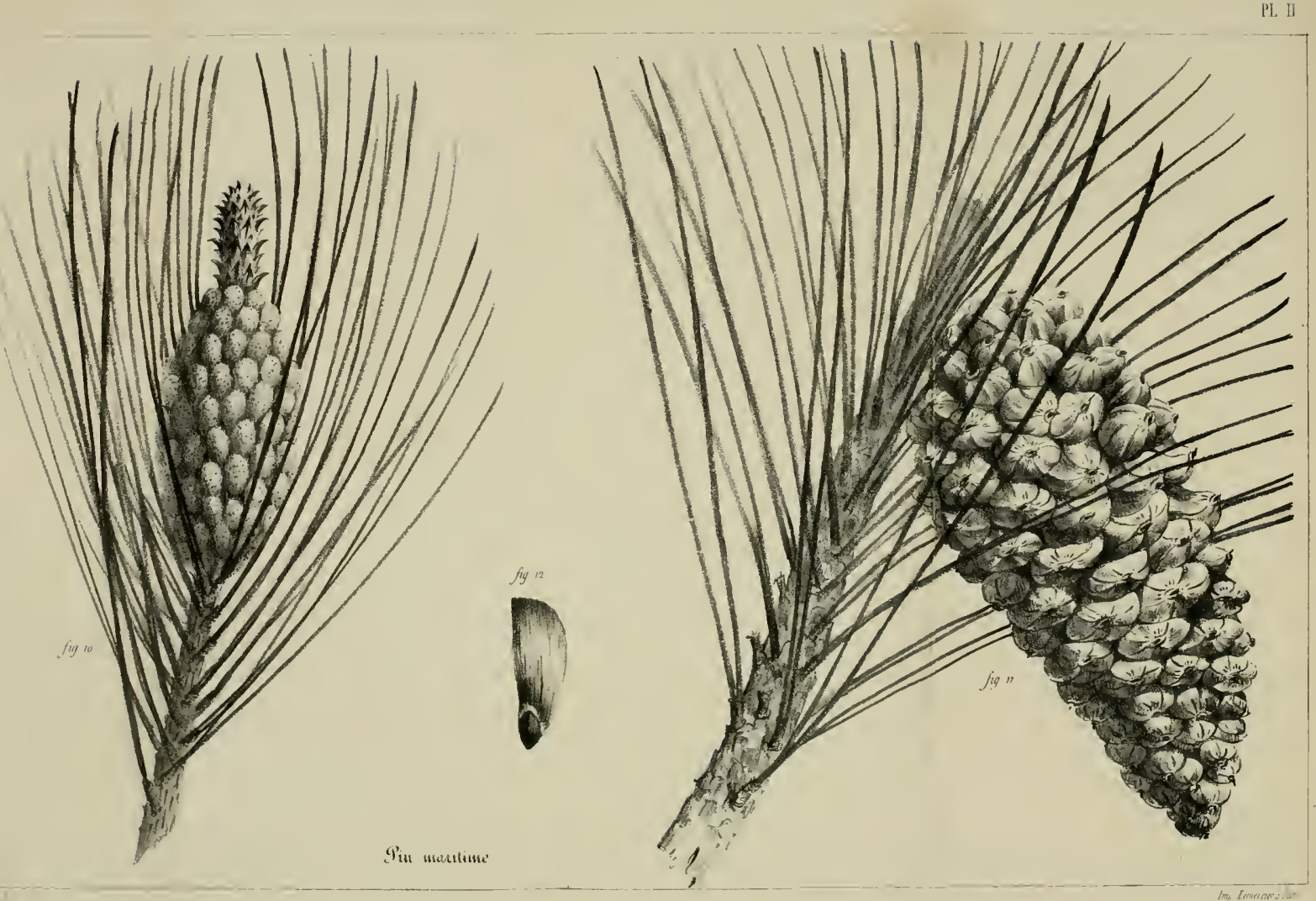
PJ. III

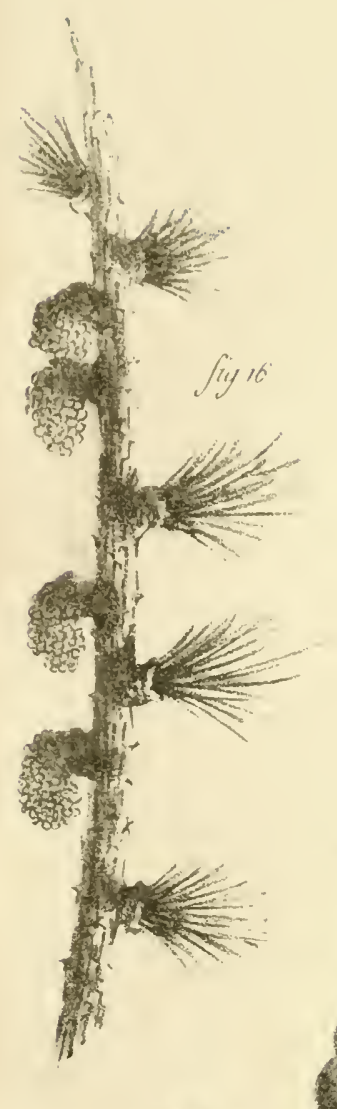



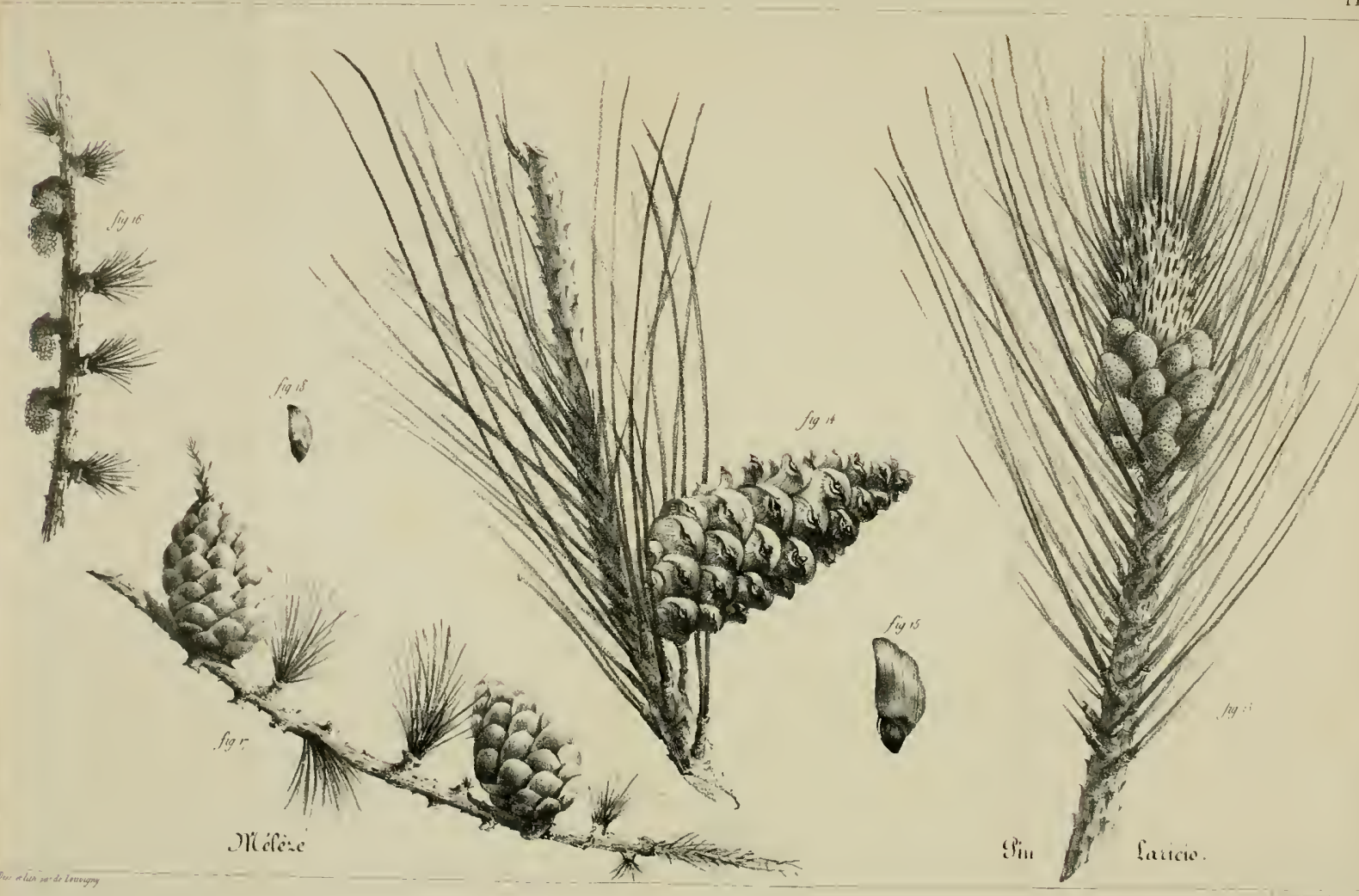
H.. II.
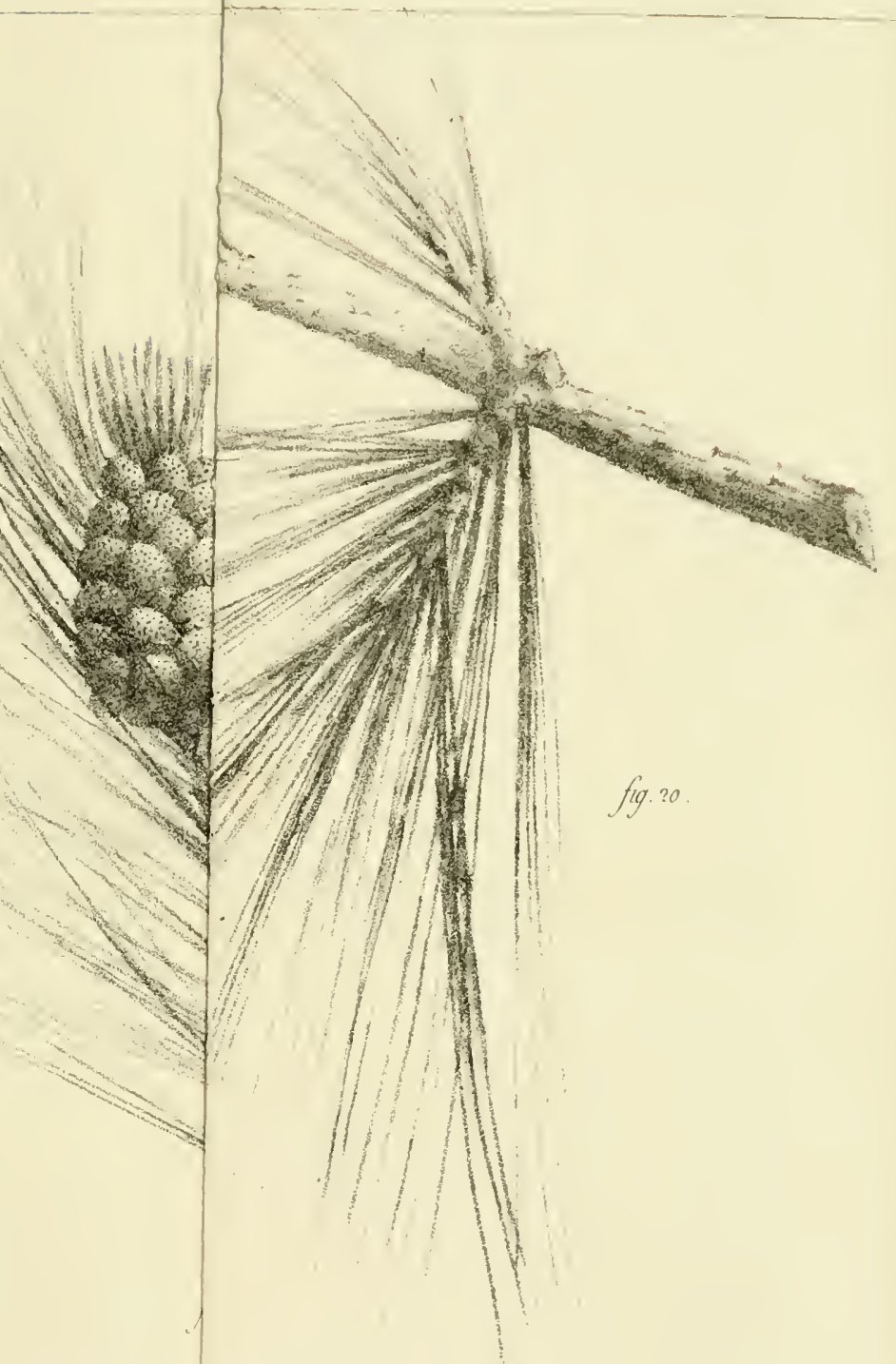

Ires Somerer Bmard $a^{2}$ 

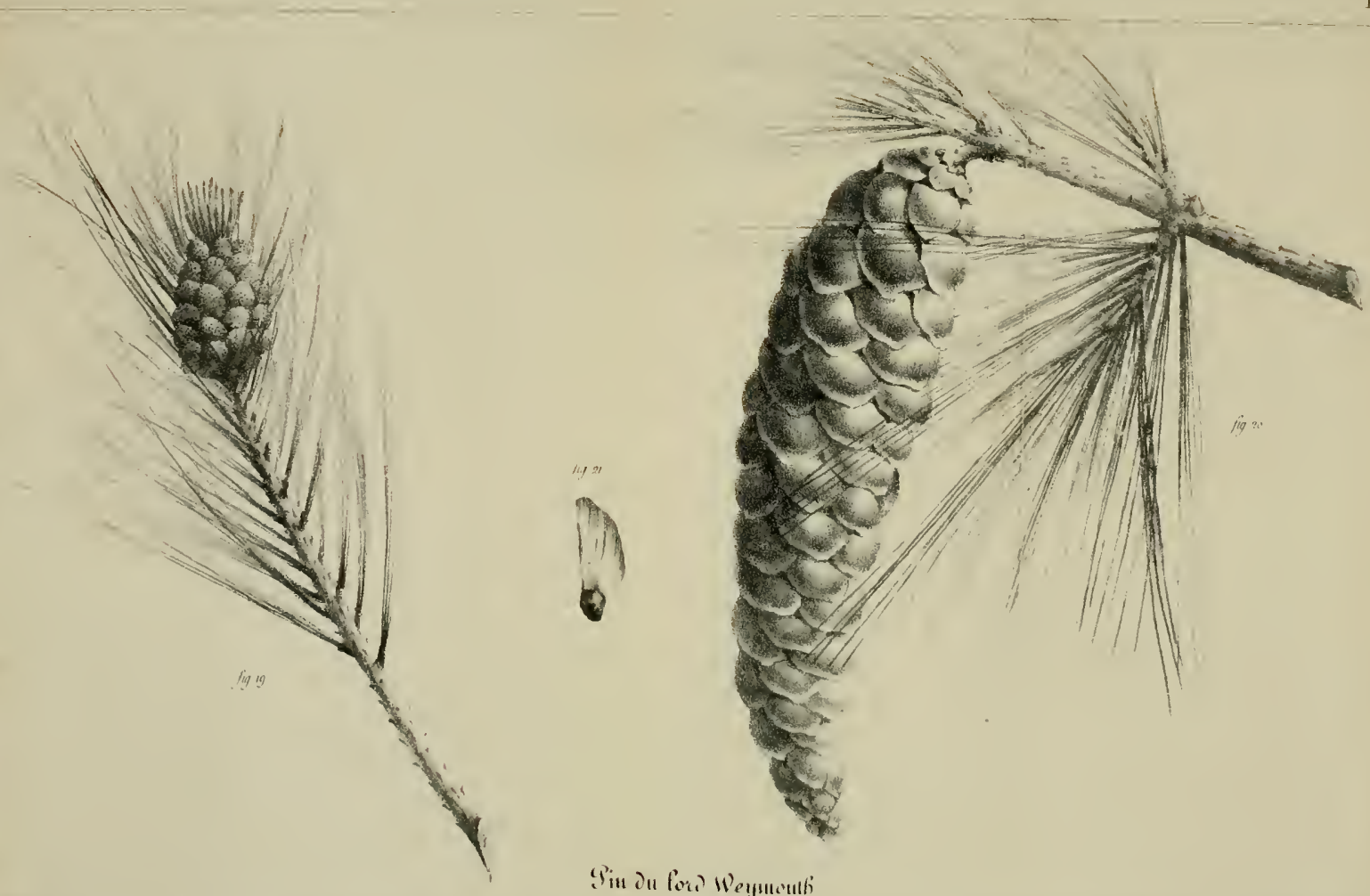

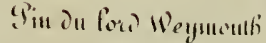

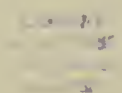



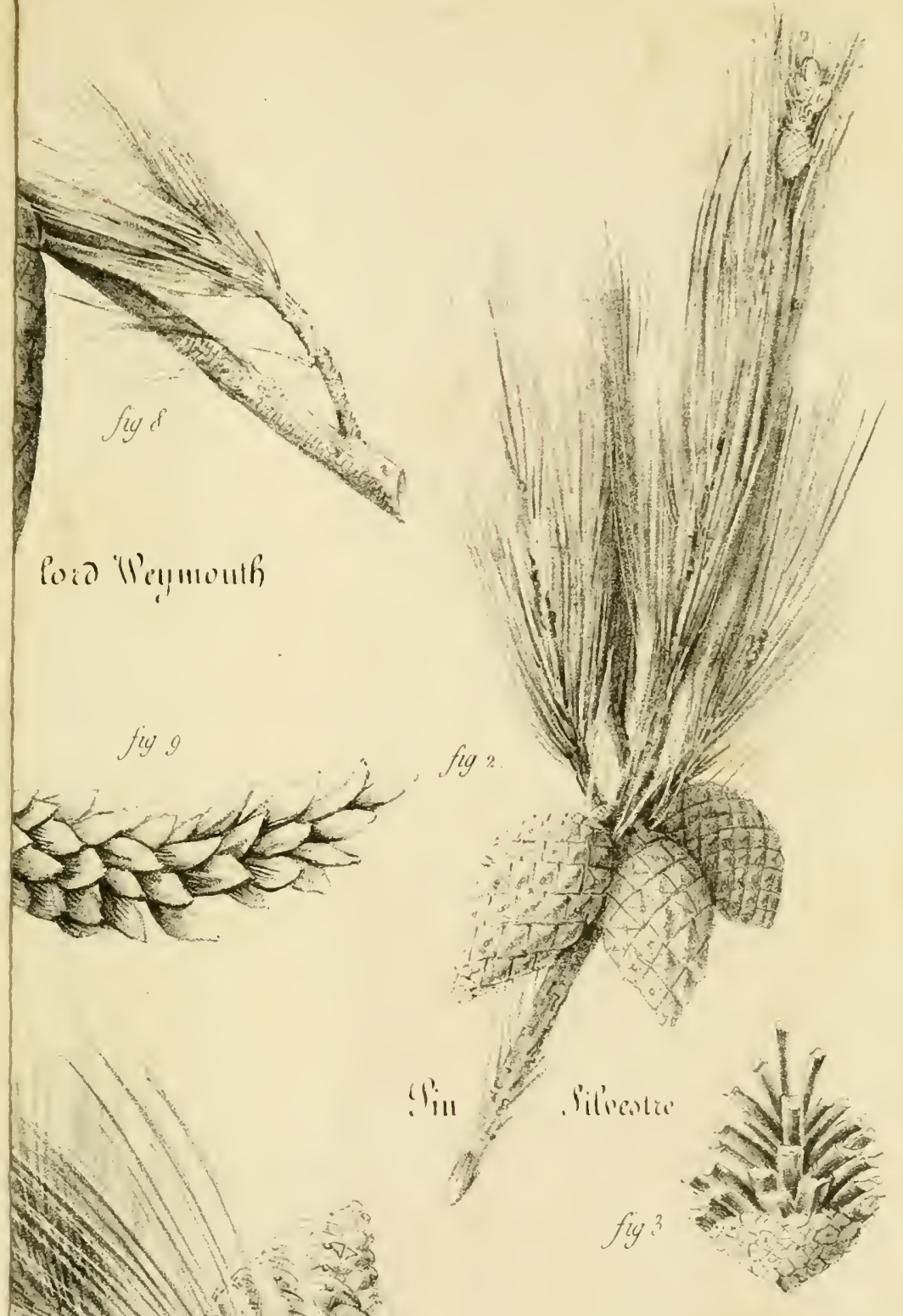

poa Meymouth

fig 9

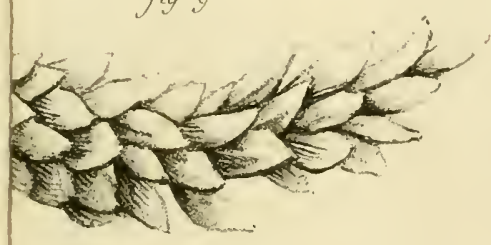

(19.
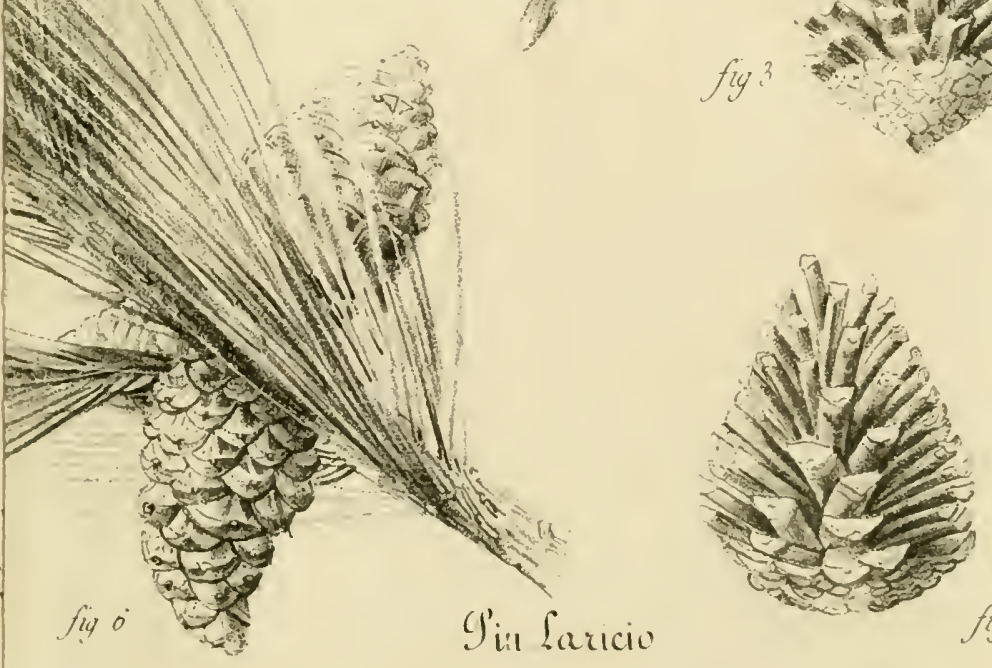

fiy : 


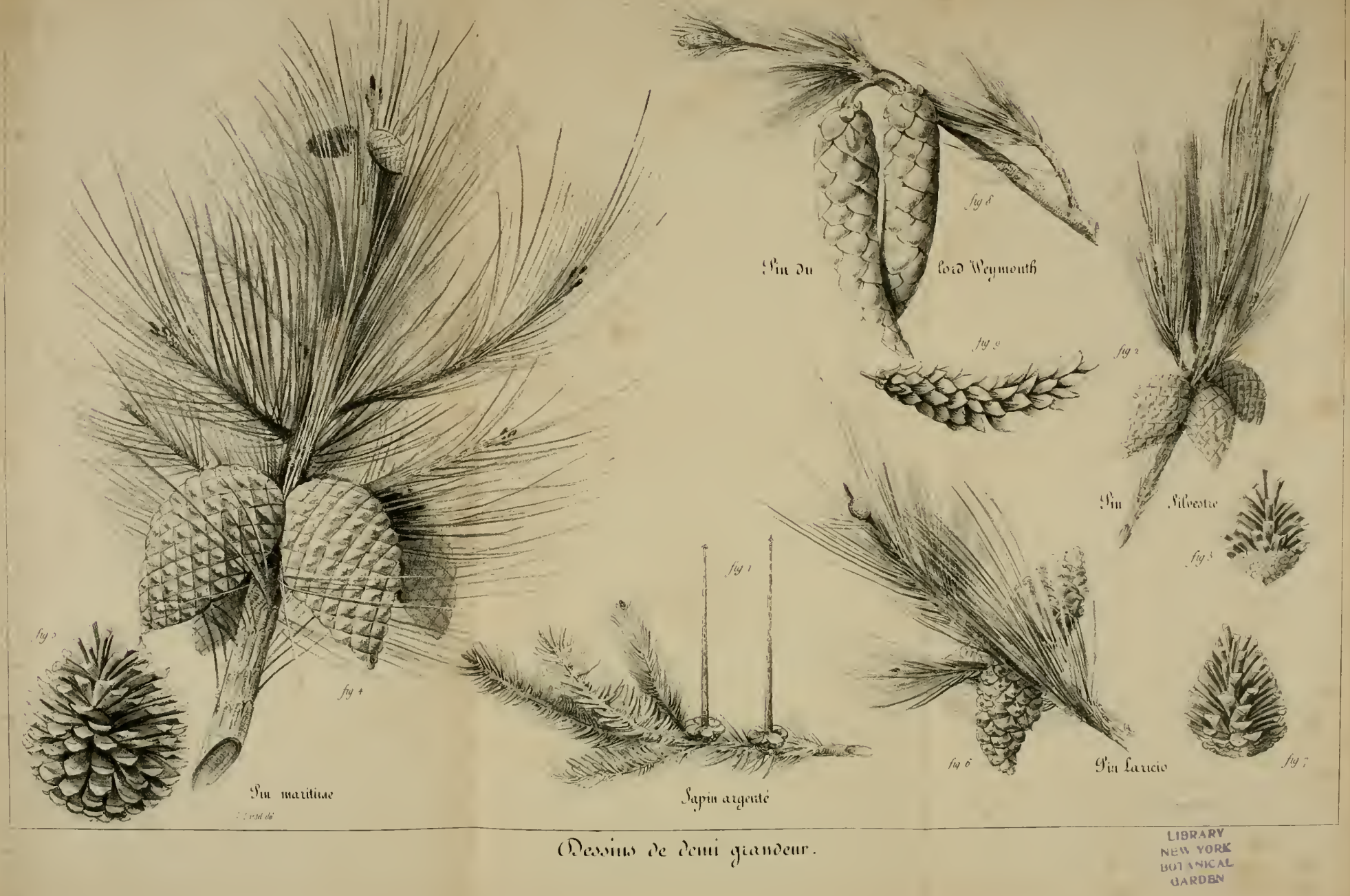




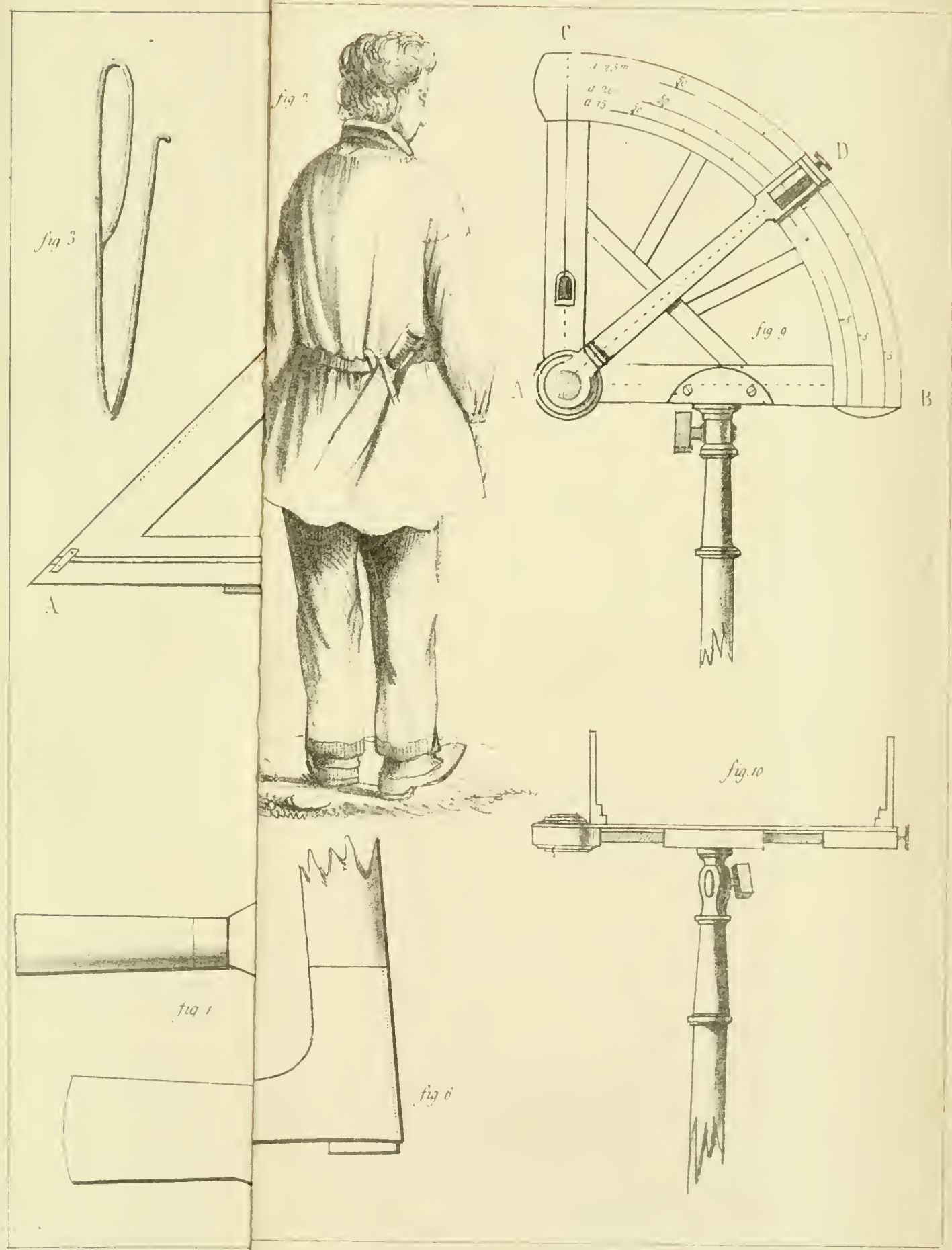




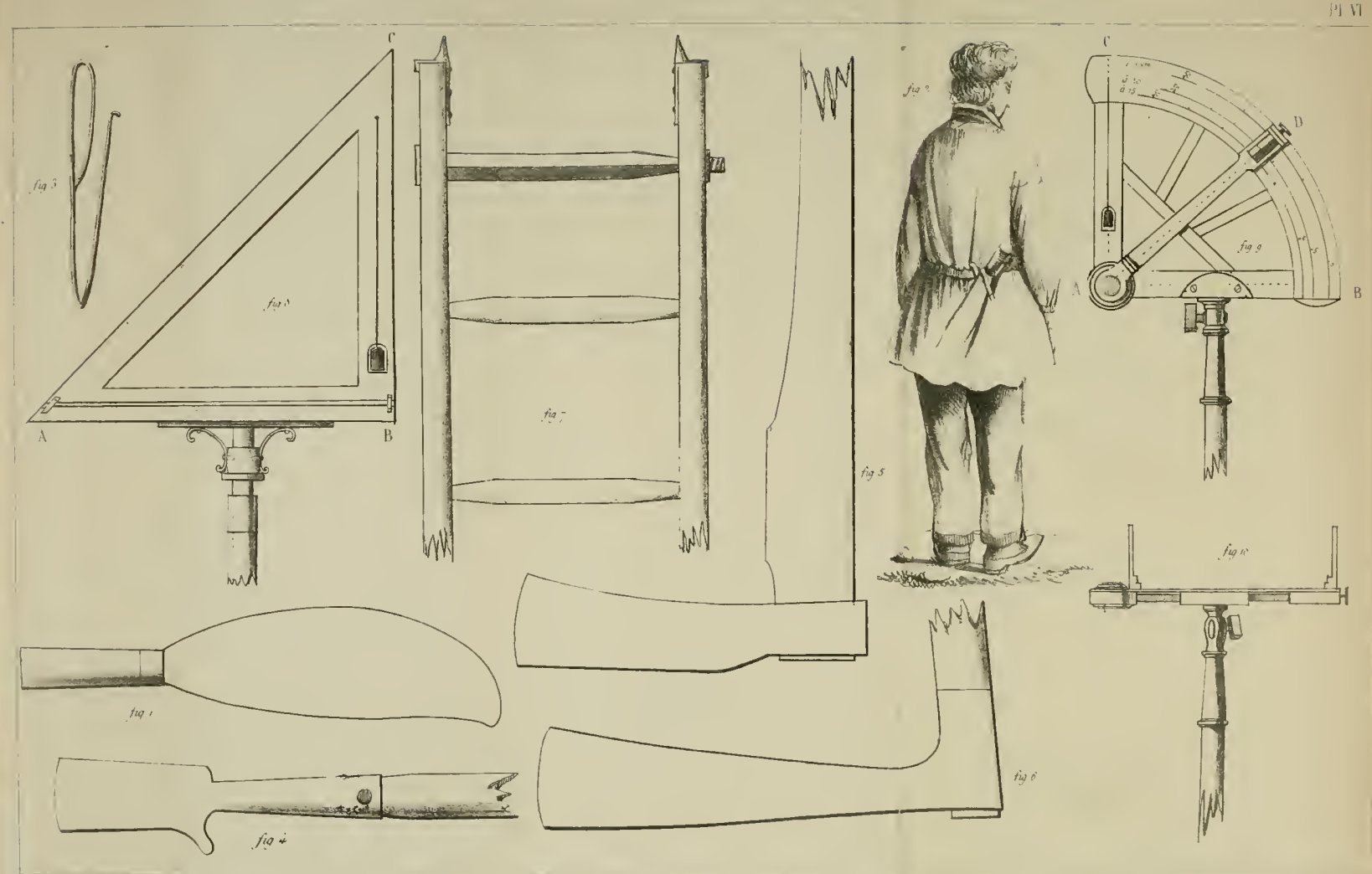




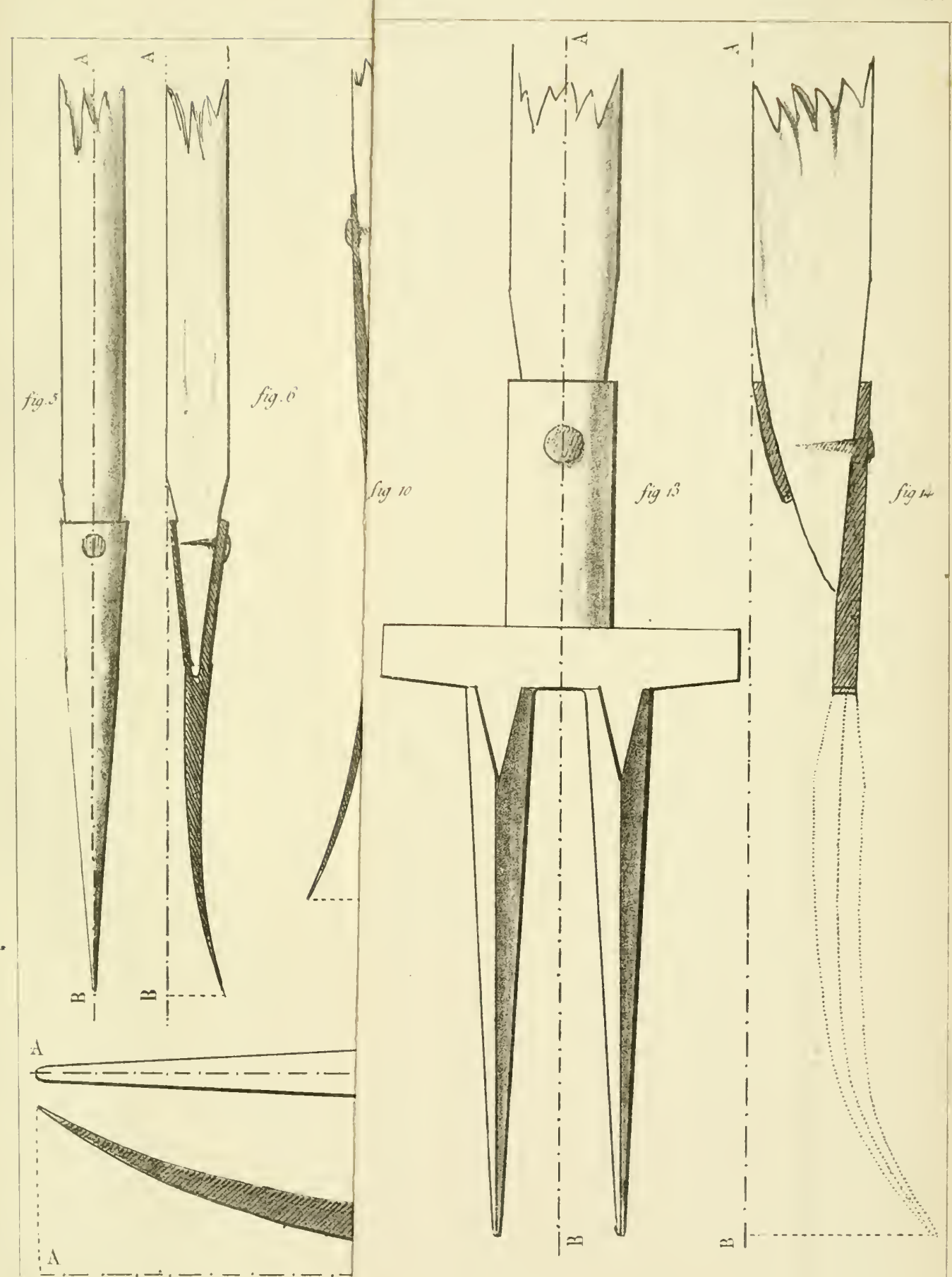


PI. VII
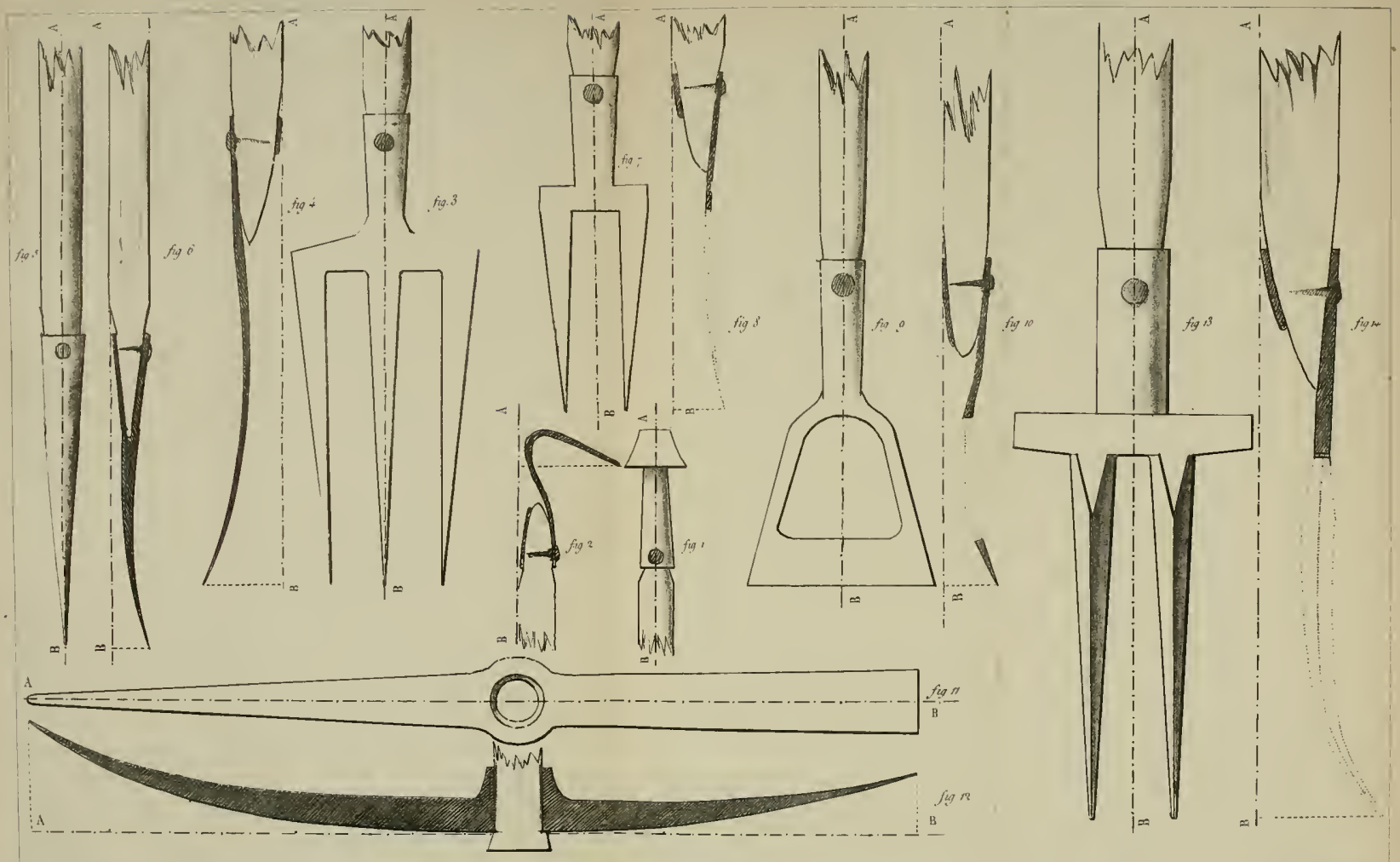





